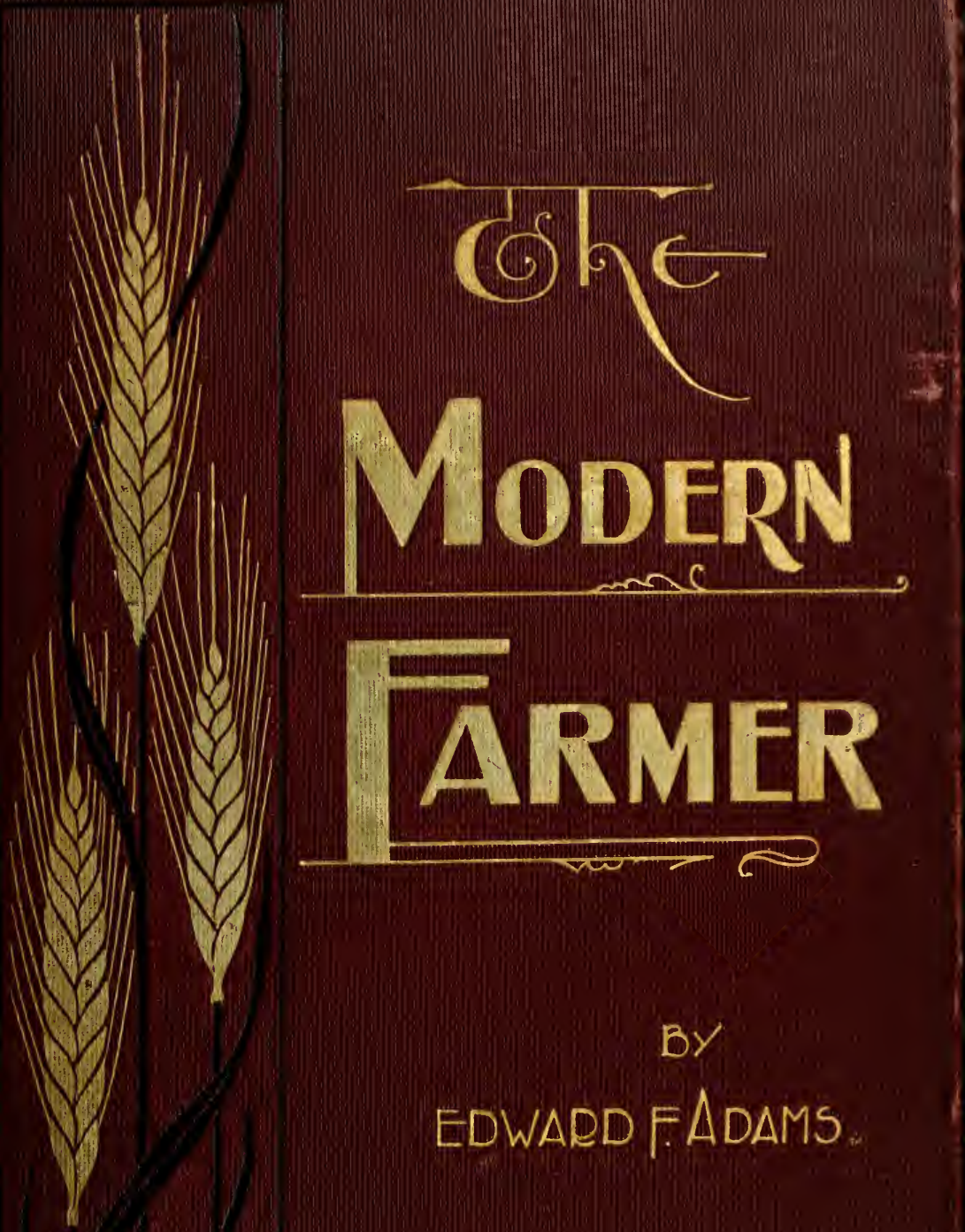



2. 2.conmon

$(2)=20=20$

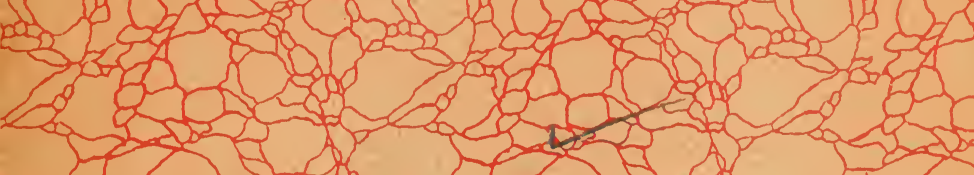
(1)

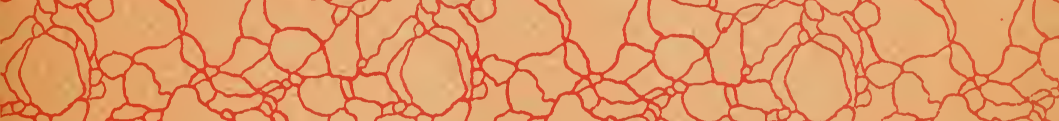

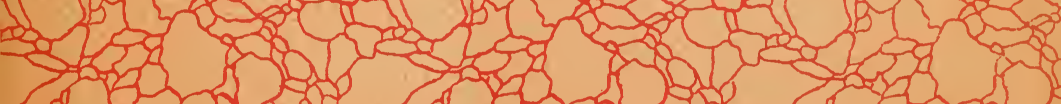
S.5 (र) से

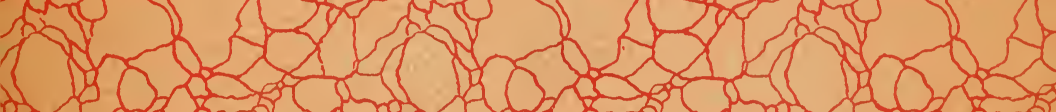

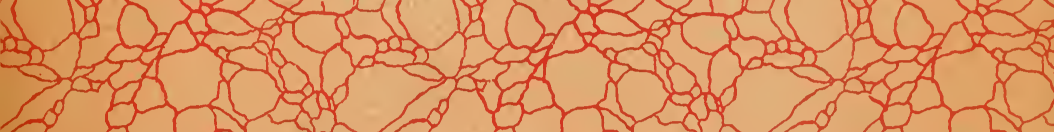

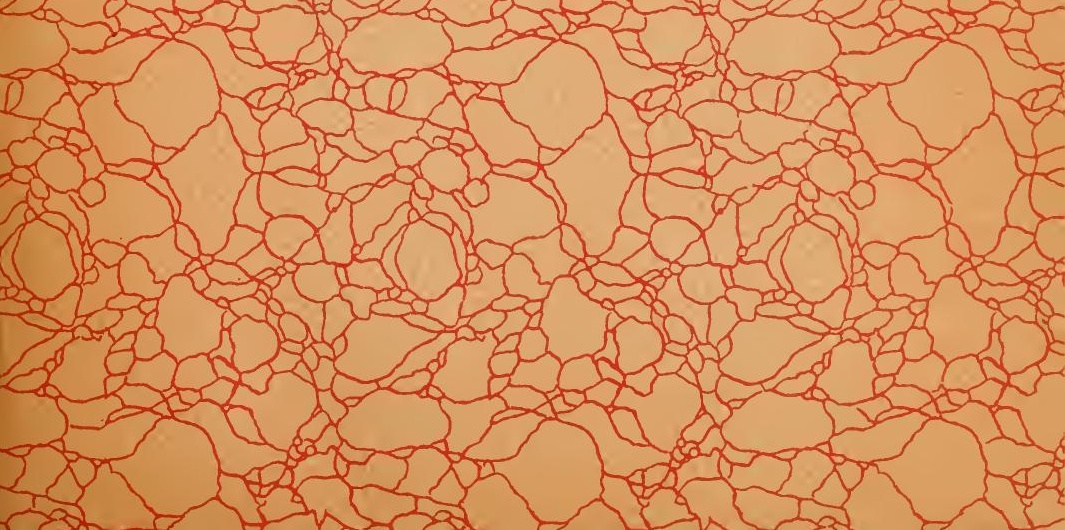




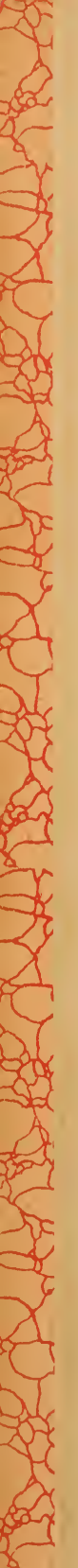



. 


\section{THE}

\section{MODERN FARMER}

IN HIS

\section{BUSINESS FELATIONS.}

A Study of some of the Principles underlying the Art of Profitable Farming and Marketing, and of the Interests of

Farmers as affected by modern Social

and Economic Conditions

and Forces.

By EDWARD F. ADAMS

With a Chapter by Mr. L. A. Clinton, of the College of Agriculture in Cornell University.

N. J. STONE COMPANY

SAN FRANCISCO, CAL.

1899

ALL RIGHTS RESERVED 


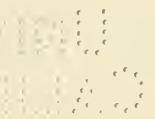

Entered According to ACt of Congress, in the Year 1899, By EDWARD F. ADAMS

in the OfFice of the Librarian of Congress, at Washington, D. C. ALL Rights RESERVED. 


\section{PREFACE.}

W

IIEN, after a business experience extending over a quarter of a century, I became interested in cooperative work among farmers, and sought, as an officer of cooperative societies, to induce farmers to unite for business purposes, I discovered that there were no grounds, common to myself and those whom I addressed, upon which to base the proposed action. My audiences and constituents believed so much which I knew to be untrue as to greatly impair the effectiveness of my leadership. This condition was so vexing that I gradually, during three or four years of that work, prepared, largely upon railroad trains, the most of the chapters which comprise this volume. Later, some chapters were amplified, and others added. If I had happened to be one who had had unusual experience in raising cabbages, I was sure that my brother farmers would have much respect for what I might say about methods of growing them. I hoped that I might have the same influence as one who had happened to have a wider business experience than falls to the lot of most farmers. As to that, however, I have some doubt.

I pretend to no great knowledge of economic science, but understand it to be plain common sense applied to such business transactions as marketing produce, borrowing money, and voting upon a tariff. Common sense, of course, is the logical inference from all the facts. Inference from only part of the facts, or from "facts that ain't so," is not common sense, although, unfortunately, common practice. No one appreciates more highly than myself the value of the study of the fundamental economic concepts, but, after all, the world's business must be done mostly by those without fixed convictions as to the real meaning of "value," or the "fund" from which wages are paid. I have, therefore, written for that class, drawing my conclusions inductively from experiences common to myself and my readers, rather than deductively from the 
economic bases. I trust, however, that I have written in the scholarly spirit, and not to establish a thesis. Upon some controverted topics I have thought best, without expressing my own opinion, to present the essence of the argument on both sides. I have tried to do so fairly, and think I have succeeded. There are, however, popular delusions which have taken strong hold upon many excellent men, as to which I felt that one has no right to suppress convictions approved by universal business experience, and the teaching of all economists.

Having prepared the book mainly for farmers, I was desirous that farmers should read it. The farmer, however, is seldom a free book buyer, and I was persuaded that, except by the kindly ministrations of the canvasser-a capacity in which I began my own business life-the most of those for whom the book was especially intended would never see it. I therefore decided to publish by subscription.

Possibly it is desirable that an unknown author should state his experience, and the environment which influences him. I was once a farmer of the old school, and led the life described in the first chapter of this volume. Then followed twenty-five years of business life, for the most part dealing with affairs of some magnitude. Then, retiring from business, were three years of active cooperative work. I now live upon my farm, where I am permitted to act as agricultural editor of a daily journal. For a short time I was connected with the University of California, as Organizer of Farmers' Institutes. My pecuniary interests and my sympathies are with the farmer.

Mr. L. A. Clinton, assistant agriculturalist in the College of Agriculture of Cornell University, has been kind enough to prepare for me a chapter upon "The Study of the Farm," from a standpoint which I could not take-that of a farmer and a man of science.

Edward F. Adams.

Wrights, California, May, 1893. 


\section{CONTENTS.}

PAGE

INTRODUCTORY

Book First. The Larger Aspects of Farm Life.

CHAPTER

I. The Old Farder . . . . . . . . . . 11

II. The New Farmer . . . . . . . . . . . 15

III. The Evolution of the Farmer . . . . . . . . . 18

IV. The Hope of the Farmer . . . . . . . . . . 22

Book Second. The Farmer's Education.

I. The Scientific Farmer . . . . . . . . . 28

II. The Agricultural College . . . . . . . . . 39

III. The Experimext Stations. . . . . . . . . 46

IV. Special Schools of Farmixg . . . . . . . . 51

V. The Farmer's Institute . . . . . . . . . . 55

VI. Agriculture in Common Schools. . . . . . . 60

VII. Agricultural Papers ani Books. . . . . . . . 69

VIII. The Study of the Farm . . . . . . . . . . . . 76

IX. A Further Study of the Farm (I. A. ('linton) . . 82

Book Third. The Farmer's Relationships.

I. The Farmer ayd His Family . . . . . . 89

II. The Farmer and His Fellows . . . . . . . . 96

III. The Farmer and His Competitors . . . . . . 100

IV. The Farmer axd His Creditors . . . . . . . 106

V. The Farmer and the Politicians . . . . . . 113

VI. The Discontent of the Farmer. . . . . . . 120

Book Fourth. The Farmer as a Business Man.

I. Thle Farmer and the Banker . . . . . . . 130

II. The Farmer ani the Commission Merchant . . 152

III. The Farier and the Railroads . . . . . . . 158

IV. The Farmer and the Speculator . . . . . . . 176

V. The Farmer and the Tradesmax . . . . . . . 182

VI. The Farmer and the Tax Gatherer . . . . . . 187

Book Fifth. The Farmer as a Cooperator.

I. Principles of Cooperation . . . . . . . . . 202

II. Some Fundamental Rules of Cooperation. . . . 209

III. Comerative Corporations . . . . . . . . . . . . 218

IV. Easextals of Security in Cooperatrie Societies . . 229

V. Elements of Danger in Coopliative Societhes . . . 234

VI. Management of Cooperative Solifities . . . . 240

VII. Economic Gain of Coopleration . . . . . . . . . 257

VIII. Altrulsm is Cooplzation . . . . . . . . . . 279

IX. Organizations of Farmers . . . . . . . . . 284 

CHAPTER

Book Sixth. The Farmer and Questions of the Day.

I. The Farmer and The TarifF. . . . . . . . 294

II. The Farmer and Export Bounties . . . . . . 31:3

III. The Fardier and the Srvile Tax. . . . . . 324

IV. The Farmer and the Currency . . . . . . . 342

V. The Farmer and tile Labor Question . . . . . 384

VI. The Farmer and the Trusts . . . . . . . . . 396i

VII. The Faruer and the Referendum . . . . . . 41:)

VIII. The Farmer and Soclalism . . . . . . . . 42\%

Book Seventh. The Cooperative Fruit Marketing Societies of California.

I. Their Character and Objects . . . . . . . 434

II. Conditions Leading to Their Orfinization . . . . 442

iII. The California Fruit Union . . . . . . . . 452

IV. The California Raisin Association . . . . . . 458

V. The Dried Fruit and Nut Ascociationis. . . . 470

VI. The California Frutt Exchaxge . . . . . . 489

VII. The Citrus Exchanges . . . . . . . . . 505

VIII. The Wine-Makers' Corporation . . . . . . 517

\section{APPENDIX.}

A. Morrill \& Hatch Acts . . . . . . . . . 533

B. Curriculum of Dairy School: and Silort Agricultural

Courses . . . . . . . . . . . . . 546

C. New York Agriculutural Endcation Extension law and Helps to Teachers . . . . . . . . . . 553

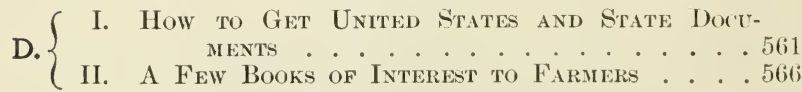

E I. Statistics Relating to Banks. . . . . . . 576

E. $\{$ 1. Decisions of U. S. Interstate Com. Commasions 580

II. $\{$ 2. Extracts hron Report of Inters' e Com. ('ON's 599

3. Statistics of Rimboans in Untted states. . 599

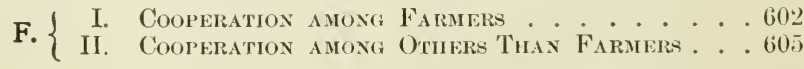

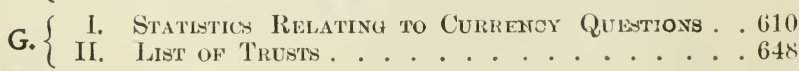
INDEX 


\section{INTRODUCTORY.}

THE present volume is, so far as I know, the first attempt to present any comprehensive review of the farmer's position and relations as a business man. I am quite sure that it is the first to pursue those relations to their ultimate foundations, group them together, and place them in popular form for convenient examination, disentangled, so far as they can be, from the affairs of other classes. The book is, in fact, an elementary treatise in applied economics, in which the farmer's interests are employed as a constant standard of comparison. The facts and principles set forth are, of course, entirely familiar to economists, and, to a great degree, to the different classes of business men, as to the points where their interests directly impinge on those of the farmer. The farmer, for the most part, has not had his attention called to these matters, and, so far as he has considered them, has been prone to rely too much upon a partisan press, and the utterances of political and other orators, who seek to accomplish some present end by exciting and increasing his prejudices. As a result, the farmer is continually at a disadvantage in his pecuniary dealings with those better informed than he as to the trend of commercial movements. The only remedy for the farmer is a study of fundamental principles, in the light of which he may correctly read the meaning of current events. This book is intended as an aid to such study. By our own intellects we must form our own judgments, but we all need the aid of the experience of others.

While nothing in this book will be new to economists, and very little to experienced business men, I am quite sure that much will seem strange to many in the classes for which 
the book is intended, and especially to some farmers. A study of the business relations of the farmer takes us far from the farm. The farmer's interests are intertwined with all other interests. The great social and commercial movements of the dayiare matter of dollars and cents to the farmer. All political questians are money questions, and can not be omitted frori aliy book" whisk "purports to deal adequately with the farmer's business interests.

The farmers constitute the one class which is essential to the existence of the race. Without the farmer we should perish. Whatever concerns him concerns all mankind, and whatever affects other classes reacts upon him, and this not merely in an esoteric sense, but in the dollars and cents which he takes in and pays out. What occurs on and about the farm the farmer can see, understand, and in some measure control. What occurs elsewhere, however profoundly it may affect him, he may never even hear of, and can hardly influence at all. It is essential that the farmer know more than he does of these distant forces, because it is necessary that he adjust himself to conditions which he can not control. The farmer, for example, can not control the operations of railroad magnates, the machinations of speculators on grain exchanges, the rate of discount at the Bank of England, or the standard of life of the Indian ryot, but all these help to determine the price he shall receive for his wheat, and what he shall pay for the supplies he needs. The intent of this book is to set him thinking more about such things.

It is hoped, also, that it may be equally useful to others than farmers. Relations are reciprocal. It is as important to the tradesman or the artisan to thoughtfully consider wherein the interests of the farmer coincide with or differ from his own, as it is for the farmer to understand his position. Besides, whatever affects the farmer equally affects other classes, although possibly in different ways, and while in this book the welfare of the farmer is the standard by which interests are judged, yet all interests may be fairly well judged by any fixed standard-and it will be astonishing to many to discover how closely the true interests of us all are united. 
I suppose some of my readers will disagree with me in many things; possibly this may be because they will not understand me. A strong English author* has said, in substance, that the most difficult of intellectual feats is for one man to precisely understand another in anything. But when good men differ it is never upon questions of logic, but always upon questions of fact. One believes one thing and reasons upon it, while the other thinks some other thing to be true and reasons accordingly. When two men agree upon the facts in the major and minor premises, the conclusions which they reach will be identical. The way to settle differences, therefore, is to ascertain the facts and let the argument take care of itself. But if, after all, there should remain differences of opinion, I may say to my non-agreeing friends that for myself I learn very little from those who think exactly as I do, while I learn a great deal from those who think otherwise. Possibly they may have the same experience. At any rate, this book is not written to prove anything whatever, but to render such aid as it may to those who wish to find economic truth wherever, it is.

*Ruskin- "Sesame and Lilies." 



\section{BOOK FIRST.}

\section{The Larger Aspects of Farm Life.}

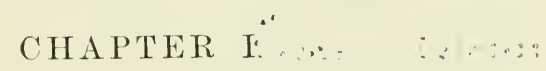

THE OLD FARMER.*

\section{$\mathrm{T}$}

HE old farmer was a jack of all trades. I remember that in the then new country of Northeastern Ohio each farmer sought to raise two or three acres of wheat, of which he took what he needed to the neighboring mill, paying toll for the grinding at the rate, if I remember rightly, of two quarts to the bushel, and taking home his flour, middlings, and bran. His surplus wheat he sold usually in my time at $\$ 1.00$ a bushel. He had from five to ten acres of corn, which he mostly fed out on the place to hogs, of which, after filling his pork barrels, he would have one or two to turn off. $\Lambda$ steer or "farrow cow," also fattened on the corn, was usually killed in the fall, half sold among the neighbors and half corned or dried for family use, incidentally furnishing the tallow for the dipped candles. From three to a dozen sheep

* This chapter first appeared over my signature in the San Francisco Call, in September, 1895. It was an expansion of a portion of a lecture by Prof. E. A. Ross, of Stanford Iniversity, to which I had listencd a few weeks previous. Due credit was given to Dr. Ross in this original publication. The article was somewhat widely copied in the press of the day, and subsequently I saw similar articles-some by well-known authors-which were also widely copied. The contrast between the old and the new conditions is very obvious, and the subject is evidently fascinating to those of us whose borhood memories run back to those days. Portions of three chapters immediately following also appeared in the series of which this chapter formed a part. 
supplied the wool, which was taken to the "carding-machine" and made into "rolls," paying for the work with a certain number of pounds of wool. Before my time the women of the house used to do this work with hand-cards, and I have seen this done, but generally in my boyhood women had emancipated themselves from this work; but they spun the yarn and knit the stockings, and in most houses was a loom constructed by the men, whereon every year was woven by the women one or two pieces of stout woolen cloth to be made up, in the house, into garments for both sexes. The bad-smelling dye pots sat about the fire all winter. Every year or two an s.cre of fiax was zaised, which the men "broke" and "hetcheled," and the women spun and wove and made up into clothing. The hide of the beef killed for family consumption, with those of a calf or two killed during the year, were taken to the tannery, and after six months brought home and made up into boots and shoes, sometimes by the men of the house, but more often by the neighboring or traveling shoemaker. A half acre of potatoes and a good garden supplied the vegetables for the year. A few cows furnished a surplus of butter, which, with the eggs not consumed on the farm, was traded at the store for the calicoes, white shirting, an occasional ribbon, and the necessary crockery and small groceries. The orchard supplied the fruit, cider, and vinegar. The "sugar bush" furnished the maple sugar, which was sometimes used for sweetening, but more usually traded for "muscovado," or brown sugar. The elder males of the. family had Sunday suits of store cloth made up by the village tailor; this was before the days of "ready made;" these suits, after some years' wear, were turned and made up by the women for the boys, and were worn out by them, one after another, as they grew into them. The elder women liad each a sober, dark dress for Sundays, but the girls mostly went to church in fresh calico, and very trim indced they looked as I remember them. Corsets and similar feminine gimcracks were unknown-at least to me; but it is likely the town girls had them, and if they did our girls knew all about them. Bomnets and hats were worn, with an occasional change of ribbon, until they 
wore out. A cast-iron plow, with the necessary hoes, rakes, and scrthes, constituted the "boughten" farm machinery. The grain was threshed with a hand-flail on the barn floor in the winter, while the women spun and wove in the house. Many continued this practise long after throshing-machines came in.

The boys got their spending money by picking up nuts in the woods and from the sale of the fur of an occasional mink or muskrat. Our social gatherings were husking bees and house-raisings for the men, quilting parties for the women, and apple-paring bees, and, above all things, the winter singing-school, for the young men and women. The centers of influence were the churches, of which two or three denominations-not too sure of each other's full hold upon salvation -were always represented, the ministers receiving from $\$ 200$ to $\$ 300$ per year, partly in money and partly in provisions, with the necessary wood and an annual donation party. The reading matter was the New York Weekly Tribune (I do not remember what standard paper the Democrats took; there were very few Democrats where I lived), Godey's Ladies' Book, the New York Ledger in families of doubtful piety, the Phrenological Journal by those of advanced thought, the religious paper of the denomination, and the county paper. Each family had a few books, which were exchanged until all had read them, and there was always the Bible, the Sunday-school library, and Dick's or Josephus' works, to fall back on. The education was in the district school.

The above outline comprises or suggests the essential features of the life of the thrifty 100 -acre farmer on the Western Reserve in Ohio fifty years ago. Further east there was a little more ready money and luxuries; further west there was less, and more dependence on wild game for meat and for furs to get money with. The great prairies had hardly been touched. Transportation was slow and expensive, and the products of each district were mostly consumed therein, the small surplus which accumulated painfully finding its way to the seaboard in exchange for such necessaries as we could not ourselves produce. The farmer's interest 
in markets outside his general vicinity was very small; his average trade with the outside world would not probably exceed $\$ 50$ or $\$ 75$ a year. He received very little money, and kept it almost no time at all; his currency was the notes of banks that he knew nothing about and smooth Mexican silver that would not circulate elsewhere. The young man got his "start" by being permitted to raise a pair of steers or a colt or two on the family farm, and by working out at odd jobs. If by the time he was twenty-five he had saved a couple of hundred dollars, or his fatlier could help him make up that sum, he would buy a piece of timber land, cut the logs for his house, which the neighbors would help him raise, marry, and start to follow his father's footsteps. He would have a sheep or two from the farm, liis wife would bring a feather bed and bedding, a cow, and such crockery as could be gotten hold of, and a new family was founded. This was the lot of the thrifty. The unthrifty married earlier, got hold of some kind of a house, worked out for a living, multiplied rapidly, and died off. But for the most part they were thrifty after a fashion and prospered. The land was new and abundant, with plenty more "out West," and the people had all the knowledge required to put it to the best economic use possible at the time. They were, therefore, in the main well nourished, sturdy, free from worry, and therefore happy. The farmer of those days was a producer and manufacturer, with the knowledge requisite for conducting his business, and a standard of comfort which his business would maintain. He was the independent man. 


\section{CHA PTER II.}

THE NEW FARMER.

$\mathrm{T}$

HE new farmer is primarily a business man. He is assumed to know how to make crops grow, and usually he does. The main question is whether he knows how to produce crops which will sell for more than they have cost. If le can not in the long run do this, his inevitable destiny is to become the servant of some one who knows how to direct his labor to profitable results. Below this lies the problem as to whether the majority of men possess the business ability requisite to successful farming under modern conditions, and upon the answer to this question depends the future of our rural civilization. If it be decided in the affirmative, the race of independent small farmers will continue; if in the negative, farm labor will come to be exploited by able men conducting huge agricultural operations, just as mechanical labor is now exploited by Captains of Industry.

In this age no such life as is described in Chapter I is possible to the farmer in America, nor, with our changed habits and desires, would it be agreeable. It would involve a distinct lowering of our present standard of comfort, which, with all our complaint, is far higher than formerly, and would not result in the same content and consequent survival which the same conditions formerly induced. The impossibility of the life will be seen by any farmer who will trace out what would happen should he attempt it. Doubtless the farmer could produce more for his own consumption than he does, but, in the main, under the changed conditions of modern life, he is compelled to sell, for money, most of his products, and buy, for money, most that he consumes. The mechanical facilities of modern times have enormously reduced the cost of production, and improved transportation has made every farmer of the civilized world the competitor of every other 
farmer in the sale of products consumed at his own door, and he who can produce cheapest will survive. The furmer, therefore, must have the best machinery, and make it available over the largest possible area, and this, again, restricts the small farmer at least to the production of the specialty best adapted to his location. There is another reason for this; formerly, when his surplus product was consumed near by, he could know the capacity of his market, and the competition to be expected; now, when his surplus is often consumed many thousands of miles away, and sold at the price fixed by the competition of the world, it is very difficult for any farmer to inform himself of the probable profit of production of many articles. And yet this knowledge, while far more difficult than formerly for the farmer to obtain, is far more essential, because, while formerly the farmer was interested in the money value of but a small portion of his product, he is now interested in the money value of nearly all of it.

Still other elements now have to be considered by the farmer. The increased use of money involves borrowing and debt. With proper business knowledge, borrowing is legitimate and profitable to the borrower; nearly all business men are large borrowers; but borrowing in excess of the knowledge to use wisely involves risk, paid for by high interest, and often leads to disaster. The farmer, unaware of his ignorance, has become greatly indebted, and is now profoundly interested in a stable currency. From being a very small buyer he has become a very large one, and is vitally interested in the control of trusts and other combinations affecting the price of the necessities of life. As all that he sells and all that he buys are necessarily transported over the great routes of commerce, he has come to have a money interest in the conduct and control of transportation companies. Paying more taxes than he did, the farmer is more interested in the maintenance of a just system of taxation, and the economical conduct of all public affairs. All these and kindred subjects form part of the great science of economics, as to which it is highly necessary that the farmer be well informed, in order, in the conduct of his business, and by his vote when necessary, to intelligently protect his own 
interests. From the lack of this knowledge he is continually misled by agitators, and often by the partisan press.

It appears, then, that from being a producer and manufacturer on a small scale for the lome market, he has become a producer and merchant on a large scale for the markets of the world. While once little knowledge would serve him, and that mostly such as his own observation could supply, it is now essential that he be a broadly-educated man, familiar with the conditions affecting his own business in all parts of the world. Ilenceforward the successful farmers will be only those so educated. If the product of the small farm will not justify the expense of this information-and it will not-there remains but the alternative of the combination of farmers to secure it at the common expense for the benefit of all, or the gradual absorption of the small farms by the strongest, and the extinction of the small farmer, who will sink into the condition of dependent. This process, of course, will not be sudden, but gradual, as the world always moves, beginning with the weakest.

This conclusion is not to my liking, but I know it to be the opinion of such business men as I have heard express themselves, and I believe it to be the teaching of science and the judgment of all competent to form one. 


\section{CHAPTER III.}

THE EVOLUTION OF THE FARMER.

I , as the result of some natural cause, the mean ammual temperature of the United States should be reduced ten degrees within the space of a few years, it is evident that many plants which now flourish in that region would find it impossible to survive. Others would struggle on in the effort to live, and among these the hardier individuals would pull through. They would not, however, have altogether the same character that was before typical of the species, but would be more or less changed. The natural conditions would no longer suffice to produce a product identical with the former, but the organs of the plant would be made use of to produce something more or less similar. The place of those species whose entire organism was destroyed would be filled by new species calculated to thrive under the new conditions. Between those plants which died outright and those which promptly adapted themselves to the new environment, there would be some classes which would struggle hard and long, and of which some would eventually survive in a modified form, while others would give up the fight and perish.

This illustration is but a supposed application of a universal law operating through all nature, animate and inanimate. Had its bearings upon brute animal life been chosen for the example, other factors would have had to be considered, as the power of locomotion, the power to choose food, and to protect themselves in various ways, as their instinct might prompt them. The law, however, would operate. IVith still greater limitations, it would also operate on man.

What luas been supposerl as having happened in the natural world is almost exactly analogous to what has actually happened in the world of affairs. The prodigions activity of man in his conflict with nature has caused changes of conditions to 
occur more rapidly than man has been able to arlapt himself to them. Within the trifling space of a half century there have been greater changes in the conditions of life than had before occurred in any five hundred years of the world's history. With all his marvelous power to adapt himself to natural conditions, man las not been able to modify his own nature as rapidly as he has modified his environment. The result is the distress which we see in the classes and the individuals whose habits and impulses are most fixed. It is found in all ranks of society, but we are now concerned with it only as the farmer is affected.

In comparing the classes of men with respect to their material prosperity, it is convenient to divide them roughly into capitalists and non-capitalists. By the former I mean at this time all who live by the application of their labor to property owned or controlled by themselves, as opposed to those who live by the sale of their labor only. Under this classification the farmer would, of course, be placed in the capitalistic class. The farmer is at a disadvantage in his material conditions as compared with other property-owning classes, because he knows less about his business than they know about theirs. This was not always the case, his relative retrogression being due to the fact that in his isolated life he has not been so well able as others to keep pace with modern progress. The tendency and inevitable result of this condition is to deprive farmers, beginning with the weakest, of their property, and reduce them to the condition of dependents; and nothing can change that tendency or prevent that consummation except the general diffusion among farmers of such business education as will prevent them from engaging in unprofitable enterprises. The annual cost of the information necessary for the profitable conduct of a farm under modern conditions, however, is more than the revenue from the farm will pay after supporting its owner in reasonable comfort; and the alternative confronting the small farmer is combination with his fellows for erlucational and other purposes, or gradual extinction.

In order to make this clear, let us consider for a moment what must befall the farmer if lie loes not educate himself; 
and we must remember that nature is relentless and remorseless; the quality of mercy is unknown to her; she does not consider abuses but conditions, and, whether weakness is occasioned by misfortune or perverseness, the penalty is the same, and is death. To fully understand this we must leave farm life for a little and see what the evolutionists say. Evolutionists are mostly professors, a breed which some of us farmers do not esteem very highly, often referring to them as "fellows with a lot of theories," using the term in the contemptuous sense of vague speculations with no basis save in the mind of the speculator. This, again, is because we do not know that the science of modern days is built upon facts ascertained and verified with a patience and precision of which we farmers have very little conception. The scientific man does not, as we sometimes vainly imagine, spend his days and nights in rapt but dreamy contemplation of the infinite, but, on the contrary, is mostly concerned with minute detail; he dissects pollywogs, and extracts the bones from dead and bad-smelling fish, which he patiently compares with the petrified relics and imprints of those that died years ago. This he does, not because he likes to clean fish or break rock, but because he seeks to learn what has been the rule of life in all ages, inferring therefrom what now the rule is and what it shall be. The collection of actual facts-verified by men trained to observe, upon which modern science now rests, is amazing, and daily the store is increased. After some lives have been spent in gathering and classifying facts in a certain line, the mass begins to take shape, so that some law running through it can apparently be discerned; and with that law assumed to be true, more lives are spent in patiently collecting other facts and comparing them with the assumed law; if all fats as verified harmonize with the working hypothesis, the law is strengthened and gradually tends to become part of settled science; but if one undoubted essential fact be discovered inconsistent with that law, the whole edifice of reasoning is destroyed and the work of rebuilding must be patiently begun. Hence science must, above all things, be sure of its facts, and so endeavors to be.

The facts thus collected, verified, classified, and analyzed 
through all time until now show that all life has one law, and this law, at first merely assumed, by long-continued observations is now considered settled and part of science-one of the things which we know as well as we can know anything in this world; it is a law that has so far run through all time, operates now, and, so far as can be seen or judged, will always operate; it applies alike to the birls of the air, the trees of the forest, the floating microbes about, and to man himself; it is universal, unchanging.

This law is that the only condition under which any species can maintain itself is by the introduction of a greater number of individuals than existing conditions will sustainthe survival of the fittest, and the death of the unfit. Could this process be checked, the species would degene:ate, because individuals of all species greatly differ in the qualities to secure sustenance from their environment; and were all to propagate and transmit their qualities alike, the total result of vigor would be less than if only the strongest survived and left descendants; and it is necessary that the aggregate vigor shall constantly increase in order to cope with increasing difficulties causer by the increasing pressure of population.

The operation of this law upon man, as distinguished from other forms of life, is modified by the fact that man has reason. As his numbers press upon the means of subsistence, he is able, of his own volition, to add to those means. The races which have least of this quality die. It is evident that the present population of America could not live without better means of obtaining subsistence than the red Indians had, or have been able to acquire. The time will come when existing populations will not be able to subsist without better means than we now have.

If all this be true it follows that the weaker farmers will be unable to sustain themselves; the weaker farmers will be those who direct their labor least wisely; these again will be those who know least. It is, therefore, a logical necessity that those farmers who expect to live as such shall adapt themselves to their changed environment by acquiring the information necessary to enable them to sustain themselves under their changed conditions. 


\section{CHAPTER IV.}

THE HOPE OF THE FARMER.

HE present generation has the means to produce comfortable subsistence for all. I do not know that this is or can be scientifically settled, but I think no one disputes it, and I shall assume it. This subsistence, however, is very unequally distributed. Looking into this further, we see that in the long run those who know most have most; those who know most about matters which directly concern their own income have most money, accumulating a surplus which they can not use; those who know most about things which affect the incomes of mankind generally, have most honor, usually in addition assuring themselves of comfortable subsistence. Knowledge which affects nobody's income is worthless, and is not sought.

It is best to make clear this money value of knowledge. Of course all I can say may be admitted in advance, and yet those who admit it may not after all know it, because real knowledge inevitably influences action. We do not touch a red-hot stove, because we know it will burn us. If in that sense we knew the danger of ignorance, which is just as real, we should strive for knowledge at any cost. The only real knowledge is that which we habitually and unconsciously act upon. Any so-called knowledge which comes short of that is mere vague impression, unavailable for practical use. Now, although it can not be actually demonstrated, I am sure that the incomes of those engaged in any business vary almost in a direct ratio with the number of essential facts pertaining to that business which they know accurately and certainly. Of course it is true that individuals greatly vary in capacity and vigor, but then it is the smart and strong who know. All that the weaker and less capable can do to maintain equality is to study more hours, to toil more nights and days. It is knowl- 
edge that brings the income. Farmers are apt to denounce the great salaries paid in some walks of life, but they are nearly always the price paid for knowledge, or supposed knowledge, at market rates. The farmer who prefers the life of a banker has merely to know better than any one else what property is safest to lend money on, and to make his ability known; some bank will soon want him. Farmers are large borrowers, and as they are apt to seek loans which they have not the knowledge to use wisely, the bank president must be a better judge of the possible profits of farming than the farmer limself, lest the bank's funds be invested where they can not be got back when wanted. This means a high salary for the bank officer, which goes to reduce the profit of the farmer; for ignorance must pay its own bills. If farmers could know enough about their own business to make loans to them certain to be so wisely used as to pay interest promptly and the principal at maturity, a less expensive man could lend them money, and the farmer's profits be so much increased.

I have said that the most capable know most, and consequently get most. Fortunately it is not necessary for us all to know as much as the most capable. Nature requires that we know enough to get a living, and kills us if we do not; but she does not concern herself with great accumulations. If we are strong enough and know enough to make such accumulations, she does not mind it, and, if necessary, will kill off such weaker ones as may stand in our way; but if we attempt to accumulate beyond our strength, she will kill us for that, too. All she requires is that we be warmed and well nourished, and our minds kept free from worry, but for the lack of those, whether with or without our own fault, no excuse will be taken.

Since evolution teaches that the penalty of ignorance is death, it is well to understand just what the evolutionist means by death; we may be dying, and not know it. Evidently the evolutionist does not mean that the ignorant shall fall down in their tracks and give up the ghost, or even that within a short time they shall all disappear and leave no sign. $\mathrm{He}$ 
means simply this: that by reason of our ignorance we shall be unfortunate; being unfortunate, we shall be worried; being worried, we shall not be well nourished; not being well nourished, we shall die before our time, leaving half-nourished and nervous descendants to live still shorter lives, until our names finally perish from the earth. That is what death means to the evolutionist, and it is the process which the ignorant are now going through.

We are, then, atoms in a struggling mass of humanity, of whom it is certain that the weakest must die, but amid which it is the highest duty of each one of us to make sure that he shall live. If we can also aid others to live, we shall do well, but nature does not demand it of us, nor can we do so until we have first satisfied our own debt to the awful force which controls us; but by as much as we maintain or increase our own vigor, by so much we add to the aggregate vigor of our race. It is, therefore, not only essential, but morally right that, up to a certain point, we look out for ourselves; and we are compelled not only to live, but to live up to a certain standard of comfort which is customary among those with whom we mingle. The Chinaman lives in happiness and holds his own among the races amid environments which would be death to the American farmer.

I have now to disentangle from this seething multitude the farming class, and especially the American farmer, in order to note his condition as compared with others of his race, and see whether or not he is holding his own, and, if not, whether of his own volition he can strengthen himself, recover any ground he may have lost, and maintain his position among those who shall live; and, as I am now considering mankind solely with reference to the relative power of survival, I am compelled, as already stated, to again make the rather heartless division into owners and non-owners of property, meaning by the latter class those who, in the prime of life, have not in their possession the means of supporting themselves without serious worry during their years of decliue. For the acquisition of the means of subsistence according to one's station in life is not only the best, but the only evidence of power of 
survival. Those who ean not do that may be of the salt of the earth, but they are delivered over to the bondage of death. The farmer, from the nature of his business, must be, or ought to be, a property lıolder, and I wish here to compare him only with other owners of property. In past years the American farmer has been regarded as the type of an assured prosperity within a very moderate range, and his occupation considered as, upon the whole, the safest to engage in by those who were prepared to be content with abundant nourishment, warm housing, and moderate intellectual and social enjoyment, with freedom from serious care. It has been thought that, upon the whole, those who contended for the more brilliant prizes of life, even if they achieved them, paid more for them than they were worth; much more the majority, who strove for them and yet failed. It has been believed that the strain and worry of the severer strife so seriously impaired their power of survival as to far more than counterbalance any comforts or enjoyments which they were able to secure. If, now, comparing the farmer of to-day with the farmer of lialf a century since, we find that estimate still holding good, the farmer is still holding his own, and need not be discouraged. If, on the contrary, we find habitual worry, care, and dependence gradually taking the place of the independence, comfort, and security which he formerly enjoyerl, then he is losing ground, and must bestir himself. I do not propose to enter upon a detailed comparison of the condition of the farmer as compared with other property-owning classes. Each of $m y$ older readers is as competent as I to compare for himself; I simply record my own judgment, which is that the farmer has ceased to be the independent man whom I knew in my boyhood. $\mathrm{He}$ is attacked by the care and worry of the business man, without the business man's equipment to meet them, and he is losing ground. If I am wrong, I am glad of it, but I shall proceed upon that assumption.

Now this decadence of prosperity, in my belief, is entirely unnecessary. The farm is the storehouse of vigor, without which and the application it makes possible there can be no knowledge, or the prosperity which knowledge brings; from 
the farm the ranks of the prosperons are being constantly recruited; the drift of our best into the cities is notorious; farm boys make the best records in school and in college. Their mother earth has given them the vigor which is the foundation and the means of all progress. 'We have, then, as farmers, the basis of success in the physical strength which makes success possible, and yet we are falling behind in the race. We have the earth, and are frittering it away.

It would be worse than useless to write in this strain if our condition was such as to admit of no remedy. If we are doomed, it is better not to know it; but if we are merely in danger, he who points it out is indeed a benefuctor. Certainly the position of agriculture is not in danger; those who control the sources of sustenance may laugh at all others. But the question is, Who shall control them? It is the hope of mankind that they shall continue to be controlled by the class of small farmers who have thus far been the producers, and not be delivered over, like the other classes of mankind, to be exploited by Captains of Industry; nor do I believe this a vain hope. But it is certainly worth while, if possible, to discover and set forth the causes why the farmer of to-day is less happy than the farmer of former days, that we may see how, if in any way, those causes may be removed, and the farmer be enabled to regain his earlier position. If we can once be made to see plainly the road by which we passed from prosperity to misfortune, we may find it such that we can retrace our steps upon it. We may be sure of one thing, -that if the American farmer was ever prosperous and happy it was because at the time he had all the knowledge which he needed to maintain his power of survival. What our investigation should disclose is why he has not now that knowledge, whether he can regain it, and, if so, how.

What has been said is, perhaps, sufficient to indicate why we have fallen behind in the race, and the opinion of the present writer, at least, of our power to regain our position, which lies in the possession of physical strength. What chiefly concerns us is the exact method by which this may be accomplished. There can be but one way. We must know 
more. We are being distanced, not by greater strength, but by a wiser use of strength. Other classes know better than we what it will pay to do or avoid. This knowledge comes not by vague speculation, but by the mastery of facts. ITe farmers reason well enough upon what we think to be true, but we are so often mistaken in our facts that we are as apt to be led into doing unprofitable things as into attempting those which are profitable. To ascertain truth is usually difficult. To act upon error is the easiest of all things. So we take the easy road. This we must stop. There are signs that we are stopping. In fact, those who are in a position to do so already see a gondly multitude leaving the broad road and climbing the more difficult paths which really lead to the summit which we seek. This is the Hope of the farmer, the prospect of better things. 


\title{
BOOK SECOND.
}

\section{The Farmer's Education.}

\author{
CHAPTER I. \\ THE SCIENTIFIC FARMER.
}

I $\mathrm{T}$ is hard to account for the intense prejudice, often amounting to positive hostility, which many farmers entertain towards "scientific farming." An editor of a long-established agricultural journal once told me that he never allowed the term "scientific" to be used in its columns as applied to any farming operations, knowing, as he did, the intense dislike of many farmers for the term. And as the subscribers to agricultural jouruals comprise the most intelligent farmers, we can imagine what the prejudice must be among the more unintelligent class, which reads no such papers, and which my friend did not, therefore, have in mind.

Of course, like all prejudice, this has its origin in a misunderstanding, since no sane person would or could object to scientific farming, if he knew what is meant by it. What those dislike who ridicule scientific farming is what everybody dislikes, which is unfounded pretensions to superior knowledge.

While engaged for a short time in promoting Farmers' Institutes for the University of California, it was my duty to become fully informed of the feeling of farmers in regard to the work, in order that we might adapt our lectures and discussions to the real feeling, and not attempt to lead in any way until we had first gained confidence. It was, therefore, my habit to ask two or three of the most interested to carefully 
note what was said of us behind our backs, and let me know, without mentioning names. The subjects discussed were the usual ones of soil composition, the action of water in the soil, plant plyysiology, the physics of plant growth, and the like, and, as a special effort was being made by the College of Agriculture, care was taken that each subject should be presented by specialists. In almost every instance the reports made to me showed that, while most of those present were interested, there were always some who were not, and the great majority of farmers did not come near us at all. The usual remark made about us by this class of farmers was that we were a "lot of theorists." I indicate the adjective in order to show that the speakers were moved not merely by indifference, but by positive dislike. They considered us conceited mischief-makers. One of this class, after listening for a short time to a lecture on the treatment of faulty soils by one of the greatest living authorities on that subject, went out and reported to a congregation of his fellows on a street corner that "them fellers can't l'arn me nothin'," and straightway the party repaired to a neighboring grocery, and spent the day playing pedro. Of course these were specially lowminded men, probably incapable of improvement, and not destined to survive, but there is no doubt that more or less of this feeling exists in much better men, and is the greatest obstacle to profitable farming by small firmers.

The word "theorist," by the way, is a favorite expression among this class of persons. Now no sane person ever engages in any agricultural operation except upon some "theory" of his own. He performs certain work upon the "theory" that some particular result will follow. So we are all theorists. If our theory is based upon accurate and complete knowledge, it is pretty sure to be sound; if otherwise, there is great danger that it may be unsound, and results not desired follow our work. In calling scientific farmers "theorists," the uneducated man means, so far as he means anything, to say that the scientific man does not know his facts, but assumes things to be true which are not true, or not all the truth. In this assumption the objector is guilty of the same intellectual crime of which he 
accuses others, and is himself wholly mistaken in his premises; for the men who are now employed in this work by the great universities do understand their subjects. The part which the farmer knows they assume, and do not waste time in talking about. "Science" does not bother itself with teaching a farmer how to hold his plow, or when to put in his crop, or the time to harvest, or any other of the mechanical operations of the farm. These are learned on the farm by practice. What science does for the farmer is to discover and make known to him things which he can not or is not likely to discover for himself, but which, if he knows them, will enable him to apply his labor to better profit. The foolish farmer is the one who thinks he already knows all that is worth knowing, and refuses to learn more. When lie competes with the farmer who studies, he finds that his competitor is producing more cheaply than he, and is underselling him, with the result that, sooner or later, he goes to the wall, and his farm passes to one who knows how to make better use of it.

Briefly, therefore, the term "scientific farming" simply means farming in the light of all the accurate information obtainable from experience, observation, persons, or books. It excludes farming on the basis of inaccurate or incomplete information. It makes no difference where the information comes from. A veterinary surgeon may never have been out of a great city, and yet be able to give the farmer essential information. The farmer must learn from the entomologist, the chemist, the physicist, and others who can teach him perfectly, although they never saw a plow. Per contra, the unscientific farmer is one who attempts to carry on the farm in the light of the trifling amount of information which one man can gather in a lifetime, and who imagines that the experience of able men ceases to be raluable when once it is written down in books.

The object of science applied to agriculture is to reduce cost of production. Science has cheapened, and is constantly cheapening, all products which the farmer has to buy. Until lately it has not, in America, been much applied to agriculture. There are various reasons for this. For one thing, 
scientific knowledge is extremely expensive, and in a new country, with insufficient capital, there were better inducements for enterprise in other directions. It was also the fact that our great areas of virgin soils enabled us to make money while employing wasteful methods, just as the earliest users of the steam engine made money by the use of machinery whose employment now would insure prompt bankruptcy to the user. Our competition while using even these wasteful methods has compelled the older European countries to make use of science in reducing costs to a degree of which we have little conception. Now our own virgin areas having all been occupied, the owners of our partially-exhausted soils are brought into competition with the farmers on virgin soils of the tropics and the southern hemisphere, and we feel their competition just as the European farmers have long felt ours. Among our own farmers some have been quick to see and utilize the economies which science suggests, and are producing cheaper than their neighbors. Whenever produce sells "low" for a considerable time that fact is usually evidence that some are employing cheaper methods than others, and that their product is supplying the market. Those who do not employ as good methods are crowded out. It is in this way that nature kills off the weak.

It is not necessary or usually possible that the successful farmer should be a scientific man. It requires a lifetime to become a good scientist or a good farmer; very few men can be both. What is necessary is that the farmer shall make use of the discoveries of science to lessen costs of production, and the farmer who does this is a scientific farmer, no matter how le gets the necessary information.

In discussing the larger aspects of farm life we reached the conclusion that the "Hope of the furmer is in greater knowledge." The literature of the Patrons of Husbandry says that "education is the corner-stone of the Grange." Without some further explanation both these expressions are mere platitudes-meaning vague statements which no one will dis- 
pute, but to which no one attaches any special significance. It is proper at this point to inquire what are some of the definite things which the modern farmer needs to know, and which constitute his "Hope" of better progress towards material comfort.

The mechanical operations of the farm are, of course, not referred to, for those the farmers already understand, although those who know most about even them will be the first to concede that they are constantly acquiring helpful information as to operations which they have conducted from boyhood. No farmer of fifty years of age will concede that he has not learned much since he was forty, as to management of soils, methods of drainage, ways of combating pests, desirable varieties of crop plants, treatment of crops in harvesting, the feeding and breeding of stock, and the like, which, taken together, constitute what we call farm practice. He does know more, and part of his increased knowledge has been attained by his own experience, and part by observation of the experience of his neighbors. The ordinary farm practice in different localities is very well understood by those who live in them, and is best learned on the farm itself, if, indeed, it be possible to learn it well elsewhere. Such knowledge, therefore, is assumed to be possessed by the farmer. So long as he is on virgin soils in a growing country with extending markets, it serves his purpose very well.

But the modem farmer does not live under such eonditions. He lives, for the most part, upon deteriorated soils in communities which seem to have gotten their growth. There are no longer new settlers coming in to make a home market for produce. It seems harder, for some reason, to get on. The shiftless families whose ehildren once swarmed in the schoolhouses have been gone for years. Where?-No one knows. They are undergoing the process of extinction. Of late years there has been in many neighborhoods another process going on. One by one the small farmers have been "selling out" to the larger farmers adjoining, and these families also have gone. Why did they sell, and where have they gone? These questions are not so easy to answer. Doubtless 
in many cases the reasons for selling were founded in the general spirit of unrest which is an American characteristic, and doubtless, also, in many cases they have bettered their condition by so doing. In most cases, however, I suppose they have sold because they found it yearly more difficult to live. The pressure of competition was becoming too strong for them. They needed to know something which their neighbors knew, or they would not have been able to buy. The majority of these families have doubtless started the down-hill road. Finally, of late years, in the newer states there are many who, no longer able to obtain good land by merely settling on it, have purchased at high prices, and run in debt for it. These families are usually paying very slowly for their land, if at all. Interest is eating them up. Plainly there was something which these people conld have learned to their advantage.

First of all, the farmer needs to know how to reduce the cost of his products. The prices he can not control. $\mathrm{He}$ finds his margin of profit insufficient. His one resource is to reduce costs. The farmer is now only passing through an experience which all other industries have encountered, but from which, until lately, the American farmer has been exempt. The farmer knows that costs of manufactured articles have decreased, because he buys them cheaper. When he inquires how costs have been reduced, he will find that in every instance it is the work of scientific men - mainly engineers and chemists. When he understands this, he should at once be prepared to expect aid from the same source. And he is getting it from that source. The farm-yard fertilizers produced are wholly inadequate to the requirements of many agricultural industries, and commercial fertilizers are bought in enormous quantities. All that we know as to these we have learned from the chemists. The entomologists and botanists have learned the life histories of injurious insects and fungi, and the chemists have compounded the materials for combating them. When the farmer "bluestones" his seed wheat, he is doing merely what some chemist at some time taught some furmer. The mechanical engineer fashions the modern farming implements accord- 
ing to the unvarying laws of mathematics. The veterinarian and entomologist have located the cause of Texas fever in a parasite which the chemist has taught us how to destroy, as he long since taught us how to eradicate sheep scab. The pliysicist has learned how soils are formed, has definitely classified them according to the size of their particles, and discovered precisely how water behaves in the different classes. This aids the farmers who understand such things to plant and till crops with better judgment. The meteorologist has iscovered the laws of storms, and learned how to gather data by which he makes the forecasts whereby we save our crops. $\mathrm{He}$ is likely, within a generation or two, to correctly foretell wet and dry seasons, and thereby guide us in our planting. The bacteriologist has taught us innumerable things, for example, the ferments which make or mar our butter and cheese, and the organisms which cause infectious diseases of live stock, and, in a great measure, has put them under our control. The biologist has taught us the laws of heredity, and thus enabled us to work intelligently for the improvement of our live stock. The physiologist has taught us the laws of digestion, and enabled us to stop wasting feedstuffs.

It is unnecessary to extend the catalogue of which the above is but the beginning. If we took from the farmer the knowledge which pure science gave him so long ago that it has become part of the inherited information of the ordinary farmer, he would be lost. If we took from the progressive farmer the additional information which he habitually uses, he would produce no more cheaply than his more ignorant brother, who is growing poorer every year, he knows not how. When I was seventeen years old, I went one day to hire out in "haying" to a hard-working farmer who was one of the best men I ever knew. I found him hoeing corn, and faithfully working every inch of the soil between the rows. Many of his neighbors had horse cultivators, but he said he had no faith in them. The hoe was the only tool to be relied on. There were many excellent men of his way of thinking in those days, just as there are now many who have no faith that science can aid them. The horse tool saves money to the 
farmer by enabling him to do more work, and perhaps better work, for a given sum of money, thus reducing cost. The bacteriologist saves money to the farmer in enabling him, for example, to avoid raising swine to die of hog cholera, by inoculating them with serum, upon the same principle that he protects his child from smallpox. The object of all applied science is to reduce cost by reducing the labor of production, or protecting the finished or half-completed product.

A portion, then, of the "knowledge" which is the "Hope" of the farmer is the acquaintance, so far as he can possibly obtain it, with whatever science is from day to day discovering of that which will reduce cost of production. Nothing else will enable the farmer to compete with his fellows, and maintain his economic existence. Thrift and industry are assumed. All understand the necessity of those virtues; but industry improperly applied will fail of its reward, and it is only knowledge which enables industry to be wisely directed. It is essential that some portion of the time which the thrifty farmer now devotes to manual labor shall be withdrawn from that and expended in learning how to most wisely employ that labor.

But all this is only one aspect of the case. While the art of production is possessed in some degree by all farmers, very little is known by them of the science of marketing, and the art of maintaining business-like methorls is hardly understood at all. In the matter of rerlucing costs, for example, very few farmers know the cost of anything which they produce. The subject of reducing the cost of a product can only be intelligently approached upon the basis of a record of the details of present costs. It is not necessary to enlarge upon this, for every farmer knows it. He does not keep these records in America, because hitherto lie has been able to live without it. A merchant who has no competition within fifty miles need not know his cost very accurately, for his selling prices will be high enough to cover waste, but to the merchant in a busy town every item of cost is essential and is duly recorded. Increasing competition and deteriorating soils make this equally essential to the modern farmer. 
But there are other things equally important. At this point, however, it is necessary to draw the distinction between the farmer producing for a special market, like the vegetable grower near a large town, and one producing for the general market, like the wheat grower or the cotton planter. The latter requires far wider knowledge and greater ability. $\mathrm{He}$ must be, to succeed, a well-informed business man. It will be well to consider briefly some things which the farmer needs to know as a business man.

In this category I must place, as not only first, but far more important than all other business information, a knowledge of what his competitor is doing. I was for years connected with manufacturing interests, and the one thing which gave us more concern than anything else was to learu what our competitors were doing. It is the most important thing for any business man to know. It is a matter about which most farmers never think. As a matter of fact, he can not know very accurately what they are doing. The farmer who raises wheat in Illinois can get no more for his product than the farmer in Argentina will sell for. The price for both is determined by the outcome of the competition between the wheat growers of all parts of the world under existing conditions of demand. But while the Illinois farmer can not be fully informed of the factors of the cost of wheat in Argentina, he can know a great deal about them. He can, if he will, obtain fairly accurate conceptions of the possibilities of wheat culture, one year with another, in Argentina. The cost of wheat production in any country will be mainly controlled by the physical character of the country and the standard of life of its inhabitants. Of course the amount of capital available is an important factor, but capital is intelligent, and does not go where conditions are not favorable for its use. It leaves such places to the uninformed.

At the head of a farmer's business equipment I would therefore place a good knowledge of plyysical geography, including commercial routes, which were formerly determined and will always be greatly influenced by physical geography. This is not yet fully recognized by the universities, whose 
curriculums are usually arranged by those without commercial experience. I have looked in vain through courses of study in agricultural colleges for evidence of any understanding of the supreme importance of such knowledge to the farmer producing for the general market. 'The subject is much better understood by commercial men, who find some knowledge of it essential. The great organizers of industry know a great deal about it. None need it so badly as the farmer, who must bear all the risks of production. In due time the universities will understand its importance, and begin to send out men equipped to deal with it, and with the standard of the lives of the different peoples.

In so far as one knows the cost of his own products, those of his competitors, and the cost of the transportation which each must bear, he is fairly well equipped as a producer and seller. He can judge what it will pay him to produce. The largest farmers understand these things very well. But there is another side to this marketing problem-the side of the consumers. It is the desires of consumers which create demand. These desires may be stimulated. It is a part of the trade of a good marketer to create desires which do not exist. A wise producer also understands existing demand and seeks to learn whether he can profitably fill it. If he proposes to grow flax, for example, he seeks to learn what qualities are required in flax for different uses, so as to decide whether or not his farm will produce that kind of flax.

But, in addition to the mere questions of marketing, the farmer's net income is affected in liundreds of ways, by forces which he can not control, but may, if he will, understand. Society itself is a product of an evolution not yet complete. Its development is proceeding according to natural laws, some of which, at any rate, we can perceive. The science which deals with those phenomena of society which most directly affect men's incomes is called "Economics." It considers such questions as taxation, banking, cooperation, transportation, currency, commerce in all its forms, and kindred topics, many of them the subject of political action. The farmer needs to understand these subjects as they really are, not only in order 
that he may think and vote intelligently, but that he may not wear his heart out in struggling with imaginary causes of evil, or with economic tendencies which can not be changed. A great part of the education which is the Hope of the farmer lies right liere. It is a part that has been too much neglected. One agricultural college only that I know of (Wisconsin), recognizes by its course of study that some knowledge of economics is a necessary part of a farmer's education. In time more will do so; meantime it is hoped that this book will be found helpful. It deals with matters which the farmer must understand if he is to use his faculties and his influence to the best advantage of himself and the world. 


\section{CHA PTER II.}

THE AGRICULTURAL COLLEGES.

$\mathrm{S}$ is well known, the Agricultural Colleges of the country
received their first endowment by a donation of lands
from the United States.* The sale of these lands and the application of the funds were left to the states, some of which have conserved them and have large endowments, while others permitted them to be sold to speculators at low rates, and now suffer for their folly. In addition to this endowment, these colleges now receive an annual money appropriation from the general government, whose expenditure is in some degree supervised by national authority. All these are Colleges of Mechanics as well as of agriculture, and while called "Agricultural" Colleges, are as much bound to derelop mechanical as agricultural science. In most states there is now a "State University." In some states the national endowment for the Agricultural College has been turned over to the State University, in which case the institution is usually known as the "Agricultural College of - University." In other cases the management has been kept separate, and the location made in some other place than the University town. This has frequently been determined simply by the relative strength in the Legislature of rival places sceking the advantage of the school and the trade it would bring. For the most part, the so-called "purely Agricultural" Colleges are weak for the reason that they have not the means to support a sufficient number of instructors, or provide suitable laboratories and shops. To make their money go as fur as it will, they are compelled to pay lower salaries than the stronger colleges, and so are unable to attract the strongest men or retain such strong men as they develop. Certainly I do not

${ }^{*}$ See Appendix A for Morrill Aets and Hatch Aet. 
say this of all separate Agricultural Colleges, but this is the tendency. An Agricultural College attached to a strong University does not have to maintain professors of botany, mathematics, chemistry, physics, languages, and the like, which are part of the equipment of all great Universities, but can expend all its means in the applications of those sciences to agriculture. Higher education is a very costly thing. Mechanics includes machinery, and can not be taught without machinery, and the maintenance of the necessary engineering plant is too great a strain upon the resources of most of the separate Agricultural Colleges. The inevitable result is that many students are drawn from the colleges of their own states to the larger and better-equipped institutions of other states. In most cases, whether the colleges are separate or included in the State University, they receive aid from the treasury of the state. A great University requires an income of at least $\$ 1,000$ per day, with a tendency to increase. A first-rate Agricultural College alone will need at least $\$ 500$ per day. It is not believed that any of our strictly Agricultural and Mechanical Colleges have anything like this income, but a first-rate Agricultural College can be maintained in connection with a great University upon an income of from $\$ 200$ to $\$ 300$ per day.

The proper office of the Agricultural College is not well understood. The popular impression of it is as a place where young persons are educated to become farmers. This impression is wholly erroneous. Such was never the intention of an Agricultural College, nor is any such function possible to it. We can not afford to spend years in learning one trade, only to forsake it and practise another. Nor is it done. Those who have been sent to Agricultural Colleges with the expectation of becoming farmers have almost invariably ended by being something else. This has led to the common complaint that Agricultural Colleges "educate the boys away from the farm." Of course they do. That is what they are for.* The error is

\footnotetext{
* This must not be misunderstood. The meaning is that a full graduate from a first-class Agricultural College is equipped for something different from manual labor-not "better," but "different." The farm worker is helped by the "shorter," or "speeial" courses. See chapter 4 of this book.
} 
not in the Agricultural Colleges but in the false popular impression of their nature and function. A rich man's son, who may expect to become the owner of a large landed estate, or the poor man's son, who may hope for the superintendency of such a property, will do well to graduate from an $\mathrm{Agricul}$ tural College. As a preparation for the life of an ordinary farmer, a course at an $A$ gricultural College is a foolish waste. The reason is, as we shall see, that nine-tenths of the time of the student will be expended in learning what he will have no occasion to apply, and will soon forget.

The office of the Agricultural College is to investigate phenomena connected with farm life and the operations of farming, and disseminate the information gathered. Of its graduates, the functions of some must be to continue original investigations, and others to convey what is learned to the people at large. Occasionally, as stated, they will serve as managers of large properties. For this, however, vigor, executive ability, and common sense are essential. An individual possessing these qualities will be made more valuable by the education to be obtained in an Agricultural College. But if the knowlelge gained is to be applied only to an ordinary farm, the cost of obtaining it would be as unwise an expenditure as the purchase of a combined harvester by the farmer who raises only twenty acres of wheat. Besiles, eight years spent in sedentary employment when a young man, is almost sure to cause a dislike for the physical work of a farm. Habits are not easy to change.

The graduate of an Agricultural College should be able to analyze soils and foods. The farmer does not need to do this, nor could he usually have the laboratory and appliances for accurate work; neither, unless constantly engaged in it, would he be able to retain his skill. Nowadays, when a farmer desires an analysis of his soil, or of any special food, he gets it done for nothing, by experts, by sending it to his Agricultural College. Why spend much money to prepare one's self to do poorly that which he can get well done for nothing? The agricultural graduate should be a bacteriologist. That is, he should be familiar with known forms of bacteria, and 
be able to investigate, isolate, and propagate new forms. It is never necessary for the farmer to do this, nor would he have the appliances to do it, or the time to devote to it. He does not even need to know how they look, for he can never see them without an expensive nicroscope, nor, if he should see them, would he be able to distinguish one from the other, unless constantly engaged in cbserving them. It requires a long time to become a bacteriologist, and constant practice to retain the art. It does not pay to teach such a difficult thing to one who can never make use of it. If the farmer suspects the presence of malignant bacteria in a plant or a product, his Agricultural College will make the investigation for him. Such accurate knowledge of the anatomy and physiology of plants and animals as will enable one to trace and remove the causes of disease, is gained only by dissection and microscopic examination of living organisms, or those which have lived. This art, also, could not be practised by the farmer if lie knew it, for lack of time, practice, and appliances. Why, then, learn it? Most of what he needs to know, in this and other lines, has already been discovered at great cost. It is silly to spend money to do over what has already been well done. His Agricultural College and its graduates will tell the farmer what is now known that concerns him, and will undertake the investigation of all new phenomena.

The phenomena of nature are infinite in variety, and new occasions for investigation are constantly arising. Upon these problems able men in all civilized countries are engaged, and the results of their studies are emborlied in the special literature of their own languages. To keep abreast of these discoveries, and therefore save the cost of unnecessary duplicating work in investigation, the ability to read other languages than one's own is required. For this reason some part of the time spent in an Agricultural College is, or should be, devoted to the acquiring of a reading knowledge of one or more modern languages, usually the German and French, which are rich in accumulated information not accessible in English. It is seldom that any real mastery of these languages is attained by students, but they do become qualified to discover 
and dig out what they need from time to time as they need it. It is evidently a waste of effort to devote time and money to learning how to imperfectly read what one will never see, when it is certain that the imperfect knowledge acquired will vanish in a year or two without constant use.

The time required to become a graduate of a first-class Agricultural College is seven or eight years, of which three or four are spent in preparatory work, and four in the college. The cost can not well be less than $\$ 300$ per year, or $\$ 2,400$, besides eight years of time. This sum, and time, after deducting the cost of a reasonable and well-directed education after leaving the common schools, would go far to buy and stock a small farm. If applied entirely to an education, it should be considered a capital sufficient to assure its possessor a means of livelihood for his life without the additional expense of buying a farm.

It should be plain, then, that the Agricultural College is an essential factor in assuring agricultural prosperity, but that its graduates are not necessarily to be working farmers. I do not say that the working farmer will not be the better for a complete education, provided he will work on his farm, but after spending time and money to fit himself for other work, he is not likely to do so and seldom does. A person, however, who can not or will not work on his farm ought never to own one. It is useless to know how to do things if we do not do them, and if an agricultural education is worth anything, it must qualify its possessor to do what the uneducated man can not do. The educated farmer who does not work on his farm may have the barren satisfaction of knowing somewhat more definitely than others just where he loses money, but this knowledge not followed up is hardly worth the cost of it.

The agricultural graduate is a professional man, who will usually, like the doctor, the lawyer, and the engineer, gain a living by the sale of his professional knowledge. There is no more need, and need be no more intent, that the graduate in agriculture should own a farm than that a mechanical engineer should own a factory. He is equipped to give professional advice, and, if desired, superintendence. Until lately there 
has been almost no demand in America for the services of agricultural graduates, and their services are never likely to be so well rewarded as those of other professions. As a consequence, few students are found to take the full agricultural course, and of such as have done so the majority have drifted into other occupations. Nevertheless, as the demand for instruction in the branches of science bearing upon agriculture increases, the attendance at Agricultural Colleges will increase. It is increasing now. But most students are poor, struggling painfully to acquire knowledge and training by whose sale they can live. They have little use for education which will not sell. General culture is a beautiful thing, but it is a luxury, like a greenhouse or a yacht. A practical education is an education which will sell.

This, of course, is the purely commercial view of the subject. It is the view, so far as my observation goes, which the majority of university students are compelled to take. In the older and richer communities, from which I have been absent for many years, there are doubtless many who, having graduated from an Agricultural College, return to the manual labor of the farm. Whether they do or not, however, they have acquired true conceptions of the dignity of agricultural life; of the relationship of agriculture to the other arts; of the claims of agriculture upon the state for material aid, and of the nature of the aid which should be given; and they are prepared, as well-rounded and useful citizens, to become centers of powerful influence in the communities in which their lot may be cast.

For there is another view of ligher education, far more comforting and inspiring than the commercial aspect in which I am presenting it, and with which, although I do not make it prominent in these pages, I can not permit myself to be thought unimpressed. It is well to be a good farmer; but it is far nobler to be a good citizen. While from the standpoint of the poor student the mercantile view may of necessity be almost overpowering, yet from the standpoints of the wise statesman who plans public aid for higher education, the strong teachers who rise to the direction of its effort, or the 
mature citizen who is a lover of his race, the true end of education is not that the educated may be housed, and clothed, and fed, but that with a mind trained to think, and a heart inspired by daily contact with great souls, living and dead, he shall go forth in the fulness of his youthful strength, a good citizen and a noble man, to carry the light which he has received to all who may cross his path. 


\section{CHAPTER III.}

\section{THE EXPERIMENT STATIONS.}

THE original idea of the Agricultural College included an experimental form, usually with the collateral idea that students might earn part of their support by working upon the farm, and that the farm would be some source of income None of these things were found practical. In the first place, it is not possible to endure the strain of securing a modern education and at the same time to do any considerable amount of physical labor. At least it is possible only to persons of far more than ordinary strength. An old-fashioned education such as answered very well a half century since could be obtained while performing a good deal of physical labor, provided the student had ordinary strength. So much, however, is now required to equip students to compete with others that the strength of the strongest is fully taxed. In fact, no good student can begin to do what he sees he needs to do, and it is only a question of what he shall neglect least or most. Students so engaged certainly need exercise and change, but hoeing potatoes is not found to answer the purpose It distinctly lacks the element of recreation which all young (and old) people desire and require, and, besides, the potatoes must be hoed when they need it, especially if there is a rain coming up, and the farm necessities were found to continually clash with the requirements of the class-room. The work done under such circumstances had no heart in it, and so was not well done; a portion only of the students engaged in it, and these could not keep pace with the others in the classes; and the practice has been abandoned nearly everywhere.

Besides the student difficulties there was the trouble with the instructors who were supposed to supervise the operations. It was discovered that there were first-rate professors of agricultural science who were horrible farmers. An accomplished 
entomologist might not know wheat from barley or a sulky plow from a hay rake. He might know all about bugs, and have a rare faculty of imparting instruction, and so be invaluable in the class-room, and yet be perfectly helpless if called upon to deal with a piece of boggy ground. So it finally came to be seen of all men that few men could be good farmers and good scientists at the same time-not even agricultural professors. A good farmer must be a gool executive man, and many good agricultural professors are not such men, and while there are always attached to Agricultural Colleges some who are both good instructors and good farmers, the two arts can not usually be practised by the same man at the same time.

Neither was there any chance of an income from an experimental farm. Experiments are costly, and the most of them fail. New plants are tried in orler to see whether or not they can be cultivated at a profit; new methods of culture or of feeding are tried, for the same reason. If the plant or the method is not profitable it is worth while to know that, and it is better to have one experiment tried at the public expense, and the result widely published, than for hundreds of individuals to try the same thing, fail in it, and say nothing. These things are not always well understood by farmers, and as a farm which continually tries things which do not work, is sure to get a bad name, the college farms, however unjustly, became the subject of derision in their communities to an extent which largely accounts for the general prejudice against Agricultural Colleges which so long existed among farmers. It was also the fact that it is not always possible, when starting an Agricultural College, to secure the services of a full staff of clear-headed, sensible men, with the requisite knowledge and executive ability. Political methods have often controllerl appointments, and there have been some weak men connecterl with the colleges, and some foolish things done, such as could hardly occur now. Men have found their places.

But with the practical abandonment of actual farming in connection with most Agricultural Colleges, the necessity became more urgent for actual experimental work for the 
public benefit. To meet this necessity the United States Government appropriates $\$ 15,000$ per annum to each state to be expended exclusively in experiments for the benefit of agriculture. This sum is, I believe in all cases, placed in the hands of some one connected with the Agricultural College, and usually the head of it. This person is known as the Director of the Experiment Station, and is held strictly accountable to the United States Treasury for the expenditure of the funds. He is also obliged to publish at least four bulletins in each year, in which the work done at the station is described, with the results.

Some of the most valuable work ever done in the agricultural interest has been performed by these stations, and the work is likely to go on forever, continually increasing in value as more experience is gained. These bulletins, issued by these stations, liave come to be the principal sources of exact information in agricultural matters. Experimenting is an art, and it is by no means every one who can experiment in any such way as to secure valuable results. It is also very costly, and entirely beyond the means of the ordinary farmer.

In a general way all intelligent farmers are now familiar with the work of these stations, and yet their educational value is not well understood. Perhaps their greatest value is in teaching what to avoid. An experiment which is successful on a small scale and with constant watchfulness and care, may be wholly unsuccessful under the ordinary conditions of farm life, but a culture which will not succeed under station conditions should not, as a rule, be attempted under ordinary conditions.

Experiments in feeding and digestion have been very valuable. An animal can only grow or yield work by the assimilation of food. When food was abundant and cheap, and the market known, almost any kind of feeding might show a profit. But when food is dear, or prices of animals very low, it becomes an object to know, as exactly as possible, the relative feeding value of all feedstuffs. It is not what an animal eats but what it digests that counts, and if an increase of muscle is desired, it is a waste to feed fat-forming foods in 
excess, or if work is desired, an excess of flesh-forming foods. If the weight of an animal be taken, and all it eats and drinks for a period be weighed, and at the end of the period the animal be weighed again, it can be determined exactly how much the animal has assimilated from its food. If, then, the food be analyzed, and also all the excreta of the animal, it can be determined just how much of the flesh-forming and heatgiving elements the food contained, how much was digested, and how much voided unused. This, of course, will give the facts only for that particular animal under the particular conditions obtaining, but in the course of time a large number of such experiments have been made at different places and with different foods and animals, from all of which an average can be had which should show very nearly the feeding value of the fool in question. At this point exact knowledge stops, and the result is ready to be turned over to the farmer to be used in the light of his own observation and common sense with his own stock. The result is found to be a large saving in the cost of feed per pound of weight gained, or per horsepower of work done. Those who employ these methods can do work or produce meat or milk or wool cheaper than those who do not use them. In like manner all farm operations are experimented upon and tested by exact methods for the benefit of the farmer. Forage and other plants are tested for their food or other value, and new plants as to their adaptability to soil and climate. The effects of fertilizers are also closely tested and different methods of intensive culture.

The experiment stations are among the most valuable of the educational agencies which the public puts at the disposal of the farmer. Their means are limited, and no station cin do all the desirable things at once, but gralually an immense fund of accurate information is being gathered by the different stations in this country and Europe, all of which is made available to the agricultural world. Most stations send their bulletins freely to all applicants, and all stations do so to applicants within their own states. The farmer, howerer, must apply for the bulletins, and, to be benefited, must study them after he gets them, and make us of their lesions. The number who as yet do this is extremely small as compared 
with the whole number of farmers, but is rapidly increasing. Those farmers who live near enough to their stations to make them an occasional visit, can bencfit still more from them if they will only ask questions. What they will see there will be mostly new to them, for the stations do not spend money in finding out what is known already. A visitor, therefore, who merely passes through without inquiry is not likely to learn much. He will not understand what he sees, and possibly will imagine that the station men are also working in the dark, in which he will be wholly wrong. I do not think the station work is usually well appreciated by farmers living nearest the stations.

Akin to the bulletins of the Experiment Stations are the publications of the Department of Agriculture at Washington. The greater part of these are prepared in a popular form for general use, and are distributed free upon application to the Secretary of Agriculture at Washington. Some, however, are sold at the cost, as fixed by the public printer, and are obtained by inclosing the price to the Superintendent of Public Documents at Washington. None of the documents are sent regularly, as they appear, to any address, except a monthly list of publications, which is mailed regularly to all who request it of the Secretary of Agriculture. From this list the farmer can see what the nation has published for his benefit, and by application can obtain what he desires.

These publications of the Experiment Stations and the department are among the most available sources of information for farmers. They are supplemented in many, and perhaps all states, by the publications of State Boards of Agriculture, Horticulture, Dairying, and similar official bodies, all of which are always mailed free to residents of the state. It is the part of a live modern farmer to know the exact places from which this information is to be had as it appears, and to apply for it and make use of it. Great sums of public money are spent yearly for the benefit of the farmers. The information supplied is anthentic and useful. No other industry receives any such assistance from the public, and thus far the hardest task of all has been to get the mass of farmers to take and use the information which is supplied to them without price. 


\section{CHAPTER IV.}

SPECIAL AGRICULTURAL, SCHOOLS.

W

E have seen that the office of the Agricultural College is to equip students to deal with all agricultural problems. While much practical information is acquired and assimilated, that feature is necessarily subordinated to the main object. We have now to note how the power generated in the college is to be transmuted into work on the farm.

The most important of the special schools of agriculture are what are known as "short courses" conducted at the university itself. These courses vary in length from twelve weeks to two years. No special preparation is required for entrance, nor do they lead to any degree. Certificates of work done are often, and perhaps usually, given to attendants, who may use them for what they are worth. The object of these short courses is to convey to working farmers practical information which they can use in their business. It is not attempted to equip students to test the accuracy of the information given them or to fit them to deal with all contingencies as they arise. Much of what is taught must be accepted on trust. Students desiring to inform themselves in regard to special branches of agriculture are given special facilities. The students are assumed to be mature enough to know what they want, and they are helped to get it. For the longer courses a special line of work is laid out, calculated to meet the wants of the majority, but up to the limit of the strength of the teaching force, individual work is assisted. If one is anxious to qualify limself to become a lorticultural inspector, he may learn more about insects, pests, and fungous diseases than a full graduate will know; if he is or expects to be a grain farmer, he will learn about smuts, the Hessian fly, the characteristics of the different varieties of the various 
grains, as they are grown throughout the world, the special uses to which each is adapted, their relative value in the market, and whatever else may be found helpful to the grain farmer. In the same way desired special information is given in all branches of the farming industry. In most cases I think that the students in shorter courses are expected to reduce by specific study their general knowledge of the nature and properties of soils to some exactness, and especially to learn definitely how water acts in the soil, and how plants are constructerl and grow, but in general the object of the shorter course is to give to the student such knowledge as he can at once put to evidently profitable use, as, for instance, the care and management of dairy machinery, the testing of milk and. its manipulation so as to save as nearly as possible all the butter fat, the principles of feeding, and simple methods of testing its results, the nulsing of sick animals, and the like.

To many students perhaps the best thing which the shorter courses gives him is something which he did not come for, and that is some notion of the immensity of what he does not know. When once a young man has perfectly acquired this notion, he is in a way to get on, for he is then likely to begin to learn from everything he sees.

The other special schools directly comnected with the College of Agriculture are those in which practical instruction is given by practical men to students of special branches of agriculture. (of these the dairy school is the most common, and, indeed, almost the only one of this class of schools as yet established. In the dairy school it is possible to reproduce the exact conditions of farm life. The school dairy is exactly like any other good dairy, and students who themselves feed and care for the animals by what are said to be approved methods. can see whether or not these methods actually produce the better results which are assumed for them. Outside milk is deliverert just as it is to other ereameries, which the students themselves can test, and by reference to the books can see whether and how well good milk and good methods pay. They can learn to judge very exactly of the value of cows for the dairy. They can learn the most economical methods of 
handling milk in the production of buter and cheese, and how to properly care for machinery. They will not learn much about bacteria, but they will learn a great deal about their effects, and how to encourage the good and repress the evil in the process of ripening butter and cheese; and this knowledge is all that the practical dairyman requires. Finally, as his product is sold, he will learn, in marketing, exactly what customers think of it.

His instructors in the art will be experienced working dairymen, who make their living by that means, and can make it anywhere. With that instruction he will receive regular lectures from the scientific staff, on the principles underlying the art which he practises, which will put him in a way to get the most profit from his experience at the school, and subsequently in the dairy where he is employed. It is by the dairy school that all the work-renowned dairy districts have attained their excellence. In these districts the graduates of these schools are sought for as workmen and superintendents of creameries. For the latter position, however, while dairy knowledge is essential, it is not all that is required. No one can be a good superintendent of anything who does not possess, in addition to accurate knowlerge of the details of the business, executive ability, vigor, and tact. The reward of the dairy school graduate is not munificent, but it is something. With good bodily vigor, it should be $\$ 35$ per month, or $\$ 50$ if he boards himself. The "butter maker" of a large creamery should earn $\$ 900$ a year. There are large creameries which pay $\$ 100$ a month, or even more, for a "manager" or "superintendent," or whatever lie may be called; but, as already stated, the requirements of these positions call not only for dairy knowledge, but for other qualifications.

The courses at these dairy schools greatly vary. In some of the newer states a single winter course of three months is all that is attempted. The Wisconsin school, than which there is no better in America, requires attendance at one winter course, then a summer's practice in the dairy, then another winter course, and the final certificate is not given 
except upon evidence of successful dairy practice for some time after leaving the school. While undergoing probation, the students are visited, wherever they may be at work in the state, by representatives of the University, who personally satisfy themselves of the character of students' work before the certificate is granted.*

* See Appendix B for curriculum of the Wisconsin Dairy School, which is typical of the best class of schools everywhere. 


\section{CHAPTER V.}

\section{THE FARMERS' INSTITUTE.}

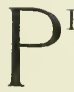

ERHAPS the most useful, and, at any rate, the most widely useful, of the methods of diffusing agricultural education is the Farmers' Institute. I have not taken pains to trace the origin of this institution, but it has gradually developed, apparently from rather crude beginnings, in all the progressive agricultural nations, of course varying in character as well as in name in different countries. The essential feature is the gathering of farmers at some convenient place near their homes, to meet successful specialists in the branches of agriculture most follower in the vicinity, for the discussion of practical problems in agriculture. Wherever this is done, by whatever name the meeting may be called, there is a Farmers' Institute.

In their order of relative importance, I conceive the objects of the Farmers' Institute to be, first, to get farmers to thinking clearly; second, to get them to talking; and, third, to convey information. The latter is by far the easiest, as the specialists who conduct the institutes always have abundant information to give, and are accustomed to giving it to public assemblies; but the mind untrained to such work can receive and assimilate but a small amount of the information conveyed in a continuous session of a day or two, and in a few weeks there will remain of the information given, in the minds of most present, at least so far as it has been given by formal lectures, little more than a vague impression. The best institute conductors fully understand this; and, instead of seeking to occupy the time themselves, find the highest exercise of their skill in drawing out the experiences of the farmers present. This is best, for several reasons. In the first place, the aggregate of useful experience in any neighborhood is always very large, and, as developed under local conditions, very apt to be more 
valuable than the more general knowledge of the lecturers. At least it has a value of a different kind, and is always more quickly appreciated by those present. A farmer who will forget in a week the greater part of the good points of a set lecture from a stranger, will remember to his dying day the relation of experience by a successful neighbor. He will also, from time to time, have opportunity to talk it over, and to observe the actual workings of the method advocated. If, encouraged by the relation of his neighbor, lie is led on to contribute his own experience on some special point, great good has been done. If, as is commonly the case, there is more or less disagreement, so much the better. When two men disagree, a new center of intellectual activity has been set up. If the disagreement is of sufficient importance to interest the community at large, they are all likely to engage in investigations upon their own account, and the influence of the institute may be felt in the neighborhood for years, and far longer than the effect of an address of a very able stranger would have endured. When the disagreements are of slight importance, the skill of the conductor is shown by the measure of his success in diverting the discussion without offense to any.

In this country the Farmers' Institute is a matter of state concern, the Legislatures of most states making anmual appropriations for their expenses. This fund is, in some cases, expended by the State University, or Agricultural College, and sometimes by State Commissioner or Boards of Agriculture. In most states the majority of the institutes are crowded into a few winter months, when the staff of the Agricultural College is fully employed in college duties. In such cases. the lecturers are mostly themselves farmers who have been specially suceessful in some lines of agriculture, and who are, besides, thoroughly endowed with strong common sense, backed by wide experience. The lectures and discussions at such institutes tend to take on what is called the "practical" form, by which is meant a relation of experience, or observation and results, with the underlying scientific doctrine not prominent. The paid lecturers, however, even if not highly 
educated, either are or rapidly become fairly well versed in elementary agricultural science, and are able to solve most questions of that kind that arise.

On the Pacific Coast, however, where the institute season extends over most of the year, and in most states where the system is new, the conductors of institutes are usually of the university staff, who get away from their college duties for a few days at a time for this work. At such institutes the strong feature is apt to be popular presentations of agricultural science, with an effort thereafter to draw out the practical experience of those present, for comparison with the general doctrines advanted. At first thought the latter form would seem more desirable, and the tendency is to regret that the number of university instructors must always be too small to do any great part of the work whenever the demand calls for a large number of institutes. I am inclined, however, although I have never attended institutes where the university work was not the prominent feature, to believe that.the best results are secured by non-professional instructo"s. In the first place, they are pretty sure not to talk orer the heads of their hearers, which, with all their care not to do so, university professors are not always able to avoid. The set lectures are more apt to deal with details with which all present are personally familiar, and, therefore, more readily draw out discussion from local men, which after all is the chief end of the institute. There is less shyness in asking questions as to detail of some one who is known as a successful furmer, than in cross-questioning a "professor" on statements of general principles. There is also the general prejudice of farmers against "theorists," by which they mean all persons who do not live by manual labor on the farm, and yet presume to discuss agricultural questions; and this prejudice although unfounded and irrational, must be taken into account in estimating probable results. It therefore seems probable that the best results in institute work will usually be achieved by nonprofessional, but competent, lecturers when those can be had. Here, however, lies a difficulty. At the beginning they are seldom to be had at all. The best farmers are apt to be busy 
farming. The small pay that is offered will not justify a successful farmer in leaving his business unless favored by special circumstances, while it is quite sufficient to attract a large class who can do no possible good, but may very likely have a "pull," which the appointing power can not always resist. I am told that there is much trouble from this cause in some states. Good farmers are, also, not always good talkers, and good talker's are not always good teachers, and some who may be good farmers, good talkers, and good teachers, are unable to realize that it is not best for them to talk all the time.

The requirements for a successful non-professional institute worker are high character and consequent good reputation at home, infinite tact and good-nature, sound common sense, readiness and clearness of speech, a high order of intelligence, a fair education, with readiness to learn, reasonable success in whatever he has attempted, and respect for the opinions of others. That is a pretty good man. One can not blow a horn and collect a crowd of such men about him. At the beginning the main work must fall on the staff of the Agricultural College, with such help as can be got in the locality where the institute is held. In the end the progress of the work will develop the men who can carry it on, just as only a war can . develop the great generals.

The ideal two-day institute is doubtless one or two lectures by college men, on underlying principles, with the remainder of the time occupied by local papers or non-professional lecturers, with a full half of the time devoted to brief and pointed discussion duly kept within bounds by a tactful conductor, and the "question box" always going. The question box is a feature of all good institutes, and affords an opportunity for any one to ask any question on any agricultural topic, with a probability that it will be intelligently answered by some one. Stated times are always set for answering questions in the box, as questions during or following an address should always be comnected with the question discussed. On certain topics-like veterinary science, or entomology-the services of a university man, or a specialist of some kind, are almost essential. When not available the 
second-hand information of the non-professional must be made to answer. Non-professional lecturers, from their frequent opportunities to hear university or other specialists, and their own experience and observation, rapidly become able to anthoritatively answer most questions relating to common pests and diseases, soil chemistry, plant physiology, and the like; and a successful and well-educated farmer will discuss feeding and culture problems with more convincing authority than a professor.

This discussion of what an institute and institute workers should be ought to give any reader who is so unfortunate as never to have attended a Farmers' Institute, a very good idea of its objects and methods. At the institute, so far as possible, there are taught the laws and processes of animal and regetable growth, the causes, nature, and prevention or proper treatment of diseases of plants and animals, the mechanical and chemical constitution of soils, the action of water in the soil, the commercial value and proper culture of old and new plants, the science and practice of feeding, the details of techmical dairying operations, and all the numberless major and minor subjects bearing on rural life. Not that all these things are taught or discussed at any one institute, but such a selection is made as will best suit the needs and desires of the members and the special abilities, knowledge, and experience of those who lead and address it. The institute is successful in a direct ratio with the spontaneous questioning and discussion which it elicits. It is, therefore, what its members make it. I have heard farmers say that they could learn nothing at such an institute, as they already knew their business. Such farmers, if they have the least spark of humanity in their bosoms, should be the first ones on hand and the last to leave, in order that they may communicate some of their knowledge to the unfortunate majority who still have something to learn. 


\section{CHAPTER VI.}

AGRICULTURE IN THE COMMON SCHOOLS.

W

ITHIN a few years there has been some effort to introduce the study of what is termed "agriculture" in the common schools of rural districts. As discussion has progressed, there has been a tendency to substitute the term "nature study" for "agriculture," as more definitely descriptive of what is proposed to be taught. This term also has the advantage of being commonly employed by teachers. As understood by them, however, it includes subjects not directly pertaining to agriculture, and has the disadvantage of not conveying to the majority of farmers the distinct idea of the connection between the proposed work and the art of husbandry. In default of any single English word expressing precisely what we mean, I prefer for the present to retain the term "agriculture," meaning thereby the study of such natural phenomena, directly bearing upon farm work, as can be profitably presented to pupils of school age.

In this work, so far as I know, the authorities of the state of Connecticut first took official action, but the first real progress was made when, in 1894, the New York Legislature, at the request of the farmers of certain counties in the western part of the state, appropriated $\$ \$, 000$ to be expended by the Agricultural Department of Cornell University in promoting improvements in the practice of horticulture within those counties. The terms of the act permitted the promotion of studies in aid of agriculture in the common schools, and the authorities of the University devoted part of the appropriation to that work. This work was entirely experimental, but it could not have been placed in better hands, and the success was such that the appropriations for the purpose were largely increased, and the work extended to cover the entire state. The New York work attracter the attention of the entire 
nation, and is likely to ultimately become part of permanent educational policy everywhere.

It began in New York, as it must begin elsewhere, in personal visits of skilled instructors from the University, going from one school to another and spending half days in instruction. The teachers quickly caught the idea and were eager to take it up. To aid them in this the University printed a series of "leaflets" containing sample lessons to be given orally to pupils, and oprened "correspondence elasses" with teachers, of whom orer ten thousand were enrolled as students by 1897 . From this the work has extended in New York and other states, anıl will be more or less familiar to most of my readers. No more promising effort in aid of agriculture has ever been marle.

$\mathrm{UP}_{\mathrm{P}}$ to the present time the term "agriculture" has been generally employed by the press in discussing these new studies, and it will probably hold its place. The vagueness of this term, alrearly alluded to, has resulted in all sorts of misconceptions as to the nature of the proposenl work, and it is desirable to inquire a little further as to what is really meant by teaching "agriculture" in common schools.

On the part of farmers I fear that in many cases nothing in particular is meant. There is a vague idea that in some way these common schools can help to make farming more attractive to young people, as well as more profitable, and thus tend to stop the drift of the young to the cities, where most of them lose all chance of ever attaining an independent life. Not knowing how else to express themselves, they speak of introducing "agricuiture" as a study, and sometimes of the necessity of a proper "text-book" for the pupils.

There is no doubt that the common schools can be very helpful in this respect, and that they are thus helping in some comntries. It is not, however, nor can it be, by the pursuit of a formal "course" leading to definite attainments within certain limits, nor is any "text-book" whatever required for the use of pupils. The first step in any useful study of agri-

* See Appendix $C^{*}$ to this book, for New York law and specimen leaflets. 
culture in common schools must be the acquirement of the ability to learn from nature direct with no text-book for an interpreter.

The rural common school deals with pupils from six to fifteen years of age. What can be done in the way of agricultural teaching must be what can be comprehended by pupils of that age, and which in practice can be imparted to them in the time which their own desires, and that of their parents, and public opinion, will permit to be devoted to that purpose, in view of the other claims upon their time and attention. It excludes the ordinary occupations and processes of the farm which they see going on every day, and in which more or less they take part. All such things they will and do learn at home to far better advantage than in the school.

In their earlier school days the children are engaged in accumulating facts; later the facts begin to unconsciously arrange themselves in classes in the mind, but they begin to reason upon them and formulate theories hardly at all during the years commonly reckoned as of country school age. If compelled to undertake this process they dislike it, seldom succeed with it, and the reasoning which the teacher may seem to force upon them for the time is generally forgotten before the end of the first game of "I spy." If the pupils seem for the moment to comprehend, and do, in part, answer intelligently, an examination on the same points a week later will prove that they really never understood the subject. For all abstract matters involving exercise of the reasoning power, they must wait till they are older. Childhood is the time to learn facts, and such facts as really interest them are never forgotten. This limitation of the powers of childhood forbids any attempt to teach "agriculture" or any other science in any didactic, formal way, or presenting the subject by means of text-books.

What they can do is to study nature. They can learn how plants grow, not by reading books, but by planting and pulling up plants and taking them to pieces at various stages of their growth. That is the way "professors" continue to study plant physiology as long as they live, and it is the only way to really 
learn anything about it. The way is as open to children as to professors, and they take never-ending delight in it. A fair microscope is within the means of any school district, and with that the cells and tissues of plants and animals can be seen, diseased growths studied and compared with healthy growth, insect pests can be identified, and their life history and habits can be determined. Much of this can be done, and a good foundation in systematic botany laid, with merely a good common hand glass. The instinct for making mud pies, with a little ingenuity, can be directed to a practical study of the action of water in the soil. The mechanical character of soils can be thoroughly studied, and about everything learned that any one can know. As they get older, they can experiment with simple chemical reactions, so as to understand at least what they are, and understand fairly well the nature of the chemical changes which take place in the soil and the leaf. Such work as this is what is meant by those who intelligently discuss introducing the study of "agriculture" in the rural schools. It is good work for any school. It is adapted to the mental nature of the child. Its acquirement is a source of real pleasure to all children, which is certainly more than can be said for the elements of "grammar." 'The knowledge thus gained will never be forgotten. It is a fitting preparation for any walk in life. It is essential to the making of the farmer who hopes to survive in the struggle for independent existence. It is knowledge which he will apply every day of his life. The little that he learns will teach him the methods of learning more as special neer arises for special knowledge. It is the best foundation possible on which to build up a successful farmer.

Of course the child can not learn all this by himself. $\mathrm{He}$ must, at least at first, be told where to look, and possibly how to look, and when he sees a thing lie must be told what it is. And there is the rub. The teachers know very little more about these things than the children, and the most of them have no wish to learn. They have passed the age of curiosity, and are thinking of other things. If compelled to learn them to hold their places, they will do so, and, very likely, for the 
most part, get highly interested in the end, and finally become good teachers if it is in them, but nine out of ten of them will attack it with regret.

The teachers are by no means to blame for this. They are exactly like the rest of us, and substantially reflect public sentiment. Our ideal of elucation is one of our inheritances from England, and comes down from a time when only rich men's sons were educated, for whom general literary culture was the training desired, and very likely most desirable. When Massachusetts, and others after her, established the common-school system, the ideal of education was the English ideal, which was always before that portion of the public which expected or hoped to go beyond the three R's, and directed the aspirations of teachers and parents. After the Revolution, and especially during our periods of most rapid expansion, all children were regarded as the sons of sovereigns, and the ideal of their education was that of other princes. When the pressure of population began to be felt, there arose a demand in the most populous centers that some portion of the school time be spent in direct training for special avocations, and this again raised the techiical dispute among teachers as to whether the pupil is not best prepared for all avocations by general training without special reference to any.

This educational question will be settled by experiment under demand created by the increasing difficulty of obtaining subsistence and maintaining the standard of comfort. It is significant that the demand for special instruction is now beginning to be heard from the rural districts. In most cases, however, it does not seem to come from the masses of the people, but from a few who feel that some technical instruction is needed. The fact is that for the most part farmers' children do not wish to be farmers, and their parents sympathize with them, which results in a feeling of apathy which it is difficult to overcome.

Another difficulty lies in the fact that the teachers are not farmers, and while many are the sons or laughters of farmers, their feeling is not for the farm. The outcome of all these influences, new ideas struggling to get into the schools, and 
old ones refusing to make room for them, is a very crowded curriculum. When anything new is introduced no time allowance is made for it, but the teacher is expected to accomplish just as much as ever with everything else. Special instruction is called for in many things, which involves special fitting on the part of teachers, until they come to wish to avoid every new subject. In elucation, however, as in everything else, there is a competition of ideas, and the fittest will survive. Wherever the farmers in rural districts unite in the desire for such special instruction as I have outlined above, to be given in the rural schools, they will get it. They can in most cases get it to-day, without legislation or the aid of any one. There is a keen competition among teachers to get schools, and any school in most states whose officials let it be publicly known that they will employ no teacher who does not bring a certificate from the State Agricultural College, ${ }^{*}$ of competence to teach the elementary science underlying husbandry, will get such a teacher as is desired. Any considerable demand of this kind would at once make the subject prominent in all normal schools, and within a short time teachers will be as competent to teach "agriculture" as anything else.

It is a fact, however, that such teaching as I have outlined requires excellent ability. It is not every one who can do it successfully. The teacher must have decided power over a subject to be prepared to teach it orally. If a teacher has learned to distinguish a cottony cushion scale, and a child brings a specimen which, under the microscope, proves not to be that scale, the next question will be, "What is it?" and if the teacher can not answer, there is a certain embarrassment. For this reason, and also owing to the fact that proper preparation for the oral teaching of elementary natural science is really beyond the reach of many teachers, systematic instruction in these subjects should usually involve the employment of special teachers who will go from one school to another,

* Or any university or normal school in which husbandry and the application of nature study thereto are properly recognized in the courses of instruction. 
spending a half day with each in turn, the week between each visit being carried on by the regular teachers by the aid of suggestions contained in leaflets or hand-books specially prepared for their use. This, in fact, is the method adopted in New York, where Cornell University supplies, at the expense of the state, competent traveling instructors. This method is also employed in Germany, where, however, there is less need of it, as the teachers are mostly men who make teaching the avocation of their life. In this country, where the majority of the teachers are women, many of them quite immature, and for the most part with quite other views for the future than continuous teaching, the employment of special teachers will probably usually be found essential.

The compensation for such teachers will necessarily be sufficient to justify the expense of a suitable preparation, and to support a man with a family and a horse. Such a teacher could visit about ten schools a week, spending a half day with each, and about twenty schools would be the limit for each teacher, if real progress is expected. In most states there is probably no provision in the laws for the appointment and payment of special teachers serving a large number of schools, and the securing of such legislation must be the first practical step towards the introduction of such studies, except as individual districts may act by securing regular teachers who are qualified for the work.

Little good will be accomplished by moving too fast, and in advance of public sentiment. At one time the law of California required that "entomology" should be taught in all the common schools of the state. This provision was inserted in the statute as the result of the work of one enthusiast, who appreciated the importance of such instruction in fruit-growing clistricts, and who had himself prepared a text-book for the purpose. It was, however, a subject harlly understood by anybody. The methods of dealing with insect pests were crude and unsatisfactory. There was no attempt to deal with fungi, which are almost as destructive as insects. In the majority of the districts there were no important fruit interests. The teachers, of course, knew nothing about the subject, and 
asually ridiculed the idea of teaching any such thing to children. Such attempts as were made to carry out the law were in most cases wholly futile. In a few years the law was repealed, to the relief of all connected with the schools. In the meantime, however, since the law was on the statute-books, a large number of teachers endeavored to prepare themselves for it. The subject was introducerl in the normal schools, and the classes in entomology in the University, which had always been very small, at once began to grow, and were soon large and interesting. When the law was repealed they at once fell back almost to their old numbers. All this shows that it is usually impossible to push reforms much in advance of public sentiment, and yet that, if enacted into law, and kept long enough on the statute-book, such a movement will in the end result in an adequate supply of those competent to carry it on. The California law was repealed just as it was about to become possible to properly execute it. It was very faulty, however, in that it made insect life the main end of study, which should be plant physiology and hygiene.

The foregoing, with a perusal of the documents relating to this subject which will be found in the appendix, will give an idea of the conception of agricultural instruction in the common schools as it exists to-day. Its object is to impart to children such elementary knowledge as is jossible of all the natural sciences underlying the operations of the farm. In the present crowded state of our school curriculums, the introduction of a new subject, in which any real progress is expected, must usually involve the displacement of something else. One practical question must be as to what shall be omitted that is now taught. There will be advocates of that subject, whatever it may be, who will fight its displacement. In rural schools it is not at all unusual for the teacher to conduct twenty-five or thirty recitations each day. The actual school day, deducting recesses, is about three hundred and twenty minutes. Dividing this number by thirty, the average time that can be devoted to a recitation is but little over ten minutes. If there are but twenty recitations per day, the average time for each is sixteen minutes. Any effective study of natural science will use up several of 
these periods, and invariably occupy the attention of every pupil in the school as long as it lasts, which should be evidence that it is adapted to their mental attaimments. This practical question, with that of the securing of competent teachers, suitable appliances, and the necessary financial support, are the main problems to be dealt with in connection with the study of agricultural science in common schools. None of them are yet solved, and in fact have hardly yet been seriously considered. 


\section{('HAPTER VII.}

\section{AGRICULTURAL PAPERS AND BOOKS.}

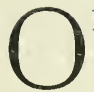

NE of the curious things which must be taken account of is the intense prejudice which exists among large masses of farmers against what they call "bookfarmers" and "book-farming." Everything has its cause, and there is, of course, a cause for this prejudice. In part it is accounted for by the very unpractical character of some popular books on farming which were published a lualf century since. There was good literature on the subject even then, but it did not seem to get into popular form. Allowing for the advance in scientific knowledge since that time, there is very little to which modern science can take exception in the old cyclopedias, for example, which had the widest popular circulation, and in which the agricultural articles, written by the best men of the time, are clear and sensible. The first really popular movement towards scientific agriculture was based on the idea of controlling fertility by the operations of chemistry. There were then few agricultural chemists in this country, and they doubtless had rather exaggerated ideas of the possibilities of agricultural chemistry; and these, as conceived by the people, were still more impossible. There was an abundance of virgin soil to be had for the asking, and more money could be generally made by robbing that than by improving that which had begun to be exhausted. Analysis of his soil in advance was practically impossible to most farmers, who, so far as they used commercial fertilizers at all, used them blindly, and often without much regard to mechanical and climatic conditions, or the special needs of the different plants. The result of these exaggerated notions, usually still farther exaggerated and unintelligently applied, was a great reaction from what at first was a promising movement, and a deep-seated prejudice against "scientific fellers" of all kinds, which has been 
transmitted to this day. Agricultural chemistry is even yet one of the least-understood sciences, and while certainly of great importance, is less reliable as a source of profit than almost any other of the applications of science to agriculture. At the same time, so deep-rooted and permanent are these popular impressions, that the general notion of "agricultural science" and "agricultural books" is almost exclusively that of the employment of commercial fertilizers under the direction of chemists.

Another reason for this wide-spread prejudice is the fact that very few farmers ever read the books they condemn. As a matter of fact, with all the shortcomings of the old books on agriculture, they contained a great deal of useful information and sensible discussion. For the most part, what the farmers objected to was not what the books contained, but what they imagined they contained. No prejudice is so bitter as that founded on absolute ignorance. Still another reason is the gradual sapping of the farmer's intellectual vigor by the flood of cheap periodical literature, seldom reliable, largely sensational, and always ephemeral, which now infests the earth. In the old days most farmers had a few well-bound books, handed down from former generations, very solid in character, and which were read and reread of the long evenings until thoroughly mastered. The daily paper he happily knew nothing of. Such training tended to make strong minds and thoughtful men. It is now hardly possible, from sheer intellectual weakness, for a large portion of our farmers to attack and master the intricate agricultural problems which confront them. The majority will yield to the inclination to drop study for the newspaper the moment it comes in. And yet it is seldom that the contents of the daily paper are of any special consequence. The habit of newspaper-reading also begets the habit of superficial, hasty reading of all publications, whereby the real meaning of the author is missed. If it be said that what is said here is by no means true of all farmers, the reply must be that it is in the main true of that portion of them who are most prejudiced against bookfarming. 
Another cause of the prejudice is the undoubted fact that comparatively few farms owned by city men, who are usually the devotees of book-farming, are a source of profit to their owners. In some cases these gentlemen, doubtless, make grave mistakes, for a successful farmer is as unlikely to be made by the study of books alone as a successful merchant or manufacturer. All books on farming presuppose their readers to be practical farmers, familiar from boyhood with the details of farm work, and consequently able to apply scientific doctrine in the light of common sense and experience. Whoever, without experience, undertakes to carry on a farm, is as likely to come to grief as he who so undertakes to carry on a factory. Finally, it is as true now as in Ben Franklin's time that

"He who by the plow would thrive,

No farm to which the actual owner does not give his principal attention and thought is likely to be profitable. The "practical farmer" who should undertake to carry on his farm by weekly visits only, would be even less likely to secure profitable results than the eity man who adopts the same course.

As a matter of fact, however, substantially all books on agriculture which are now issued, are the work of intensely practical men who place their experience and observation at the command of mankind. They are compact and complete statements of what the author knows, and are of the utmost value to the practical farmer who will make use of them. It would be difficult, if not impossible, for a poor book to find a publisher, for even the very best books yield hardly any revenue either to publishers or authors, for the reason that farmers do not buy them. In the long run, I suppose those which get published pay for themselves, but I doubt whether Professor King's invaluable book on "Soils," for example, has ever paid its author a dollar a day for the time actually spent in writing it and correcting the proof sheets, to say nothing of pay for the time spent in acquiring the information. I have prepared, as very valuable information, a list of some late hooks on agriculture, with publishers and price, which will be 
found in the appendix.* It is doubtless not complete, but it will enable readers to find reliable information on most subjects connected with farming.

The most important sources of information for farmers are the publications of the state and national governments. I have already (page 49) alluded to these, and the appendix will indicate how any farmer may obtain them. They are, for the most part, sent free on application, and when a price is fixed, it is the exact cost. I call these the most important because they are the most accessible and cheapest. They are nearly always brief monographs on special subjects, and do not by any means serve the purpose of more extended treatises by the same or equally competent gentlemen, which are published as books by private publishers.

The agricultural press as now conducter, is of very great value to farmers. All farmers worthy of the name take one or more agricultural jonrnals and find them essential. At the same time there are various limits to their usefulness. The first and most important is the necessity of publishing such a paper that the income will pay its expenses, and if possible leave a profit. A paper which does not pay must soon stop. For most agricultural papers, however, there is little or no profit in subseriptions. It eosts so much to get and collect them that if it were possible to obtain an income from advertisements by printing only a sufficient number to suphly each advertiser, in a great many cases the publisher wonld be a gainer. But the circulation is necessary in order to secure advertising, and it is kept up by canvassers, by sending the paper on credit, which always involves large losses, by "premiums," "clubbing" arrangements, and other derices, all of which cost money. The alvertising space in papers going exclusively to farmers is also of less value than in papers of general circulation, because farmers are consirlered as baving least money to spend.

The necessity, therefore, of an alvertising patronage in order to publish any agricultural paper, in various ways

\footnotetext{
* See Appendix D.
} 
interferes with its value. A manufacturer of fertilizers will not advertise in a joumal which persistently advises its readers to compound their own fertilizers; and if the money is needed, the editor must keep still, whatever he thinks. The commission merchants will not advertise in a paper which urges the farmers to form cooperative marketing associations, or the insurance companies in those which advocate farmers mutual insurance companies, and so on through the list. In fact, to most agricultural journals the free discussion of the real merits of any article or interest in which private capital is involved, is practically impossible. Wild horses would at the present time be unable to drag from any agricultural editor his printed opinion as to the relative merits of the competing milk separators. We may say that this is not right; that the subscriber pays the journal not only for the infor mation which it gires, but for the best jurlgment of the editor on all questions that concern agriculture. The reply, however, must be that the farmer does nothing of the kind. As a class he pays next to nothing for the paper, after deducting the cost of getting the business. There are, of course, some agricultural journals of which this is not true, but of the majority it is quite true. They get their income from others than farmers, and must so shape their course that those who keep them alive are satisfied. If they do not they will die. They do the best they can, and seldom or never lend themselves to actual deception, but free discussion, wholly in the interest of farmers, will never be possible until the farmers supply the income to support it. On these terms they can get it any day.

Another limitation is the intricacy of morlern agricultura] affairs, the constant intermingling and conflict of agricultural interests with each other and with competing interests, and the world-wide ramifications, which it requires world-wide information to comprehend. There is also the constant progress of science, which must be followed and treated. Before all this the agricultural journal is positively helpless. No such journal in the world can pay from its receipts the expenses of adequate treatment of agricultural topics. 
The agricultural press, therefore, on such matters is compelled to fall back on public documents and the utterances of experts at Farmers' Institutes and similar gatherings. Of these, fortunately, the supply is abundant, and one of the most useful functions of the agricultural press is the republication and condensation of this material.

The journals of special industries, like the dairy, the poultry yard, or the fruit farm, are usually conducted by successful specialists in those lines, and give much original information. Of the important papers of general agriculture probably all are conducted by those who are or have been successful farmers. Many of the editors own and live upon farms, but this tends to be otherwise, because no man can be a good editor and successful farmer at the same time. To do either will require all his energy, and he will tend to give up one occupation or the other.

The live agricultural paper keeps the farmer well informed as to improved methods, progress of science, and the introduction of new farming industries, and for this purpose it is worth to the farmer far more than he pays for it. It gives him a great deal of definite information of value to him, and shows him how to investigate further. It will always gladly investigate special problems, as to which, although the editor may know little, he is usually in a position to ascertain the facts.

In an agricultural journal nothing is read with more interest, or is really of more value, than the correspondence which it contains from practical farmers on practical subjects. It is also true that few things are more valuable to the farmer than the habit of contributing lis experience to his agricultural paper. In the first place, the act of writing condenses his ideas into a compact form, and discloses to himself any errors of reasoning or gaps in information. It puts his knowlcige into more workable shape, for lis own use, or for imparting to others. To an extent which will surprise limself, it will also make him known to his community, and to the extent that his views are sensible, he will find himself respected and influential, which is always a pleasure. One who is in the 
habit of contributing, over his own signature, to an agricultural journal, will be astonished to find how many have heard of him, and are glad to know him, should he happen for the first time to visit a state fair or other large gathering of farmers. The habit of writing also leads to the habit of study and self-improvement.

Some farmers who would frequently contribute valuable experience to the public, are restrained by the feeling that they can not express themselves well, perhaps can not spell well, or write well. These neerl not trouble any one. The writing must be legible, and be written on one side of the paper only. Otherwise it does not matter how it looks, or what the spelling is, or how it is expressed. If it is all right, it will save the editor some work, but that work is what he is paid for, and what he has to perform on the majority of communications sent in. As it appears in the paper it will rear all right, and nobody but the editor will ever know that it was otherwise, and he will forget it in a week. Any editor who can obtain valuable suggestions or narrations of useful experience, is only too glad to put them into proper form, provided only that the communication is legible, and not written on two sides of the paper, which always involves copying out for the printer, which no editor will do unless the subject matter be more than ordinarily important.

The agricultural press does its very best for the farmer, and should be cordially sustained by prompt payment of subseription money and the contribution of experience and suggestions for its columns. 


\section{CHAPTER VIII.}

THE STLDY OF THE FARM.

THE foregoing review of the principal agencies external to the farm which the farmer may employ to increase his knowledge, has prepared us to consicler that greatest of all means for self-improvement, which is the study of the farm itself. If the somewhat elaborate study of other agencies has led any reader to imagine that I suppose that any one can become a good farmer by any other means than by faithful devotion to the duties of the farm, I beg that he now recognize that he is in error. It is only on and by the farm that the man (an become a farmer.

It is this feeling which all engaged in any industry possess that only by the practice of an art can the art be learned, that is doubtless at the bottom of the farmer's distrust of "book farming;" his error consists in supposing that any intelligent person believes otherwise. The external aids in the way of schools, lectures, books, and experiments, are to be understood as aids and nothing more. They put the farmer in possession of information acquired by others, which he may apply to his own advantage upon his own furm; and the farmer who thinks that he can successfully compete without more or less of this aid, and refuses to accept it when offered, is in all probability a lost man. Any farmer who could by any possibility be considered smart enough to succeed with only his own experience as a guide, will be the first man of all to avail himself of the experience of others. But of all studies, that of one's own farm is the most important.

In the study of a farm, it is probable that hardly any two men would proceed alike. Each man, knowing certain things, would endeavor to add to his knowledge in such directions as he felt a lack, and in so doing would proceed according to the 
nature of the knowledge already in hand, and his own habit of mind. What I am about to say will simply indicate how I should personally approach the subject, and will give some idea of what I mean by the study of the farm.

When a man has lived upon a farm for ten years, the number of things which he knows about it is enormous. If it is a small farm, tilled with his own hands, he can lie on his bed and call to mind an infinite number of details: the slopes, the different soils, the weed patches, the fruit trees, and even insignificant details of the fence corners, clumps of brush in the pasture, a stray thistle here and there, and a multitude of things, some important and others of no consequence. If called upon for any special item of information, the question will suggest to him many other things not before thought of; in short, he will himself be surprised at the number of details which he has unconsciously absorbed, and which are ready for his use so far as they have value. Of course men differ wonderfully in their capacity for seeing; some see almost everything, and others comparatively little. The latter class will possess a great part of their knowledge as a rather hazy impression, which they would find it very difficult to reduce to words. For such men the first thing of all is to learn to see. This habit is easiest acquired in childhood, when curiosity is active and the eyes at their best; and the greatest benefit to be derived from the study of agricultural science in the common schools is the early acquirement of the art of seeing.

A systematic study of the farm consists first in the separation in the mind of the important from the mimportant facts; second, the formation of a mental judgment as to the relative importance of each, and the reason therefor; third, acquiring a clear perception of what essential knowledge is lacking, and finally the acquirement and utilization of that knowledge.

I will assume that a man has lived ten years on a farm with ordinarily good health, and no serious misfortunes, such as fire or pestilence, and yet has made no headway. If he owed money at the beginning, he owes it still. He feels that he has been prudent in expenditure, and knows that he has been industrious, and yet has not got on. He now, having 
read the foregoing, sits down to "study his farm," to find out what the trouble is.

The first thing he will require is absolute frankness with himself. If he sets out in lis study with the intent to prove something, he might almost as well not begin. He is about, whether he knows it or not, to engage in "scientific farming," and the first teaching of science is to follow truth wherever it leads. If his study of the farm convinces him that the farm is all right but that the error is in the way he has used it, he must be prepared to accept the conclusion.

In the first place he will consider what crops he has raised and is now raising. He is producing to sell. Where is his market? Who will ultimately consume his produce? How is it to get to the consumers? What will it cost to get it there, including pay to those necessarily handling it? What competition will it meet in the final market? How is he prepared, under natural conditions as they exist, to sustain competition? From what points can an adequate supply be delivered to the markets in which he must compete? Of these points which can probably produce cheapest? With all these questions satisfactorily answered, he is prepared to study the conditions of his own farm. If the result of this study convinces him that he is among the number of those who ought to produce most cheaply, and his crops are articles of staple production, he has established the fact that it is probably not by a change of erops that he is to better his condition. More especially will this be the case, if, upon looking about, he finds some of his neighbors who have been producing the same crops, to be personally prosperous. His conclusion must be that his crops cost him too much, and more than similar crops cost others.

The next step is to tum to his own books and examine closely the items of his own costs. If, as will perhaps be the case, he finds there only blank pages, or accounts so kept that he can not accurately tell the details of the cost of anything, he can only, for the present, reach the conclusion that some one is producing cheaper than he, but he does not know how. This may seem an awkward way to reach a study of the 
farm. It may not be the best way. It is the way I should naturally reach it, because I could only study it with real interest when looking for some particular thing, and before minutely studying the farm in the search, shonld wish to satisfy myself whether it is probably there.

Suppose that I discover that in raising wheat my average crop is fifteen bushels per acre, and I am making no money, while my neighbor, who is getting ahead, gets twenty bushels to the acre on an average. My sturly would be, how, with the least additional expense, I could add five bushels a year to my average crop. My trouble may be either in insufficient tillage, or insufficient fertility, or both, or in the character of the land. If the latter, it is evident that unless by drainage, or some other practicable methods, I can change the character, of the soil, I had better make a change of my crop. If bad tillage or insufficient fertility is the cause of light crops; my object will be to discover how I can most economically change these conditions. If my neighbor's land and my own were originally alike, and his is now in better condition, it must be accepted in my mind that he is an abler man than myself, and better farmer, and that I can not probably do better than to watch his methods and follow them.

This is always the conclusion hardest to accept. No man will willingly admit that another is abler than himself, but if the facts show it, it must be accepted if any progress is to be made. Failure in farming, in the absence of sickness or other special misfortune, is due either to the farm or the farmer. The study of the farm should show which, and, the conclusion once reached, effort must be directed to the improvement of the element at fault. If the farm is fertile, or has once bcen so, the fault is evidently in the farming, and this may be either in choosing crops not suited to the land, or for which there is no adequate market, or in poor rotations, or the absence of any rotation, or in constant robbing of the soil with no return of fertilizers, or in bad tillage, or in uneconomical management. The study of the farm, especially in connection with a book showing details of cost, should show which. 
The study of the farm means the aequirement of a detailed knowlertge of the soils, exposures, and moisture, in connection with erops adapted to them. It is no reflection on farmers to say that few of them know how to study the farm or anything else. The art of study is itself one of the most difficult of ali arts. The main object of a University education is to learn how to study, and the seven or eight years required for the Bachelor's degree is none too much to aequire that ability. It is, therefore, no reflection on any one who has not had that training, to say that he probably does not know how to study, and the following suggestions as to methods for studying the farm may serve to show how a trained mind might approach the subject.

First, make a complete list of farm crops possible to be raised in the locality. Among these are almost sure to be some not now raised at all. Mark this list in the order of their importance as indicated by their relative volume. Those of which the most are used are most certain of prompt sale. Against each crop note the nature of the soil and climate best adapted to it. Then study the markets for each product, your distance from them, and the cost of transportation thereto. Flax products, for example, are consumed in linen and twine factories, and in oil mills. A farmer at a great distance from either might find it difficult to dispose of lis crop even if well situated for its economical production. Wheat, on the contrary, is salable everywhere because consumed everywhere. It is always an advantage to raise a crop largely produced in the vicinity, because its volume will tend to attract cash buyers, while a crop of which little is produced must always be transported to market at prorlucer's risk and expense, and usually sold through commission merchants. At the same time men of exceptional shrewdness and vigor often do well by devoting themselves to something out of the way for which they have discovered or ereated a special market.

When, by carefully eliminating from the list of possibilities those crops which seem to offer least hope of profit, it has been reduced to a comparatively small number, it is time to take up the capacities of the farm. These are determined 
by its chemical constituents (fertility) and its physical qualities, including texture, moisture, exposure, and climate. Comparing these with the conditions required for the different crops, the farmer will be able to judge what he can produce most cheaply, and sell most surely, and by what rotations he can best maintain his land in good condition both as to fertility and mechanical condition. The farmer who has once made such a study of his farm will feel such a confidence and assurance in prosecuting whatever branch of the industry he may finally decide upon, as he never felt before. He will feel that he is master of his business. If it he said that our fathers succeeded without any such study, the reply is that our fathers lived under different conditions. Modern competition has invaded farm life, and those only can succeed who are competent to sustain themselves under competition; and those who can live under competition are those who know how to so direct effort that there shall be the least possible waste. It is waste of effort that kills, and it is study that prevents waste. 


\section{CHAPTER IX.}

A FURTHER STUDY OF THE FARM.

[By L. A. Clinton, Assistant Agriculturlst Cornell University.]

\section{The Farm as a Home**}

NY person who contemplates purchasing a farm, upon. $\triangle$ which to establish himself, and secure a living, should 1 make a most careful study before deciding upon the farm to be purchased. There are many features which should be considered besiles the one of securing a competence, "for it is not all of life to live." First, there should be considered the adaptability of the farm for a home. Unless it possesses in itself and by environment those qualities which go toward making a pleasant and healthful location for a home, then the study should not proceed further, but some other farm should be selected.

In selecting the site for a home there should be considered healthfulness of location, character of the people in the surrounding district, nearness to churches and schools, quality of the land in the neighboring farms, nearness to the market town, and quality of roads leading to and from the farm.

Healthfulness of location should receive first attention, for if the land is so located that the conditions are unsanitary as regards drainage, water supply, etc., and these conditions can not be remedied, then no matter how favorable the other conditions may be, the farm should not be selected for a liome.

The character of the surrounding people, whose intelligence and honesty will very largely give the reputation to the community, will materially add to or detract from the value

* For a more complete discussion of this subject the reader is referred to a book entitled "Rural Affairs," now in preparation, by Prof. I. P. Roberts. 
of any farm as a home. The social adrantages, the schools and the churches, will be no better and of no higher order than the people who compose the community. We are influenced more or less by the people with whom we come in contact. The children of a home are influenced for better or worse by their playmates. Then in selecting a home an important consideration should be the character of the people who will be our neiglıbors.

The churches and schools are important civilizing and educational agencies. A live church in a community adds to the desirability of that community as a home. It tends to create a better moral atmosphere; it raises the general standard of the people; and, whether we will or not, its effect is to increase the value of any district as a location for a home. The importance of the country schoolhouse is generally recognized, and its importance is increasing each year as better methods of instruction are adopted and more attention is paid to education. All classes, educated and uneducated, recognize in the school an agency the influence of which is second only, if not equal, to that of the church. The desirability of the home is increased then as it is located within easy reach of the schoolhouse, so that the children of the family can receive the benefits of the instruction there imparted.

It is not only important that the land be fertile on the farm to be purchased, but also that the neighboring farms be fertile. The character, disposition, and temperament of people are very largely influenced by the amount of labor necessary for them to secure a living. If the surrounding land is poor, and of such a nature that it requires the maximum expenditure of labor for a minimum of results, then the opportunity of people who live upon such land for intellectual development is limited, their interest in public improvements is likely to be small, teachers hired for the public school are usually the cheapest that can be procured, and thus, in many ways, is the value of a farm as a home enhanced or diminished according to the nature of the surrounding lands.

Distance from the market town is, to a large extent, determined by the quality of the roads. With the advent of good 
roads, when it will be possible at all times of the year easily to reach the town, the distance in miles will become of less importance. But with conditions as they are now in a very large proportion of our rural districts, when, for a part of the year, the public highways are in an almost impassable condition, the distance through which one must travel such highways in passing to and from the market should have an important influence in determining what farm should be selected for a home.

The Furm as a Source of Income-Being in possession of a farm, there is then at hand abundant opportunity for study, and the ways in which different ones will take up the study will probably be as various as the farms to be studied. There are, however, certain important considerations which should be given careful thought, for, no matter how pleasant the location as a liome, if one can not secure a competence upon the farm, then it will be necessary to look to other employment as a means of sustenance.

With the farm there is possessed not only a certain area which can be measured in acres, but also a vast amount of plant foor, raw material, from which are to be manufactured certain products. The plant food in the soil really constitutes the stock of the farmer. The value of this stock will be determined, very largely, by the treatment the land has received, the availability of the plant food in the soil, the texture of the soil, and the methods of agriculture to be pursued.

There will be found certain fields of the farm which exceed the average in fertility, and other fields will be found deficient. Those fields which are deficient will naturally receive attention first. A fertile field is one which will produce crops at a profit. If a field is found not to be producing crops at a profit, then investigation shonld be commenced at once to determine the causes. The most common causes of infertility are abuse of the land, poor texture of the soil, lack of adaptation of soil to crop grown. It is probable that the first cause mentioned is the most difficult of any to detect, and it is one of the most common causes of infertility.

The abuses most frequent are the annual removal of crops 
without any returns in the way of manures, fertilizers, or organic matter, and the leaving of the land naked during the rainy season, and thus exposed to the action of rains and floods.

So generous has been the supply of plant food that the abuse first mentioned may have been going on for several generations. On the newer lands of the west, this system of soil robbing is still going on. On the older-cultivated lands of the east, the ruinous effects of the system have become apparent, and the practice has, of necessity, been checked. If it is found, upon a study of the various fields of the farm, that this form of abuse has been going on, then, first of all, the practice should be discontinued, and means taken at once to restore the land to a fertile condition.

The loss of fertility is not because the plant food has all been used, for that has been impossible. Only that plant food has been used which could be most easily extracted. There still remains an abundance of plant food in the soil for the production of many crops. It is some other feature besides plant food, then, which needs first to be studied and remedied. The organic matter or humus of the soil has been so depleter that it is no longer loose and mellow, slightly springy or elastic when trodden upon, but is heavy, compact, and runs together in an almost impervious layer under the action of beating rains. This condition must be remedied. Returns of organic matter must be made either by the plowing unde: of green crops or by the use of barn manures. Humus is capable of holding over one hundrerl per cent of its weight of water. A soil that is deficient in this important constituent, humus, is thereby deficient in its moisture-holding power. As the humus of the soil is increased, within certain limits, the power of the soil to hold moisture is increased. If a careful examination of the condition of the soil shows that it is lacking in humus, one of the cheapest and best ways by which it can be supplied is by the plowing under of leguminous crops, as clover, peas, beans, vetches, etc. If the land is so poor that these plants can not be grown, then any plant which is hardy in the locality and is what we call a "coarse 
feeder" may be grown. Among such feeders may be mentioned rye, buckwheat, spurry, and weeds of infinite variety, for a crop of weeds plowed under is far better than nothing. But why all this work and apparent loss of time?-Simply to bring to our command some of the vast stock of plant food which we possess, that we may be enabled profitably to manufacture the raw materials of the soil into a product for which there is a demand. The fermentation and decomposition of organic matter in the soil creates carbonic acid; this acid acts upon the elements of the soil and makes available some of the plant food which has been heretofore locked up; the condition of the soil has been ameliorated and brought into a condition more favorable for the production of a higher class of plants than formerly. When the soil has been thus improved, commercial fertilizers may be tested, not because the soil is deficient in potential plant food, but because the supply of available plant food may be deficient.

One practice which is most wasteful and improvident is that of permitting the land to remain naked during the winter and thus allowing it to be washed and plant food wasted. Lands which are left naked, that is, with no plants growing upon them, during the rainy season, lose more plant food in the drainage water and by surface washing than would be removed by several crops. Where thorough tillage is practiced on crops grown during the summer, a large amount of plant food, especially nitrogen, is made available in the first few inches of surface soil. Not all of this plant food is used by the crop growing upon the land. If, when the crop is removed, the land is left bare, this soluble plant food in the surface soil is washed out or changed into a form which is less available. To prevent these wastes the soil should, at all times when possible, have plants growing upon it. Rye or wheat may be sown in the late fall after the regular crop is removed. While the plants may not make much growth, yet they feed upon the soluble plant food and thus prevent its waste; the roots permeate the soil and hold it in place, and when the land is plower in the spring some addition is made to the organic matter of the soil. Seed for this cover crop 
may be sown without replowing the land, and it may be drilled in or sown broadcast and harrowed in.

The texture, or physical condition, of the soil has much to do with fertility. Not all fields of the farm, nor all parts of the same field, can be treated alike to secure the best results. A field of grain is unsightly as well as unprofitable where on large portions of the field there was failure in securing a stand, or where the crop is a partial or complete failure. Earnest endeavors should be made to discover and remove the causes which produce these conditions.

A study has been made of the means by which the moistureholding eapacity of soils may be increased, but an equally important subject for study is how the surplus water of the soil may be removed by some other means than by surface drainage or evaporation. If the subsoil is porous and open, then it is probable that no artificial drains will be required. But when there is an impervious subsoil, or where owing to seepage a soil is kept in a water-logged condition for a consiclerable length of time, then the matter of drainage should receive careful study. In planning for the removal of the surllus water it is probable that a complete system of drainage would not be put in at first, but a complete systern should be planned and a partial system provided for those places which seem most to need drainage.

The farm is not only a storehouse for plant food, but it is a factory where, through action of sunlight, moisture, and warmth, the raw material, plant food, is changed into a more or less finished product according to the system of farming pursued. In deciling what class of products shall be manufuctured it is absolutely necessary for success that the farmer make a study of limself. If he loves the form and lines of the Jersey cow and takes delight in her beanty, then it would be manifestly improper for that man to breed IIolsteins. He should breed that class of animals which he loves and will take pride in and care for. If a farmer takes delight in growing potatoes and it gives him pleasure to see their luxuriant foliage, and to care for them and keep them free from blight and insects; then he should make a specialty of potatoes, pro- 
viding his soil is adapted to the crop. There should of course always be adaptation of crop to the soil upon which it is to be grown. Once it is decided for what crops the soil is arlapted and what crops or products it will give pleasure to the farmer to produce, then the energy of the farmer should be concentrated in mastering all the details which enter into their production. Success on the farm can not be obtained by fluctuating from year to year between various products. Some fixed policy should be decided upon, and then that policy should be adhered to and not thrown up because of one season's failure. By this we do not mean that one's energy should be all concentrated upon che crop, but whatever crops are decided upon as specialties they should not be changed from year to year, because permanent success with a crop depends ulon mastering all the details which enter into the growth and sale of that crop. There is almost no farm product for which there is not a market; but it may be safely said that there is always a greater margin of profit on those products which require in their production a maximum of brains. The location of the farm with reference to the market will, in a large degree, determine the class of products to be produced Those farms far from market, where there is necessitated a long haul, or a long shipment, should produce as nearly as possible a finished and concentrated product. Instead of selling the bulky hay it should be manufactured into a finished product, as beef, or mutton, or butter and cheese. Those farms within easy access of the market can better afford to sell the coarser products. They are in closer touch with the consumer; fluctuations of the market can be studied, and advantage taken of any temporary rise in prices, while the farmer at a distance must largely produce those articles for which there is a staple demand or for which he has created a special demand.

In brief, a study of the farm shonld begin with the adaptation of the farm for a home, and as a means of securing a competence. If it is not calpable of meeting both these requirements, then some other farm or some other occupation than that of a furmer should be selected. 


\title{
BOOK THIRD.
}

\section{The Farmer's Relationships.}

\author{
CHA PTER I. \\ THE FARMER AND HIS FAMILY.
}

$\mathrm{T}$

HE moral and emotional features of the family relation so greatly overweigh, in most minds, its economic importance that it may at first seem out of place to consider it in a volume avowedly devoted to business affairs, and yet the manner of discharging even these sacred obligations has its bearing on the family prosperity. Obligations of business duty, as well as of affection, exist between husband and wife and parent and child. These business obligations are not one-sided, but mutual.

The farmer's family consists of his wife, his children, and his employees. Of these, more important than all the rest is the wife. If there is or ever could be about a firm a being who is entitled to the utmost consideration and respect, it is the one who feeds the family and bears the children. If any one earus an easy time, or the easiest time possible, it is certainly she. And yet I do not believe that there is in all America a farmer so distressed as to willingly ehange places with his wife.

The husband, to a great extent, does what he will; the wife, to a great extent, does what she must. The woman, when she marries, voluntarily puts herself in the power of one who is stronger than herself. If that power is exerted to protect and comfort, she is happy; if it is employed to oppress, 
she is miserable. It makes little difference whether the intent be to oppress. If the result is oppression, she is unhappy. The wife thinks continually of the happiness of her husband and family. She constantly sacrifices herself for their comfort and welfare. If she is repaid by the little attentions she received before marriage it is all she asks. She seldom gets them, and that this is true is evidence of the meanness of men. Work does not hurt a healthy woman any more than it does a healthy inan, and the girl who becomes a farmer's wife expects to work, but she ought not to work more hours than the man does, nor to work at all when unable to do so. She does both. There are very few farmers' wives who do not work hard for days when their husbands, feeling no more able, would lie on the bed and be waited on. Doubtless some of this is inevitable. Most of it is not. The farmer could make his wife's life easier if he would, and he would if he were less selfish. He thinks less of his wife than of his stomach, and in this American farmers are the worst offenders in the world. We commiserate the lot of the European wives who work in the field. They probably have an easier life than the American wives who kill themselves cooking and washing dishes while their husbands sit by and smoke.

To most men women are incomprehensible. They love flowers and ribbons, and all things that are beautiful. They not only love them, but must have them or be unhappy. They like a friendly chat with a neighbor, and a horse to go and visit. They enjoy social intercourse to relieve the monotony of their lives. The farmer may care for none of these things. Ilis work is not monotonous and his business takes him about. He comes home to rest while his wife must go away to rest. These things she pays for, and if she does not get them she is cheated and yet can not help herself. The wife studies her husband and knows him through and through. No weakness of his is hid from her, and since the man will not pay his debt to her in a manly way, she plays upon his weakness to get her dues by indirection. Watching her time she cooks a good dinner and then asks for help to make her flower garden. The rest obtained by going away 
from home, and the pleasure of a flower garden, and neatness about the house, are part of the necessary cost of carrying on any farm. These and similar things are the wife's due. 'The man owes them. If he does not pay, he defaults, simply because his wife is helpless. She gives lier love and her life. She is entitled to affection in return, shown daily in the little things that make up her life. And how she repays such things! The wife will work herself to death for a kind word, and deem it happiness. As a pure matter of business it is as profitable to treat a wife well as it is to feed a steer well.

Men are accustomed to assume that they alone provide the family income. This is not true. In farmers' families it is true that the man usually provides the gross income, but the net income is what counts, and for this the woman is in great part responsible. Money saved by the wife is as much a contribution to family support as money earned by the husband. The wife's contribution to the partnership has upon the arerage as much pecuniary value as that of the man. In some cases it is more, and in other cases less. The man, being stronger, is not inclined to recognize this. The woman is entitled to control one-half the net family income, and to the independent use of what she needs for enjoyment. She has the same right as her partner to take partnership funds for individual use.

If a man has children he has a certain duty towards them. If unwilling to discharge that duty he should not marry. If he has a family and neglects his duty he is as much a defaulter as if he fails to pay money that is due. I have no occasion or intent to discuss the duties of parents to children except in so far as they are peculiar to the condition of the farmer.

The farmer's children are more subject to illusions than those brought up in towns and eities, because they are brought less in contact with reality. Their imagination is stimulated by the unwholesome fiction which constitutes much of what is called literature in country homes, and their tendency is to acquire a distaste for country life and a longing for the imaginary ease of the city. This tendency is increased by the 
unquestionably authentic statements of remarkable successes achieved by American country boys who, with no special training for anything, found their way to the eity and pros. pered.

It is the duty of the farmer to impress his children with the truth that the day when such things are possible to the ordinary boy is forever gone in this country. Ninety-nine out of every hundred who hereafter may try this route to success will fail. Every avenue to employment in American cities is now choked as completely as it has been for centuries in Europe. In every mercantile or manufacturing establishment those already employed are constantly on the watch for every opening in behalf of their own dependents and friends. There are twenty applicants for every place. It is also an age of specialization. The boy wanted now, when any is wanted, is not one who is willing to do anything, but one who knows how to do something. The farmer's duty, therefore, is to train his children to be either farmers or something else. Some trade or profession they must have, or they will be terribly handicapped in the race of life. City boys themselves understand this. Country boys do not realize it.

There are many things which are desirable in life, but only food, shelter, and clothing are essential. 'These are easiest come by in the country, and country life will therefore always be easier than city life. The boys do not realize this, and it is a farmer's duty to seek to convince them. At the same time the city will always be recruited from the country, and of those who go to the city a certain portion will succeed.

But the best evidence of probable success in eity life is unusual effectiveness on the farm. The boy who is most helpful at home will be most likely to be successful elsewhere. The shiftless boy may be a genius but is probably a defective. The boys and girls, therefore, should be trained to work. The old-fashioned doctrine that boys were bound to work for their fathers until twenty-one years of age is thoroughly wholesone and useful. The chiliren have duties to parents as well as parents to children, and children ought not to expect what their parents are evidently unable to bestow. 
A man's duty to his children is measured by his ability. He is not bound to imporerish himself, or to burden lis declining years with debt, in order to make life easy for his children. The boy who attains influential position in life will do so by the qualities inherent in himself. All his father can do is to aid in preparing him for a useful career. When he does this to the extent of his ability he has done his duty. In so far as he fails to do what in reason he can, he fails of his duty. American fathers seldom fail in their desire or effort to do well by their children, but often do fail in good judgment. It is the nature of children to play, and it is proper that they should do so, but it is also essential that they acquire habits of work, and not only of work but of responsibility. The farmer has in this respect great adrantage over the resident of the city. He always has light work for which he can make his children responsible. This should be begun at an early age and increased as the boy grows older, until, after fifteen years of age, the greater part of his time, when not in school, should be devoted to work. It is by work only that the habit of work can be acquired, and only by exercising responsibility can faithfulness and judgment be tested. When the circumstances of the parents permit, it may be well to give boys a pecuniary interestin what they may do, but, so far as the boy is concerned, the value of it is mainly in giving him the experience of the difficulty of earning money and the importance of keeping it. The majority of children must look forward to a life of work, prudence, and small reward. The farmer's son who remains on the farm may with reason look forward to a life of independence-working on his own land. Not one in a hundred of those who drift off to cities can possibly achieve anything but a subordinate position in which he must do the will of another so long as he lives. The farmer owes to the son the duty of making him understand this. Neither is a modest life an unhappy life.

In the matter of education a common-school education is due to all farmers' children, and they all get it. Additional education is good if it is of the right kind. Indeed, knowledge of all sorts tends to broaden the boy out, but I am one of 
those who believe that for the boy who expects to make his own way by his own work, the quicker he gets to learning what he will directly inake use of, the better. So, after leaving the common school, the special agricultural or trade school seems to me the most desirable.

Aside from the common school the best education which farmer's' children can have is good books. Of these, good biographies of successful men are undoubtedly the best. They supply the consecutive "story" which the young mind craves, and incidentally convey useful information. The daily paper in the farmer's home is a nuisance. Nine-tenths of what it contains is of no value to airybody, and a great part of it is positively injurious. Few young people take kindly to books of a purely instructive character, but those who do should be supplied with them. If there are signs of an especial bent towards any useful occupation, it should be encouraged, whether in boys or girls. The city youths have a great advantage over those of the country in the great libraries to which they liave access. This deficiency of country life it is the duty of the farmer to supply to the best of his ability.

In short, the duty of the father as a farmer seems to me to be to get out of his children's heads the notion that city life is in any way easier than country life; to train them to habits of work and responsibility not beyond their strength and their years; and to the best of his ability to supply them with the means of getting useful information. When this is done, if there is anything in them of value it will develop itself. If there is not, that is the end of it. The father has done his duty.

The farmers' employees will be mostly young men. Toward them his duty is to make their lives such as he would be willing that his own son should live. 'The old custom of farmers' sons "liring out" to neighboring farmers seems to be grarlually dying out. It was a good custom, and yet nothing that I can say is likely to revive it. Farmer's sons seem inclined to drift off to work among strangers and to spend what they earn in hunting for new jobs. In the end they tend to degenerate into the irresponsible and transient laboring class 
with which farmers and employers of unskilled labor have to deal. Away from the restraints of home and family influence, their tendency is downward. What each farmer can do to check this, is to employ farmers' sons of his acquaintance so far as he can do so, and whoever he employs, to treat them with social consideration. The faithful young man who works on a farm is as good a man as the farmer he works for. If he is not treated as such he will be discontented. There is no social distinction between the farmer and the farm hand. If one is artificially set up, desirable men will be driven out of the business, and the most promising opening for the son of the farmer himself be cut off 


\section{CHAPTER II.}

THE FARMER AND HIS FELLOWS.

THE fault with farm life is the lack of social intercourse. Where farms are large this is hard to overcome. 'The natural time for social intercourse is the evening, but when the farmer, his wife, and his team are tired, and the time for rising five o'clock the next morning, there is not much inclination to start out. These conditions must be overeome. Man is a social animal. He must mingle with his fellows or deteriorate. Where farms are small the difficulty is less serious. Modern improvements are doing much for the farmer in this respect. The country roads are improving and the trolley and the bicycle are never tired.

It seems to me that farmers must systematically attend to these social duties if they are to be happy. I am not speaking of social intercourse for "improvement" but for recreation. If circumstances forbid it of evenings, the time must be taken from the day. The American farmer is among the least social of men. Such social gatherings as occur are mostly left to the young people, who, unrestrained by the presence of their elders, are not always decorous. The country "ball," held upon holidays in some public hall, and open to all comers who will pay the fee, is not always a desirable place.

This rather questionable mode of recreation has grown up as the result of rural conditions in this country, and can be exterminated only by a change of those conditions. Young people will certainly meet for social enjoyment, and if the way is made difficult to rational methods, they will take other ways. The amusements which from time immemorial have had chief place among the people of all nations, have been the card table for the elders and the dance for the young. I am not aware that either. of these amusements was ever considered questionable until the rise of the great Puritan move- 
ment in the seventeenth century, which, mainly through the New England settlement, has left its impress on all Ainerica. At the present time large numbers of the most excellent people we have are profoundly convinced of the essential immorality both of eard playing and dancing. Some churches make it a matter of discipline; some wink at it, and some see nothing wrong in it.

On the other hand, many estimable people, doubtless comprising the majority of the community, believe dancing in itself to be an agreeable and innocent amusement, and that the evil consists in the promiscuous entertainments, conducted in public places and open to all, which are common in rural districts. As to "card playing" they claim that it is an absolutely innocent recreation, which has proved its acceptability for ages, and in all countries, and deny absolutely that it has any tendency whatever to lead to "gambling," or that in fact it ever does so lead. It may not seem clear to all what this has to do with the economic relations of the farmer to his fellows, but the fact is that in many rural districts this question of dancing and card playing lies at the root of rural discontent. It did so in the neighborhood where I was brought up. The people of most sterling worth set their faces strongly against these amusements, which the rougher element freely indulger in. The more lieadstrong of the youth of the better families tended to break loose from home restraints and associate themselves with the rough element, to the inquestioned deterioration of their morals.

Youth craves amusement and will have it. Age really requires it more than youth. The trouble with rural society is not the modesty of its pecuniary rewards, but the griuding, cheerless habit of life, which, by the way, is more marked in the American farmers than in any other people in the world. The youth do not drift to the cities so much with the idea of making more money as of having a better time. The remedy for much of the farmers' discontent is more abundant social intercourse, in which it is extremely desirable that parents and children should participate together.

The difficulties in the way of this seem almost insurmount- 
able. Farmers' houses are not usually built to accommodate large companies. This of itself often compels the resort to the objectionable public hall. It is always possible, however, for heads of families to unite to engage such halls, control the company invited, and by their presence exercise all necessary restraint. When gatherings are held at farmhouses, the labon of preparation, and, worse still, of clearing away after, often falls almost entirely upon the already overworked womer. of the family. There is often, also, an unfortunate strife to outdo each other, which adds greatly to the labor, and bears harder on the weaker.

No one can settle these things but the farmers themselves and their families, in the light of their sturdy common sense, and their regard for themselves and their youth. But one thing is sure, if rural conditions are to improve, the beginning must be made in its social features. The American farmer does not need to work harder but to play more. $\mathrm{He}$ must mingle with his fellows for the mere enjoyment of it. And when gatherings are held, they must be so managed that a good time is assured. Grange meetings are good, but the majority of farmers are not grangers, nor can any formal organized meeting take the place of the unrestricted freedom of intercourse at the home.

And such gatherings do not need promotion in any organized way. Any family can begin a round of "visits" to other families, which will be quite certainly returned in due time Or the more formal course can be taken of issuing invitations for an afternoon and evening, or for the evening alone. There would be more of this if the women of rural households would content themselves with such preparations as are within their strength. Perhaps this is not possible, the vice of "showing off" being apparently inseparable from the make-up of a good housewife. But in some way the social conditions of rural life must improve if fathers and mothers are to be contented, or the brighter youth to be retained there.

I do not think it an ignoble view of life to consider its main end rational enjoyment, for the highest pleasure unquestionably comes from labor profitably directed, interspersed 
with suitable recreation, and accompanied by the discharge of civic, social, and religious duties. The importance of the social side comes from the fact that through that we in a great measure shape the lives of our youth. Recreation they will have, and if they deteriorate it will almost certainly be through companionships formed in pursuit of recreation in which parents do not participate. The economic importance of this chapter grows out of the danger that under present social conditions the drain of vigor from the farm to the city will be greater than the farming class can endure without impairing its power of survival. The weaker residue left may not be able to sustain themselves in competition with other classes. As the lack of social enjoyment on the farm is unquestionably the main factor in driving boys away from the farm, it is best to frankly recognize the fact. Rational recreation is an economic factor of great power. 


\section{( HAPTER III.}

\section{THE FARMER AND HIS COMPETITORS.}

I

$F$, in a certain town upon a certain day, two men need loads of hay and two farmers are in town with hay to sell, the demand is exactly equal to the supply. Each can buy what he needs or sell what he has to spare. If the hay in the two loads is of the same quality it would seem that the element of competition hardly entered into the transaction. As a matter of fact, it is operating as strongly as ever. The competition of sellers prevents a rise in price and that of the buyers a fall. It is also evidently true that neither buyers nor sellers would probably know that the market was in exact equilibrium, and consequently would act under the full influence of the competitive feeling.

Aside from the competition of these buyers and sellers in reference to these loads of hay, in any town there is likely to be grain and straw for sale, which may entirely take the place of hay, and would do so if the price of the latter were placed too high. If, instead of considering the competition merely with reference to the business of one day, we consider it in the long run, as in fact it always operates, we see that timothy hay, for example, competes in the market with all other forms of forage and grain which will serve for stock food. It is the same with food for human beings. All food materials compete in the market with all other food materials. So also the fibers suitable for clothing compete among themselves. When wool is extremely high as compared with cotton, more of the latter will be used in cloths. As the business of the farmer is mainly the production of raw material for clothing and for food for men and animals, all farmers are in competition with all other farmers for the sale of their products. The wheat farmer does not merely compete with other wheat or even with otlier breadstuffs, but with all other food products. 
But there is another way of looking at this matter. The combined labor of mankind for a given time, together with the use of the accumulations of ages, results in the power to obtain a certain number of satisfactions which those belonging to the race may enjoy during that time or reserve for future enjoyment. Each one of us is struggling to obtain for himself in each year the largest possible portion of this common stock of satisfactions.* In common language we do not use the term "satisfactions," but "money," which, so far as they are objects of economic thought, will procure them. What, however, we really seek is the satisfaction which firs obtajn ky the use of money.

When a farmer who has hay to spare cieas svith. one whe desires to buy hay, we do not usually think of the temporary relation as one of competition, but as an exchange of satisfactions for the mutual benefit of both, as in fact it usually is; but the farmer desires to get the highest price possible for his hay, with no thought for the profit which the buyer may obtain for its use, while the buyer desires to purchase as cheaply as possible without regard to what it may have cost the seller. They are competing with each other for the possession of money.

The economic transactions of modern times have become so inextricably interwoven with each other that they can by no possibility be separated, and the result is that all men are competitors of all other men. This competition which pervades all nature is called the struggle for existence. Its only limit is that imposed by affection, which leads men to forego personal satisfactions for the sake of their families and friends, and by an altruistic $\uparrow$ feeling which impels a comparatively few men and many more women to prefer the general welfare to their personal gain. Economic science recognizes the existence of this influence but does not deal with it. It assumes competition to continue unhampered.

* "Satisfaction" is a term used in economic science to denote anything which is the object of human desire, even though its use may be actually injurious.

†Altruism means "regard for others." 
It is not necessary to my purpose to consider the farmer as a man competing with all other men, but only in the narrower view of a farmer competing with all other farmers. We shall find this wide enough.

Among an ideal race of beings the object of each party to an exchange of commodities would be to get for himself and for another exactly what would fairly pay each for the necessary cost of acquirement. As human beings are now constituted, however, it would be a waste of time, from a merely economic standpoint, to discuss exchanges on the assumption that 'such moufyes will control their character. Any such discussion belongs to the science of ethics, which deals with himan afiaine fros the standpoint of what ought to be. Economics deals with facts as they are, and therefore necessarily assumes universal competition.

The relation of the farmer to his competitors is, then, the relation of one struggling with another, not necessarily in an unfriendly spirit, but with intent to beat if possible, regardless of the feelings or interests of the competitor. In such struggles the fundamental requisite for success is to keep watch of the opponent. An athlete who should pay no attention to the actions of his opponent could only hope to win by means of very great superiority of strength. This principle of watchfulness as a condition of success is universal, applying equally to physical, intellectual, and business contests.

It is in neglect of this principle that farmers fail most completely. Tery few farmers know what their competitors are doing. In this respect they are immeasurably inferior to the mercantile and manufacturing classes. The cause of this is not altogether intellectual inferiority, although it is true that the most alert and vigorous men tend to engage in other occupations than farming, but it is also true that men of no great mental endowments may and do succeed fairly well in business. Merchants and manufacturers watch their competitors more closely than farmers because they are compelled to. Competition is such that failure to watch is ruin. When a manufacturer finds a competitor persistently meeting him with goods of equal quality but lower price, he knows at once 
that the competitor is in financial difficulty and striving to realize, regardless of cost, or that he is producing eheaper than himself, the latter involving his own ruin unless he can himself reduce cost. He is, therefore, constantly on the alert to discover the details of the manufacturing and business methods of all his competitors in order to promptly avail himself of any improvement which any one of them may make. He is able to do this much easier than the farmer, because he is himself, through his agents, the year round, in close competition in all markets, and his place of business will be in some populous center of intelligence. The majority of farmers live in a rather isolated way, do not mingle freely with well-informed business men, and make their principal sales of produce but once a year, and they are, therefore, greatly handicapped in such efforts as they do make to inform themselves in regard to markets and competition. Their main reliance is the columns of the daily and agricultural press, which are of very little value except as to conditions affecting a few staple crops, such as cotton, grain, and, to a less extent, tobacco and wool, which are the objects of speculation on a large scale. Even as to these things the press obtains very little information which has not been obtained by the trade and used for its own purposes, and to the disadvantage of the farmer, before publication. The journals of general circulation do not obtain this information in advance because it would cost too much.

The farmer, also, is greatly hampered in ascertaining the cost of his competitor's products because such eosts vary so greatly from year to year. It requires more labor than most farmers are willing to bestow to ascertain their own yearly costs of produce, much more to discover the costs of others; and if by any means they may ascertain substantially the cost of competing products raised in some distant section in a given year, it may never be correct for any other year.

The fact is it is far more difficult for a farmer to find out what his competitors are doing than for merchants or manufacturers, and yet it is equally necessary. The competitors of the American wheat farmer are, first, lis own neighbors, then 
those of his district or state, then those of other states, and finally those of all foreign wheat-producing countries. The task seems hopeless and indeed is absolutely hopeless for the indiviclual farmer. The cost of obtaining, independently, from original sources, the facts which the farmer needs to know in order to act with reasonable intelligence in selling, would in any year be more than the value of the crop and the farm itself.

The only thing which the farmer can do unaided, in this case, is to familiarize himself with the physical geography of all competing districts, the standard of life of their people, and the length and character of the transportation rontes connecting them with the commercial center which fixes the world's price of that particular commodity. The physical facts will largely determine the size and character of the crop. These are accessible. The best cyclopedias give them very fully. The standard of life of the laboring class will determine the relative cost of the labor bestowed on the crop. This he will get less from cyclopedias, although much as to this can be learned from them, but more from good books of travel, and similar publications. The nature of the transportation, whether river, sea, or rail, and the relative length of each, will enable him to compare his situation in that respect. Such matters as national tariffs of course have to be considered when one is in a business, but should not be regarded when proposing to engage in one. Tariff protection is very uncerlain, as rates of duty are constantly changing. The farmer is best situated for competition who can produce absolutely at the least cost.

Consiclered with reference to competition with his immediate neighbors, the farmer's position varies according to his product and his market. If producing a product of limited use for the local market, and unsalable elsewhere-as the market gardener-lıe is in intense competition with all neighbors engaged in the same business. He needs to observe the varieties, methods of culture, and methods of packing employed hy all in order to make sure that no one excels him. If, however, he is engaged in producing the same commodities 
on a large scale, for distant shipment-truck farmung-the farmer in Florida, for example, needs specially to know the conditions existing in Mississippi, Texas, California, and other states adapted to raising early vegetables. In this case the farmer's relation to his neighbor as a competitor is entirely overshadowed by their greater common interest in knowing what is going on in distant competing districts. So far from competing it will usually pay them far better to unite to incur the expense of finding out what distant competitors are doing, and to deal more effectively with transportation companies, selling agencies, supply dealers, and others with whom they are all competing for the possession of money. It is these conditions which supply the sound logical basis for cooperation, which will be fully discussed hereafter. For the present I wish only to say that it is by cooperative effort only that any ordinary farmer can ever expect to obtain from year to year the accurate detailed information in regard to erops and markets which he needs to intelligently meet distant competitors. Except as he is willing and able to cooperate with his few neighboring competitors, he must usually remain in substantial ignorance of the doings of his distant and more dangerous competitors-more dangerous because in the aggregate they constitute the controlling factors of the situation, upon which any single district will usually have very little effect.

The object of this chapter is gained if it has been marte clear that the farmer as a competitor needs to know the conditions of all others in his industry for the purpose of thereby improving his own practice, and that such information as he needs will always cost money, which will be a legitimate and necessary expense in his business. That farmers are enabled to live at all under their usual slipshod methods of dealing with competition and competitors fully proves that the farmer's lot is far easier and happier than that of other men, for in no other important occupation would it be possible to continue in business with so little information about competitors. 


\section{CHAPTER IV.}

\section{THE FARMER AND HIS CREDITORS.}

T

$\mathrm{HE}$ condition of the indebted farmer who is not mortgaged requires no special discussion unless he is so deeply indebted that a mortgage has become necessary, in which case what is here said is fully applicable.

A large number of our farmers have mortgages upon their property, and of the mortgaged farmers the majority have floating debt in addition, and the majority of the unsecured indebtedness of farmers is due and unpaid.

Since this is a condition which a multitude of farmers are compelled to face, it is worth while to give some study to the business principles involving the proper treatment of all serious indebtedness.

From the first settlement of the United States to the end of the first third of the nineteenth century, our progress was slow and uniform. Conditions were rude, land abundant and cheap, communications difficult, the rewards of labor moderate, money scarce. The temptation to incur debt was small, and while there are no available statistics to disclose the exact facts, we may safely assume that in the main serious indebtedness in the farming population was confined to the improvident, who will always exist and always suffer for their improvidence.

In the thirties, however, the great tide of immigration from northern Europe began to show its foree, and for nearly a half century there was a great and continuous influx of thrifty and vigorous stocks, to whom our cheap lands, and at last our free lands, opened the way to a vast improvement in their material conditions. The majority of these immigrants pushed at once to the frontier, all taking more or less money with them for the purchase of farms already opened, or their support while themselves opening new ones. The farmers of our own middle 
states joined in the westward march, their places to a certain extent being taken by those farther east.

This movement had two important results: in the first place, it brought large sums of money into the country to be expended for farms or land, and, in the second place, it created a constant home market on the frontier for supplies of all kinds to be used by families while opening up their own farms. In addition to this the rapid increase of population greatly increased the home market for all kinds of manufactured goods; the building and lumber trades were marvelously stimulated, as towns and cities sprang up everywhere.

The result was a steady increase in the value of land on the western frontier and for a long distance to the east of it. Farmers bought the best of land for a dollar and a quarter an acre, lived on it a few years, and sold out at a lirge advance.

As this process went on continuously for many years, there grew up in the community a settled conviction that the way to wealth for the farmer was to incur debt for land. The more land a man owed for the faster he was assumed to be getting rich. Whenever an entire community becomes imbued with a speculative disposition of this kind, and results regularly continued for generations seem to justify anticipations, nothing will cure it except an absolute demonstration continued through many years, of the final bursting of the bubble. Such a demonstration began with a panic in 1893 , and will continue until rural communities thoroughly learn that never again in this country is it likely to be safe to incur debt in the expectation of paying any portion of it from the "rise in land."

Agricultural land is now as high in the United States as it ever will or can be until the cheap lands of other continents are settled and the population of the earth so increased as to require its entire surface for its support. A great portion of the indebtedness of the farming class is of this speculative character, and of such indebtedness a great part can never be paid. The early settlers in a new country, who endure the privations incident to settlement, and build the roads, schoolhouses, churches, and other public improvements, are entitied to the natural increase in the value of their holdings which 
results from such improvements, but in most of those sections of our country which are still sparsely settled, all this ultimate value is assumed by holders to have accrued, and land is held at prices full as high as it can ever reach within the lifetime of men now living, and in many cases at higher prices. And yet it is a fact that a great deal of the indebtedness of farmers has been incurred for land at such exorbitant prices that the debts can never be paid off from the products of the soil.

Another matter which must be considered in this connection is the wonderful growth of our transportation system, itself also largely speculative and developed almost entirely by borrowed money. Our early railroads were built mainly by the proceeds of stock. The inen who were the nominal owners were also, in fact, the principal real owners. So long as this was continued, the increase of mileage was no more than sufficient for the increase of traffic. Then it came to be considered that it was sife to incur indebtedness for half the cost of the roads. Finally extensive lines came to be built almost entirely on borrowed money and extended into districts in which at the time no traffic existed. The building of a railroad through a well-settled country where the traffic to support it already exists, is a legitimate business enterprise. To build a road into an unsettled country with the hope of ultimately obtaining traffic as the country fills up, is purely speculative. It may settle up quickly and it may not. If the traffic does not come the mortgages take the road. In many cases the roads thus built have not been worth nearly the face of the mortgage. Farmers are not the only people who speculate unwisely.

But whatever the ultimate result of the speculative building of railroads, the immediate effect is always wonderfully stimulating to business along the line. A district is always prosperous while borrowed money is being expended in it on a large scale. The pinch comes when that money has to be repaid, in addition to large disbursements for interest. While this building activity is at its height, great efforts are always made to sell land to farmers, who, carried away by the prevailing excitement, pay more than the land can ever be worth; 
often, if not usually, incurring serious debt. In the more sparsely-settled portions of the United States a great part of the mortgage indebtedness was incurred in this way, and of this much is never likely to be paid. This is especially true of the semi-arid districts.

There is another kind of speculative indebtedness among farmers which concerns a great number of individuals, although for the most part concentrated in comparatively small and well-defined districts, which is indebtedness incurred for developing the fruit industry. The production of fruit is, perhaps, the most speculative occupation which farmers can engage in. No one who plants an orchard can by any possibility know what will be the outcome of his enterprise. He may make a great deal of money, or he may lose every cent of his investment, and that from causes wholly beyond his control. Similar speculative indebtedness has been incurred in the development of dairying, truck farming, and other agricultural industries whenever the hope of selling land or supplies has induced effort to create undue expectations of profit from special agricultural operations.

The foregoing brief review of the causes of speculative indebtedness among farmers is given for the purpose of making clear to all who are indebted in this way just where they stand. No debtor is likely to make any wise move towards extricating himself from lis indebtedness without looking the situation frankly in the face. Until he is ready to acknowlerlge to himself, his family, and others interested, the exact facts and probabilities of his situation, he will act under the influence of illusions, and his premises being wrong, his conclusions will certainly be unsound.

An indebted farmer who finds himself regularly able to meet his interest payments, make some reduction of the principal, and keep clear of floating debt needs no suggestions from these pages. He understands his business. If, however, he is working to the limit of his strength, with old age coming on, his wife breaking down from overwork and anxiety, and the mortgage interest kept up only at the cost of an increasing floating debt, with its accompanying torment of duns, he will, 
if willing to frankly consider his own condition, be ready to concede that he has sometime committed grave errors from whose consequences he is now suffering. If at some former time his judgment has been at fault, he should be willing to acknowledge to himself that he may even now be in error in some things, and that there may be suggestions which have not occurred to him which are yet well worth his consideration.

The farmer who is indebted beyond his ability to pay is very apt to consider his creditors as his enemies who are oppressing him. There is no sense in this. If he does what he has agreed to do they will not be his enemies. If to any extent they are so now it is because of his own failure to keep his agreement. Evidently, since he is unable to keep his agreement, it is one that he should never have made. It may be true that his inability to pay arises from changes in conditions over which he had no control; but, as business is universally conducted in this world, the possibility of such changes must be considered by all who make agreements to be executed in the future, and margins reserved for all contingencies. Whoever fails to do this must take the consequences when things go wrong. Farmers are as strenuous as other classes in exacting this from their debtors. If a farmer sells a horse, taking a note in payment, and the horse dies the next day, he will still require payment of the note at maturity, and collect it if he can.

But, while farmers must abide the consequences of their bad judgment in increasing indebtedness, there is yet a limit beyond which they ought not to go. Neither law nor society requires impossibilities, nor is it desirable that one man shall be the slave of another for his lifetime. While the debtor, as a rule, has asked the credit, considered himself at the time fortunate in obtaining it, and agreed to take all risks of depreciation or other misfortune tending to prevent payment, the creditor also took his risk. Under ancient civilizations the debtor who could not pay became the slave of the creditor, and could be bought and sold. In modern times creditors, in making loans, or giving credit, know that they will not have this ultimate recourse. They must look to the property for 
payment, and not to the person of the debtor. But as a rule they do not wish the property. What they desire is interest regularly paid. Especially is this true of banks and other money-lending corporations who, above all things, hate foreclosures and the care of property. If the debtor, living upon the property, and familiar with it and with farming, can not make it pay interest, the bank almost certainly can not. The debtor who can not pay interest, usually has but a most meager living, and no wages besides. If the bank takes the property it must pay good wages for its care, and is not likely to get interest in addition.

When an indebted farmer finds that he is killing himself and his family and still making no progress, it is time to stop. He has done his best and failed, and society asks no more of him. It is not right that he and his should be slaves. His creditors have erred in extending credit, as well as himself in obtaining it, and, while the severest consequences must fall upon him, it is proper that the creditors should bear their share. At this juncture the duty which society imperatively demands of the debtor is absolute frankness and honesty, first with himself, and secondly with his creditors. It is also best for himself. There are chords of sympathy in the human breast which reach out even from creditors to debtors. Honesty, frankness, and courage will cause these chords to vibrate.

The first step is to put on paper a complete schedule of liabilities, down to the minutest item. Then there should be a complete schedule of property, and a statement of income by items as far back as possible. This should be taken first to the mortgage creditor. He is the most secure, and it will be to his interest to aid his debtor to a compromise with others. The question to be decided is not one of intent or desire on the part of the debtor, but what income the property can be made to produce in his hands, or whether some other available person can get more out of it. It is for the interest of all concerned that the property shall be so used as to produce the largest net income, and as to this lenders of money will often be better judges than borrowers. If it 
should appear that, while the income is not sufficient to pay everything, it can be made to produce a good part of the indebtedness, some kind of compromise will be made which will enable the farmer to go on. All that can be got out of a place is what it will yield after supporting the family which works it. As various considerations will impel the indebted farmer to work cheaper than any one else, and with a better understanding of the capabilities of the farm, there is nearly always a ground for such a settlement and reduction of liabilities as will, under the circumstances, be best for all. If the settlement is complete, and the margin for living is not cut too close, the advantage to all will be great. What kills debtors is not hard work but worry. No man can endure continuous attempts to achieve the impossible with a penalty overhanging in case of failure. When the task is reduced to what can be done, the hard work continues but not the worry. Life takes on a different aspect. The arriving mail is no longer looked to with dread nor the calling stranger feared as one who may have papers to serve. Hope takes the place of despair, and the old renew their youth. Misfortune has befallen and has been bravely met. The best that could be done has been done, and there are respect and esteem in place of suspicion and doubt.

The above is the course always taken by good business men in financial difficulties. It should be imitated by farmers. In attempting such settlement, legal advice should be secured. In most country towns there is some elderly, sensible lawyer whom everybody knows and respects, and who makes his living by keeping people out of lawsuits. Go to him, and to the principal creditor. Lay all the facts before them, and trust your legal adviser and your principal creditor to reach an agreement and bring in the rest.

The relation of the embarrassed farmer to his creditors must be one of perfect frankness and honesty. Many lose their homes who need not do so. 


\section{CHAPTER V.}

THE FARMER AND THE POLITICIAN.

B

Y "politician" I mean a person who habitually seeks to obtain a livelihood from the emoluments of public office or to influence the bestowal of office. He may and probably will have some other ostensible or actual means of support, and is quite certain to be an alert and capable person, entirely competent to live independent of office, but he has acquired the office-seeking habit, which is one of the hardest luabits to break. A politician may become a statesman, and as such one of the most honored and useful members of society. Most of them do not, but at the same time it must be recognized that the majority of the office-seeking class are intelligent and homest, and faithfully discharge the duties of any position to which they may be elected or appointed. At any rate, they must have the appearance and reputation of so doing or they could not, at least outside the large cities, hope to succeed. In the aggregate there is doubtless a good deal of official corruption in most countries, but in the main I believe our officials personally discharge the duties of their offices with zeal and fidelity.

And yet it is true that when once an honorable man becomes a candidate for an elective office, or a "worker" who expects, in case of the success of his party, to be rewarded by an appointive office, he becomes possessed of an absorbing lesire to win. This feeling is by no means wholly mercenary. The joy of overcoming is of itself a sufficient inducement to many, and, once engaged in a contest, all means esteemed honest within the purview of the very loose code of political morals are freely employed.

There is no doubt that in the long run the means deemed most certain to lead to success are what is commonly suoken of as "humbug," and of all classes that deemed most suscep- 
tible to the influence of political deception is the farming class. Whether right or wrong, this opinion is practically universal among political managers, and party platforms are framed, and political addresses delivered to rural audiences, upon the assumption that those audiences are easily deceived. Public questions are almost never fairly presented by political speakers, and it is rare that political platforms unequivocally pledge parties to definite courses of action on strongly controverted topics. The art of drawing a political platform consists largely in skill to frame language in such a way as to appear to be very binding, while in reality it leaves candidates elected nearly free to do as they please.

The relation, therefore, of the farmer to the politician should be one of profound distrust. He must be recognized as one who means first of all to win if he can, and who believes the surest way to success is rather to excite and play upon prejudice than to appeal to reason. He probably will not lie outright, for this is bad policy, and lience not good politics, but if he can deceive without actually lying he will do so freely where he thinks it desirable, and if he does his work skilfully, he will stand the higher in the councils of his party. Of course many politicians in heated campaigns do not hesitate to lie outright, but these are always the small fry, and in the long run they fail. But the farmer must never expect a fair presentation of a public question from any political orator or political journal. What he must expect, and what, in nine cases out of ten, he will get from poth these sources is, first, flattery, to gain his good-will, and, next, rhetorical appeals, more or less effective, according to the ability of the speaker or writer, to his passions. and his prejudice. The first thought of the political orator is to arouse enthusiasm-to "bring the house down;" now candid argument can never have this effect, while rhetorical praise or denunciation always has it. It is natural, therefore, that those who desire to win over an audience or excite it to greater endeavor, should employ the means which experience has shown to be successful, rather than to employ others which are known to be less productive of results. All popular 
audiences are susceptible to this play upon emotions, but it is a fact that must be reckoned with that among all classes of politicians it is considered that farmers above all others can most certainly be led captive by the use of bold, unblushing humbug. I am not guessing at these things. I have myself helped to make party platforms, and have appreciated the grim humor of astute politicians as they suggested phrases which we all knew to be meaningless, but well adapted to catch the rural vote. I have heard good political orators arouse an audience to enthusiasm, and afterwards discussed with the speakers the tricks which they employed. I know that shrewd politicians have a very low estimate of the intelligence of the farmer, and that those are in most demand by party managers who have most skill in playing upon rural prejudice and passion.

Now all this has its effect on the farmer's pocket, and it is only from this standpoint that I wish to consider it. The farmer is at every election called upon to rote upon the adoption of policies which will affect his material welfare, and for the election of men by the exercise of whose judgment his income and taxation will be affected. If he will imprartially examine facts before roting, his common sense may in the main be relied on to lead him right. There is no important public question which does not inrolve an economic question, and it is certain that nearly all who really understand how the result will affect their pockets, will vote as they think their interests dictate. I think this right, because if all vote intelligently as their pecuniary interests require, the greatest good of the greatest number will result, which is the aim of all good govermment. But if people vote after considering but one side of a question, or if the habit of roting with a party leads them to knowingly vote for unworthy men, they must take the consequences.

The most important offices to the farmer are those nearest to him. It is of vastly more importance to him to secure a good road-master than a good governor. In voting for a member of the Legislature, it is of far more consequence that he elect one who will be effective and influential in state affairs than one who is sure to vote for the senator of his party; 
and yet it is the fact that whenever a United States senator is to be chosen, the members of all prarties are frantically adjured to let nothing prevent voting for the nominees of their party for legislative positions, whatever may be their opinion of the candidate or however much his opponent is the better man. And these exhortations have a tremendous effect.

I do not belittle the importance of national issues, but it is very rare that they are overpowering. As a rule, when he must choose between them, local and state issues are far more important to the farmer. A good governor is of more importance to him than a good President under ordinary peaceful conditions. I fully recognize the necessity of party organizations and the wisdom of party nominations for state and even local offices. A party organization is a great power, and it is important to have some responsible organization stand as sponsor for candidates, to be held responsible if they are derelict in office, but party "loyalty" should not be expected from the mass of voters unless it deserves it, not only by adherence to party principles, but by the nomination of upright and capable men for office. Nor will anything have so great an influence in preventing improper nominations as knowledge on the part of party managers that voters will not accept bad men for the sake of sustaining a good principle, and that they will place more importance on state and local issues than on those of a strictly national character. The first thought of a politician is the success of lis party, to which he looks for his reward. What the voter most needs is good goverument, regardless of party. I belong to a certain political party with which in the main I am in accord upon national issues, and from habit, if for no other reason, I prefer to vote for its nominees, but if it by its nominations sacrifices my important local interests to my less important national interests, I will not go with it. I will vote with my party for President and congressman, but if it nominates a bad or weak man for the Legislature I will vote for his opponent if a better man, regardless of its effect on the United States Senate. I believe that to be the proper course for all men. If the states are well governed, the country will be woll governed. 
There are certain offices which ought to seek the man, and certain others which it is proper for the man to seek. Roughly the line may be drawn between those positions which require the entire time, and yield a livelihood, and those which involve only a partial service and whose pecuniary rewards are trifling. The latter offices should seek the mant. No man who is fit for a legislative office will willingly soek it, except occasionally a young man who is smitten with political "ambition" and sees in such an opening the beginning of a political "career." While it is a misfortune to any one to desire a political career, yet an ambition of that kind is entirely honorable. No such ambition, however, should have any weight with the voters. The men whom they need in legislative positions are the solid, substantial, successful men whose own success betokens their good judgment, and who have weight in their own communities. Such men will very seldom seek any office, but will usually accept it if tendered. What farmers should do is to make their influence felt in securing the tender of nominations to men of that kind. They are not likely to do so, however, nor is any change from present customs likely to be effected in the near future. It will not, therefore, be profitable to pursue this subject further, but it has seemed proper to point out that for economic reasons farmers should exert themselves to make sure that those who levy taxes upon them, and determine for what purposes the public funds shall be expended, shall be men of sound judgment and good repute. It is in legislative positions that opportunities for corruption exist. Large sums of money are often expended to procure nomination and election to such positions. Why is this?-If the candidates are rich, it may be pride or political ambition. If they are not well off, and are spending money freely, they should be defeated if possible. There are no emoluments to such positions which can be accepted by honest men. When money is expended to elect a poor man to fill them, it almost invariably happens that some private interest is supplying it, which will expect to control the vote.

In great campaigns enormous sums of money are spent. 
Bonfires, halls, brass bands, uniforms, toreh lights, and all the paraphernalia which are used to awaken enthusiasm, cost money. Who pays it? Whoever it is, he expects his reward. It may be a suitable reward which is proper to be given. It may be the reverse. In any case the farmer and the public are entitled to know the facts. Such expenses are legitimate and necessary when not on an extravagant scale, and it is creditable to any one who is able to do so to contribute to the success of his party. It is entirely proper, therefore, that the names of those who contribute shall be made public. If they are not, and there is any unwillingness to disclose them upon request, the farmer may surely know that it is for some reason which will not bear the light, and concerns the control of men and measures in prirate interests. It is money spent to humbug the farmer into voting for he knows not what. The money whose contributors are unwilling to be known should never be spent in political campaigns. The key-note of a campaign for political party should be a demand for the publication of the names of contributors to party treasuries. Whenever an election of a Legislature is pending which is to elect a Lnited States senator, it is not unusual for a canclidate for that office to pay the election expenses of all candidates which can be got to accep,t such aid. It is seldom that these candidates can themselves afford the expenses. Who does really meet them? It can seldom be proven, but it is a matter that farmers should take note of, although it is a matter in which they can not protect themselves by giving their vote to the other party, for all parties are alike, but they can sometimes do the right thing by voting for the party which seems to be poor. Poverty is the most honorable condition for a political party.

There is another class of offices, including most appointive offices, and all those about county seats and state capitals which afford a means of living for a term of years. If any one is foolish enough to desire them it is proper to seek them, and to be at reasonable expense to obtain them. In this case the public can usually see who pays the expense, and understand why he pays it. The man pays the money to get the office because he wants it. If the voter likes him, let him vote for 
him. If he prefers some one else, let him cast his vote accordingly. With none of these administrative positions should "politics" have anything to do. Their incumbents are employed by the public to perform certain duties laid down in the law. Sometimes they have opportunities to steal, and do so. Usually they discharge their duties honestly. It is in the legislative positions connected with state and local governments that there is most danger of corruption, and the voter has his greatest safeguard against dishonesty in these, when he knows whose money is spent to elect the candidate. 


\section{CHAPTER VI.}

THE DISCONTENT OF THE FARMER.

PHE subject of this chapter includes the relation of the farmer to himself and to mankind. The farmer mingles less than others with other men, and so tends to become introspective - to think about himself. This, when carried to extremes, always produces a morbid condition of mind, as is shown in criminals condemned to solitary confinement, who tend to become insane. There is no doubt that the comparatively isolated life of the farmer often produces an unhealthy condition of mind, of which the leading symptom is an unreasonable discontent with his own lot. I do not mean by this that all discontent of the farmer is unreasonable, but that some of it is, and that it is often hard to distinguish between that which is and that which is not reasonable.

In discussing the relation of the farmer to the politicians I have had occasion to point out the low esteem in which the intelligence and astuteness of the farming class is held by those whose trade it is to induce masses of men to vote as they desire, and the same feeling is prevalent to a considerable degree among all classes of men and with regard to all classe. of subjects. The business world does not believe in the mental competence of the farmer.

I do not think this popular judgment upon the farmer's capacity well founded. I think the farming class contains as large a proportion of vigorous although untrained minds as any other class, but they are, for the most part, inarticulate. The habit and environment of the furmer are not favorable to the practice of oral or written speech, nor has lie at command the library facilities wherewith to fortify himsclf for public utterance. It is also true that the majority of farmers, like the majority of other classes, are occupied in transacting business rather than in thinking upon its principles. Finally they 
suffer in the estimation of mankind from the utterances of their self-eonstituted champions. As with workingmen, the mercantile class, and even lawyers, the capacity of farmers for public speech is often in an inverse ratio to their practical wisdom, and the desire to engage in it is very apt to be in such ratio. The deliverances of men and organizations in whose judgment the substantial farmers themselves have little confilence, are assumed to be the opinions of the great body of farmers, from whom, in fact, we really hear very little.

So far as the farmer is discontented it is because he is unable to obtain from the prorlucts of his farm the satisfactions which he desires. This corers the entire subject, and so far as the mere statement of the causes of his discontent is concerned, this chapter might well end here. When I have said all that I shall say, this will be the final summing up. But in this the farmer is not peculiar. The majority of mankind are in the same condition. The workman-skilled and unskilled-is also discontented because the sum of his possible sacrifices will not secure the aggregate of his desired satisfactions. So is the merchant, the lawyer, the doctor, and the money lender.

If it be said here that I should confine myself to such causes of discontent as affect only the farmer, I may say that if $I$ am to deal with real causes, and not their mere operation or manifestation, I know of none which do not operate upon all classes alike, nor do I believe there are such. One law seems to me to govern mankind. Its violation always, and sometimes its fulfilment, causes suffering; and suffering, discontent. Through all nature runs the grim story that the strong survive and the weak perish, and that discontent lies mostly with the weaker. I do not find that well-to-do farmers, or shop-keepers, or workingmen suffer very much, or that they are possessed of any but that rational discontent which we usually call ambition, and which is the mainspring of progress.

It is then with the poorer farmers that we luave mostly to deal in considering the causes of such discontent as is the result of real suffering from economic causes. Almost invariably these will be found in debt beyond their ability to pay. 
The actual owner of five acres of land from which he gets a living for himself and family, is a small capitalist who proves by keeping out of debt that he has adapted himself to his environment and is thus in a way to survive. If he has irrational discontent, the causes thereof are incident to his personal character, and demand no special thought. It is the indebted farmer who complains aloud, and the causes of whose discontent deserve investigation. And yet, putting aside the question of his weakness, which we can not mend, we can not reach the real sources of his discontent without considering the situation not only of all other farmers, but of all other classes.

The causes which are usually assigned as the sources of the farmer's discontent are appreciation of money, inequality of taxation, monopolistic combinations, excessive transportation charges, donations of public lands to be worked in competition with land which farmers have paid for, the exploitation of new lands and inferior races, and the competition of expensive machinery which the small farmer can not own. Most of these subjects are considered in detail in other chapters of this book. In this place it is only necessary to call attention to the fact that the operation of these causes is not uniform even upon farmers. They help some while injuring others. The Nebraska farmer who owes an old debt is hurt by the appreciation of the purchasing power of money, while the Connecticut farmer who holds the little mortgage is greatly comforted thereby. The farmer who hires help in fruit harvest desires cheap labor. The one who, with his family, works in the cannery after his grain is cut, desires wages to be high. All these are farmers. The farmer desires cheap cloth, cheap machinery, and cheap transportation, but the owners and operatives who produce these commodities all desire them to sell high. Here the farmer clashes with other classes. By as mueh as he is satisfier in these particulars, by so much some other class tends to discontent. Wre are on boggy ground unless we can hit upon some law which operates uniformly on all.

And this brings us face to face with a question whose 
determination is an essential prerequisite to any intelligent or useful discussion of the causes of discontent in any class. What ought the farmer to get from his farm? Is his discontent reasonable or unreasonable? If the latter, we need pay no attention to it; if the former, there must be a remedy. But certainly before we can consider a remedy we need to know the exact nature and extent of the injustice. Otherwise we at once sink in a quagmire of muddy thought. The farmer on rich bottom land is discontented because his smaller neighbor will not sell out to him. Ought his farm to yield him the means of offering a temptation which his neighbor can not resist? The farmer, on some poor hillside is discontented because his farm will not pay off a debt improvidently incurred for unremunerative improvements. Ought the poor farm, or society at large, to be held responsible for the unwisdom of its owner? What is a reasonable standard of life for the farmer? What ought to be the reward of the thrift by which means to buy and stock the farm were provided, and the physical and mental capacity required for its successful management? And since the satisfactions of the farmer must largely come from the sacrifices of other classes, we can not determine the measure of the injustice, if any, which the farmer endures, without considering what is rlue also to others. And if we do not know the exact injustice we can not know the real cause of his just discontent, much less intelligently discuss a remedy. What is the rational standard of life for all of us? What ought we to have the means to procure? Ought the standard to be uniform for all? If not, what ought each class to get, and individuals, according to their ability and thrift, within their class? Can we improve on nature's method of letting us all fight it out among ourselves? It is easy to make a list of things which farmers do not like, and call them the causes of their discontent; but are they causes, or are they mere manifestations of some deeper cause?

I think the latter, and that in this country the one cause of unreasonable discontent among farmers is the absence of any well-defined ideal of a standard of life such as most farmers may reasonably hope to reach and maintain. Our 
experience in the development of a new country has been such that boundless opportunities seemed open to all; all have had, consequently, boundless ambition, and boundless ambitions are never satisfied.

Of course we may go still deeper, if we desire, and inquire whether unreasonable discontent is not part of man's nature, and irremediable except by a slow evolutionary process which shall kill off the discontented, if incleed it is not that class which is likely to survive. But it is bad enough to get out of economics into ethics without leaving that perhaps rather boggy ground for the wide ocean of psychology, and antropology, and evolution, wherein no man may touch bottom. And yet, when we approach an economic subject, we are compelled to recognize that beneath every problem in economics there lies a deeper problem in ethics which can not be ignored if there is to be intelligent discussion. The ethical problem which underlies the question of the causes of the farmer's discontent, is that of a rational standard of the farmer's life, and as the farmer is not alone in the world, of the rational standard of all life.

In attacking this subject I am compelled to break what, so far as I can discover, is new ground. So far as this subject has been considered at all it has been approached from the standpoint of the artisan or the urban resident. It seems to me that the first class to be considered is the farmers, because this is the only class essential to the existence of the race. Other classes exist for its comfort, and are entitled to due consideration, but from an economic standpoint the farmer is the only necessary man. In addition to that, his manner of life is in a great measure fixed by external causes entirely beyond his control, which is true of hardly any other class except sailors. Early in the morning and late at night the farmer must minister to the animals which serve him. When the ground is right, he must cultivate it, sometimes as long as he can sce. When the crop is ripe, he must work hard and for long hours to gather it. There can be no eight-hour day for him. Why should he work twelve hours that those who make his shoes or build his houses should work only eight 
hours? And the farmer's wife, how many hours must she work? And the workman's wife? Who ever heard of an eight-hour day for them What is just for one is just for all, men and women. And the necessary standard of the farmer must be the basis for other standards.

It seems to me that the farmer and his wife must expect to work twelve hours, on the average, every day, some of the time at light work. I believe they are perfectly healthy in so doing, and happy when they get reasonable satisfactions in exchange for their sacrifices. I think a reasonable satisfaction for a farmer is a comfortable but molest home, abundant but plain food, plenty of stout work clothing, and a good suit for Sunday, a comfortable conveyance to take his family to church in, moderate education for a reasonable number of children, and such an income beyond that as will enable him to safely, when a young man, incur interest-bearing debt for half the value of the land which he tills, with the expectation of paying it off by the time he is fifty years old, and retiring from labor when sixty. For his own blunders or extravagance he must pay, and by as much as he expends effort in this way, by so much he should fail of earned satisfactions in other respects. I think this a just standard of life for the farmer, and that the standards of other lives should be based on this.

Only the stout farmers can now attain this standard-those who would get over the heads of their fellows in any walk of life, not always, by the way, the most useful or the most amiable of men, but the most effective. It is unsafe for the farmer of ordinary abilities to incur debt, and without debt it is not usually possible for young farmers to get farms. The reason of it is that too large a portion of their income is taken by capitalists, traders, and workingmen, of whom the latter take by far the most, and yet not sufficient for their necessities.

It seems, then, to me, that the fundamental cause of the farmer's discontent is the absence from his own mind of a clear-cut ideal of the measure of the reward which is justly due him from society, with, in many cases, a notion more or less vague of an ideal which he could not reach without injustice to other classes; for it must not be forgotten that 
although the farmer is the only man necessary to our existence, and as such certainly entitled to something more than what may happen to be left after satisfying others, yet it is to other classes, after all, that we are indebted for what really makes existence worth supporting, and they are entitled to their due. To this fundamental trouble is added the fact that the farmer, through ignorance, largely wilful, of facts, and his unwillingness to work with his fellows, does not in the main succeed in getting what he should and might have.

As for the "remedies" proposed or possible for this state of things I have not much to say here. Many of them are discussed in other chapters. Many of those proposed by the farmers themselves I do not think of much value. But, as I have already said, it is not the wisest farmers that we hear most from. Those who speak, who are usually the indebted, do not seem to me to always understand their own case. A great physician once said to me that he never knew a man who was smart enough to correctly count his own pulse. Perhaps most of us are not good judges of our own ailments. The articulate farmers do not say that they are weak and erring, or recognize that with the end of our new lands the era of speculative farming is over in America, and that of close business methods begun, but attribute their trouble rather vaguely to "rings," "combinations," and "monopolies." Now these agencies, so far as they exist, can inflict economic injury upon the farmer only by lowering the price of what he has to sell, or raising that of what he lias to buy. As a matter of fact they have not done the latter, for all commodities, even transportation, which the farmer has to buy, are now lower than at the date when any long-standing debt was incurred. The farmer must have estimated, if he estimated at all, upon paying more for what he buys than he does pay, and in so far as the prices of what he has to sell have fallen, they have done so largely as the result of cheaper production and of overproduction in which he has himself participated, often induced by the representations of bright and unscrupulous men that the impossible would happen. I have little faith in the legislative remedies to which farmers 
continually turn, not even in such matters as the currency and the tariff. So only that any policy be made permanent, it seems to me that we shall all get on about alike under it. As matters stand the only remedy which I have to suggest for the next few generations is that farmers must know more and fight harder. As a farmer I desire cheap labor, cheap transportation, and cheap merchandise of all kinds that I have to buy, and high prices for everything that I have to sell. All other classes are in the same situation. It is a law of commerce that no agreement is possible between contending interests, until after an exhaustive trial of strength. It is also a law that agreement, when possible, invariably follows such contests. We are now engaged in the conflict, which I suppose will continue indefinitely, and sometime close in the usual way. None of us now here will see the close, or can even imagine the nature of a settlement. But we know that it will be inade, for it is the law.

The law of nature is that the due of every man shall be all that he can get and keep. She seems to have filled the world with warring organisıns, for the mere pleasure of seeing them fight, caring nothing who shall conquer. 'This process, which results in the untimely death of the majority, we have learned in these later years to call evolution. But evolution has at last developed a race which, having overcome all other beings, shows signs of trying conclusions with nature herself. The history of mankind is a story of constant warfare with nature, and constant victory for man. Of later years there is an increasing number of those who are determined to abolish the method of distribution of satisfactions according to strength alone, which is the corner-stone of nature's method. Who shall say that the progress of evolution shall not destroy evolution itself? Possibly it may, and then may come the end of all things. Certainly we can have no conception of life unaccompanied by struggle. The condition wherein no struggle is, we eall death. This may be all wrong, since the ages which will be required for such development may be sufficient for the evolution in us of qualities which will make existence without struggle endurable. We can not tell. Such 
a race would, perhaps, differ no more from us than we differ from the primeval man. So far as we can now conceive, it would be a race of degenerates.

But if we fight nature, we must fight together. So long as we are divided, she is too strong for us. And yet by her own law she may be contributing to her own destruction, since, if we reach unity, it must be by the extinction of those who will not cooperate. The single man can not compete with organized man-is not now doing it successfully. The best organized are the most prosperous. Those who will not cooperate will die. The farmer, being now less organized than some others, suffers in ways that we have seen. Gradually he will cooperate more, because his environment will compel him. In part, it may be the present farmers who will do this, and, in part, the successors of those who will die because they will not cooperate. At present, his incompetence to act for the common ends with his fellows is a great cause of the farmer's discontent.

It will be seen that I do not think that the real causes of the farmer's discontent lie upon the surface, or can be removed by local treatment. If the farmer could pay all his debts with what he calls cheap money, be relieved from all taxation, and be given free transportation for himself and his produce, with a bounty on all his exports, so far as he is discontented he would be discontented still. Possibly he would be more discontented, since the seemingly more genial environment would attract to the industry still more of the weaker sort. As I have said, we do not know what qualities may yet develop in our race, but, as we are now, the rugged conditions of competition tend to eliminate discontent by the brutal process of the destruction of the discontented.

We are all children of one family, governed by one law. I can conceive of no adequate treatment of the condition of the farmer except in connection with the condition of others. In the operation of the law which controls all of us, I have seemed to myself to find the real causes of the farmer's discontent, and to get some glimpse of the remedies which must cure it. The first step is to decide what is a reasonable 
standard of life for the industrious, honest, and thrifty, with which, when attained, we should be content, and beyond which desire is unreasonable. The next step is to learn how to control the unreasonable. Here is where we must fight nature, who favors the unreasonable, if they be strong. We do not need to concern ourselves with the lazy, the dishonest, or the unthrifty. Nature will take care of them. She will kill them. 


\title{
BOOK FOURTH.
}

\section{The Farmer as a Business Man.}

\author{
CHAPTER I.
}

THE FARMER AND THE BANKER.*

THERE are mean men in all walks of life. The accumulating instinct, where it is decidedly strong, involves a certain hardness of character which is not lovely. But on the other hand, the accumulating instinct has its corresponding virtues. The accunulating man is careful in promise, but punctual in fulfilment. When a strong desire to possess is joined to a character of weak moral fiber, we have the typical "mean man" of the country town. Those are the men who are on the watch to take advantage of necessity, lending money at rates which no business ean pay, and ruthlessly sacrificing the security when default of payment is made. These men seldom attempt to do anything which they have not the legal right to do. They prey upon the weakness and bad judgment of their fellow-men.

Somehow, rural popular opinion tends to associate men of this class with the banking business. Nothing could be further from the truth. Occasionally, of course, a "mean man" controls a bank, but very seldom. In the first place, such men are not usually satisfied with the profits of the banking business, but, even if they were, they are not able to get into it, for the reason that the other stockholders will not have them. The

* See Appendix E for documents relating to subjects of this book. 
essence of the banking business is a profit on deposits, and those in control of the bank must not be obnoxious to the mass of the people. The mamagers of a bank must be men who have the respect and good-will of the comnunity, or deposits will be light, and the bank unprofitable.

It is allother popular error to consider the managers of banks as persons of great wealth. Of course, wealthy men often do manage banks, but, as a rule, the officers of banks are men of moderate means, but high character, employed upon fair, but not large, salaries. They are not handling their own money, but that of others, and the rules upon which they handle it are not made by themselves, but are the result of the experience of all banks. The money of the banks is not largely the property of the stockholders, much less of the managers, but belongs to those who have deposited it, and who have the right to take it out without notice. The profit of banking arises from the known fact that, while every dollar of deposits in commercial banks is subject to check at sight, as a matter of fact the greater portion, in ordinary times, will be allowed to remain indefinitely, the withdrawals and deposits about balancines each other from week to week. From seventy-five to eighty-fire per cent of the dejosits can, therefore, be loaned with safety, and the interest on these loans, less the expenses of the bank, is the profit of banking. To this is added commissions on collections and exchange, and on the sale of securities. If local bonds are issued, either by the public or by industrial enterprises, a local bank may subscribe for the entire issue with the view of selling them to customers at a small profit. Sometimes, in spite of the low interest which first-class bonds usually bear, they are retained as permanent investments of the bank, because, in case of sudden calls for money from deposits in unexpected amounts, first-class bonds are highly available as securities upon which the bank itself may borrow money to pay depositors. In cases of sudden demands for money, country banks frequently have to borrow largely of city banks to pay depositors, although ordinary demands are usually foreseen and prepared for. It is quite evident, however, that if a bank owes $\$ 100,000$ to depositors, of which $\$ 75,000$ is loaned out and 
not due, it is not in a position to pay on demand, if the greater part of its depositors call for their money. For this reason the loans of commercial banks are always made on short timeusually from thirty to ninety days-so that its funds may be available to pay depositors at short notice. A country bank which should owe depositors $\$ 100,000$, would probably have a capital of $\$ 50,000$, of which a portion would probably be invested in its business premises and furniture, a portion in some reliable bonds, capable of being quickly turned into money, and the remainder paid into the business for loaning. The bank's capital is the security to depositors. In most states, also, the stockholders are personally liable to depositors, to a certain extent, in case of failure.

A high character for integrity is, of course, a prerequisite to employment of any kind in a bank. In addition to this, the responsible officers must be personally popular, in order to attract deposits, and sound judges of the value of property, and of men, in order to make safe loans. In addition to the judgment of the president and cashier, all considerable loans must be passed upon by a "security committee" of the directors.

Bank failures occur from bad loans. The officers of the bank have lent money on property which is unable to earn interest upon it, or upon personal security which proves bad. In the majority of cases, this occurs from putting too much confidence in one man-usually the president-who has lent the bank's money either to himself, or to enterprises in which he is interested, or to personal friends.

$\Lambda$ s farmers are quite as much interested in sound banking as any other class, they can do much towards effecting a radical reform by urging the passage of laws forbidding banks to make any loan whatever to their own officers, or to any business in w.ich any one of them has any important pecuniary interest. Such a law, well enforcel, woukl prevent the majority of bank failures, and work no hardship to any one. If the security is good, the bank officer could obtain the loan elsewhere. If it is not good, he ought not to expect it. Nearly all bad bank failures occur as a result of loans to bank officers. 
There is no state in which the Legislature rould not comply with a demand from farmer's to pass a proper law, and no class but the farmers is ever likely to move in the matter.*

It is conclusive evidence of the integrity and sound judgment of bank officers that so few bank failures oecur, and this leads to the point which I wish specially to emphasize in this chapter, which is that the president of a country bank is the very best firiend that a farmer can have, when he becomes financially embarrassed, or when about to engage in any enterprise involving debt. By virtue of his position, the president of the bank must be a good judge of what will and what will not pay. If he is not such a judge, the bank will lose its money in bad loans. If the farmer finds his ereditors pressing him, the bank president is the best man in the world to advise lim whether he can probably pay his debts, or whether he har better give up and compromise, and, if he can pay, to help him to the money or extensicns. As a rule, the president of a country bank knows pretty well the circumstances of the people in his vicinity, and what margin of profit there is in the business carried on. He is in contact with all who handle any considerable sums of money, and the ebb and flow of deposits in his bank is an almost perfect index of the prosperity of the community. He knows whether those engaged in the different industries are making money, and hence whether it is safe to borrow money to engage in them, or whether, if one is alrearly seriously involved, there is a prospect of winning out. It is this knowledge which farmers can seldom possess, which makes him the best adviser that the farmer can have.

There is some disposition among farmers to regard "banks" as their natural enemies. The foundation for this feeling is doubtless the fact that money borrowed from a bank is expected when due. Farmers, in their dealings among themselves, and with tradesmen, are not accustomed to make payments witl such promptness, and are inclined to resent the enforcement of such rules against them. If, however, the

\footnotetext{
* In some states, at least, savings-banks are prohibited from loaning to their
} officers. 
same farmers become prosperous, and deposit their surplus in savings-banks, or possibly buy a little bank stock, they are quite sure to promptly call for their dividends upon the first of January and July, and to roundly blame the management if they are not satisfactory. Througlıout the country there are thousands of poor people whose little all is invested in savings-banks, and who depend for their means of living upon the regular dividends. These, however, can not be paid unless debts due to the banks are promptly met. In the main the money of the banks, and especially of country banks, is owned by comparatively poor people, whose small deposits, when combined, form the capital which is available for loaning. When, therefore, farmers denounce "banks," they attack, for the most part, poor people like themselves. It is true that in large cities there are large financial institutions which control great blocks of accumulated capital owned by capitalists. These, also, have their functions, which it would require a volume to intelligently explain and discuss. They are essential to society as it exists. Without them the great financial operations of the age would be impossible. They loan great sums of money at low rates, upon unimpeachable security. It is through them that governments and large municipalities borrow money in time of need, and that the great railroad and other corporations float their indebtedness. They are not themselves "monopolists," but they supply the means by which only are "monopolies" possible. Their function is limiter to collecting and Yending great sums of money at very low and constantly decreasing rates of interest. By this taxation is reduced, as well as the cost of service in all the most important departments of life, and they thus render a service to society. So far as these loans are made to the public, society at large is a direct gainer, because it borrows money in amounts and at rates which would be unattainable without the agency of these institutions. In lending money these concerns make the best terms possible for themselves, just as the farmer does in selling his products. If loanable capital at any time happens to be scarce, those who have it will set their own price to those who are in great need of it, just as the 
farmer will not take less than $\$ 20$ per ton for his hay if he can get it, although he knows that his neighbor who buys it can not afford to pay $\$ 10$ per ton. Perhaps neither ought thus to take advantage of necessity, but both will do so when they get the chance. But in the long run the great capitalist must lend money at low rates just as in the long run the farmers must sell hay at low rates. The price of money and of hay is determined by the profits which can be made from their use, and profits are constantly decreasing. When, instead of dealing directly with government, capitalists lend at low rates to corporations, the loan is a service to society, because it cheapens commodities or service. Those who have borrowed the money, and taken the risk, will, if they can, secure the whole of this benefit to themselves, giving the public no advantage whatever, and even, if possible, increasing the public burden. As a rule they can not do this, the public usually deriving some benefit from the cheap money, no matter who the borrower may be. The public, however, knowing that power will be abused so far as it can be, is always on the watch, and is never satisfied with its share, even when, if it knew all the facts, it would be. There is, therefore, the chronic and increasingly bitter warfare between the public and the "monopolies." This is a grave subject, discussed elsewhere in this volume. It is hardly a question between the farmer and the banker.

Hitherto banks have been considered as if all of one class, differing only in size and importance. As is well known, however, there are two general classes of banks, known as "commercial" and "savings" banks. Commercial banks receive deposits subject to check at sight, and to assure the ability to always pay on demand they are restricted by law to short-time loans, and required to always keep on hand, in cash, a certain portion of their deposits. Money deposited in savings-banks is not subject to check. 'The amounts as deposited are entered in a depositor's book, and can be withdrawn only upon presentation of the book, after due notice as required by the law of the state and the regulations of the bank, the time varying from thirty days to six months. As a matter of 
fact, deposits may usually be withdrawn without notice, but the bank has the right to require notice. The reason of this is obvious. Savings-banks are created to lend money on long time, and for the most part on landed security. Deposits are made in order that they may be so loaned, and in that way earn interest. There is usually no requirement for a "reserve" sufficient to pay deposits upon demand. In times of panic, however, there is usually no sale for land, or for securities based upon it. Savings depositors are, to a large extent, poor people, easily excited, and quite prompt to demand their money if they think they can not get it. And yet they all know that their money has been lent, and is for the most part out of the bank's control. They do not, however, reason upon this, but simpiy demand their money. Under such circumstances the bank, if it can, takes its mortgages to some large financial institution and borrows, upon them, the money to pay off the depositors whose money is invested in them. If it can not do this it closes its doors and goes into "liquidation." The money loaned out is collected by the "receiver" as rapidly as possible, and returned to depositors, less expenses. It is a long, tedious, and expensive operation, and depositors get back but a portion of their money. A "run" upon a savingshank is one of the silliest of things. Depositors who make it are really making a run upon themselves. Of course savingsbanks do sometimes loan money unwisely and so fail. This is a risk that depositors must take. As a rule the money is wisely invested, and is safe with time given for collections. Farmers who have borrowed money dislike extremely to have their mortgages foreclosed. They can hardly dislike it more than bank officers. No foreclosure takes place when the mortgagor can sell the property for enough to pay the loan. In case of foreclosure the bank nearly always has to take the property. Having no use for land or any machinery for successfully managing it, banks are less likely to get interest and expenses from it than the former owners. They never foreclose until satisfied that the mortgagor can not pay. When that is the case, the quicker the foreclosure is made the better 
for the farmer. He is put out of the misery of strugging to accomplish the impossible.

Bank checks and drafts* form the main part of the money of the world. While they are not money, their use enables society to dispense with most of the money which would otherwise be required. They are used instead of money because they are more convenient. In the large cities fully ninety-five per cent of the payments are made by means of these instruments. In the smaller towns the ratio is less, and among farmers actual money is probably used more than checks. The existing stock of money at its present valuation would go but little way towards transacting the business of the world, and if used would be very inconvenient and expensive. In times of panic the greatest effect is the stoppage of the flow of bank checks and drafts. It is, of course, not true that modern society could not exist without banks, but it could not do business in the way business is done now, nor so conveniently and cheaply. This subject, however, has been sufficiently discussed elsewhere in this volume. $\dagger$

There is one function of the bank yet to be consideredthat of issuing paper money. In all new countries which can not attract gold and silver because they have little to sell, there is a demand for something which will serve as currency. To supply this demand there are three courses open, all of which have been employed in the United States; the first is the acceptance of some commodity as money, wampum, cattle, or tobacco; the second, the emission of promises to pay money by the government; the third, the emission of promises to pay money by banks, duly authorized thereto.

This general subject has been fully treated elsewhere, $\dagger$ the discussion of the latter alternative, issues of bank-notes, being reserved as more appropriate in this place. During the period between the close of the Revolutionary War and the

* A "draft may be roughly described as any order for money other than one drawn by an individual upon a bank in which he has a deposit.

† Book sixth, chapter IV. 
beginning of the Civil War, bank-notes were in universal use in this country, forming practically the only currency, except, after 1849, on the Pacific Coast. No bank can issue paper money except as authorized by law, and the laws which authorize the banks to exercise this function always prescribe conditions which are presumed to assure the redemption of the notes in coin, on demand, at the counter of the bank which issues them. In the wealthier states of the east these laws were fairly well framed and enforced, and, as a matter of fact, did, as a rule, assure the redemption of notes on presentation, except in times of the occasional "panics" against which probably no legislation which will permit bank-notes to circulate at all, can be effective. A bank which is required to keep on hand such a coin reserve as will enable it to pay off nearly all its outstanding notes at once, would have no motive to issue the notes, and would not do so. Any country whose currency is mainly bank-notes must expect a general suspension of specie payments in times of panic. But while, during our period of bank currency, the laws of most eastern states assured the redemption of bank-notes in most eases, such laws in the then western states would have prevented the issuance of any bank-notes. In those states there was almost no coin, because there was nothing to exchange for it except land, and those who had the coin did not want the land, or if they did, could obtain it without coin. Any law, therefore, which required coin reserves even sufficient for ordinary purposes, much more for stability in times of trial, could not have been complied with. "Money," however, of some kind, the people must have or they could not speculate, and speculation was the one thing which they were determined to engage in. The Legislatures, therefore, permitted banks to issue notes without any adequate provision for their redemption in coin. In most cases the notes were supposed to be secured by bonds or other securities, usually based on land and exchangeable for coin only in case the lands could be sold for coin, which everybody knew was impossible. It was a time when banks were organized by special charters rather than under general laws, and many of these charters were so loosely drawn as to make 
the way easy for all manner of frauds, and cheerfully passer by Legislatures, sometimes, doubtless, corrupt, but for the most part only ignorant. The result was a sudden abundance of what ras called money, but which had little or no value except in the imagination of the community. When people ceased to believe it to be money, as they did whenever presented in any quantity for redemption, according to its promise, it ceased to be money. This is known as the era of "wild-cat" money, and is one of the picturesque eras of financial history. Men were rich one day and paupers the next. Bank-bills passed from hand to hand, with little or no knowledge of their value, the shrewder sort carefully retaining the bills of such banks as they believed to be strongest, and paying out the shaky, the worst of all in rariably finding their way to the poorest and most ignorant, who lost all when the crash came. Whenever there is a debasement of the currency, it is the poorest who suffer most. The above is a fair description of the condition of our bank currency as it existed prior to 1837 , in which year occurred the worst financial panic in our history. The majority of western banks went out of existence, and the people who held their notes lost them. There was the same necessity for money, however, and gradually new banks were formed or old ones reestablished, and the issues began again. Wealth, however, had been gradually erceping west, and it was now possible for some banks, especially in the larger places, to give real security for moderate issues of notes; and, taught by experience, legislation became gradually more stringent in all the states. Spreculation started up, although less wildly than before, followed by another panic in 1857. Again banks went down, with the same unhappy consequences to poor men, ${ }^{*}$ but the prostration was not so complete as in 1837 . By 1860 the country liad pretty much recovered from the shock.

* Of course in all panics the rich and well-to-do suffer losses, but they come rather in the form of loss of deposits than loss upon currency. The wealthy keep comparatively little money by them, it bcing their custom to deposit in banks. It is mainly the poor who lose directly by a depreciated currency. 
The breaking out of the Rebellion caused an immediate and complete change in the character of our bank-notes, and in place of the issues of uncertain and fluctuating value, circulating locally and constantly counterfeited, we obtained a uniform bank currency, circulating freely at par in all parts of the United States, and by which no man, rich or poor, has ever yet lost a dollar by failure. The change was marvelous, and was completed in a few months. The operation was natural and very simple. At that time the privilege of issuing notes to serve as currency was considered of great value. By retaining in its vaults $\$ 15,000$ to $\$ 25,000$ in coin for redemption, a bank could issue notes to the amount of $\$ 100,000$, which it could loan. Its profit was the interest on the amount of difference between the face of the issue and the coin kept for redemption. If the reserve was faithfully maintained, and the loans made with common prudence, the currency was safe under all ordinary conditions. At this time the national goverument was in great need of money, and its credit was very low. If some means could be found to induce a strong demand for United States bonds from the banks of the country, it would be greatly to the advantage of the nation. The Secretary of the Treasury therefore proposed to give such banks as would buy United States bonds the exclusive privilege of issuing banknotes. Congress approved the suggestion, and the result was the National Bank Act, which, with few modifications, still stands. The principle of that act is this: In the first place the bank lends the United States, let us say, $\$ 100,000$. It deposits the bonds thus received in the Treasury of the United States as security for any notes which it may issue. The Treasury then causes notes to be printed and delivered to the bank to the amount of $\$ 90,000$. These notes are not legal tender, but they are payable on demand, either in coin or in United States notes, which are legal tender. For the redemption of these notes on demand, the bank must, in most places, retain 15 per cent of the amount issued either in coin or legal tender notes.* 'The bank's outlay is $\$ 100,000$, lent to the govern-

\footnotetext{
* National banks in the large cities must retain 25 per rent of deposits.
} 
ment, upon which it draws interest, and $\$ 15,000$ retained in its vaults for redemption. Its profit is the interest upon $\$ 75,000$ to $\$ \$ 5,000$, provided it can keep that amount constantly loaned. It pays to the government an annual tax of one per cent on its currency in actual circulation. The national banks are assured of a monopoly of the privilege of issuing bank-notes by means of a tax of ten per cent per annum upon all issues of state banks. This tax renders the business of issuing notes unprofitable, and as soon as the tax was levied, all state banknotes were called in. In case of failure of a national bank its outstanding notes are relleemed by the government from the proceeds of the bonds deposited as security, thus making them absolutely safe. Under the state bank system nearly every note issued was successfully counterfeited, and the loss to the public from this cause was very great. The notes on an Ohio bank might be counterfeited in New York, and put in circulation in Iowa. If the counterfeiter was not detected at the place of issue, he would probably never be caught, and if arrested, the "plant" for counterfeiting could seldom be located. The work of detecting and punishing these criminals was wholly in the hands of the state authorities, who found it very difficult to pursue criminals beyond their own boundaries. Enterprising persons published "counterfeit detectors," which were issued weekly or oftener, and were at the elbow of every one who handled money in any great quantity. No one would receive a bank bill from a stranger without consulting the last number of his "detector" to ascertain whether that bill had been counterfeited, and, if so, as was usually the case, to obtain a description of the counterfeit. Every bank had its "rating," that is, the rate at which, if at all, its bills would be received for deposit by New York banks. None outside that city were taken at par, a sufficient discount being always taken to pay for cost of collection; all country notes reaching New York being promptly returned to the bank of issue for redemption. The strongest banks maintained redemption agencies in the principal cities, thus maintaining the credit of their notes. The notes of the weaker country banks were at various rates of discount in the large cities, and brokers did a thriving busi- 
ness in buying them and sending them home. No prosperous nation ever had so bad a currency.

The passage of the National Bank Act was a great blessing. The people, for the first time in their history, had a stable and perfectly secure bank circulation, for whose redemption, on demand, the faith of the country was pledged, and which circulated at par with United States notes in all parts of the country. The government got large sums of money, of which it was greatly in need, and the banks marle money very rapidly. There was an active demand for loans at good rates of interest, so that the bank issues were kept constantly earning money, and there was interest, paid in gold, on the bonds deposited as security. It has been thought that the banks made too much money. Doubtless they did, but without the prospect of great profits the bonds could not have been sold to the banks, and the government would not have got the money which it needed so badly. The nation was in clistress and had to pay roundly for loans, just as an individual in distress has to do to-day. A money lender will show no more consideration than a tradesman or a farmer. All will get the highest price possible for what they have to sell. Even at the rate of profit which the banks were making, public sentiment regarded their bond subscriptions as acts of lofty patriotism. It was a common feeling at the time that the government could get men easier than it could get money, and the citizen who invested in government bonds was regarded as only less patriotic than he who shouldered a musket and went to the field. It was recognized that there was some risk in taking government bonds at that time. We were not then the rich and united people which we have since become. We were a distracted nation, struggling in the throes of what at times seemed to be dissolution. That the bonds would be paid sometime was believed. Except for that belief they could not have been sold at all; but when they would be paid, or in what kind of currency, there was grave doubt in the minds of many, regardless of the covenant to pay in "coin." The magnificent recuperative power shown by our united country could not be foreseen, nor was it anticipated by any one. As a result of it, 
however, the national banks profited enormously. Their bonds doubled in value, while all the time paying six per cont interest in gold, in addition to the profit on circulation. They paid for the bonds all that the govermment could get from any one else, in many cases unquestionably as a patriotic duty, and they turned out a bonanza. The result of all this has been a very bitter feeling on the part of the farming community towards the national banks. They are commonly spoken of as leaches who sucked the life-blood of the nation in the hour of its extremity. There is no foundation for this opinion. The bankers were quite as patriotic as others. During the Rebellion many farmer's invested their savings in government bonds, often, as in the case of many bankers, from patriotic motives. They paid only the current market price for them, just as the bankers paid, nor would they have paid more. Had they kept them they would have made the same profit that the bankers made. Very few of them, however, did so.

The punishment which it is proposed to visit upon the national banks of to-day for the alleged sins of their predecessors of a generation ago is to deprive them of the privilege, or at least the exclusive privilege, of issuing circulating notes. It is true that the majority of those who hold these views, hold them as their views of a proper fiscal policy, but the alleged extortions of former days are the main arguments used to fire the popular heart and arouse to action. In fact, it is a popular belief that the national banks are still in receipt of the enormous profits which they formerly made. This belief is held by so many of our people that the question of continuing our present bank circulation is in some measure a "question of the day." Its proper consideration raises two questions: First, do the national banks now make an undue profit from their circulation? Second, is or is not onr present national bank currency safer, and, therefore, more desirable for the people, than state bank-notes, or goremment notes. Let us consider these questions in their order.

The national banks do not now make an undue profit on their circulation. It depends upon circumstances whether they make any profit at all. As a matter of fact, many banks can 
make no profit, and have withdrawn their circulation, while remaining national banks. Few, if any, of the large banks which some people would like specially to reach, care anything about the matter. The wealth of the country has so increased that deposits furnish about all the loanable capital which can be profitably employed. In times of stringency or panic, when deposits are withdrawn and hoarded, it would be profitable to the banks, and convenient for the public, to be able to loan their own notes. During the years following 1893 many national banks which had withdrawn or reduced their circulation, drew out new currency to be applied to this purpose. Doubtless it was profitable, or it would not have been done. But it was also very convenient for borrowers. The reasons for this changed condition are quite obvious. In the first place, goverument bonds no longer bear six per cent interest but three per cent. Most banks can make more than three per cent upon money, and whatever more they could make is a loss if they lend to the govermment at that rate. Let us see how the account stands in the case of a national bank issuing its own notes. It deposits in the treasury $\$ 100,000 \mathrm{in}$ bonds, upon which it receives three per cent interest. Upon this security the bank is permitted to issue notes to the amount of $\$ 90,000$. The account would then stand, assuming that the entire issue is loaned:-

\section{Outlay:}

Bonds .................. \$100 000 Income:

$$
\begin{aligned}
& \text { Interest on bonds . ......... } \$ 3,000 \\
& \text { Interest on } \$ 90,000 \text { notes, } 6 \% \ldots 5,400 \\
& \$ \$, 400 \\
& \text { Less tax on cireulation (1 per cent) } 900 \\
& \text { Total income .......... .\$7,500 }
\end{aligned}
$$

In this computation I have assumed the rate of interest on circulation loaned to be six per cent, which is probably a fair average rate for the country, and also that the entire issue of 
notes is kept constantly at interest, which would seldom be the case. Upon these assumptions there is a revenue of seven and one-half per cent, less expenses of conducting the business and occasional losses which no bank can avoid. The stockholders could not possibly receive much over six per cent dividends, which would be satisfactory but not exorbitant. I have also assumerl that the banks purchase the bonds at par, which they could not do. United States three per cent bonds, at the time I write, are at a premium of thirteen per cent, at which rate they pay about two and six-tenths per cent interest. In the large cities, also, the majority of bank loans are made at much less than six per cent-three and one-half to four and one-half per cent being the ruling rate in New York as I write. It is therefore obvious that there might easily be a loss instead of a profit on circulation under the terms of the National Bank Act, which explains why so many national banks issue no notes. The small country banks, loaning in a more retail way, get higher rates of interest, but they could also get higher rates for the money which they have loaned to the government as security From all this it should be evident that, taking the banks together, the majority care very little about the privilege of issuing notes under the terms of the Bank Act as it stands. To some there is doubtless a reasonable profit or no notes would remain in circulation.

This leaves us free to discuss the second question, whether it is for the general interest to retain the national bank circulation. The public convenience demands a paper circulation of some kind, and if we eliminate the national banks, there remains only the alternative of state banks or government issues. No one who remembers our former state bank currency will seriously consider the first alternative. While we should not again have, under a state bank system, any such wretched currency as we had previous to 1860 , it could not be made a good one. The state laws would be made far more favorable to banks than the national act, and in some states the laws would certainly be very lax. There would be some weak banks, and their notes would almost certainly be found mainly in the hands of poor people when they failed, as the 
wealthy would be better informed about them and not take them. There would be more counterfeiting, and there would not be the aid of the exceedingly efficient secret service with which the United States Treasury protects national government interests. The notes would assuredly not circulate at par in all parts of the country. As no reversion to this system is likely to be seriously considered, sufficient has been said on this subject.

Another measure proposed, and what has found much favor in banking circles, is that the privilege of issuing paper currency should be given, exclusively, to national banks, under government regulation and supervision, the entire assets of all banks to be security for the redemption of the notes of all banks, and a redemption fund to be provided by an annual tax on circulation.

This would certainly give an "elastic" currency, as banks would extend and contract their circulation according to the demand for loans. A large body of people object to it in the belief that bankers would combine to withdraw circulation for the purpose of raising rates. While this would not be very likely, the popular fear of it will probably prevent its adoption in the near future. There is also an objection to the measure on the part of some strong banks who will object to be bound to aid in the redemption of weak banks except under conditions to which the latter would object. It is not impossible that this proposal may become the subject of active popular discussion, but it has not yet become so.

The question then remains whether the general interests of the country will be best served by national bank-notes or government issues. This is a topic debated with some passion. It is claimed by those favoring government issues only somewhat as follows:-

1. That it is necessary to restrict the great power of the banks.

The answer to this is, as already shown, that depriving them of the exclusive privilege of issuing notes under present conditions would affect them but very little.

2. That the government would save the interest upon the 
amount of the currency issued, less expense of administration - say a net saving of two and three-fourths per cent. This would amount, upon the amount of the national bank currency extant at the present time $(\$ 238,109,059)$, to $\$ 6,5+7,99 \$$ annually.

This is, of course, true. The question then remains-and it is the only question of importance in this connectionwhether there is an indirect gain to the nation through employing the national banks in this service, sufficient to overbalance this possible direct saving of interest. The indirect benefit deriverl at the beginning of the system-that of finding a market for its bonds-is, of course, no longer of any consequence to the government, any more than the issuing of notes under the restrictions of the present act is of much consequence to the banks. The indirect benefit, if it exists, must be sought elsewhere.

As to this, those who favor national bank issues claim that those issues, as well secured as under the present act, are preferable to any issue of government paper money, in three respects:-

1. The bank issues are safer.

This somds queerly, and is likely to shock emotional patriots, but it is true, for the reason that, in addition to the security of the bonds, the property of the banks may be attached and sold, while the property of the government can not. In case the United States should pay off its debt, which it is quite likely to do, if we escape further war for some years, it has been anthoritatively proposed, by a workable plan already alluded to, to make all the assets of all the banks liable for the notes issuerl by any one of them. This, under the strict supervision of modern financial methods which the banks, in their own interest, would require of the government, would make a perfectly safe currency. No govermment currency is perfectly safe, for the reason that, when taxation has reached a certain limit, the people will not tax themselves further, no matter what happens. There is no financier in the world who would not prefer a currency secured by all the assets of all the banks, which he can levy upon and sell, to the pledged faith of any 
government whose assets he can not touch except with the consent of the owner. Of course, as we stand now, the credit of the United States Government is unimpeachable, but, at the close of a long war with united Europe, it might not be so, Such a war, although very unlikely, is not an impossibility. and its cost would be fearful. It is such contingencies that financiers consider.

2. The bank currency is the more stable.

This, also, is true, under the present National Bank Act, and would be equally true under any act which would attract the assets of all the bauks as security. The amount of issues would be regulated by law, at a sufficiently high limit, and could not be exceeded, while the obligation to redeem on demand would prevent any excessive issues in any erent. If too much were issued, the coin would be demanded, and the notes retired On the other hand, there is no instance in history of a nation issuing paper money without being led into excessive issues. In the times of distress which come to all nations, and which we must expect, as we have already experienced them, nothing will prevent a Legislature from issuing paper money rather than incur the unpopularity of taxation. Our Congress has done this, and another Congress, under similar stress, would do the same thing, were the way once opened. Then follow rapid fluctuations, involving loss to all, but most of all to the poor, and, in the end, of necessity, contraction, whose effects the present generation lias so bitterly felt.

3. The bank currency is the more "elastic"-that is, it will be issued promptly and freely, without legislation, within its limit, when demanded in sudden emergencies, or regularly at the busiest seasons of the year, and, when the use for the excess ceases, the notes will be presented in due course of business, and be retired until again needed. The government, however, has no machinery for doing this, for the reason that it does not lend money.* It can disburse to the people only in payment

* A certain number of our fellow-citizens ask that government should lend money "directly to the people." It is assumed that the nation can borrow money at from two to two and a half per cent, and should do so and lend to its citizens, upon proper security, at a rate suffieiently higher than it pays to cover 
for what it buys from them, and can receive from them only what they pay in taxes. The inflow and outgo of currency would be regulated solely by the taxation and disbursements of the government, which might or $\bullet$ might not coincide with the necessities of business, and, in any event, although large, are a mere trifle in comparison with the business of the country. Except as government paid out for salaries or supplies, no increase of currency would be possible, no matter how badly needed.

All this is not only true, but is not disputed, and needs no further explanation.

It is claimed by those favoring a bank currency, as opposed to govermment issues, that these considerations enormously outweigh the mere saving of interest upon those issues.

The gravest problem of the day is the control of the money power. Money is a useful servant, but a terrible master. The proper object of social effort in this respect is not destruction but control. It would be a waste to destroy power, if it were possible, which it is not. We can change its form, and direct its work, and that is all. In some form the accumulations of thrift and foresight will influence mankind. The highest efficiency of all power results from concentration, and the tendency of capital is therefore to concentrate. Thereby it does more work. It is desirable that the benefits of this work shall be equitably - not necessarily equally-distributed among the greatest possible number, while it is the object of those who use capital to retain all its benefits for themselves. If the owners of accumulated capital could exact fifty per cent

cost of administration. The objections to this are, that the United States probably could not borrow the large sums required to be used for that purpose, at any such low rate, as those who have money to lend would have no confidence in the ability of the government to engage in any such business without very large losses from bad debts, which the people would be unwilling to make good by taxation. The majority, however, who wish the government to "issue money direct to the people," ask that paper money be manufactured in quantities as called for, based upon "the faith of the people," and loaned to those needing it. This subject will be found fully covered in another chapter. See book sixth, treating of "Questions of the Day." 
annually for its use, they would do so. But they can not. Four or five per cent, regularly collected, is all that can be expected, and is considered satisfactory. Much of it, and perhaps most of it, earns very much less. A great deal is lost to its owners by barl debts. The total loss of the money loaned by capitalists to the confederacy during the Rebellion is an instance familiar to all in this country. Take it all in all, it does not seem to me that capital when loaned earns for its owners rewards which farmers would deem exorbitant, and therefore it does not seem to me that efforts to control the use of money should be mainly directed towards banks, which, in the popular mind, are the representatives of capital.

Farmers are themselves large borrowers, and are more clamorous for "cheap money" than any other class of our citizens. All attacks upon money, whether by overtaxation,* interference with collections, or any other method, tend to drive loanable capital from the states where those practices prevail, and correspondingly raise the rates of interest. I am not able to see any business sense upon the part of farmers, in making scarce and dear that which so many of them desire to obtain.

The fact is that all the great enterprises of the world are conducted with borrowed money, and it is towards the borrowers rather than the owners of capital that efforts for control should be mainly directed. Money is borrowed at low rates, expecting that the enterprises in which it is invested will pay high rates. The relations of the farmer to some of these enterprises are considered elsewhere.

So far as farmers can influence legislation affecting banks, the measures which, in my judgment, they will be wise to promote, are sufficiently indicated in the foregoing pages. They should be directed to insuring the safety of money intrusted to their custody, and if they issue notes, to assuring their redemption on demand. Under the laws of all states note issues are a first lien upon the assets of banks issuing them. After they are paid, the depositors come in for what is left.

* All money is almost necessarily overtaxed, because it can hardly be assessed otherwise than at its full face value, while in many states all other property is assessed at but a small portion of its real value. 
Under our national banking laws this, of course, is not material, as the bonds deposited are ample security for the notes, but the principle is the same.

All states provide for state supervision of banks. Officers are appointed to examine the books and securities from time to time, and if, in their judgment, the funds are being unwisely invested, to take measures to compel reform or closing. It is a physical impossibility for these officers to personally examine all securities and count the money in the vaults. In the main they must rely on the books. Official examinations are not therefore very effective as against actual crime, but should prevent unbusinesslike methods, which are often the first steps to crime. Much depends upon the capacity, vigilance, and honesty of official bank examiners. Farmers should understand this, and should aid legislation for the effective inspection of banks, and insist upon the appointment of men of high character to such positions.

They should promote legislation positively forbidding the loan of the bank's funds to any officer or employee of the same bank. This would work inconvenience and hardship in many cases, for heavy depositors are the most profitable customers as borrowers, and, indeed, must borrow, when they need to, or they will deposit where they can, and it often happens that these same men are large stockholders in banks and the most desirable for directors and officers. And yet it is to loans obtained by inside influence, which would not have been made except for such influence, that most trouble comes to banks. If permitterl at all, I do not see how such loans can be controlled or restricted, and can therefore see no safe way except to positively prohibit them and endure the inconvenience. 


\section{CHAPTER II.}

\section{THE FARMER AND THE COMMISSION MERCHANT.}

$\mathrm{N}$

EARLY all perishable products, a majority of the semiperishable, and probably a majority of staple goods, are sold by the farmer, through commission merchants or brokers. A "broker" is a commission salesman who canvasses for orders, but maintains no store or shop. The commission trade of the United States, in all lines with which I am familiar, is in a thoroughly unsatisfactory condition. It is probably so in all lines. While any experienced business man could suggest effectual methods for correcting the abuses-real and imaginary - attaching to this business, the cooperation of too many would be required for carrying them out to admit of any hope of success. What can be done is to indicate the nature of the troubles, with their ultimate causes, and leave the matter to be dealt with in the light of the sturdy common sense of the furmer.

A commission merchant or broker is one who sells goods for account of another, receiving and accounting for the proceeds. He is what the law terms the "agent" of his consignor, and the law holds him strictly to the powers and duties of au agent as defined in the statutes of different states and countries. In practice, the letter if not the spirit of these obligations is openly violated every day by most or at least many commission men. For an agent to apply the proceeds of a commission sale to his own purposes is, in inost states and countries, if not in all, a crime. Nearly all commission merchants deposit the proceeds of their sales to their own account, intermingled with their private funds, and where it would be attachable for their private debts. This is doubtless a matter of convenience, and it is very rarely that losses accrue to the farmer from this cause, but it is not a correct transaction.

The duty of the commission merchant is to faithfully prose(152) 
cute the business of his consignor to the best of his ability and judgment, disposing of the property to the best advantage, and making immediate remittances of the net proceeds. It will be ordinarily understood that he will at the same time be acting for many principals, who, as between themselves, will be competitors of each other, and all that can be expected is that he will act impartially as between them. At the same time it is true that often, in a glutted market, the common agent will have to decide, as between two or more of his consignors, whose produce shall be sold, and whose shall be left unsold, perhaps to deteriorate. The consignors never hear of these occasions, which, indeed, can not be avoided. They have no recourse but to rely upon the fairness of their agent, in striking a fair average one day with another. It would be too much to expect, however, that agents, in making these decisions, should not be more or less influenced by their opinion of their own interests in securing or retaining trade. I have never heard farmers complain of unfairness upon the part of commission merchants in this respect. Many of them have probably never thought of it.

But while commission merchants may, in the main, be safely trusted to deal fairly as between different consignors, it would be contrary to all human experience to expect them to deal fairly as between themselves and others. If a commission merchant has my goods for sale, and some of the same kind of his own, and the market is bad, he will sell his goods first, and then do the best he can with mine. It often happens, indeed, that he inust, for he may have bought his goods with the proceeds of some sale for a consignor who may call for his money. In some lines of trade there is a great deal of this.

It was once a fundamental principle of the commission trade that the merchant should not, under any circumstances, buy and sell for his own account. I am not acquainted with the practices of the commission trade in foreign countries, but am of the opinion that in some of them, at least, there is a survival of this good old-fashioned principle. In America it is dead. Commission merchants may and do speculate freely in the products for whose sale they are agents, and often, 
unquestionably, with the money of their consignors. In some lines of trade there is much petty fraud. As the capital required is small, the business is greatly overdone in all cities, and among those who enter the trade there is certain to be an undue proportion of dishonest men. This is inevitable because dishonest men will seek to enter those lines of trade which afford the best opportunities for dishonesty. For this the commission trade has no equal. The consignors are not business men. Many of them live far away. They have no means of knowing what is done with their produce, and no ability to prosecute if wrong is discovered. The field could not well be more inviting to dishonesty, and there is dishonesty. At the same time there are as honorable men in this trade as there are in any business.

I think the fundamental trouble with the commission trade is that public opinion permits the commission agent to buy and sell, if not to speculate, in the products for which he is agent. It affords the temptation to dishonesty, and the means of covering it up. When my commission agent returns me an account of sales, he does not usually say who has bought the goods. He may have sold them to himself, to be immediately resold at a higher price. It is done every day in all markets. It is not considered fraudulent, at least by the trade. The only remedy is a return to primitive customs. This can only be secured by the organized action either by farmers or commission men themselves. It is not likely to be done by the latter until organized farmers compel it. The first step towards this is the adoption of "resolutions" against the practice by the grange and similar influential organizations of farmers. This educates public opinion, and prepares the way for other steps. Even this stage, however, has not been reached. On the contrary, farmers are always extremely eager to sell outright to their commission agents, not understanding that these men almost never buy except upon almost a certainty of a rising market, and not reflecting that a commission merchant who has this habit is a very unsafe person to consign to, as the farmer may be doing in a few days. I will not willingly put my produce into any 
man's lıand to be sold by him in competition with his own.

If I deposit money in a bank, or if I insure my property, paying a premium therefor, $I$, at least in all civilized states, have the protection of a rigid system of law governing the conduct of the business, supplemented by inspection by state agents. The commission business is as much a trust business as banking or insurance, and the small producers who are compelled to intrust their produce to the firlelity of commis sion merchants, are eren more in need of the protection of the state than the depositors in banks. The commission business should be recognized as a trust business requiring state regulation. The obvious method of dealing with it is to impose state licenses sufficient to provide the revenue to pay for inspection. The license fee for commission merchants desiring to buy and sell upon their own account should be placed very ligh, perhaps at a prohibitory rate. They rould thus, at any rate, be known, and consignors could avoid them if they so desired. There probably would be none of that class registered. The enactment of such a law would probably reduce the number of commission merchants by fifty per cent, as those most familiar with the business estimate that not more than half the present number could live, if the business were reduced to a legitimate basis.

The majority of commission merchants and brokers make only a living, and sometimes a poor living. Competition is fiercer than in almost any other line of business. The notion of some farmers that commission merchants habitually "combine" against them is an error. They are harder to unite than the farmers. Combinations in a small way are often attempted, but they are seldom direelly against the interests of the farmer, and for the most part are directed towards protection from bad debtors. An open and responsible organization of commission merchants is a very desirable thing both for themselves and the farmers. At this writing there is a national society of commission merchants in this country, which, it is to be hoped, will grow and become strong.

With all its faults the commission business is here to stay. The alternative-cooperative marketing-will be dealt with 
elsewhere in this volume. A cooperative marketing society simply does the work of a commission house, sometimes at a saving, as compared with the employment of commission merchants, and sometimes at a loss. The ordinary rates of commission charged in the different branches of the commission trade are fixed by competition and are not too high. Large gains by commission merchants can only be legitimately made by very able men, competent to organize and sustain a large business. The principal gains in the business are often made not so much from commissions as from side interests commected with the handling of the crops, of which the farmer never hars. They may come from speculative or other buying and selling, from rebates on freight, from transportation companies, or draymen, or in other ways, depending upon the branch of trade. These methods are less open to cooperative companies, whose main reason for existence lies rather in their power to prevent combinations or speculative movements to the injury of the farmer. While cooperative marketing is increasing, and likely to increase, the commission trade is increasing also with the growth of the country. It should be recognized and regulated.

As it stands, the relation of principal and agent, which should be cordial and confidential, is too often one of mutual distrust and dislike. The farmer says that the commission merchant cheats in his returns, and the merchant says that the farmer cheats in his packing. Both are often correct. In selecting a commission merchant a farmer should be at the expense of visiting his man in his place of business. Nothing else will really answer. Seek a firm whose members look honest, and appear to act honestly. Give them your confilence, send them honestly-packed produce, and stay by them. Upon the occasions when a commission merchant has to choose between the interests of two customers, he will, if he is bright, favor the regular instead of the occasional shipper. Sometimes they do not do this, in the endeavor to attract new trade, while trusting to habit to retain the old. But such a course is unwise, and most merchants know too much to attempt it. A man shipping to two commission merchants 
has his own brand competing with itself in the same market. It does not pay either firm to specially advocate the brand, because it has no monopoly of it.

A feature not touched upon yet is that of advances. When a farmer accepts a loan from one who should be his serrant, the natural conditions are reversed. The real owner of the produce is the commission merchant who has made the advance, if it is a large one, and he will treat it as his own, so far as he chooses to do so. It will probably be loaded with an expense which will bring a profit to the commission merchant. If the final account does not show the advance repaid, the crop for the next year is "tied up," as all contracts for advances run in that way. The proper place for a farmer to borrow money is at his bank. If his credit is insufficient to effect that, he is farming on inadequate capital. In this cuse lie must do the best he can, which is probably to go to the commission merchant. If compelled to borrow of your agent, frankly accept the situation, inform him fully of your affairs, pack your goods in the very best manner, seek to fully understand market conditions, and be satisfied with the result, whatever it is. Under such circumstances the commission merchant will be very likely to do his best for you, and these unnatural relations may continue pleasant for years. A farmer who is upright, frank, and prompt will be almost certainly met in the same spirit by the commission merchant who has lent him money. 


\section{CHA PTER III.}

\section{THE FARMER AND THE RAILROADS.}

$\mathrm{T}$

HE measure of profit to be derived from a study of a few problems in transportation will depend largely upon the degree in which the reader succeeds in forgetting all that he has read upon the subject in the partisan press, and in banishing from his mind the prejudices arising from heated controversy. This will be quite difficnlt to readers in new and sparsely-settled districts, whose products must be transported over long lines of railroad constructed by speculative methods. Under such circunstances the owners of the roads will be engaged in constant struggles-usually unavailing-to extort from an inadequate traffic a revenue to pay interest upon an inflated capitalization. The railroads thus situated will represent the dominant money power of the state, and the money force will be relentlessly applied to promote the ends of the management. The railroads will be constant applicants for legislative action or non-action, and what they seek will be sometimes proper and sometimes improper. In either case they will be in a very difficult position. To all Legislatures the people will send a certain number of members, who will not, if they can help it, permit any bill desired by any financial interest to become a law unless they themselves derive from it some personal profit. For this condition of affairs the people alone are to blame. The railroads have to deal with it. There is a widespread opinion that railroads desire to see corrupt men in Legislatures. This is not true. While I have no personal acquaintance with railroad political management, yet my opportunities for observation of other financial interests have been such as to warrant the unequivocal statement that all men who are in charge of great enterprises know it to be to their interest that Legislatures and municipal councils should be incorruptible. 
Doubtless if the people are to elect corrupt men the corporations prefer those whom they can control most cheaply, and will endeavor to get them. In the newer states the corporations can not afford to openly advocate the election even of an honest man, for a certain portion of the public press is quite as corrupt as any Legislature, and, unless itself couciliated, will denounce any candidate believed to be favored by railroad interests, as "wearing the railroad collar." In matters of legislation, whether what may be desired by the railroads be proper or improper, to favor anything which is desired by "the railroads" is in some states quite sufficient to assure denunciation from a large portion of the press, and suspicion and discredit from the public. In the older and richer states, where other great financial interests compete with each other for the distrust of the public, the railroad issue is not so overpowering.

While fully recoguizing the baleful influence which cor. ruption, engendered in railroad offices, has had upon our legislation, and whatever our familiarity with the disgraceful history of railroad management in America, no good whatever can come from indiscriminate attacks upon these indispensable instruments of civilization. What society has to do is to faithfully and impartially study facts and conditions, with the intent, whenever these shall be mastered, of deciding what is right and compelling obedience to it. Thus far, in the contest with railroads, while the farmers have been very active, they have been almost entirely uninformed, and consequently have as often been wrong as right in the subjects of detail over which contests have arisen.

The fact is that in nine cases out of ten the real interests of transportation companies are identical with those of the communities which they serve. This is probably true even as to the matter of freights and fares, in regard to which contests are continually occurring. It unfortunately happens, however, that railroad properties are not always managed in the interests of their real owners, and it is equally true that the most of the community laas very little knowledge either of its own interests or those of transportation companies, and espe- 
cially of the enormous difficulties attending the reconciliation of the innumerable conflicts of interests between localities, each entitled to equal consideration, with which railroad managers are compelled to deal. Railroad questions are more often contests between the people of one locality and those of another, than between railroad owners and the people at large. The deciduous fruit-growers of California, finding it difficult to meet, in distant markets, the competition of those living nearer, demand from the company which receives their products, and which they think of as omnipotent in the matter, rates low enough to hold the market, whatever they may be, basing their demands on the contention that even although the traffic may yield no profit, the local traffic which will arise in a prosperous community will fully make good the failure. Suppose this to be recognized by the California company, it is powerless to make a rate which is not satis. factory to its connecting lines, who may be, and in fact are, interested in building up prosperous communities upon their own lines. The fruit-growers of Colorado, for example, are interested in having high rates on the California product, and the contest, up to a certain point, is between the fruit-growers of California and those of other states. This entire volume might easily be filled with compact statements of similar cases. They are constantly arising before the Inter-state Commerce Commission. The "railroad problem" in such a country as the United States is too complicated for even the strongest intellects to deal with in such a way as to do exact justice to all interests involved. To deal with it in a spirit of passion and vindictiveness, and without the light of all information which can be obtained and digested, is not only absurd but ruinous. We may recognize, with sorrow, that the history of our railroad development has been largely one of plunder, both of investors and of the public, and with satisfaction that the very magnitude of the business is at last compelling honesty and wise statesmanship to assert themselves, but neither of these considerations should be allowed to occupy our minds. The question is along what lines of public regulation can these enormous properties be best made to serve 
the necessities of the public, while protecting honest investors from spoliation, and assuring them a just revenue from their investment. It will be possible, here, to consider but a very few even of the most important questions which must arise. As a preliminary to our study it is necessary to make a few statements of fact.

The nominal capital of a railroad company is represented by its outstanding stock and bonds. The bonds represent money which has been invested in the road, and in theory is a debt for whose payment the stockholders are responsible. In fact, it is a debt never intended to be paid, but forever to remain invested and earning interest. The stockholders control the property, so long as interest upon the bonds is met. The bondholders get their interest in full before stockholders receive anything. If default is made in interest upon bonds, the mortgage securing them is foreclosed, and the stockholders lose whaterer investment they have made. While the above is true, in theory, in many cases, of late years, bondholders, by means of agreements which are made effective, are assured a certain representation in the directory of the road.

In 1896 the nominal capitalization of the railroads of the United States was $\$ 9,744,399,332$, of which $\$ 5,226,527,269$ was stock, and $\$ 4,517,872,063$ was bonds. Upon stock to the amount of $\$ 3,667,503,194$, or 70.17 per cent of the rated stock outstanding, no dividends whatever were paid, and, for the most part, probably, ought not to have been paid, as not representing actual investment, although to some extent actual investment is represented, even in this class of stock. On the remaining 29.83 per cent of the stock, dividends to the amount of $\$ 87,603,361$ were paid, or 5.62 per cent on the par value of the dividend-paying stocks, the actual rates paid varying from one to ten per cent. The dividend-paying stocks are mainly in the old and thickly-settled parts of the country, and to a large extent, but not wholly, represent actual investment. The capital of a few railways in New England is entirely represented by stock, upon which large dividends are paid. The capital stock of some prosperous railroads has been "watered" by "stock dividends," until a small dividend on 
the outstanding stock represents a very large dividend upon actual investment. Upon the outstanding bonds, interest to the amount of $\$ 249,624,177$ was paid. There were, however, bonds to the amount of $\$ 515,029,668$, upon which no interest whatever was paid; upon 7.83 per cent of the total outstanding bonds, three per cent was paid, which in all cases doubtless indicates partial default. The bonds of a railroad are supposed to represent actual investment, but do not always do so. In some cases they represent, practically, "bonuses," given to certain security liolders in the process of reorganization, and in other cases exorbitant profits to constructors, often obtained by collusion with officials supposed to guard the interests of stockholders.

The above figures show that the question of "watered stock," which so largely occupies the attention of farmers, is not a very important one, the fact being that watered stock, except in the case of old railroads in rich communities, seldom pays any dividends. It is valuable, first, as a means of controlling the properties by those who expect to make profit by their control, and, secondly, upon the chance that it may sometime be made to pay dividends.

The people, in 1896, paid for transportation of persons and freight the sum of $\$ 1,150,169,376$, or about three and one-half times as much as they paid for the support of the general government, and over $\$ 100,000,000$ more than the combined federal, state, and local taxation in 1890 . This great revenue is best considered, when considering the subject from the standpoint of the public, as a tax, levied by an assessment upon the immediate beneficiaries, and by them passed on, so far as possible, to the public at large, as other indirect taxes are passed on. This makes clear the interest of the general public, even although that term may include persons who never saw a railroad.

In their early history railroads were regarded as private property, to be-administered according to the will of their owners, subject only to the provision of the common law that as common carriers their charges for service must be "reasonable." It is obvious, however, that a road bed, constructed 
and paid for by a private company, upon which no transportation is permitted except in conveyances owned and operated by the company, bears very little resemblance to a public thoroughfare, built and controlled by the public, and upon which any one is free to travel. The old precedents-even those relating to toll roads-were practically valueless. A new system of law was built up, and in the absence of legislative action was built up by the railroads themselves. As any private interest which has power will abuse it, this power was abused, and then came a confliet, which was finally settled by the Supreme Court of the United States, by the deeision that the public had the right to regulate the administration of railroad affairs, including the power to regulate fares and freights, subject only to the limitation imposed by the common law upon the railroads themselves, that the tariff's so fixed must be "reasonable" - a court of proper jurisdiction being, in the last resort, the judge of what is "reasonable." Practically the term "reasonable" has eome to mean such rates as, in the aggregate, should provirle a revenue sufficient to yield a proper rate of interest either upon actual investment, the cost of reproduction, or the present value as affected by existing conditions, ineluding competition, or by such a combination of all three methods of computation as may seem just to all parties in any particular case.

This brings us to the consideration of a vexed question which is fundamental. Upon what sum shall a railroad be permitted to earn dividends? In popular discussion the adroeate of the railroads points to the enormous aggregate of outstanding stoek and bonds, and asks to be allowed to earn interest upon that. At this, however, the publie laughs, as well it may, and indeed that contention is now seldom marle, even in popular diseussion. It is never attempted before any competent tribunal. The aggregate of paper indebtedness is recognized as of no value, except to maintain the balance, which the exigeneies of bookkeeping requires.

Some say that interest should be earned on actual investment. But there have been so many "reorganizations" and "consolidations," and such a disappearance of old books of 
original or construction companies, that only in a few cases could actual original investment ever be discovered, even by the most laborious investigation, and, if it were possible, the time, labor, and expense of it would be beyond all reason. Besides, the public can not afford to accept the principle. Individuals make losing investments, and must suffer the consequences. Shall railroad investments be held so sacred that the public must be taxed forever to pay interest upon the cost of a railroad improvidently or extravagantly built? The original cost is not seriously considered by courts, although, when it can be proven, it has due weight. In some cases, of course, the public would be a large gainer by the adoption of this principle, as, for example, doubtless, in the case of the original Hudson River Railroad in New York.

Another class wishes income to be allowed upon the cost of reproduction, which can always be computed very closely. The cost of railroad building, like that of other things, is much less than it used to be, and tends constantly to grow less. Every railroad built lessens the cost of constructing a competing railroad. Shall we make a new estimate of cost of reproduction every year, or every five years, and raise or lower the rates at each valuation; or, having once fixed the value in that way, shall we continue to allow income upon that value forever? And if the latter, in what way does that differ, in principle, from accepting the actual original cost, when it can be known? The railroad owners say that in making their investment they took their chance of profit. If business does not follow as they expected, they must lose; on the other hand, if the movement of population favor's them, they expect to gain, as others who take similar risks gain by unearned increment.

Still others say that we must consider not only cost of reproduction, but other conditions, external to the road, as, for example, the construction of a parallel line. Such lines have been built in this country, along valuable railroad properties, notoriously with the intent to make a profit only by so reducing the value of the original line as to compel its owners to buy in the new line. Obriously, so long as the competition existed, the question of excessive rates would not be raised, 
but upon what sums shall income be allowed, either to the two lines before the inevitable consolidation, or the single company afterward?

My intent here is not to decide all these hard questions, for if I could do so, justly, my services would be in too great demand to permit me to write this book, but to indicate the difficulty of what seem to some simple matters. The fact is that the question of the just capitalization of railroad properties can only be decided as individual cases arise, by competent tribunals with all available information before them; and upon human judgment and integrity, thus acting under a sense of responsibility, we must finally rest There can apparently be no general rule which will work justice in all cases.

The rate of income to be allowed is seldom the occasion of popular discussion. All seem agreed that capital honestly invested is entitled to remumeration, fixed by the current rates of long-time interest, with a proper allowance for risk, and with some consideration for the length of time for which the property has been unproductive, as in the case of development roads built into new country. The public is not mean about such things, but, on the contrary, is generous.

But suppose the proper capitalization agreed upon, and the income to be produced fixed, in what way shall the burden of producing it be adjusted? And this leads into a whole nest of knotty questions.

I pick up, at random, an old report, and find that in a certain year a railroad company transported freight to an amount equal to $704,772,506$ tons one mile, and that the total expense chargeable to freight traffic, divided by the number of ton miles, gives eighty-three one-hundredths of a cent as the average cost of hauling one ton one mile. The cost of the individual services rendered of course varied greatly, for the road is a long one, and hauling is much cheaper upon some divisions than upon others. The cost of transporting a certain commolity a certain distance by rail is not computable by the most skilled transportation expert, but it is affected by many things, as, for instance, length of haul, cost of coal, rate of wages, gradients and curves, presence or 
absence of snow and floods, equality, or lack of it, of traffic in each direction, and volume of business. Assuming, however, eighty-three one-hundredths of a cent as the average cost per ton per mile upon that road, there may be some who would think that the production of a revenue would mean simply the addition to the average cost of whatever is necessary to pay the desired income upon the capital, and making that rate apply to all freight carried.

The result of such an attempt, however, would be the immediate disappearance of a large part of the traffic, which could not bear the average rate. Railroads can not be run upon this principle. Any attempt to apply it would so raise the price of such commodities as coal, lumber, cement, pigiron, and the like, where transported by rail, as to make their delivery impossible to many communities now obtaining them cheaply. It would prevent the working of numberless mines of low-grade gold, lead, copper, and silver ore, whose output is now carried to smelters at any rates which will pay any profit at all, above actual cost of train service. No railroad, whether owned by a private corporation or the state, ever was or ever can be run upon such a principle, if it is proposed to adequately serve the public, while producing any income upon the capitalization. The method always adopted is to classify the commodities, and charge the highest rates upon those which are able to pay the most-that is, those having the highest value for the same weight or space. A car-load of silk might perhaps easily pay from San Francisco to New York a rate of $\$ 5.00$ per one hundred pounds, which is about three and one-third cents per ton per mile, while California fruit-growers, who now pay $\$ 1.25$ per one hundred pounds, or about eightyfive one-hundredths of a cent per ton per mile, find it very difficult to deliver their product at such rates as will enable it to be sold at a profit. It is not intended to discuss or even explain further the principles of rate making, but simply to show that freight rates must be fixed according to "what the traffic can bear." By this it is not meant that railroads should be permitted to seize all the profit arising from the movement of commodities, but only to assess the necessary revenue largely upon the basis of that profit. 
It is in the application of this necessary principle, however, that some of the worst abuses of railroad power have occurred, and in regard to which most of the contests between the railroads and the people arise. The expert knowledge required to arrange such a tariff sheet as shall be just to all concerned, and yet produce the necessary revenue, is perhaps even more than that required to adjust a national tariff on imports, because, in addition to an intimate knowledge of industries and localities, the details of rail traffic must be known with equal accuracy. Even when all these are mastered, there comes the factor of intense competition from other carriers, whose conditions are constantly changing. So that the ratemaker of a railroad, even with the best intentions in the world, is likely to be driven to let go every other consideration except the procurement of all the revenue possible for his road, regardless of any other interest. This, however, the public can not permit.

The abuses which have resulted from the struggle for revenue are of three classes:-

Discriminations between individuals.

Discriminations between localities.

Discriminations between industries.

Discriminations between individuals, which have always been in favor of the strong and against the weak, are abhorrent to the natural sense of justice which is common to all of us. They are, and always have been, contrary to law, but there has never been any remedy. The lawyers will, of course, say that any one who can prove himself to have been damaged, could get a judgment against the offender, but as individual discrimination can seldom be proven, and as no one could afford to litigate on such a subject with a railroad company, there has practically been no remedy. It is necessary that the public assume the duty of assuring equality of treatment as between individuals. In interstate commerce United States law makes discrimination between individuals, criminal offenses, and the same is usually true by state law, as to traffic within the 
state.* The difficulty has been to get the facts. The United States Interstate Commerce Commission, which was organized in 1887 , attacked this problem with great vigor, and within two years was able to report that, in the opinion of the commission, this abuse, as to interstate commerce, had ceased. At that time the commission and the railroad companies supposed that the powers given to the commission by the act were ample to discover the facts and enforce its authority. This being the case, the practice probably did stop. Subsequently successive discussions of the Supreme Court took away from the commission most of its power, and as a consequence law-breakers have ceased to fear it. All railroak companies resolutely deny that discrimination between individuals now exists, but nobody believes them. Some high railroad officials have unquestionably committed perjury in swearing that they "did not remember" as to matters which they doubtless did remember perfectly. Such perjury can not be proven, and therefore can not be punished. Indirect methods of giving individuals preferences have been devised. A rich concern may own its private cars, for whose use, over its lines, the railroad company may pay an exorbitant rental. This is not possible to the poorer rival. "Refrigerator car" companies are capable of being, and are, made use of as means of discrimination between large and small shippers. What are known as "terminal" or "switching" charges are remitted or rebated to large shippers. Finally, actual cash rebates, usually in the form of "commissions," are doubtless paid to large shippers in some cases. The actual rates paid by individuals are the same. In some form, however, the stronger get some of it back, and the richer the concern the more it gets. Of these statements probably not a single one could be proven in any court. But they are true.

Discriminations between localities ean not, in the nature of things, be secret. They are always earnestly defended by the favored localities, and bitterly attacked by communities injured. They are as unjust and unlawful as discriminations

* I assume that all understand that Congress has exclusive jurisdiction of all traffic passing from one state to another, and that states have exclusive jurisdiction of traffic wholly within their own boundaries. 
between individuals. They are, perhaps, not now made to such an extent as formerly, as when complaint is made some excuse must be given. The defense almost invariably set up is "competition." In the cases which came before it, the Interstate Commerce Commission laid down the principle that competition by water, which is not regulated by law, is a sufficient excuse, but that competition by rail, which, if undue, could be controlled by law, was not a good defense. The Supreme Court, however, held that it was, and localities injured by the preference of other places under such circumstances, probably have no redress until the law is changed.

"Competition" is the defense usually made by railroads for all violation of the law that no greater freight rate shali be made upon the same commodity for a shorter than a longer distance in the same direction, ${ }^{*}$ the shorter distance being included in the longer-and "conditions" being substantially similar. In interstate commerce, the commission, in cases where it finds conditions not similar, may give permission to make a larger charge for the shorter haul.

There can be no doubt that this is sometimes to the interest of the general public, even although contrary to the interest of some particular locality. It is necessary that each road raise a certain revenue from its traffic. Whatever it can obtain from any one source decreases by so much the necessary collections from all other sources. Each commodity handled ought, if it be possible, to pay its just share of all the expenses of the road transporting it, including its share of interest upon capitalization. If, howerer, by reason of competition at terminal points, it is unable to secure certain classes of traffic at rates which, in comparison with the other traffic upon the line, it ought to receive, it will be to the advantage of the public that it derive whatever revenue may be found possible, so only that it be greater than the actual cost of train

* Farmers often wonder why a railroad should ever be permitted to charge more for hauling one way than another. Evidently it costs more to haul freight up-hill than down-hill. If traffic is naturally heavier in one direction than another, the railroads must be permitted to bid low for freight which can be had at such rates, rather than to haul back empty cars. 
service and repairs. Railroads will even carry freight at less than actual train charges, providing that it tends to produce other traffic which yields profit enough to more than make good the original loss. If it does not pay its proper share of the fixed charges, still, if it pays anything at all towards them, it by so much reduces the necessary charges upon other traffic. This is the principle upon which all railroad companies are managed, and which is accepted as sound by all who are familiar with transportation problems. The question, however, will rise, in each case, whether or not the rate fixed is "reasonable" under all the circumstances, and it is a question which should always be decided by some impartial tribunal, and not by the railroad authorities, or by the people of any interested community. It is also proper to note that there is the competition of markets to be considered, as well as the competition of carriers. There may be, and, in fact, on long railroad lines nearly always is, some commodity which will not bear transportation at its just proportional rate, but which can be carried at a rate which will yield something, more or less, towards the payment of fixed charges. In such cases the carrier will wish to transport it, and the community which produces it will be desirous that it should, without any regard whatever to its propriety or impropriety, when all interests are considered.

Discrimination between industries may be illustrated by an extreme case. Upon the line of a certain railroad there was a limited amount of timber suitable for railroad ties, which the company desired to have kept there, and to have the price always very low, so that the ties could always be bought cheaply for the uses of the company. To effect this the company adopted the very simple expedient of a prohibitive freight rate.* This, of course, was little better than open robbery. But there are constantly arising cases in which a company may desire to favor or oppose the growth of a particular traffic. $\Lambda$ company may have upon its line a large manufactory from whose business it derives a large local revenue.

* The Interstate Commission, in this case, compelled the company to make its rate conform to other lumber rates. 
It would be unwilling to see this factory crippled by outsicle competition, and might therefore refuse to join, as part of a through line, in making a reasonable through rate upon competing produets. In this ease, and in fact in nearly all cases except discriminations between individuals at the same shipping point, the interests of loealities, individuals, and industries are inextricably involverl. Railroad eontroversies are usually, in the main, conflicts between the people of different localities. It usually makes little difference to a railroad company how it shall collect its revenue, when once the amount has been agreed upon, although it will preferably collect it in accordance with the interests of the immediate community served by it. If, however, there is a question of its obtaining the necessary revenue, or if, as usually is the case, it is struggling for all that can be got, regardless of necessity, railroad officials will ruthlessly sacrifice every interest except that of their company-precisely as farmers or other people will do under similar circumstanees. Railroad officials are exaetly like other people, exeept that they are usually far abler than most of us. The extent to which railroad officers will go in wrong-doing, the methods which they will employ, and the ability to discern how closely the interests of railroads are identified with those of the communities served by them, depend wholly upon the individual character of the men. Some are far-seeing and honorable. Others are narrow and unscrupulous. In this, again, they are exactly like farmers.

My object in what has thus far been written has been simply to point out, as elearly as my space will permit, that the preparation of a classification, and a rate sheet based upon it, extending over a large territory of diversified interests, which shall be just to all interests concerned, presents, perhaps, a problem as complex as any with which the human intellect has to deal. The practical question lere is in what way farmers, and others who are profoundly interested, can aid in solving it.

Certainly they can not solve it themselves. Railroad tariffs have been constructed by acts of Legislature, under the pressure of popular excitement, but such tariffs have been invari- 
ably set aside as unreasonable, as they doubtless should have been. Legislatures can now deal only with tariffs within the state, which are doubtless, however, of great importance.

There are many who favor govermment ownership of all railroads. This would doubtless remove the abuse of passes, the evil of stock jobbing in railroad securities, corruption in aid of private interests, and discrimination between individuals. It would not, however, remove the conflict between local and industrial interests, which causes most of our trouble. It would merely transfer the combat to the lialls of the Legislatures, and the private offices of officers appointed by we know not what influences. It would involve an indebtedness of several billions of dollars, * upon which interest must be paid, whether earned by the properties or not, and an increase in the number of employees of the nation to the number of nearly a million. If the eight-hour day were insisted upon, and the scale of wages fixed as in other government employment, the number of employees would be largely increased, and with it the cost of transportation. Of course it could not all come at once, and I have such confidence in the comirion sense and executive ability of our people that I feel confident that the gravity of the situation would compel soberness in dealing with it, and that we should evolve a competent and effective service. It would take a long time, cost a great deal of money, and many lives, but we should do it. Frankly, however, as a business proposition, I am unable to see much wisdom in buying what we can control without buying. At any rate it will be time to discuss the matter when seriously presented in concrete form, by men who understand the subject. We can buy the roads whenever we decide that we wish them. Most railroad owners would prefer United States three per cent bonds to their present railroad securities, and the val-

* It is hard to say how many billions. As stated on pages 161, 162, the railroads of the country, in 1896 , paid dividends and interest to the amount of $\$ 337$, 227,538 . This, at 3 per cent, represents a capital of $\$ 11,240,917,933$, which is $\$ 1,496,518,601$ more than the total alleged capitalization of all the roadswatered stock and all. Capitalized at 4 per cent, it represents $\$ 8,215,356,725$. Capitalized at 5 per cent it represents $\$ 6,744,550,760$. Capitalized at 6 per cent it represents $\$ 5,620,458,966$. It is a tidy sum, at all events. 
uation could probably be agreed upon. If we chose to pay in two per cent bonds, we could do so by increasing the valuation.

The immediate question is of the method of control.* Unjust control will be defeated in the courts, as it should be. The Constitution protects rich and poor alike, and the rich know how to make its protection effective. Just control can only come from exact information, and to this we are entitled. The fundamental principle which, as the first step, must be comprehended, adopted, and acted upon is this: No quasipublic corporation can have any secrets which the public is bound to respect. U $\mathrm{U}_{\mathrm{p}}$ on this must come the second fight. The first fight was over the right to control. That has been won by the people. Logically, the next step is the knowledge requisite for intelligent control. That demand has never been

* Many people, including most railroad officials, insist that the public can not control the railroads, and that the only practicable method of removing the glaring evils which largely arise from unrestricted competition is to permit competing roads to form pools, upon such terns as they may mutually agree upon. As they will then have no interest in underbidding each other, they will have no motive to continue the unjust discriminations, which are more injurious to the public than excessive rates impartially applied. The Interstate Commerce Commission, in its report for 1897, intimates that unless the power of the commission is to be increased, railroads may as well be allowed to pool under the supervision of the commission. I am not willing, myself, to concede that the large measure of failure which has thus far attended our efforts for control proves that we shall not ultinately succeed. To a large extent failure has been due to prejudice, excited by agitators and demagogues, leading to popular demand for what is not only unjust but opposed to the interests of those who demand it. In the end such demands come to nothing, but meanwhile the attention of the people is distracted from the real issues, so that no popular support is given to such bodies as the Interstate Commerce Commis. sion, which knows very well how to control the railroads, and will do so if the people will compel their representatives to give them the power. It is my belief that most railroads would welcome a control which would control competitors as well as themselves, provided that the control be intelligent and bonest. What railroads most fear is control by men who do not understand the transportation business. The short terms of state railroad commissioners ex pire before they have had time to learn anything about transportation. Even the Interstate Commerce Conmission has nerer had a member who was a trained railroad man. Probably no really competent railmad man could be got to serve at present, as such men would not work for the salaries of public officers. If the time ever comes when real power and great honor attach to these positions, trained railroad men of the highest character will consent to serve, just as our greatest lawyers accept appointments to the Supreme Court of the United States at salaries which are very small compared with what they earn at the bar. 
properly formulated that I know of. The formula given is the proper one to adopt. As the first step in the education of the public it should be adopted, and published, without rhetoric, and without passion, by every body of farmers in the land. By law, the Interstate Commerce Commission has power to prescribe methods of accounting to be followed by railroads in their interstate commerce traffic, and the roads seem generally to comply with it. But there are subjects upon which the publie demands details, which it must insist upon getting. Details of certain expenditures, with a requirement of vouchers, would be more effective in the prevention of improper practices than any other method which could be adopted. The public is entitled to them and should insist upon getting them. Should occasion be found to require it, railroad auditors should be public officials. At any rate, whatever degree of severity and coercion may be found neeessary to put the public in possession of the information required for intelligent dealing with railroads, should be relentlessly applied.

No intelligent public opinion can be created to guide farmers or anybody else in formulating specific demands for reform without some knowledge of the facts and principles involved. Of these farmers are now practically ignorant. What, from their reading of inflammatory literature, they believe to be true, is mostly not true, and what they demand is as apt to be unjust as otherwise. They can usually see only their own interests, and will not understand that others, and rery likely other farmers, must be considered. I know of but one place where the American farmer can get the information which he needs on this subject, and that is from the Reports of the Interstate and State Railroad Commissions. The Reports of the Interstate Commission from 1887 to date, give complete and impartial discussions of all problems of interstate traffic, and the syllabi of the great number of cases decided give more facts than can be had anywhere else. A set of these may be found in any good public library, and can be collected by granges or individuals. A sufficient inquiry would doubtless resuit in a republication of these documents, 
omitting repetitions. The citizens of each state can obtain the reports of their own states.

Farmers, while insisting upon disclosure of all railroal secrets, and fully informing themselves as to what is now known, should work for the strengthening of the Interstate Commerce Commission by the legislation which it has asked for, but which Congress refuses to give, and for the strengthening, in certain directions, of state commissions. In the newer states the railroad commissions are usually objects of public contempt-and this whether honest or dishonest. They are usually expected to accomplish the impossible, and having foolishly accepted office must suffer the consequences. I do not see how a good railroad commissioner can ever be evolved from the tumult of a political convention, but it is a fact that good men are often both nominated and elected to those places. The trouble is apt to be with their mental calibre. They are expected to become allvocates, and are not usually able to cope with the intellectual forces against them.

The true functions of a railroad commissioner are not those of an advocate, but of an investigator and judge. A railroad commissioner can not make a freight tariff. He does not know how. Just classifications and rate sheets must be a matter of growth. The railroads must make their own tariffs, and the commissioners must hear complaints, and decide them after due hearing, ordering such changes as may seem just. The decisions once made, and upheld, if contested, by the courts, must be enforced relentlessly, and at all hazards, by the people, whether in favor of the complainants or against thenı. When decisions are just, as they usually will be, the railroads will, in nearly all cases, promptly comply with them. What the farmer must do, therefore, to secure justice from the railroads, is: First, insist upon finding out and publishing whatever the railroads desire to keep secret. Secondly, study the railroad question from original official documents; 110 other publications, especially if controversial, are of much value. Third, insist upon strong national and state commissions, with full power and wide discretion in investigation and review. Fourth, get good men into those positions. Fifth, sustain them when they are there. 


\section{CHAPTER IV.}

THE FARMER AND THE SPECULATOR.

THE science of economics recognizes the existence of moral obligations, but does not concern itself with their enforcement. It merely takes account of economic results following their observance or non-observance. That "honesty is the best policy" is an economic, not a moral precept, meaning that in the long run uprightness is most profitable. With the resemblance, if any, of speculation to gambling, or the immorality of that practice, if it be immoral, this work has nothing to do. What I have to consider in this chapter is the economic result to farmers, of speculation, by others than themselves, in the products of the farm.

"Speculation" is the purchase of a commodity not needed by the purchaser for consumption (or for sale to customers in the ordinary course of business), in the expectation that the market price will be higher; or the contracting to deliver at some future time a commodity not owned by the seller, in the expectation that before the maturity of the contract he will be able to purchase for delivery at a price lower than that contracted to be paid to him. The speculator who buys will profit by higher prices, and is interested in promoting them, which he commonly does by the persistent circulation of facts or rumors indicating a scarcity of the commodity. He.is called a "bull" from the habit of that animal of tossing things up on his horns. He desires prices to go up. More commonly, of late years, he is called "long of the market," meaning that he has a supply of the commodity in excess of his contracts to sell. Speculators who contract to make future deliveries are called "bears," from the habit of that animal of tearing lown things with his claws. They wish prices to go down. More commonly, of late years, they are called "short of the market," meaning that they own less of the commodity than 
they have contracted to deliver. They will be compelled to buy, and desire to buy cheaply. They therefore promote low prices by circulating facts and rumors indicating an excess supply of the commodity. "Bulls," or "longs," are speculators for a rise in prices. "Bears," or "shorts," are speculators for a fall in prices.

As speculation is commonly conducted, the speculator for a rise does not actually receive, pay for, and store the commodity which he buys. This, if done on any important, sale, would require far more capital than speculators usually possess, and would also involve the expense of actual delivery, storage, and insurance. He therefore merely contracts that he will receive, at some definite time in the future, a given quantity of the commodity at a price named, the seller contracting to deliver. Although, in these cases, actual delivery is contracted and can be demanded by either party, neither usually expects it to be made. At the maturity of the contract the one who would lose by its literal fulfilment pays to the other the amount of that loss.

A "corner" occurs when the speculators who have contracted to receive the commodity secure control of the entire stock available for delivery at the time and place agreed upon. Those who have contracted to deliver to them can buy for delivery only of those who are to receive it, who set their own price, which is usually the highest which it is estimated that sellers can pay. They do not compel general bankruptcy, since that would defeat their object. When actual and complete control of a commodity has been obtained by the bulls, the bears have no recourse but to accept the situation and settle as best they can. Complete control of any of the most important farm products, like wheat or cotton, is impossible. At most, control can be obtained only of the supplies, which, at reasonable expense, can be delivered at the time and place where the contracts mature. Outsicle these limits there are always supplies available, and if prices are raised so as to admit of it, these will be purchased and rusherl in and tendered for delivery. These additional supplies must be taken and paid for in cash, or those attempting the corner will fail, and 
prices at once collapse. In such cases payment of any difference in value is seldom accepted, as the object is to supply the commodity in such quantities that the bulls can not raise the money to pay for it, when, of course, they fail, and the corner is broken in that way. Corners seldom succeed, but every few years some wealthy combination of speculators attempts italmost invariably with disastrous results to themselves. Speculation, however, is continuous in the leading farm products, and the contest between bulls and bears goes on forever. This speculative business is conducted in public, after the manner of an auction. The rooms where the business is transacted are called "exchanges," and at a regular hour on each business day an official "caller" calls off, one by one, the list of commodities dealt in on that exchange, and pauses for members to offer to buy or sell. None but members are admitted to trade on the exchange, and these must be known to be responsible. Failure to comply with any contract thus made forfeits membership in the exchange. The business is not commonly transacted by the principals to the transaction, who usually do not wish to be known. The actual trading is done by a class of men called "brokers," who receive orders to buy or sell the commodity, taking on deposit a sufficient sum to protect themselves against loss. This deposit is called a "margin." The ordinary fluctuations of leading commodities being small, the deposit of a small margin will enable the speculator to purchase a large quantity of the commodity. The profit to the brokers is their commission on sales and purchases, and it is the custom of many of them to flood the country with circulars tempting men of small means to attempt to get rich suddenly by speculating through them on the exchanges. The order is given, and the deposit made, and notice is at once received that the broker has bought so many bushels of wheat, or barrels of pork, or bales of cotton, for account of the one ordering, the right being reserved to call for more margin should the market require it, in default of which the commodity-may be sold. If the market goes right, the new speculator makes money. If it goes wrong, he loses his margin. The broker always protects himself by selling out before the margin is exhausted. 
The above describes the methods of transacting speculative business in farm products. The question now to be considered is the economic effects of the practice upon farmers. As to this it is claimed that farmers are benefited by the daily publication of values, all transactions of the exchanges being published and widely circulated by the daily press. These include not only transactions in "spot" goods, which, of eourse, are not speculative, and show actual current values, but the extremes of opinion as to probable values in the future. There is no doubt that this is an advantage to the farmer. When speculative trading in "futures" of farm products was taxed out of existence in Germany, there was immediate complaint from the farmers at whose instance it was done, that they could no longer find out the price of grain, but were at the mercy of dealers better informed than they. It would seem that the ordinary commercial reports would suffice, but it is not possible to obtain accurate knowledge regarding transactions privately made, and at best the press reports give only the prices of the day, affording no means of judging of what the best-informed men consider will be the probable course of the market.

When this has been said, it is difficult to find anything further of advantage to the farmer arising from speculation in farm products. If it be said that it is to the advantage of farmers to have a large body of men systematically engaged in spreading rumors tending to raise the price of a commodity, this is neutralized by the fact that another body equally large is actively at work in the opposite direction. There is the further fact that no reliance is to be made upon the statements of either party. The farmer is as likely to be deceived to his disadrantage by the one as the other. What the farmer needs above all things is to know the real facts affecting the market price of what he bas to sell.

Let us now examine more closely as to how a farmer in the Mississippi Valley, for example, would be affected by a successful or unsuccessful "corner" on wheat in Chicago. In the first place, any speculative morement of this kind is always preceded by a long period of quiet buying at the lowest possi- 
ble prices. To avoid attracting attention by very large purchases by one party, a large number of brokers are employed. This is continued as long as possible, and it is evident that the farmers who thus part with their wheat are not benefited. At last the time comes when it is evident that some one is manipulating the market, and then comes a wild rush to break the price by pouring wheat into Chicago in such quantities that the bulls can not raise money to take and pay for it. Whichever party wins, the result is an enormous accumulation of wheat in the Chicago market, very fur in excess of local requirments. When the day of settlement arrives, the deal closes, and all their accumulated wheat is thrown upois the market, to get rid of the interest, storage, and insurance charges which are eating it up. This closes the usual outlet to farmers who still retain their wheat, and the product remains unsalable, except at rates so low that speculators see that it will be safe to buy and hold. The only farmers who have made money by the speculative movement are those who were wise enough to sell during the period elapsing after the attempt to make a corner becomes evident, and before the market breaks, or the day of settlement arrives. As farmers are themselves very prone to speculate, large numbers will certainly refuse to sell when the product is at its highest, holding on for a still further advance. As most attempts to corner markets fail, there is almost sure to come, some morning, the announcement that the operators for a rise have been unable to fulfil their contracts, and in a twinkling the whole edifice of prosperity is gone. While the farmer has been imagining himself rich, he has probably neglected his business to watch the market, and very likely incurred expenditures or obligations beyond his real means. He will be fortunate if he has not also acquirerl bad habits which will follow him through life. Nothing is more demoralizing than the feverish excitement of speculation.

One of the leading demands of the Grange is a prohibition tax on speculative dealings in farm products. It is an exceedingly difficult problem to deal with, since the speculative contracts do not, or need not, differ at all in form from legiti- 
mate contracts, and it is a business necessity for millers and other manufacturers to purchase stock for future delivery, ancl to put up or require margins or bonds to assure fulfilment of obligations. Until the transaction is closed, it can not be assumed to be speculative. Legal ingenuity will find means of evading the law. But while, therefore, effective enforcement of any "anti-option" law is hardly to be expected, it may be well to put upon it the stamp of illegality.

The most effective means of supervising speculative trade in farm products is a wide diffusion, among farmers, of their actual value. This subject, including the agencies for gathering and diffusing this information, is considered in other chapters of this book. 


\section{CHAPTER V.}

THE FARMER AND THE TRADESMAN.

TRADESMEN-meaning especially retail tradesmenseldom make as much money as farmers suppose. In the first place, the actual cost of transacting a retail business will vary from fifteen to twenty per cent upon the value of the goods sold, depending upon the amount of business done. A very large retail establishment may reduce cost of carrying on business below fifteen per cent, and a retailer in a town or city is in danger if his cost runs above that. But upon many articles, like sugar and flour, whose wholesale cost is known to the public, the profit is usually less than fifteen per cent. It is essential, therefore, that at least equal quantities shall be sold at a profit greater than is required upon the average, to cover the cost of business, or it is only a question of time when failure must follow. There are also other losses, notably bad debts and dead stock. The dealer will try to purchase only what he can sell, but he is as liable to error as other people, and accumulates unsalable stock, which becomes shelfworn and must be sold for whatever it will bring. While an estimate of fifteen per cent upon the "turn over" may be assumed to cover depreciation and bad debts, whether or not it actually does so depends mainly on the good judgment of the tradesmen. A little calculation will make this plainer. If a small dealer puts $\$ 3,000$ into stock, and "turns" his capital three times a year, his annual sales will be $\$ 9,000$, upon which fifteen per cent will be only \$150. It is evident that in a business conducted on so small a scale, fifteen per cent will not pay cost of transacting it, but with an a verage profit of twentyfive per cent, yielding $\$ 750$, the dealer can live, if he has help in his own family, and does not make too many bad debts. For retail stores, such as the farmer most commonly deals with, an average profit of twenty-five per cent is necessary if 
the business is to be profitable. As the volume of business increases, the percentage of expense runs down very rapidly, and in such wholesale trades as I am most familiar with, may not exceed five per cent. A gross profit of ten per cent on staple goods is quite satisfactory to wholesale merchants.

The retailer who sets out to make lis profits average twenty-five per cent of his sales, must charge a very much greater profit on many of his goods, since competition compels the sale of many staple goods so low. The large profits are made on goods whose cost is not generally known, such as olive-oil, extracts, "repairs" to farm machinery, and numberless other articles of the kind. Upon the whole, it seems to me that the small retail tradesman is about in the situation of the farmer. His invested capital is the price which he pays to assure himself permanent employment. If he ever sells out his business, he will be lucky to get luis money back. Very few accumulate much, although the percentage of accumulating men in retail trade is doubtless in excess of that among farmers.

A good retail dealer is a great convenience in a country neighborhood. If it were not for one in the vicinity of my home, we might sometimes have to send twenty miles for a spool of thread-the seamstress meantime waiting. But if the retailer is to stay there, he must live, and if the most of the trade goes to larger towns, or to wholesale stores in the city, he must necessarily charge roundly for whatever goods he does sell. Especially, if the most of those who can pay cash carry their trade to the city, leaving him only the trade of the slow. pay or never-pay customers, eked out by odds and ends from the better class, he is absolutely compelled to charge prices to cover the risk, and he does. Some dealers of this class are very shrewd, and encourage indebtedness until the time finally comes when they demand a mortgage, which, later, they foreclose.

The real question for farmers to consider is, how they can best assure the convenience of good retail stores in their vicinity, without paying exorbitant prices for their goods There are two courses open: they may continue to take their 
eash to the larger market, and uncomplainingly pay the high prices for whatever they are compelled to buy locally, or they can contract to give the local store all their trade, paying cash, at an agreed profit upon actual cost to the dealer. When the trade of an individual is large, this last arrangement can ordinarily be made, provided the dealer feels confident that nothing will be said about it. It will not usually pay him to get only one customer at the expense of letting the whole neighborhood know his scale of profits. It is quite customary -and it is an excellent custom - for granges, or other farmers' societies, to buy at wholesale, for cash, and distribute to their members. It will frequently, if not usually, happen that quite as much profit, and far more convenience, will be gained by working the trade through the local dealers. In the first place, the dealer, if in good credit, can usually buy cheaper than any grange. It is entirely common for granges ordering from wholesale dealers, to imagine themselves to be getting the lowest net rates, when, as a matter of fact, a local dealer may be regularly receiving a percentage on all their purchases. There are many wholesale firms which will fill orders from such bodies at what they term "wholesale rates," and credit any customer in the town with a fair profit on the transaction, or, if there be two customers, divide it between them. The reason is that the trade customer buys more goods than the farmers, and is likely to buy much larger, and it will not pay to offend him for the profit to be made on a few direct orders from those who should be his customers.

Still, if the grange buyers spend time enough and study. enough to keep fully in touch with the market, they can obtain, for such ordinary goods as they buy, lower prices than the local dealer can make for them under any circumstances. They can liunt until they find some wholesaler from whom the local dealer does not buy, and who will not therefore care about "protecting" his trade. Even this, however, is not certain. I have known a wholesale house to fill such an order, and credit a profit to a dealer who was not dealing with them at all. $A$ little later, of course, the dealer's trade will be solicited, and some part of it probably obtained. It wiil 
take farmers a long time to understand all the tricks of trade. It is a question whether it will not pay them best to work with the local dealer. It depends, of course, upon circumstances, but as a rule I think most money will be made in that way by the farmers.

But one thing is sure: if the farmer becomes seriously indebted to the local tradesman he will pay roundly for his folly. This is not, necessarily, because the dealer is a grasp)ing, hard-hearted man, but because he must charge high prices to pay for the risk. For some of the goods sold on credit he will never be paid. He can not tell which these will be, or usually would not sell them, but it is a necessity of business that those who pay must help to support those who do not. The dealer can not bear the entire burden. Those who can pay cash, however, need not pay any part of these bills unless they choose to. If, as alrealy said, one's trade is large, he can manage this matter individually. If it be small, he can only obtain this benefit by combination with his fellows.

I have but one thing farther to say upon this subject, which is that all retail trade is infected with fraud. If a farmer buys ground coffee or spices, oils, paints, or even flour and sugar, he can not be certain that he gets what he pays for. The demand of the farmer for "cheap goods" induces extraordinary efforts to supply it. This is done by manufacturers who adulterate goorls, or skimp the weight of packages at the demand of retail dealers who wish to be thought to sell cheaply. It is well to beware of all who pretend to offer extra inducements in the way of prices. The manufacturers and wholesalers usually make no more money on sophisticated goods than upon those which are honestly made, or put up. The retailer, if he at all understands his business, knows perfectly well what he is buying. He should be held riginly accountable to customers for quality and weight. All persons dealing with concerns having a special reputation for low prices should faithfully check off goods bought by weight or measure. The cost of goods is about the same to all retailers in good credit, and except as they transact specially large volumes of business, their scale of profits must be abont the 
same. Still it is true that the retailer with a surplus of available cash-capital can save money in buying, just as the farmer can. No general rules can be laid down other than those already suggested, as to the best profitable methods of dealing with retailers. It will depend upon the circumstances of each case. 


\section{('HAPTER VI.}

\section{THE FARMER AND THE TAX-GATHERER.}

T has become evident that the pressure of taxation in the United States is to increase until our burdens are quite eyual to those of the European people. There is a tendency to demand a constantly increasing service from the national, state, and local governments, and all this service costs money. We shall certainly push these demands until we have reached the limit beyond which the people will not endure taxation. The fact that there is such a limit, not difficult to reach, impairs the credit even of the richest nations, in regard to what may be termed questionable forms and occasions of indebtedness. Unirersal experience shows that when a certain limit of taxation has been reached, a nation, or any political subdivision thereof, will repudiate its indebtedness. It will usually be possible to raise some quibble, or even some equitable contention, but at any rate no people will tax itself above a certain limit. So long as public funds are expender in such a manner as to make an equivalent saving in private expenditure, the limit of taxation may be extenderl indefinitely. If they are expended wastefully, the limit will be reached whenever the public burden, added to the necessary private expenditure, according to the prevailing standard of life, consumes the income of the average man. When a people is brought to a choice between erading a portion of the public debt, or permanently reducing the standard of life, it will not, if it can be avoided, adopt the latter alternative.

While we are as yet, happily, far within the limit of endurance of taxation, it is never too early to take into consideration the fact that there is a limit, or to remember that every dollar wasted in the expenditure of public funds is a dollar less to be expended for the comfort of him who has earned it. In this 
country there is great waste of public money-more, doubtless, than in any other nation of the blood of the thrifty nations of Northern Europe. This is not because we are not intelligent and vigorous, but because our past has been to us a time of great things, and we have been too busy and too prosperous to feel the necessity of economy in public affairs. The opportunity, as always, has brought forth the men, and we have developed a class, larger and more astute than exists elsewhere of the same sort, which expects to thrive at the unnecessary expense of the public. Habits have been formed, and precedents set, which we now find it difficult to get rid of.

Our fiscal misfortunes include inequalities of taxation and extravagance in expenditure; and extravagance may include economical expenditure for desirable objects, when beyond the means of the community incurring it. It is no more possible to the poor community than to the poor individual to practice all the economies of wealth. A rural community might bankrupt itself by the building of a stone ruad or an irrigation system, in the absence of other capital to make use of them. There must be traffic to justify the stone road, and the use of lands to justify the building of an irrigation system, and both these involve large investments of capital in addition to the cost of the improvements.

It is doubtless true that few taxes are justly assessed. Incidentally I have said something about our system of taxation elsewhere in this volume.* I do not intend to add much to what has been said there. We are committed to the system of raising most of our taxes for state and local purposes by an ad valorem assessment upon what is called the "value" of all property which can be found. Experience shows that propertyholders will lie to get rid of taxation, and that the number who do this is. so great that it is a physical impossibility to deal properly with the criminals. In medieval times the thumbscrew and the iron boot were employed in assessing rich ment Even those methods seem not to have been

* See book Sixth, chapters I and IV.

† Farmers, and other comparatively poor men, doubtless pay an undue share of taxes, but it is mainly because they can not conceal their property. When 
effective. At any rate, they have been abandoned, and none better-at least more effective-have been discovered. I presume it may be accepted as impossible to get an approximately correct list of property for the purposes of an ad valorem assessment, and that increasing financial pressure will, in the end, comnel us, as all other countries are compelled, to rely more and more on licenses, income taxes, inheritance taxes, taxes upon traffic, ${ }^{*}$ and the like, to produce a revenue. Certainly I see little use, within the limits of a chapter, to try to suggest remedies for the evils of ad valorem taxation, which have baflled the ingenuity of generations of statesmen.

It will be more profitable to consider some possibilities of economy in expenditure.

One great source of waste is the salary account. For that part of its work which involves little or no exercise of discretion, and no financial responsibility, the American public pays, probably, nearly twice what private concerns would pay for the same work. Under proper conditions the same men who now do the work-or as many of them as would be necessarywould undertake to do all the work that is now done, for twothirds the present total expenditure, and in so doing would be

they can do so they are as bad as others. The number of pounds of wool produced in California in 1896, as compiled by the wool dealers, divided by the number of sheep assessed in the state, gives the average clip of about fifteen pounds per head. The real average could not have exceeded seven and one-half pounds, which would show that sheep owners lied about the number of their sheep. In that state "Angora" goats are assessed higher than "common" goats, and the assessors, in 1896, could find but eight thousand two hundred'and thirty-four such goats in the state. The largest breeder wrote me, at the time, that there were not less than seventy thousand Angoras in the state. In my own eounty not a single "Angora" was returned, and yet I personally know of two large flocks and there are doubtless others. To save a little tax the goats, none of them less than half bred, were listed as "eommon" - and the lists were sworn to.

* We now tax ineoming foreign traffic, eollecting the tax at the port of entry. It has been proposed than Congress tax interstate traffic, relying, apparently, on the books of the railroad companies for the assessment, the railroads, of course, to pay the tax. This, at any rate, would have the adrantage of definitely separating interstate and intrastate traffic, so that, in assessing for state purposes, the revenue derived from state traffic, and assessable there, could be known. 
far better off than they now are. They would have a career, modest or otherwise, according to their abilities, but something to be depended upon. At present, outside the services to which what are known as the "civil service" rules are applied, I hardly know a more unfortunate lot than that of a bright young man who has obtained a place in the public service. As a rule these men are quite capable of sustaining themselves in private life, for it requires a good deal of vigor, wisely or unwisely displayed, to get into the public service, and the result is quite likely to be the wreck of a useful man. The two or four years of public employment are quite sufficient to sever his relations with the business world, and impart tastes and habits incompatible with business success. Then comes a new election, with a change of appointing power, and the man is left stranderl, to begin life over, with no openings which he does not force. Very few in public service find themselves able to save money. They are not permitted to save it. They get their places as a reward for party sorvice, and the party will demand all that they might otherwise save. In corrupt municipalities the tribute may be in direct monthly payments to the "boss" who secures the place and holds the man in it. More often it goes in party "assessments," and constant small expenditures to maintain acquaintance and "influence." A large number of public employees regularly anticipate their salaries by pledging them, at a heavy discount, to brokers. A party has little use for a frugal man. He must spend his money, or out he goes.

From the standpoint of the public, the aspect is equally bad. The appointing officer usually has ten men to whom he is under "obligations" for one that he can appoint. He contrives places for as many as he can at the public expense. Perhaps he is himself an appointed officer, and under obligations to look out for the dependents of the mill above him. Appointed state officers have told me that the work in their charge cost twice as much as it should, by reason of "requests" from governors and state party committee men, which were equivalent to demands. Places must be found for certain men, and if they did not exist, they must be 
created. A private printing office will send out its proofs, and make small deliveries of work, by means of boys and young men at from $\$ 6.00$ to $\$ 10$ per week, and one such boy will serve many customers. As I write, this morning's paper tells me that one house of our Legislature has three "messengers to the state printer"-located in the State House grounds-at $\$ 3.00$ per day each, and two mail carriers at the same salary. This, of course, is robbery, pure and simple, for which the party in the majority is responsible. When the other party is in power it plunders in the same way, and is also responsible. There is, in a certain state, a state printing office. As I write, I see in the morning paper an offer from a responsible firm to take over the office and plant, pay a fair rent for it, pay the same wages that are now paid to all employees needed, and do the same work, for $\$ 100,000$ per annum less than the state now pays, with no rental charge. A law of the state requires that all printing for state institutions must be done at the state printing office. A week since an officer of the State University told me that he was seeking to get that institution excepted from the rule, as it could get its work done for one-third the sum charged against the university appropriation by the state printing office. In the city where I spend part of my time, the usual working hours for clerks are from 8 A. м. to 6 P. м., with the usual lunch time, two weeks' vacation in the year, with no deduction of pay, and occasionally, of course, a half day off when business is light. The compensation will possibly average $\$ 75$ per month. At the City Hall the department clerks work from 9 A. . . to 5 P. M. There are many more than are needed in some of the offices. The report before me does not give the individual salaries, but they will doubtless average $\$ 100$ per month. In a road district in a certain county, I have known a road master who employed his own sons and his own team, to leave his home at $S$ in the morning, drive slowly five miles to his work, take his hour for lunch, and leave in time to reach home by five in the afternoon, the law making eight hours a "day's work." The pay was $\$ 2.00$ per day per man, or $\$ 1.00$ for man and team. Wages in the same community have never been higher, for 
single day's work, than $\$ 1.50$ per day, without board, for ten hours' work, the laborer to come and go outside of working hours. The hours for department clerks in Washington, if I remember correctly, are from 9 A. M. to 3 P. M. Opposite a house where I once lived for a time, was a small city park. Two gardeners were employed in it, probably at $\$ 75$ per month each. It was a matter of never-failing interest to the families whose dwellings fronted on the park, to see the ingenious ways which those men adopter to seem to be at work, and yet not work. There was real work for about one man half the time.

The plundering of the public through party machinery, by means of unnecessary employees, shorter hours, and higher wages than are paid by private employers, is perennial and fearful. On the other liand, the higher positions, requiring special attainments or involving great responsibilities, are sometimes not paid enough. The Secretary of Agriculture states that it is usually not possible for his department to retain, in the scientific divisions, the best men which the service develops. Higher salaries elsewhere draw them away.

The responsibility for this state of things lies upon the people-upon me who write this, and upon the reader who reads it-there, and upon those like us, and nowhere else. It is as much my business and yours, rearler, as that of anybody else, to endeavor to put a stop to it. The managing editor of a great daily paper lately said to me that it could not be stopped. That is not true. We not only can stop it, but we shall do so-when poverty compels us, and not before. So long as we can endure the plundering, we shall permit ourselves to be plundered.

But in the meantime we can lay down the principles upon which we must proceed when we decide that we have been plundered long enough. We can discuss them in our granges and other assemblies. We can formulate our conclusions, and publish them in the local press, and thus educate the people. Finally we can pledge the delegates whom we send to political conventions to seek to incorporate them in party platforms, and pledge candidates for office to work for them and abide 
by them. Then, regardless of party, we can vote against candidates who evade definitely committing themselves to them. Honesty and economy in public affairs are more important than the success of any party. 'The farmers can be and should be the leaters in this movement. Among the farmers, let any man lead who is impressed with the necessity. If he is clear and definite, he will be astonished at the following he will have.

The lines upon which, only, reform can be expected, are the following:-

1. A permanent career for the civil servant. A railroad clerk may expect to retain his position as long as he lives. He learns his business, and expects to live by it. Railroad presidents come and go, but the clerk stays. It does not pay to break in new hands. If he develops ability, he may expect promotion, but at any rate, if he is faithful, he is sure of his position. IIe can therefore afford to work for a small salary, and for full hours, and he does.

2. Hours of work, and rate of compensation to correspond with current usages in private business. This will involve reduction of salaries in positions involving routine work, and increase, in some cases, for positions requiring great vigor, judgment, and organizing or executive ability. It will not pay the public to let private business absorb our ablest business men.

3. Entrance to the service and promotion in it up to certain grades, to be upon competitive examination. This, except for positions requiring technical knowledge, merely insures that the public servants shall be intelligent men and women, with a good amount of vigor, for it requires vigor to succeed in any competition. It does not assure honesty, executive ability, or judgment. It is certain, however, that from the body of an intelligent civil service, there will develop a sufficient number of those possessing those qualities to fill all the positions requiring them. The rest will remain as they are, faithfully and contentedly fulfilling the duties for which they are competent. The norst possible method of entering the public service is by means of a political pull. A 
better method than that would be to assign all the places to persons with red hair, permitting them to draw lots, if the number offering were more than were needed.*

Politicians of all parties are bitterly opposed to such reforms. The most common argument is that it will create an "aristocratic class." Those who employ this argument usually know that it has no merit, but they trust to the stupidity and prejudice of the general public to gain their ends. "Aristocracies" can never be supported upon the salaries which are paid in private life, and which the public ought to pay, for routine work - and nine-tenths of the public service is of that character. On the contrary, except to the very few who win promotion, not only by faithful service, but marked ability, the service is of a very humble chanacter. The public servant becomes part of a machine. He loses individuality and initiative. His name is not known outside his immediate circle. By strict economy only can he make financial ends meet. But his future, such as it is, is assured. He has chosen a humble lot and abides by it, doing his work faithfully therein. No private employer would discharge such a servant without cause. Why should the public be less merciful than individuals in it? It is true that the public service should be, and in well-regulated civil service it is, evidence of honesty and faithfulness. But an "aristocracy" based solely on those qualities, and bound by what is practically a vow of perpetual poverty, is not a bad thing.

There is somewhat more force in the argument that in a republic it is desirable that as large a number as possible become familiar with the details of public business, and that changing employees with every election, or "rotation in office," as it is called, accomplishes that end. That it is well for citizens to know all about the pubiic business is true, but if knowl-

\footnotetext{
* The mere establishment and enforeement of what are known as the "civil service rules" for entrance and promotion will not, of itself, cure the evil. It is but one step. There will still be intrigue to ereate unneessary places on the part of those who think themselves likely to obtain them. There must also be legislation compelling publie employees to keep ordinary business hours, and requiring a rigid aecounting for time.
} 
edge is to be had only at the cost of an extravagant administration of that business, the ruin of the majority of the public servants, and the general demoralization of the people themselves, the price is too high.

By taking the business affairs of the public entirely out of politics, the expense of administration of all national, state and local affairs can be enormously reduced, and the demands of the tax-gatherer correspondingly lessened.

To the above I would add the letting all public work by contract which is possible to be so disposed of. This is bitterly opposed by all organized labor, which insists that all pullic work shall be done by "day's works," at higher wages anl shorter hours than those usual in private life. Many of those advocating this method are unquestionably patriotic citizens, and yet they seem to me to err greatly in permitting their zeal for the welfare of one class to ontweigh their desire for the welfare of the public. They know that what they seek leads not only to higher wages for those employed, which we might not complain of, since the public should aid in maintaining the standard of life of the laborer, but in the employment of unnecessary men, and consequent shirking of work to make room for as many as possible, ${ }^{*}$ and the general debauching of public morals. It seems to me that they would have a stronger and more effective claim upon the public regard, and its aid in accomplishing their legitimate desires, by aiding to secure purity and efficiency in the public service. I work twelve hours in the day, upon the average, and always have done so. I am not willing to work thus to pay a man for working eight hours, and half working at that, in mending the road which runs past my house.

This entire volume could be filled with detailed suggestions: for eluding the tax-gatherer by promoting more economical methods in public affairs. Any reader, when he considers the

* Of course there is a certain portion of the non tax-paying element, especially in large cities, which undisguisedly seeks the lavish expenditure of public funds, regardless of necessity, with the open intent to despoil all who have money, in the expectation that they will get some of it; but I do not in the text refer to them. 
circumstances of his own community, will see many ways of saving money for the public. $\mathrm{My}$ object in this chapter is mainly to give an example of methods of study, choosing, for a subject, the most glaring examples of wastefulness. I will, however, take up one more subject, which especially appeals to farmers.

Next to schools, the occasion of the largest expenditure of public money in rural districts is that of roads. In the district in which I live we spend more upon roads than upen schools. It is doubtless the case in many districts. It is a subject which especially appeals to the farmer as a business man.

The cost of moving freight by rail varies materially on different roads-probably from one-half cent to one and onehalf cents per mile, and averaging somewhat less than threefourths of a cent per ton per mile.* The average cost of moving freight upon the roads of the United States, as they are, and one season with another, is computed by the Uniterl States Department of Agriculture to be twenty-five cents per ton per mile. This being an average, actual costs will usually be higher or lower than that, probably varying from five or six cents per ton per mile on roads where one horse can pull two tous, to forty or fifty cents on roads where it requires four horses to pull one ton. In 1896 the railroads moved the equivalent of $76,207,047,298$ tons one mile. Some of this freight was moved over country roads before or after being moved by rail, but not nearly all of it. Much coal, ore, lumber, flour, and the like, never passes onto the country roals. I have not met with any estimate of the freight traffic by country roads, nor can I find data for making a computation. Although the tomnage is large, the distances hauled were short, and the number of ton miles was small compared with that of the rail traffic. $t$ If we guess-for I am unable to estimate-the ton

* The average rate paid by the publie in 1896 was .806 cents per ton per mile. The average cost to the railroads was, of course, less.

$\dagger$ The price paid for hauling the rail traftic of 1896 was $\$ 786,615,837$. The cost of bauling the same number of ton miles over country roads, at the estimated average cost of twenty-five cents per ton per mile, would have been $\$ 19,051,761,826$-an interesting fact, as showing what railroads have done for civilization. 
miles of road traffic at one-tenth the volume of rail traffic, which does not seem to me absurd, the cost of moving it, at twenty-five cents per ton, was $\$ 1,905,176,182$. If we guess it at one-twentieth, the cost was $\$ 952,588,091$, which seems to me entirely reasonable, and probably, as to tonnage, an underestimate. If, however, the average cost per ton per mile could be reduced, as it easily might be without excessire taxation, to fifteen cents, the cost of moving the conntry-road traffic would be only $\$ 571,552,854$, which would be an annual saving of $\$ 381,035,273$, or about the cost of sustaining the national government. This, of course, takes no account of the increase of speed and comfort, with corresponding reduction in cost, of transportation of persons either on business or for pleasure. Some farmers in the United States compete directly with French farmers in our home markets, and can hardly understand how the Frenchman, in spite of our protective duties, is able to hold his own so well. There are various reasons, but one of them unquestionably is that, by reason of good roads, one French horse does the work, in hauling, of at least two American horses.

While such illustrations as these are commonly employed, and are very striking, they are probably exaggerated. There are not many whose main business is farming, who are compelled to keep extra horses to haul their produce to market. The teams which are necessarily kept, can usually do the work; but still the saving is great; the driver's time is saved; the wear and tear of animals and wagons is reduced; in some industries-as sugar-beet growing, for example-when deliveries of bulky produce have to be rapidly made in seasons of bad roads, the importance of a good road bed can hardly be overestimated. My object, however, is not to present an argument for "good roads." It is not now needed in America. There is even danger, in some districts, of overexpenditure, under the stimulus of excitement created by enthusiasts. What seems to me likely to be useful in this place, is a brief study of the problem as a business man would view it. If my method of study commends itself to the reader, he can apply similar reasoning to the circumstances of his own case, and 
decide for himself as to his dealings with the tax-gatherer in this matter, so far as he can control them.

I live on a farm, of which I cultivate about thirty acres. I am four miles from a railroad station, and the road is a mountain grade, rising, upon the average, something over three liundred feet to the mile. As near as I can estimate, the hauling in connection with my farm is equivalent to something like fifty tons per annum, hauled between the farm and the station, of which something less than two-thirds will be down-lill. That is equivalent to two hundred tons hauled one mile. When I hire hauling done, I pay $\$ 1.00$ per ton from $\mathrm{my}$ house to the station, and $\$ 2.50$ per ton from the station to $\mathrm{my}$ house. This is equivalent to twenty-five cents and sixty-three cents per ton per mile, respectively, or an average of about thirty-seven cents per ton per mile. Two hundred ton miles, at thirty-seven cents, makes $\$ 74$ per year which my hauling would cost me, provided that I could always take full loads. This, however, I can not do. Farming on a small scale, my team must make many journeys half loaded, or less. It is also seldom possible to load both ways, which would make a difference. But I go to the city every week, and, while I usually walk down the mountain, I prefer to have horses take me back, so that, with other necessary personal travel of the family, I must send a team to the station at least seventy-five times a year. When the roads are good, one horse can make these trips. When bad, it requires two horses. The road is a fairly good mountain grade, as grades run, but could be greatly improved. If it were a level road, its capacity per horse-power could be trebled by sufficient expenditure, but it is obvious that, when two-thirds of the haul is down-hill, that can not be done on a mountain road. The road serves about thirty families, many of whom ship their produce in a less concentrated form than mine, and so have a correspondingly larger tonnage. Most of my neighbors have larger acreage in cultivation than I. I suppose that three hundred ton-miles each for the thirty families would be a fair average, which would give a total of 9,000 ton-miles, of which 6,000 would be down-hill. This, at twenty-five cents and sixty-three cents per ton, would give 
$\$ 3,390$ as the total sum paid for freight traffic over that road, of which I should pay, probably, $\$ 100$. The passenger traffic is also to be considered, and it probably runs, like that of railroad traffic, at about half the cost of the freight traffic, making a grand total of $\$ 150$ for myself, and $\$ 5.085$ for the neighborhood, as the present cost of our traffic on country roads. Considering all the circumstances of our particular case, including the fact that the influence of gravity can not be removed, and that little or no extra stock is kept by reason of road work for business, it is probable that, by suitable improvement, the cost of that traffic could be reduced one-third. If it was on level ground, it could certainly be reduced one-half. The question then arises, how much, as a purely business proposition, we could afford to pay on such reduction. Computation would show that I could afford to pay $\$ 50$ a year, and the neighborhood could pay $\$ 1,962$, and our profit would be in the pleasure. The roads serving this entire community, however, aggregate about ten miles. Stone roads, at $\$ 6,000$ per mile, would cost $\$ 60,000$, upon which interest, at six per cent, would be $\$ 3,600$, or far more than our saving, or even than the saving to a community with the same traffic, on level land, of such a character that the saving might be one-half. Even considering the reduced cost of maintenance, and the increase in the value of property, it is obvious that stone roads would not be economical in such a community as ours. They would be simply a luxury, to be indulged in if we could afford it.

The above is given simply as an example of a method of study. Any reader can, in a similar manner, analyze the facts with which he is himself called upon to deal. The character of road improvements which a community can properly undertake, must always be determined by the nature and the volume of the traffic. Increased value of property is likely to follow, but it is speculative, and should not have much weight. It brings increased taxes for all purposes, which is right if productive value is also increased, but usually the economic saving will be measured by the decrease in cost of traffic. The comfort of good roads is an entirely different matter. Its value is measured, not by the income from it, but by what one can afford to pay for it. 
The farmers can, however, if they will, stop much of the waste of road money now permitted. They can stop the farce of "working out" the road tax, still too common. In my time, when we were "warned out," the resolute, ambitious men brought mattocks; the reasonably thoroughgoing sort brought shovels, and the rest of us took hoes. The hoes were always in a majority, and it is doubtless the case still. When road taxes are paid in money, a resolute public opinion can prevent its waste. The surest way to do this is to let the care of the road by contract, for a term of years, under specifications carefully drawn. This can always be had, in rural districts, by farmers, but only after a battle royal with the small politicians.

Of course I do not propose to deal with methods of road building, but I can not forlear saying one or two things: The first steps in road improvement must be to perfect the alignment and gradients, remembering that the road is to be traveled for thousands of years. We at least owe it to our posterity to put the roads where they belong. The next step is thorough drainage, with permanent stone or tile culverts, and culverts and fills in the place of small bridges. These are the first steps towards building stone roads, which may come later, on the same foundation. When that is done, proceed according to the wealth of the community and the requirements of the traffic. A community which knows how to do so much will never fail in the rest.

Whether or not it will pay to incur debt for road improvement can be determined only by cold-blooded calculation on the volume of traffic. It will never pay to do it for any speculative motive. There must be a plain saving on the existing volume of traffic, sufficient, with a wide margin of safety, to pay interest. The total outgo of the individual citizen must be decreased by it, unless the community expects to incur debt for comfort, what, usually, it ought not to do.

The question of state aid-which means the aid of the people of cities, and others who are not likely to travel much upon the improved roads-involves various equities which I have not space to discuss. Where the disposition to extend such aid exists, it is evidence of a noble public spirit. Disregarding 
equities, it seems to me that it would pay the people of the older, richer, and smaller states, to encourage the building of permanent roads by state aid. To a large extent they are doing it. In the newer, poorer, and larger states, there is more doubt about it. These undeveloped communities have usually very serious local burdens of their own.

Possibly the grouping of subjects in this chapter may seen to some not altogether logical. Whether it be or not, the chapter contains various matters which it seemed necessary to include in such a volume as this, and to me it seemed best to present them as methods of economy in public affairs, to be considered, largely, by farmers and others, in connection with the functions of the tax-gatherer. 


\title{
BOOK FIFTH. \\ The Farmer as a Cooperator.*
}

\author{
CHA P'TER I. \\ THE PRINCIPLES OF COOPERATION.
}

I the conduct of any business there are two elements whose combination produces success or failure; these are the principles upon which it is established and the character of those in charge of it. A business, whether great or small, must be founded upon correct principles or it can not endure the strain of competition, and in the end will be unprofitable. An exceptionably capable or industrious man may for a time sustain a business against unfavorable conditions, and an incompetent or idle managenent may ruin a business however well planned, but in the long run a business must be wisely planned in order to endure, and if thus well founded it will succeed under ordinary management.

In a generai sense all enterprises are cooperative wherein more than one person is concerned. A bank is a cooperative society for lending money; a railroad company is a cooperative society for building a railroad. Any business is cooperative wherein many persons unite for the attainment of an end desirable to all, but unattainable, or less readily attainable, by any of them singly. The illeas and conduct of such enterprises as are mentioned above, are fully competitive, and involve the profit of the few at the expense of the many.

It is desirable that the public acquire clearer ideas than are

* See Appendix $\mathrm{F}$ for documents relating to corporation. 
now prevalent as to the real meaning of cooperation. It is already a great factor in the business of the world whose importance is but dimly recognized by economists, or statesmen. No census of this, or, I think, of any country, includes in its tables the volume of cooperative business, of which no reliable statistics are attainable, but in California alone there are over eighty cooperative irrigating companies, ${ }^{*}$ besides fruit marketing societies whose aggregate annual business is several millions of dollars. Cooperative business is increasing yearly, from natural causes. It is a natural development from excessive competition, and must increase as competition grows more severe. It is well, therefore, to understand precisely what it is.

Cooperation is the union of those of like interests for the purpose of more effectively competing with those of adverse interests. It is middle ground between individualism, in which each man competes with all other men, and State Socialism, or "Collectivism," which assumes such a union of all interests as to entirely suppress competition. It recognizes permanent differences of interest between classes, and assumes that these differences will be adjusted with least friction, by able representatives of the different classes, meeting together in the light of complete information and under a sense of responsibility. Incidentally the weaker in each class are helped by the stronger of the same class, as a matter of self-interest, regardless of sentiment, yet more or less moved by sentiment. Socialists favor it as a stepping-stone to socialism. Cooper ators regard cooperation as the final step, because it recognizes as permanent, cleavages of interest which socialism ignores or supposes can be united. The perfect form of cooperation is exhibited in the Trust. Socialism aims to make the state the industrial unit, involving the competition of one state with another, and ignoring the conflict of interest between classes within the state. Cooperation makes the class the unit within the state, and does not necessarily regard international

* From statistics gathered by myself, as Special Agent of the U. S. Department of Agrieulture, unpublished when this is written. 
boundaries. A distinct term is needed for this phase of cooperative effort.

In these pages, however, because I wish only to cover, in some detail, a rather narrow field in which I have had personal experience, I shall use the term cooperation and cooperative in the more restricted sense in which they are still used in common speech, and which includes only organized societies of operatives or producers to market their labor or their product, or of any class of individuals to purchase supplies. In this class of societies the fundamental idea is that of saving rather than of gain; of keeping what is already in possession, rather than of securing additional income or increase of capital. Of course the result, if success follows, is an increase of net income which may be expended or become capital. These enterprises also exclude the idea of individual profit to any one connected with the management.*

It is true that cooperative enterprises in the above sense are sometimes established with the same idea of profit that obtains in other business; as a cooperative shoe factory, or a cooperative cannery, but it is probable that when such concerns are set up it is with the expectation of securing a higher price, or a more certain market, for some commodity produced by the founders, as the labor in the case of the shoe factory, or the fruit in the case of the cannery, and the tendency is to consume what would be profit in an ordinary business in higher wages, or higher prices.

In referring to the probable success or failure of a business enterprise, normal or ordinary conditions are supposed to exist. A flood, a fire, a robbery, or some general calamity may bring the best planned and best conducted enterprise to ruin. These are the chances of life to which all enterprises are subject.

The more common forms of cooperative enterprise are societies for the purchase of supplies needed, or the sale of products produced by their members. Societies for the pur-

* While a bank is a cooperative money-lending concern, certain individuals, by engaging a certain amount of their own capital, and assuming the management, expect to profit by lending the money of their depositors. 
chase of supplies on any considerable scale are in the nature of regular mercantile concerns; the tendency of these in America is into the hands of a few persons, by the purchase of the stock at less than cost, or otherwise into the liands of the sheriff. In Great Britain they are remarkably successful.

The simplest cooperative enterprises are those for the sale of products of their members, and it is with these that these pages will be occupied, although of course the more general principles are applicable to all forms of cooperation. A "cooperative store" buys and sells, but the fundamental irlea is buying eheaply and saving by its members. The fundamental idea of marketing societies is the highest attainable prices for products. These ideas are contradictory, but both forms are included in the term "distributive cooperation."

All business is a science whose laws must be obeyed or failure will result. It is not abstruse; on the contrary it is the simplest of sciences. It is a science best learned in the school of experience, and all who succeed in business have mastered its principles so far as they apply to the business which occupies them. They may never have, and most likely have not, seen or heard of any book relating to the principles of business, but if they pick up such a book in which the underlying principles of business are set down in an orderly way, they find little or nothing with which they are not perfectly familiar and are surprised that it should have been thought worth while to write and print such simple things. And yet it is true that the majority of business enterprises fail because these principles are not followed. Of course it is also true that many fail in business who understand its principles well enough, but have not the vigor and will power to always follow them.

The fundamental principles of business apply to the conduct of a farm, of course, as well as to pure trading, but their application to trade involves the knowledge of a good many facts and the perception of many relations which do not usually come within the experience of farmers or workingmen. If, therefore, farmers, through cooperation, engage in trade, they must, if they expect success, become familiar with these 
things through other sources than their own experience. They must obtain and profit by the experience of others. The object of these chapters is to set forth the most important things to be considered in establishing cooperative enterprises :nd the most convenient methods of procedure both in establishing and conducting them.

Those characteristics of a person which are peculiar to himself as distinguished from the qualities and nature of mankind of his comntry and race are called his "personal equation." As these personal characteristics must be con stantly taken into account in considering the probabilities of success or failure in business, it will be convenient as occasion arises to use this term for them.

The establishment of a cooperative enterprise is, in one respect, more complex than the founding of a personal business, in that its constitution must be such as to insure the best ability available, and perfect honesty for the conduct of its affairs. In a private business, the personal equation is fixed. What a man is, he is, and he is inseparably attached to his business. In a cooperative business the directors change, but, in the main, will usually represent the best available experience and ability of the membership; their election proves that, in the judgment of their fellows, they are the proper persons to direct the common affairs, and we can not go beyond that. But the active executive management, to be efficient, must be in the hand of one person, whose personal equation will have much to do with the prosperity of the concern, and there are natural laws which, if enacted into rules by the main body of the society, and carefully obeyed, will almost certainly insure honesty in this important position, and sufficient competence for its duties.

It has been said that the fundamental and natural laws of business will apply to the conduct of the farm and the workshop, but it is also true that business is the subject of municipal or statute law as well, and that statute law deals with traders in some respects otherwise than with farmers or workmen; and, in many cases, it has to deal with transactions which would not occur in a strictly farming business. Cooperative trading 
is subject to the same law as private trading, and it is important that the members of cooperative societies shall have at least such general knowledge of their legal relations and responsibilities as will prevent them from involving themselves more than they intend. This is not a law book, and it will give no advice or caution beyond such teachings of plain common sense as a layman may properly attempt, but business is business, and, if not done properly, may lead to trouble, and when it does, it is invariably the ignorant or incautious who suffer. There are some things which it is safest not to do, and it will be proper to point these out.

The only way in which cooperative business on any consid erable scale can be safely and effectively carried on is by the means of a corporation. Now a corporation is wholly a creature of statute law, and must be founded and governed strictly in accordance with the mandates of law. These are not intriate or hard to ascertain; on the contrary, they are simple and within the understanding of all, and, if carefully followed, enable cooperative business to be transacted readily and safely.

It seems to me probable that cooperative husiness will gradually become an important and permancht feature of our social fabric. This opinion is based upon the belief that extreme social pressure will always find the most realy relicf in cooperation. Even farmers will combine rather than reduce their standard of comfort. The well-known saying in regard to railroarls, that "where combination is possible, competition is impossible," is based upon the experience that between points furnishing a good business, more railroads will be built than are required to do the business, and that competition will ensue until bankruptcy threatens one or both, when combination in some form will follow. In competitive society there is the same tendency in all business, except that the great number of individuals concerned makes combination very difficult. The natural man desires above all things to do what he pleases; so long as he can do that, and be reasonably prosperous, he will make no agreement whereby he foregoes any part of his liberty of action. A few seasons of real trouble, 
however, make him ready to unite with others in the same occupation for mutual relief. But successful cooperation is a sure sign of trouble in the industry involved.

It does not necessarily follow, however, that returning prosperity will break up cooperative business. It may, or it may not. Business is sure to seek the easiest channels. The pressure of circumstances may cause a cliange from competitive to cooperative methods, and then, certain habits having been acquired, and certain investments made, business may more easily flow in the new channels than return to the old. It depends on the wisdom with which the cooperative enterprise lias been planned. 


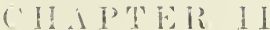

CERTAIN FUNDAMENTAL RULES OF COOPERATION.

$\mathrm{I}^{\mathrm{T}}$

$T$ has been said that cooperative business is subject to the same natural and municipal law as other business, and that this is not a treatise intended to cover that subject; but there are certain of these laws which are absolutely fundamental, and yet, as experience shows, quite likely to be overlooked in cooperative enterprises, and which it is therefore lesirable to consider here.

Cooperative business requires an adequate capital. One would suppose this truism to be universally recognized, but it is not; or possibly it would be more correct to say that proper estimates of the capital necessary to cooperative enterprises are often not made in advance. A sum is assumerl to be sufficient which is not sufficient. This is the result of ignorance. The promoters of cooperative enterprise among farmers are usually those who have not had mercantile experience, and who do not, therefore, foresee all the occasions of outlay, or the disastrous consequence of being without means to meet them. The result of inadequate capital is debt with no means of payment, and the end is often failure. Of course this does not always happen; new efforts may be made, and the debt wiped out. A cooperative business once started, and some money expended upon it, can hardly be permitted to drop without trial; the work begins, unforeseen and pressing necessities for expenditure arise, and debt, more or less serious, is incurred; in any business it is seldom possible, during the first year, to pay debt from income; if the management is sufficiently wise and vigorous to promptly appeal to the stockholders for additional capital, the moment the necessity for debt appears, all may go well; but even in that case, confidence is impaired; the management begins to be distrusted; new members are afraid to join, and old members are disposed to drop off. But it seldom 
happens that a management which has been unwise enough to accept duties for whose execution sufficient funds have not been provided, will have thereafter the wisdom and courage to promptly meet financial difficulty in a business-like way. The beginnings of cooperation are very apt to be among the leastprosperous classes, some part, at least, of whose misfortunes may always be attributed to their own lack of foresight and vigor. These qualities, carried into the management of cooperative affairs, are quite apt to lead, in emergencies, to the ereation of debt, with the vague idea that payment can be made "somehow," when the time comes.

In this I am speaking rather from my own observation of societies organized for the sale of products produced by their members than of those formed for regular mercantile enterprises where goods are bought as well as sold. In the latter case all would recognize the need of eapital, and so long as purehases and sales were made entirely for cash, there could hardly be failure, although there might not be prosperity. But the success of such concerns depends so entirely on the personal equation of the manager and membership that I regard them as unsafe. A few of them have been successful in this country and many notable suceesses have been achieved in Europe. In this country, however, where success lias been attained, it appears to have been mostly owing to the personal qualities of the managers. There is, perhaps, more stability of character among the masses of England. I can not otherwise account for the great success of cooperative mercantile enterprises there.

There is no sentiment in cooperation. So far as a eooperative movement is based on sentiment, it is likely to fail; and it ought to do so.* If the results of cooperation are to increase the incomes of the cooperators the facts will appear in due time, and cooperative enterprises will multiply; if the results do not increase individual incomes, such societies will properly disappear. It is a question of individual advantage rather than

* For further discussion of this aspect of eooperation, see Chapter VIII of this book and Appendix $\mathbf{F}$. 
of public duty, and should be treated as such. There is doubtless at the begimning of important cooperative enterprises a necessity for the useful exercise of public spirit, during a short time, in educating the masses in the aims and methods of cooperation. The British cooperative societies maintain such a propaganda permanently, relying upon it as a principal means of extending their business.* But in America, at least, popular enthusiasm is entirely unreliable as the basis of business enterprises, and any action taken should be based on cold business calculations. Cooperative enterprises must be projected in the light of human nature as it is, and not as we may wish it might be, or hope it may become. Social evolution may sometime produce a race which is unselfish, and broad-minded; but it has not yet done so, and if its operation tends that way its movement is too slow to permit the present or the next generation to seriously consider it in founding business enterprises. It is generally believed that cooperative societies for marketing products tend to equalize receipts among growers, and to prevent undue depression of prices at the point of production. All growers will therefore encourage their formation by others, but great numbers will seek to avoid any risk, expense, or obligation connected with them, fully intending to make use of them if made successful at others' risk, and to compete with them by slightly underselling if they feel so disposed.

Of course this is utterly contemptible, but it is so general that it must be considered characteristic of human nature. It must be taken into account in founding cooperative societies, as the experience of dealing with this class may be certainly expected. It is therefore necessary to make sure that there are enough members who believe it will pay them best to support and carry through the undertaking. There are, of course, those who once having entered upon such an enterprise, will stand by it as a matter of good faith, whatever temp-

* Some of the best English tracts place the public welfare as affected by the nfluence of cooperation upon membership before the material advantage to the members. See Appendix F. 
tations may be offered them to leave it; but there are too few of these to be considered.

Business, in the end, will certainly flow to the easiest channels; if cooperative enterprises succeed, it must be because experience shows individuals that it is not only more profitable, but unusually more convenient, to deal through them than elsewhere. Men will not long subject themselves to personal inconvenience to promote any enterprise even though they really believe it to be almost essential to the general prosperity. They will almost muiversally rely upon its receiving the necessary support from others, and not concern themselves personally. It is, therefore, of the utmost importance that cooperative enterprises shall be well planned, properly located, and equipped to do in the most economical and effective manner whaterer they propose to do at all. There is really no difficulty in this, nor need there be any lack of money. While the general complaint of producers is lack of capital, yet it must never be forgotten that the aggregate capital invested in producing any given quantity of material is very far in excess of the sums required to market it. The advantage over farmers which outside capital possesses is in its form-money-its concentration, and power of repeated use within a short time. Whenever farmers once combine in a firm and legal manner, their financial strength is enormously greater than that of the mercantile concerns which, in the absence of cooperation, would handle and market their crops.

It is this fact which makes successful cooperation possible. It is a maxim never to be forgotten that those who supply the capital will control the business; and it usually does not much matter whether the funds are invested as profit-sharing capital or as loans; in the latter case capital is almost certain to so protect itself as to practically control, so far as it desires to do so. If you borrow money on produce, for example, the control of sale nominally remains in your hands, and may actually so remain so long as the margin of security is abundant, and the lender has no more profitable use for his money; but if he needs his money, or if for any reason he becomes dissatisfied with your management, you will find that within a short time 
you will be compelled to sell regardless of the market. Money is bound to control. It is therefore of the utmost importance that when loans have to be made, as will orlinarily be the case by marketing assuciations during the erop moving period, they should not be accepted from any person or firm having any possible interest alverse to that of the association, or whom the association may wish to control or direct. When you have borrowed money of a man, lie controls you, not you him; under no circumstances, therefore, should adrances be accepted from commission firms. The proper source from which to obtain necessary loans is the local bankers whose prosperity is always in a direct ratio with that of the community in which they do business, and who, in spite of much popular prejudice against them, may almost invariably be relied upon to supply, so far as prudence will permit, all funds legitimately required for temporary use. They are nearly always the ablest and most disinterested adrisers in financial affairs, that a cooperative society can have. It is distinctly to their interest that all legitimate business enterprises in their community shall prosper.

No man can successfully prosecute a business which he does not himself understand. The owners of a business are those who put money into it. Whoever puts money into a business which he does not understand is almost certain to lose it.* There are no business maxims more important to cooperators than these. They supply the standard whereby those cooperative enterprises which are safe can be distinguished in advance from those which are dangerous.

The topic requires some elaboration. In a cooperative society the average of the personal equations of its members will represent a certain degree of ability and experience, which will be quite accurately reflected in the Board of Directors, and which changes very little from year to year. If the society is organized to transact, on a large scale, business which each

* That the small investors in British Cooperative Societies do not lose their money is due to the fact that in Great Britain the cooperative movement has developed some wonderful men,-I might say a wonderful race of men. We have not, in America, yet developed cooperators with business capacity of firstrate caliber who will practically donate their services to their fellow-men. 
member is accustomed to transact for himself on a smaller scale, there need be no apprehension of lack of ability to manage the business well, and with ordinary prudence in providing capital and keeping out of debt, there is no reason not to expect success. For example, in a dairying community there is general information as to the processes and general expense of butter or cheese making, and a cooperative creamery may be expected to suceed; so in a fruit-drying community, whose members are accustomed to dry fruit extensively on their farms, there is no difficulty in maintaining successful fruit-drying associations. Such societies are also able to successfully take a step in advance, provided the step be not too great. For example, the fruit-growers of California are accustomed to sell their dried fruit each year to local buyers, who concentrate it in warchouses and sell it in distant markets. It has been found entirely practicable and economical for growers to bring their own fruit to their own conperative warehouses, and have it sold for themselres in the distant markets, by their own officers. In this case there is the simple advance from a retail business of a few tons each, to a whole. sale business dealing only in car-load lots, and collecting through the banks in the ordinary mercantile way, instead of receiving cash on their farms from the local buyers. There has been no trouble whatever, but no one would expect a dairy association to manipulate or sell dried fruit successfully; nor could any association of farmers suceessfully carry on a cooperative shoe factory, although a boly of shoe-making operatives might do so. These distinctions are obvious, but often they are less so, and producers induced to invest money in a business too complicated for them; for example, while any farmers' society can dry and sell fruit successfully, it can seldom, if ever, make a success of a cooperative cannery, which is a complicated manufacturing business in which several times as much money has to be paid for sugar, labor, and packing materials as for the fruit. It has not been found safe to permit salaried employees, themselves mostly without experience, to expend three or four thousand dollars of money, usually borrowed, in the purchase of material and labor to 
put witl $\$ 1,000$ worth of fruit owned by the cooperators. The finished product has usually sold for less than the aggregate cost, and as canning operations very rapidly run into money, the losses have often been such as to involve heavy assessinents on the stockholders to make them good. It is not safe for any cooperative society to attempt such things. They may succeed, but when they ilo, it is because one or more public-spirited persons give to the community the benefit of their talent and industry which they might have used to build up their own fortunes.

Cooperative societies must do a strictly cash business. Any serious departure from this is nearly certain to involve disaster. If there is no money in a community, or among those who wish to cooperate, it is best not to try to do business. If there is little money, keep down the scope of the enterprise to suit the amount of capital. By retaining all the profits in the business, as additions to capital, the business can soon be extended.

This is a very important point. Few understand the accumulating power of capital judiciously managed. Suppose one liundred persons, having $\$ 10$ each, start a cooperative store, undertaking to buy only for cash. Such an enterprise could not possibly succeed if ordinary rents and mercantile salaries were paid, because the expense would exceed any possible profit on staple goods to that amount. If any show whatever is made, or attempt to attract trade by advertising or display, the capital is almost certain to disappear. But if the owners will not despise the day of small things, and will be content for a time to go to some out of the way place, involving little or no rent, and undertake to make their purchases of evenings, it is possible for great results to follow; by restricting the commodities dealt in to a few staple articles, it would be quite possible to turn over such a capital once a month, at an average net profit of five per cent; a hundred families loyally supporting their own business, would certainly purchase goods to the value of $\$ 1,000$ per month. This, at the end of the first year, would give a capital of $\$ 1,500$; at the end of the second year, $\$ 2,250$; at the end of the third year, $\$ 3,375$; of course, as 
capital grows larger, it can not be "turned" so often, and after a time expenses would increase, as the manager would tire of working for next to nothing, and no one would expect it; but that is the secret of a successful cooperative store: buying and selling for cash, and keeping the profits in the business, until the capital is sufficient, when cash dividends can be paid. Our uneasy and show-loving populations are not likely to be willing to practice this self-denial; successful managers want more and more of the profits, because they too are easily affected with the notion of keeping up a certain "position." It seems to be this national characteristic which has usually rendered cooperative mereintile enterprises unprofitable in America. The reason of this is very obvious. It would probably be easy in any community to find a shrewd, hard-headed workman or farmer, who conld lay out $\$ 1,000$ in staple merchandise wisely; but if he were called to invest $\$ 30,000 \mathrm{in}$ the same way he would be all at sea. Sharp salesmen would be almost sure to load him up with unprofitable stock. It is a very puzzling thing for a new man to lay in a stock of merchandise. He must have the ability to say "No" to very persuasive men, pretty much all day long. But as the business increases it becomes easier both to determine what you shrould buy, and to refuse what you do not wish. The manager's ability grows with his business, so that there is much more hope of an enterprise starting with a very small capital than of any other. But cooperative "stores" have proved very hazardous things in Anerica.

Cooperative and individual business enterprises are subject to the same statute laws governing "trade," which are in some respects different from the laws affecting transactions between persons not in trade. If a farmer does not pay his note at maturity, he is of course subject to suit and judgment and the sale of any property that can be reached to satisfy the jurgment; a "trader," however, will ordinarily be in debt to many persons, and have many more indebted to him. In case he should fail to pay some obligation when due, the creditor, if permitted without restraint to take the above course, might unnecessarily break up a business and render it impossible to 
satisfy other claims against it. Most states, therefore, have insolvency laws whereby a trader unable to pay his debts at maturity, may be compelled to surrender his property and business to be administered for the benefit of all his creditors.

Cooperative societies engaged in trade would be subject to these laws, and the object of this reference to them is to impress on those proposing to cooperate the vital necessity of maintaining credit, by promptly meeting all obligations when due. As already stated, all permanent debt is dangerous to cooperative societies, but if unfortunately debt be incurred, provision must always be carefully made in advance for prompt payment. 


\section{CHAPTER III.}

\section{COOPERATIVE CORPORATIONS.}

S cooperative enterprises will usually be carried on by
corporations created for the purpose, it seems necessary
to devote some space to their consideration. I can not say too often that this is not a law book, and that while there are many things which can be profitably said here in regard to corporations, whoever proposes to organize one should take no guide whatever but the printed law of his own state, and the advice of a competent lawyer. As laws affecting corporations are continually being changed in all states, one must not only consult the law, but be sure that it is the law as left by the last Legislature. In fact, if a corporation is worth organizing it is worth doing it under the advice of an experienced and capable lawyer.

The popular use of the term "corporations," of late years, to denote the great aggregations of capital which are so often employed to oppress the masses, has been such that there has grown up against those very useful institutions a certain unreasoning prejudice which often renders it very difficult to induce people-especially farmers-to go into them. This prejudice has been greatly strengthened by unfortumate results which have befallen many who did go into them blindly. There can be no business without risk of loss. If I buy a farm at current prices, circumstances beyond my control may create conditions which will make it unsalable at half what I pay for it. If I have paid casls, I have then lost half my investinent; if I have borrowed half the cost, I have lost all my capital and must pay rent in the form of interest so long as my creditor permits; when be chooses he will take my farm to repay his advance. If I lend money, no matter how well secured, there is a possibility of loss. If I engage in mercantile business there is still more chance of loss. If I 
raise produce it may be burned before sale, or I may sell it at less than its value. If I unite with my neighbors to do any of these things in a cooperative way, there is the same danger of loss. If I incur debt I am holden to the extent of my property for its payment. If I duly authorize another to incur debt in my behalf, I am properly held as firmly as if I had myself conducted the transaction. If I enter a partnership, either of the partners may incur liabilities of which I am ignorant which may sweep away my entire property. If I join an association, however loosely united, and indebtedness is incurred in pursuance of the objects for which the association is founded -as, for example, if the association guarantees the freight on a car-load of fruit-I am responsible not only for my share of the guarantee, but, if I am the only member able to respond, for the entire amount. It is a principle not only of law but of equity that $I$ be responsible for the act of my agent within the limit of his agency, and the association is my agent; and there is probably no limit to my responsibility except the limit of my property.

A corporation is a means provided by law whereby a large number of persons can safely and conveniently do business as one person. By incorporation individuals are enabled to escape many inconveniences and liabilities which they would incur by doing business as a partnership, or an unincorporated association, which is legally the same as a partnership.

1. By the death of a partner the whole business is liable to be thrown into conrt, with varying possibilities, according to circumstances, of hindrances in transacting its business, or a possible enforced winding up of its affairs. The death of a stockholder in a corporation need make no difference in the conduct of its business.

2. In an ordinary partnership, any of the partners may create liabilities involving the property of all the partners; in a corporation the law provides means whereby the power to incur debt is restricted to certain persons named by the stockholders, and who may be restrained by by-laws, and caused to give bonds not to violate them.

3. Instead of each stockholder being liable, like a partner, 
to the extent of his property, for the entire indebtedness of the concern, he is liable only for a certain definite amount, which is fixed by statute in each state; in California he is liable for such a ratio of the indebteduess as the stock owned by him is of the total stock issued; if he owns one-tenth of the stock, he is liable for one-tenth of the indebtedness, and no more. Each state has its own law upon this matter. Some states may permit so-called "limited" corporations, * in which stockholders in corporations are liable only to the amount of their stock subscription; when their stock is fully paid up there can be no further call upon them, no matter what indebtedness is incurred.

Corporations, therefore, are not only more convenient, but far safer than partnerships or associations, when any considerable number of persons unite to establish a permanent business.

Among farmers who become stockholders in cooperative enterprises there is a very common source of complaint, which has no foundation in reason, and that is "assessments" on stock not fully paid up; if I subscribe for ten shares of stock at $\$ 10$ a share, I obligate myself to pay $\$ 100$ at such times and under such conditions as the by-laws of the corporation and the laws of the state prescribe; and having thus promised I have no right to complain that I am held to the promise. There is often some uncertainty as to the exact capital required, and it is quite usual to take subscriptions for more than is supposed necessary, and call in only a certain portion. lisut the calling in of more is always a matter entirely within the discretion of the directors, but if they do call it no one can complain; if I do not wish to pay I must not promise to lo so. The cause of the general complaint among farmers when called upon to pay "assessments" on non-paid-up stock is doubtless to be found in the self-delusions of entlunsiastic promoters of cooperative societies, who have exaggerated ideas of the profits of business, and insufficient knowledge of the

* I know of no such state, lut I have not investignted carefully. They are permitted by British law 
amount of capital required to transact it. In soliciting suijscriptions to stock they are apt to represent-as they fully believe-that the first payment is all that will be required; hence when the call comes for the second and the following payments, there is disappointment and complaint.

But the assessment of stock which has been fully [aid "1) is quite another matter. If I subscribe for stock to the amount of $\$ 100$, I must not complain if I am called upon to pay $\$ 100$; but if I am called upon to pay more than that, there is almost certainly some one to blame. The mere fact of such an assessment is ordinarily evidence of mismanagement. As a rule, when such assessments are made they are for the purpose of paying indebtedness which should not have been ineurred. 'The one who is usually to blame, when assessments on paid-up' stock are made, is the stockholder himself. In all corporations the power rests with the stockholders, and where the power is, there must rest the responsibility. It is true that corporate aflairs must be mostly transacted by directors, but those directors are chosen by the stockholders, who have aiso power to instruct them, and to see that they follow instructions. It is true that we may be deceived, both as to the honesty and the ability of our agents, but if we use ordinary diligence in attending to our own corporate business, we are almost certain to discover it in time to prevent serious injury. If we fail to use such diligence we have no one to blame but ourselves.

In nine cases out of ten financial trouble in cooperative corporations, leading to assessments on paid-up stock, is due to non-attendance of stockholders at stockholders' meetings and non-use by stockholders of the facilities which they have provided for themselves, and which it would be to their advantage to make use of. By attendance at stockholders meetings, and by frequent calls at its place of business, and conversation with the managers and with other stockholders, the owners of the business may be kept constantly advised of its condition and prospects, and may always avert serions financial trouble.

One very common cause of financial trouble in cooperative societies is lack of patronage by the owners of the business. 
Suppose a society organized to market the product of its members; the projectors of the society induce one hundred members to join them; storage and other facilities are provided to take care of the product of all; connections for selling are made at considerable expense; a manager is employed at a salary proportioned to his responsibility in handling the entire output of the meinbers; the charge for selling is fixed upon the supposition that all will sell through their own agency, and, in general, all the preliminary expense of selling the entire output of the membership is incurred; if, then-as I have known to be the case-three-fourths of the members compete with their own business by selling through other agencies, one of two things must happen: either those members who use the agency must pay an unreasonable sum for its services, or a deficit will be created, to be met, in default of actual cash on hand, by an assessment on raid-up stock; in different instances I have seen each method used by cooperative-marketing associations. In the case of a cooperative store, the result would be the same. A mere deficit in expense, however, can never be serious, as it is hardly conceivable that a cooperative business would be run at a loss for a long time. The worst cases occur as the result of attempting business not suitable for farmers to engage in, wherein employees are permitted to make large purchases of material on credit or with borrowed money, or to make sales of manufactured products for future delivery, before purchasing the raw materials. In one case that has been reported to me, some stockholders in a cooperative cannery have been driven to the verge of bankruptcy by operations which, as stated to me, were about as follows: an employee of a cannery desired to be, or to be retained, as superintendent; not succeeding, he went among the neighboring farmers and organized a cooperative cannery, to be managed by himself; indebtedness was incurred for buildings, inachinery, sugar, packages, and labor; the superintendent was an active man, and succeeded in making very large contracts for canned goods early in the season; the fruit crop, however, proved short, and he was compelled to pay much higher prices than he expected, making, however, most of his 
purchases from stockholders, who were to be paid from the sales of the canned goods. In due time they were shipped, and rejected; they had not been properly put up, and were spoiled; meantime canned goods had advanced, and the purchasers insisted on delivery of sound goods, according to contract; this the corporation was unable to do, and those to whom they had sold bought elsewhere, at much higher prices, charging the difference to the cooperative society, against which they obtained judgment; and the outcome of the whole business to the stockholders was an entire loss of their crop, which was spoiled, and an assessment to pay for all the other material and labor used, as well as the machinery and other permanent plant, which was worth next to nothing at forced sale; and in addition to all this, there were large sums due as damages to those to whom they sold goods, but could not deliver. A single individual, in such a case, would simply surrender his property, go through insolvency, and begin again; the stockholders in this corporation, however, being all farmers with more or less property, were generally "good" for their share of the loss, which was put into judgments against them, and gradually collected.

The above iliustrations are given to show the causes of failure, and the dangers of cooperative work; in one case, the trouble arose because the stockholders did not attend to and sustain their own business; in the last, because they engaged in a risky business, which they did not understand; in both cases, the stockholders alone were responsible; they could have sustained the business which was suitable for them, and could have kept out of the other. In both cases they were better off in an incorporated society than they would have been without incorporation. It is not "corporations" which farmers have to fear, but irresolution and foolishness.

No corporation can lawfully engage in any business which is not specified in its articles of incorporation. The first step, therefore, toward safety in cooperative corporations is to exactly specify in those articles the business to be engaged in, in such terms as to exclude everything else. It is a common practice, in drawing these articles, to make them very general in their 
terms, so as to permit almost anything at all related to the proposed business to be done; as, for example, "to buy, receive, sell, dry, can, or preserve fruit," when the real intention is simply to receive and sell fruit, and the articles should read, as the purpose of the corporation, "To receive, store, and sell fruit, for cash only." Under their powers, by the first reading, an incompetent board of directors might lawfully bankrupt every stockholder; by the latter form, at the worst, they could be only mulcted in a small sum for expenses. Thoughtless persons, in preparing these articles, often think it just as well to put everything in, with the idea that they "may want to do some of these things sometime;" this, however, is no reason; if the purposes, as originally drawn, are ever found insufficient, a little trouble, and a few dollars, will at any time set everything right, and meantime no stockholder can be involved in any way that he did not intend. The articles of ineorporation form the constitution of the society; they constitute a public record, to be filed for public reference, in the manner provided by the law of the state, and when so filer, can only be changed by the stockholders themselves in accordance with the provisions of the local law. They should nerer be prepared except under the advice of an experienced attorney, who shotil carefully inform stockholders of the exact obligations they assume. Experienced business men are far more competent than farmers to frame such a document, but it is safe to say that no such experienced person ever frames such a document except under competent legal advice.

The by-laws of a corporation also constitute a public record, but are usually filed only in the office of the corporation itself, where they must always be subject to public inspection. It is well to have legal advice in preparing these also, but it is not so important as in the case of the articles of incorporation. As a draft is usually prepared in advance for submission to the stockholders, it is very desirable to submit the proposed by-laws to an attorney before presenting them to the stockholders.

The reason of this is obvious. The by-laws of a corporation should contain :- 
1. Such formal directions for conducting the business as may be prescribed by law; these must all be observed, whether in or out of the by-laws, but as the printed statutes are not always conveniently accessible to the officers, they should all be in the by-laws for reference, which is very necessary, as all corporate business inust be transacted strictly in accordance with law.

2. Such other directions, and limitations upon the power of the directors, not inconsistent with law, as the stockholders may desire. If inconsistent with law they are of course void, and if not properly drawn they may fail of their intended effect. It will be readily seen that good legal advice may be very valuable in preparing by-laws. In general, whatever is worth doing is worth doing well.

In fact, it is desirable to act under legal advice until the corporation is fairly started in business, with all the required legal records made, and all books requirerl by law to be kept openerl; after that the common sense of the directors, and especially of the president and the secretary, should be sufficient for such simple transactions as cooperative societies ought to engage in. Corporations controlled by trained business men, act constantly under legal advice in all transactions outside the regular routine of business; cooperative corporations, however, ought to engage only in simple transactions, as to which, when the routine is once learned, no further atrice is necessary.

The nain reason for such care in the organization of a cooperative corporation is the effect which it has on its credit. Many cooperative societies are so situated as to require temporary loans during the marketing season, in order to avoid undue pressure in marketing their output. This is customary among the trade, and is perfectly legitimate. Suppose a cooperative incorporated society for marketing dried fruits, of which there are many in California. The object of these societies is to prevent undue depression in the local market from the pressure to sell by those in immediate need of money. Nearly all that class of persons may be glad to unite in a cooperative society, but they need a portion of the value of their crop as 
soon as it can be delivered to the warehouse. As it will not be immediately sold, the corporation must borrow money to make the advance. It will be found difficult, however, to give the necessary security. It is inconvenient, and in fact usually impossible, to pledge the product, as it is ordinarily graded and inseparably mixed with other products, upon which, perhaps, 110 advance is desired, and at any rate as the material is constantly coming in and going out, it is exceedingly inconvenient to be constantly executing pledges, and obtaining releases from day to day as it moves. It is desirable, therefore, to obtain these necessary loans upon the general credit of the corporation, which is itself fully secured, as it holds possession of the product upon which the advance is made. If, however, application is made to the local bank, it is probable that any loan to the corporation will be refused.

The reason of this is apparent. It has already been shown that a corporation is safer for the individual stockholder than an unincorporated society; but by as much as it is safer to the stockholder, by so much is it rendered unsafe to a creditor of the corporation; a bank, therefore, will often refuse a loan to a corporation which it would gladly make on the joint note of a small number of its stockholders. It is easy to see the reason of this; of course notes executed to banks in the ordinary transaction of legitimate mercantile business are usually paid at maturity; but sometimes they are not, and prudent bank officers, in making loans, must invariably consider what would happen should they be forced to collect the note by law; if, therefore, a loan to a corporation were contemplated, the matter would be referred to the attorney of the bank, who would proceed to inquire as follows:-

1. Is the society legally incorporated?

2. Are its present directors legally chosen?

3. Have they, under the articles of incorporation and the by-laws, the authority to authorize the proposed loan?

4. Have they so anthorized it?

5 . What officers are authorized to sign the note?

6. What other indebtedness, if any, is outstanding against the corporation? 
If, upon examination of the records, the attorney is able to give an unequivocal "yes" to the first four questions, and satisfactory replies to the last two, the way to the desired loan is greatly smoothed; if the records do not permit such unequivocal replies to be made, the bank-if a safe one to deposit in-will refuse to loan.* These six questions having been satisfactorily answered by the bank's attorney, the bank itself has then to consider the amount of property sulject to attachment, belonging to the corporation, the value of goods in its possession, upon the security of which the proceeds of the proposed loan are to be reloaned to indiriduals, and the character and ability of those in charge of the corporate business; if a satisfactory showing is macle on these points, there is no reason why the loan to the corporation should not be made.

In farmers' cooperative societies there is almost no question of the honesty of the president and directors; known to each other as the stockholders are, it is practically certain that the management will be honest. There is, however, danger of mistakes resulting from business inexperience, and it frequently happens that banks require a year or two of successful experience before granting loans to cooperative societies, even if known to be properly organized. In this case money can only be borrowed for the corporation on the joint individual notes of the directors or other stockholders. This is a common custom in the case of corporations organized for profit, in which the directors frequently own a controlling interest which makes them willing to become personally liable in transactions wholly under their control, and from which they expect to derive, through their holdings of stock, personal profit.

* The officer primarily responsible for the orderly conduct of corporate business and the due entry of the necessary records, is the secretary. $\Lambda$ good secretary is invaluable, and should never be changed if it can be avoided. His familiarity with what has been done, and with the necessary legal forms of transacting corporate business, make him invaluable to the business. It may be proper to suggest that the secretary should have no executive connection with the business, or any responsibility for funds or monetary transactions; let him be purely a recording officer, under no possible temptation to falsify or obseure the record. 
Corporate notes are not liked by banks, and some banks refuse them entirely, for fear of legal informalities in their business; banks are unwilling to incur the trouble and expense of investigations. Stockholder's liability is never considered as a basis of security, although, should the worst happen, it is made use of.

Directors in cooperative societies, however, ought never to be expected to become personally responsible for debts of the corporation. They seldom have more direct interest than other stockholders, devote much time, gratuitously, to the common business, and are sulject to all the criticisms of the censorious and unjust. If, therefore, without hope of personal profit, they are asked to impair their own credit by borrowing money for corporate use, it is hard to get good men to serve. For these reasons it is of great importance that the organization of cooperative corporations be conducted with the utmost care, and under competent legal advice. By this means those concerned with the organization, and who are likely to be the first directors and officers, become familiar with the proper methods of conducting corporate affairs, and are thereby enabled to maintain the credit and standing of the corporation, and prosecute its business with the effectiveness and vigor which knowledge alone can give. 


\section{CHAPER IV.}

\section{ESSENTIALS OF SECURITY IN COOPERATIVE SOCIETIES.}

T

HE principal elements of safety have been already mentioned; they may be summarized as follows:-

Adequate CAPital.-In order to proceed safely a careful estimate must be made of the sum required for permanent investment. If a cooperative "store" is contemplated, whatever actual cash can be collected is enough, provider the members of the societ $y$ are of the right material, and can be depended upon to purchase their supplies of their own store, each, for a time, at some personal inconvenience. If there be any doubt about this, don't start. If a creamery, or fruit drier, or selling agency be contemplated, carefully estimate the cost of the necessary land, buildings, machinery, etc., together with expense of organization and expense of carrying on the business until it begins to earn income; when everything that can be thought of has been estimaterl, add fifty per cent to the amount so obtained; when stock to that amount has been subseribed, it will be safe to go ahead.

Freedom from Dert.-By this is meant permanent debt, upon which interest is paid and which forms a permanent lien on the property of the corporation; temporary loans for the purpose of making advances on produce, and which are to be paid from the sales of the produce, are usual for marketing societies, and are entirely safe. State laws should, and probably always do, set a limit to the indebtedness which corporations may incur; in California the limit is the amount of subseribed capital stock. In the purchase of the permanent plant it is reasonably safe to incur indebtedness payable in yearly instalments rumming not over three years, provided the stock necessary to pay the indebtedness has been subscribed and partly pair up, the umpaid portion to be used, as paid in, to pay off the indebtedness; but no indebtedness 
is safe 111 excess of seventy-five per cent of the outstanding amount due on unpaid stock. Allowance must always be made for subscriptions which will never be paid. 'The standing of the subscribers, howerer, has much to do with this, and the directors will usually be fair judges of the value of the unpaid stibscriptions. Subscriptions on which no payment has been made at the first call are usually of no value. 'They should be counted as nothing, at all events. If payment could be enforced-which is often doubtful-it would be foolish to do it. In case of indebtedness to be met by deferred payments on stock, each stockholder should perfectly understand that he has an obligation that must be met, so that there is no surprise on his part, or complaint of "assessments." Except for permanent plant, for which stock has been subscribed, and for a limited amount calculated to pay rumning expenses not to exceed a half year, there should be absolutely no debt permitted, except for advances on products under the control of the corporation.

Caution in Making Advances.-In this matter it is best to be governed by your banker; indeed, you will probably be compelled to be so governed, as he will lend you no money if he is not satisfied that you are making safe use of it. It may be best, however, to consider the matter a little for ourselves.

Farmers are apt to consider banks as the owners of the money which they lend. This is true, however, only to a limited degree. The greater part of the funds available for loans from banks is the property of depositors, who are liable to call for them at any time; banks, therefore, have to be extremely cautious in lending; the time must be always short, and the security such that it can be instantly converted into cash if necessary, and the margin between the amount of the loan and the market value of the security must always be such that the amount of the loan can be realized in any emergency. Some farm products form such a security, and some do not, and some would be consilered gool security in one locality and not in another. Their value as security depends, first, upon the usual demand for them; secondly, upon their keeping qualities; and, thirdly, upon their situation. 
Wheat is good security the world over; the demand is universal, and it will keep, for years; but a larger margin is necessary in California than in Chicago or Liverpool, because it is farther from market. Indian corn is far better security in Illinois than in California, because the demand is greater there; on the contrary, any one can see that a car-load of fresh fruit is worthless as security ; it is not accepted as security even for freight. All prolluce is better, as security, in the hands of a trader, on the way to market, than in the warehouse of the producer, unsold.

Dried fruit is a very important product of California, but until recently has not been considered proper security for sound banks to accept, except in the hands of dealers and in the process of marketing; in the hands of growers it has been practically worthless as security outside of one or two localities where the interests were so large as to compel bankers to familiarize themselves with its value. The stability of the demand has not been assured, and it is very liable to deterioration in unskilled hands; it is entirely unsafe to carry over to the second year, as old fruit always sells at a discount.

The fact that the result of the labor and investment of the California fruit-grower has resulted in a perishable or a semiperishable product, regarded as unfit for security, together with the great distance of California from the great markets, has placed the fruit-growers of that state in a very serious position, for which cooperation seems to be the only remedy. The coonerative societies, however, are subjected to a competition from commission houses so severe as to be sometimes actually vicious and unscrupulous; the strongest wenpon of commission houses is the "advances" which they make to growers; in many cases they advance cash to cultivate the crops, taking crop mortgages; this they do largely from their own capital, bank loans not being always arailable for that use; the moment, however, the dried product is ready, banking capital can be had through commission houses to "move" it, up to the amount of perhaps three-fourths its current value, and even more; with any such amount of advance as that upon it, however, it must be kept moving and got into the 
hituds of the purchaser at the earliest possible moment; this the owner of the money secured by it will insist upon at all hazards, and it will ordinarily be done regardless of any promises to growers.

Perhajs the main object of the cooperative fruit associations of California has been to relieve the selling pressure during the first month or two of each season, by providing means whereby growers can obtain reasonable advances for a short time, upon their proluct, while still retaining control of its sale. It is considered that since the erop requires the entire year for its consumption, during which time it will necessarily be "carried" by some one, it will be to the grower's interest to avoid a forced sale of the entire crop during the first month or two, by "carrying" some portion of it himself, not, however, in a speculative spirit, or with any special expectation of more than the proper slight advance to offs' $t$ interest and shrinkage, which a dealer would expect.

This, however, the grower can not do, if he loais up his product with advances approaching its market value; when he does that his product will have to move; the inducements which eommission houses sometimes offer of very large advances, as against comparatively small advances attainable through a cooperative society, are in reality no ald vantage to the grower; in almost every instance when his circumstances require him to immediately realize nearly the full value of his crop, he will do better to sell outright to some person able to hold it if he desires.

Dried fruit, nuts, raisins, etc., in a fruit warehouse in California, in charge of experienced men who a re responsible for its condition, is security for fifty per cent of its current value, and would now probably be so considered by most California bauks, for a short loan, with the understanding that 110 renewal was to be asked, but the fruit sold before the maturity of the alvance upon it; this wonld probably be all that a banker would advance, and it should be all that any cooperative society should advance. Holding any produet which you can sell, and the proceeds of which you need, is speculation, and he who speculates on borrowed money is 
lost. The cooperative societies of California were organized as selling agencies; if they acquire the habit of sceking to "corner" the markets, and do it on borrowed money, they are doomed. Hence, while advances to a certain extent are necessary and proper, cooperative societies should use caution; if the pressure for adrances is quite general, and tends to approach half the value of the product or more, push sales a little harder. Inave no fear of "weakening the market;" the market is already weakened when the owners of a product are compelled to borrow money on it; a cooperative marketing society will be tested by its efficiency as a selling agency rather than by its effectiveness in obtaining loans on products held for an advance.

Smiplicity of Object. - It is perhaps unnecessary to add to what has been said before on this topic. At present cooperation is not competent, in this country at least, to deal with complex mercantile or manufacturing operations. If success is achieved, it will be due to the public-spiriterl efforts of one or two persons, and not to the inherent force of the cooperative body. A creamery, a fruit drier, a selling or purchasing agency, and similar enterprises may be expected to succed in communities requiring them.

There are some other matters essential to success, which may perhaps be more appropriately considered under the beading of the next chapter, but on the whole a cooperative enterprise designed to accomplish a simple and desirable end, with adequate capital and free from debt, ought to succeed. 


\section{CHAPTER V.}

\section{ELEMENTS OF DANGER IN COOPERATION.}

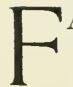

AILURE in the main to be governed by the rules suggested in the last chapter, or carelessness in the matters of organization, are of course elements of danger, but in this chapter I shall have reference to matters which, although seriously important, are yet not absolutely fundamental; matters in which such errors as may occur may be corrected without reconstruction of the entire business.

Neglect of Stockholders. - This has been already alluded to, but it can hardly be made too prominent. The stockholders are the owners of the business, and if they do not carefully watch it, who will? I have never myself seen serious trouble from this cause in neighborhood associations which have been started on a sound financial basis, and whose members are necessarily well acquainted with each other, but in more extensive marketing associations, whose operation extends over considerable areas, and perhaps an entire state, the inattention of stockholders is a serious difficulty. The tendency of farmers in such cases is to regard "the company" as a mysterious entity, existing somehow and somewhere, to which they have perhaps "contributed" grudgingly something, and whose operations are calculated to help them in some way without thought or effort on their part. The notion of the corporation as a business enterprise of which they are part owners, which expects the support of their business, and for whose financial success they are in part responsible, can hardly be said to exist among farmers. Perhaps this point may be treated more profitably by considering the infirmities which are the cause of it.

IgNORANCE. - This is the foundation of most trouble, and certainly of the non-support of cooperative societies by their own stockholders. The ignorance of most farmers in regard 
to business transactions outside the immediate operations of the farm is astonishing. The merchant is perhaps as ignorant of farming operations as the farmer is of trade, but he has no need to be otherwise, as he deals only with completed products, and need not concern himself with the processes of production-although to be sure he is a better merchant if he does understand them-but the farmer who must bear all the risk of production is vitally interested in the mercantile conditions and operations affecting the distribution of his product.

I can best illustrate my meaning by an example. The fruit-growers of California are engaged in a very risky business; their product, if sold fresh, is perishable; if sold dried, is semi-perishable; they are thousands of miles from market, and, on nearly all their products, are exposed to competition from other districts or other countries having cheaper labor and cheaper transportation to the great markets; their business requires far more capital than ordinary farming, and their investments require careful attention and constant increase for years before yielding any returns whatever; they are probably the most intelligent body of agriculturists in the world, and yet up to the beginning of cooperative work in that state it is doubtful if there were a dozen of their number who eould give any intelligent account of the processes by which their product reached the table of the consumer, the necessary expense of those processes, or of the character and extent of the competition to which they are exposed. The mixed farmer of Ohio, or the wheat-grower of Minnesota, has not the same need of this knowledge; his goods are staple and the markets are at hand; if one crop proves unprofitable he ean the next year change to another erop); but to the specialist, eultivating orchards under the circumstances prevailing in California, this mereantile knowledge is vital, as hundreds who entered upon the business without it have learned to their sorrow.

Suspicion.-This is the child of ignorance, and invariably attends it; and it is born not only of ignorance, but of experience. The ignorant man is the natural prey of the designing man, and having been often deceived is eonstantly expecting 
deception. A man ignorant of business processes has no means of distinguishing the projects of the schemer or the enthusiast from the sensible proposals of the sound business man, and as the former always promise more largely, he is more likely to be attracted by them, and to be continually disappointed. It is surprising to meet persons so generally intelligent as many farmers are, and yet so completely ignorant regarding many business transactions which concern them, and consequently so suspicious of those proposing improved methods.

INFIRM WILL.-This seems to me the greatest infirmity of human nature. It seems to be possible for bright talkers of strong will power to persuade most men to act contrary to what would be their cool judgment. It is my observation that when cooperative societies are formed the majority of the members are obtained only after the most earnest canvassing by a small number of enthusiasts; I have personally assisted in the formation of a large number of cooperative societies, and perhaps have induced as many persons as any one ever induced to sign their names to the stockholders' lists of such enterprises, and I can remember hardly an instance where any one not of the number of the original promoters gave his signature without serious and exhausting arguments; I have always been a hard worker, but have never done any work so exhausting as canvassing for membership in a cooperative society; of the hundreds whom I have induced to join sueh societies, I do not believe that one-third could have been secured except as the result of this earnest canvassing; nor do I believe that there were more than one in three who could not be persuaded after having joined the society to compete with it by doing their business elsewhere.

The experience of the California Fruit Union, with which I was never connected, is a fair sample of this. Sometime in "the eighties" the growing output of fresh fruit in California had outstripped the then existing shipping and marketing arrangements, and the growers were making no money. In this state of affairs, as the result of many large meetings, and amidst much popular enthusiasm, the "California Fruit 
Union" was organized as a fresh-fruit shipping association, owned and controlled by the growers themselves. A very large number of growers, including most of the largest, became stockholders, and for some years the Union was the largest shipper of fresh fruit from California, and all its operations appear to have been honestly and effectively conducted. It secured, from the start, many concessions and advantages to the growers, which would otherwise have been delayed for rears. After a successful existence for several years, the Union, in 1894 , went out of business.

The canse of this practical failure of eooperative work was the instability of character of the mass of its stockholders. Personal dissensions arose between some of the largest shippers, causing some withlrawals, but it is probable that the majority of the withdrawals of large shippers grew rather from a speculative fever which passed through the state, causing some who had been successful to engage in large plantings on credit, which soon brought with it the necessity for large advances, which could only be secured by a practical or actual mortgage of the erop to commission men, who, of course, insisted on marketing the fruit. But it was found that the great mass of smaller growers, whose aggregate output is, on the whole, the controlling factor, could not be depended upon at all. Commission houses, seeking the business, flooded the state with incisive "talkers," who found no difficulty whatever in exciting in the minds of the fruit-growers distrust of and even enmity to the agency of their own creation. The plan of concentrating the shipments under one general management, sufficiently powerful to insure the widest distribution possible, was thus defeated by the mental weakness of its members. There was never any ground for serious complaint of the management, and even if certain alleged abuses had existed, growers would have been far better off to have shipped through the Union, and permitted them to continue. But they were infirm of purpose, and sharpers were quick to take advantage of them. There was another reason which brought about the final winding up of a business which was still large and reasonably. prosperous. Fresh fruit is a very perishable commodity, upon 
which freight has to be always guaranteed; the freight between California and the east was not less than $\$ 300$ per car, and it often happened that, when sold, it did not bring enough to pay charges. These, however, were guaranteed by the Union, and paid, but when it attempted to repay itself by collecting the loss from the individual owners of the fruit, in many cases it practically could not be done. The result was that the large and responsible shippers, who could be reached, were compelled to pay the majority of all such losses of others, and they got tired of it. All these things are useful as illustrating the real character of human nature, with which cooperative enterprises must deal.

I have stated, at the beginning of this chapter, that the dangers I was about to discuss were not absolutely fundamental, whereas those which are based on the characteristics of human nature of course really do lie at the foundation of things. But, in the use of that term, I referred to the constitution of the organization, and not to the character of its members. With a proper organization, and sufficient time and patience, we may expect, by education, to overcome the infirmities of human nature.

Ixcompetexce in MANAGEMent.-A merchant, thoroughly understanding his business, knows exuctly what qualities he desires in his employees, and, being in continual contact with them, knows whether they have them, and whether they do their duty. As there are no personal profits in cooperative work, it is very difficult to insure the same supervision of the salaried staff that is found in a private business. The real owners of the business have none of them an amount at stake which justifies them in taking the time necessary to properly overlook it. It is also nearly always the case that the manager and other paid persons know more about the business than any of their employers. Under these circumstances, which are almost inseparable from distributive cooperation on any large scale, the principal guarantee of good management lies in the value of the personal equation of the directory, which, in a large organization, covering a wide area, is certain to be much higher than that of the average equation of the stockholders. 
There are, however, many facts and considerations which can be definitely formulated, and which, if thoroughly digested and properly acted upon, ought to insure both competent and honest management. Some of these things might be quite properly discussed under the heading of this chapter, but their importance justifies a separate grouping.

In this connection I may say that it is not necessary, nor will it usually be possible, that the manager of a cooperative enterprise should be one of the class known as "successful business men"-that is, men of wealth. Such men invariably have a strong accumulating instinct, and the idea of cooperation does not permit the accumulation of private fortunes by the profits of distribution. There is no money to be made, honestly, in these positions. As a class, also, such men are nearly destitute of sentiment, a fair touch of which is essential to induce men of ability to lead cooperative movements.

Fortunately, such men are not necessary. The majority of really good business men do not possess the accumulating instinct. They are often unwilling to submit to the privations upon which, in most cases, the foundations of large fortunes are laid, preferring the comforts of home and the advancement of those dependent upon them, to the accumulation of wealth. The brains and push of all great business organizations is largely composed of such men, who sell their talents and vigor for a fixed compensation, to colder-blooded men, who make a profit on them, and secure the reputation for business ability, which should, in great measure, be shared by their employees. They are also, of course, themselves men of ability. To become very rich, you must be very able; but you may be very able and never become rich. 


\section{('HAPTER YI.}

\section{MANAGEMENT OF COOPERATIVE SUCIETIES.}

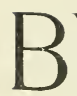

$Y$ the "management" in this chapter I mean the salaried staff, who will ordinarily be appointed by the directors, and not be nembers of that body. In making these appointments-especially the principal officer-there are four things to be particularly considered:-

1. The qualifications necessary.

2. Methods of determining the possession or lack of those qualities.

3. The money value of the service to be rendered.

4. Influences to be guarded against.

It will be profitable to consider these points in their order.

Necessary Qualifications.-The perfect manager of a cooperative distributing society will possess many qualifications not usually found in one person, and the perfect manager is not likely to be found; but it will be useful to set down the qualities which the perfect manager would have, that in considering the appointment of a mere human being, directors may check off in their minds just which of these qualities the candidate has, and which, if any, he lacks.

Integrity. - That this is essential needs no argument, nor is there much danger that one not believed to be honest will be appointed manager of any important cooperative enterprise; but the grade of integrity required in the manager of an important cooferative concern is of no ordinary kind; and there is always some danger that it may not be found associated with some other essential qualitics, in those available for service in a salaried capacity. There are grades of honesty which can resist ordinary temptations and yet succumb to those which are extraordinary, and the manager of a large cooperative enterprise will be continually exposed to the latter.

I do not refer to the mere custody of funds; ordinary pru- 
dence on the part of directors will nearly always be a sufficient guard against embezzlement; and in all events there will be the security of a bond. And this bond, by the way, should always be that of a security company, and not that of an individual. No man's integrity can be absolutely assured, and there is no reason in asking an uninterested third party to pay for his mistaken confidence in the honesty of a friend. Besides, such bonds are often unsafe and uncollectable. The bond of a security company for $\$ 1,000$ is better than a friendly bond for $\$ 10,000$. In the first place, the thorough investigation which the comprany must make, before insuring, is a great safeguard, and, secondly, the absolute certainty of prompt and relentless prosecution to follow the discovery of any wrong-doing is the most powerful restraint on any such inclination. The usual charge for such insurance is one per cent per annum on the amount of the bond. It amounts to a reduction of silary to that extent, and should be paid by the corporation, who will in that way most readily secure a bond of that kind. It will be hard to refuse the tender of what appears to be a sufficient individual bond, and the tendency of the employee will be to save limself the expense of the security bond by inducing some friend to become responsible for him.

But there are more serious temptations, arising from the power of the manager to throw business, and against this no bond can provide. If there are purchases to be made, he can, if he will, secure private commissions on these purchases; and if there are sales to be made through brokers, he can obtain a private interest in the brokerages.

The Manager Is Sure to be Tempted.-Sooner or later these advantages will be offered him by some unscrupulous person who believes that all men have their price. It is not likely, at first, to be a direct and open offer which can be openly resented and reported, but there will be conversation opening the way to advantages of some kind to be given to the manager, in return for undue favors, which will rapidly crystallize into actual business, if the manager proves susceptible. And it is possible for so large an advantage to come to him, with 
such infinitesimal injury to any individual member of the company, that the temptation may be very strong.

The Manager Is Sure to be Suspected.-I think this the great danger-point of cooperative distribution. There is a mean streak in humanity which seems to make us unable to assume good motives when those which are improper can be imputed. I fear there is no sanction of honest life, however long continued or conspicuously displayed, which can insure against insinuations of evil, which are all the more galling that they are seldom so openly made that they can be disputed; indeed, it would be useless to dispute them, for they can no more be disproved than proved; for it is true that honest life does not insure continued honesty; and the knowledge of the suspicion which will surely come to all in these positions, seems to be more likely than all other influences to break down the moral fiber of the suspected man. The honest man has usually the confidence of those with whom he is in immediate contact, but in a cooperative society, doing business for hundreds of members who never see the manager, there will be continual questionings of his honesty. Knowing this to be true, there is danger that the time may come when, under temptation, he may say, "Of what use is the honest life since one gets neither the credit of honesty nor the advantage of dishonesty?" and will conclude that since fidelity is repaid with ingratitude, and no one can know certainly whether he has been honest or not, he may as well do what many believe that he does.

This fault of suspicion lies in our own nature, and the remedy must be found in our own knowledge of that nature. The surest way to keep an honest man still honest is to trust him; there is happily in our nature, amidst much evil, a noble impulse that leads us to be faithful to those who really trust us. Implicit confidence, and monthly verification of accounts, will keep most men honest.

There is also another safeguard, which, with that mentioned in the last paragraph, may be expected to maintain honesty in service, and at any rate, in connection with reasonable trust, is all that we can do to maintain honesty in 
cooperative service, and that is make the positions worth haring. I shall speak of this more fully when discussing methods of determining value of personal service, but I may say here that cooperative societies almost universally err in making compensation of learling officers too small,* the result being that the mental caliber of those employed is ant to be inadequate to their duties, and inferior to that engaged in competitive distribution. The consequence is that really capable men will not care for the positions, and when they hold them are less likely to be kept honest for fear of losing them. An honest man fully trusted, and paid what the same ability and responsibility commands in competitive business: is pretty sure to remain honest.

Brains.-The manager of a cooperative business must have acuteness and judgment in accordance with his duties. Greater mental strength is of coursa required for complex operations covering a wide field than for simple duties restricted to a more narrow sphere. The mental ability required increases in a direct ratio with the number of things the manager is required to know, and to consider at once when acting. A great war always affords conspicuous examples of excellent division generals, and even corps commanders, who have not the mental grasp to conceive and execute the combinations necessary to properly direct an army. It is the same in business.

Tigor.-There are men who know but can not do. In the time of action they fail. Usually this will be found attributable to insufficient bodily strength, and is especially to be guarded against in those whose age and experierce have otherwise qualified them to assume responsible positions. In competitive business such men by natural selection have worked their way to the conduct of a business whose policy has long been established, and whose active work is performed by younger men. Those charged with direction have not the

* I must again call attention to the fact that this view is utterly at variance with that taken by all others who have written upon this subject, and contrary to the practice of the most successful cooperative societies in the world. The contrary view is that capable business men, from adtruistic motives, will give their services at less than their competitive value. 
exhausting labor of detail, and can save their strength. There is danger that cooperative business may not develop this class, and at any rate in their beginning, the manager, from considerations of economy, will usually be compelled to do the double duty of direction and execution, and the sound mind in the sound body is essential.

Experience.-Something has already been said as to this. I suppose no one ever entered upon a new business without making errors, which by experience he gradually learns to avoid. The more experience, therefore, that is available, when accompanied by brains and vigor, the more fortunate the society will be. If, however, the experience is lacking, the society will do very well with lonesty, vigor, and brains, provided it fully understands that errors will be inevitable, and is prepared to endure them patiently, and pay for them cheerfully; for all errors in business cost money. Errors occur and are paid for in competitive business, but they are reduced to a minimum by natural selection and regular promotion of the most competent, and when they occur they are not heard of outside. It is the misfortune of cooperative business that all errors are subject to public discussion, often leading to change of management just as the manager has learned to be useful. Nothing is more wasteful than continually paying for the experience of new men, and it is a danger to which cooperative business is peculiarly exposed. In cooplerative business experience is desirable not only in all branches of the business to be conducted, including personal acquaintance with those from whom or through whom trade may be expected, but also in dealing with such masses of disorganized men as cooperative societies, at the beginning, will usually consist of. $A$ hopeful, earnest man, without this experience, will be likely to expect and to rely upon many things which will never lıappen.

Tact.-A manager is presumably a salesman; at least he must direct salesmen, and few men can profitably attempt to direct others in matters in which they are not themselves expert; the salesman's tact is reasonably plenty, and it is not to this that I refer, but to that far rarer accomplishment which will 
enable the manager to keep in solid phalanx his own employers. This problem is ever present to the mind of the manager of a cooperative enterprise, and the necessity of its contimul solution by new processes is the one thing, next to the suspicion with which they are regarded, which most tends to drive capable men out of cooperative service. Competitive business has not to deal with this trouble; of one thing the employee of a competitive business is sure, and that is the earnest and unfaltering support of his employer. The entployee of a cooperative society, however, is not only not sure of this support, but he may be perfectly certain that he will not have it. With some experience as a leader of cooperative effort, I can testify that nine-tenths of my vital force, while engager in it, has been employed in holding to their professed intentions those at whose solicitation I engaged in the work. I have never yet been able to employ more than one-tenth of my power in forwarding the real objects of the association. Of course I have rather been a pioneer, and engaged in the beginnings of enterprises, but I have harl goor opportunities for observing the operations of establisherl societies, and believe that upon the average one-half the force expended for, and paid for, by cooperative societies is used up in keeping the members together. It seems odd that we should have to hire people to persuale us to continme in a path which we say we wish to walk in, but we seem to be built that way. It is a feature in which cooperation, in our present state of development, inrolves a distinct waste of power, as compared with competitive business, and to that extent is eooperation uneconomical. State socialists, recognizing this difficulty, would substitute the power of the state for the persuasions of individuals. This-even if theoretically sound-we are certainly not now prepared for, and cooperation, which is one phase of voluntary socialism, must meanwhile depent on persuasion and "management," and for the present the manager of an extended cooperative society must be superendowed with tact.

Doubtless other qualifications could be enlarged upon, such as conrage, hopefulness, patience, earnestness, foresight, punctuality, and in fact all the cardinal and minor virtues, but 
upon the whole I think that whoever possesses in a ligh degree, integrity, brains, vigor, experience, and tact, is quite likely to possess most other necessary qualities, and at any rate to be an exceedingly useful person, and probably a good manager; but in summing up the requirements it must never be forgotten that the manager of au important cooperative business must be equipped to cope successfully with those who by natural selection have passed through the period of salaried employment, and in the fulness of experience, are now managing, as owners, the great competitive establishments with which cooperation itself must compete.

Methods of Determining the Possession or Lack of Qualities Necessary to Conduct Cooperative Business.-It is evident that the value of one's personal equation cannot be determined with scientific accuracy. Whaterer conclusions are reached will always be subject to a large margin of error; in forming our judgment of ability and character we are influenced in very complex ways by our impressions of the person's conversation, writing, personal appearance, and his associations and history so far as known to us, and from the sum of all these impressions our judgment is formed. As one becomes more largely an employer of men, he acquires the habit of analyzing these impressions, and assigning in his mind a certain definite value to each, and directs his preliminary inquiries toward the ascertaimment of such definite facts as will throw light upon character. It must be remembered that in competitive business the candidate for a respousible position will usually have long been known by the employer, either as an employee in a subordinate capacity, or as a competitor in the same line of business; while the beginning of an important cooperative enterprise is subjected to this disadvantage, that the selection of manager must be made by those who have perhaps not had experience in employing business men, are imperfectly acquainted with each other, and may not have clear concentions of all the qualities required; and that the selection must usually be made from those without previous experience in the exact business to be lone, or upon the scale which is proposed, and who are also perhaps not well 
known to all who must vote upon the appointment. It seems probable, therefore, that what follows may be useful to those coming to this experience for the first time, in directing their minds to such definite points as are essential to the formation of correct judgment of personal character.

Integrity. - A security company, when insuring the fidelity of an employee, must usually rely upon such information as it obtains of the business, and personal history, associations, and habits of the candidate. These items are scrupulously obtained both from the statements of the person in question, and from those with whom he has been associated, whether given as references or not. Bad character is almost certain to carry with it bad repute; or if most carefully concealed, at least suspicion. A man of clean record and good habits and associations, and free from debt, is a first-class risk of a security company, but even such men sometimes go wrong. In addition to this the employer will always have the advantage of at least some personal acquaintance. One thing must always be inquired into: Is the candidate in debt beyond reasonable expectation of payment? and if so, under what circumstances was the indebtedness contracted, and what arrangements have been made for its extinguishment, either by payment or compromise? Especially is he harassed by unsecured small debts? Indebtedness can not be considered a bar to responsible employment, although freedom from debt is certainly a great recommendation, but no concern can afford a responsible employee who does not pay his bills; and there are unfortunately many attractive and even brilliant men who intend and really believe themselves to be lionest, who are in that position. They will not do, for they are not good business men.

It must never be forgotten that when previously good men go wrong it is almost invariably under the pressure of indebtedness improvidently incurred. There may be instances of men of good reputation, and free from debt, who violated trusts, but I have never heard of them. Those who go wrong are those who live beyond their means. I do not speak of gambling, hard drinking, betting, or stock speculation, because 
I assume that men with those habits would not be considered. I have often thought that honesty is in the nature of a luxury which most men desire; those who fall are invariably those of infirm will who permit extravagance-and sometimes confidence in others-to beget indebterness, under whose pressure they come to think they can not afford the luxury of honesty.

Ability.-Business ability consists more than anything else in the accurate knowledge and classification of facts relating to the business. Judgment is the most common of business qualities; you can find it anywhere. I make this apparently paradoxical statement purposely to emphasize the fact that what we call the poor julginent by which the majority of men are unquestionably swayed is simply insufficient knowledge. When men of identical interests differ it is because one believes something to be true which the other disputes or has not thought of. Of course vigor is essential to success, but I am now speaking of intellectual qualities. But the possession of accurate knowledge is almost complete evidence of vigor, because accurate knorledge is only attained by industry, and there can be no industry without vigor. The man who accepts a casual newspaper paragraph, or any unauthenticated statement of a fact essential to his business, may seem to have knowledge, and yet may be worse than ignorant. If he does not think he knows, he will probably seek to ascertain before acting, but if he acts on inaccurate information he invites disaster. The man of ability therefore will know things definitely, either of his own knowledge or from the definite authenticated statement of one who does know and who is worthy of trust.

The larger and more important the business the larger the number of facts it is necessary to know definitely in order to conduct it successfully. For example, the manager of a cooperative dried fruit marketing society should know all the facts relating to the following matters: Varieties of dried fruits, their modes of preparation and packing in all producing districts; cost of production and transportation in all districts, that he may estimate the probable strength of com- 
petition; the quality of his own and competing goods; usual annual world's consumption at a given price; ratio of increase of consumption upon reduction of price; financial condition of his own and competing people, and of consumers; stocks on hand in consuming districts; names of wholesale purchasers; names, standing, and connection of brokers; character and disposition of his directors and stockholders; and many other matters. It is the same with any other business: the manager needs to know accurately and in detail all the facts bearing on that business; when all the facts are known, the proper policy will be apparent to all. I have seen many meetings of directors and stockholiters, and when facts have been once settled, there has invariably been manimity in opinion as to policy. It is needless to say that no manager can be expecter to know all that a manager should know as to the business committed to him, but the nearer lie approaches to perfect knowledge, the more useful he will be.

Right liere is a point at which cooperative business will always be at a disadvantage as compared with competitive business. The owner of a competitive business will usually be a person who by long experience has become a master of the business, and by natural selection has proved his vigor; if he has occasion to employ a person for a responsible position, he is an excellent judge of his qualifications since he will almost certainly be the better informed; and his personal interests will lead him to the utmost care in selection. In cooperative business, on the contrary, the proposed manager, at least in the beginning, will almost certainly need to know more than any of his employers, and how shall they who have not the qualifications, sit in judgment on one who knows more than they? They can only do it as they select their doctor or their lawyer, by their general judgment of the man, exeeptand it is a very important exception-that they have the opportunity to ask the policy of the proposed manages, and his reasons for that poliey, in the course of his explanation of which the extent of his knowledge will appear. A man who has no definite policy to propose, or who is unable to state clearly, with the autherity given, his reason for that policy, 
is unfit for manager. When he gives his reasons he must state facts, and those facts can be verified by the directors, and upon the accuracy of his knowledge a fair judgment of his ability may be based.

Vigor--Extent of accurate knowledge, as already stated, will usually indicate vigor, but vigor is of two kinds, one arising from an active nervous temperament, involving quick pereeption and rapid execution, and not unfrequently associated with a weak stomach - from which all human power conies -and a tendency to wear out and break down; the other the outgrowth of a more sluggish nature, with slower perception and more deliberate execution, but accompanied by noble digestive organs and wonderful staying qualities. This type is by far the most valuable, but is seldom available in middle life for salaried positions. It is the class which grows rich and is oceupied with its own property. The physique and conversation of the man indieates the quality of his vigor.

Experience and Tact.-Experience, of course, is only to be ascertained by inquiry, but there is something to be said about tact. This almost indefinable quality may be the result of the natural prompting of a kind and honest heart, or it may be the studied expression of a cold and calculating villain; one of the most tactul and winning men I ever met was also one of the greatest scoundrels. Intimate acquaintance will disclose the type, but casual or limited accuaintance will not always do so. Tact is essential in cooperative business in order to keep it together; its presence may usually be determined by the effect of the person on one's self; to the extent that he wins you to him he has tact, and, if the opportunity occurs to observe him in a difficult or amnoying position, the impression that he makes upon yourself under the circumstances is the best evidence you can have of his tact. Your opinion of the source of his tact will be determined by your investigation as to his integrity.

The I'alue of Salaried Service.-I know of nothing more puzzling to the directors of a fumers' distributing society proposing to do business on a large seale than fixing a compensation of its principal oflicers. They often lave not the 
means of judging either of the value of the desired service to themselves, the cost of it to the individual, or its value in the competitive market. It is, of course, inpossible to lay down, in a scientific way, definite rules wherely the value of any given personal service may be determined, but something may be said which will assist stockholders in forming just views of this subject.

The one thing which should have and necessarily must have most consideration in determining the value of personal service is the number of facts which must be accurately known in order to properly perform the serrice. The Brook Farm enthusiasts, in the ideal community which they established a half a century since, laid down the fundamental principle that all labor should be paid at a uniform rate, regardless of its nature; with the idea, of course, that the more disagreeable occupations should be shared in turn by all; and in fact, for a time, the head of the community, the accomplished Dr. Ripley, received the same price per hour, whether serving as an instruetor in psychology, or as chambermaid to the cows; but in due time it was discovered that, while almost any of the community could satisfactorily replace the gooi doctor in the malodorous functions of the stable, his duties as instructor could not be so well performed by any other. It also doubtless occurred to them, in due time, that while a moment's observation was sufficient preparation for the one service, ability in the other could only be acquired at the price of years of not immediately remunerative labor. At any rate, they abandoned the system, and so long as preparation for special work has to be marle at the expense of the individual, he must receive the increased value of the service prepared for.

A common laborer needs to know few points, and earns a dollar a day; the skilled workman must know more, and earns $\$ 3.00$ a day; the foreman nust know still more, and earns $\$ 4.00$ per day; the superintendent, who must have a far wider knowledge, earns according to the extent and importance of his business; and, in general, the compensation of personal service increases in a direct ratio with the extent 
of the accurate knowledge required for the proper discharge: of its duties; the number of facts necessary to be known by the traffic manager of a great railway system is beyond calculation; very few men possess the acuteness, tireless industry, and physical endurance, combined with the opportunity, to acquire them; in like manner, the men who have charge of the investments of the enormous accumulations and business of the great banking and insurance companies must know all the facts affecting the prosperity of almost every business, and keep constantly advised of changing conditions; consequently, positions like these command the largest salaries paid in the world.

But it must be remembered that it is information bearing specially on the subject to be dealt with, which has commercial value. The foreman of a creamery may be an accomplished astronomer, and yet be able to make no better butter. I suppose no man ever lived who knew accurately more facts than Charles Darwin, or had greater power of classifying them, and reasoning from them, but $I$ do not imagine that the information of the author of the "Origin of Species" had any great commercial value, and it is with commercial affairs that business organizations have to deal.

Of course, many considerations besides possession of knowledge affect the value of personal service, such as vigor, tact, integrity, and so on; but I think knowledge the great factor, hecause knowlerlge is the exponent of labor expended in preparation, and of industry; other qualifications are the gift of nature, and nature is bountiful. One can find natural qualifications anywhere; a navvy on the embankment may be more vigorous than the president who directs his labor from lis luxurious office.

Reflections of this kind will materially aid in forming fair estimates of the value of personal service in any capacity, whenever the employer himself knows what qualifications he requires. With the average wage of the unskilled laborer as the starting-point, and some inquiry as to the usual compensation of the quality of service desired in competitive business, and of the expenses necessary to sustain the employee with 
reasonable comfort among the people with whom he will necessarily associate, a fair idea of the commercial value of the desired service may be obtained. If the location is in a city or large town, the total expense of an ordinary family will usially be about five times the rent of a house suitable for their occupation. Any income above that can usually be laid by.

These considerations are useful as aiding to determine what a cooperative society can cijord to pay for certain service. As a matter of fact, however, the society will and shoull, like competitive employers, pay not what it can afforl to pay, but what it can get the necessary work done for. And this will be determined by the same influences which fix the prices of other commodities in the competitive market. So long as cooperation is competing with individualism, its dealings with all outsicle its own organism must be competitive.

If there is in the market a scarcity or excess of persons possessing the necessary qualifications, that will, of course, correspondingly affect the market value of their services; but assuming, as is doubtless correct, that there is no lack of natural ability, the cost of acquiring and maintaining the necessary qualifications will determine the limit below which compensation can not be reduced without impairing efficiency. The cost of acquiring the qualifications can be fairly well estimated in the light of what has been said. The cost of maintaining them is not likely to be fairly estimated as to the most important concerns, having their operating centers in large cities, by persons accustomed only to country life. Those intrusted with important interests must mingle with those in charge of similar interests, and who, in competitive business, will be paid either by salary or by profits, in accordance with their responsibility. These business associations will lead to certain social relations, all of which involves a certain expense. The cubic feet of living space, and the sunlight, without which no farmer would consider himself comfortable, will cost, in a large city, more than the net income of most small farms. The reasonable recreations, and social enjoyments, which, in the country, cost little or nothing, are a 
constant source of small expenditures, and the items of dress, fuel, and other necessary living expenses, mount to totals which would surprise farmers.

Now in a modest way the principal employees of cooperative societies must be able to enjoy reasonably what are considered to be the necessary comforts of life by the class among whom they should mingle, or they will cease to associate with that class; their general knowledge of affairs and their touch with them will become impaired, and their usefulness lessened. If they are able men they are likely to abandon cooperation for the greater prizes of competition and the society will incur the expense of constantly breaking in new men and paying for their mistakes. There will be discontent among the employees and their families, and strong temptations to dishonorable means of increasing their income. By some of these methods, any attempt of cooperation to reduce the salaries of employees below cost of acquiring and maintaining the necessary standard of efficiency, will certainly lead to trouble. If the employee is able he will not permit himself to suffer; if he lacks ability he is unfit for responsible service. Gratuitous or half-paid service of able men can be counted on but for a short time. They will soon tire of it and refuse to serve. At the same time it is unnecessary to say that all these matters should be settled in the light of common sense, and conservatism, and with no tendency whatever to extravagance or foolishness. The employees of a cooperative society can never expect to receive the financial reward open to the high grades of alility in competitive business. A large part of the compensation received by the managers of important cooperative societies must be in the respect and esteem of the community. This respect and esteem, when assured, have a commercial value of which the society may avail itself. It is doubtful if there is a lawer in the eountry who wonld refuse an appointment to the bench of the Supreme Court of the United States, although the salary is far less than those fitted for it can earn in private practice; but the honor attached to it is immense, and this consideration suffices to procure for the service the highest ability which the country affords. The 
same principle applies to the smaller affairs of life. If fidelity and ability in important positions in cooperative business are assured of the reward of public approbation, and the tenure of position made as secure as that customary in private business, a high grade of ability can be retained at a cost far less than competitive business will pay for it; but if such positions are permitted to become the reward of intrigne, and the incumbents subjected to suspicion and distrust, and no permanence of position opening the way to a career is assured, bright men will be driven from the service, the costly experience of paying for the mistakes of new men will follow, and cooperation will not be so well served as competition.

Influences to be Guarded Against.-Economists fear that cooperation on any extensive scale will be wrecked on the rocks of selfishness and jealousy. They expect their first manifestation to appear in insufficient provision for the salaried staff, coupled with such grumbling and fault-finding, if no worse, is will tend to drive capable men out of cooperation and into competition. They fear that while, at the beginning, able men, under the influence of a generous enthusiasm, may give bountiful service either freely or for less than its market value, they will soon tire of it, or will die and leave no successors, and that the management will drift into incompetence. This is predicted by those opposed to cooperation.

As good management is essential to success, and as there is at present greater personal advantage to men of ability in competitive than in cooperative service, it is necessary that important positions in cooperative service be made to approach the comfort of similar positions in competitive service, in security of tenure, and in general respect. As it stands now, no man can engage in cooperative service without falling in the esteem of many having important favors to bestow; they will distrust either his ability or his honesty, because competitive service being obviously the most desirable, men will be slow to believe that one having the ability to succeed in competitive life should for any good purpose engage in cooperation. The influences of stinginess and suspicion should therefore be avoided. 
The influence of sentiment can never be relied upon; whatever the race may sometime become, it can not now be governerl, in business affairs, by anything but selfishnessnot, of course, using the term in its offensive sense, but meaning the general desire of personal advantage. Many very estimable persons expect successful cooperation based on the idea of brotherhood. This, when analyzed, is found to mean that a few persons should do the necessary work of a community for nothing, or for less personal advantage than competitive business would afford. This analysis may not be at first apparent to some, but it is exactly what "brotherhood" in business affairs means. The influence is dangerous, for the business will not long be done except for full payment in money, as far as the necessity of the individual requires, and the remainder in honor, which has, as already stated, a market value in a good sense, as well as a bad one. Cooperation based largely on sentiment will fail.*

There will invariably be more or less intriguing for place and power in important cooperative enterprises, just as there is in political affairs, and precisely of the same clsaracter. In one cooperative society of large membership to which I belong, I note at each annual meeting the effort of tradesmen competing for its business to influence the choice of directors who may be favorable to one or the other party, and to displace those in the management whom the interfering parties deem undesirable, and I sometimes see those efforts in a measure successful. It must be expected and guarded against.

In general all influences must be considered which can be supposed to have effect upon men in charge of large interests in which, as individuals, their share is small, and who receive little or no compensation for their service. Adequate compensation either to directors or management is the most certain insurance of faithful service. Directors usually should not be paid in money, but they may be well paid in the esteem and loyalty of their associates.

\footnotetext{
* Ineidentally it may be said that a community which will on the pretense of "brotherhood" accept continuous urratuitous or insufliciently-paid service in business profitable to the community, is as despicable as any other mendicant.
} 


\section{CHAPTER VII.}

\section{THE ECONOMIC GAIN OF COOPERATION.}

T is doubtless true that the popular imagination exaggerates the possible economic gain of cooperation. The reasoning in regard to this and all other socialistic and semi-socialistic problems assumes certain conditions in the nature of mankind which do not exist. It is assumed either ( $a$ ) that mankind is moved by a desire for the general good, or $(b)$ that by legal enactment men can be made to act as if they were so moved; while, as a matter of fact, (a) mankind is moved by the desire of personal advantage, and $(b)$ no legal enactment can produce any other condition.

I have no occasion here to consider the effect of this undermining of premises upon the doctrines of pure socialism, which have been expounded with clear and perhaps unassailable logic if all the premises are accepted, but all reasoners are aware of the fatal effect upon logical edifices of any insecurity in the premised foundations. Illustrations occur everywhere. For example, all engineers know that but for one thing hot air is a far more economical and safer source of power than steam, and one of our greatest engineers, in ignorance of that one thing, devoted years of his life, and several fortmnes, to the construction of hot-air engines; the one fital defect, which experiment only could demonstrate, was the fact that under the high rate of temperature necessary, the working parts of the engine could not be constructed of iron and operated profitably, if at all. Hot-air engines of high power are therefore impossible until science shall disclose some new methods of dealing with iron, or the use of some other metal becomes economically possible. In like manner I am sure that those who have had most experience in concrete dealings with mankind in business affairs will agree that many plans of social reform which seem perfectly feasible to many 
earnest enthusiasts will be found practically unworkable until social evolution has wrought decided changes in human nature.

And yet I am convinced that, after making all allowances, there is a residuum of economic gain in cooperation quite sufficient to justify its application in many cases, and it also seems to me certain that as years go on the tendency to cooperation will increase, as the art of practicing it becomes better understood, and that it will become economically gainful over a gradually-increasing area of usefulness, all of which will be simply a manifestation of a social evolution which is leading us we know not where.

Promoters of cooperation commonly err not only in overestimating the present cooperative power of human nature, but also in overestimating the profits of competitive business. Having constantly before them the few great fortunes which have been the reward of exceptional ability, they forget the innumerable instances of failure which investigation would disclose. The so-called Bonanza mines of Nevada yielded great fortunes to a few men, but it is doubtless true that more money has been expended in the district around Mount Davidson than was ever taken out of it. It would not be difficult with sufficient study to make a fair estimate of the average profits of competitive business, and it has probably been done, although I have not met with it, but it is unquestionably true that cooperation offers no such possible field of economic gain as the popular mind pictures to itself. I have known enormous gains to cooperative societies in single seasons, as compared with the returns which competitive methods would have brought to the members, and I have known of small losses in other seasons; but it must be remembered that in the long run cooperation will have to deal with average conditions, and it will tend to solidity and permanence if those engaging in cooperation do not do so with expectations that can not be realized. It must never be forgotten that exceptional fortunes gained in competitive business are invariably the result of exceptional ability joined to the accumulating instinct, and that cooperation offers no inducement to those capable of such accumulations to engage in its service, or if in it, to devote to 
it that strenuous eflort which alone can produce snch results.

To illustrate the economie gain of cooperation let us suppose a problem which exhibits substantially an actual case. Suppose a product of twenty thousand car-loads of fruit produced by perhaps twenty-five thousand individuals in California to be distributed to the tables of say one million consumers living at an average distance of two thousand five hundred miles from the place of production. Let us eliminate from the problem the question of transportation, as not concerned with the aspect of sooperation which we are considering, and endeavor to ascertain what persons not comnected with transportation are necessarily concerned in this distribution, their proper and actual compensation, and at what points and to what extent any saving can be effected by cooperative methods, whether to the consumer or producer.

Of the above volume of fruit, part would go forwarl in a fresh state, part dried, and part canned or otherwise specially prepared. As these different forms of the product do not all follow the same channels, we shall best avoid confusion by selecting some one form, preferably dried fruits, whose distribution is widest, and in which the methods employed are the simplest. The study of this example will indicate the method which any one familiai with the facts may apply to any other industry.

A consumer desiring dried fruit will apply to his family grocer. Living, as I do, in a fruit-producing district, if I needed some variety which I do not myself produce, I should order of my grocer rather than to spend the time necessary to effect the slight saving which could be made by hunting among my neighbors till I found it. Much more would one living where the article is not produced find the help of his grocer essential. It is self-evident that the consumer can not buy direct from the distant prorlucer, and that the retailer, at least, is a necessary middleman, performing an economic function of certain value, and who can not be dispensed with.

It may, however, and often does happen that the retailer exacts a price for his necessary service in the way of such an excessive profit as tends to check consumption, and thereby 
injures the producer by restricting his market. As a matter of fact, this condition does obtain as to many products, and in California it is a subject of continual complaint among producers.

The question is, By what means, if any, can cooperative associations of producers control the retail distributive agencies as to prices charged to consumers?* This can be best understood by a brief exposition of the customary profits of retailers. The expenses of conducting a retail business probably range from ten to fifteen per cent of the gross amount of business done; the profits range from frve jer cent or less on such staples as sugar and flour, to fifty per cent and even more on certain lines of fancy groceries. I have before me a retail catalogue which gives a rate of twenty-five cents per pound on some imported goods which, I happen to know, can be deliverer in moderate lots at twelve and a half cents; there are doubtless many articles on the list with whose cost I am not acquainted, which yield an equal profit. In the ratio in which any article approaches the list of "staple" goods, in large demand, and of general sale, the retailer's profit tends to grow less. The average profit, of course, must exceed the cost of doing business, or the business must cease; every hundred dollars' worth of goods sold at less than the cost of doing business must be offset by an equal amount sold at an equal rate above such cost.

From the above it is evident that, in so far as any product can be brought into general demand, the retail profits tend to lessen, which in turn helps to extend the market. A very desirable product will, in the course of time, work its own way into consumption, as people learn about it from one another. and no undesirable product, however strongly fushed, can

* It is evident that this field, so far as it is covered by cooperation, properly belongs to cooperative societies of consumers, united to purchase supplies. 'This subject I do not wish to enter upon. It is evident, moreover, that any cooperative society of consumers is likely to be organized to escape high retail prices of any single product. If a cooperative "store" is started, it will be to secure lower prices on all ordinary supplies. I confine this discussion in the text to cooperative methods of selling. 
have a permanent sale. But any product can be pushed into sale far more rapidly by judicious advertising, and the better the article, the more certain the profit in advertising. And adrertising is any means whereby public attention is called to the product, whether by newspapers, circulars, expositions, public lectures, or any of the hundred forms whereby mankind is informed of what was before unknown. It is in this way that the thousand proprietary articles with which we are all familiar have been brought to our attention.

The special "advertising" of any product must invariably be done at the expense of the original producer, or not at all. No "middleman" of any kind will spend any money in this way, unless casually, in connection witl some private "brand" of his own. Neither can any individual, or small group of individuals, afford, at their private cost, to do any important work of this kind, whose benefits are shared by everybody in the business. Of course the indivilual efforts of thousands of producers to sell their product, constitute, in the aggregate, a large amount of advertising, but this is simply the normal "pushing" which all products inust obtain to find any sale. To rapidly introduce a new product, or one whose production is in ereasing faster than the consumption, an extra and systematic effort is required.

At this point, therefore, there is a distinct economic gain possible throngh cooperation, by enabling producers to unite for the purpose of advertising their product, pushing its sales vigorously, and finding and opening new markets.*

There are, of course, special methods of increasing markets by forcing lower retail prices, which cooperative societies may use, but they are hardly possible, or at least desirable, for

* Incidentally we may here note a difference between cooperation and socialism. The income of the average individual being fixed, all producers are struggling with each other to get the largest share of it. By as much as one's outlay is increased in one direction, it must be diminished in some other. Distributive cooperation of producers is the organization of one class for the purpose of more effectually competing with all other classes in the strife for a larger share of the purchasing fund. Socialism contemplates the abolition of all competition. It is best to keep in mind those distinctions. 
general use. By advertisements in papers of general circulation, the public may be informed of the actual cost of the product, in which case public opinion wonld cause a reduction of profits; or consignments may be made to enterprising retailers upon condition that the goods should be sold at fixed prices for a given time. Either of these remedies, however, would excite the bitter enmity of retailers, leading to strong efforts on their part to discourage sales and introduce competing goods. There is no economic gain in beginning a fight where all the odds are against the attacking party, as they would be in this case, but I often hear such methods proposed. I can conceive of them as proper only in some very exceptional case.

The retail merchant most conveniently obtains his supplies from wholesale merchants in the same line. In the case which we are considering, for illustration, the retail grocer would get his Californian-dried fruits from his wholesale grocer. It is the most popular of delusions to imagine that manufacturers or associations of producers can profitably ignore the wholesale merchant, and sell direct to retailers. In the case of California merchandise seeking eastern markets, this would evidently be impossible, except by establishing depots in the leading wholesale centers, since the difference in freights, on so long a distance, between car-load and less than car-load lots, is, and is always likely to be, more than the wholesale merchant's profit. This distribution to retailers is a measure very rarely attempted by any competitive manufacturer or produces. and probably never, except for urgent and special competitive reasons. I do not believe the present or the next generation likely to develop, in cooperative enterprises, sufficient energy and administrative ability to so control important outlying agencies in distant cities as to make them a source of profit.

But assuming the ability to manage such agencies-and it is a fact that in the particular case under discussion, the exigencies of competition between Californian and other producers may soon render them a necessity-let us consider the results to Californian producers which would follow systematic attempts to sell the retail trade from those depots. 
The first result would be the bitter and unyielding lostility of every wholesale grocer in the districts invaded. Of this there can be no doubt whatever; nor is there any doubt that the conduct of the fight on their part would be under far abler direction than that which any rewards which conperation is likely to offer will bring to the management of the cooperative side. And it is easy to see the lines on which they would conduct the contest. Their first step would be to put all their strength on any lines of goods which would best compete with the California product. These they would advertise and push by all possible means, diverting every order which cane to them, and which they could influence, to the competing article, and not hesitating a moment to sacrifice profit, or even incur small losses, in order to do so. This they would hardly feel, since their business would be sustained on their profits in other lines, while one product alone, and that not of universal consumption or necessity, must bear all the burden of the other side of the contest. The cooperative agency would be seriously handicapped. In the first place, nearly all retailers receive regular monthly visits from the traveling salesmen of many wholesale concerns, who are very certain to get most of the trade unless the cooperative agency employs the same means. Now a good salesman traveling among retailers at the east will cost $\$ 10$ a day, for salary and expense; to earn this at one-half cent a pound he must sell a ton of dried fruit per day, six days in the week, the year round, which he can not do. No single salesman traveling among retailers ever sold thirty car-loads of dried fruit in the year. Even supposing the impossible, there would be the general expenses of the agency to be added, which would certainly bring the cost of selling to retailers to at least three-fourths of a cent, which is more than the average profit of the wholesale merchant; and this is supposing impossible results from a traveling salesman. With such sales from them as it is reasonable to count upon, the cost of selling to retailers in the face of opposition and price cutting by the wholesalers, would probably be four times the ordinary wholesaler's profit.

But there is another consideration. Retailers are nearly 
all men of small means, who depend upon collections at the end of the month to pay for goorls which they have purchasel during the month; in the case of country retailers having a large trade among farmers, they have to give, and consequently to obtain, longer credit. Large numbers of them are practically "carried" by their wholesale merchants, and could not do business otherwise. It would be simply impossible for the majority to pay cash for their supplies, and those who could do so would do it only when compensated by a good reduction in price. It is impossible to solicit trade from those whom you refuse the credit customary in the trade, and those from whom trade is got most easily by those newly seeking it are invariably those whose credit is pretty well exhausted elsewhere, and the result of any systematic attempt to sell retailers direct would inevitubly be either a very small business gained at a very high price, or such a gradual accumulation of uncollectable accounts as would bury the idea of profit out of sight.

There is still another consideration. The same idea of convenience which leads the individual to buy supplies of his grocer rather than to hunt among individual producers, will lead the retailer to purchase of the wholesale merchant from whom he can order at once, not only one article but whatever he needs, to be orlered at one time, shipped at one time, handled at one time, and paid for at one time; especially if he is having hard times with his own collections, and consequently, although solvent, in need of some extra accommodation, he will be careful not to invite pressure upon himself by offending those who can press him.

From all the above it is evident that there can be 110 economic gain to a society of producers in dispensing with the services of the retail or wholesale merchant in the lines which ordinarily handle their product, or in engaging in any sort of controversy or contest with them; but on the contrary it will be most gainful to work in entire hamony with them, understanding fully that each one of them will seek to buy at the lowest possible price, and sell at those prices which in his own judgment will yield him most profit, but seeking con- 
stantly to diminish those profits by bringing the product involved into constantly more general demand, and more and more into the position of those staple articles of universal consumption upon which the least profits are made. A profit of ten per cent upon a staple and non-perishable article is entirely satisfactory to the wholesale trarle, whose expenses should not exceed five per cent upon the volume of their business.

We may now consider the necessities of the wholesale trade in the matter of buying. It is only the very largest trade, doing a business of many millions a year, and over very wide areas, who carry large stocks of all classes of goods. For the most part their needs will vary according to the extent and character of their trade, and the section of country in which they are located. To continue the illustration with which we began, a wholesaler in Galreston would desire smaller quantities of dried fruit than his competitor in Chicago, and very likely a different assortment from the merchant in Duluth. It is necessary, however, that each be able to buy what he needs, when he neerls it, and from some one who is responsible for its quality and quantity and for its delivery at the time agreed.

As no agricultural product is precisely or even substantially the same either in quantity or quality from year to year in any locality, it is evident that the goods required by the merchant in Duluth or in Galreston are not likely to be obtainable, every year, from the sime producers, or even the same producing locality. It is also evident that the distant merchant can not hunt up individuals, or they him. By some means the product scattered among individual producers must be gathered at one place, separated into its various varieties and grades, properly packed, and held ready for sale and shipment in car-load lots, either of one variety and grade, or assorted, as the demands of different merchants may require.

By competitive methods this concentration is accomplished by an army of young men who scatter through the country, visit the producers at their homes, examine the product, and in behalf of their principals, buy it, paying therefor the 
agreed price when delivered at the point where the concentration is to be made. This has the advantage of giving the producer his money at once, and the further occasional advantage - if it be an advantage - that buyers in their an $\mathrm{x}$ iety to get their supplies with the least possible trouble and expense, sometimes get to competing with each other and pay more, in individual cases, than the product is worth.

The immediate payment and closing the transaction is an unquestioned advantage to the average producer, although in the long run it must be paid for in reduced prices. For all agricultural products require the entire year for consumption, during which time they are of necessity "carried" by some one, who must in the meantime sustain all the expense and risk of storage, interest, insurance, shrinkage, and depreciation, and if, in the long rum, there is not a profit on all this, business could not continue. As to the occasional or even frequent instances where the competition of buyers causes them to pay to producers more than the market value of goods, I have only to say here that it is at least questionable whether it is ever to the advantage of an industry to have tradesmen lose money on its products. 'That this does oceur is proved by the frequent failures of the class of speculative buyers who purchase largely with no definite idea of where or when they are to sell.

But in the long run this does not occur. On the contrary, very large profits indeed are often made jossible from the fact that buyers as a class are alert, well informed, incisive, and free to buy or not as they please, while the producer must sell, and often must sell at least a portion of his crop at once, and in all other respects is ordinarily at a great disadvantage with the buyer. With the average of advantage so greatly on the side of the buyer it is not possible that the average returns to the grower should be all that they might be.

The illustration which we are considering, of California dried fruits, is perhaps an extreme instance of the disadvantage to the producer of competitive methods-a semiperishable product not in universal demand, annually increasing, as the result of undue stimulus, more rapidly than 
markets are inelined to absorb it, produced at a distance of thousands of miles from its prineipal markets, and in great part by uneconomical methods, and exposed to strong foreign and domestic competition from those with whom fruit is rather in the nature of a by produet.

Under these circumstances it was found that the dumping upon an unprepared market of such annually-increasing products within a space of sixty to ninety days led to such a large number of foreed sales at prices ruinous to the producer as involved a practical breaking down of the market. Although a few of those most farorably situaterl, and free from debt, were at least able to take in from year to year more money than they paid out, the average farmer, more or less in debt, and with insufficient capital, began gradually or rapidly to fall behind.

The local buyers, who, under the competitive system, collect and grade the product, sell to the wholesale merehant. Under the eireumstances above deseribed, it was proposed, as a remedy, that the producers themselves should collect and grade their own product, and from their own storehouses sell to the wholesale merehant in car-load lots.

There is certainly an apparent economic gain in this methorl, as it involves the elimination of, first, the expense of the buyer's visiting each farm, often many times, and, second, the service of the employers of those buyers in selling their goods. The first of these items is nearly elear gain; against the gain in the second item, lowerer, must be set the expense, whatever it might be, of those engaged in selling the goods on the part of the growers.

The greatest gain anticipated in the transaction, however, was the relief to the market arising from the fact that instead of marketing an entire crop within a few weeks, the process could be extended over some months, during which time, and by the usual business methods, the immediate necessities of the grower could be relieved by advances from banks, obtained upon the general eredit of the associated growers, and secured by the fruit in store.

There are also gains, not so readily apparent as the fore- 
going; in the first place, there is a better assurance against loss. There is no credit business without risk, and cooperative business is not entirely free from risk, but produce is usually solk in car-load lots to jobbers, for cash on inspection and delivery. With only ordinary management on the part of a cooperative society, the proceeds are nearly certain to at once reach the hands of the producer. If sold through a commission house the returns ought to be equally prompt and certain, but it is quite possible, and it is alleged to be not unfrequent in the trade, for a commission house to retain, for some time, the proceeds of a sale, and employ them to make advances on other goods, or even for spæculative purposes. Commission houses frequently fail, and, although owing to the custom of making large advances, they are seldom much indebted to farmers, yet it is a fact that the risk of loss to producers is greater in dealing through a commission house than in selling through a cooperative selling agency which ought never to buy for its own account and seldom does.*

It is also a fact that a strong and well-managed cooperative marketing society will nearly always be preferred by buyers, at equal prices, to almost any private packing-house, by reason of the greater assurance of honest packing. This is simply because it is not to the private interest of any cooperative official to pack dishonestly. Of course it is to the interest of all men to be honest, but there are many business men who do not understand this, and while the best business firms unquestionably endeavor to protect their "brands" by honest packing, yet they are not all of this class, and no one familiar with any trade will deny that frauds in packing are constantly attempted, and frequently successful. The reputation for honesty which is generally enjoyed by cooperative companies as compared with the average private company is of decided economic value.

Another economic advantage is that of associated credit.

* The strongest cooperative selling agency that I know of does upon occasion, buy produce not controlled by it, in order to prevent its owners from underselling. It has always protited by so doing thus far. 
Credit, like everything else of value, must be paid for by those who enjoy it. If the producer makes use of the credit of a commission house, in order to get advances on produce before actual sale, he must pay for it in some form, and it is entirely proper that he should. If, by cooperating with others, a joint credit is made available to those who need it, with compensating advantages to those who do not need it, there is a distinct economic gain.*

Finally, and possibly of more value than all the rest, there is a great economic gain to cooperators in the knowledge of business acquired. In California, ten years ago, producers were in dense ignorance of the process necessary to convey their products to distant consumers, of the location of important buyers, and of the methods and their cost, necessary to reach those buyers. This was true even of the most intelligent. It is still true in the sections where cooperative methods have not been introduced. The nembers of the great cooperative societies, however, are coming to be wellinformed on such matters, of the competition which they must meet, the cost, to producers, of competing products, and their qualities, as compared with their own, and in general of all the facts of which knowledge is essential to intelligent production in marketing. The value of this training can not be computed in definite amounts of money, but it is very large. The members of these societies who give ordinary attention to the cooperative business can seldom be taken advantage of in trade by anybody.

In these and similar circumstances, therefore, distinct economic gains are possible through cooperation of producers, as follows:-

* The most valuable use of associated credit that $\mathrm{I}$ know of is in the case of the cooperative loan associations common in Suxony, and spreading in other parts of Europe. In these associations the entire property of each member is liable, without reservation, for all debts of the association. Upon this credit the association issues bonds, and loans the proceeds to its members. The securities are in great favor with capitalists, and in consequence money is borrowed so cheaply that it can be reloaned to members, on mortgage, at from hree to four per cent per annum. 
1. Elimination of the expense of concentration for sale.

2. Elimination of expense of any local intermediary between producers and wholesale merchants.

3. Elimination, to a great extent, of the necessity for forced sales.

4. Better insurance against loss.

5. "Good will" of business arising from assurance of honesty.

6. Associated credit.

7. Business education acquired.

The saving under the first two heads, although unquestioned, is not large. If, instead of downright sales to local buyers, it is preferred to use them as commission agents selling to wholesale merchants, all the service required for concentration of product and local service in selling in the trade taken as an example, can be obtained for about two and one-half per cent of the receipts for goods sold. The actual cost of all the local service required by cooperative methods will of course vary partly by the amount involved, and much more by the personal equation of the management. It should not exceed one per cent, but as a matter of fact will vary from three-fourths of one per cent to one and one-half per cent. Even this slight saving, if applied to the entire product of a large state, would be well worth distributing. Upon the total fruit and fruit product output of California it would amount to about a quarter of a million dollars annually.

But the most important gain arises from the elimination of forced sales, and the deliberate marketing of the product in the light of the full information as to its value which grarlually becomes disseminated during the marketing season. The amount of the gain to the producer can of course never be known, or even estimated with much approach to accuracy. It will vary greatly in different industries and different localities, and in different seasons in the same locality and industry, but I do not think any one familiar with the conditions of the Californian industry taken as an illustration would estimate the probable gain, if all producers were cooperatively united, at less than ten per cent, or that following the organ- 
ization of any reasonable number at less than five per cent. The possible gain would diminish as the locality of the producers should approach nearer to the great markets of the world, inducing more competition among buyers and better information among producers.

In opposition to this conclusion, some, and possibly most economists would insist that natural selection would attract to trade those best qualified to conduct it, and that competition among them would enable producers to obtain their services at the lowest rate at which they could live and prosper, and that any attempt to interfere with the regular operation of these economic forces will in the long run be futile, and in so far as temprary success might seem to be achieved, investigation would certainly disclose real economic loss.

To follow this discussion far in this direction would certainly make these pages too technical for popular reading, and would moreover involve the study of data as yet uncollected, so far as I know, and unavailable. The situation of the industry mentioned as above given correctly, unquestionably shows the possibility of economic gain. The argument opposed to it is based upon the law of natural selection as applied to human effort. Perhaps the best rejoinder that can be made in general terms is that from the foundation of the world the progress of man has been a series of struggles with nature-including his own nature-and that no man can yet say that the evolution of the race does not tend towards forms of life wherein cooperative effort slall take the place of competitive struggle.

There is another matter which is perhaps best considered in this connection, which is the moral gain under cooperative methods. Without argument I shall assume that any established and continued moral gain in the management of any industry inevitably carries with it a corresponding economic gain. Returning to our illustration we find the facts to be these: the increasing output of fruits of California has developed under competitive methods such an annually-increasing distrust of values as to, in some branches, almost entirely destroy the local market which I have been assuming, and 
which can always be relied upon, in àny industry when the demand equals or exceeds the supply. When, as in the case in question, the supply has outrun immediate demand, buyers refuse to take the product in quantities sufficient to relieve the producer, but offer, instead, to act as commission merchants in its sale.

This introduces an entirely new element. The farmer, unaccustomed to business, and with no means of distinguishing between honest and responsible, and dishonest and irresponsible men, is practically compelled to put his product for sale into the hands of those who may be entire strangers to him, and who have no settled place of business within his reach.

Sucl a state of things is a direct temptation to dishonesty, and the possibility of dishonesty with small likelihood of punishment or even public exposure, is as. certain to attract those disposed to dishonesty as sugar is to attract flies. This results in drawing to the commission business, among many as honorable and trustworthy persons as can be found anywhere in business, an undue proportion of the dishonest and contemptible. An observation of some years convinces me that a large number of those engaged in the produce commission business really merit the unenviable reputation they have among producers, and from which even the most upright conduct of many individuals is unable to relieve them. The consequence has been an immense amount of friction between producers and those who should be their confidential and friendly agents, leading to a profound dislike and distrust of the entire class of commission merchants, honest as well as dishonest; and there is no question that the amount of dishonesty and trickery practised by those among them who have that disposition, while by no means so great as is popularly supposed, is really sufficient to cause serious loss to the class of producers, and consequently to demand remedy. The standard of honor among commission men is certainly far lower than the proper conduct of business requires, and lower than among merchants who buy and sell upon their own account. 
It would be easy to show in detail just how this distrust and dislike on the part of producers, even if not justified, would lead to economic loss, much more when there is a certain amount of foundation for it. But I assume that the consequence is as patent to others as to myself. All this is completely done away with by cooperation on the part of producers, although, as has already been pointed out, its place is to too great an extent taken by distrust of their own salaried agents. But, on the whole, as the motive and the opportunity for dishonesty will be far less in the latter case, so, also, on the whole, will the reality be less, as well as the distrust. I am convinced that there is in cooperation a decided balance of moral gain under such circumstances as have been described, and that it leads to a distinct economic gain which exists none the less that it can not be computed and set down in figures.

There is, however, a word of caution which must not be omitted. There can be no economic gain unless there is forthcoming a volume of business sufficient to warrant the fixed expenses necessary to transact it. A small neighborhood association can seldom profitably attempt to sell in distant markets, because the cost of securing and maintaining the necessary business comnections, when spread over a small volume of business, will make the cost to individuals too great. Such associations can secure the gain of concentration but must sell to local buyers, or through some other agency. The tendency of modern business is into concentration in trusts. This tendency is reaching the farmers and must ultimately prevail with them as with others.*

* During the season of 1898 , the raisin-growers of California perfected and maintained through the year an effective trust controlling about ninety per eent of the output. The trust was for one year only, and as these lines are written they are endeavoring to renew it for two years, and the prune-growers of the state are attempting to form a similar trust. The grape-growers of New York and Ohio maintained a similar trust during the same season. The California walnut-growers have a trust, and the orange-growers ulso, except that the latter has never yet been able to control a sufficient portion of the output to make it effective. These trusts are not yet as effective as the great mercantile trusts, but the farmers are learning. 
It should be apparent from the foregoing that there can be no economic gain to cooperative associations of producers in dispensing with the services of wholesale and retail merchants, or in any attempt to directly control prices at which they shall sell the goods for which they have paid their money, but that, on the contrary, loss is almost sure to follow such attempts. It seems also clear that cooperation does offer opportunity for gain within reach of such reasonable ability and persistence as onght to be available in concentrating and grading the product for the market.

It remains to examine the manner in which the concentrated and graded product in the hands of associated producers can be best sold and delivered to the wholesale merchant; and in this I shall assume that the product is to go direct from the warehouse of the producers to those of the wholesale merchants. Those warehouses may be situated near the point of production, or, if the market is distant, and competition compels, they may be in the principal marketing centers. I have already stated that I do not believe cooperative organization equal to the strain of maintaining and profitably supervising distant warehouses from which goods can be sold in small lots, and under conditions which retailers would require, but it is possible, although to be aroided unless compelled by competition, to simply arrange for sales for cash only in such considerable but less than car-load lots as wholesale merchant; can use.* .

The product must be brought to the attention of the wholesale merchant by solicitation. Farmers sometimes appear to suppose that merchants go out and canvass the market for their supplies. They do not. They sit in their offices and

* It may be said that it is always unwise to refuse to sell to any one, either wholesaler or retailer, who offers to pay in cash the price asked for the goods offered. The price of ear-load lots of any product, however, must ulways be less than the price of small lots of the same goods, and the wholesale merchant whose aggregate annual purchases may be many car-londs, may always with propriety buy at the same price such smaller lots as he may from time to time need to complete his assortment; while an oceasional customer, whether wholesale or retail, buying a small lot, would expect to pay a higher price. 
buy from samples which are brought to them. ()f course, if for any product there is a large demand and small supply, merchants will hunt for it; but I know of no such agricultural product, and if there be one, its producers are not interested in cooperation, which, as has already been said, is seldom undertaken by those who readily find profitable sale for their products without it.

An association of producers, therefore, having collected its product, and prepared it for market, has only one thing to do, which is to obtain a list of wholesale customers-of whom there are but a few hundred in the country in any lineadvertise their goods, either by circulars or newspapers, and then cause each customer to be regularly and persistently solicited for orders. There is absolutely nothing more to the selling of goods than this. It is, however, a matter of infinite detail, requiring, in any considerable business, the unremitting attention and effort of very capable men, not only to obtain the orders, but to fill them with such promptness and entire honesty as to retain customers when secured.*

The necessary solicitation must be done by one of two classes of men-brokers, or salaried traveling agents. Brokers are men usually of some standing and responsibility, not usually-but sometimes-having a "store," † but living by the sale of commodities to merchants for a commission usually paid by the seller. Of course, brokers are often employed to buy goods, in which case they act for the buyer, and are paid by him, and have regard to his interests only; while the broker paid by the seller is bound mainly to consider his interests, although, as a matter of fact, since his income depends upon actual sales made, his tendency, from various causes, in case of disagreement as to price, is rather to induce sellers to lower

* For the benefit of cooperative societies, I will say that they will have little trouble in finding managers who know how to do these things, but there will be very great trouble indeed in finding those who will actually do them. Attention to detail, not knowledge of principles, is the test of the business man, and it is this labor which breaks men down.

† A broker with a "store" is a commission merchant. The two clasges merge into each other. 
their price than to get buyers to raise their offers. Brokers endeavor to represent as many interests as possible, so that if a possible customer does not need one thing, he may sell him another. They also like to represent as many persons as possible in the same line, so that if, for any reason, one seller will not accept offer's which he can obtain, another one may. His first and last desire is to make sales. The brokerage or commission paid to him by sellers varies according to the commodity; the better known and more staple the article, the easier sales will be made and the smaller the brokerage. Upon dried fruits, which I have used for an illustration, brokerage upon orders passing direct from the seller's warehouse to merchants, range from one and one-half, or even one per cent, to two and one-half per cent. If, however, the goods are shipped to them, as commission merchants, stored, insured, and disposed of in broken lots, their brokerage may be as high as five per cent. Upon the average, two and onehalf per cent must be reckoned upon. Tliere is never any advantage in so reducing rates of brokerage on competitive articles that the broker can make no money on them. The broker will be compelled to neglect them and lay out his strength on what pays him better.

The other class of solicitors is traveling salesmen. The advantage of this class is that they are wholly in their employer's interest, with nothing to distract their attention. Their disadvantage is - in the wholesale trade-that they can see their customers but seldom, while the resident broker can see them almost daily, and they also cost more money. W'hen the broker is not selling goods he is costing lis employer nothing, while the salary and expense of the traveling salesman go on every day. In some lines, however, travelers are doubtless the most profitable. Whether they are ever so in the lines in which cooperative societies of producers are interested is more than doubtful. It is not difficult to make a comparison, once more recurring to the dried-fruit trade for an example. The average value of a car-load of dried fruit may be placed at $\$ 1,000$, upon which the hrokerage at two and one half per cent would be $\$ 25 . \Lambda$ capable and experienced salesman, 
strong enough and sufficiently informed to interest and hold the able men engaged in wholesale merehandising, will command say $\$ 200$ per month. His expenses, traveling long distanees between principal cities, will not be less than $\$ 150$ per month, making $\$ 350$ per month in all. He will, therefore, have to sell a car-load of fruit of the average value of $\$ 1,000$ every other day from the time he leares home until he returns, in order to make his salary and expenses less than two and one half per cent of the value of goods sold. While this result would unquestionably be achieved in some months and by some men, it ean not be connted upon, and would usually not happen. Especially it is true that cooperative societis are not likely to employ men capable of doing such work. There are more salesmen sent out by such societies who come home with few or no sales than of those who can earn their cost out of a reasonable commission. It is very difficult for the very best men, in the face of constant competition from brokers and others, to earn their cost by selling any one article. It is therefore unquestionably safest for cooperative societies to follow the usual eustom of the trade in employing brokers rather than traveling salesmen. Of course a good brokerage system requires a certain amount of traveling supervision, to keep in touch with the brokers and with the market, but one trip a year among them is ample for this, and the allowance for brokerage which I have made, should fully cover that expense in a large business.

Whichever method is employed there is no possible gain to cooperation as compared with competitive business in this operation. Whether the product be collected by local operators, or by cooperative societies, the methods of reaching the wholesale trade will necessarily be the same, and involve the same expense.

An economic gain, therefore, possible to producers by cooperative methods, is confined to the initial stages of the progress of the product to market.

Having thus followed out in detail the application of cooperative methods of distribution to one product produced at a great distance from its principal markets, any one by apply- 
ing the same analytic method to the known facts and conditions of any other industry in which he may be interested, and taking into consideration the special infirmities of human nature which have been pointed out, can very well judge whether, and to what extent, cooperative effort in distribution is likely to lead to economic gain. My own conclusion is that under some circumstances, and in some industries, economic gain may be expected from cooperative methods applied to the entire progress of the product from the hands of the producer to the wholesale merchant; in other cases, the entire possible gain will be achieved by confining those methods to the initial stages of the work, that is, the concentration, leaving the actual distribution to be effected by competitive methods; in still other cases perhaps competition unhampered can best do the work. It depends upon the facts in each case. Human nature will be found very much the same everywhere.*

One thing is certain: cooperation based entirely on sentiment offers no hope of economic gain. It will be mismanaged and will probably fail. It must be a business organization, based and conducted on business principles, expecting no unpaid or half-paid service of any value, but always ready to compete in the market for such talent and labor as it needs, and not expecting to secure able management for any less compensation than the same ability can obtain in competitive service. All hope of economic gain depends on this; for it is on industrious and intelligent attention to detail that the success of either cooperative or competitive business depends, and this attention can only be continuously obtained by the expectation and enjoyment of adequate reward.

* The possibilities of societies of cooperative purchasers, that is, eooperative "stores," reaching ont to obtain their supplies from cooperative societies of producers, which are often alluded to, I purposely pass over, because they are merely possibilities. It would, of course, form the next step in the social evolution which is the dream of many. I think, however, that an assoeiated society of small purchasers would be hard customers to sell to, and that they would find societies of producers the worst possible lot to buy from. They would doubtless agree in the desire to erowd out the "middleman," but each side would expect ull the profit of the transuction. Of course $n$ cooperative store would take the place of any other retailer in distribution. 


\section{CHAPTER VIII.}

\section{ALTRUISM IN COOPERATION.}

\section{LTRUISM means regard for others. It is the key-note of A the exhortations of many advocates of practical cooper-}

1 ation. We should cooperate because public welfare demands it. An earnest worker in practical cooperation once wrote me that he had no faith in the success of any cooperative movement not inspired and sustained by the altruistic spirit. For myself I must confess that when observing the inception and conduct of cooperative business enterprises, I have never yet been able to think clearly enough to settle to my own satisfaction the degree in which altruism contributed to results. The philosopher says truly that we can not contemplate any joint action of one's self with another for a common purpose without having regard for the welfare of that other, which is altruism. However true this is, it is not satisfying. The question is, What is the motive which impels one to act? I liave personally observed some hundreds of men sign subscriptions to the stock of cooperative societies, and participated in the conversations which preceded that act. In all these conversations, I presume, the public benefit to accrue was made prominent, and in a great many it was the motive avowed as the leading one which induced signature. I seldom believed it to be the real motive, although in some cases there could be little doubt of it. I have never been able to analyze even my own motives in joining such societies, and in promoting them. Certainly I never joined one without seeing in the act a distinct personal advantage to myself, and yet reason told me that if I wished to exert myself in the proposed lines of trade, it would be more profitable to employ my business experience and vigor in exploiting the more ignorant than in aiding them to resist exploitation. It happened that I had no such wish, so that in joining them I was 
merely giving up something for which I had no desire, in the prospect of getting something which I might enjoy. I do not care to imply that I have no altruism in my make-up, for I suppose myself to be an average man in that respect, but merely to avow that I can not say that I think altruism could have prevailed against strong self-interest. Had I wished to engage in dealing in the commodities which we were organizing to market independently of dealers, I am quite sure I should have not become a cooperator. My judgment of my own motives corresponds precisely with my judgment of the motives of others, and the number of those whom I have observed in the act of joining cooperative societies has been large enough to afford a very fair foundation to generalize upon. In a few cases the force of altruism was probably paramount. In a very few it was probably entirely lacking. In some instances it was merely the temporary yielding of a weak will to a stronger one. With the majority I am convinced that the controlling motive was self-interest, more or less aided by altruism and other motives which do not concern this discussion. At any rate, the conclusion I have reached is that the altruistic spirit affords no safe foundation upon which to erect a business enterprise. It is a noble spirit, and it is powerful in the affairs of men. But it is not business. And upon the whole I am constrained to doubt whether it is desirable that acts intended to increase our aggregate of economic satisfactions should spring from motives which in any great degree ignore that object, and are even, possibly, nore or less contradictory to it. It does not seem to me that results will be so good, or the aggregate of satisfactions attained for equitable distribution so large. As stated in previons chapters of this book, it has not been my observation that altruism is a reliable thing to build up a business upon. While, happily, no man is entirely without altruism, with the average man these emotiona impulses are not persistent, and the impulse which moves a business enterprise must never fail.

There is an unquestioned field for altruism in cooperation, but it seems to me that its most effective use will be in the promotion of the cooperative work at the hands of those who 
are for the time being independent of it. A notable instance of this is the promotion of cooperation among the Irish peasantry by a society of wealthy men and women. This society raised funds, printed and distributed documents, employed traveling lecturers, counseled with newly-formed associations, and in all ways sought-and is still seeking-to promote cooperation, especially in dairying, among the Irish peasantry. The society has been successful aud is accomplishing great good. The motives of its members are purely altruistic. They seek the good of the people. But the object which they hold out to induce cooperation is not the good of Ireland, but the welfare of the individual cooperators. That is an entirely legitimate motive, and it seems to me the proper one in this case. No one can appreciate the altruistic spirit more profoundly than I, or have higher regard for the many who are unquestionably dominated by it; but I have never seen it mix well with business. On the contrary, it is apt to mix very badly. There is an innate suspicion of those who avow an altruistic motive for what they expect to profit by. To promote our own welfare is not sordid or ignoble. It is what we are here for. It seems to me best to clain no higher motive for cooperation than the material advantage of the cooperator. Doubtless there are many populations, like those of Ireland, and, doubtless, some parts of America, where there is a great fielı for an altruistic propaganda of cooperation on the part of those who are perhaps not engaged in the industry which it is proposed to organize; but among the intelligent farmers of the United States it seems to me best that they should say to each other, "Let us do this because it will pay us."

I say this while perfectly aware that some of the most successful cooperative enterprises in the world are avowedly based on the fraternal spirit. The great British cooperative stores do an immense amount of work for the moral as well as the material welfare of their members, and the literature which they distribute is highly altruistic in tone. It doubtless helps to hold their membership more strongly. But, after all, it is the benefit to the individual that is made most prominent. The great life-insurance secret societies are unquestionably 
made possible only by the spirit of fraternity which is cultivated in the lodges. But life insurance itself is essentially altruistic, and even in these societies it is the expectation of benefit to one's immediate family, and not the welfare of mankind, which holds the lodges together. And mankind is benefited just the same, as it will also be by successful cooperation among all classes.

Of course I do not belittle the influence of the fraternal spirit, which waturally grows up among those associated for a common purpose, nor would I fail to make use of it, as the British cooperative stores and the life-insurance societies do, but I think that the avowed motive of all business action should be the economic advantage of those concerned in it. It may properly be promoted, and helped through its infancy, by unremunerated work contributed from altruistic motives, but a cooperative enterprise when once established should be run on business principles. Its directors may, and ustually will, contribute their time, except in very large societies, but beyond that the society should expect no gifts. When the sense of mutual advantage will not hold the members of a society together, it is usually an indication that they have not yet been sufficiently disciplined by disastrous competition. They need a few seasons more and should have it. When they have been reduced to the necessary distress they will cooperate. Until that time they can not, so far as my observation goes, be held together by their love of other people. It would be well if they could, but they can not. The logical end of cooperation is the formation of an effective trust. Whatever stops short of that is by so much the less effective. The same economic pressure which resulted in the formation of the Sugar Trust also resulted in the formation of the liaisin Trust of the California raisin-growers, which has been in existence for a year as I write, and may or may not be permanent. The motives of those who united in it were identical with those who united in the Sugar Trust. A much larger number of individuals were concerned, and they were enduring a far greater degree of suffering than is likely to befall a body of capitalists or manufacturers, but it secms to 
me that the result in each case was produced by the same economic law, and it was not the law of altruism. In the case of the Raisin Trust there can be no doubt that to a considerable extent it was promoted, from altruistic motives, by those who expect no direct personal profit. The function of altruism in cooperation seems to me to be that of inducing other people to act according to their own best interests. And it is doubtless a noble object. 


\section{CHAPTER IX.}

SOME FARMERS' ORGANIZATIONS.

$7 \mathrm{HE}$ organization of farmers in the United States is proceeding on lines materially different from those in which it is proceeding elsewhere, but it must not be supposed that the causes which are forcing farmers together in the United States are not equally strong elsewhere. The details of the working of the societies of farmers are difficult to obtain. Publications of such societies in this country have hitherto been largely rluetorical in their character and often give a better idea of what the members think ought to be done, than of what they are actually doing. There is naturally some lack of statistical skill, and more lack of money to pay for printing. The daily press, the great purveyor of news, seldom deals with the subject. The farmers of all nations, however, are beginning to organize, each according to the national character, and the circumstances of the people. If we knew nothing of the actual facts, we should still know that organization is in progress, or will soon begin among the farmers of all civilized nations, because we know that everywhere the forces are at work which compel organization. We also may know that whatever form organization may take among the farmers of any country, it will be very uneven in its progress. It may sweep like wild-fire over a certain district for a season, and in a year or two there may be hardly a visible sign of organization. It is eertain, however, that the process is going on among farmers, as among other classes. There are no reliable statistics, for there is a constant succession of societies organizing and disbanding.* $A$ few years

* (Of a list of farmers' marketing socjeties of California, compiled by myself, some three years since, for the U.S. Interstate Commerce Commission, nearly half were out of existence before the list was published, and yet the volume of cooperative business done in that state was last year larger, probably by a million dollars, than in any previous year. 
since the number of farmers' purchasing organizations in France was said to exceed six thousand. A year or two later they were reported to have greatly fallen off in number. In northern Europe the farmers' organizations are mainly connected with dairying. In Germany their most prominent form seems to have been that of associations-not composed entirely of farmers-for borrowing money at low rates. In all these countries the govermments exercise some control. In Ireland, cooperation among the peasantry is being systematically promoted by altruistic methods. In England there have been similar efforts less successful. These general statements may give some idea of the manner in which similar causes are everywhere tending to produce similar results. While few reliable statistics-official or unofficial-are attainable, it is possible for all governments, when taking a census, to ascertain the volume of cooperative business done, and the total membership of farmers' societies. A comparison of the figures with those of the same schedule of the following census would show very clearly the trend of rural society.

The organization of farmers in the United States has proceeded upon lines peculiar to this country. Its most prominent feature has been the use of the fraternal principle in the organization of friendly societies, usually lıaving a secret ritual, and invariably, I think, open to men, women, and youths.

Of these societies the oldest and most influential is the secret* order of Patrons of IIusbandry, commonly known as the "Grange." This society, so far as I know, was the first society of farmers to be planned and organized on a national scale, as it was also the first secret society to admit women to full membership upon equal terms with men. It was organized, in 1866 , by conservative men, of broad views, for the

* Secret mainly in the sense that it has a secret ritual, not guarded with much care, and "passwords" changed at regular intervals. There is an economic reason for this in that it is practically the only method by which the trifling dues required for little expenses can be regularly collected. The same may be said of other farmers' so-called secret societies. It may be proper to say that I am a member of the Grange, and for a short time belonged to the Farmers' Alliance. 
time, and was designed to be, as in the main it has finally become, simply a fraternal society for enriching the social life of rural people, broadening their views of eeonomic questions, and uniting them in all efforts for the local, state, and national welfare. It is, and always has been, kept strictly non-partisan in political matters, carrying the rule, possibly, to extremes in discouraging, in the Granges, discussion even on some vital economic topics-such, for example, as the tariff-on which the people are divided sharply by party lines. While this extreme care sometimes appears unfortunate in preventing temperate discussion of such subjects in subordinate Granges, it probably, after all, has been the main source of strength of the Order, and is its strongest assurance of permanence. It is being constantly made manifest that in this country, at least, any endeavor to exert political influence by the control of party organization, will result, if persisted in, in the death of the secret society attempting it.

While the Grange was organized by conservative men, substantially on the lines as above set forth, it would have been impossible, at that time, for the order to have lived on those lines. In very few eommunities, at that time, would it have been possible to have secured the regular attendance of farmers in assemblies for reereation and mutual improvement. The order struggled along, and was apparently abont to die, until the organizing force reached the central Mississippi Valley. They found there, among the farmers, a condition of social discontent which was particularly favorable to the spread of a new order whose object was the removal of the ills of the farmer. The order as it existed, however, did not answer the purpose. A proposal to study the eauses of evil did not appeal strongly to those who wished to remove the evils first and diseuss them later. Energetie men of the west saw, as they thought, in the Crange, the means of an immediate reconstruction of rural society by the abolition of the middleman. The principle of buying together and selling together was engrafted on the orler, and made its ehicf eornerstone. This was wholly against the judgment of the founders, and only accepted by them because the only alternative was 
evidently the death of the order, involving not only the mortification of failure, but serious pecuniary loss to some who had advanced money for the expenses of starting it. Under the stimulus of the new idea the Grange began to grow and speedily overrum all the northern states. As it grew, eooperative stores were established everywhere, as well as manufacturing and other business enterprises. Nearly all these were in the lıands of men entirely unskilled in the business which they were to conduct, and to a very large extent were established and carried on upon credit. Complete failure, of course, was the inevitable result in nearly every case, involving great individual losses, and very nearly the death of the order.

But, while carrying out the principles of cooperative trading, the Grange also took up the doctrine of the control of the railroads by government authority. Railroad management in those days was entirely arbitrary, and as a necessary consequence, harsh and op ressive. The Grange adopted the doctrine that the state liad the right to regulate fares and freight rates on all railroads, and under the impulse of the Grange movement, and mainly by the influence of the Grange, state laws were passed in several of the western states, prescribing maximum rates for freight and passenger service. The power to do anything of the kind was disputed by the railroals, and the cases were carried to the Supreme Court of the United States. The Grange won, and in so doing established forerer the inestimably valuable principle that no quasi-public corporation can escape legitimate regulation by the authority which created it. Of course this doctrine, being sound and just, was certain, in due time, to be recognized and established. None the less is credit due to the agency by which the work was actually done, and this agency was the Grange. The cases in which the doctrine was finally established in the United States, are universally known and referred to as the "Granger cases," and constitute the first grand triumph of organized rural society.

This great political triumph, however, did not come in time to save the Grange from the consequence of its egregious 
economic errors in attempting to do business without capital and without experience. As a result of its failures in trade, and the widely-distributed losses which followed, the Grange nearly died. Its very errors, howerer, had been its salvation. Without the impetus given by unfounded hopes, it could not, at that time, have acquired the strength and influence which numbers give. Among the million and a half members which the order at one time possessed, there were enough who could appreciate the value of the original conception, or who had become attached to it by the ties of sentiment, to keep it alive, and, although its membership fell off and the majority of subordinate Granges went out of existence, it did not die. In due time it began to grow again, this time on the original conservative lines, until to-day it is far more useful and powerful than ever, and seems certain to continually increase its usefulness.

The Grange, like all other organizations, has just so much moral force as there is reason in the doctrines which it arows. Its effective force varies with the character of its membership. The National Grange las always been distinguished for the dignity and wisdom of its publisher deliverances. Some State Granges have consistently sustained this character, and some have not. To a greater degree this is true of subordinate Granges.* The discipline of this order, however, prevents its name from being used in furtherance of any object of national importance not indorsed by the National Grange. A subordinate Grange is useful in local affairs. These are usually well understood by the membership, and Grange influence is certain to be used wisely. Whether it is used effectively depends upon the executive ability of the membership. If there are, in any subordinate Grange, a number of persons who know how to make things liappen, it will be exceedingly useful to the community in which it exists. The same may be said of State Granges in the smaller states,

* The masters of State Granges are of eourse eleeted by the Grange. These, with their wives (or husbands), constitute the State Grange. The masters of the State Granges, with their wives (or husbands), make up the National Grange. The National Grange, therefore, is a very select body. 
where rural interests are homogeneous, and where a comparatively dense population conduces to large and regular attendance, with corresponding opportunities for discussion before action. In the larger and newer states, in which rural interests are more or less diverse, where there is less intercourse between farmers, in or out of the Grange, and where a prevalent speculative spirit has warped the judgment of the people, there seems less ability to get the full grasp of all sirles of practical economic subjects, which is an essential prerequisite to wise decision. In the nature of things this condition will improve.

The presence of woman in the Grange is of the utmost value. Without woman it is quite safe to say there could be no Grange. They bring to the order the social and recreative element of which rural people stand in most need. They have not aiways the training or the temperament suitable for wise discussion of economic questions which directly involve their domestic interests, but they seldom attempt to discuss them, and usually vote with their husbands. But they keep the Grange in existence, which men alone would never do. The ritual of the Grange is well conceiver and well written. When well rendered it is very pleasing. It is not always well rendered, but there is no doubt that the use of a ritual, and the observance of the little ceremonies which are used in friendly societies, is of great value in accustoming those whose environment is sometimes rude, to the trifling courtesies which make social intercourse agreeable. There are a few who object to the Grange because of its "secrecy." I can not, myself, however, understand how any one can object to a mere promise not to tell a few things of no earthly consequence in themselves, and which have been found essential to the permanence of the society. There is no record of the survival of any important society of farmers for promoting local and general welfare, except upon the principle of "fraternity" as exemplified in a friendly society. The friendly society, with its ritual, has proved, by survival in many forms, that it is adapted to the nature of mankind. When other societies of general membership are formed, they die. Farmers must probably 
understand that their choice must be between a society of this kind or no organization for edncational and social purposes.

The "Farmers' Alliance and Industrial Union," in its present form, grew out of the amalgamation of a number of societies of farmers, ${ }^{*}$ which grew up as the result of the Grange movement. They were nearly all, I think, started during the wave of excitement which accompanied the triumphant progress of the Grange, and, in the main, represented the most "radical" element of the farmers. A "radical" is one who has mastered but one side of a question. $\dagger$ The founders of all these societies were very much in earnest, and believed that reforms could come, in a free country, only by means of political action. 'The proposal of the Farmers' Alliance and Industrial Union, therefore, was to bring pressure to bear upon existing political parties, and, failing of results there, to organize a political party of their own. The result, as is well known, was the organization of a new party. The regulations of the Farmers' Alliance are as strictly non-partisan as those of the Grange. In practice it was, during its years of greatest success, a secret political organization. If, as was seldom the case, some overscrupulous member objected to "political" discussion, it was easy to close the meeting of the "Alliance," open

*Among these were the "Agrieultural Wheel," founded about 1876; the "Farmers' Alliance," founded in 1873; another "Farmers' Alliance," founded in Texas; the "Farmers' Union," founded in 1887; and perhaps others. A final amalgamation of all these societies was effected in 1889 , under the name of the "Farmers' Alliance and Industrial Union." At one time its membership was said to be nearly $3,000,000$.

$\dagger$ There are at least two sides to all questions, and those who have fully comprehended what can be said on all sides of a subject, are apt to be much less positive in their opinions than those who have studied but one side. It is the radieals, however, who are the cause of most reforms. They usually get less than they ask, beeause they ask too mueh, but it is their work which gets something to be done.

‡ This is true so far as my experience goes. I have always made it a rule to "join" any local soeiety which would bring the neighbors of my community together for any purpose. When the Alliance fever reaclied us, I "joined" with the rest. There was nothing in its declaration of principles which I could not approve. I did not approve its practice as it then was in our state. 
the doors, and proceed with the discussion of what really interested those present. 'The Farmers' Alliance has been, and sliould continue to be, a very useful body. It has manifested far more energy than the Grange has of late years, resembling the Grange in its early days, when it was marching from one victory to another. Its tendency must be to lose some of its effective force as its members become more familiar with the difficulties attending some of the subjects with which it deals. It has created a national party, to which most of its members probably belong. It has, however, lost its initial enthusiasm, which it can never regain. Its membership has fallen off, just as that of the Grange fell off, after its first flush of success. In the case of the Alliance there was the additional disadvantage of its dealings with practical politics, which will, and should destroy any secret society. It is probable that this is now disappearing from the meetings of the Alliances. But where it has a hold, its organization should be maintained. While I am unable to accept all the economic theories of the Alliance, I fully recognize the value of the social and educational work which it has done, and may do, and have no fear of the outcome of discussion. If the more radical doctrines of the Farmers' Alliance are right, we shall all of us, in the end, become convinced. If they are wrong, they will, in the end, be abandoned by those who now hold them. The educational and social work of the Alliance is identical with that of the Grange. Its opportunities for useful influence in local affairs are also the same as those of the Grange, and are as certain to be wisely used. If its membership can become satisfied to exert their political influence wholly through other channels, its doors will become open to those who differ with the majority of the members upon some things, which is the best thing which could happen. In most matters the Grange and the Alliance can heartily work together, and exert their combined influence for the welfare of husbandry. When farmers have organized, they should never let go their organization.

Farmers' clubs are later forms of organization, differing from the ritualistic societies in that their meetings are open, and that no particular stress is laid upon the principle of 
"fraternity," which is one of the corner-stones of all secret organizations. There can be no question of the effectiveness of farmers' clubs as educating influences. They can do some things to better advantage than any secret society. It seems difficult, however, to devise any bond of union by which their united influence can be exerted in state and national affairs. Certainly there could be a state and national organization of farmers' clubs, just as there is of political clubs, but the lack of any rule of discipline common to all would be quite sure to result in efforts to commit the organization to action on controverted topics, which in turn would lead to disruption. The freedom of the meetings of the clubs would render this the more certain to be attempted, and the more likely to succeed. If this rock were escaped there would be that of the lack of revenue. No society, secret or non-secret, can make its influence felt outside the circle of its habitual attendants, except by the expenditure of money. I am a member of one farmers' club, and familiar with several. None of them have any revenue of consequence, and the general opinion is that any serious attempt to raise it from the membership would merely break up the clubs. Some clubs which have a large nominal nembership find themselves entirely unable to contribute to the small expenses without which no popular movement ean make any progress. The early meetings of farmers' clubs are likely to be well attended and interesting. After a time the regular attendants who can taik or write have said to each other about what they have to say; there is no ritual to occupy a little time; no "initiations" to prepare for and earry through; there is seldom the fraternal feeling which, in a hearty rural community, is apt to find expression in the loaded boards of the "Harvest Feast," which invariably brings out the membership; there are no "communications" from superior authorities suggesting discussion or action for the common weal; there are no visits from state or national officers to renew interest and inspire to effort. In the absence of all these the tendency is for the attendance at farmers' clubs to gradually fall off, until the local press no longer deems them worthy of attention, for dues to become delinquent, and 
the club to pass out of existence. When this does not happen it is usually because some one provides work to do in which the club is interested. Some local improvement or business organization fostered and promoted by a club will maintain interest. There are some working clubs. They are more apt than secret societies to provide "club rooms" for their members, where agricultural books and papers can be found for reference, and where farmers' wives and daughters can rest and "freshen up" after a dusty ride to town. Where a revenue can be had for the purpose-and it takes very little-the club is likely to become a valuable center of influence. It is a valuable form of organization, doubtless capable of accomplishing anything which a friendly society can accomplish, but, considering the notions of mankind, and especially farmers, perhaps not so likely to do so. It will depend upon the community, but I think there are many more rural communities that can permanently sustain a Grange or an Alliance than will be found to keep up an effective farmers' club.

The foregoing covers the forms of farmers' organizations other than those for actually transacting business, that are most common in the United States. Business organizations of farmers include marketing societies, cooperative creameries, irrigating companies, and doubtless other business organizations* which have not come under my observation. The principles which should govern the formation and management of these companies have been sufficiently discussed in the preceding chapters of this book.

\footnotetext{
* In 1898 the U. S. Department of Agriculture undertook to get a list of cooperative societies of farmers in the United States. The list has not been published, as I write, but I collected the data for the State of California, and, exeluding those which gave no promise of permanenee, I reported seventy irrigating companies, thirty-two marketing societies, three milling companies, four tire insurance companies, and ton organized for other purposes. A large number of cooperative ereameries have been organized in the state, but it was not found possible, except by a personal visit to each one, to determine how many were still adhering to the cooperative plan. The list of societies reported was incomplete, and of the marketing societies reported two were central organizations representing twelve or fifteen local societies, all of considerable magnitude. At the present time there are about fifty marketing societies in operation in California.
} 


\section{BOOK SIXTH.*}

\section{The Questions of the Day.}

\section{CH A P T R I.}

THE FARMER AND THE TARIFF.

TARIFF on merchandise imported into a country is pre-
sumed to be primarily a means of raising a national
revenue. In that aspect, however, it is by no means a "question of the day." Practically all parties in the United States have agreed to regard a tax on imports as an important if not the principal source of revenue for the national government. The question upon which the people are divided is as to the policy to be pursued in forming the tariff; the extremists of one party insist that the tariff should be arranged solely with reference to producing the necessary revenue with the least possible disturbance to business, the tax being made as nearly uniform as possible upon all goods imported, or if any are taxed more than others, such articles to be those not produced in this country. The extremists upon the other side insist that in framing the tariff the items should be carefully examined one by one, and such tax imposed on commodities which can be produced here as shall as nearly as possible prevent their importation, only enough import trade in such goods being left to supply the necessary revenue, and that no article which can not be produced in this country shall be taxed at all, except in time of war. Between these extremes there is

* See $\Lambda$ ppendix $\mathrm{G}$ for documents relating to the subjects of this book. 
every conceivable shade of opinion. The intent of this chapter is to make the clearest possible statement of the reasons urged by each party to this controversy in support of its views. Extremists are more likely to be logical than compromisers, and it is believed that by a clear statement of the arguments of the extremists upon both sides, the reader will be best prepared to understand for himself the merits of the innumerable compromise measures which from time to time are proposed. Neither party in this country has ever been able to pass, or at least to long maintain upon the statute-book, a tariff act logically constructed according to the theory of the most clear-headed of the party.* In fact, the views of such men seldom find expression in party platforms, which are always drawn up by "practical" men, with the view, not of teclaring economic truth, but of carrying elections. As a rule, therefore, such platforms are capable of two or more meanings, in order that in each section of the country that meaning may be applied by political orators which seems most likely to win votes. The exceptions to this rule are too few to be worth considering, which relieves me from the necessity of any further reference to political declarations upon the subject of the tariff.

Before taking up the main topic it will be useful to devote a little time to the general subject of taxation, of which a tariff act forms only a part. The American citizen pays taxes for the support of at least three and usually four or more different goveruments; in all cases he contributes to the national, state, and some local government, and usually to more than one local subdivision, as county, town, city, school district, road district, irrigation district, or the like. Assuming an equal per capita division of taxes, and five inhabitants to one taxpayer, the taxpayers of San Francisco, for example, contributer, for the fiscal year ending June 30, 1897, per capita, to the United States, $\$ 23.75$; to the State of California, $\$ 27.35$; to the city of

* The Morrill tariff act of 1861 was possibly an exception to this rule, and in the main it stood for many years. But it was originally passed as a war revenue measure. 
San Francisco, $\$ 56.20$; total per taxpayer, \$107.30. - The amounts paid were $\$ 1,520,000, \$ 1,752,250$, and $\$ 3,599,785$ respectively. The population of the United States is assumed to have been seventy-three million, and that of San Francisco, three hundred and twenty thousand. In this case the city absorbs all local taxes. The aggregate of taxation is very serious and tends to increase.

Taxation is coexistent with civilization, and from time immemorial the devising of a just method of assessing taxes has been the most difficult problem of statesmanship. It has never been solved and probably never will be. It is perfectly safe to say that no entirely just tax was ever yet assessed and collected. It is the most intricate and puzzling of all problems. Even if we assume that whatever is logically just can be practically carried out - which is not true-it seems impossible to make any single statement of principle which will be true without modification. It is not even true that men should pay entirely according to their ability, for nearly all agree that those who indulge in such articles as spirits, tobacco, opium, and the like should pay in extra taxation for their indulgence, and there are many who believe that those who withhold from others who would use it, land or water which they do not themselves use, should pay extra taxes as a compensation. The principle adopted in all highly-taxed countries is to closely scrutinize every industry, and place upon it whatever burden it can bear without being destroyed, or if not necessary to go to that extreme, whatever it should fairly pay as compared with other industries, its income-producing power being the main factor considered. To the sums obtained in this way are added the proceeds of taxation of unproductive property used for purposes of luxury, and upon commodities whose use it is desired to discourage. In highly-taxed countries it is absolutely necessary to pay strict attention to the income-producing power of the different industries, as otherwise there will be taxes which can not be paid.

There has hitherto not been sufficient pressure of poverty in the United States to compel any adequate study of methods of taxation. While taxes, especially local taxes, have often been 
high and very unjust in their assessment, the public has been able to meet them without great distress, and has done so. All state and local revenue has been raised by assessing such tangible property as could be found at a valuation fixed according to the judgment of local assessors, supplemented by the proceeds of licenses for transacting business. Much rural property has been assessed relatively higher than its incomeproducing power would justify, and practically all rural property in well-peopled farming communities is listed, while personal property in cities has often been assessed at relatively low rates, and much has escaped altogether. Our system of state and local taxation is unjust to farmers, and will be further described in a later chapter.*

Previous to the War of the Rebellion, our entire national revenue had for a long time been produced by duties on imports. In some countries duties are collected on exports. These are forbidilen by the Constitution of the United States, and are gradually disappearing from the fiscal systems of all nations. They are possible only in the case of commodities whose production is confined to a few countries, and for which the demand is greater than the supply. Brazil, for example, has hitherto levied an export tax on coffee. When competition is active between different countries in regard to a commodity, an export tax operates to restrict or suspend exportation, and divert the trade to competing countries. As great competition between countries now exists with respect to nearly all commodities, export taxes are likely to soon be a thing of the past. As levied in colonial times by Great Britain in some of the colonies they were regarded as oppressive, and were therefore forbidden by the Constitution of the United States.

Upon the breaking out of the Civil War national necessities required a great increase in our revenue which import duties could not supply, and Congress was compelled to impose taxes on all commodities and all business transactions from which taxes could be collected without too great cost. After

*See Chapter III of this book. 
the elose of that war nearly all these taxes were gradually withdrawn, those on beer, spirits, tobacco, opium, playing cards, and imported wine being all that remained* of our system of national internal taxation. Upon the outbreak of the war with Spain some of these taxes were reimposed, and will necessarily remain until the cost of that war is paid off. It is not likely that the nation will ever again dispense entirely with revenue from internal sources, as, even if we remain in profound peace, the tendency is for the people to demand an ever-increasing service from the national government. While we are the richest nation in the world we have less capital in proportion to our requirements than many other nations. IVe have an immense territory whose inhabitants are clamoring for rapid development. We might be called "land poor." We are called to expend for public buildings, rivers and harbors, the conservation of forests, the control and storage of waters and similar objects, within a short time, sums whose collection and expenditure would, in older countries, have been distributed over centuries. We are expending for these purposes the money which, but for our happy situation and hitherto conservative policy, would have been required for the support of a great standing army. In the event of war, or important increase of national debt from other causes, national taxation would be imposed on many commodities and transactions which are now untaxed.

It will be noticed that the most important national taxes are what are known as "indirect taxes"-that is, taxes which are collected by the government from merchants or manufacturers, with the expectation that they will repay themselves when selling to the consumer. This is because the resources of direct taxation are so fully used for state and local purposes that public scntiment requires that the national government shall, so far as possible, be restricted to indirect taxation as a

* Such taxes as those upon "filled eheese" and oleomargarine are not measures for produeing revenue, but for controlling or preventing the manufueture or sale of produets deemed undesirable. I, therefore, do not mention them in the text. 
source of revenue. The Constitution requires that all direct taxes-which include income taxes-should be apportioned to states according to their population. As the ability of states to pay is by no means according to their population the tax is too obviously unjust to be levied. During the Civil War such a tax was imposed, and collected from some states, but the sums so raised were repaid to the states, the tax being recognized as unfair. Subsequently an income tax law was passer, which the Supreme Court held to be a direct tax and; therefore, unconstitutional and roid. We can have no national income or other direct tax without an amendment to the Constitution of the United States.

It is obvious that indirect taxes are in one way very undesirable, as the consumer pays much more than the government receives, the tax paid by the importer and manufacturer being treated as part of the cost of the product and paying a profit to all who handle the goods, the tax with profits added being finally paid by consumer. While profits vary greatly in different lines of business, we may say, roughly, that the profit to the importer, is twenty-five per cent, to the jobber ten per cent, and to the retailer twenty-five per cent, out of which must come their expenses. If, then, an importer pays on a certain lot of goods an import tax of $\$ 100$, he collects from the jobber $\$ 125$; when the jobber sells the goods he adds to the tax which he has paid $\$ 12.50$, making $\$ 137.50$, to which the retailer in turn adds $\$ 34.88$, making \$171.88, which the consumer pays in taxes in order that the government may get $\$ 100$. Sometimes it would be more, and in other cases less, depending upon the nature of the goods and the stress of competition, but the range of profits given is about what is necessary to pay the expense of the purchase and distribution of commodities, with a reasonable profit. On such staple goods as sugar, tea, and coffee, the profits are much less, and on some other classes of products they are greater.

These facts, which of course are well understood by legislators and economists, have led many to insist that all taxes should be so levied that the one who ultimately pays the 
tax shall pay it directly to the government, and save any intermediate profit, but this is a matter often hard to determine; the real incidence of taxation is a vexed question in economics, and while in the main authorities seem to agree that the "consumers" pay nearly all taxes except those on fixed incomes, yet sometimes they do not. The fact is that whoever pays a tax does his best to pass it on to some one else by adding it to the price of some commodity or use, but sometimes does not succeed. That it always in the end falls upon the weakest is about the only general statement that seems to me entirely truthful, and the weakest is most likely to be the consumer. Sometimes, however, he is not. A very weak consumer who can keep his head is often stronger in a bargain than either of two much stronger men who are competing with each other for his trade.*

But, aside from the difficulty which exists in locating the real taxpayer, there are considerations which favor the indirect tax. The loss to the taxpayer by the profit of the middleman is less than it seems, for the taxpayer must pay the cost of collection, and it costs much less to collect from a few importers or manufacturers than from the entire community. Individuals can entirely escape taxation by refraining from the use of taxed commodities. Except sugar, no important article of prime necessity is now the object of indirect taxation

* In the case of artieles or brands not produeed in this country, as tea and Wostenholm knives, it seems evident that the consumer pays all the tax, and yet even in this case the competition of coffee, or of other brands of knives, might compel the producer to sacrifice some part of his profit, which would be equivalent to paying a part of the tax. In the ease of products which we export largely, as wheat, it seems evident that the foreign producer must pay all the tax. Some wheat is sent from Manitoba to Minneapolis, and there ground, presumably because the freight to $M$ inneapolis, and the duty, are less than the freight to a Canadian port. While one would think that in this ease the Canadian producer must pay the duty, yet it is quite eoneeivable that the railroads, for the sake of the traffie, might so reduce their freight rates as to practically pay part of it. The subject does not seem to me profitable for popular discussion, as each alleged ease must be examined upon its own merits. The statement in the text seems to me the best general statement that can be made. 
in the United States. ${ }^{*}$ The taxpayer is also enabled to pay in small and even trifling instalments as he buys his supplies from day to day, a privilege which must always be paid for in some way, and by many is considered worth all it costs. By timing his purchases to suit other contingencies he can in a great measure select his time of payment of such taxes as he elects to pay at all, a privilege also worth paying for. These considerations have more or less weight, even from the standpoint of the economists, in favor of indirect taxation. The thing, however, which possibly has greater weight with legislators than all others, is the fact that by indirect taxation the people pay taxes and do not know it, and therefore endure a rate of taxation which would excite grave discontent if paid openly, and at one certain time, and under compulsion. On the other hand, there are thoughtful men who believe this the greatest evil connected with indirect taxation. If the sums paid by the people for the public service were more forcibly brought home to them they would compel greater economy in public affairs.

While upon nearly all the above matters there are honest differences of opinion among economists and the public, none of them are the subjects of partisan controversy in the United States, although upon some of them, Congress may at any time happen to divide upon party lines. But they do not enter into party platforms, or form the subjects of active political controversy.

The protection of home industries, however, by means of a tariff on competing imports, irrespective of the necessity of revenue, has been the subject of political controversy in the United States from the foundation of our goverument. All persons having occasion to buy commodities, desire the prices

* Of course the prices of many important articles of domestic origin are raised by the indirect taxation of competing products, but there ean be no brief popular exposition of economic doctrine if every statement is safeguarded by exceptions. Each subject would require a book. 
of them to be low, and will buy where they can buy cheapest. What we should all really prefer is free trade in what we have to buy, and a stiff protective tariff on whatever we have to sell. Some of us are so situated that what we have to sell is not affected by foreign competition, and so long as we remain in that condition we tend to be free traders; others of us produce goods with which foreign commodities compete, and so tend to become protectionists. If our occupations or the conditions affecting them change, we gradually but surely tend to change our opinions; unconsciously, and in entire good faith, we permit our interests to control our convictions. From the standpoint of economics this is exactly as it should be; interests will differ, and we should quickest reach the greatest good of the greatest number if upon economic subjects each individual voted in accordance with his real interests. It has happened sometimes in our history that individuals whose productions were not affected by foreign competition were closely grouped in one section of the country, while those whose products could not compete in price in the home market were grouped in some other section. This resulted in sectional differences of interest, which are always unfortunate, and, if permanent, frequently dangerous to the stability of government. With the progress of the country, however, these sectional differences tend to disappear. New industries become established in districts which were once solidly devoted to a single industry, and while individual differences of interest and opinion remain, their sectional and consequently dangerous character is gradually disappearing.

The tariff problem in the United States has always been greatly complicated by the fact that all parties have always been agreed in regarding a tax on imports as a principal source of national revenue. They have also agreed in concluding that the necessary revenue could not be raised by any reasonable tax on commodities not produced in this country, but must be extended, in order to produce the necessary amount, to articles which we also produce. But any tax on imports, no matter for what purpose levied, is to its extent protective, if the articles so taxed are produced in this country. 
The rate of tax which the different articles can properly bear, considered merely as objects of taxation, and the rates which will produce the most revenue from each, are matters of expert knowledge, as to which the public is seldom in a position to judge. All interests likely to be taxed are alert and watchful to induce Cougress to impose the highest or the lowest tax possible, as the interests of the opposing parties may lie, and it is seldom possible to separate, in the public mind, the revenue question involved from that of protection. This has made the way easy to misrepresentations on all sides which the public is unable to detect, and added greatly to the complexity of the questions and the confusion of thought attending their discussion.

Nearly all modern economists are free traders. By "economists" is understood professional men, usually comected with universities, who devote their lives to a search for economic truth, and usually to teaching it as they understand it. These gentlemen usually have no personal pecuniary interest to serve by the alvocacy of either side. What they have to sell is economic science, which is not an object of taxation, and can neither be helped nor hindered by "protection" or the lack of it. Their great learning, their alsence of bias, and their high character give great weight to their opinions among thoughtful men, and they are entitled to the highest respect. The opinion of this class of economic students is so nearly unanimous and so emphatic on this subject that it may as well be conceded - for it is a fact-that economic science as taught in universities pronounces against the doctrine of protection. Nothing is gained by belittling these men, after the manner of the protective press and political orators. Ridicule and abuse are signs of intellectual defeat. They are the weapons taken up when argument fails. Advocates of protection will stand on stronger ground by conceding that the economists who oppose them are able and candid men.

Economists of this class reason that in the long run production will be most abundant and economical, and commerce most profitable, if products are permitter to move entirely unhampered by tariff walls. They claim this to be 
self-evident, and that economic science, regarding the entire world, can never approve a protective tariff which is intended to benefit one nation at the expense of others.

I am not aware of any published book or article which squarely grapples with these propositions, which, indeed, as claimed, seem almost self-evident. Men would indeed seem to produce most abundantly and economically when producing that which they can secure most readily. Commerce, like a river, would indeed seem likely to move most freely in channels wholly free from obstruction. Protectionists, therefore, have usually, and very naturally, directed their argument to showing the advantages of the system to the particular country for which they were writing, without concerning themselves as to whether or not the advantages thus claimed were to be gained at the expense of other nations, or with protection as a fiscal system for developing the entire resources of the world. To these fundamental postulates of the free traders, however, it may be replied as follows:* Unrestricted free trade is disastrous to any country, for the reason that it tends to premature exhaustion of its natural resources. With trade entirely unlampered, the result would in truth be, as free-traders claim, that all men would engage in those industries from which they could obtain the quickest and most profitable results; this would in all cases mean the exploitation of accumulated stores of coal, timber, iron, and other minerals, while the fertility of agricultural districts would be rapidly diminished by extensive cultivation, for the reason that food prorlucts will not bear the cost of the intensive cultivation essential to the maintenance of fertility, in addition to the cost of transportation to distant markets. In due process of time this would leave all nations shorn of what had been their greatest strength, and with

* For all but the language of the remainder of this paragraph, I am indebted to Mr. John P. Young, of San Franciseo-probably the best informed, most logical, and most uncompromising Protectionist now living in Ameriea. Mr. Young has been kind enough to read the proof shcets of this chapter, and permits me in the above paragraph, to anticipate a little from a book of his own, to be entitled "Protection and Progress," now in manuseript, and about to be published. 
greatly impaired powers of maintaining their commercial and political integrity. On the contrary, such a wise application of the protective principle as the eireumstances of each nation will suggest to its statesmen, will maintain the natural resources of each nation in equilibrium within itself, tend to better cultivation of agricultural districts by reason of the home markets which render it possible, and to a longer and more useful national life for all nations. To recur to the illustration employed in behalf of the free-trade argument; while it is true that the river will flow more freely if left unobstructed, it is only by damming at proper places that it ean be made to do the most work of which it is capable.

The usual argument for a protective tariff begins by denying that abstract economic truth has very much bearing upon the subject. It is claimed that we have to deal not with a world wherein the standard of life is uniform, and all business ordered with an eye to the equal comfort of all, but with one in which each individual and each nation is struggling for advantage over all others. Finding ourselves in this hurly-burly, we must protect ourselves or be trampled. Our resources are so vast and varied that we can produce everything essential to our welfare, except the products of the tropics, somewhere within our bounds, as cheaply as the same goods can be produced elsewhere by those whose standard of life is equal to our own. We know that whatever we may do, our products ean not usually pass from our borders without meeting tariff walls erected by others. We must so arrange our own tariffs that we do not suffer in the contest. The tendency of eivilization is doubtless towards an equalizing of condition for those following the same occupation throughout the world. This is favorable to those having low standards of life, but unfavorable to those of high standards. Our standard of life is a high one, and it is our interest to prevent the leveling of standards as long as we can. It is true that to some extent our high standard is maintained by the exploitation of natural resources which it would be graceful to leave for the enjoyment of future generations. As a matter of fact, however, no human being has ever refrained from the use of opportunity available 
to himself for the purpose of benefiting posterity, and none ever will. No elements of fertility are lost except those which flow into the sea, and even of those some portion is returned.* Each generation finds itself able to meet the conditions of its time, and we must assume that this condition will always continue. The best markets are always home markets, and the promotion of diversified industries does make openings at home for the differing tastes and talents of our youth, and by keeping them here increases the market for home-made commodities. Economic science assumes a condition of commercial peace, while, as a matter of fact, the world is the theater of unceasing commercial war. In this war the best defense of a nation so richly and variously endowed as our own, is claimed to be such a protective tariff as shall result in full occupation for all our people in producing commodities and exchanging them among curselves. $\dagger$

The arguments for and against the protective principle as a fiscal measure for world-wide application, as condensed on a previous page, are of course the most important, as they go to the root of the whole matter. They are not likely, however, to become prominent in popular discussion, which has usually been and will probably continue to be mainly directed to the

* The coal burned seems to be largely lost to future economic use.

$\dagger$ It is proper to note that the advantages of a protective tariff havr probably been moro obvious during our national career to this time than they can be hereafter. During our period of most rapid growth, a continuous stream of immigrants, in connection with a high birth-rate, afforded a prompt market for all the manufactures which could be produced with our limited capital. The abundance of food and of opportunities for labor restrained the growth of uncm. pl y. $d$ and dependent classes. With the abundant capital now accumulaterl. we can easily produce a surplus of manufactures, with a constant increase in the capital and labor which can be profitably employed only in producing tor foreign markets. These conditions must result in such reductions of cost, in part, unfortunately, involving a lowering of our standard of life, as will render our manufacturers more independent of foreign competition in home markets. This will not, however, reduce the demand for protection, which our manufacturers will continue to seek in order to be able, by obtaining good prices at bome, to show an average profit, while disposing of surplus stocks at lower rates, if necessary, in foreign markets. 
circumstances of the particular nation in which action is proposed or resisted. As shown below, the necessity of preparing for war by making ourselves industrially independent is a common argument, but war, in its usual sense, is infrequent in modern times, and at any rate its losses, both of life and property, are insignificant as compared with the casualties of commercial war in which we are constantly engaged. More people have starved as the result of commercial war than were ever killed in battle. A common argument for protection is its effectiveness as a weapon in commercial wars.

Political writers, however, do not concede that, even from any economic standpoint, the free trade arguments can not be met. The economic arguments against protection, and those for it, as commonly employed, are as follows:-

In behalf of protection it is urged that-

1. Protection establishes and maintains a great number of industries which otherwise, either from our inferiority in natural advantages, or lower standard of life in competing countries, could not exist here.

2. That these industries are both manufacturing and agricultural.

3. That these industries furnish profitable employment for a great number of people who would otherwise necessarily be engaged in the production of commodities for which this country may be best adapted under existing circumstances, but in which, so far as they are exported, we must compete in the world's market with those of an inferior standard of life.

4. That whenever a reasonable protection will maintain such industries, those engaged in them are more profitably employed than if engaged in producing for a more strongly contested market.

5. That the employment of large numbers in protected industries supplies a home market for great quantities of products of other industries whether directly protected or not.

6. That this diversity of industries renders the nation better able to endure the stress of warfare, whether commercial or military.

7. That a home market saves expense not only in trans- 
portation, but in profits, the profit of middlemen necessarily increasing as the market is more distant.

S. That wages are made higher, and that even if no greater, in purchasing power, per unit of time employed, by reason of the general increase of prices, their aggregate purchasing power is greater by reason of more constant employment.

9. That, as a matter of fact, our natural exports being so largely agricultural, and likely for some time to remain so in the absence of protective legislation, we are making undesirable drafts on our natural resources, and that it is better that some larger portion of our population be employed in other industries.

10. That since a tariff for revenue is a fixed part of our fiscal policy, such industries as are taxed at all are protected to that extent, and it is therefore only just that all industries have equal protection, and as we know that as a matter of fact all industries will seek and many obtain a greater protection than the necessities of the treasury would require, the surest way to assure justice to all is to protect all to such a reasonable point as will not entirely cut off revenue by preventing importation, while giving the public the benefit of free trade on such commodities as we can never produce.

11. That import trade in such commodities as we can produce is wholly unnecessary in such a country as the United States, whose vast extent gives ample scope for domestic exchanges which move freely, and that as a matter of fact the nore our foreign trade increases in the face of the stress of competition, the greater our necessity for vast naval expenses to protect that trade under the danger of the intermational clashes of interest which are always arising; the more we expand our export trade the greater difficulty we shall have in maintaining our traditional policy of freedom from foreign entanglements. To the extent, therefore, that a protective tariff diversifies our industries, and directs our efforts to domestic exchanges, it is a wise political policy.*

* I do not cumber the text with the argument for protecting an "infant industry," until fairly established, with the intent of removing the protection 
The opponents of protection insist:-

1. That every industry established by protection displaces some other that could exist without protection, and which it would therefore be most profitable for us to pursue.

2. That therefore no more people are employed under protection than would find employment without it.

3. That, in despite of the low prices which must be expected, there is always more net profit in producing those commodities for whose production our natural advantages are greatest, and purchasing those which others can produce cheaper than we.

4. That, while it is true that protection makes a home market for commodities which we should otherwise export, the extra profit in their sale is more than absorbed by the higher prices which we pay for the protected articles.

5. That the argument of the necessity of maintaining diversified industries as a resource in time of war, is of little or no force as applied to the United States, as under any circumstances we should be able to supply ourselves with whatever is essential.

6. That the saving in transportation and profits in the case of industries requiring protection is less than the extra prices paid for the protected commodities, because if it were not so they would be produced without protection.

7. That, while wages will be nominally higher under protection, their purchasing power is less than that of the wages which would prevail under free trade.

8. That a protective tariff involves continued intrigue in legislation, with the result that the strongest industries always receive undue protection.

9. That protection leads to oppressive inonopolies, because the strong industries, protected by law from foreign competition, will combine in trusts to extinguish competition among themselves, and that this combination will be against labor

after it is well on its feet. The argument given is for the permanent maintenance of the protective prineiple. Most modern economists admit that it may frequently be wise to give a new industry a start by protection, while calling attention to the fact that no such industry ever lets go of protection, no matter how prosperous. 
as well as against the public and so tend to keep down wages while increasing profits to employers.

10. That, as a matter of fact, industries which can live only by protection are always in a precarious position, on account of the fluctuations in popular sentiment. At any time the protection may be abandoned, and the industry consequently crippled, people thrown out of employment, expensive plants rendered useless, and losses incurred which will far more than absorb whatever profit has been made during the period of fictitious prosperity.

11. That the largest amount of products will be secured at the least expense if all portions of the earth are devoted to whatever they are most fit for, and that this will always be the case, in the long run, when there are no artificial barriers erected.

From the above résumé of the arguments on the two sides of the question, the reader may determine which side he will espouse.

I have not introduced into the argument on either side of the tariff controversy the question of the "balance of trade" -that is, the question whether we do or should try to sell more, in the aggregate, to foreign nations than in the aggregate we buy of them, for the reason that I do not think it belongs there. Protectionists, however, sometimes insist that a protective policy always assures to any nation the power of obtaining for itself a favorable balance of trade, while freetraders claim that if this power, if it exists, which they deny, were regularly employed, it would be often at a cost which no nation could endure. As I doubt whether either can prove the other wrong it will be most profitable not to go very far into the subject. It may, however, be well to consider it briefly.

The discussion in regard to the balance of trade in international transactions began more than a century and a half since, but most early discussion is so complicated with reference to ancient ideas in regard to a supposed necessity of regulating the international movements of the precious metals, as to be almost worthless as an aid to a consideration 
of the subject from a modern standpoint. In its modern form the "balance-of-trade" theory may be stated as follows: It is evident that, except by incurring debt, or drawing upon capital, no individual, in any one year, can purchase commodities except such as he can pay for by the proceeds of his own produce or labor, plus his income, if any, from interest, rent, or other income from accumulated eapital. If he spends less than he receives, he accumulates wealth; if otherwise, he falls behind. The balance-of-trade theory assumes that in this respect a nation is precisely like an individual. As the movements of money, however, can not be traced, we can regard only the movements of merchandise, of which records are kept in the custom-houses of all nations. If the value of imports exceeds those of the exports, there is an "unfavorable" balance of trade, and the nation is said to be losing money, paying for the surplus of imports by money received from ocean freights, or from the income or principal of previous foreign investments, or by incurring debt. This seems sufficiently obvious, and is, in fact, the universal popular belief in all countries. Not only the public, but statesmen and financiers look with great satisfaction upon annual treasury statements showing that the country has sold more than it has bought.

This doctrine, however, is not only vigorously disputed by most economists, but is treated with contempt as an "exploded theory." I can not go into the detail of their argument, which it requires a rather highly-trained mind to appreciate, but in substance it is this: As a matter of fact the total exports of a country do substantially pay for its imports; but each purchase for importation is presumed to involve a future profit, while from goods sold for export nothing beyond the purchase price is to be expected; therefore the more imports the more profit, and a healthy balance of trade is one which shows a large excess of imports which have been paid for by exports of less value.* As this is not a treatise on abstract economic

* McLeod illustrates by the example of a sailor who might buy an axe in London for 65 cents and trade it to a South Sea islander for a pair of shells, which he might bring to London and sell for $\$ 50$. In this case the value 
doctrine I shall not attempt to settle the question, but will refer the reader to works on economic theory. The modern theory of trade supposes that ordinary mercantile transactions involve a profit to both parties thereto, and the more trade on either side the more profit on both sides, but, like the majority of my countrymen, I confess to a more comfortable feeling when I think we are taking in for commodities more money than we are paying out for them. As to this, however, I do not think we can tell very much from treasury statistics, for the reason that, except when valuing for the purpose of assessing ad valorem duties, the valuations are not reliable. In the commission trade, which is enormous, the valuations on invoices are wholly pro forma. Roughly the figures give us some idea of what we are doing, but they are not, in any trade with which I am familiar, reliable for calculating balances. There is also the question of ocean freights to be considered, which form part of the cost of the delivered merchandise; and it has always to be considered whether a country, like England, produces no precious metals, or whether, like the United States, it produces enormously more than it can use at home. I have thus briefly touched the subject, partly because it is a matter that largely enters into popular discussions of the tariff question, and partly to give my plain readers an idea of the subtlety of some doctrines over which controversial economists dispute. I think most of us will be happier if we reach conclusions without trying to solve such problems as this. Their solution is not essential to the application of ordinary common sense to ordinary transactions.

of the imports would enormously exceed the value of the exports, and yet no one eould dispute the profit of the transaction to the thrifty sailor, which MeLeod assumes to be the same for the nation. It will be a good mental exercise to think out whether or not this assumption is correct. 


\section{CHAPTER II.}

\section{TIE FARMER AND AN EXPORT BOUNTY.}

MONG the minor questions upon which effort is being
expended to secure political action is a proposition that the United States shall pay an export bounty on "staple" agricultural products, the word "staple" probably" being intended to include cotton, grains, tobacco, and any other important agricultural products which we might export largely, and whose home price is entirely controlled by the prevailing prices in the markets of the world outside the United States. I speak of this as a "minor" question in the sense that it has never yet obtained sufficient following to be able to secure the endorsement of any great political party. It has, however, been energetically pushed among the farmers, and has been indorsed by one or two State Granges. It has never, however, obtained the support of the National Grange, or any other important national body.

A bounty on exports is a tax paid by the entire nation for the benefit of the producers of the article on which the bounty is paid. The supposition is that, although the bounty will be pairl to the exporter, who is not likely to be the producer, the latter will be able to obtain for his product a price increased by the amount of the bounty.

In the case of the United States it is claimed that such a bounty is just and necessary, for the reason that our staple agricultural exports, like wheat and cotton, are produced enormously in excess of our home consumption, and, although nominally protected by the tariff, are in reality not protected in the least, for the reason that, as we always have a great overplus, there is and could be no imports from any source, of any consequence. The price of the produce exported is determined by the competition of the entire world at the centers of consumption, and will always be, as compared with 
the average of prices in a protected country, a low price; but the home price of commodities largely exported will always be determined by their value for export, which they can never exceed. This is not only theoretically true, but as a matter of fact every farmer knows that the price of wheat in America is always governed by the price at Liverpool, which is daily cabled to this country, and which our home prices, within certain very narrow limits, implicitly follow. The same is true of all other commodities which we produce largely in excess of home requirements. The result is, as is claimed, that the producer of these commodities in the Uniter States is greatly at a disadvantage as compared with his fellow-citizens, since he is compelled to purchase supplies at protected prices, with the proceeds of commodities sold in competitive markets. In order, therefore, that the producer of exported staples should have equal jrotection with the producers of other commodities, it is claimed that it is necessary to compensate him by a bounty on all staples exported. As it is claimed that this rould raise the price for export by the amount of the bounty, it would raise the price of all consumed at home by the same amount, since no one would s: ll for home consumption at a lower price than he would receive for export. The protected classes would then pay to the farmers such an increased price for the commodities in question as would afford to them the same protection that they themselves enjoy. This is claimed to be evidently just.

To this argument one party replied that the injustice disclosed is self-evident, but that the remedy proposed is inadequate and futile. The proper course, as they claim, for the producers thus injured to pursue, is not to attempt to juggle by balancing one injustice against another, but to abandon the whole scheme of protection, thus putting all upon an equality at once. This opens up the whole question of free trade and protection, which was liscussed in the last chapter.

The protectionists meet the argument in another way. They agree with the free traders that the remedy is inadequate and futile, but deny the injustice, claiming that the producer of staple exporterl prorlucts shares equally with others the 
increased prosperity which they claim to be given by protection, by the increased home market for general agricultural products, which they may, if they choose, produce. 'They say that if the farmer deliberately continues to produce commodities which he knows must be sold at competitive prices, instead of other commodities for which protection provides a home market, he must not blame protection for the consequences of his folly, and that as a matter of fact he will not do so, but that gradually, under a jermanent system of rational protection, the agricultural industries would be directed to the production of such commodities, including staples, as the increasing manufacturing and trading population would require, and that they would thus come to participate in the benefits of protection as rapidly as other classes. Some of them say that, while the attempt to conquer foreign markets by means of bounties forms no part of the policy of protection, which is confined to the assuring of the home market, yet they would not seriously object to engrafting on the bounty system, were there any possibility of accomplishing its object, but as there is not, they decline to support it.

It is plain that the argument of this class, like that of the free traders, reopens the subject of protection and free trade, already considered.

The principle of giving aid to an industry by means of a bounty on exports of its products finds no support from any quarter entitled to respect for anything but its honesty. American economists, if they allude to the subject at all, do so only in the most cursory manner, nor has the discussion in this country ever yet assumed proportions sufficient to draw the attention of those most competent to engage in it.* In some countries of Europe it is a question of national and international importance, but the question discussed is not that of imposing the bounty but of how to get rid of it. In

* I should make one exeeption to this remark. Mr. David Lubin, of California, the apostle of the export bounty in Imeriea, is a man of very keen intellect. There is some internal evidence, however, that be entered upon this propaganda without adequate previous study of the working of the export bounty system in other countries. 
Great Britain, it is true, there is some respectable support of a proposal to pay bounties on staple agricultural exports, but the object sought to be attained there is not economic but military. Great Britain being an island, not producing sufficient food for its population, the fear is expressed that in case of war involving danger to the control of the sea, its inhabitants might be reduced to great distress for lack of the staples of life, and it is therefore held by some that it would be economical for the country, by bounties, to stimulate the production of those substantial food products which are absolutely essential, even at the expense of increasing its importations of such products as vegetables and fruits, which in case of emergency could better be spared. This is antagonized by others who claim that it would be cheaper for the nation to build immense storehouses, and keep on hand supplies of grain purchased at competitive prices, sufficient to last through one of our modern short wars. If the bounty plan were adopted for Great Britain, it would seem to be necessarily a bounty on production rather than upon exports, as the country does not wish to encourage exports, and indeed wonld not be likely to export. In the seventeenth and eighteenth centuries, when the population of England was less,* export bounties were paid on grain, and did have the effect of greatly stimulating production. In Great Britain, however, the proposition, so far as considered at all, is considered solely as a measure of national defense.

A sufficient objection to the export bounty as proposed in

* From 1689 to 1815-a period of 126 years-England paid an export bounty of 5 shillings a quarter ( 8 bushels) at all times when the home price of wheat did not rise above a eertain amount, which at first was 48 shillings a quarter, and after 1773,41 sliblings. In 1815 the bounty on exports was repealed, and imports of wheat prohibited whenever the home price did not exeeed 80 shillings a quarter, reduced in 1822 to 70 shillings. In 1829 the prohibition was removed, and an in port duty of $23 \mathrm{~s}$. $8 \mathrm{~d}$. levied when wheat was below 64 shillings a quarter, with a smaller duty as prices should rise, the systrun being abolished in 1846. I have not verified these figures, considering the Mark Lane Express, in which I find them, a sufficient authority. This artificial regulation of the prices of bread at times caused great distress. For the most of this time England was able to produce all her own food. 
the United States, is that it will not accomplish what its advocates expect. The reason of this is that the bounty so stimulates production that the commodity soon falls in value by the full amount of the bounty paid. This does not happen at once. On the contrary, the first effect is to raise the price of the commodity precisely as anticipated by its advocates. The foreign price is not changer, as of course it could not be by such means, but the domestic price is raised. If wheat, without bounty, is worth $\$ 1.00$ per bushel for export, and a bounty of 10 cents per bushel is paid on exported wheat, the exporter will receive $\$ 1.10$, and will therefore pay to the farmer 10 cents, or nearly that, more than he would otherwise pay lim. So long as there is an export demand the farmer will refuse to sell at a less price for domestic use. The domestic consumer will therefore pay an extra 10 cents a bushel for all wheat consumed at home, and the government will pay the farmer the same amount on all sold for consumption by foreigners.

This, however, in a country like ours, where wheat production can be largely increased, will at once stimulate production, and within a year or two the foreign price will tend to fall by reason of the increased supply. Oats and corn and linseedfor all products largely exported would certainly claim the bounty - would be still more easily affected. It is still possible, however, that for some years at least there would still remain an appreciable advantage to the farmer if competing exporting nations would pay no attention to what is going on. They would not and indeed could not do this, however, for this is what would happen: The grain being made by the bounty worth more for export than for feeding, the tendency would be to increase our exports of feeding grains: and so of all other aided commodities. The tendency would be to push the profitable export market to the utmost, and in the effort to get all the trade possible, such reduction as might be required to gain a larger share of the trade would certainly be made;

* Because before the bounty all that could be profitably fed to animals would be used in that way. 
this would immediately begin to take trade away from competing exporting countries, which, in order to protect themselves, would surely begin to pay export bounties on the same commodities. We know that this would happen because it always has happened. Nations, no more than individuals, will permit trade to slip out of their hands without a fight to retain it. This would enable competing nations, to meet our cut prices and perhaps go a little lower in the effort to quickly recover lost trade, the result being a competition between all exporting nations as to which should sell cheapest to the importing nations. This would please the consuming classes of those nations very much, but would excite great antagonism among the farmers of the same nations, who would see their home markets cut off by what they would consider unfair competition, since it would not be competition between themselves and other farmers, but between them and other farmers aided by the taxation of other classes. The consequence would be that foreign goveruments, even of nations which profited most by the low prices, would be inclined to take retaliatory measures on account of the injury done to a portion of their own people. It is not necessary to further speculate as to what would happen, because this is not really a "question of the day" in this country, and never can become so. The bounty which has been roughly proposed by the advocates of this measure, as a fair offset to existing tariffs, is ten cents a bushel on wheat, five cents on other grains, and one cent a pound on cotton; to these, before a bounty law could be enacted, it would be necessary to add bounties upon every other article which we export or have any probability of exporting, certainly including ships. The bounty on even the articles above enumerated, for the quantities exported in 1897 , would amount to more than $\$ 51,000,000$, and with the other articles which could certainly find a place in the lawfor it could not pass except by including every industry which could possibly gain by it-and the rapid increase of exports to be expecied under such a stimulus, an expenditure for this purpose of not less than $\$ 100,000,000$ a year from the treasury would have to be expected in the immediate future. It should 
be unnecessary to say that it would be impossible to obtain from any Congress appropriations for bounties on such a gigantic scale; the country, rather than do that, would unquestionably abandon the entire policy of protection and adopt free trade. Indeed, it is alleged by protectionists that such discussion as there has been in this country upon this subject, is the result of sly fostering by free traders, who hope in this way to ultimately get recruits for their ranks. At any rate, the experience of this country shows it to be opposed in sentiment to paying bounties. In 1590 the duty on sugar was reduced to a point which it was expected would destroy the sugar planting interest in Louisiana, and as compensation a bounty on production was given of two cents a pound. This was repealed, with general approval, in 1594. There is no reason to expect that in a nation of such varied and differing interests as our own, an export bounty, even if enacted, would remain on the statute-book for any considerable time. In the meantime, if it should be permitted to remain, its effects rould be as above stated. Stimulated production in this country, followed, as it certainly would be, by similar stimulation in other exporting countries, would soon glut the importing countries with products which could only be disposed of, if at all, by reducing the price until all vestige of benefit to the farmers in any country had disappeared. The inevitable repeal would assuredly follow at that time, and the farmers whom it was intended to benefit would be worse off than ever. The prosperity of the first year or two would certainly induce debt for machinery, land, and an increased scale of living on the part of farmers unfamiliar with the laws of trade, only to be followed, upon the explosion of the bubble, by the serious and widespread distress which is the necessary consequence of such errors on a large scale.

I have stated the theoretical position which is held, without exception, by all economists and well-informed statesmen, with perhaps more positiveness than I should have employed had there not been at hand an illustration on a very large scale, absolutely confirming, in every particular, the position of modern "theorists." Up to a recent time the production of 
sugar was mainly confined to tropical countries, a few subtropical districts like our own gulf states producing more or less, but always at a disadvantage, except as aided by tariffs or bounties. The discovery that sugar, identical with that of cane, could be made from beets was made many years ago, but at first the processes were too expensive and unsatisfactory for commercial use. Gradually they were improved, until, about the middle of the nineteenth century, beet sugar began to appear in the markets of Europe. Protected, as it was every. where, by a very high tariff, the manufacture increased, with improved processes, until many countries, including Germany, France, Russia, and Austria, were producing more sugar than their populations could consume. In all these highly-taxed countries, however, sugar, while protected by a high tariff, was subjected to an internal tax, similar to that which, since the Civil War, we have imposed on spirits and tobacco, and collected in the same manner, at the factories. So long as their product was all consumed at home, this did not matter to the sugar makers, who simply added the tax to the factory price, and the people paid it. The sugar supply of a country, however, important as the article is, is easily made to exceed the demand in uny country where labor is abundant, because it is produced from a comparatively small number of acres. The main cost of the raw material of sugar is labor. In all these countries, therefore, the supply came to increase to a point where competition between factories became intense, and the weaker were in danger of bankruptey. At the same time they found it impossible to export sugar upon which the internal tax had been paid, because importing countries could procure it cheaper elsewhere. In this emergency the sugar producers appealed to the government to remit the internal taxes on all sugar exported. This was very properly agreed to, as it only placed the producers of those countries on an equality with those of other countries, if any, which were not subjected to internal or export tax, and gave an advan. tage, perhaps legitimate, over producers who did pay such taxes. The government still received a tax on all sugar consumed at home, which was all that had been intended, and 
yet left their people free to compete unhampered in the world's market, for the sale of their surplus. This atforded a relief for the time, but with the increasing outlet, new plantations and new factories came into existence, and as one country after another adopted the rebate, it was but a few years before all were as badly off as ever. More sugar was being produced than conld be sold anywhere at remunerative prices. In practice the internal tax had continued to be paid at the factories as before, a part at first, and then the whole of this tax being refunded on all sugar exported.

At that time it is probable that the beet-sugar factories were at a disadrantage in competition with the tropical canesugar producers, the process of extracting and refining the beet sugar being the more expensive. At any rate, as the renewed crisis approached in the beet-sugar countries, application was made for actual bounties in excess of the internal tax, on all sugar exported, and this finally was entered upon, one after another, by all the beet-sugar countries, with the exception of Russia, which stopped with the refunding of the internal tax. This gave relief to the countries adopting the plan, but only for a brief time, for production quickly caught up with demand, and competition resulted in giving away the entire bounty to foreign buyers, and the sugar producers of Europe are just where they were, in point of price, when they reached the limit of home consumption. On all sugar which is consumed in the country where made there is a possible profit to producers, as it is protected by a high tariff, but most sugar exported is sold positively below cost of production, the loss being made good by the export bounty produced by general taxation. Of course, also, this excess of supply reacts on the home market, causing sugar to sell even there, for the most part, without profit. In the meantime the other classes of these nations are becoming tired of paying taxes whose only result is to supply foreigners with sugar at less than cost of production,* and are

* Great Britain is the largest buyer of sugar, and has for years got all her sugar at less than cost. As a result, sales have increased there until the per capita consumption of sugar is greater than in any other country in the world. 
clamoring for a repeal of the bounty. This, however, is not an easy matter. If one nation discontinues the bounty, it at once loses all its foreign trade, which will be seized by those nations which continue to pay it. If one or all discontinue it, millions of capital which have been invested, on the faith of the continuance of the bounties, in factories, will be lost, and the owners will be bankrupt. There is a strong pressure to avoid this calamity, and yet it is seen that the present situation can not continue.

All this had been long foreseen by the different governments, which at the same time could see no escape from their dilemma, when the crisis was intensified by the passage of the United States Tariff Act of 1896, the United States and Great Britain being the largest sugar-importing countries. In the United States, however, the gulf states have for a long time been producers of cane sugar, although, as has been stated, at a disadvantage as compared with tropical countries, and since 1890 there has been an increasing disposition to produce beet sugar. This country can easily produce all the sugar consumed in the world, the reason why it has not done so, since beet-sugar factories became established, being mainly the high price of labor. But on the passage of the Tariff Act of 1896, the domestic sugar producers demanded that they should not be compelled to compete in their home market with foreign sugar, a portion of whose cost was borne by general taxation of the country which produced it, with the result that there was incorporated in the law a provision that in addition to the import duty collected on all sugar, there should be levied, on all sugar coming from a bounty-paying country, an additional duty-called a "countervailing duty"-precisely equal to the bounty paid. This at once deprived the producers of those countries of all benefit of the bounty so far as the market of this country is concerned. This led to much ill feeling, especially on the part of Germany, which was at first inclined to consider it a violation of treaty rights inviting retaliation.

In the meantime the sugar producers of the British West Indian colonies were being reduced to despair by the compe- 
tition of the bounty-aided beet-sugar countries, not only in the markets of the United States, but even in what they considered their rightful "home market"-Great Britain. Improvements in beet-sugar processes have so progressed that when taken with the greater vigor inherent in the populations of temperate climates, European beet-sugar countries could undersell even the well-governed British colonies. A royal commission visited the islands to study the matter, and as the result of their investigations it is reemed the policy, even of the nation whose people have most benefited by the insane competition, that it should stop. The Government of Great Britain does not desire that the inhabitants of the British Islands should be able to obtain sugar at less than cost, at the price of the ruin of their West Indian colonies, whose staple product is sugar. As a consequence of this final cumulation of difficulties, the bounty-paying nations of Europe are seeking by mutual agreement to abolish the system, the only difficulty being to save, when so doing, those engaged in the stimulated industry from ruin.*

All these matters are now so well understood that there is no likelihood that the proposed plan of export bounties will receive much further attention in the United States. The system certainly has not the slightest chance of being adopted. Producers of staple agricultural products, like all others, must take their stand one way or another, upon the general arguments for and against free trade and protection.

* At the time when the above paragraph was written an International Congress of the representatives of European sugar-producing countries was in session in Brussels, Belgium, endeavoring to reach some plan by which all could simultaneously discontinue the bounties. They could not agree, however, and the conference came to nothing. In Great Britain the agitation for a countervailing duty for the protection of the British West India Colonies continues, and will apparently result in the levying of such a duty. 


\section{CHAPTER III.}

THE FARMER AND THE SINGLE TAX.

$\mathrm{H}^{\prime}$

ENRY GEORGE ("Science of Political Economy," Book II, Chapter V) defined the "single-tax" doctrine to be "the abolition of all taxes whatever on the making, the exchanging, or the possession of wealth in any form, and the recourse for public revenues to economic rent; the net or surplus product; the (to the individual) unearned increment which attaches to land wherever, in the progress of society, any particular piece of land comes to afford to the user superior opportunities to those obtainable on land that any one is free to ise."

The term "rent," as employed in the above definition, has a meaning somewhat different from that given to it in common speech, and includes only the sum paid, or which could be paid, for the use of bare land, entirely destitute of any improvements. The term "ground rent" as used in cities to denote a sum paid for the use of land upon which to erect buildings, conveys some idea of the meaning of the term as used in economic science, but in common speech the term "rent" is confined to sums actually paid out for the use of land, or, indeed, personal property, while in economic science it is absolutely restricted to land, but includes not only sums paid, but which could be paid; in fact, every profit of any kind which accrues to the individual from the use of land.

Advocates of the single tax hold that there can be no such thing as ownership of land. Land, like air, should be free for all to use. The custodian of the land is the state, whose sole duty, in respect to it, is the regulation of its use. A proper regulation is that individuals using the land shall pay to the state, to be employed for the public good, whatever profit arises from its use. Those who hold land, claiming to own it, and therefore paying no rent to the state, are held to be 
robbers, and those holding this view contend that the state can not too quickly perform its duty by imposing a tax upon land equal to the entire profit which arises from its use,* which would yield, as they claim, a revenue quite sufficient to supply the state with funds for all public purposes, national, state, or local. The term "land," of course, in economic science, includes the entire surface of the earth, even if covered with water, so that coast and river fisheries, and mines, would be included. It does not, however, include buildings, fences, orchards, roads constructed by private enterprise, or anything which is the result of man's labor, the theory being that man is entitled to the fruits of his own labor, but that all gifts of nature belong to the public at large.

This doctrine is similar to one of the chief contentions of socialism, but single taxers, as such, differ from socialists in not antagonizing the idea of profit or interest. They would permit men to compete with each other in the products of their own labor, as to which they may do what they please, but insomuch as they make use of any gift of nature, of which the supply is not unlimited, as air, or water where it is in abundance, it is insisted that the state should be paid all profit derived from that source, the individual having no claim upon a farthing of it. "Franchises" are treated as interests in land, and to be taxed to the extent of taking the entire profit of quasi-public corporations, except interest on cash investments.

The answer to the contention of the single taxers, of course, is that whatever might have originally been just with respect to land, as between individuals and the public, and even conceding, which the opponents of the theory do not concede, that private ownership of land in old countries originated in robbery, as a matter of fact, society has for ages recognized private ownership in land; that upon the faith of that recognition the unquestioned profits of labor have been

*Single taxers call this "restoration;" their opponents call it "confiscation." 
invested in its purchase; that, in particular, all the land of the United States, whose title was once vested in the people, has been solemnly conveyed by the jeople to individuals; and that the state can not question the title conveyed by itself; to which the rejoinder is made that one generation has no right to attempt to bind succeeding generations by any such promises as this, and that none of us are bound by any such engagements of our forefathers.

To this it is rejoined that, even conceding the last contention, which is not conceded because it would destroy the power of defending national life by creating national debt, it is still expedient and for the best interests of society, that private ownership of land should continue, because only under such stimulus will land be put to its best use, since no one would properly improve land which he did not own. To this, however, the single taxers reply that he could retain it so long as he paid a just tax upon it, and would be entitled to all profits from the use of his improvements which he could sell, as he does now.

The arguments for and against the expediency of the single tax can not be condensed into a single chapter. I therefore do not go further into the merits of the question, but shall confine myself to some inquiry into the probable effect of single tax upon farmers.

It is contended by some advocates of the single tax that labor devoted to commerce and manufacturing yields far more profit to indivicluals than labor to the same extent directed to agriculture; that this increase of profit is due, mainly, to the special advantages of location which enable the operations of commerce and manufacturing to be conveniently carried on, and that proper investigation would disclose that the majority of agricultural land, not including improvements, yields little or no profit after defraying costs of living and wear and tear of improvements, and would therefore pay little or no tax; and that under the operation of the single tax, only the richest and most favorably located agricultural lands would pay any considerable tax, and they not in excess of what they now pay on land, improvements, and personal property, and seldom so 
much, but that the greater part of the public revenue would be obtained from the taxes on town and city property, manufacturing sites, mines, monopolized fisheries, and the owners of valuable franchises, whose owners would pay to the state the entire rental value of the property devoted to such uses, which would provide sufficient revenue for most or all purposes of the state. While this extreme view is held by some it is probable that a majority do not anticipate so much from city property and special privileges, but expect agricultural lands to bear some share of the fiscal burden. All single taxers agree, however, in insisting that under the single tax the farmer's burden would be much less than he now bears. This chapter will be confined to a brief and necessarily superficial inquiry into the probabilities in these respects.

The inquiry must necessarily be superficial from the fact that as to the United States, at least, there are, except in a very few instances, no data from which to compute the rental value of land in either city or country. It is true that we have "valuations," each year, of all the property in the country, and every ten years the census authorities do their best to reduce the conflicting state valuations to some common denomination, and the result, whatever it is, is accepted as the "true value" of the various classes of property. The "true value" of property, however, is determined only by the net income which it produces, or is capable of producing under proper management. The rental value of land is the yearly sum which, under conditions as they are, individuals will pay for its exclusive use, and as a matter of fact do pay when they have the opportunity. If income is known, a capital value can be fixed according to the prevailing rate of interest. If interest is six per cent, land is worth sixteen and two-thirds times the yearly rental; if five per cent, twenty times the yearly rental; and if four per cent, twenty-five times the yearly rental. In estimates of this kind it is usual to reckon interest at five per cent, and therefore to place the value of land at twenty times its rental value for one year. We have, in America, as to the most part of our land, no data on this subject. There is a speculative taint upon all our land valua- 
tions. For generations we have been accustomed to think of land values in a large way with little or no definite thought as to income, or indeed any means of ascertaining it, since the majority of farms are occupied by their owners, who do not know what part of their income is attributable to their use of bare land. In the business portions of large cities the value of ground rents is very well known, but this knowledge grows less as we push into the residence and suburban districts, and tends to disappear as we get into the country, where, indeed, there are only the most hazy ideas of what "rent" really is. For the purposes of a single-tax discussion, we must consider "rent" as the sum which a capitalist farmer could afford to pay for a year's use of bare land, in the expectation of making a profit on it. What some poor "cottier" might be willing to pay for a small patch for the purpose of living on it and raising a crop is not "rent" in any sense applicable to this discussion. As to real "rent" of agricultural land in the United States we have almost no data, and consequently none but purely arbitrary estimates of land value. Somewhat careful reading of a considerable number of advocates and opponents of the single tax leaves me wholly disinclined to accept the general estimates of any of them as a proper hasis of reasoning. In Great Britain, where rent is actually paid upon a great part of the agricultural land, the data are of course better, but even there are unsatisfactory, as land and improvements are confounded in one valuation. Mr. Thomas G. Sherman* estimates that upon the average of city and country lands sixty per cent of the total rental of improved lands is to be considered as economic rent-that is, the rent of the bare land, and all his estimates of the workings of the single tax in Great Britain and the United States, and in city and country, are based upon that estimate. But certainly if this approaches accuracy for city property it does not do so for country property. Mr. W. I. Mallock, Edward Atkinson, and others, insist that the total ground rent of the world would not pay the world's taxes. We not only do not know what the

* “ Natural Taxation," G. P. Putnam's Sons, 1895. 
total economic rent is, but we have no such an approximation to it as would justify any opinion, except in a very general way, as to where taxation would fall under the single tax. We can discuss the principle, and if just should aceept it, and if unjust reject it, no matter what the consequences.

At the same time it is not unprofitable to consider how in the light of such information as we have, the interests of the farmers would probably be affected. To gather such facts as would justify a decided conviction is too formidable an undertaking for any one but an official commission. In the absence of such facts, while the study, as stated, be superfieial, it will not be without its value.*

In eonsidering this subject farmers must understand that it is not a question of ehanging from a just and satisfactory method of taxation to one which may prove otherwise. The present method of raising state and loeal revenue depends mainly upon a uniform ad valorem tax upon property. If property were fairly assessed there could be strong arguments both for and against the method as a just and expedient mode of raising revenue. It is, however, notorious that assessments are very unfair, and that the rich, to a great extent, escape their due share of the burden. This is accomplished partly by eustom, partly by ineompetence of officials, partly by influence, partly by bribery, and partly by perjury. The injustice of assessments and the impossibility of reform are alike conceded by all investigators. Ad valorem taxes seem never likely to be more fairly assessed than now. There is no doubt, and nobody denies, that farmers are the greatest sufferers from unjust assessments, for the reason that their property is mostly visible, and its approximate value well known to

* The single tax is advocated not, primarily, as a fiscal but a social reform. Its advocates believe that its adoption would result in a just distribution of comfort-in other words, that it would abolish necessary poverty. The best exposition of the subject from this standpoint is "Progress and Poverty," by the late Henry George, a most brilliant book, to which no adequate reply has ever been made. I am not able to agree with $\mathrm{Mr}$. George as to the probable social results of the single tax, but wish every farmer might read that book. In the text the subject is considered merely as a revenue measure. 
assessors and neighbors, while the property of the city business man is usually known to nobody but himself, and if known to the assessors could not in most cases be properly valued by them. The farmer's personal property consists of horses, cattle, and implements, which can be and are comnted and valued. The merchant's property goes in as "stock in trade," necessarily at his own valuation. In the matter of money and "taxable credits" there are suppression and perjury, ${ }^{*}$ which yearly increase. In the city of Chicago in 1894 the money of bankers and brokers (other than national banks) was assessed at only $\$ 43,925$, and their "taxable credits" at only $\$ 10,000$. Aside from "brokers" this included twenty-seven banks whose combined capital, surplus, and individual profits were $\$ 20,464$,986. It is probably true that it was sought somewhere to assess and tax the "stock" representing this large sum of money, but there is no likelihood that much of it was reached. At any rate it can not be traced. To suppose that those twentyseven banks had upon hand and subject to draft on assessment day only $\$ 43,925$ is absurd. Such a statement made as a fact, in a morning paper of that day, would have started a "run" which would have closed every one of the banks before night, for at that time the same banks owed to depositors the prodigious sum of $\$ 67,272,832$, and doubtless had ample funds, which the law required them to return for taxation, to meet all demands. The lank officers simply committed perjury. It is not likely that they could have been convicted of perjury or of any other crime. The officers doubtless acted under legal advice, and had a good technical defense. But they committed perjury just the same. That the Chicago estimate of the value of an oath has not yet been reached by the country banks and bankers is shown by comparing the assessment of money on hand on the same day in the country banks of Illinois; ont of twenty-two counties-one of less than twelve thousand population-not one showed so small an amount of

\footnotetext{
* It is perjury when the real owner of property puts it on the day of assessment where, technically, it can not be taxed, and makes oath to a return made upon that basis.
} 
money on hand in banks as the twenty-seven strong state banks of Chicago.* The county in which the city of Peoria is situated returned $\$ 279,684$ in the hands of banks.

While the instance given is but one, although a very bad one, the reader may be assured that it is typical. This entire volume could be filled with evidence officially gathered, and undoubtedly true, that the wealthy men of large eities do not pay taxes on considerable portions of their personal property, and can not be made to do so; that those of the smaller cities are seeking to imitate them, and do so to the extent that they dare-the local assessors and the public being better informed as to their assets-and that the evil is extending to the wealthier citizens of the rural districts. In some states-and in many cities-the assessment of personal property is decreasing year by year as the communities increase in wealth and population. Whatever burden is shaken off by personal property must be assessed upon real estate. The owners of land, however, in the main, are also the owners of personal property, and, as a matter of fact, doubtless pay fully three-fourths of the personal taxes. There are many persons who are not "single taxers" who believe (and for many reasons not here stated + ) that it does not pay to try to tax personal property, and that it would be better for all concerned if personal property were relieved from all taxation. I am here, however, only showing that the present system of taxation is bad for the farmer.

I can not, however, leave the subject without saying that the farmer himself is to blame for a great part of this evasion. Much of the taxation which the farmer most earnestly demands

* For a great mass of statistics on this point see Report of Illinois Bureau of Labor Statistics, 1894, from which the figures in the text were ohtained.

$\dagger$ Any adequate exposition of the difficulties attending the subject of taxation, or of the prineiples or possibility of seientific taxation, would expand this chapter to a book, of which there already are abundance. For one thing the farmer above all things wishes to see " money" taxed, and at the sanie time is equally anxious to have money "cheap." But to tax money is to make it dear, and to tax it more than property-and it always is so taxed since it is assessed at full ralue-is to make it scarce by driving it out of the country. 
is very unjust taxation, and when the law imposes it the victims soothe their consciences with the thought that if they do employ perjury and bribery it is only to escape an injustice not otherwise avoidable. For example, "stocks" and "bonds" are considered by nearly all farmers as eminently proper subjects of taxation. Now this can only be because they do not realize what stocks and bonds really are. Let us suppose that ten gentlemen in Boston decide to build a railroad in California. They have not the money to complete the road, but they have enough to make a good start, and rely upon borrowing what is required to complete it. They organize a company and put in $\$ 2,000,000$. For the money they put in, which is probably not in equal amounts, they must lave something to show, for which purpose "stock" is issued to each one for the amount which he paid in.* This stock is merely a written statement that the holder has paid in the amount stated on its face towards building the railroad. The actual property would be in California. Let us now suppose that when the $\$ 2,000,000$ is exhausted, the company-that is, the stockholders- borrow of twenty gentlemen in New York $\$ 8,000,000$ to complete the road and do complete it and put it in operation for that money. To secure the people who lend the money the company gives its note, which, in the case of railroads, is for some reason called a "bond" instead of a note, and a mortgage upon the railroad. The bond is evidence that the sum named in it has been expended on a railroad in California, and the whole value of the bond depends upon the ability of the property which it represents to pay interest. Under these circumstances the Boston gentlemen who supplied the original $\$ 2,000,000$ would own one-fifth of the road, and retain the right to manage and operate it so long as they paid interest on the borrowed money and no longer. The New York people would own the other four-fifths, and could take

* It would probably be issued for an amount a good deal more than was paid in, upon the plea that the "franchise" -that is, the right to build and operate the road, and to condemn land for its use, was worth a great deal of money, which might or might not be the case. For the purpose of the text I prefer to consider that the stock issued represents actual cash and nothing elsc. 
the whole, if the company failed to pay interest. The stock and bonds alike are simply evidence of interests in property located in California.

Now in this case it is only the railroad itself that can pay any taxes. The stock and bouds earn nothing but what the railroad earns for them. But the railroad is in California, and the authorities of that state, finding it there, tax it for $\$ 10,000,000$, which it cost. The New York assessor, however, finds certain of its citizens with evidence of ownership in a railroad some thousands of miles away, and taxes them upon $\$ 8,000,000$, while the Boston assessor is equally prompt in taxing the $\$ 2,000,000$ owned in Boston. These gentlemen all vigorously protest that all that they own is a railroad in California, which is taxed already in California, but it avails them nothing. So far as the assessor can find the stock and bonds they are taxed. This, if there is an honest assessment in each state, is certainly double taxation, and will be evaded so far as possible, even by improper means. The case of a mortgaged farm is precisely similar. A farmer with a farm worth $\$ 1,000$ may mortgage it for $\$ 2,000$, thereby parting with one-half his property, while retaining the control of the whole so long as he pays interest. He pays taxes, however, in most states, upon the whole farm as if he owned it all, while the owner of the mortgage, if he can be found, is taxed on $\$ 2,000$ additional. If the assessment is honest, taxes are collected on $\$ 6,000$, when there is really but $\$ 4,000$ to be taxed.*

If a manufacturer of agricultural implements sells plows to the value of $\$ 1,000$ to a local dealer, and takes his note at six months, he is taxed on the note. If the dealer sells them

* In California, and possibly in other states, the mortgage is assessed to its owner as appears by the county records, who pays the tax on the face value of the mortgage, the owner of the equity being taxed only on the diflerence between the face of the mortgage and assessed valuation of the farm. This is a correet prineiple, but it did not accomplish what it was intended for. It was demanded by the farmers in order to reduce interest by making the mortgagee pay this tax. As a matter of fact the tax is added to the interest and a little more for contingencies. The mortgage is taxed at its full face ralue, while the land in excess of the mortgage is assessed much lower. 
promptly to one humdred farmers for $\$ 1,500$ and takes their notes he is taxed upon them; and the plows are taxed in the hands of the farmers where the assessor finds them. The only property whose use can earn the taxes is the plows. In this case it is treble taxation. These illustrations might be multiplied indefinitely. What have been given are sufficient to show the nature of the unjust taxation which the farmer demands, and of which he is sometimes the victim. It is demands of this kind which serve as an excuse to rich men for evading taxes. The farmer claims that the rich do not pay their just share of taxes, and it is true, but the way to reach them is not by double taxation. If it be asked how we are to reach them, the reply is that that is one of the most vexing questions in political economy, and not to be fully dealt with in a chapter. We are, however, in this chapter, considering one method which is strongly urged as certain to accomplish the desired end.

Conceding for the moment that taxes on personal property are to be abandoned, the farmer will find that in the assessment of real estate, city property is greatly undervalued as compared with rural land. The evidence upon this point is abundant, but the most striking case that I know of is disclosed in a report (1894) of the Illinois Bureau of Labor statistics. This is a volume of over four hundred pages entirely devoted to the statistics of the taxation of real estate and improvements in the city of Chicago, in comparison with taxation in other parts of the state. The assessed valuations are also compared with true valuations in a great number of cases, the true valuations being based not on estimate, but on actual transactions. One of the most remarkable cases described is that of a lot containing eight thousand two hundred thirty-five square feet-a little less than one-fifth of an acrewhich had just been leased for ninety-nine years at an average rental of $\$ 78,611$. Assuming interest to be 5 per cent, the value of this lot is $\$ 1,572,220$, which is obtained by multiplying its annual rental by twenty. It was assessed in 1893 at $\$ 89,952$, or 5.72 per cent of its value. Assuming the land adjoining to be equally valuable, which it is not, the lot in 
question being perhaps the most valuable corner lot in Chicago, an acre located there would exchange for two hundred fiftythree thousand seventy-seven acres of Illinois farm land at $\$ 32.87$ per acre, that being the average estimated value of farm lands in Inlinois. No property in Illinois is pretended to be assessed at its true value, but assuming farm lands in that state to be worth as estimated, and as seems reasonable to believe, $\$ 32.87$ per acre, they are assessed at 27.75 per cent of their true value as against 5.72 per cent of its true value for this piece of fancy eity property. The report in question shows almost equal unfairuess in all the Chicago assessments as compared with country property. It may be claimed, and it may be true, that Chicago projerty is more grossly undervalued for assessment than that of any other city, but no one familiar with the facts as they exist throughout the country will doubt that city property generally is greatly undervalued as compared with rural property, and the farmers thereby burdened with a wholly undue share of the burden of supporting the government. Whatever, therefore, their conclusion may be, they can approach the subject of the single tax on ground rents, as a fiscal measure, without any prejudice in favor of the abominably iniquitous system which now oppresses them.

In 1890 about one-fourth of the ad valorem taxes levied in the United States were assessed upon personal property, and three-fourths upon real estate. From what has been said it is evident that the ratio of taxes paid by real estate is constantly increasing. The single tax, considered as a fiscal measure, and not as a question of social reform, involves abandoning the attempt to collect taxes on personal property, placing unon gromud rents the entire burden now borne by real and personal property, and adding thereto all the taxes now produced by tariffs and other indirect taxation, poll taxes, and licenses. I do not understand it to inclute the abolition of postage, and otber sums paid by individuals to the government for services rendered. Excluding postage, seigniorage on silver, and some other items, the total taxation, local, state (ad valorem), and national, in the United States, in 1890 , was $\$ \$ 52,459,405$. The 
estimated "true value" of all real estate and improvements was $\$ 39,544,544,333$, of which $\$ 13,137,145,842$ was for "farms" of thirty acres or more. If the ratio of improvements to land was the same as in California in $1896 *$ ( 37.2 per cent) the value of the land alone was $\$ 24,933,973,842$, and the rate of tax on land alone to produce the sum raised by national and ad valorem, state, and local taxation would have been $\$ 3.40$ on $\$ 100$, or 3.4 per cent. The total rental value of the land, assuming interest to be 5 per cent, was $\$ 1,246,668,692$. The taxation of that year would not, therefore, have consumed the entire rental value of land. This, however, gives no indication of how the burden would have been divided between city and country.

I am not aware of any statistics of assessments and taxation within the United States which give a better indication of the probable results of the single tax as a fiscal measure than those of California. Since 1879 all land in California is assessed separately from the improvements upon it, and "city and town lots" are consolidated in the returns separately from other real estate. All property, also, is required to be assessed at its "actual cash value," which in an ultimate analysis must mean a certain number of times the cash rent which is paid, or might be obtained for it. If interest is assumed to be five per cent, the "cash value" would be twenty times the annual rent which could be paid for the use of the property. As a matter of fact property is not assessed at its true value, especially city property, nor can its true value be known in many cases, because the income which it yields is not known. As in other states, the cities are doubtless regularly undervalued. Still, the State Board of Equalization seeks to remedy this, and the fact that in 1890 real-estate values in California were grossly inflated both in city and country, and that the item "city and town lots" includes large areas of what was really farm property, incline me to consider the real-estate assessment of California in 1890 as nearer to the "true value" of

* In the older and colder states the ratio of improvements would be greater, and the land tax rate would be higher. 
the property than any other assessment or estimate that I have seen. It has the advantage of being a regular assessment, and not a single special inquiry, and was made after eleven years' experience, largely by the same officials, in the valuation of property on that plan. The assessors were at least "sworn" to assess at true value if they could find it. Railroads, which are treated by single taxers as "land," were separately assessed, but as I do not believe that the bare land used by the railroads-except street railroads-of the state yielded any rental, after paying fair interest on honest cost, I do not include them as taxable real estate. The street railroads, also not assessed as real estate, doubtless had a value to be reckoned as land rent, but as I have no means of ascertaining the aggregate, I can not include them. With the exception of a few lines, the street railroads could not pay much rent, and it would make no great difference. Still, whatever their rent was should be included as taxable, from a single-tax standpoint.*

The state and local taxes in 1890, in California, aggregated $\$ 18,754,850$. The federal taxation of that year was $\$ 381,094$,265. The population of California was 1.9 per cent of that of the United States. Adding to the state and local taxes $\$ 7,240$,791, which is 1.9 per cent of the federal taxation, there is a total of $\$ 25,995,641$ to be assessed, upon single-tax principles, upon the real estate, not including improvements, of the state.

Unfortunately the California reports of 1890 do not segregate the real estate from improvements, as they have since done, and I am compelled to take the returns for 1891, which are much higher, although the property assessed was the same. The State Board of Equalization that year took great pains to ascertain what was the "true value" of the property assessed, according to their judgment, and raised the assessment in San Francisco as returned to them, thirty per cent, and that of Los Angeles County fifteen per cent. The equalized assessment for 1890 , of real estate and improvements, was \$891,-

* This omission of property is offset by the omission of poll and license taxes. 
449,172 * The equalized valuation of the same property fou 1891 was $\$ 1,013,394,461$, an increase of $\$ 121,945,209$. If it was really a "true valuation" in the sense that single taxer. use the word, that is, free from any speculative taint, it should, at five per cent, have yielded or earned a net income of $\$ 50,669,723$. In my judgment single taxers could well afford to accept the valuation of 1891 as really the "true value" of everything which they would call "land"-and as I write this I have no idea how the tax is coming out, for I have not yet made the computation.

The equalized value of "city and town lots" without im provements was $\$ 348,763,183$. If the local state and national tax of 1891 of $\$ 25,995,641$ had been assessed on city and town lots alone, the rate would have been $\$ 7.10$ on $\$ 100$, or 7.1 per cent. No other property would have been taxed at all.

The total assessment of real estate without improvements, including farm property and city and town lots, was $\$ 764,311$,877. If the national state and local taxes had been assessed on this property the rate would have been $\$ 3.40$ on $\$ 100$, or 3.4 per cent. The averaged equalized value of country lands taxed in 1891 was $\$ 11.56$ per acre. Under the single tax land owners would have paid an average rental to the state of 39.3 cents per acre, and paid no other tax-local, state, or national. $\dagger$ Of course some would have paid more and others less.

The total assessed valuation of all property in California,

* The "true valuation" of real estate and improvements subject to taxation in California in 1890 is given in the census returns as $\$ 1,517,565,300$, which gives an average value per acre for the land taxed of $\$ 35.27$. To those who know California and have viewed the enormous areas of taxed land which is worth almost nothing, any such valuation is sufficiently absurd. If from this "true valuation" the total equalized assessed value of eity and town lots be dedueted, and the remainder divided by thirty-five million nine hundred fifty thousand four hundred sixteen-the number of acres assessed in 1891-the value per acre of country lands will appear as $\$ 32.79$, which at five per cent should give a rental value of $\$ 1.64$ per acre. The areas of arid and almost worthless land are so large in California that $\$ 15$ to $\$ 18$ per acre for land and improvements is quite high enough for an estimated average.

†These computations do not include poll or license taxes, as data are not available. 
after equalization, in 1891 , was $\$ 1,275,832,510$. If the total local state and national tax had been levied on the valuation the rate would have been about $\$ 2.00$ on the $\$ 100$, or two per eent upon all property at very nearly, at least, its true valuation. This is a very serious burden, which tends to inerease annually as we require more and more of our local governments, and as a nation concern ourselves more with the affairs of mankind.

The tax levied in 1891 in California for state purposes alone was $\$ 4,873,848$. Had this tax been levied on city and town lots alone the rate would have been $\$ 1.39$ on $\$ 100$. Hard it heen levied on all real estate, without improvements, the rate would have been 63 cents on $\$ 100$, in these and other similar supposed eases, no other property being taxed. The actual rate levied on all property in the state, for state purposes only, was 44.6 eents on the $\$ 100$.

A somewhat elearer view may be obtained by arranging some of these figures, subject to the assumptions in the test, in tabular form.

The single-tax theory applied to United States and California valuations of 1890 , the California assessment being that of 1891 , and the total taxation as given in census returns of 1890:-

California.
True value of land without improvements.....\$1,013,394,461

Rental value at 5 per cent

$50,669,723$

$25,995,641$

Total tax, local, state, and national

Rate to raise the tax if levied on land without improvements

Rate to raise tax if levied on true value of all property ...\$2.00 on $\$ 100$

Rate to raise tax if levied on city and town lots only $\$ 7.10$ on $\$ 100$

Total tax for state purposes only, California, 1891 $\$ 4,873,848$

Rate of tax if levied on city and country land without improvements $\$ 0.63$ on $\$ 100$

Actual rate levied on all property for state purposes only. $\$ 0.446$ on $\$ 100$
United States. $\$ 23,933,973,842$

$1,246,668,692$ $852,459,405$

$\$ 3.40$ on $\$ 100$

$\$ 2.15$ on $\$ 100$ 
In 1890 there was collected of ad valorem taxes in the United States about $\$ 3.00$ from real estate and improvements to $\$ 1.00$ on personal property. Assuming that California farmers paid the average tax on personal property, a farmer owning land and improvements assessed at $\$ 6,000$ should have been assessed on $\$ 2,000$ personal property. $*$ Of his total realestate assessment, if he was an average man, $\$ 5,160$ should have been upon land, and $\$ 840$ upon improvements. Under laws as they are he was taxed, for state purposes only, at the rate of 44.6 cents on $\$ 100$ and his total tax was $\$ 35.68$. Under the single tax he would have paid 63 cents upon the $\$ 100$ on the valuation of his land only, which was $\$ 5,160$, and his tax for state purposes would have been $\$ 32.50$. This being the tax of the average man, it would appear that farmers having the best land would pay somewhat more than they now pay, and those having the poorest land considerably less. It seems to me quite probable that this would be the usual result. It seems evident to me that if all taxation was collected from city and town lots, the tax would exceed the rental value.

The proposal to confine taxation to land valuest is more than a century old, but it seems also to have been original with Henry George, who, in "Progress and Poverty," without being aware of the earlier proposals, first brought it prominently before the world. As already stated, Mr. George advocated the single tax as a means of social reform rather than as a method of raising revenue, and his discussion, from a fiscal standpoint, is not satisfactory. While the work of Mr. George is neces-

* The personal property taxed in California in 1890 was 16 per eent of the real estate and improvements. In the rural districts it was more and in cities less. It is not, however, likely that it was anywhere near $33 \frac{1}{3}$ per cent as assumed in the tax. In 1861 the personal property assessed was 49.62 per cent of real estate, from which it has declined regularly to 14.03 per cent in 1896 .

† Single taxers draw a sharp distinction between "land" and "land values." They would tax no land for which, exelusive of all improvements which are the result of man's labor, the user could not, after defraying all expenses, including his own labor, afford to pay a cash rent. This rent, whatever it might be, would be the tax. 
sarily controversial, it is brilliant, and bears evidence of earnest conviction. Of the innumerable "replies" to Mr. George, all that I am familiar with are too ill-tempered to be commended to the general reader. While I think him entirely in the wrong as a social philosopher, it seems to me that the convincing reply can only come from one who to the necessary ability adds the same earnest desire for the welfare of the unfortunate classes that is evident in the life and work of Mr. George. 


\section{CHAPTER IV.}

\section{THE FARMER AND THE CURRENCY.*}

F I have sheep to spare and need wheat I do not have to find one who has wheat to sell and needs sheep; whoever needs sheep will give me money and with the money I can buy wheat. One of the functions of money in this transaction is that of a "medium of exchange." In common language I am said to turn my sheep into money and my money into wheat.

In regard to money as a medium of exchange there are always questions of convenience arising, as, for example, with reference to its form, denominations, and the like, and with respect to paper money, the question of responsibility-that is whether it shall be issued by banks or government-seems to me connected mainly with this function; with this exception, however, which has been discussed in another chapter, there is no "Question of the Day" in regard to money as a medium of exchange; such questions as arise are settled by the authority whose duty it is to deal with them, with little or no concern on the part of the public.

The usefulness of money as a medium of exchange, however, involves one characteristic which all good money possesses, and without which it is not good money; it must be something which every one is willing to take in exchange for whatever he has to part with. I do not mean something which some are willing to take, or all are willing to take for some things, or which all ought to be willing to take, but something which as a matter of fact all are willing to take at all times.

The only substances which all men are willing at all times

* See also Book Fourth, Chapter I and A ppendix G. 
to take in exchange for all commodities are the precious metals-gold and silver. These constitute what is called international money because they are recognized as money by all civilized nations. Considered merely as instruments of exchange these metals constitute the best money.

Instead of the metals themselves, promises to pay the metals, in the form of notes issued by responsible governments or banks, are more convenient when large sums are involved, and are preferred by some for use even in small amounts; these constitute good money so long as they can as a matter of fact be exchanged at any time for the metals which they represent, and so long as everybody believes they can be so exchanged. Such notes constitute what is called "representative money." If, as a matter of fact, they can not be exchanged, on demand, for what they represent, these notes are not really good mones, even though they are believed to be, and perform the office of good money until their true character is discovered. A counterfeit note does the work of good money until it is found to be counterfeit, when it immediately loses its value.

A note that can really be exchanged for the metal it represents is not good money if any one to whom it is offered doubts whether he can get coin for it on demand or fears that he might not be able to make the demand. No farmer in the United States doubts that if he should present a note of the Bank of England at the counter of the bank he would get gold for it, but he can not go to the Bank of England, and he may not find any one who can conveniently send it there, and, not being familiar with its appearance, he might fear that it might be counterfeit, and so might be unwilling to receive it, even although actually good; a United States "greenback" would be in a similar.situation in England, while each will circulate freely in its own country. No merely representative money is therefore "interuational money," although the notes of contiguous nations often circulate readily among themselves, as those of France and Belgium and the United States and Canada do to-day. Circumstances, however, are at any time liable to arise to prevent the convenient return of repre- 
sentative money to the place of redemption, so that it never is certain to be at all times the best money.

Sometimes national or bank notes are known not to be redeemable according to their face at the time, and yet it is believed in regard to them that they will sometime be redeemed. That was the case with United States "greenbacks" for many years after 1861 , and is the case with regard to the notes of many 'other countries to-day. Such notes may still be good money, or they may not. If no more are issued than would represent the metallic money which would have circulated had no paper money been issued,* it is the opinion of most economists that they would circulate as freely as if actually redeemable, and be "good money" in the sense of being able to buy as much as the coin which they represent. As no such experiment has ever been made, lowever, we do not actually know this; no nation refuses to redeem its paper money if it can help it, and no nation, once started in the practice of issuing currency not actually redeemable on demand, has ever yet refrained from issuing very much more than the coin which would have circulated in the absence of paper money. When this happens the paper money still circulates, but not at its face value. It is said to be "inflated." It ceases to be even good national money. It is received at some lower value, which is fixed partly by the general opinion as to the probability of its ultimate redemption, but more especially by the amount of excess issues. The larger the issue the greater the depreciation. I shall discuss this further in connection with the functions of money other than as a medium of exchange. A familiar instance of excessive issue is our greenback and national bank circulation issued during the Civil War. Probably few doubterl the ultimate redemption, in coin, of all paper money there issued, by the United States, but at

* Under ordinary circumstances, when nothing impedes the natural flow of undepreciated noney, there will always be present suffieient to make the exchanges, just as there will be food to eat and elothes to wear. As the people need it, somehow they will get it. There will be something for sale, and those who wish to buy will send money to pay for it. 
one time one gold or silver dollar would buy two and one-half times as much as a paper dollar. This was the result of excessive issues. When, however, it becomes evident that representative money will never be redeeined, it very soon loses all value. "Confederate" bills, after Appomattox, were known to be valueless, and nobody would take them at any price. Until other currency could be provicled such exchanges as were necessary took place by means of barter, which is the exchange of one commodity for another. But where there are goods to be exchanged there money will go, and there was very soon other money in circulation.

Money is an element so essential to the transaction of modern business-barter being so extremely inconvenientthat no community will do without it. If gold and silver are not available, something will be substituted as a temporary expedient. Horace White enumerates the following as having been used as money within historical times: cattle, cacao beans, salt, silk, furs, tobacco, dried fish, wheat, rice, olive-oil, coconut oil, cotton cloth, cowry shells, iron, copper, platinum, nickel, silver, and gold; indeed, he says, "it would be difficult to say what has not been used as money at some time or place." The "wampum " and tobacco currencies of our early colonial times are familar to every one. On the Pacific Coast, cattle were commonly used as money up to recent times. The abstract of my farm in California sliows two cases in which the property was sold for "cattle" with no money value attached to them, and to be delivered at a future time.

It is even insisted by some that notes upon which are printed by national authority the words, "This is a dollar," or some equivalent expression, are as good as any money for all necessary purposes, even though issued with no promise or intent to redeem in anything. There is just enough of truth in this contention to make it a very dangerous error among those who have not thought carefully about money, and who are anxious to be able to get money cheaply. There is no doubt that the necessity of money is so great that, in the absence of anything better, such money as this would perform all the necessary functions of money within the territory of 
the nation authorizing it, but provided only that no more of it were issued than would equal in nominal value the gold and silver necessary to conduct the business, if that could be had. Such money is called "fiat money," "fiat" being a Latin word meaning, "let it be done," that is, in this case, "let this be money." The people of a new country, like our first colonists, have no means of getting gold and silver-international money-except by the exportation of goods. But exchanges among themselves are all the time going on, domestic exchanges, in fact, at all times greatly exceeding international exchanges in volume, and for these money is needed. In such cases there is no doubt that, as a temporary expedient, fiat money carefully restricted in volume would be much better money than cattle, or tobacco, or rice, whose production would increase, and ought to increase, and so cease to be a good medium of exchange. When such money had served its turn it would be received in payment of taxes and so return to the authority which originally received goods for it. Practically, however, there are difficulties in the way of even this use of fiat money. The infirmity of human nature is such that no government would be able to restrict its issues of fiat money to the amount required to pay for what itself requirerl, which would be very small, because, when issued, it would immediately begin to return in taxes, so that the government would soon receive money enough for its uses in the ordinary way. This would not satisfy the people, who would insist upon the government printing the money and lending it to them. This would very quickly introduce into circulation a much greater amount of money than would naturally be present of gold and silver or its representatives, in the course of freely moving national and international exchanges, when it would immediately depreciate, and cease to be a good medium of exchange. And still it is true that pure fiat money, with issues carefully restricter to displace only its face value of metallic or representative money, would probably make an entirely satisfactory medium of domestic exchanges. I say "probably," because the experiment has 
never been made, and we, therefore, do not know exactly what would happen.*

An issue of fiat money thus carefully restricted would save to the country making use of it the interest upon the value of the metals displaced, and the loss of their abrasion, less the cost of preparing and renewing the paper currency. It would not, however, accomplish what its only adrocates desire: it would not make money "cheap" and easy to get. If its volume were restricted to that of the other money which would circulate, it would be as hard to get as other money; if it were increased above that point it would depreciate and cease to be good money.

When paper money is issued in excess of the gold and silver which would circulate in its absence, the currency is said to be "inflated." No nation, I think, which has ever resorted to the use of irrerleemable paper money, has failed to issue it in excess-usually very much in excess-of the gold and silver previously in use. Such money when issued by banks is issued to earn interest, and when issued by nations, is issued to save interest. $\dagger$ Experience shows that so long as it can be made to have the appearance or the prospect of accomplishing these objects, the issues will be increased. If issued, as the adrocates of "fiat money" desire, as loans to the people, there would hardly be any restraint on the volume. As the issues increased it would denreciate. If redeemable, the people would in the end be taxed to make good the depreciation. If pure "fiat" money, the loss would fall upon its holders from time to time.

But all popular demand for the issue of fiat or irredeemable paper money is accompanied with the demand that it be

* Many economists of repute are of the opinion that sometime in the future all accounts will be kept in what they call "ideal money "-that is, money which has no actual existence. There are no theoretical difficulties in the way of this, and it offers very tangible advantages, but it does not contemplate the disuse of actual money, and is not yet a "question of the day."

† Of course government paper money has often been issued because other money could not be had, even by borrowing. 
made a "legal tender." A legal tender is money which the law compels creditors to receive in payment for debt. It will be more convenient to discuss this a little later. It is sufficient to say here-where we are discussing money only as an instrument of exchange, that what the advocates of fiat money desire is the opportunity to pay debt with noney which is easier to get than gold or silver. I am not discussing now whether this would or would not be just, but merely defining the real issue. But whether just or not the experience of mankind is that attempts to raise prices by the excessive issue of representative paper money have proved very disastrous, and that there can be no doubt that the issue of pure fiat money would be even more so. The first to suffer are the rich. In the end the rich get their money back from the poor.* Those who always suffer most and longest are the farmers. The injustice connected with the use of money I shall come to soon. The use of irredeemable or fiat money is not the way to remedy the injustice, for the reason that a popular government is never able to refrain from abusing the privilege of issuing such money, and the people, especially the farmers, have not the strength and shrewdness to prevent the consequences from in the end falling mostly upon themselves.

There are one or two popular fallacies that may as well be disposed of here. Nany suppose that it is a great misfortune to have money "go out of the country," and even advocate the use of irredeemable or other purely "national" currency because it "can not be exported." As a matter of fact, no money ever does go out of the country except to buy something which we desire more than money, or to pay debt; in the former case it would be a misfortune not to have the money go out, and in the last case it is just that it should go.

*An instance in point is the greenback and bond issues of the Civil War. In Ohio, where I then lived, one who in 1860 borrowed $\$ 1,000$ could buy with it 1,000 bushels of wheat. Four years later he could have paid the debt with 500 bushels of wheat. The ereditor lost half nis loan. He could, however, and many did, invest the money in U. S. bonds at fifty cents on the dollar in gold, and the farmer later helped pay it at face value in gold. The farmer lost by the transaction. 
No money is "non-exportable" except for the reason that nobody outside the country will take it. It is never desirable to have money that other people do not want and will not have.

Another fallacy is that the population of a country affords any means of determining the amount of money required to "transact its business." There is a great deal of futile comparison of the "per capita circulation" of one country with that of another. Such comparisons have no value in the discussion of any question of much interest to the people. When a statesman observes that any country has a very large per capita circulation he knows that either business is very lively there or that there is a large irredeemable circulation. Without further inquiry he can not tell which. As an item of popular information it has much less value than the amount of annual rainfall.

Money is used for effecting small exchanges and paying balances. In the majority of exchanges which enter into the record of the business transactions of the country it is not used at all. Payments are made by the balancing of credits based on the ownership of commodities, by means of bank checks. Some economists have estimated the actual money used in effecting exchanges as low as three per cent of the total volume; a more common estimate is five per cent. I am certain that this is far too low, as the aggregate of small transactions in which money actually passes is enormous, but the estimate may be quite correct with regard to those transactions which we think of when we use the term "commerce." As what we call "civilization" advances, the ratio of money to the business transacted grows smaller. It will be within the knowledge of all my farming readers that the number of those who have bank accounts increases year by year. Every man who opens an account in a bank by so much diminishes the demand for actual money.

But subject to this modification, that a scattered rural community needs more money to transact a given amount of business than a city community where money circulates more rapidly, and more use is made of banks, that community 
needs and will have the most money per capita where most "business" is done. There are.seldom any means of knowing the amount of money actually in a community or a nation at a given time, or how long it will stay there, ${ }^{*}$ and absolutely no means of knowing in advance how much is required. At any rate, whatever there is is enough so far as the transaction of the business is concerned, or the use of money merely as a medium of exchange. Least of all is any "per capita" estimate, such as we often see, of any value whatever. It simply tends to a confusion of thought. I have said that whatever money there is, within reason, is enough, so far as getting all necessary enchanging done, because the absence of money to effect an exchange, proves that it is not necessary to be made. No one wants the commodities that are for sale, or they can be more cheaply bought elsewhere. If, however, money, or credit in a form to serve the purpose of money, is scarce, as it will be when there is fear or uncertainty as to financial conditions in the near future, while exchanges will not usually stop, prices will be low, while if money and credit are abundant prices will be higher.

This brings me to the second branch of my subject-money as a measure of value. It is only in regard to this function of money that there is ever any serious popular controversy. There are a great number of definitions of money, and I do not intend to add to them. The definition which is nost commonly employed in popular discussion is that it is " a medium of exchange and a measure of value." $\dagger$

The second part of this definition, which I take because it

* All my readers are familiar with the fact that in the autumn when most crops are for sale, money is brought into the country "to move crops." The farmers are paid cash. This they distribute to their ereditors, and in a week it is all back in the banks ready to pay for more crops. This is nearly all borrowed money. When all the erops are bought the money goes elsewliere to be used in other ways.

† Socialists insist that the only proper measure of value is the labor units employed in production, exeluding rent, interest, and profits whose justice they do not acknowledge. Single taxers also eonsider labor the ultimate measure of value, although they do not exelude interest and profits. 
is most in use in common speech, is not strictly correct, nor is the common comparison of money with the yardstick and the bushel correct in all cases. To measure cloth the measure must liave length, as a yardstick; and to measure bulk the measure must have bulk, as the bushel. So to measure value, the measure must have value. Now value as ordinarily conceived means the results of labor applied to the production of some object of desire, as gold or silver. Neither metal can be obtained without substantial labor, and both are objects of desire, irrespective of their use as money. Wampum, however, or fiat money, is not the result of much labor, nor does any one desire them except as money. They have no value, and hence can not well be said to measure value. I say they have no value to make the point clear, and yet that is not quite true. So long as society accepts them as money, they have a value for that purpose, and to the extent that they have such value they can measure value. The trouble is that, for reasons already given, society is constantly changing its opinion in regard to them, usually for the worse, and with every fluctuation of opinion there is a change in the capacity of the measure, which is distinctly what we do not desire in any measure. Such money may be likened to a leaky gallon measure; it will give us a rough notion of the amount of liquid, provided we are very deft and move quickly enough; if we let the milk stand a little in the measure, there will be less of it; if we accept shaky money in payment and keep it a few days, we perhaps can not again buy with it that which we sold for it. We none of us desire any such measure of value as that.

If now the law steps in and prescribes that this wampum or fiat or irredeemable money shall be legal tender-that is, that creditors must take it in payment for debt-a value is certainly created which did not before exist. The money at once becomes an object of desire to those who have debts to pay, especially so long as it can be obtained more cheaply than anything else that will pay debt. So long as it has value for paying debts it will be received, at some rate, by those who have no debts to pay, but know that they can pass it on to those 
who have that use for it. If we could conceive that the time would come when there were no debts outstanding, the fiat money might lose all value, since no law can compel any one to part with property in hand except in exchange for what he desires. In former ages this has sometimes been tried and the severest penalties imposed for refusal to accept whatever the law called money in payment for goods. It has never succeeded, except as for a short time the terror of the law coerced some individuals. In modern times no such attempt would be inade, and if it were would simply result in a return to barter.

As, under any conceivable modern legislation or condition, there will always be debts to pay, it is the belief of many excellent persons that the demand for any legal tender money for debt-paying purposes will always be sufficient to keep it at its full face value for other purposes. As a matter of fact, it will not, if issued in excess, and for this reason that, vast as the volume of pending transactions may be in any nation, they are but a trifle in comparison with the aggregate volume of all future transactions, and when men part with property, and have no debts to pay, they will value the money they receive for it solely with regard to the use they can make of it in the future; they will therefore accept money having no intrinsic value of its own, solely with reference to what they conceive its value may be in the future; and if they part with property to be paid for at some future time, knowing that they may be paid in money which they do not like, they will set their price sufficiently high to make themselves good.* It is in this way, also, that we most readily see the operation of increased volumes of money in raising prices, a raise in the level of general prices being precisely equivalent in meaning to a depreciation of money, although from force of habit we seldom think of the occurrence except as an advance of price,

* The alternative, when the law permits it, is to contract to be paid in some money satisfactory to the creditor. This is what is now taking place in the United States with regard to loans, and other long credits, which are generally made payable in U. S. gold coin. 
which is usually, for the producers, a time of prosperity, because costs seldom advance as rapidly as prices, ${ }^{*}$ and because confidence in the future induces free purchases.

From all the foregoing, upon which I believe all economists are substantially agreed, it must be evident that the only money which is satisfactory to everybody, even for strictly national use, is coined gold and silver, or paper money known to be actually and conveniently convertible into coin, the actual coin or certified bullion being the only reliable international money, at least between distinct nations.

This is because these metals represent actual labor in substantial quantities, applied to the production of materials which are objects of desire irrespective of their use of money, and which are practically indestructible. They have intrinsic value, which means that they are desired for themselves, and not solely for qualities which have been imparted to them.

A satisfactory national money, not redeemable in the precious metals, is theoretically possible, but not practically so, by reason of the inferiority of human judginent and of human nature, which renders it impossible to prevent over issues.

The fact that a merely national currency is non-exportable is not only of no value to the nation which uses it, but is a slight hindrance, as the nation having the non-exportable currency must pay the cost of procuring the precious metals to pay foreign obligations, if, as will usually be the case, it is a debtor nation. This is not a very serious matter, and apparently does not seriously interfere with trade. If there were any special advantage in having a national currency-as silver-for domestic purposes, the matter of foreign exchange should not stand in the way, since in all countries the volume of domestic transactions is enormously greater than that of its foreign transactions, and therefore entitled to first consideration in mere matters of convenience.

It is also true that as human society is now constituted, all the money, or what serves the purpose of money, in the world, must be considered as one stock, which flows freely where it is

* Neither can they be reduced as rapidly, when prices are falling. 
most demander-that is, where profitable use can be made of it-except as hindered by international barriers in cases where any nation uses non-exportable money.

In such cases the non-exportable money displaces, for all domestic uses, the precious metals, which go elsewhere to perform their functions in the money or the arts. This is the well-known Gresham's law, which is merely that any person having two kinds of money will pay out the less valuable to him, and keep the other, which is thus withdrawn from circulation. In due time this better money finds its way to the banks, usually at a premium, and thence to some other country where there may be use for it.

The non-exportable money, whether entirely inconvertible or not, adds to the world's stock of money, not its own volume, but the amount of the precious metals which it displaces.* Its extensive use, therefore, must tend to depress the general level of the world's prices, even although it has the effect of raising prices in the country which uses it.

In a large sense it is true that the more money and credit there is in the world at any time, the higher the level of prices. The volume of money does not vary much, but the volume of credit fluctuates greatly. $\dagger$ Credit is confidence in

* If $\$ 1,000,000,000$ is assumed as the amount of metallic money which would circulate in a nation in which all money was equal to coin, and subsequently irredeemable money to the amount of $\$ 2,000,000,000$ was issued, the irredeemable money would simply take the place of the $\$ 1,000,000,000$ of coin, which would be set free to do its work elsewhere in the world. In this case there is no question that the world's stock of money is aetually increased so long as the irredeemable money does its intended work. But it does not add $\$ 2,000,000,000$; for the exeess of issue is not money but inflation. It adds to apparent value in the country using it, but not to real value.

† It must not be understood by this that we can make prices bob up and down like corks in rough water, by constantly tinkering with the eurrency. The operation of money on prices is very slow, which we are apt to forget in our glib discussions of the subject. We can state in a sentence a result which is the work of years. Effeets are first felt in the money centers, where those whose business it is to study these movements, foresee what is coming and adapt their business to it. Gradually the effects-possibly not for a year or twobegin to be felt in the rural districts. Before this, however, they have been 
the future. When this fails the stock of money is also locked up, and we say that money is scarce, when there is nearly as much money as ever. Money alone, however, will go but a very little way towards transacting the business of the world. When we say that money is scarce, what we really mean is that it is generally thought that a great many people are not going to be able to pay their debts, and that consequently immense quantities of property are going to come on the market, for much of which, at least for a time, there will be no profitable use. Those who owe money, therefore, hoard it, in order to pay their own debts in case they fail of collections, or for fear they will lose it if lent, and those who desire to borrow are unable to get either money or eredit. Of course, under such circumstances, money is as plenty as before, perhaps more plenty, since all who have the power will call it in from other countries, but it can not be borrowed. As the greater part of the commercial business of the world is done on borrowed money or credit, business tends to stop and prices to fall. When the alarm is acute and excessive, there follows what we call a panic, when everybody tries to collect every dollar that is owing to him and hoard it.

But while credit, more than money, fixes the prices of commodities, the volume of money is so large that in the long run as money increases prices tend to decrease. Money never decreases, except by the withdrawal of inconvertible money from circulation, or by the loss of purchasing power of some part of it. When this occurs there is a depression of prices, subsequently, if the loss is local, by withdrawal of irredeemable money, made good by the inflow of other money. If the depression is severe, and accompanierl by a loss of eredit, this may take a long time. If by loss of purchasing power of intermational money, the effect is world-widle.

I have hitherto treated gold and silver as of equal impor.

discounted by more acute and better-informed men, and the farmer pays high prices for merchandise sometimes before he gets high prices for produce, and continues to pay high prices after produce begins to fall. None suffer from an unstable curreney so severely as the farmer. 
tance as money metals. Up to about 1870 this was true. Since that time a great alteration has taken place in their relative values, which has resulted in a great political controversy. The money "question of the day" is the question of the use to be made of silver as a money metal. Upon this question I intend to give no opinion of my own, but to present the argument for each side in a form acceptable to its most earnest advocates, and leave the reader to decide for himself, prefacing this with a statement of facts conceded by all well-informed persons on both sides of the question.

Silver and gold have been used as money by all civilized nations from time immemorial. They have never been held at the same value in exchange, pound for pound. Since the dawn of history a pound of gold would always buy more commodities than a pound of silver. This difference has tended to increase slowly, with occasional fluctuations the other way, since such matters have been carefully noted. At the opening of trade with Japan a pound of gold was valued in that country at four pounds of silver. Of course it very soon rose there to its value in silver elsewhere, doubtless making some fortunes quickly for shrewd traders. In England, in 1262 , there are records of exchanges at the rate of nine and two-fifths pounds of silver for one of gold; in 1485 , the ratio of silver to gold was declared to be thirteen and three-fourths to one; this was in England. About the same time the ratio in Spain was about ten and one-half to one. Gradually as commercial intercourse increased, the ratios in different countries tended to come together, although not very closely; in 1724 the ratio at the French mint was fourteen and one-half to one, and at the English mint fifteen and one-fifth to one. On the continent of Europe, in the latter part of the eighteenth century, the more common ratio was fifteen and one-half to one, at which ratio it is still maintained so far as coined.* When the Uniter States began coinage the ratio was fixed at fifteen to one; but as a pound of gold would buy, in France, half a pound more of silver than it would buy here, all our

* Silver, except subsidiary coins, is not coined in Europe. 
gold went ont of the country, and we were on a silver basis, although nominally the basis was bimetallic.

The fact was that silver and gold refuser to remain permanently at any ratio in any country. The law had no effect on the ratio, except when debts were to be paid. The commercial importance of England, in the meantime, so increased that there was frequent occasion for the payment of rery large sums, upon which the saving of one-fourth or one-lualf of one per cent was an object. The half of one per cent on $\$ 100,000$ is $\$ 500$. Of course all debts were paid in the chealpest metal for the time being, which led to constant friction in the mercantile classes; and partly to get rid of this inconvenience and bickering, Englaud, in 1S10, after some rears of experiment, made gold the standard and the only legal tender for debts above $\$ 10$. That law has never bcen changed. It was enacted for the benefit of the trading and manufacturing classes, has always been acceptable to them, and did not interfere with the use of silver in the small transactions of the masses. No economist has noted that the use of silver seriously decreased in consequence of the act, or that its price, as compared with gold, fell. In fact, it did not, the ratio of silver to gold remaining just as it had been, gently fluctuating about fifteen and a half to one in all commercial countries.

In 1834 the United States, partly in the hope of increasing the "home market" for gold, which was then believed to exist in large quantities in the southern states, changed the ratio from fifteen to one to sixteen to one. Our silver was now overvalued, with respect to the European market, and in two or three years all our silver had disappeared, even to the dimes and half dimes, and its place was taken by gold which came back from Europe. For small climge we were reduced to Mexican and other foreign silver which had become too much worn to circulate in its own country, aurl was bought up cheaply by speculators, shipped to this comntry, and put into circulation at its face value. This was the silver used in all rural districts up to the time of the Civil War. All elderly persons will remember the squabbles as to whether the "pillars" could be seen on the pieces. If they could be seen the piece 
was a quarter of a dollar; if not, it was ten cents. This disappearance of small coin is not likely to occur again, as all commercial nations now introduce alloy into small coins, so that their metal value is much less than their face monetary value. This renders it unprofitable to melt or export them, and they remain in the country for the use of the people. If they were issued greatly in excess of requirements for small change, they would depreciate to their metal value.

During the Civil War, and for some years after, we had an irredeemable currency, neither silver nor gold being in circulation except on the Pacific Coast, where a strong local sentiment kept them in use. Even our small change was paper. This was the first thing to be remedied, as the gradual appreciation of the paper brought the debased subsidiary coins into circulation, while the silver dollar and the gold coins were still at a premium.

As the time for resumption of specie payments approached, it became necessary to revise our coinage laws, which were antiquated and in many respects inconvenient. We were coining some pieces, as the three-cent piece and the twentycent piece, which were not found desirable. At that time we had become used to paper money of small denominations, and there seemed to be no desire for silver dollars. It was at any rate useless to coin them, as they were worth more than their face value in gold, and consequently would not circulate, but go to the melting pot as fast as made, thus keeping our mints at work absolutely for nothing, with a loss to the country of from $\$ 20$ to $\$ 40$ upon each $\$ 1,000$ coined, as the silver bullion cost the nation so much more than could be obtained for it when coined. This, of course, govermment would not permit, and as no owner of bullion would offer it for coinage, no silver dollars had been coined for many years. In 1S61, when the silver dollar was worth $\$ 1.03 \mathrm{in}$ gold, the director of the mint recommended either a change in the ratio or the abolishment of the coin. The breaking out of the war, however, prevented action at that time.

In 1871, however, when, after some years of investigation by committees, Congress set about enacting a new coinage law, 
a bill passed the senate, which had been prepared by the Secretary of the Treasury and the director of the mint, which adopted the gold dollar as the monetary unit, and discontinued the silver dollar* which was then worth $\$ 1.02$ in gold. The matter attracted no public attention, for it was not thought of as having popular interest. For lack of time the bill failed to become a law at that cession, but subsequently, in 1873, was duly enacted. It was freely discussed in both Houses, but attracted little attention, as very few congressmen or editors knew anything about the subject. It was a matter upon which Congress and the public were accustomed to rely upon the experts of the Treasury Department, and coinage committees.

It has been believed by a great many people that these experts were corrupt, and that the omission of the silver dollar, which amounted to a demonetization of silver, was the result of a criminal conspiracy, intended to operate to the improper advantage of capitalists. There is not the slightest evidence that such was the case. On the contrary, in the light of the experience of the world up to that time, and of the condition of economic science st that time, it would seem that no economist or statesman could have had any reason to suppose that any serious results, affecting values on a large scale would followt $t$ of course if we had known then what we have since learned it would have been different. Most of the really important things bearing on this question had not

* Three otber coins were discontinued in 1873-the three-cent, two-cent, and silver five-cent piece.

$\dagger$ It was predicted by a few, notably by Mr. Ernest Scyd, an English expert, and a strong bimetalist, who foretold, at the beginning of the movement, which he strongly opposed, almost precisely what has happened. By a curious inversion of facts, which is really comical, this most pronounced of all bimetalists appears in the popular legend of the "Crime of 1873 " as the head devil in corrupting our congressmen to demonetize silver. Very few economists or statesmen-none in fact who were in a position to act-were impressed with this prophecy, and I do not think they can be blamed. Men who can sce a generation ahead are called cranks, and have very little influence in their own generation. 
then happened. Any notion that there were then living bankers with shrewdness enough to foresee what has happened as the result of the demonetization of silver, and faith enough to act on their belief, is a popular myth. Those who employ such a statement in argument, luurt their cause. There was no "crime of 1873." There may have been a misfortune. The standard was changed for greater certainty and convenience in dealing with large sums of money, with no reason to suppose that it would have any important effect on small transactions. But it did.

At the time when we were revising our coinage systems, other nations, partly for the same reasons which determined us, and partly for local reasons, were doing the same thing. Germany first, and then other countries, wholly or partially demonetized silver. The result has been a fall in silver as compared with gold, unprecedented in the history of mankind. In 1870 fifteen and six-tenths ounces of silver would buy one ounce of gold. Now it requires thirty-four and seven-tenths ounces of silver to buy an ounce of gold. This did not happen all at once. For the first ten years the depreciation was gradual. In 1883 eighteen and six-tenths ounces of silver could still buy an ounce of gold, an increase of the ratio by only three in ten years.

The importance of keeping the two metals at a uniform ratio has always been recognized, although, until recent years, the object was merely to prevent the ininor fluctuations, which were embarrassing in large transactions, no one apparently fearing any such depreciation as would actually affect prices of commodities. With this object in view, France, Belgium, Switzerland, Italy, and Greece formed, about 1866, what is known as the "Latin Union," which was an agreement between the countries that their coinage of gold and silver should be at the ratio of fifteen and one-half to one, both being legal tender. Within a few years after 1873 , public attention in this country began to be directed to the effect of the disuse of silver upon prices, largely, at that time, owing to the exertions of our mine owners, who by the disuse of silver for coinage began to find increasing difficulty in marketing their bullion. The arts 
would not absorb the annual output of bullion at prices which had hitherto been paid. For the purpose of sustaining silver, which was then at a ratio of seventeen and nine-tenths to one, Congress, in 1578, directed the coinage of silver dollars to be resumed, and made them legal tender, concurrently with gold, in unlimited amounts, at their face value, which was at the ratio of sixteen to one, ${ }^{*}$ at the same time pledging the faith of the Uniter States that all money issued by its authority should be constantly maintained at its face value at the existing ratio of sixteen to one. 'This, in effect, pledged the United States to give gold dollars for silver dollars on demand, which has always been done, although by indirect methods involving more trouble than a direct exchange of one metal for the other. The latter, however, is usually done at all sub-treasuries when requested.

As it was evident that when any one could, with an ounce of gold, buy seventeen and nine-tenths ounces of silver, have it coined, and buy back the ounce of gold for sixteen ounces of coined silver, every one would be eager to do it, and that, therefore, unless silver should promptly rise, there would be a great loss to the treasury, individuals were not allowed to deposit silver for coinage, but the Secretary of the Treasury was directed to buy the bullion and coin it for account of the government, which in this way made the profit between the market value of silver bullion and the face value of the coin. This profit to the government is called "seigniorage." The amount directed to be coined was not less than $\$ 2,000,000$, and not more than $\$ 4,000,000$ per month. It was believed that coinage to this amount would sustain the price of silver. In the meantime the authorities of the Latin Union had become alarmed, $\uparrow$ and in 1873 had agreed that the aggregate aninual

* The exact ratio is 15.98 to 1 .

† When the Latin Union was formed it established " free coinage" for both gold and silver. Any one could deposit either metal and receive coin for it less a trifling mint charge. When silver began to fall, the market ratio had only to increase to $\mathbf{1 5 . 7 5}$ to induce deposits of silver for coinage in France, to an amount greater than the capacity of the mint for two years. In one year the 
silver coinage of ali its members should not exceed $\$ 24,000,000$, and that it should not be legal tender for sums above $\$ 10$. Subsequently, in 1876, all coinage of silver, except subsidiary coins, was discontinued by the Latin Union, and a similar course was gradually taken by all other European countries except Russia, which is on a silver basis, and subsequently by British India and Japan.

As silver continued to fall in spite of purchases by the United States, the Secretary of the Treasury, in 1890, was directed to increase his purchases to $4,500,000$ ounces per month, of which $2,000,000$ ounces were to be coined, the remainder to lie in the treasury as bullion, unless called for, as coin, by the demands of commerce. Gold and silver were at that time at a ratio of nineteen and six-tenths to one. It was hoped that these liberal purchases would surely sustain the price of silver, but they did not, and in 1893 the purchasing clause of the act was repealed, and since that time no silver lias been purchased by the United States, and little, if any, coined. On November 1, 1894, the United States, since 1873 , had coined silver dollars of the face value of $\$ 421,776$,408 , and had on hand, in addition, silver bullion to the amount of $138,809,681$ fine ounces. The total cost, in gold, of the coin and bullion had been $\$ 508,993,975$. It was worth, at that time, $\$ 293,549,258^{*}$ in gold, and as this is written, with the ratio of silver to gold thirty-four and seven-tenths to one, is worth, as bullion, $\$ 278,472,525$-the United States being pledged, as to the portion which is coined, to maintain it at its face value of sixteen to one.

It became evident that the United States could not sustain the price of silver in this way, and that the attempt to do so

deposits of silver to be coined rose from $5,000,000$ franes to $654,000,000$ franes. If a difference of .25 could cause such a rush to dump silver, it can be imagined what would happen if the difference were greater. As the Latin Union, like the United States, guaranteed the ratio of $16 \frac{1}{2}$ to 1 on all its coinage, it was compelled first to restrict and then to suspend free coinage of silver.

* At average prices of silver for 1894. These figures are not extended to absolute corretness. 
was seriously impairing its credit and that of its people.* The United States, while nominally on a binetallic basis, because gold and silver of its own coinage are both legal tender in unlimited amounts, is really upon a gold basis, because the United States stands pledged to redeem the silver in gold. We receive a silver dollar at the same value as a gold dollar, not for the silver there is in it, nor wholly because it is legal tender, but because of the promise of the United States to see that we get gold for it. If we should lose faith in that promise, silver dollars would depreciate. Should its legal tender function also be withdrawn, United States dollars would be worth no more than Mexican. So long as we have faith in the promise of the United States, the withdrawal of its legal tender function would make no difference in its value in ordinary transactions. National bank notes are not legal tender, but we accept them without question, or caring anything about the banks which issue them, because we know that the United States will redeem them, if the banks fail.

Upon the failure to sustain silver by monthly purchases, and after international conferences had made it evident that $n \Theta$ international agreement for the remonetization of silver could be reached, the advocates of silver in this country cut their bridges and took the only position which it was possible to take with any show of reason. They demand that we open our mints to the free coinage of silver, by whomsoever deposited, at the ratio of sixteen to one, and that the silver so coined shall be legal tender in unlimited amounts, for all

* The expression in the text means exactly what it says. The business, and especially the creditor, classes did not believe that the United States were rich enough to make good the difference between the market and our legal ratio of all the silver in the world, nor did they believe the people would long submit to be taxed even to make good the difference on the amount then authorized to be purehased. They did not know what would happen, but were sure things could not go on as they were. Hence they began to press for gold while they could get it, and refused to lend more money exeept on gold eontracts, and then with much eaution, or to undertake any new enterprises. We could not get trusted to the extent of the difference between the bullion value and the face value of all silver which we might choose to coin. 
debts, public and private. Whether or not this shall be done is the money "question of the day."

From the discussion of this question it is desirable to eliminate two subsidiary questions:-

First, shall the United States bonded debt be paid in silver? By its terms it is payable in "coin," and silver is coin. At the same time it has not for a very long time bees customary anywhere in the world to employ silver in these very large transactions, and, although silver, when our earlier bonds were issued, was worth.more than gold at a ratio of sixteen to one, no creditor would expect silver in payment, because the custom was to use gold in such payments. When our later bond issues were made, and for the express purpose of strengthening our credit in borrowing money, Congress explicitly pledged the nation to keep all currency issued by it on an equality with gold. Many millions of our hourls have been issued on the strength of that pledge, and if any are outstanding of earlier issues, they have continually changed hands on the strength of it. The faith of the nation is unquestionably pledged to the payment of these bonds in gold, which was received for all issued since the war, and the pledge must be made good. To pay the national debt in silver would be repudiation to the extent of the difference in value, and would not only be dishonest, but unspeakably silly. Our national credit would be gone, and when we need to borrow money again, we should be compelled to pay well for it or go without it. The fact that our credit was poor would make us a weak nation, certain to be imposed upon by other nations. This would require increased taxation for defense, and in one way and another we should pay very dearly for our dishonesty. In modern times the ability to borrow money cheaply goes fur to take the place of a standing army and a great navy. While the intent to pay the national debt in silver may be inferred from the specific demand that it be -as it is now-a legal tender for that purpose, and while many who are presmmably ignorant of the equities of the case, honestly believe that it should be so paid, it is impossible to suppose that such a thing should ever be officially proposed 
except by some demagogue who hopes to win favor from the ignorant. At any rate I decline to consider it as a debatable question or include it as a "question of the day."

Secondly, in the event of the adoption of free coinage of silver, is the United States to stand pledged, as it is now, to maintain all silver coined by it at a ratio of sixteen to one with gold? This question, so far as I know, has never been made a matter of prominent popular discussion. No demand has ever been made by the advocates of silver for any change in the existing law, and in the absence of a change the Uniterl States would stand so pledged. At present prices of silver bullion, under such an arrangement, any one with $\$ 100$ in gold could buy silver for which, when coinerl, he could get $\$ 200$ in gold. It is needless to say that we should all of us drop everything else and do this. It is the belief of the advocates of free coinage that this scramble for silver to dump onto the country would result in the immediate rise of silver to its old ratio with gold. That some rise would occur is practically certain; that any such rise as would fully protect the treasury would oceur, 110 competent person believes; at any rate, the risk would be too great; the United States alone can not afford to pledge itself to make good the difference in value between the silver and gold of the world; none of us are willing to be taxed for any such purpose, or to take any chance of it. I shall assume, also, that this is not a practical question, but that should we adopt free coinage of silver, the United States, as to all silver coined after that date, would assume no responsibility except for weight and fineness. The-new dollars must take their chance. They would be legal tender.

Under such an arrangement no competent person will undertake to predict what would happen, except in a very general way. The more competent the person, the more certainly he would not predict; but all well-informed persons believe that gold would immediately disappear from circulation in this country, and that silver would rise, as compared with gold, to some ratio intermediate between that at present existing and the nominal ratio of sixteen to one. The real 
"question of the day" is whether we shall change from the gold standard to a silver standard, and even those who have most faith in a rise of silver realize that they must defend the silver basis in order to win.

There is one alternative which may as well be mentioned here. If the United States and the principal commercial nations of Europe would agree to coin both gold and silver freely as deposited, making both legal tender at a uniform ratio, it is the concensus of well-informed opinion that the two metals would remain at that ratio indefinitely, except in the case of events not reasonably to be expected. There is not, however, agreement that they could be maintained at sixteen to one, some thinking that the ratio would need to be as high as twenty to one, even if all commercial nations were to unite. I know of no way of determining this without trial. It is not likely, however, to be tried. Repeated attempts by this country to induce European nations to unite with us in remonetizing silver have made it evident that other nations will not join unless England comes in, and that England, at least for the present, will refuse. The reasons assigned by Great Britain for her refusal to join in such a movement, are those usually assigned by the advocates of gold monometalism. The strongest reason, however, is believed to be one not officially given, which is the belief of a controlling majority that Great Britain, as a creditor nation, is directly interested in preventing money from being easier to get. A minority, however, even there, think that England's prosperity can best be promoted by the prosperity of the world, and that, unless prices begin to rise, the loss of debts by bankruptey, and the loss of trate, will more than offset any possible gain by the maintenance of low prices, and so believe it to be in the interest of Great Britain to unite with other nations in remonetizing silver. Besides, there are many debtors in Great Britain itself. But for the present there is no likelihood that Great Britain will abandon her exclusive gold standard, and hence no likelihood of international bimetalism. This is not, however, a "question of the day" in America. There is an orerwhelning majority in favor of it. Its adoption depends upon other nations. 
It is also proposed by some that if the United States alone should undertake to find sufficient use for silver to materially raise the price of the world's stock of silver, it should not attempt to raise it to the ratio of sixteen to one, which very few believe it ean do, but that it should expend its effort towards something easier, in which, as they claim, there is a fair chance of success. They therefore propose that we estahlish free eoinage of silver at a ratio of twenty to one, or even twenty-four to one. If in this manner, as they claim, the United States can raise the market price of the world's stock of silver even to one of those ratios, we shall have gainerl much while still retaining the advantage of an international currency. This proposal, however, has so far received little indorsement in this country, although in the discussions relating to international curreney it has strong advocates. It is possible, at any time, that the discussion may center on this proposition even liere, but at present the advocates of silver say "sixteen to one or nothing," and their opponents oppose any action whatever by the United States alone. And so the issue is marle up.

The important arguments on both sides of this question can be stated quite briefly, but their proper apprehension requires the presentation of one or two other matters not yet alluded to. It may be assumed that as the world's stock of inoney inereases, prices, other things remaining equal, will rise; and that if money decreases, or even remains stationary while commodities and exchanges increase, prices will fall. While assuming this, howerer, I have hitherto made no distinction between money used to pay, on the spot, for purchases, and promises to pay money in the future. In transactions of this latter kind money is said to be a "standard of deferred payments." It is obvious that when money is received on delivery of goods, and immediately, or soon, paid out again in other transactions, the rise or fall in the value of money is of slight importance in the deal, although it is true that when prices are believed to be steadily falling the number of transaetions will be less, as men tend to stop production of goods on a falling market; but considered merely as a meas- 
ure of value, fluctuations do not seriously affect individuals in their cash transactions. But when debts are to run a long time, as usually in the case of mortgage loans, the change in the value of money may become very distressing either to creditors or debtors, according as prices rise or fall. The change in the value of United States money which occurred between 1861 and 1863-64 worked great hardship to creditors; those which have been taking place since have worked great hardship to debtors. In the case of public debts, usually running for a long term of years, the difference may become very great. It would, in 1898, have required the sale of forty per cent more commodities to pay the national or any private debt than would have paid debts to the same amount in 1870 . It is really over money as a standard of deferred payments that political controversy principally rages.

We are continually speaking of money as a "standard." Now a "standard" is supposed to be something which does not vary, and as a matter of fact it is elaimed by some that money, or at least gold, does not vary, but that the variation of prices is merely an indication of the variation of the value of commodities. 'There must be some way of settling this preliminary matter or we can not get on at all. It is evident that gold and silver are "commodities," as much as wheat or iron, for they are constantly bought and sold in the market as bullion, without reference to their use as money. It is claimed, however, that on account of their great value they are carefully preserved, that the waste is small, and that the accumulations of ages have now become so enormous that the annual additions, however large, have but a trifling effect on the total volume. Wheat, on the contrary, is consumed almost as fast as produced, so that price is immediately and greatly affected by the annual supply, and that as to iron, while comparatively indestructible, it is so cheap, and used in such enormous quantities for purposes for which demand is constantly changing, that this, also, constantly varies in value. Taking these as illustrations it has been claimed that, while perhaps not actually stable, the precious metals, and especially gold, are so much more stable than any other known substance as to 
be on the whole a very satisfactory standard, and at any rate the best that ean be had, and that we shall all be better off if we assume it to be the standard, and govern ourselves accordingly without worrying.

When we come to look deeply into the matter we are indeed compelled to confess that in regard to value there is, and apparently can be, no single substance which by any course of reasoning can be shown to be a satisfactory standard of value, and that in fact no one has yet been able to see how in any way we ean get such a standard. The best thing we can do, or, at all events, the best thing any one has yet been able to suggest, is to compare one or two commodities with the aggregate of all other commodities, the latter being taken as the standard.

It is evident that if we had a complete list of everything bought and sold in the world, with the exact quantity used of each in a given time, and the totals of the sums paid for each commodity for that time, we could obtain, by dividing, the exact average price for each commodity at that time, and the aggregate sum paid for the whole. If, then, the next year, and thereafter each successive year, we should repeat the operation, always using the same quantity of each commodity, but the prices current in each year, we should be able, by comparing the aggregate sums paid, to know whether prices had risen or fallen. Usually the aggregate prices would be found not far apart, for, although the prices of the articles might not be the same in any successive years, yet as some would certainly, according to all human experience, be higher, and some lower, these would tend to balance, and the aggregate remain the same. But in this case we compare the aggregate of all commodities, with their compensating tendencies, with a single commodity, gold, or, at most, with gold and silver. It is, therefore, more reasonable to assume the aggregate of all commodities as the standard, and if the aggregate of money paid is larger, to say that money has fallen, and if less, that money has appreciated.

Now while it would not be possible to enumerate all the commodities bought and sold in the world, much less to 24 
ascertain the quantities used of each, and the prices paid, it is possible to take a large number, and of many to determine the approximate amounts used, and the current prices for a long series of years; and this has been done. As the aggregate sums each year, however, would be unwieldy and inconvenient, quite impossible to remember, and difficult to compare, the aggregate of the first year is usually taken as one hundred, and those for the succeeding years at the proper percentage over or under one hundred, as the case may be.* These numbers are called "index numbers," and are taken by economists the world over as the standards by which to compare money. No one pretends that they are perfect standards, but only that they are the best we have. They are imperfect as standards to measure money by, not only by reason of imperfections in their construction, but because prices are

* The method of constructing the index tables is very simple, the difficulty lying in the selection of proper articles, giving each its due weight in the table, and in the labor of ascertaining the current prices. Disregarding all niceties of construction, and not attempting to quote actual prices, let us suppose that we were constructing an index table, beginning with the year 1880 , and that the average prices of five commodities for three years were as follows, the same quantity of each commodity being taken in each year:-

\begin{tabular}{|c|c|c|}
\hline 1880 & 1881 & 1882 \\
\hline 100 bushels wheat............\$\$90.00 & $\$ 100.00$ & $\$ 75.00$ \\
\hline 100 pounds beef................. & 6.00 & 5.00 \\
\hline 100 yards sheeting............. 12.00 & 9.00 & 10.00 \\
\hline 100 gals, olive-oil.............. 100.00 & 125.00 & 115.00 \\
\hline 1 ton pig iron.................. 30.00 & 20.00 & 25.00 \\
\hline Total ..........\$240.00 & $\$ 260.00$ & $\$ 230.00$ \\
\hline A verage...................... $\quad 48.00$ & 52.00 & 46.00 \\
\hline Index numbers............... 100.00 & 108.00 & 96.00 \\
\hline
\end{tabular}

It is evident in this case that the commodities which, in 1880 , could be bought for $\$ 240$, would cost $\$ 260$ in 1881 , and $\$ 230$ in 1882 . If for convenience we take 100 to represent the price in 1880 , as an index number, conlputation by the "rule of three" will give 108 , and 96 as the index numbers for the two following years. The cperation is, disregarding fractions,

$240: 260:: 100: 108$

All index tables are compiled in a similar manner, a larger number of articles being taken, with care to obtain correct prices. 
affected by other things than abundanee or searcity of money. The tables are used by those upon all sides of monetary controversy to sustain their views. From these and other tables diagrams may be construeted to represent quickly to the eye whintever the tables may teach. Some things can be thus shown with entire aceuraey, as, for example, the appreciation of gold as compared with silver, or the depreeiation of silver as compared with gold, as one may prefer to term it. In this case there are but two commodities eoncerned, and their variation may be shown with entire accuracy, but where a large number of elements come in, it is not always so easy to determine what the lesson of the table or the diagram actually is. A number of tables, diagrams, and other statistical matter, will be found in Appendix G, to which the reader is referred for the material for an exhaustive study of the currency question.

The argument for the single gold standard may be stated as follows, in the language of a supposed earnest advocate of that policy:-

I. It is just. The variation of prices is not caused by the appreciation of metallic money, the volume of which increases as steadily as that of other commodities, indeerl more stendily, since nothing else is so carefully preserved from destruction, but by the decrease of eost of production of commodities. As production and transportation are cheapened by modern proeesses, prices must decrease, and in so doing will still leave the same margin of profit to the producer and transporter. The late fall of prices in the United States by no means represents a real fall in values, but a squeezing out of imaginary values which never really existed, and this is true not only of such property as is usually represented by stocks and bonds, and exhibited in failures of manufacturing enterprises, and the "reorganization" of railroads, but of real estate, which, especially in the west, has been held at highly inflated values, upon which it could not possibly be made to earn interest. What we call a fall in value is therefore nothing but a sudden realization of true value, and the shattering of hopes which had .never any real foundation. Statesmanship considers the per- 
manent welfare of nations, and will not seek to relieve one generation which is suffering from the reaction from an inflation of values of property, by plunging it into a new era of speculation in inflated money, certain in time to react upon another generation, causing the people distress like that which we have endured. Statesmanship is just not only as between individuals, but between generations.

As between gold and silver it is the fact that gold has long been used in large transactions in commercial nations, to the exclusion of silver, by reason of its greater convenience and smaller cost of transportation and storage; and as transactions constantly tend to grow larger, the increasing demand for gold, without corresponiing reduction in cost of production, has kept its value steady with respect to commodities at their decreasing cost, while silver has depreciated by reason of new discoveries and great economies of production, without corresponding increase of demand either for money or in the arts. The facts show that silver production continues, even at its present low prices; geology teaches us that the supplies of silver in the earth are practically inexhaustible, and it is plain that any increase of price would at once cause the working of the best of the enomous deposits of low-grade ore whose locations are known, but which can not now be profitably worker, and that if by remonetization or any other means the purchasing power of silver could, for the time, be cloubled, as is imagined, silver mining under modern processes would become the most profitable industry known, and the world would be inundated with such a flood of it that the power of all the governments of the earth would be wholly insufficient to maintain any ratio between silver and gold materially (lifferent from that of the relative cost of the production of the two metals. The depreciation of silver is therefore the inevituble result of economic forces of irresistible power, and correctly represents the value of that netal as compared with goll. Dealings upon the gold basis are therefore just, and dealings upon any other basis are unjust, and the consequences of any attempt to enforce such dealings will inevitably fall on the least informed and least organized, among whom are cer- 
tainly the farmers. Under present conditions the production of gold is rapidly increasing, which, in due time, will cause an increase of prices.

II. It is expedient. Justice is always expedient. The serious proposal to admit silver to free coinage in this country was sufficient to seriously affect credit and is responsible for a great part of the business troubles of the past few years. Men will not invest in business, or lend money to be so invested, while they fear that their returns may be in a currency which they do not desire. Arguments based upon prophecies of general prosperity are of no arail. That men with money think of is their own prosperity. They put in gold, and wish to know that they are to take out gold. If this country does not wish their gold on these terms, they will smol it elsewhere. The success of a party pledger to the adoption of free coinage would, for this reason, absolutely paralyze business until the new basis should be established. This period might extend from the November elections in one rear till some time in the summer of the second year, and must do so unless an extra session of Congress were called. This entire period would be such a season of distress as no country has erer witnessed in modern times. There would be a universal scramble for gold, and an equal universal refusal to lend it, on any terms which legitimate business could pay, because it could be more profitably employed in speculation. Foreign holders of American securities woukd become alarmed and return them to this country for sale at prices far below their value. Of course this would be foolish, because those securities are as valuable in foreign hands as in those of our own people, but capitalists are as easily panic-stricken as other people, and the return of these securities could be absolutely depended upon. Our omn capitalists would be better informed as to these securities than foreigners, and would use their knowledge to profit by the panic of foreigners; but it would, for the time, lock up money all the same. Such money as should be absolutely required to "move crops" could, of course, be had, but at high prices, which would mean low prices for crops, foreclosurers of mortgages, stoppage of manufactures, and mercantile failures. The 
gold would disappear, while yet there was no provision for other currency. Property of all kinds would be in the market at ruinous prices and be bought up by speculators. Granting all that the advocates of free coinage claim as to the injustice which luas been wrought upon the debtor classes by the alleged appreciation of gold, the attempt to remedy it by a sudden inflation of money by free coinage could only result in additional losses tenfold greater, during the interim between deciding to change to a silver basis and the actual accomplishment of the act. These losses would not fall wholly upon the rich, who in one way or another would know how to protect themselves, nor upon the unindebted, who could doubtless live, but on the debtor classes, who are clamoring for free coinage. It is true that the actual unincumbered owners of the property of the nation, as they would be when the legislation was completer, and the new silver coinage began to circulate, might look forward to an era of rising prices, as measured in a rapidly depreciating currency; that rising prices excite hope and confidence, and lead to renewerl effort, general employment, and increased production; but prices can not continue to rise indefinitely; sometime they must reach a limit, and if all former human experience is a guide, must fall from that point. Inspection of the diagrams of prices shows that they are never stable, but are always rising and falling, in more or less defined cycles; and so long as they move slowly and regularly along a general level, that is the normal and most prosperons condition of business; whereas, all abuormal increases, whether causer by inflation of currency, or speculative ideas of the value of property, have been invariably followed by corresponding abnormal depressions, with all their accompanying distress. We luave lately been at the bottom of such an abyss; many inevitable liquidlations have taken place; doubtless there may be yet some more to come; but in the main business has adjusted itself to the actual relations of commorities and gold. All loans marle or renewed by the great money-lending agencies are now made payable in gold coin; no money can now be borrowed in the money market, on long time, except upon such agreements. Almost the only cases in which mort- 
gages are now made payable in "lawful money" are those for deferred payments due to the seller of the land. There are many of these, held by farmers, who, in case of frec coinage, rould lose the difference between the gold value and the silver value of the face of the note. If any farmer doubts that such a mortgage is even now depreciated, let him try to sell one to a bank.

Another matter to be considered is the life-insurance interest. The amount of life insurance outstanding in this country is enormous. With free comage of legal tender silver, such insurance would be payable in the depreciated money. In a multitude of cases the policies are assigned for debt, or kept i1] for the purpose of paying off a mortgage on a homestead, on the death of the father of the family. Under free coinage the value of this insurance as security, or for the protection of a family, would be enormously depreciated. In like manner deposits in savings banks would depreciate, except as they are being protected in making or extending loans, by contracting for gold payments.

The amount of indebtedness that would be relieved by free coinage is enormously exaggerated. Short-time indebtedness, while of huge proportions, does not count, as for the most part every such debt involves a corresponding credit. The manufacturer borrows from the bank, but has a corresponding note coming from the jobber; the jobber has the note or account of the retail merchant, who in turn has the obligation of the farmer, who must dig up the money. If free coinage were seen to be coming, he would be made to pay while yet he could be made to pay gold, and in default of payment would be sued. The only indebtedness which could in any case be "relieved" by free coinage would be mortgage debts not specifically payable in gold, which should not become due until the silver basis was established, and upon which interest should be carefully kept up so that the principal could not be declared due in advance of maturity. With every day this class of indebtedness grows less; before any change of the money basis could be made, very little would remain. It is not worth while to invite certain calamity to all other interests 
for the sake of relieving this small remnant of the old form of debt, even if it could be relieved by free coinage.

Finally, the gold standard is the more stable, because international, and therefore less liable to disturbance from local causes. A currency which is national only, as between the nations recognized as commercial, would constantly fluctuate from eauses arising within the country-as popular agitations for changing the coinage, the exhaustion or discovery of mines, and the like, which would not affect, or would affect in a much less degree, money circulating at full face value among all commercial nations. The natural and most desirable standard of money is that used in the largest transactions, and which is universally recognized as money. As a matter of fact, since silver and gold have never yet remained stationary in any country at any ratio, it is reasonable to suppose that they never will. Whatever we may say, or whatever fiction of law we may adopt, the real standard will always be either gold or silver, and gold is the best and most just. In so far as we have obligations not yet due, payable in "lawful money," either to foreigners or our own people, it would probably be a relief to the immediate debtors to pay them in depreciated silver. As, however, all such obligations have been contracted under the pledge of the nation to maintain all currency authorized by it on a par with gold, the creditors, in such cases, would consider themselves cheated, and when other Americans, as is sure to nappen, wish to borrow money, they either could not get it, or would be compelled to pay dearly for it. This would result in relieving present debtors at the expense of future debtors. This is not good statesmanship and would not pay. We want sound money.

The above is the argument for a gold standard condensed into the strongest form in which I am able to express it.

The argument for free coinage of silver by the United States, regardless of the action of other nations, at the ratio of sixteen to one, both gold and silver to be full legal tender, may be staterl as follows, in the language of a supposed earnest advocate of that policy:-

I. It is just. The fall of prices can by no means be 
accounted for by decreased costs of production. Even if this could not be demonstrated as to some particular articles, as to large classes of products something more than decreased costs is certainly needed to account for the low prices. This is especially the case in regard to agricultural products. The decreased cost of manufactured articles depends largely upon what economists call the "law of increasing returns," which is that as capital is increased and concentrated upon the manufacture of single articles in great quantities, costs are decreased and returns per unit of capital increased. While this, however, is recognized as true in respect to many industries, economists are equally agreed that it does not apply to agricultural operations, but that, on the contrary, they are governed by the "law of diminishing returns," which means that after passing a point easily reached, costs can not be decreased by the application of additional capital, but, on the contrary, will tend to increase with decreasing returns per unit of invested capital. As a matter of fact, costs of agricultural products have not decreased in any important degree; the apparent reduction at points of consumption is mainly due to decreased costs of transportation, the farm costs remaining very much as they formerly were; interest is not less; * land did not fall until forced down by continued low prices of produce; the cost of living has not decreased, by reason of the advancing standard of life; farm wages have not fallen in any important degree, or much more than in other arocations, in which, in fact, wages have not fullen at all, except by irregularity of employment, but have tended to an actual rise, and their purchasing power has increased enormously; the alleged low costs of the so-called "bonanza" grain farms are assumed; these assumptions rest on no

* Interest on farm loans is not less. Interest on money in large amounts, upon security believed to be unimpeachable, has fallen, and a few economists have insisted that conceding the appreciation of gold, the appreciation laus been made good by the fall in interest. There is a monograph by Prof. Irving Fisher, of Yale University, taking this view, among the publications of the American Economic Society. I can find little or no trace of any fall in the retail price of money-that is, in the interest on small loans. 
authentic data, as these concerns do not publish their balance sheets; there is no reason to suppose that even by the rapid robbing of nature by machinery have bonanza farmers been able to reduce average costs below those of ordinary farming; the quantity of grain produced by "extensive" farming is but a small part of the grain produced in the world, and if costs were reduced, the bonanza farmers would be able to save the profit for themselves, since prices, so far as affected by supply, would be regulated by the great bulk of grain produced in the thickly settled and most fertile rural districts, and not by the comparatively small amount produced by machinery on great plains. As to savings by the use of machinery by small farmers, it is an open question whether there are savings; the prices paid by farmers for machinery are usually exorbitant, and for "repairs" still worse; machinery is usually bought "on time," at rates of interest which no industry can afford, and the annual waste by carelessness and neglect is fearful; it can neither be affirmed nor denied with much assurance that the use of the more expensive machinery has reduced the cost of agricultural products, but conceding that there has been some reduction from this cause, it is not much, nor does the examination of any and all elements of the cost of raw material disclose any possibility of reduction of cost at all corresponding to the fall in prices, the only considerable saving-the reduction in prices of merchandise-being fully absorbed by the advance in the standard of life, which the farmer seeks to share, and ought to share, with other classes. All agree, however, in assigning either to reduction of cost, or appreciation of money, the reduction of prices; since it is evidently not the former, it must be the latter; but it is absurd to say, and noborly will say, that appreciation of money has reduced prices of agricultural products, and not affected prices of other products. Therefore it is mainly appreciation of money which has reducer the prices of all products. The remedy is therefore the depreciation of money by increasing its volume, not by fiat or irredeenable paper money, but by restoring to its monetary office the metal which has been discarded by so many commercial nations. 
As between silver and gold, the diagrams show that while silver itself has appreciated slightly during the last twentyfive years, it is shown to be a measure of value far more just than gold. But in relation to agricultural products these tables of index numbers are very unfair to the farmer, for the reason that the index numbers of agricultural prorlucts are based on prices at centers of consumption, and therefore include cost of transportation, which is the only element in which there has been important if any decrease of cost. Tables in which the index numbers should be based on farm costs would evidently show a still greater appreciation of money, and especially gold, and if applied to agricultural products alone would show the conditions to be worse than have been claimed.

To the contention that all existing contracts in the United States are based upon the pledge of the United States to maintain all forms of currency issued hy it, upon a par with each other at established ratios, it may be replied that that has nothing to do with equities between man and man upon which the argument for free silver is placed, and that, as a matter of fact, the consideration has never entered into the formation of contracts; the fact that the United States has promised to and will redeem its outstanding silver coinage in gold at sixteen to one may or may not involve a national loss, but is certainly no reason why the people of the nation should forever retain gold as its standard of value. It is conceded that remonetization of silver would in some degree raise its price, so that even were silver remonetized, and upon the assumption that the monetary standard is hereafter to be silver, the farmer, at least, would still be at a disadvantage. The decline in the value of silver as compared with gold can in nowise be attributed to increased production, which has not been anything like the decrease in price, but is mainly due to its general demonetization by commercial countries, and more than all else to the fear of commercial classes everywhere that it will soon be practically abanioned as money. The remedy is speedy and full remonetization, produced by such a display of voting strength on the part of the classes which have been injured 
as shall make it evident that silver money has come to stay. It has fallen in price from a lack of confidence. Its price must be restored by a restoration of confidence. To set gold as the permanent standard of value is to doom all the indebted classes to slavery, for geology teaches us that the supply of gold in the earth is limited, and mainly near the surface, and when found in deeper veins its extraction becomes excessively expensive, so that with the rapid exhaustion of the placer deposits now going on throughout the world, the cost and value of the metal will rapidly increase, with a corresponding increase in the obligations of the debtor who is compelled to obtain it. Silver is not a good standard of deferred payments; it tends to appreciate, ${ }^{*}$ to the disadvantage of the producers, whose costs are stationary, and to debtors with long-deferred payments; there is, however, some reason to hope that by improved processes of production, under the stimulus of better demand, its production may be so increased as to in some measure relieve this injustice. At any rate, it is a better standard than goll, and some approach towards justice is at present all that anyborly is demanding.

II. It is expedient. Justice is always expedient. The standard of payment should not be that money which is most used in large transactions, but that which is most largely diffused among the people of the earth, which is the most bulky and unwieldy, and therefore moves about less freely and is less subject to local and even general influences. There will always be gold enough to pay cash balances between nations after offsets of credits have been balanced. Let it be used for that on the basis of its commercial value as compared with silver, which is the proper standard. The notion that there will be occasion for the expensive transportation of silver on a large scale is a myth. The proper place for silver is in the hands of people for daily use, to the extent to which that can be stimulated by the withdrawal of paper money of small denominations, and for the rest in banks and national

* There are no adequate data for determining this question of fact. See Appendix G, for all there is upon this subjeet. 
vaults, from which it is represented by praper. Of course it will cost more to build vaults for that purpose than to build them to hold only one-sixteenth or one-twentieth of the bulk, but in consideration of the end to be gained, the cost is not serious enough even to be spoken of.

As to the calamities which are predicted during the season of transition, they are doubtless overdrawn in the arguments of the gold monometalists; but something of the kind would happen; there would be a scramble for gold as stated; there would be pressure to collect debts; production would diminish, and men be thrown out of employment; the rise of prices would not come at once, and would be preceded by a spasm of severe contraction; there would be much suffering and some bankruptcy among those who might aplarently escape if things remain as they now are. But it would not be so serious as anticipated; men liave been preparing for it too long; too many liquidations have alrearly taken place; he that is down needs fear no fall; there could never be so good a time as now to make the plunge; still there would be trouble; for this we are sorry; we would avoid it if we could and still be just; but it is an awful fact that no great injustice can ever be remedied without great suffering, and the suffering does not always fall on those who have simner; it falls upon those who are in the way. The abolition of slavery brought woe to multitudes who were innocent of slavery. The return to an honest measure of value will bring distress to many who have never profited by a dishonest measure This can not be helped; we must endure it as we may; it wiln not last long, and in the end the recompense will come, if not to those who have most suffered, to the country at large. We shall be doing business honestly, at least as honestly as seems humanly possible; prices once more will be on a normal basis, and will proceed with the ordinary minor fluctuations which mankind have hitherto endured without complaint. We want an lionest dollar.

The foregoing is the argument for free coinage in the form which appeals most strongly to me. It is quite evident that there is something to be said on both sides of the question. To shirk difficulties or deny facts is trivial and unworthy and 
does not tend to the settlement of questions so that they will stay settled. Mankind learns daily, and in the end the truth will prevail.

I have not included, in the discussion, any opinions as to the acts of other nations in case of our adoption of free coinage. Some insist that other nations will be forced to follow our example in remonetizing silver; others insist as strongly that our fiscal affairs will be permanently separated from other commercial nations. As a matter of fact, neither party knows what would happen. All nations will be guided by the opinion of the ruling majority for the time being as to their interests. These opinions are liable to change with the march of events. Of course, should other nations remonetize silver, its value would tend to rise, and prices to correspondingly fall.

From all the foregoing, with a study of the tables which appear in the appendix, and of such official documents and standard works upon economics as are available, the reader must form his own judgment. In so doing one of the first things to do is to form an opinion as to the facts in which the two arguments do not agree. Especially, does the variation of prices which has occurred indicate appreciation of money or reduction of costs? If both, what is the relative influence of each? An intelligent, independent opinion on this point involves a careful study of conditions surrounding the student, and a patient study of detailed data collected by economists. The matter can not be further elucidated here. It would require a volume. A definite opinion on this point should be conclusive as to the equities of the case.

It is, however, necessary to caution the student against placing much reliance on the deliverances of the political press, or controversial pamphlets or books. Least of all should we be influenced by the utterances of political orators. The first object of a political paper or speaker is to uphold its party and elect its candidates. Economic discussion at such times is always superficial. Things which make for the support of the view which is favored are magnified; those which make for opposing views are belittled or suppressed. 
The object is not to find truth, but to get votes. The writers or speakers may be, and probably usually are, perfectly honest in their views. It is easy to get strong convictions by the exclusive study of one side. The way to find truth is to impartially study all sides, shirking no facts which may be disagreeable. The caution here given applies to all parties, and, I am sorry to say, on this particular subject, to nearly all literature. 


\section{CHAPTER V.}

THE FARMER AND THE LABOR QUESTION.

$\mathrm{T}$

HE farmer does not sell his labor, but the products thereof. He is largely an employer of labor, hoping by the sale of the product thus obtained to make a profit. The "laborer"-especially the skilled laborer-sells his labor direct to capitalists, who hope to sell the resulting product at a profit. With the money obtained from the capitalist from the sale of his labor, the laborer buys produce from the farmer. Economically, therefore, the relation of the farmer to the laborer is that of either a buyer of labor or a seller of produce. It is to the farmer's interest to have labor cheap and produce dear. It is to the interest of the laborer that produce shall he cheap and labor dear. Nothing can change these conditions so long as men are deemed entitled to the products of their own labor and land, and permitted to buy and sell as they may agree with each other.

It does not follow that this economic antagonism should produce enmity. All classes are in economic antagonism with all other classes, and must remain so while men compete with each other, and yet upon the whole they get on together, because at the bottom they have an identical interest in the fact that each has a surplus of what some other lacks. Their mutual necessity to trade together is the bond which unites all classes, and should prevent economic differences from culminating in mutual hate. As between individuals brought into personal contact, hostility does not ordinarily result from trading. Occasionally it does, but friendship results quite as often. As between classes whose members do not mingle freely with those of other classes there is more danger. If one class, upon the average, is prosperous, and the other, upon the whole, unfortunate, enmity is quite certain to result. In this lies the danger to modern society, to be escaped only 
by mutual forbearance, and mediation or repression by the consolidated social force.

Between the fummers and the laboring classes there is a certain bond of union in the fact that both conceive themselves to be suffering from the oppression of consolidated wealth. The most discontented farmers and the most discontented laborers are at times quite inclined to unite for political action. This tendency is promoted by the fact that between the farmers and the workingmen there is a buffer class of tradesmen, which impartially receives the kicks which the two classes would bestow upon each other if they dealt directly. At the same time farmers belong logically with capitalists and employers (or exploiters), and as attached to the private ownership of land, must oppose one of the fundamental dogmas of a large body of workingmen.

Before considering the relations of the farmers to the labor question it is necessary, if we can, to define the labor question. This is not easy to ilo, because workingmen do not agree in their demands. Wre are compelled to deal only with the lemands of organized labor, because those only are formulated. Organized labor, however, is a minority of labor, and the quarrels between labor factions, like other civil wars, are more bitter than the contests with outsiders. As I write I have before me a copy of a weekly paper which is the organ of one branch of workingmen which denounces the national leacler of another branch in terms of positive ferocity. I imagine that both the writer and the person attacked are honest men carried away by one-sided views of the ills of society.

Trade unionism seeks to incorporate in "unions" of the different trades all workers therein, and to prevent the employment in that trade of any person not a member of the union. At the same time it seeks to limit the number of workmen in the trade, by fixing the number of apprentices in each shop at a fixed ratio to the total number of employees. At times and places where the unions are strong enough these rules are strictly enforced. Without the consent of the mion an employer may not put his own son to work in the shop. The 
hours of labor to constitute a day's work are fixed with reference to giving employment to the largest number possible. At first, in this country, the day's work was ten hours, then nine; now all trades are striving for an eight-hour day, and some have achieved it. In case of disagreement with employers the ultimate remedy is a strike. The unions clain to, and probably do in most cases, include the best workmen in their respective trades. In most cases, however, the places of strikers can be promptly filled by other workmen who are out of employment. The new men, however, are seldom so efficient as the old, and strikes in large establishments, and especially when important work is pressing, cause great loss to employers. In some trades, as locomotive engineers, for example, an extensive strike may almost paralyze trade, since there are almost never at hand skilled engineers, who can safely operate a locomotive, in sufficient number to run trains. When strikes are organized on a large scale, and the result is doubtful, efforts are made to induce "sympathetic strikes," in trades more or less closely comnected with the striker's, but who have at the time no grievance of their own. This adds to the embarrassment of the employers, and by interesting a larger number of people, increases the pressure of public opinion. For example, if locomotive engineers were on a strike, they would seek to enlist the fireman's organization, or that of the trainmen, in the hope of absolutely stopping transportation. This would tend to bring the public to the side of the strikers, because it would desire business to be resumed and travel made safe, with little regard to the interest of contending parties; and as the railroads can usually be coerced easier and quicker than the strikers, the pressure tends to be put on them to yield.

It has come to be generally conceded that a strike is a legitimate and proper method of procedure in ease of extremity, provided it be conducted peacefully. No one questions the right of any person to stop work when he does not wish to work longer, and very few now question the right of organized bodies of workingmen to stop simultaneously by virtue of a prearranged agreement. Early in the history of trade union- 
ism this was not the case. A "conspiracy" to injure one in his business is now, and always has been, a penal offense, ${ }^{*}$ and in the early days of labor organization in Great Britain the conspiracy laws were invoked and applied with great severity to members of trade unions. It is now conceded that action by an organized trade union is not a conspiracy within the meaning of the law. A notable exception was in the case of the great railroad strike of 1594 , when a United States jurlge enjoined certain labor leaders from "conspiring" to interrupt the transportation of trains carrying the United States mails and also certain employees from quitting work without notice, when interruption of the passage of mails would result. This, however, was not approved by public sentiment, and no similar instance is likely to occur. The right to engage in a peaceful strike may be considered settled.

The trouble is that great strikes are never conducted peacefully. They are almost certain to result in riots, destruction of property, and murler. When strikes occur there is always a rush of the unemployed to obtain the vacated positions, and, as a rule, a strictly peaceful strike would simply result in a change of workmen, those who were formerly employed changing places with those who were not. Work would go on with more or less hindrance and loss for a time, and finally resume its normal condition. This is perfectly understood by the workmen, who, upon the occurrence of the strike, congregate about the place where they were employed, entering it if permitted, and by all means in their power seeking to dissuade others from taking their places. The persuasion is backed up by a strong display of force, and if unsuccessful is followed by insults and abuse. The thugs and thieves always join themselves to the strikers, in the hope of a resulting tumult in which they may ply their trade. The new workmen can only reach or leave their employment under police protection, and

* This chapter can not deal with the history of the organization of labor, or even its present condition or the ethies of the subject. It must be confined to an elucidation of the topies which may involve political controversy, and the relation of the furmers thereto. 
are assaulted whenever they are caught alone. The property of the offending company is injured and destroyed so far as possible. Riots may follow and the military be called out.

For all these disturbances the unions invariably disclaim responsibility, stating them to be the work of sympathizers whom they can not control. This is sometimes literally true and sometimes not. It is always disingenuous, however, to disavow responsibility, for tumult is known to be an almost certain result of a large strike followed by even peaceful dem onstrations against new workmen. Jn most cases it is only by intimidation of persons and destruction of property committed by somebody that strikers can hope to win, and they count on them accordingly. Nobody claims that strikers will be molested if they do not provoke attack by insult or worse, and the quibble of disclaiming responsibility for riot, even where not actually engaged in it, is discreditable.

When such conditions arise it is the first duty of society to preserve order. Those seeking work have the right to be protected, even from intimidation and insult, and owners of property have a right to its protection. With the original cause of quarrel it may or may not be desirable that society should concern itself. As to the duty of society to preserve order under all circumstances, there can be no question whatever.

The concrete questions which arise out of this condition of things, and which tend to become the subject of political action, are substantially as follors:-

It is demanded that the state make and enforce a short-day law-eight hours being the length usually demanded-forbidding all contracts for payment by the hour, or for days to exceed eight hours; that the state itself shall set the example, hy making its days of work eight hour's long, and prohibiting the performance of public work by contract, unless the contractors bind themselves to the eight-hour day.

'This involves a number of things. In the first place, there is the question whether the state should pay more for its labor than individuals pay. Doubtless it does pay more if it, at present, makes eight hours a day's work in all departments. 
As a proposition by itself this can not be sustained except upon the supposition that eight homrs is a proper day's work and the sum paid for such a day a fair price. As a matter of fact, what is demanded is that the state shall pay for eight hours at least as much as indivicluals pay for a longer day. Another matter to be considered is the logical effect of making an eight-hour day for all workingmen. "All" workingmen include the employees of farmers. $\Lambda$ s farming life goes, eighthour days are impracticable. The work must continue longer, and I do not think farmers would be satisfied to continue work for three or four hours while the employee smoked his pipe and looked on. And yet it is difficult to see how the state can discriminate in favor of one class of workmen and against another. It is difficult to see, but not impossible. As a matter of fact, the state can do, and ought to do, what is for the general good of society, and if that should be seen to involve an eight-hour day for one class and a twelve-hour day for another, that ought to be the law.

The question then arises whether it is just that the farmer work twelve hours-as he must-while the artisan works eight, and especially that the farmer should aid to pass law for securing to the artisan that advantage which he is not able to obtain by unaided efforts. It is also a question how much workingmen can be helped by the eight-hour day. In the end, unless society comes to the aid of the artisan, the result must be a lowering of wages, but the advantage will doubtless be gained of a wider distribution of wages. These are questions which must be settled after more profound study than can be given here, upon the principle of doing that which is best for society. There can be no question of the deplorable condition of a large fraction of humanity, or of the economic wisdom, saying nothing of the moral obligation, of afforling relief. At first thought the interests of the farmer would seem to lie in the direction of opposition to the eight-hour day and permitting the full operation of the law of competition among workingmen, and between them and their employers, but I am not at all sure that that would be the conviction after final thought. 
It is demanded that the state make and enforce a compulsory arbitration law for the settlement of disputes between workmen and employers. To this it is objected, on the one hand, that it is a violation of the freedom of contract, a matter which has already been considered in reference to the eighthour day. A more definite objection is the elaim that arbitration might result in awards which the employer could not comply with without ruin, and which, yet, could be enforced against him, since he has property, while an award distasteful to the workmen could not be enforced, since they ean not be forced to labor against their will. In regard to this, public sentiment seems to be crystallizing in favor of official arbitration which shall not be compulsory. 'This involves the creation, as disputes may arise, of official boards of arbitration, whose proceedings shall be official records, and which shall, in cases of dispute, clearly formulate the issues, hear the evidence, and render a decision, relying for the enforcement of the decisions on the good sense and self-interest of the contending parties and the power of public opinion. It is believed that either side, which, after a fair arbitration, should refuse to accept the verdict, would be unable to sustain itself against the overwhelming force of public sentiment. In $\mathrm{my}$ judgment this is eminently wise and desirable. The mere official formulation of the questions at issue, with an abstract of the evidence on disputed points of fact, would place the public itself in the position of an arbitrator, and night usually be relied on to assure a just settlement, even without the decision of a board. I believe farmers should favor such legislation by all means in their power. This presupposes that both sides to a controversy shall in advance commit themselves in writing to abide by the decision of the arbitrators. Should either party refuse this, I believe it would be wise to arrange for a clear formulation of the issues by the board, the presentation of the testimony upon the side which is willing to arbitrate, a statement of the facts upon the other side according to the best information of the arbitrators, and their conclusions in the light of all they have been able to learn. In such cases I believe that public opinion would soon force a settlement. 
It is demander that the military shall not be employed against strikers, but that the task of preserving order shall be left to the regular police. It is especially demanded that private police should not be employed. As to the last it is certainly necessary that life and property be protected. If the state will supply the protection, no employer will wish to pay for it. But it is notorious that the police force of most eities is totally inadequate to preserve order in times of great excitement, and it is unreasonable to expect the public to maintain, during ordinary times, a police force eapable of preserving order in great emergencies. It is notorious that a portion of the police in all eities is elosely connected by many ties to the workingmen of the city, and will act against them with great reluctance. When the workmen therefore demand that no aid be given to the police in maintaining order in times of great strikes, they are disingenuous. In a great strike they know there may be riots. When they say they are not responsible for these, and disfavor them, and yet object to the use of the only means which ean control them, they show a real sympatly which they are unwilling to avow. Neither the military or private police have ever yet been employed in this country to molest any citizen who was attending to his own business, and letting other people alone. They are never likely to be. Nobody who is doing right is in any danger of molestation. In times of riot the first duty to society is the restoration of order, kindly, if possible; roughly, if necessary; immediately, at all costs. The merits of the dispute have nothing to do with the case. There will be time to attend to them later. Those who complain of the use of soldiers are those who intend to break the law. They deserve no sympathy, and if they persist in violent actions, no mercy. The security of the whole people is the first consicleration, and the really merciful commander is one who hesitates at no necessary severity to restore order promptly when occasion requires it. No one will be endangererl who does not interfere with others. There is a rough element in society which can be safely dealt with only by rough methods.

The above are the principal demands of the trade-union 
section of workingmen, so far as they are subjects of political action. In addition there are some complaints, which have not been made the basis of regular demands. Among these one of the most common is an allegation that the judiciary of the country are in sympathy with the capitalist classes to the extent that justice can not be had of them for others. This is not true, for judiciary is not corrupt, nor is it biased; or if it is biased in any instance, it is almost invariably in behalf of the weak. The statement that great cooperations usually win their cases is doubtless true, for they act under the advice of great lawyers, and in ordinary cases are within the law in all their acts. If they win when they should not in equity, the remedy is in a change of the law, and not in an abuse of the judiciary, who simply declare the law as they find it. The judiciary and the military are the bulwarks of all honest men against the violent and the crafty. Under no circumstances should the independence of the judiciary be impaired. A mol is far more likely to intimiclate a jurlge than a capitalist to corrupt him. That justice is unreasonably delayed and extravagantly costly in most civilized countries is unquestionably true. That the fault lies largely with the judges is also true, for they have failed to withstand if they have not actually encouraged the tendency to employ legal refinements to the delay or the perversion of justice. And yet all those legal "refinements" which stand the analysis of the higher courts, and finally become incorporated in the body of judge-made law, are founded on sound principles and a correct understanding of statute law as it exists. The expression "judgemade law" has come to be a term of reproach. It is frequently used as such among farmers. This is wrong. Judges can not help making law. When counsel raises a point as a necessary inference from undoubted statute law, the judge must decide it. He can not put it aside. When he has decided it, and the decision is sustained by the highest courts, it becomes judge-made law-that is, it is found to be law, upon examination, by virtue of its necessarily following from a proper interpretation of statute law, although the authors of the statute may have never thought of it. The ignorance and 
bad English of many of our legislators are responsible for a great part of the judge-made law of America. When a law is invoked before a judge he is compelled to do something with it, and when he tries to unravel its meaning, he often has a very hard time. If he can attach any reasouable meaning to its words, he is bound to do so, and very often the language of the act compels him to decide that the law is very different from what it was intended to be, of which fact the judge can take no notice. He must read the law as it is, and not as he may suppose it was intended to be.

The remedy for the injustice which is wrought in the courts under the forms of law, is in forbidding appeals or writs of error except upon the certificate of the judge that substantial justice has not been done, and the disallowance of postponement except upon those serious occasions which seldom happen. Let the facts be brought out when fresh and a verdict given upon them, and then let it stop. It will be better for litigants and far better for the community.

This subject is germane to the labor question, for the reason that labor agitators attack our courts more viciously than any other class. The farmers should sustain the courts, and if they do not like the decisions, should change the law.

Thus far I have considered the demands only of the trade union wing of the workingmen. The views of the unorganized majority we do not know. But there is another wing, quite small in organized members, but filled with determination. The Socialist Labor party is composed of Socialists, who see in the demands of the trade unions nothing worth agitating for except as a very short step towards something else. Socialism is increasing its votaries in America, as elsewhere in the world. It is not likely, within any future that we can forecast, to be even a very powerful minority in this country, but as its strength will be concentrated in cities and be supported not only by its own honest membership, but by most of the bad elements of society which favor any destructive proposals, its apparent strength will be greater than its actual strength.

In brief, the demands of the Socialist Labor party are as follows, in the language of a late national platform of the party :- 
"1. Reduction in the hours of labor in proportion to the progress of production.

"2. The United States to obtain possession of the mines, railroads, canals, telegraphs, telephones, and all other means of public transportation and communication; the employees to operate the same cooperatively under control of the Federal government and to elect their own superior officers, but no employee shall be discharged for political reasons.

" 3 . The municipalities to obtain possession of the local railroads, ferries, water works, gas works, electric plants, and all industries requiring municipal franchises; the employees to operate the same cooperatively under the control of the municipal administration, and to elect their own superior officers, but no employee shall be discharged for political reasons.

"4. The public lands to be declared inalienable, revocation of all land grants to corporations or individuals, the conditions of which have not been complier with.

"5. The United States to have the exclusive right to issue money.

" 6 . Congressional legislation providing for the scientific management of forests and waterways, and prohibiting the waste of the natural resources of the country.

" 7 . Inventions to be free to all; the inventors to be remunerated by the nation.

"8. Progressive income tax and tax on inheritances; the smaller incomes to be exempt.

"9. School education of all children under fourteen years of age to be compulsory, gratuitous, and accessible to all by public assistance in meals, clothing, books, etc., where necessary.

"10. Repeal of all pauper, tramp, conspiracy, and sumptuary laws. Unabridged right of combination.

"11. Prohibition of the employment of children of school age and the employment of female labor in occupations detrimental to health or morality. Abolition of the convict labor contract system.

"12. Employment of the unemployed by the public authorities (county, city, state, and nation).

"13. All wages to be paid in lawful money of the United States. Equalization of woman's wages with those of men where equal service is performed.

"14. Laws for the protection of life and limb in all occupations, and an efficient employers' liability law.

"15. The people to have the right to propose laws and to 
vote upon all measures of importanse, according to the referendum principle.

"16. Abolition of the veto power of the executive (national, state, and municipal), wherever it exists.

"17. Abolition of the United States Senate and all upper legislative chambers.

"18. Municipal self-government.

"19. Direct vote and secret ballots in all elections. Universal and equal right of suffrage without regard to color, creed, or sex. Election days to be legal holidays. The prineiple of proportional representation to be introduced.

"20. All public officers to be subject to recall by their respective constituencies.

"21. Uniform civil and criminal law throughout the United States. Administration of justice to be free of eliarge. Abolition of capital punishment."

This statement of principles is not Socialism, but bears evidence of being a carefully-considered combination of "planks," calculated to catch everybody who is discontented with anything. Such of the demands as I desire to discuss are dealt with elsewhere. Those who hold these views have hardly the right to call themselves Socialists, although the platform includes many of the demands of Socialism.* In the main the Socialist Labor party represents the violent and revolutionary wing of the Socialists. Its declarations and sometimes its acts have ereated, among law-abiding men, a prejudice aganst the name of "Socialism" which is difficult to remove.

The object of this chapter has been attained if the reader, by its perusal, obtains a clear idea of the real economic relations between farmers and workingmen. It is one of conflict ing economic interests profoundly affected by common interests in relation to some other classes. So far as labor seeks the aid of legislation to accomplish its ends, the interests of farmers are sometimes with labor and sometimes against it.

* See Chapter VIII of this book. 


\section{CHAPTER VI.}

THE FARMER AND THE TRUSTS.

THE term "Trust," in popular usage, has come to mean any consolidation of large industrial or other enterprises under one management. It will be used in that sense in this chapter. This use of the term originated in the practice of effecting a practical consolidation by placing a controlling majority of the stock of each of the concerns which it was desired to consolidate "in trust" in the hands of a new corporation especially created for this purpose. It was necessary that the Trusts be corporations, for individuals might die, or become unable to perform the duties, in which case it would be necessary for all parties to agree upon new trustees, which might or might not be possible. The Trust was always created for some definite term of years, during which the real owners of the stock could not withdraw it from the Trust. The new corporation, by means of its control of the stock of the consolidated companies, could select their managers and control or consolidate their management, thus avoiding any competition between them, and dividing the net profits of all among the stockholders of the different companies, according to the terms of the Trust. The Trust corporation was always composed of members of the companies consolidated. In due time litigation ensued in regard to those Trusts, which were attacked as "in restraint of trade," and the courts held them illegal on the ground that while corporations conlu be formed to carry on any kind of business, they could not, in the states where the litigation occurred, be formed for the sole purpose of controlling the business of other corporations. As stringent "anti-Trust" laws were promptly enacted in most of the states, and by Congress, the Trusts were dissolved and the practice was abandoned.

Nothing came of the anti-Trust movement, however, except (396) 
the changing of the temporary combinations, expiring by limitation, to those which were permanent. If it was desired to consolidate a number of concerns it was only necessary to form a new company which should actually own the property of the concerus to be consolidated. This was easily effected by giving the stock of the new company in exchange for the property of the old companies, and retiring their stock. It is not possible to prevent this by any means short of the abolition of inclustrial corporations, and this, in any modern civilized nation, can not for a moment be thought of. The term "Trust" adheres to these consolidated companies, although as a matter of fact there may not be a real industrial Trust in existence in America.

In regard to these Trusts the first thing for the farmer to do is to accept them as a fact. They have come to stay. and will increase in number and importance with the growth of our civilization, with which they are exactly in line. The fact that they are thus natural outgrowths of the progress of society should also convince us that they are in the line of real progress. There is no question of their value to society in making possible more economical methods of production and distribution, of which the public should reap the advantage. The public, howerer, does not always reap this advantage. It never does if those concerned in the Trusts can help it. So far as they can do so, while the Trusts earnestly seek to reduce costs, they endeavor with equal earnestness to sell their products as high as before or higher. As the Trusts can exist only by virtue of the power of law, we have the anomaly of the power of society being used to oppress society, while the oppressors are protected by the fact that society can not use its power to abolish them without at the same time abolishing what is essential to the trausaction of its business.

The problem for the farmer in this connection is therefore how to retain the advantages which the Trusts confer upon society without enduring the ills which they will inflict if they can. The principal, if not the only method hitherto employed by farmers is the passage of denunciatory resolutions, sometimes of a very lurid nature. The trouble with this 
method is that it does not do any good. Nobody cares anything about the resolutions. There are, however, simple and entirely effective methods of preventing the abuse of corporate powers, without injury to the effectiveness of corporations for useful purposes. None of these means, however, are likely to be made use of by the present generation, as they involve a clearness of understanding and unity of action which it may require several generations to bring about. In the end the Trusts will be controlled as the result of the same influences which produce them-the impossibility of getting on in an! other way.

The first step towards any useful study of this subject must be to dismiss all prejudices, and fully recognize that no "Trust" is attempting to do anything which the reader would not do in the same position, or would not do now in regard to his own products if he had the power. Year by year the farmers of the world increase their efforts to form Trusts to control the sale of their own products, and whenever they are successful there is no limit to the price which they will set, except the limit imposed by competition or by the inability of customers to pay more. They are no more moved by contemplation of the distress which the high prices of necessaries may cause to consumers than are the managers of the great Trusts of the nation. Their Trusts, however, have seldom been successful or long-livel, by reason of the impossibility of effecting a firm combination among the great numbers of producers. If the owners of oil wells or sugar factories or whisky stills were as numerous as the farmers, they would be no more able to form Trusts than the farmers. It is very desirable that farmers should increase their effectiveness in this respect. The more Trusts they can form the better. The trend of civilization lies in the direction of the organization of those of like interests to deal through responsible representatives with classes of adverse interests. The capitalist elasses having the fewer number and the greater intelligence, are, as is natural, leading the way. The farmers are following as best they can. The faster they follow the better for all.

It is best to understand the cause of the organization of 
Trusts. The popular conception seems to be of a body of wealthy men, already in the enjoyment of exorbitant profits, deliberately uniting because thereby they can extort greatel and unreasonable profits. Nothing can be further from the truth. In this I am not speaking at random, for it has happened to me in more than one instance, to be engaged in, or to quite thoroughly know about, the formation of Trusts both among manufacturers and among farmers. There was no difference in the men, or in their avowed motives. Neither was there any difference in the outcome. In both cases the Trusts first formed were ineffective and short-lived, and for the same reason that there was no mutual confidence, or general intent to observe in good faith the conditions of the Trust. The lack of good faith grew out of the disbelief in the good faith of others. In both cases, also, repeated trials resulted in progress, and constantly increasing effectiveness. In both cases the difficulty was with "outsiders" who would not unite with the others, and in both cases the "ontsiders" were in the main those who were either strongest financiallymeaning by that freedom from debt rather than magnitude of operations-or those who believed that they could proriuce cheaper than others. Finally the farmers and manufacturers were alike in being moved to cooperate in a Trust only by the fact that they were being ruined by competition. My personal observation has been such as to fully convince me that neither capitalists, manufacturers, or farmers ever cooperate in the formation of a Trust until depressed by losses, and the fear of greater losses. There is in the breast of all human beings a desire for independent and uncontrolled action, which only gives way to the sternest necessity. Trusts being the result of unprofitable business, their first effort is an attempt to raise prices, and usually the raise is justifiable. In this the mannfacturers are quite likely to succeed, while the farmers are not so likely, by reason of the fact that they are very seldom able to adequately control the sources of supply.

Having thus, I hope, gotten rid of the feeling of prejudice with which farmers are apt to approach the subject of 'Trusts, and realized that the successful Trusts are doing nothing that 
we do not desire to do, and would do if we could, let us examine the practicable methods of the control of Trusts, whether of farmers or capitalists. The occasion for control arises from the abuse of power, of which all Trusts will be alike guilty to the extent of their ability. For the present the Farmers' Trusts do not need restraint, but encouragement, for the reason that they are not strong enough to do any harm. It is to the interest of society that they should be stronger.

To understand how Trusts can be controlled, it is first desirable to see exactly what harm they do. They unquestionably reduce costs, by consolidating administration, doing away with the expense of competing salesmen, and conferring upon all connected with the Trust the benefit of the most approved processes and ample capital. They are enabled to effect this saving by the use of the authority of the state, by which alone they become incorporated bodies, with power to control eapital beyond the reach of individuals. The harm they can do is, first, in compelling the public to pay them more than a fair profit, and, secondly, in the methods they employ to perpetuate their power. The latter is by far the most serious. To make this more clear I will take what is known as the "Sugar Trust" as an example. Now I do not know that the Sugar Trust has ever done an improper thing in the course of its existence. The newspaper stories for or against it are not entitled to respect as evidence, and personally I know nothing about it. I do know, however, some things which it could do if its managers so desired, and which it is within the power of society to prevent it from doing. In pointing out some of these things I must not be muderstood to say that any of them have actually been done. It is not within the plan of this book to attack any one, much less in the absence of proof. $A$ s it is merely an illustration I do not attempt to verify all the assumed statements. They might be correct if they are not.

The Sugar Trust is understood to be the American Sugar Refinery, located on the Atlantic Coast, and the Western Sugar Refinery, on the Pacific Coast. There is no legal bond of union between these two concerns, which are entirely 
independent of each other, but there is presumed to be a perfect understanding between them in the allotment of territory in which each shall have the monopoly of the sugar trade, undisturbed by the other. Previous to the beginning of the beet-sugar industry in the United States conditions were ideal for the formation of an effective Trust. For the purposes of the illustration I shall assume that conditions remain as they were before we manufactured beet sugar. As a matter of fact, conditions are not, at this writing, materially changed, although they may become so. The invention of a cheap process for refining beet sugar might entirely break up, the Trust, by enabling a large number of persons to engage in the business. Fifty years ago, and even less, nearly all the sugar consumed in the United States was "brown" or unrefined sugar. In those days any one could import sugar from any country where it was made, and no Trust was possible, because the supplies could not be controlled. There might be and doubtless were temporary "corners" for particular grades of sugar, when they happened to become scarce, but nothing permanent or effective. For some years past, however, nearly all sugar used has been refined. The public has become accustomed to the granulated and eube sugars, and every retail grocer must keep them or lose trade. This also requires wholesale grocers to keep them for the same reason. A retailer orders his supplies from one or two houses, and sugar with the rest. If any wholesale house did not keep such sugars as his trade demanded, the customer might take all his trade elsewhere. Under our tariff laws refiners of sugar are "protected" by such a rate of duty above that charged on unrefined or "raw" sugars, that little or no refined sugar can be imported, for the reason that our refiners can sell at a lower rate than refined sugars can be imported for, and still make a profit. As a matter of fact, the price of refined sugar is nearly always kept a little below the price at which it can be imported. There are, in many cities, refineries which were formerly independent, and used to compete strongly with each other. At last they were nearly all losing money, and by the usual steps a Trust was organized which owned nearly all the sugar refineries of 
the country. When this was accomplished, the overproduction, which had been excessive, was stopped, the refineries least favorably situated were closed, and the business of refining concentrated where it could be carried on most economically. The competing salesmen were called in, and prices raised to a profitable rate, all of which tended to economy. Under the law, and the habit which the public had acquired, of consuming mainly refined sugar, the Trust had the monopoly of the sugar trade, and the cost of selling was reduced to a trifle.

There was, however, a chance for abuse. If any one started a new refinery, and began to seek for his share of the trade, it was possible for the Trust to put down the price of sugar within the territory which the new factory could reach, entirely below cost, while keeping the rate at full figures in the greater part of the country, which freight rates would prevent the new factory from reaching. Previous to the passage of the inter-state commerce law, it was also possible for the Trust to get such special freight rates as to give it an advantage. Since the passage of that law this has been possible only at the risk of exposure and punishment-a risk, however, which is supposed to have been frequently taken without serious results. If these measures did not prove effective to ruin the new factory, there were still others possible. The Trust could refuse to sell any sugar to a wholesale merchant, except upon an agreement to purchase his entire supply of the Trust. There are differences in refined sugars, and when a community has become accustomed to sugars of a certain factory the people dislike to change. If a retailer orders a certain brand, he wants that brand and no other. As a rule, the Trust has usually controlled the only certain and abundant sources of supply, and this fact, in connection with the confirmed habits of the public, has usually made it master of the situation. It is true that the wholesale merchants could import refined sugar, but it would cost them more, besides the trouble and expense of buying in foreign countries, the uncertainty of regular supplies of uniform quality, satisfactory to their trade, and generally a great deal of trouble 
and annoyance, with a small loss instead of a small profit on each sale. As a result it was cheaper and more agreeable to the wholesale merchants, to submit to the Trust, and be governed by its rules themselves, meanwhile being faithfully protected by the Trust in the small profits which were allowed. By making prices for sugar delivered within certain territory, and different prices in other territory, it was perfectly feasible for the eastern and western branches of the Trust to divide the country between them according to the terms of any private contract which may exist. In case of disagreement between the two branches, the natural and regular course of events would be a serere "fight" in which one or both parties would invale the territory of the other with cut prices, possibly building a new refinery, and generally carrying on an expensive warfare by which the public would temporarily benefit while it was going on, and ultimately pay for, when, in the course of events, the contestants, tired of losing money, had settled their differences by a new arrangement stronger than ever.

1 have selected the Sugar Trust as the example, not only because the conditions for such a Trust are better than for most others, but because they tend to certain methods for maintaining its powers of which I wish to speak. It is not, lowever, the only important Trust. There are hundreds of them,* many of which are far more oppressive to the farmers than the Sugar Trust can be, because the margin between the actual cost of refined sugar and the price at which it can be imported is never large enough to make a very great difference in what will be used by one family, the immense quantity sold, however, making the profit to the Trust very large. In such articles as plows, sewing-machines, bicycles, stoves, agricultural machinery, and the like, in which there are or may be Trusts, sometimes far more effectively protected by patents than sugar can be by the tariff, the chance for unreasonable profits, and the loss to individual farmers thereon, may be far more serious than from any Trust controlling sugar, nails,

* See Appendix G, VI, for list of Trusts. 
thread, petroleum, or any of the staples of every-day purchase. It may be accepted, however, as a fact, that there are or will be Trusts controlling the majority of articles which the farmer buys, and, as I think, upon the whole it is desirable that there should be. Even as things are now, I am convinced that the farmer often gains pecuniarily rather than loses by the existence of Trusts. That, however, is no reason why they should be permitted to abuse their power.

The most serious injury, in my judgment, that the Trusts may inflict upon the public is in connection with the methods which they are tempted to use to sustain themselves. The profits of the Sugar Trust depend upon the action of Congress in relation to the tariff, and this, in turn, depends upon the action of voters and political parties. So long as the policy of protection is the policy of the Anerican Government, it is proper that the sugar refiners should have their share of protection. They employ a great number of men who would not otherwise be employed in this country. So long as it is our policy to protect industries, no one will dispute their elaim to a share in it. The same statement applies to all other interests which are protected by tariffs and combined in Trusts.

But the fact that these conditions create so powerful and so direct a pecuniary interest in the passage of certain laws, extending into the details of the schedules of the tariff acts, renders it almost impossible that the truth should reach the people, at least as to details, or that legislation should be impartially enacted. The policy of the United States is apparently well settled to raise a great part of its national revenue from duties on imports, and apparently with the intention of giving actual protection, whether revenue is needed or not. At any rate a tariff for revenue is protection to the extent that it goes, and while the people, in party conventions and by their votes, may determine the general principles of the legislation which shall be enacted, with the actual details of the tariff acts they do not and ean not concern themselves. But it is the details that count, and to the extent that it is possible to do so, the Trusts shape the details of the bills in which they are interested. 
They accomplish this end by the expenditure of money and patronage. In the aggregate the Trusts have the clisposal of an enormous amount of legitimate business which they may, if they choose, make use of to control political influence. There is little doubt that they do so use it. They are large contributors to the funds of political parties, and the men who supply the money to pay politieal orators, subsidize the press, supply brass bands and uniforms, and distribute partisan documents, are the ones who control the appointment to office in the event of victory at the polls. Sometimes these appointees are the servile tools, but more often I think merely the loyal friends of those by whose influence they have thrived. They are bound to them by conviction and habit, and hardly, if at all, realize the pecuniary tie that binds them They are rearly and glad to serve the friends who have served them. There are many government positions in which it is possible to be highly serviceable to friends, without eonscious? violating any official duty. In the aggregate a body of bright men thus appointed supply the "atmosphere" in which legis lation is carried on, and they can obtain and supply the most valuable information, as legislation proceeds and takes shape. The "civil service laws" were a terrific blow to influence of this sort, and the opposition to it is mainly inspired by pecuniary interests.

Congress is controlled mainly by the control of nominations. There are very few congressional districts in which the Trusts are not influential. Let any one known to be absolutely independent seek to obtain a nomination for Congress, and he will find his way blocked in ways that he can not understand. It costs money to receive a nomination and election to Congress, or to any high office, and the majority of those who seek those offices are not in a position to sustain the expense, which will always involve an "assessment" of from $\$ 1,(100$ upwarls to be paid to the party committee for "campaign purposes." This is usually but a trifling part of the expense. The money for these expenses comes largely from the coffers of the Trusts, and may be conveyed in such ways that even the most honorable men see no objection to receiving it. The candiclate 
is honestly a protectionist, and upon what grounds can lie refuse to accept aid from those who desire what he seeks to accomplish? Nevertheless, there is a personal obligation created, and when the details of the bill come to be made up, he would be more than human if he did not do his best to do well for those who helped him, even to trading votes or some detail to which he really objects. It is in these ways. beginning way back in the primary elections for delegates to the nominating conventions, that the Trusts expend their money for the control of national and state politics. Every county and every city has its coteries of bright men who are strongly interested "for the good of the party," and who by giving thought and study to detail are able to and do control nominations. To a great extent these "politiciaus" are paid outright by interested parties who may be hundreds of miles away, to "fix" a delegation. In a general election, when there are many officers for which delegations are to be "fixed," there is often quite a thriving business for a few months. In the end these disinterested gentlemen seek nothing for themselves; but are willing to accept places on the local party committees, and be ready to "fix" delegations for some one else at the next elections. Usually these local politicians will do nothing for anybody except for money, and they are at the service of any one who can pay them. Almost any one who has ever been a candidate for any office whose possession gives the power to confer favor, could give interesting evidence as to the power of money in politics, and the sources from which it comes. As a rule, however, they can not be got to say anything. If they have not received "aid," they can not prove anything. If they have they do not wish to. The amount of money spent in actual bribery of elected officers by Trusts, except in the case of senatorial elections, I believe to be small. ('omparatively few men who can be elected to a responsible office can be actually bribed. But they can be surrounded by influences which, unless persons of very strong character, they are unable to resist. The influence of 'Trust money in controlling elections is unquestionably the most serious abuse of which Trusts are guilty. The debauching of the local political mana- 
gers, carrying the corrupt influence of money to the very hearthstones of the people, does far more harm than the unreasonable profits which may sometimes be extorted from the people as the result of legislation so obtainerl. I have spoken of national legislation in connection with Trusts, because it is mainly by tariff laws and patent laws that Trusts have thus far been able to live, but the same influences are used to control state legislation, in which, however, railroads and other interests which state legislation may particularly affect, supply the corrupting influence.

The industrial Trusts exist mainly by virtue of tariff and patent laws. Other enterprises, like railroads, telephones, and the like, secure their monopolistic advantages, which must form the basis of all Trusts, in other ways. I have spoken mostly of those based upon tariff laws because they are the most numerous and most oppressive.

The remedy for the abuses of Trusts, however, would not be found in the repeal of tariff and patent laws, the result of which would be the expansion of Trusts on a more gigantic seale than ever, because they would then necessarily be made strong enough to overbear competition by the sheer weight of capital. The Trusts are now adjusted to conditions as they exist. 'They would speedily readjust themselves to such conditions as might arise. They would probably become international, after the manner of the Standard Oil Company, which is already international.

The first step in an attempt to control the Trusts is to get out of the darkness and into the light. We do not know what they are doing, and we need to know. Then we can permit them to continue doing what is right and stop their doing what is wrong. This appears to me self-evident. The army whose every move is known to the enemy, while those of the adrersary are not known until they have been made, is in a way to be surely beaten. That is exactly the condition of the contest between the farmers and the Trusis. Any continuance of the contest on the present basis is quite certain to result in continued discomfiture of the people. The warfare is carried on, as already shown, by paid guerrillas living among the 
people themselves, and supported under the protection of law: enacted by the people. It is a ridiculous situation and should end. The way to stop it is to shut off the source of supply The guerrilla politicians are entirely mercenary and will not fight a moment after their pay is stopped.

The laws-state and national-should provide that, in return for the protection of the corporation laws, the accounts and proceedings of all corporations possessing capital or transacting business above some fixed amount, should be absolutely public-no detail whatever being excluded from the public gaze, and to assure it, a representative of the public should audit all accounts and attend all meetings of directors. It will be objected by Trusts that this is exposing their business to their competitors. This is true, and exactly what is desired. Their competitors will be the most certain of all men to discover and trace out improper acts. The public can rest in comparative security when knowing that competitors are on the watch. If money is given to men who "do polities" we wish to know who gets it and exactly what he gives for it. A proper voucher monld tell the story. That should be the price demanded by the public for the certificate of incorporation which enables the corporation to do business. If its members do not like it they need not pay the price. Nobody compels them to form great corporations. The world will get on if they are not formed. It is desirable that they should be formed if they can be absolutely controlled. Otherwise not. Under proper conditions they would be instruments of great value. Under present conditions they are a menace to society.

Of course there would be additional legislation for the prevention of specific evils as discovered. It is not necessary to go into that here. Its character is obvious. The prerequisite to any successful legislation is a complete and absolute knowledge of facts. This can only be obtained by the method pointed out. When that step has been taken the next will become apparent. My object at this time is to concentrate attention on the one vital point.

If some unbelieving reader imagines that what is here said is not correct, let him serionsly set about getting one of the 
great political parties to incorporate in its platform the principle which I have announced, and which I am sure will commend itself to his judgment, and he will be speedily undeceived. He will discover that any litherto supposed contest carried on against the Trusts was a mere skirmish. Against this proposal he would see real war. And yet it does not primarily propose to hinder the Trusts from doing whatever they please, nor is there any ultimate intent to hinder them from doing whatever is approved by the moral sense of the community. Years since I myself once proposed this plankrestricting it to quasi-public corporations, like railroads and water companies-in a committee which sat up all night to construct the most thundering denunciation of railroads which human ingenuity could devise, to be adopted in a great political convention then in session. The public mind was thought at the time to demand such a bolt, and it was forthcomingbut there were those on hand to see that it was not aimed at anything in particular. I was not specially uninfluential in the committee in other respects, and so far as I could see had as much force as any other member in shaping the thought and the language of the party platform, but that proposition was voted down without a ripple.

As I have said, I do not expect the present generation to unite on this principle, simple and obvious as it is. It takes too many years to educate the public mind to grasp simple truth. That it will come in time is sure because it is the only way out of the difficulty, and in the progress of our evolution we shall come to it and take it.

This chapter, up to the beginning of this paragraph, was written about 1896 . If it had been written at the time these pages go to press, May, 1899, it is quite possible that, under the influence of the growing excitement in regard to Trusts, it might have been written in a somewhat different vein. For that reason I let it stand as originally prepared. Utterances framed under the influence of a strong public feeling are not likely to be very wise, or to be long remembered. Daily, for 
some months, the press despatches have told of new Trusts formed with enormous capital, with the apparent intent to victimize the world. The political learlers on all sides see in this movement the opportunity to divert public attention from issues which they do not wish to discuss, and are contriving how their party may most readily be made to appear as the only reliable champion of the people against unholy and oppressive combinations which the "other party" can not be trusted to oppose. So far as either party can manage to put the other at a disadvantage, the question of the Trusts now seems likely to be an issue in the next presidential campaign. What form the issue will take it is not now possible to guess. It is possible that it may be on such rational lines as are indicated in this chapter, but it is not likely. The political platforms will probably contain tremendous fulminations against the oppression of concentrated wealth and rhetorical pledges which will get votes but commit the party to nothing in particular. So long as political campaigns cost great sums which rich men are relied on to supply, political platforms can not contain definite programs for the effective control of capital, until capital itself desires it. This will come in due time, and from the same causes which have already made railroads ready to accept control,- - the competition of capital with capital, and the fear of popular disturbances.

If the reports which are now inflaming the popular imagination were true, some part of the basis of the reasoning in this chapter would be shown to be unsound, for the reports indicate that capital is combining, not as the result of unbearable competition, but, while in the full tide of prosperity, with the deliberate intent to become richer, by combining to extort additional and undue profits from a struggling people.

Doubtless there are such cases, usually not destined to succeed, but in the main I place no confidence in the reports. of course I do not donbt that articles of incorporation are constantly filed, creating corporations of enormous capital for the control of almost every commodity in common use; but the most of them, I am sure, represent nothing but the fact that some party of "promoters" have obtained, or hope to 
obtain, "options" to purchase the properties involved, usually at prices far in excess of their value, and have organized corporations to take over the property. If the "promoters" can sell the stock of these great corporations they will buy the property, and retire rich. Those who buy the stock will lose all the money paid in excess of the real value of the property In a few instances, doubtless, there will be temporary success, but capital, however concentrated, will never be able to really and permanently oppress the people, for the people will not permit it.

The fact is that the American people, after a few prosperous years, are now ripe for an era of speculation, and those who live by promoting speculation have seized upon the Trust idea as affording their opportunity. The unquestioned success-for the time being-of some of these enterprises, in which the property, depressed by long competition, was bought in at really low prices, and greatly raised in value by organization, has opened the way. Great Britain has just had such an experience. A sharp but unscrupulous person, known as Ernest T. Hooley, organized in this way one or two companies, which were really successful, and for a time brilliantly so, upon the strength of which a craze started, which brought ruin to many, and the speculator himself to the bankruptcy court. Something like this is now "in the air" in America.

At the same time the genuine organization of substantial interests, in a natural way, and under the pressure of competition, is also doubtless going on, and the problem of properly and effectively dealing with them becomes daily more pressing: I think the proper method of beginning is indicated in the preceding pages of this chapter. The next step to take will be indicated by the facts when disclosed. Wild denunciation and programs which do not go to the ront of the evil, are worse than useless. They are dangerous. If the people are inflamed, and the cause of their discontent not removed, there is danger to the public peace. No generation has ever been free from this danger, and ours is not. But we can not abolish the possibility of Trusts without paralyzing business. Whoever has anything to sell, whether it be manufactures, farm produce, or 
labor, desires to be in a Trust. A law which could suppress the Oil Trust would make effective marketing societies of farmers impossible, as well as associations for the sale of labor. There can be but one law for the rich and poor.

The proper course to take is not to abolish Trusts, but to control them; not to run from them, but to defy them; not to permit them to oppress us, but to make of them our useful servants. To allow a few to oppress the many is absurd, and it will not be long permitted. Society is not going to the dogs; none but the unjust need fear the result. It is not difficult to lay out an effective program, although doubtless it may involve some reconstruction of our habits of thought and methorls of procedure. If a Trust is enabled to become oppressive through the protection of the tariff, prescribe the conditions under which the tariff shall, without legislation, be removed from the commodity involved; if by means of a patent, prescribe the conditions under which the patent shall lapse; if by reason of legal technicalities, or the force of logical inferences from constitutional provisions, reform the procedure of the courts, or amend the constitution; if by reason of the impossibility of prompt remedial administrative measures, strengthen the executive authority. The way will open when the people make up their minds to move. And it will be a proper and just way. The people need not fear the money power. Indeed. they can not fear it half so much as the money power fears the people, whose power it knows. But with power goes responsibility. It is the duty of the people having the power, to exercise it wisely. They need capital, and should compel it to be their servant, paid properly, and protected carefully, but still their servant. This they will do as they come to understand the subject. And in this movement the farmers, the conservative elass, with something to lose an 1 yet much to rain, should take the lead. 


\section{CHAP'TER VII.}

THE FARMER AND THE REFERENDUM.

$\mathrm{D}$ IRECT legislation by the people was the ordinary method of government in the ancient republics. Representative government is a comparatively modern invention, made necessary, in nations desiring to maintain a free government, by the increasing territorial areas of states, and consequent impossibility of assembling the entire body of voters. Direct legislation in local affairs, however, has always been a feature of local government in New England, where "town meetings" regulate many of the details of local government. Traces of direct legislation in local affairs continue to exist in many places among the Germanic races.

At the present time there is a strong feeling among a large class in this country, in favor of direct legislation, not only to a much larger extent in local affairs, but in regard to many matters of state and even national legislation. The movement is based on the allegation that the people are better able to judge what they wish than to select men who will perform their will. Of those elected to legislative positions it is found that a certain number will betray their trust, frequently in sufficient number to defeat the will of the majority. The remedy, of course, is direct legislation on such subjects as the people desire to retain fully in their own control. It is claimed that the general intelligence of the people, and the facilities for the rapid diffusion of information, are now such that people can act intelligently and wisely on many subjects, which formerly their own interests would compel them to intrust to the decision of representatives who would be able to act in the light of information which would never reach the people.

The obstacle to the progress of the movement for direct legislation has been the fact that it has been most loudly 
demanded by what may be termed the "unbalanced class," meaning those who are so enveloped in one idea that they can see $n$ o force or value in anything else. The combination of a number of these extremely dissatisfied elements often produces a curious jumble of "demands," not always having much relation to each other, and very few of which, taken singly, could command any important support at the polls. As "direct legislation" is always one of the "demands" of extremists in social reform, the tendency has been to condemn this with the rest.

I do not think this is wise. All reforms have begun with extremists, some of whom in past ages have suffered martyrdom for the support of principles which are now cherished by enlightened men everywhere. Mankind is conservative, and always will be, and direct legislation will be found the most effective of preventives of radical legislation of all kinds. The real objection, from the point of view of the philosopher, is the danger that it may hinder the march of real progress; that the people will not do what the wisest of them see really ought to be done. It appears to many, however, that upon the whole it is not best to try to go much faster than the people are ready to go. Too rapid progress often means violent reaction. The nation which progresses slowly and surely in the development of its national life may thereby become the strongest and happiest. It is alleged that the people are often swayed by passion and prejudice rather than by reason, and that no one could tell what ruin might be wrought in a moment of passion by people so moved, and instances are cited in abundance from ancient history to illustrate the brutality and injustice of the voting mob. To this it may be replied that in the first place ancient history is largely partisan, and we do not know, for example, that the history of the life and death of Socrates is correct, as it has come down to us. In modern times we find bad men whose conversation is irreproachable, and Socrates may have been such a man, and the Athenians justified in putting him to death. Men were certainly more brutal in olden days than now, and human life was less sacred. Finally, the peoples of 
the ancient republics were not of races who have aemonstrated the capacity for self-government, and the republics fell because the people themselves became corrupt. Our republic will do likewise, if we lose our virtue as a people. No nation of the Germanic race has ever yet done this or shown signs of it, nor do I recall, in a cursory glance over such history as I know, any instance among people of these races where actual injustice was ever done by a solemn vote of the people.

Regardless of its origin, I am convinced that the principle of direct legislation is rapidly gaining support among the best classes of our body politic, and that it will be more and more applied in practice as time goes on. It will not be well to have it progress too rapidly. The habit of command is as essential to a wise exercise of that function in a people, as in the commander of a war ship. A man who liad perfect knowledge of the structure and powers of a battle-ship, and who had in him the stuff for a great naval comınander, would run great danger of "losing his head" if pitchforked into such a command, or into the command of a squadron, from a position in which he had always been a subordinate. He needs the discipline of smaller commands to prepare him for a great trust. In like manner the people need the practice of direct legislation in local affairs to prepare them for the exercise of power over a wider sphere of action. The habit of acting under responsibility is not acquired in a day.

The methods by which it is proposed that the people shall proceed in direct legislation, are known as the "initiative" and the "referendum." By the "initiative" is meant that upon a demand signed by a fixed number of voters, the legislative body shall be bound to submit to the vote of the people the proposition embraced in the demand. The number required to make the demand effective is usually placed at fifteen per cent of the voters, it being assumed that so large a number could not be got to unite in a demand upon any trivial occasion, or one upon which there was not good reason for demanding a vote. In practice any number of people who desired that some question should be submitted to vote would circulate a demand for signatures, and if fifteen per cent of 
the voters should sign, or any number which the law might require, the question would be submitted. Some propose to add to this what is called the power of "recall." By that is meant that upon a demand signed as already described, any elected officer would be voted upon again, and if defeated would lose his office. There are very serious objections to this. The terms of office are short in this country, and the penalties for malfeasance plain and severe. Passion and prejudice operate much more strongly in regard to persons than principles, and it would be within the power of a small number of agitators to harass unreasonably any officer who might be unpopular among them. Under the operation of the initiative it is quite probable that at first there would be unwise proceedings. There are always a certain number of unreasonable persons in the community, who are kept constantly stirred up by professional agitators. Elections are expensive, and if the people were called upon to vote too often, or at unreasonable times, they would abolish or modify the law. There is no instance, so far as I know, of the adoption of the initiative in the United States.* It has been proposed in some municipal charters, and may have been adopted, but it has never, I think, been used. It is, however, quite certain to be incorporated in the charter of some city and given a trial. In my judgment it would not amount to much. The people are good judges, but weak in execution. Any law that the people really desire they are pretty sure to get. Its greatest value would be in procuring the submission of proposals for acquiring public utilities, like street railroads or water works, to municipalities, at times when corrupt city governments might refuse to consider the subject. It would not be difficult to so restrict the subjects as to which the initiative could be invoked, as to prevent the people from

* The constitution of Virginia contains a provision for the exercise of a kind of initiative in case the Legislature fails to act in a certain case, and the constitution of Georgia prescribes, as the only method by which amendments can be made, petitions for a constitutional convention signed by a majority of voters in each county, - a provision doubtless intended to prevent any amendment for the present. No action, I presume, has ever been had under either provision. 
being disturbed about matters upon which the majority had no wish to vote.

The "referendum" is a far more important matter, and is certain, as I think, to be employed more and more. The people of the United States are no strangers to this proceeding, which is frequently employed in the adoption of state constitutions, and municipal charters, and in roting upon special taxes and the incurring of public debt, change in political subdivisions, and the like. It is proposed to extend the application of the principle, by requiring the submission of certain classes of laws to a vote of the people. There has been, so far as I know, no definite statement from any authoritative source, as to the exact classes of questions which should be submitted to the people, but in the main I suppose they would be such as would affect the public burdens. There is no doubt, I think, that the initiative and the referendum are most ardently supported by those who believe that their use would soon result in great modifications of the social order, involving in many cases the sequestration of what are now considered equitable property rights, but which some believe to lave little or no foundation in equity. As already stated, I do not believe this would be the case, and I do believe that it is desirable to submit to the people all important questions of public policy, which in their own interest the people do not prefer to have decided by their representatives. It is necessary to use common sense in matters of government, as well as in other things. There is no more exacting task than the exercise of wise statesmanship, nor any other which requires so long and careful preparation. That our people are competent to govern themselves wisely in all matters I do not doubt, but in order to do so they could liarlly do anything else. The voters of Athens attended to very little serious work except politics, but then the freemen of the city hat a plenty of slaves to support them, while we have not. For the most part the voters of these times have to earn their own bread and butter, which most of us find a quite sufficient task upon our energies, and we are glad to commit the making and the execution of laws to representatives who are paid to attend to 
it. So far as the demand for direct legislation is founded on a belief of the general venality of representatives, I believe that, outside of the large cities, it is on a mistaken foundation. Nearly all legislators are honest most of the time-being swayed by venal motives only in special matters, and the majority are honest all the time. But the judgments of honest men will often differ, and in such cases a small minority of dishonest men, having the balance of power, can work their will for reward. Aside, however, from the governing bodies of large cities, I doubt whether any measure ever became a law which was not approved by the honest judgment of the majority who voted for it. In the main, too, I believe that the action of our legislative bodies reflects fairly well the wishes of the majority of voters for the time being. The use of direct legislation-which is exceedingly expensive-should therefore be restricted to occasions in which a minority of dishonest representatives, having a balance of power, or a strongly partisan Legislature by party vote, may be likely to enact measures which the people would not approve. As a "question of the day," therefore, the subject of direct legislation is hardly ripe for discussion, because its responsible advocates have not yet defined the occasions to which they would apply it. To be in favor of the "initiative and the referendum" expresses no desire which one can put his finger on. It may mean something which we should nearly all approve, or something to which we should nearly all object. The people as a body can not concern itself with trifles. It can not make war and peace, as the old Germanic tribes used to, because a modern war is likely to begin and end before the people could get ready to vote. I am writing during the war with Spain, at a time when our navy has effected a lodgment on the Philippine Islands, and when the public is discussing the policy of conquering and keeping them. That, or the acquisition of any foreign territory, except mere coaling sta tions, would be eminently a proper question to be submitted to the people. The policy of occupying them as an act of war is evidently not a question which the people would wish to decide for themselves. There are cortain exigencies in life 
in which we must trust others. By far the greater part of the commercial business of the world is necessarily transacted by trusted men for others. The greater part of the political business must be transacted in the same manner. On certain important occasions it is, I believe, extremely desirable that even national questions should be submitted to the direct vote of the people. They must, however, necessarily be such questions as will admit of long discussion, enabling all information upon which representatives could act, to permeate the entire mass of the people. The educational result of such a discussion would well repay its enormous cost. In matters of state policy suitable occasions would arise more frequently, as people are better informed as to conditions affecting their own state than they can be of conditions affecting the whole nation.

It will, for a long time, however, be essential to limit the number of questions to be submitted at the same time to one, or at most two. Nobody who has ever noted the voting on several constitutional amendments at one time, will believe that the public has yet acquired the intellectual vigor to adequately consider more than one question of state policy at one time. There is never time to do so, in addition to earning a living, during the period for which such subjects are usually before the people. Neither can the mass of the people be induced not to subordinate questions of principle to the election of candidates in whom they have become interested. I have seen honest farmers spend days in canvassing, without reward, for the success of an officer having power to vote on the taxation of a county, who would not spend an hour in the study of a constitutional amendment modifying the policy of the entire state, and to be voted upon at the same election. Obriously, then, the exercise of direct legislation should be restricted to really important subjects, and submitted at elections when no other question is pending. When the people really take hold of a subject and master it, they will decide it rightly. They can not be got to do this very often because they have to live, and feel that they can best afford to get on with such legislation as is giren them by the representatives of their choice. 
As we come down to municipal affairs the same considerations apply, but in a less degree, because people know more about the cities they live in than about their state or nation. A wholesome check on modern city governments is undoubtedly a thing to be desired. Within reason, and properly guarded by the people themselves, so as to avoid being compelled, by a small body of agitators, to vote on proposals which they do not desire to discuss, the more direct legislation by the people there can be in American municipalities, the better off they will probably be. There need be no fear of hasty legislation by the people, or of unwise legislation upon questions upon which they have informed themselves.

There is one comntry in the world where both the initiative and the referendum are firmly established. Since 1874 the people of switzerland have been able to compel the submission of all federal laws, unless formally declared to be of an "urgent" nature, to be submitted to the direct vote of the people. To secure this, as a matter of right, there must be a petition signed by thirty thousand voters, or by the authorities of eight cantons, which must be presented within uinety days of the adoption of the law by the Ferleral Legislature. Until after the expiration of the ninety lass allowed for petition, a law does not become in force. The exception, as stated, is a case of "urgency." Laws, when thus submitted as the result of petition, are passed ly a majority of those voting.

In addition to this provision for submitting to the people, upon proper demand, all lias passed by the Federal Legislature, there is an additional provision, whereby upon petition of fifty thousand citizens, new laws, not acted upon by the Legislature, may he suhmitted. In this case the draft of the proposed statute is included in the petition, upon receipt and verification of which the Legislature must submit it to the people. It may, at the same time, if it see fit, submit a different law of its own, covering the same subject, but the people decirle. The above refers to the Felleral Government. Many and perhaps all the cantons have similar methods of employing both the initiative and the referendum. The universal testimony is that the workings of the law are satisfactory. It 
must be remembered, however, that Switzerland is a small country with a population native to the soil, and familiar with its history and traditions. Its neutrality in time of war being guaranteed by the great powers of Europe, it has no very perplexing questions of foreign policy, and is able to devote its entire fiseal energies to administration and improvements, as to which the people are well informerl.* The trouble in the United States would arise from the concentration in certain localities of large numbers of races not well qualified for selfgovermment and whose unsettled and revolutionary ideas would make much trouble for our native people. They are not strong enough, however, to do much harm. The American race is sensible and sturdy, and will have its way.

* It is also stated that one very strong reason for the establishment of the referendum in Switzerland is the fact that, although that country has a constitution, it has no supreme Court authorized to declare laws uneonstitutional and void. There being, therefore, no check upon the Legislature except its own sense of duty to obey the Constitution, and no means of preventing the enforcement of unconstitutional laws, should any such be enacted, the referendum became an essential security for the enforcement of the will of the people. 


\section{CHAPTER VIII.}

\section{THE FARMER AND SOCIALISM.}

W

E may agree in desiring that our great industrial activities be directed by persons of brains and force, and concede that to the possessors of those qualities something more is due from society than to those who are without them, and yet we may protest against the tyranny of intellect and vigor which now oppresses us, and insist that we who pay tribute to those virtues have more voice in fixing its amount. We may concede that the mighty forces which impel mankind to its destiny will move on in the line of their resultant, regardless of our views or wishes, and yet recognize that all that we say or do is both an effect and a part of those forces, and that discussion of social reform is therefore not vain or unprofitable. Insomuch as opinion is changed, desire is changed, and a change of desire in a single human being tends to a change in the direction of social impulse. With no pretense to deep reading on social topics, I seem to myself sufficiently familiar with the literature of the subject to feel justified in saying that the subject of social reform has hardly yet been touched-at least by English-speaking peoples-in any thoughtful way, from the standpoint of the interest which will have to be first considered in any new alignment of the social battalions. Discussion seems to have centered itself almost wholly about urban life and the comfort of operatives. But before there can be urban life there must be food to sustain it, and before factories can be operated there must be raw - material. For many ages mankind demonstrated its power to live without eities and without factories, and it could do so still, but the results of labor of rural society are essential to our existence. The conveniences and ornament of a structure may be more in evidence than the foundations, but it is the strength and disposition of the latter which control stability. 
If society is to be reconstructed-which I neither affirm nor deny-the reconstruction must begin with the foundation, which is in rural life. It is true that without forethought alterations in the superstructure may happen to so conform to the foundation that the edifice may remain stable, but such is not likely to be the case, nor would any good architect take it for granted. It does not seem to me to be the case with respect to the alterations in society which have been planned by urban residents and artisans. The farmer has not been called into consultation, and yet he will not only have something to say, but will have the controlling voice. Without his aid there can be no reconstruction of society except by the slow processes of natural growth. It may be worth while to hear something from the class that will decide.

I am myself a farmer, with rural education, tastes, interests and prejudices, but I an also not unacquainted with urban conditions and social movernents there, indeed, having of such knowledge, as I think, a better store than they have of rural conditions who are best known as proponents of social reconstruction. My animus is that I heartily desire most, if not all, the ultimate ends proposed by abstract Socialism, which I understand to be a perfectly just distribution of comfort. If, therefore, I am a critic of Socialism I am a friendly critic, my objections to its program being mainly a conviction that it would not remove but intensify the evils which it is intended to mitigate.

Abstract Socialism rests on three distinct propositions: First, no special reward is due from society to the possessors of great foresight, or organizing ability, or executive vigor; second, the man who saves is entitled to use his savings, but to no payment for their use by others; third, no man is entitled to ownership of land or any other part of nature, and especially to increment thereon unearned by himself. As it is only from these sources that capital, in the modern sense, can be derived, there follows the corollary that "capital is robbery."

The demands of Socialism are more commonly stated as follows:- 
State control of all gifts of nature, including the earth and everything which it produces. No private ownership recognized in anything not the product of the labor of the producer.

State control and operation of all instruments of production, including factories and machinery. I do not understand this to include such implements as individuals might require in their daily labor for themselves, but between these and the large plants which the state would own and operate, there is no closely drawn line.

State or municipal control and operation of all public mealls of transportation.

State or municipal control and operation of all public utilities, including street railways, telegraphs, telephones, water and lighting plants, and the like.

The above are the essential fundamental doctrines held by all true Socialists. In minor points there are differences more or less wide between different "schools." The platform of the "Socialist Labor party" differs from true Socialism in not excluding private ownership of land and instruments of production, or the "exploitation" of labor.

The ranks of Socialism include many most excellent men. While I am not a Socialist, I recognize that it is a movement not to be slightly reckoned with, or its arguments to be hastily put aside. It is making progress, in America, among the more emotional of the intellectual classes who contribute to the already enormous volume of Socialistic literature, and among the best class of artisans who look to it as promising relief from intolerable burdens, and who supply the numbers at Socialist gatherings.

There is implied in all Socialistic writing* the doctrine

* In the present stage of discussion upon social questions the issues are badly mixed, and individuals who profoundly disagree upon fundamental doctrine are found heartily working together for the accomplishment of immediate ends. Trade unionism is almost contradictory to Socialism, and yet Socialists are always found hand in hand with organized labor. The publie ownership of public utilities is an essential part of the Socialistic program, which is aceepted by great masses of men who are strongly opposed to its more radical demands. A great number, also, who are not Socialists, favor the nationalization of rail- 
that organized man can override, and, as applied to limself, repeal the fundamental law of nature that no species can endure, except by the production of more individuals than can be supported, of whom the weakest must die, with the corollary of misery before death. Competitive society tends to the death of the weakest; Socialistic society would tend to the preservation of the weak.

There can be no question of the grandeur of this conception. To no man is given nobler aspirations than to him who conceives of a just distribution of comfort in an existence not idle, but without struggle. It would be a Nirvana glorious only in the absence of sorrow, but still perhaps a happy ending for our race. It may, after all, be our destiny. Nor can any right-minded man forbear his tribute to the good which Socialistic agitation lias done. No man can tell how much misery it has prevented or how much it will prevent. So, also, while we may regret the emotionalism which renders even so keen an intellect as that of Karl Marx an unsafe guide, we must, when we read his descriptions of conditions for which he sought remedy, confess that he had been less a man had he been less emotional. The man whom daily contact with remediable misery will not render incompetent to always write logically is not one whom I should wish to know. But it is the mission of such men to arouse action, and not to finally determine its scope. The advocate may not be the judge.

Recurring to the fundamental principles of Socialism, as stated on page 423-and I may say that disregarding the

roads. There are multitudes of non-Socialists who favor nationalization of water, which is Socialistic doctrine, who are strong supporters of private ownership in land. In regard to land single taxers and Socialists have many more points of agreement than of divergence. No program could command the support of the multitude of earnest men who are found in the ranks of Socialism which did not contain a great deal of good, but the supporters of some one or more of the demands of Socialism may be very fur from being Socialists. To be a Socialist one must favor the abolition of profit and interest, state ownership of all gifts of nature, of all means of production, and of all public utilities, and of such control, by the state, of individual life and effort as shall be ultimately found essential to the accomplishment of the ends of Socialism. 
numberless schools into which those who call themselves Socialists are constantly dividing, I follow Karl Marx-I suppose they are to be met in this way: the first we should deny on the ground that great ability is the gift of nature to the individual and not to the race, and that the individual is entitled to the reward which it brings, and that therefore one day's work is not like all other days' works, as Marx holds, with the value of the average as the measure of payment, but the work of the exceptionally able is entitled to extra payment; that society needs this work, can afford to pay for it, and will gain a greater aggregate of satisfactions for general distribution if it is paid for. We should, however, agree that society is not bound to pay the possessor of exceptional qualities his own price for their use, and that we are prepared to join in such measures as shall assure the use of ability at a fair compensation. The second we should also deny on the ground that industry and prudence are entitled to reward; that often this can be given only in the form of interest; and that society can afford to and justly should pay interest for the use of savings. If a man builds a mill, and, falling sick, can not use it, those who do use it should pay him interest; so, also, if he has saved the money to build a mill; and, still further, if, having worked, he now chooses to rest. We would further insist that if he uses the mill, and so takes the risk of production, he is entitled to what will pay for the risk, in addition to the interest which he might have had without risk, in otlser words, to profit. There is no objection, however, as to some classes of enterprises, for the state to regulate profit upon the basis of corresponding guarantee against loss. Profit is the pay for risk. Socialism proposes that the state shall assume risk and abolish profit. We are convinced that such a course would result in a diminution of divisible satisfactions.

To the third proposition we should heartily assent. No wise man will now attempt to defend private ownership of land or water as a natural right. It is often based, in old countries, on ancient plunder of the weak by the strong. In new countries, however, where the state was once in as full possession as any Socialist could desire, private ownership is 
based on the faith of the state which conveyed its title to the individual. In old countries the state has condoned the original robbery, just as it has condoned the robbery of all unearned increment, and upon the faith of the state's guaranty those who have saved have invested their sarings. It is right that this faith should be respected, just as it is right that national debts shall be honestly paid, not because one generation is bound by the engagements of former generations, but because it is for the good of all generations that they should consider themselves so bound. All this Socialism denies. But, regardless of ethics, and if the unquestioned title to all land now rested in the state, we should faror its alienation to individuals, and consequent private ownership of land upon the ground of expediency, because land will yield more to private ownership than to the ownership of the public, and it is desirable that the most be made of it. But, while thus disputing, in part, the validity, and absolutely the wisdom of this Socialistic contention, we should be prepared to join heartily in the promotion of all measures for assuring to the public all future increment of value unearned by individuals.

But it is not with regard to abstract but concrete Socialism, as advocated by its votaries of to-day, that I wish to write. This, as I have said, centers about urban life and the welfare of artisans, inevitably so, because there only is there a sufficient concentration of those for whose labor there is insufficient market, and also, as is claimed, logically, because the needs of that class must be the basis of the standard of life. It is this contention of these societies that I wish specially to traverse. I deny that, assuming a uniform basic standard of life, the needs of the urban resident must be the standard, and assert that, on the contrary, it must be the needs of the farmer.

Concrete Socialism is in some respects exemplified in trade unionism, meaning by that expression the aggregate of the demands of organized labor. It does not profess to be Socialism, and it may be that the majority of those belonging to these organizations would not call themselves Socialists. Their objects, however, it is safe to say, have the hearty approval of all Socialists, as a stepping-stone to further 
demands, and form one of the very few concrete propositions upon which substantially all agitators for social reconstruction unite. Trade unionism practically seeks to control all instruments of production. It does not, like Socialism, demand the title to the property, but does, in large measure, demand control of its management, while assuming no risk. It does not seek to abolish employers, but to control them. The object of the control which is sought is to secure shorter hours with undiminished wages for those within the union, and to prevent those not belonging to a union from securing work, while making the privilege of membership in the union dependent upon the ballot of those already in. While this is not Socialism, it is a program favored by Socialists as a step towards its ultimate ends, in return for which trade unionism supplies the force which alone gives power to the Socialistic movement in America, and without which Socialism here would be but a vague dream of enthusiasts who conceive what could be done by a race of perfect beings, and imagine that mankind can do the same. The only present concrete Socialism is therefore trade unionism, whose demands Socialists almost unanimonsly support, and which must therefore be accepted as a part of the immediate program of Socialism. The effect of Socialistic trade unionism is to raise the price of what farmers have to buy with no provision for correspondingly raising the price of what they have to sell, and must, therefore, be obnoxious to farmers.

I wish to say here that I wish to see labor equally divided, and comfort distributed according to desert; and, above all things, I favor organization of all clisses to deal with all other classes, this being cooperation as opposed to Socialism, whose eind is the extinction of class. I therefore favor trusts, trade unions, business organizations of farmers, banks and associations of banks, mercantile combinations, cooperative stores, cooperative loan associations, consolidation of transportation companies-anything which tends to stop bickering, and bring together those of common interests whose representatives may deal and compromise with those of adverse interests, in the light of full information and under a sense of responsibility, 
with the pledge of the whole that negotiations shall proceed decently and in order, and with the power of the whole interposed as a last resort. But as a farmer I object to a program involving as its first step an act of injustice to me, and having its ultimate end based on the fallacy that the interests of mankind are, or can become, identical, or that individuals and classes will ever cease to seek their own advantage as opposed to that of others, when, as a matter of fact, human interests will always be diverse, and individuals and classes will always seek to accomplish their own ends. No one can deny this to be a just position for farmers to take, or that it has the support of the farmers generally. Their numbers are and always will be sufficient to prevent reconstruction of society on irrational grounds, and their strong common sense, unimpaired by daily contact with enthusiasts, will not fail to detect the fallacies which lie at the bottom of Socialism. It is not on such lines that society can be reconstructed.

The ownership of ordinary land is mainly valuable to the farmer in that it gives him steady work whereby, if he directs his work well, he may obtain a livelihood. It is the improvements on land which usually give it value, and these represent the savings of individuals. The improved lands of the world almost certainly conld not be valued at what the improvements have cost, or sold for what it would cost to replace them. The farmer of moderate means is simply a laborer with the use of somebody's savings invested in improvements, and the guaranty of stearly work at small pay so long as he makes no serious mistake. Money paid for farm land or its use is usually simply a bonus paid in advance for a steady job. In so far as value has been given to land by improvements for which the owner dicl not pay, he was not entitled to it and should never have received it, any more than the owner of a city lot should have received the increment caused by the movement of population. Any method which for the future may conserve such increment for the general benefit of society, should receive the support not only of farmers, but of all men, and would receive that of a vast majority. What has been sequestrated in times past, of this increment, is something lost, which, 
doubtless, society has the moral right to recover from the hands of him who first received it, but not from those to whom, with the sanction of society, he has transferred it. It is not, outside large cities, an important factor, and both in eity and country is in many cases being eliminated by the movements of the society which created it. Even if it were not so it would not pay to break up society to reclaim what the work of a short time would pay for, nor could it be reclaimed to society by such reconstruction as is proposed; it would go to the class of men who now manage our smaller politics, and who would find their golden opportunity in the Socialistic state.

The farmer, then, is a laborer; more than that, he is one who can by no means work short hours. His manner of life is determined by the elements. He takes the risks of production, and is entitled to its rewards, which, upon the average, he does not get, and will not, this being the compensation which he must pay for his reasonable security of a livelihood If he is an employer, his income is as frequently less than that of his employees as above it. He can not, and in the nature of his occupation never can have, a four-hour, or a six-hour, or an eight-hour day.* He must make hay when the sun shines, and morning and evening must tend his stock. Of rainy days he must mend harness in the barn, or pare apples in the kitchen. Nor does lie or any other human being need, or, if a normal man, desire, the short day, nor will he be content with it if he can avoid it, or be happier if he had it. The plea that many hours a day are required for "culture" is a fallacy. None but minds long trained can devote much time to serious study, nor will they try. They will play pedro in the groceries, or worse. The habit of illeness is one of the easiest to acquire. Nor is the short day necessary or desirable. (ireat learning gives no more assurance of happincss than rreat wealth. If let alone, those who have aptitude that way will choose learning for their avocation, and the rest of us can accept the results. With a twelve-hour day, not all the time

\footnotetext{
* See Chapter VI of Book Third.
} 
at severe labor, there is still ample time for such "improve ment" as we are capable of absorbing, and such recreation as is healthful and really enjoyable. The normal man gets his best recreation in forwarding business for his individual wel fare within the limits of his strength. It is not in the line of progress, but of retrogression, to reduce the hours of work beyond reason, and thereby the aggregate of divisible satisfactions, nor will it promote happiness to apply work to the general rather than individual welfare.

At any rate, the farmer can not so live, because unalterable natural conditions compel him to live otherwise. What Socialists term capitalistic methods do not lend themselves readiiy to the cultivation of land. They are now seldom profitable, and only under exceptional conditions, which, even where they exist, can not be lasting. The use of machinery quickly finds its limit in the inequalities of land, the cost of power, and the expense of wear and tear. So long as there is surplus power in self-repairing human beings, who must in any case be fed, and so long as plants and animals have individual peculiarities, which must be considered, but of which machinery takes no account, it will not be economical to dispense with human and animal labor for the majority of agricultural operations, even if inventive genius could devise the machines. Those who write most glibly about machine cultivation of farms seem unfamiliar with the operation of the economic law of diminishing returns, and do not realize that most land is rough, and that power costs money, and its use requires mechanical skill and convenient repair shops. That the aggregate of the use of machinery in agricultural operations will increase, there can be no doubt, but, relatively, it must decrease with the increase of population. So long as land shall be cultivated, its economic use will require work days of long hours, and economic rent will tend to be absorbed by the requirements of labor until it is no longer a factor in the farmer's income-a condition which it has long since reached in many lands-and in this way all value that has temporarily and unjustly been appropriated by individuals will gradually be reappropriated by society, and that not by 
the reconstruction of society, but by its development on natural lines. Towards this end it would not be impossible to construct an affirmative program, doubtless involving changes almost fundamental in our conceptions of some property rights, and therefore involving changes in fundamental law, but still based upon sound economic and ethical principles, and with due recognition of the infirmities of human nature. It would deal, among other things, with the subjects of inheritance, conservation of unearned increment, acquirement of public utilities, discouragement of the use of long credit, and similar methods of restricting the power of concentrated capital. Some thinker will evolve such a pian, and some leader of men will take it up.

In the meantime, and under present conditions, since the nature and, in a great measure, the standard of the farmer's life is irrevocably fixed by his natural environment, he denounces as unjust and impossible any reconstruction of society in which the standard of life which he is compelled by unchangeable conditions to adopt, shall not be made the basic standard whereto the lives of all other classes shall be adjusted. He objects emphatically to any, even tenative, proposals which shall compel him to exchange, against his will, more than one day of his labor for one day's work of him who makes his shoes or builds his house. He denies that such reconstruction is just or necessary, or that the evils of crowded society can be cured in that way. He recognizes those evils as well as those with which he is himself afflicted, and is ready to join in all rational-even if radical-measures for alleviating them; he declares that such measures are humanly possible, and can be formulated along the lines which the evolution of civilization has always followed, and that he will not join in or consent to a program in which the first step is an act of injustice to himself. Personally, I suppose that things will go on as they are now until gradually the organization of one class forces counter-organization in self-defense, and that, last of all, when survival without organization has become impossible, the farmers themselves will unite, formulate their demands, present them for the consideration of other classes, 
and finally compromise as seems just to all interests. But they will not become Socialists; for agricultural life and work can not be carried on under the Socialistic program, or any program which withdraws the stimulus of individual reward for individual effort. 


\section{BOOK SEVENTH.}

\section{The Fruit Marketing Societies of California.*}

\section{H A P T E R I.}

THEIR CHARACTER AND OBJECT.

T 7 HILE the object of this volume is rather a study of principles than a record of events, there are some peculiarities attending the development of cooperation in California which are well worth the study of the student of social movements; and as no comprehensive description of the California societies, or of those similar to them in other states, has ever been published, it seems desirable to include a brief sketch of the most prominent of them here.

It is obviously, as things go, an easier operation to buy than to sell, and to save than to gain, for there is required less expenditure of vigor, which, in the main, is the controlling element in human performance. That which is easier for the individual is also easier for an organization, and a French writer on cooperation, therefore, very properly remarks, in speaking of the French agricultural syndicates, which are, in the main, cooperative purchasing societies, that, marketing being the highest exercise of the art of cooperation, it is the last function which he expects these syndicates to undertake.

* See Appendix F for list of societies. 
Cooperation develops in each country according to the local neeessities of that country, which will invariably indicate the line of least resistance. The conditions attending fruitgrowing in California have been such that the cooperative element among fruit-growers was at once plunged into the most diffieult of all cooperative undertakings, which it was compelled to attack without experience in cooperation, and with little or no knowledge of the art of marketing. The movement, with many ups and downs, has proceederl steadily from the first, the co-operative fruit* sales in 1895 having reached, in round numbers, the sum of $\$ 5,000,000$. While no one can safely predict its immediate future, its work up to this time, which has attracted no attention from any writer upon cooperative affairs, $\uparrow$ has been such as to warrant a brief description.

When one once becomes impressed with the law that necessity, and necessity alone, will induce eoperation, and that the unit of cooperative life is the industry, and not the locality, it at once becomes interesting to note and compare the spasmodic outbreaks of the movement in different and distant countries. While cooperation, when once established, has more or less tendency to spread from established centers, it is, after all, always the result of social pressure, and is sure to appear when the pressure is sufficient. The British artisan suffered under the oppression of the retail dealers in the necessities of life, and the result was the magnificent system of

*I do not include cooperative dairying, for the reason that, with a good deal of effort, no one has ever becn able to gather statistics whic ${ }^{2}$ are even approximately correct.

† Mr. Charles H. Shinn wrote, in 1888, a brief monograph entitled "Cooperation in California," which was published, among other studies in cooperation, by the Johns Hopkins University Press. My good friend Mr. Shinn, whose information is very wide in most things, was apparently so interested in the literary possibilitics of some picturesque attempts to found cooperative colonies of the Brook Farm order, that he entirely overlooked a substantial cooperative business concern that, even as he wrote, was selling nearly a million dollars' worth of fruit each year, and which had been prominently discussed in the press since 1885 . 
co-operative stores, which necessarily grew up in a spirit of altruism, and which systematically foster the altruistic spirit from the instinct of self-preservation. The French peasantry, tilling, in small holdings, a soil which has been eropped for a thousand years, felt their greatest need to be economy in the purchase of fertilizers and tools, and the result was the agricultural syndicates for the purchase of fertilizers and the purchase and rent of farm machinery. The thrifty people of Denmark felt their greatest need to be the perfection and economical production of a product for which their country was best fitted, and the result was their remarkable success in cooperative dairying. The peasantry of Germany were groaning under the oppression of petty but conscienceless usurers, and the result was Schutze, and Raiffiesen, and their people's banks. Until lately, the rural people of the United States have not been enduring particular trouble of any kind, and, hence, have been unable to cooperate-a fact which neither Professor Bemis, nor Professor Ely, nor Professor Warner, nor any other of the learned men who have discussed early failures in cooperation in America, have seemed to realize. At last, the fruit-growers of California, who were confronted with a great fruit product for which they owed money, but which they could neither eat nor sell, found it necessary to work together to create and maintain the necessary markets. The pressure has made them cooperate.

I was actively connected with this movement for about three years as a leader. Since that time I have been one of the rank and file. I know all those who are now leaders in the movement too well to make it possible to give the individual mention, which always adds to the interest of a narrative, for I have learned that one's recollection is seldom to be trusted in such matters, and I know that in giving credit I should make errors, which would be exeused in a stranger, but for which I could hardly hope to be forgiven. There are many men now active and prominent in cooperative work, but of those who were so in the early days, when active friends were needed more than now, I dare mention but a few. In the organization of the California Fruit Union-the earliest of 
the large societies-those specially active were Mr. A. T. Hatch, Mr. L. W. Buck, Mr. H. P. Livermore, Mr. W. H. Aiken, and $\mathrm{Mr}$. H. Weinstock. These earliest pioneers are specially worthy of mention, from the fact that they were the first to break ground. In the organization of the Citrus Associations of the southern counties, all will agree that Mr. T. H. B. Chamblin, of Riverside, was the principal factor. $\mathrm{He}$ never, I think, served as a working officer of an establisherl society. Mr. A. H. Naftzger has, for many years, been president of these Associated Citrus Exchanges, and can show abundant evidence of his effectiveness in the vigor with which he is denounced by ontsiders. In the dried-fruit trade, the pioneer (successful) organization was the IVest Side Fruit Growers' Union in Santa Clara County, whose first president was Colonel Philo Hersey, of Santa Clara, who has also been president of the Santa Clara County Fruit Exchange from its first organization. The first meeting of cooperators which I ever attended, and which was a very large one, resulting in the organization of the Santa Clara County Fruit Exchange, was called to order by Mr. F. M. Righter, of Camplell, and the principal address was by Colonel Hersey, then president of the West Side Union, which had been in existence for a year. These two were then undoubtedly the principal leaders in cooperation in the dried-fruit trade. The organization of that industry in the southern counties has been mainly due to Mr. A. R. Sprague, of Los Angeles. In the raisin industry, in the San Joaquin Valley, cooperative work began with local packing associations, of which but two or three lasted long. Attempts were made every year or two to unite the entire raisin industry in one organization, which, however, did not succeed until 1898. I spent a portion of one winter among them in aid of one of these efforts, and some of the men then most active were Professor D. T. Fowler, now of Berkeley, Dr. L. S. Eshelman, Alexander Gordon, and John S. Dore, of Fresno, Mr. F. W. Rowell, of Easton, and Mr. B. E. Hutchinson, of Fowler; and presumably these had been lealers from the beginning; and there are, doubtless, others equally entitled to mention. In the final crystallization of almost the entire 
body of raisin-growers into what is practically an effective Trust, Mr. M. 'Theodore Kearney, of Fresno, was undoubtedly the leading spirit, heartily seconded by most of the leading men of Fresno. Previous to 189S, Mr. Kearney had not, so far as I know, been identified with any cooperative movement. Mr. B. F. Walton, of Yuba City, and Mr. John Markley, of Geyserville, are entitled to mention for helpful effort in many cooperative enterprises. Mr. Markley was one of the first directors of the California Fruit Union. Among those who were most prominently connected with the organization of the wine-makers were Colonel F. Bendel, Mr. P. C. Rossi, Mr. A. Sparboro, and Mr. W. B. Rankin. This personal mention is made, partly because it is proper that those who have been specially active should receive due recognition, and partly to give to any one who may be interested to look further into the history of these organizations the names of some who, if still living, may give further information. For reasons already stated, I have usually omitted, in the narrative which follows, to make personal mention of any one.

To the student of social movements, the cooperative efforts of the California fruit-growers are of interest in several respects. While the numbers involved are trifling as compared with those of the great cooperative societies of Europe, there are at least six or seven thousand scattered over an area of serenty-five thousand or eighty thousand square miles. The amount of business transacted, while small in comparison with that of the European societies, is respectable, and the sale of produce to the amount of nearly $\$ 5,000,000$ in contested markets from one thousand to six thousand miles away, represents an expenditure of cooperative vigor equal to that required for the cooperative purchase of commodities of many times that sum in a thickly settled country like France. The interdependence of classes, and the frequent necessity of compromises between them, is shown by the fact that the raisingrowers were unable to effectively combine among themselves for the control of their proluct, except by a compromise with an adverse interest-the commereial packers-by which the 
latter were permitted to have a share in the business. The progress of business education among the masses is shown in , the fact that this plan, in 1897, proved successful with the raisin-growers, although the suspicion and jealousy of the people broke up the California Fruit Union, conducted on that plan, some years before.

It should be interesting to note, in comparison with cooperative effort in other countries, how identical motives and arguments may be employed both to promote societies organized to obtain ligher prices and also those to secure lower prices. The California societies are instances in which people of intelligence and sufficient means, although usually greatly indebted, have organized with no great display of altruistic spirit, in the main upon commercial lines, * for the promotion of commercial ends. Such distress as existed was the result of indebtedness, and the fear of future want; and the early appearance of cooperation was due to the general intelligence of the fruit-growers. Even among this class the student will note the same jealousy, suspicion, and disinclination to unite, which the workers in more altruistic cooperation describe as existing among the classes whom they were striving to benefit, and which I found precisely the same in some cases of strictly capitalistic cooperation with which I

\footnotetext{
* The salaries paid indieate this. The salary of the president of the Raisingrowers' Association is $\$ 500$ a month. There are many cooperative officers who are paid at the rate of from $\$ 2,000$ to $\$ 3,600$ per annnm. The usual salaries paid the managers of local organizations is from $\$ 1,800$ per year down, depending upon the amount of business and the time required of the manager. It is curious to contrast these salaries with the salary of $\$ 1,500$, paid to the manager of the Leeds Cooperative Society, with thirty-three thousand members, and an annual business of $\$ 5,000,000$-the largest cooperative salary paid in England-or, still more, with the salary of $\$ 1,000$ a year, paid to Mr. J. W. T. Mitchell, for twenty-one years, and until his death, manager of the English Cooperative Wholesale Society, representing, in 1897, one million fifty-three thousand five hundred sixty-four members of affiliated societies and with net sales of $\$ 57,693,492$. Mr. Mitchell was a man who in competitive business could have commanded a salary of $\$ 25,000$. He could, of course, have had a larger salary, but, being an unmarried man, would not take it, and his estate, when he died, was probably under $\$ 2,000$. American cooperation has developed no such men.
} 
was familiar in former years. I do not wish to imply that altruism has been absent from cooperation in California. The efforts for organization have been largely altruistic, but the altruism was rather that of the public-spirited citizen, having in mind the general welfare of his city or his state, than of great souls stirred to their depths by the sight of actual poverty. The management of the society has not usually been altruistic, except that directors, and in some cases presidents, have served without pay. Another thing which has dereloped has been the competition of cooperative societies in the same branch of the industry. The California Fruit Exchange was broken up by the refusal of the older dried-fruit societies to unite with the newer creations. These have learned a lesson, and, as I write, are trying to come together. The Santa Clara County Fruit Exchange was avowedly organized to be the head and selling agent of the other Santa Clara societies, but when it was organized, not one would come in for some time; the pioneer society never did come in, and none remained permanently, although three finally united with the Exchange in maintaining a common selling agency. The Citrus Exchanges have never been all united under one head.

The history of the California societies shows the gradual development among the people of the conviction that the principle of cooperation in an industry for marketing purposes is identical with that of the cooperation of capitalists in what are called "Trusts," the arguments employed in their promotion, and the obstacles encountered, being precisely the same. The California Raisin Association is the first society of farmers to actually realize this ideal of cooperative marketing. Another fact disclosed in the California experience is the unwillingness of the most competent to unite in cooperative effort. Many persons of large means are engaged in fruitgrowing in California, and, with a few notable exceptions, they have been the meanest men we have fourd to deal with. They desired cooperation to go on, fully recognizing its benefits to the industry, but refused in any way to be compromised by it. They kept their information to themselves, but mndersold whenever they thought best, and spoke in contemptuous 
terms of cooperative effort. They have suid, with much truth, that there was no dependence to be placed upon the small farmers, who would say one thing and do another, and have left the work of organization and instruction to men far less interested than themselves, but possessed of more public spirit. Within a year or two increasing pressure, involving danger to large investments, has brought this class of men largely into the cooperative vineyard, where they are none the less welcome because they come late. They bring commercial ability and financial strength, and will get their penny with the rest.

California is, of course, not the only country where cooperative marketing has been attempted. It is a feature of some European societies, but their operations in this direction, while, probably, in the aggregate, exceeding those of California, have not attracted much attention from writers on the subject. The grape-growers of New York and Ohio maintain organizations, which have been successful in some years, and unsuccessful in others. The fruit-growers of Georgia and Oregon have made similar efforts, and one society was organized designed to include all the fruit-growing interests of the United States, for which the time is not yet ripe. The fruit-growers of Florida have also had, and perhaps still have, a marketing society. I have not the data to give the facts in regard to any of these societies, but the student of cooperation may know, without special inquiry, that the experience in those states, and in Europe, is substantially the same as that of California. Human nature and the laws of trade are much the same everywhere. 


\section{CHAPTER II.}

\section{CONDITIONS LEADING TO THEIR ORGANIZATION.}

$\mathrm{T}$

HE history of the settlement and development of California is a marvel. There has been nothing like it in the world's history. The circumstances of its settlement led to its colonization by a people of wonderful vitality; the charm of its climate, the fertility of its soil, the characteristics of its topography, its flavor of old buccaneering legend, culminating in the wonderful romance of the annexation and gold-seeking epoch, combined to insure it such an amount of gratuitous and enthusiastic advertising as no country and no community ever before received. The romance of the gold era was followed by the romance of the wheat era, with its great farms, whose furrows were miles long, in following which the plowman starting in the morning returned to his startingplace only in time for the noon-day meal, and whose soil, fabled to be of inexhaustible fertility, yielded stores beyond measure to the granaries of the world; this, in turn, was followed by the fruit idyl, far more attractive than the wheat industry, and, for a time, surrounding California, with a halo of rural blessedness which was a lure to the world. Whatever has been done in California has been great of its kind.

The hold which the fruit industries of California gained upon the imagination of the world was astonishing. The frost-pinched denizen of colder climes pictured to himself the fortunate orchardist of California as one whose happy days were passed in shady nooks, wherefrom he idly watched the gradual ripening of golden fruit in sun-kissed orchards, or recruited waning strength in gentle exercise among the laden boughs, whose luscious burden should presently supply his every want.

That was the picture. As a matter of fact, fruit-growing in California is not only one of the most risky of inclustries, but is 
necessarily pursued with longer continued, more unremitting, severer, and more prosaic labor than any other agricultural business in the world. There is no more romance in rligging about fruit trees than there is in digging post holes. It is far harder to plow an orchard than a grain field, for the trees are in the way. I would as soon saw wood as to stand on a ladder all day long, straining every nerve to reach high branches that I can't reach, in pruning, thinning, or picking. I know no occupation more certain to produce backache than the continuous packing of fruit, whether sitting or standing The sun-kissed orchard in August has a susual temperature of one hundred forty degrees Fahrenheit, which, in the moist atmosphere of the east, would mean death to most of us, and which, while safe enough in California, is about as desirable a place for a white man to stay out of as exists. The waste of the "luscious golden fruit" which accumulates about a packing-house, is about as nasty a mess as I know of. As for leaving the work for others, if there was ever a business requiring the constant, unremitting, and individual attention of its owner, who must, withal, have no mean account of technical skill, it is the fruit business. The owner depending on his orchard for an income, who attempts to conduct its operations from a hammock in a shady nook, may contemplate with certainty an early visit from the sheriff, on business of the most pressing nature. It is only the keenest of men who can make money by delivering a perishable food product in a market twenty-five hundred miles distant by land, in competition with food products raised on equally good land, held at one-half the price per acre, and which pays not more than a tenth of the freight. The men who do this do not operate from hammocks.

This contrast of the actual with the expected conditions of our fruit industry is necessary to an understanding of the origin and growth of our cooperative societies. A certain -glamor with which the poetic instinct of mankind has surrounded the fruit industry rendered a large element of society an easy prey to real-estate interests which existed in California on the magnificent scale veculiar to the state, and which 
exploited the fruit business during some years with a wonderful ardor and success. It became the fashion to own fruit farms, and no family belongings were complete without one. It was proven, as plainly as figures could prove anything, that the ownership of a small fruit farm insured competence and comfort after four years; it might be earlier, but that was not promised, and there were some so cautious as to admit that five or six years might elapse before really satisfactory net incomes would be assured; but that was the limit, and during the craze it was firmly believed by the majority of Californians that a man or woman with no knowledge of horticulture might safely purchase land at from $\$ 100$ to $\$ 300$ per acre, on credit, and, by paying a few dollars per acre for a few years for planting and cultivation, secure from his property an income which, in a few years, would pay off the debt and leave him comfortably provided for life. The result, of course, was a rush of teachers, clerks, and others with fixed incomes, to buy fruit farms on instalments. Ordinarily prudent merchants invested on a larger scale; there was a great influx from the east, especially into southern California, whose orange groves-really very profitable for some years-were a wonderful attraction to visitors from colder regions; large grain farms were subdivided into fruit plots, until in some districts one could ride for miles amid a constant succession of orchards; and the whole state was alive with prosperity and hope. The great savings banks almost alone kept their heads, and would lend no money on orchard property.

It may be useful to devote a paragraph to show in detail some of the errors in the calculations of inexperienced orchardists. In the first place, the cultivation of orchards is expensive. With no rain during the summer, the moisture must be preserved in the ground by constant stirring. The largest orchardists, employing unmarried help, who furnish their own blankets, and often live in cabins with rude bunks ranged one above anoílier, like berths on shipboard, abundantly fed, to be sure, but otherwise costing nothing for keep, and employed and discharger according to the needs of the work, were able to reduce costs of cultivation to a compara- 
tively small figure; but to the small farmer with ten to fifty acres of orchard or vineyard, this was not possible. The men with whom he and his family must daily associate must be decent men, and to kecp such he must make their surroundings decent. Especially the non-resident owner must have faithful men on his place, and house them comfortably. Nor could he be continually discharging them, and taking on new men. The succession of work is constant, and men must be there to do it. In a bearing deciduous orchard, as soon as the fruit is gathered, the pruning begins. In pruning full-grown trees an arerage of twenty trees per day is a day's work, or five days to the acre, or two liundred days of pruning to a forty-acre orchard, with a month more in disposing of the brush. The pruning over, the plowing and cultivation begin, and continue every day until fruit pits begin to harden. Then follows the thinning, often requiring three-fourths of the fruit to be laboriously picked off by hand, and always lasting until the earlier varieties begin to ripen. In the meantime there has been winter spraying with cheinical insecticides -a tedious and expensive process-and summer spraying with other preparations for other classes of insects. When the harvest begins, more help must be employed. The eastern farmer finds it hard and expensive work to gather a burden of two to five tons per acre of hay or grain, which he cuts and handles by machinery; he would be appalled at the prospect of gathering a product of ten to fifteen tons, in pieces of a few ounces, each carefully picked by liand,* from the tops of trees, and always handled several times over. The harvest orer the pruning begins again, and so on forever. The conflict with insects and parasites is unceasing. If undisturbed, they destroy the orchards, and there is a constant expense on their account. The loss of trees is very large; bad planting or poor cultivation impairs the vitality of many trees, and leaves them ready to succumb to the first injury, usually not actually dying, which would be desirable, but leading an unprofitable and expensive existence for years; sunburn destroys thou-

* Except prunes, which are shaken from the tree and picked 
sands; root-knot, thousands more; standing water in a wet winter is very destructive; and thousands of full-grown trees die annually, often fully laden with fruit, and for no cause whatever that can be discovered. A great loss also arises from the digging up or regrafting trees which have, after years of cultivation, been found unprofitable; it is not every tree that will be profitable in every place, and the infinite variety of soil and exposure, which is one of the attractions of California, vastly multiplies the chances of error in planting; nor do all varieties which thrive and bear well prove profitable; nor are varieties which yield profit in one locality sure to be desirable in other places where they ripen earlier or later; and it often happens that varieties for which there is a limited sale at fair prices, become utterly profitless when production is increased; and of the varieties which have to be sold fresh, there is not only the risk of crop failure which attaches to all plantings, but some years and from some localities they are found to "carry" well, and arrive in good condition after long journeys, and sometimes they do not. In fact, there is no end to the variety of risks which assail the business from all sides, and the replanting and regrafting of orchards is constantly in progress, so that to this time I believe that fifteen years would be an extreme limit to assign as the life of a tree in Califorinia. Of course a great part of this tree loss is preventable; and the most competent and experienced have never suffered as severely as I have indicated, and perhaps no single orchardist has endured all the misfortunes which I have mentioned; but I am considering average conditions, and a certain amount of -risk is inevitable. So that, even allowing for the better results which experience has brought, I can not put the expected average life of a fruit tree in California as above twenty years, or the average number of crops to be expected as over fifteen. There is also to be considered the inevitable deterioration of the soil, by reason of which, except in so far as it is combated by expensive fertilizers, the quantity and quality of the fruit erops will diminish as certainly as the quantity and quality of the wheat crop has diminished. Finally, it inevitably happened that, under the unreasonablestimulus applied, the produc- 
tion of all kinds of fruit and fruit products increased far beyond any existing demand, and far beyond any possible sales except as new markets were created. The raisin industry, which, in spite of warnings from official sources, was exploited long after all possible remunerative demand had been provided for, was the first to suffer, as vines came more quickly into bearing than trees; next, eastern shipments of deciduous fruits becamc unprofitable; then followed the orange industry; and, finally, the profits on prunes and other dried fruits began to disappear.

A community of fruit-growers beginning with anticipations based on conceptions more or less founded upon such views of the industry as have been described, and ending under such conditions as have been set forth in the last three paragraphs, was ripe for cooperation. To add to their troubles they found that, while in time they gradually learned the art of producing good fruit, the problem of marketing, which was still before them, was perhaps even more difficult. Their orchards were twenty-five hundred miles from the center of their most important consuming district; the nature of their product did not permit, to any great extent, the use of sea carriage, under existing conditions, and the major portion was subjected to a land haul exceeding two thousand miles, and extending to three thousand miles, where, at the Atlantic seaboard, it competed with fruit and fruit products produced in close proximity to those markets, or imported at one-fifth the freight charge, from foreign lands, where it was produced at one-half the cost of the California product. The Californian orchardist or vineyardist, with 110 traditions or general information in regard to his industry, had no knowledge of the capacity of his market, or the extent and character of his competition. At the beginning lue made money, and continued to do so as long as there was a market on the Pacific slope, and west of the Missouri, for all his product; as the pressure on the local market recluced prices, the sales, with characteristic Californian energy, were pushed farther and farther afield. The first attack on the eastern market with deciduous fruits was with fresh fruit shipped by passenger trains in an ordinary freight car, at a cost of $\$ 1,400$ for ten tons, or seven cents a 
pound. Of course at such cost it was only taken, first, as a curiosity, and later as a luxury, by the few who could afford it. In 1894 this trade had increased to over seven thousand car-loads, at a freight rate of one and one-fourth cents a pound; the citrus shipments from southern California, with like beginnings, increased to over 14,000 car-loads in 1897-98. The rainless summers and autumus of California permit all classes of fruit-except on the seacoast-to be dried in the sun, at a minimum of expense, and with excellent results. Many varieties flourish there which will not thrive in other parts of the country, or which have not been elsewhere introduced; and the excellent quality of the fruit insured, under the exceptional climatic conditions, a product which had no equal of its kind in the market. Most parts of the state were found excellently adapted to prunes, and while at first they were not looked upon favorably, they soon found general acceptance with a ready sale, and a market at eight to ten cents a pound seemed assured for all that were produced. This price, with the yield obtained on the best land, involved enormous profits, but under the increasing production, it rapidly run down to four or five cents, which, with some orchards, was then thought to involve a loss; and it has since declined to three to three and one-half cents. The total annual consumption of the country, up to 1858 , had never exceeded ninety million pounds, nearly all imported, while in 1894 there were trees planted in California alone sufficient, theoretically, to produce, when in full bearing, two hundred million pounds in a good year, which must be sold against foreign prunes, upon which the combined freight and duty but little exceeded the freight east on the California product. The raisin industry was subjected, for a long time, to even worse conditions, the Zante currants, which specially compete with the poorer class of raisins, being admitted duty free. The world-wide advertisement of the enormously exaggerated profits of the fruit industry of California, which was promoted by the land and transportation interests of the state, and fostered by the bragging spirit which the very air of California induces in all her people, set all the world at work at 
the same industry, and gradually it became evident that great districts which we had regarded as our permanent customers would soon be in the market as competitors, and it was seen that the problem of production, with which we had been occupied, was as nothing as compared with the problem of marketing the vast output at prices, not which would pay interest on land at the high rates which had been paid for it, for that was obviously impossible, but which would at least pay the expenses, and interest on something. Throughout the world the increase of fruit products had been so vast and so rapid that the problem of their sale involved the problem of displacing some other food product to a corresponding extent, and that interest would fight.

At the beginning the process of marketing was simple. A trade grew up with the business, which bought and paid for the product, delivered at the nearest shipping-point, and that was the end of the matter to the grower, and it was satisfactory. In the wine business it is the only way possible for most growers, as the necessary cooperage and suitable storage required capital not available to the small vineyardist. In the raisin business, also, it is not usually possible for small growers to pack their product to the best advantage. The orange-grower sold his fruit on the tree. When the fresh deciduous fruit production outgrew the capacity of the local market, a few of the largest growers assailed the task of opening the eastern markets; and, having demonstrated the possibility, there were buyers even for so perishable product as that.

But as the product increased there was a downward tendency in prices. The eastern trade was perfectly informed of the enormous annual increase to be expected, and more and more each year inclined to wait the inevitable effect before purchasing. The very high prices paid in some years to growers proved disastrous to many local buyers who paid them, and who found that there was a limit quite easy to reach, above which even the products of golden California would not sell. Year by year there was less disposition, on the part of local buyers, to purchase, but instead they offered 
to take the products, make reasonable advances, and market them on commission, and the grower, unable to sell for cash at any such rates as he had been accustomed to receive, was compelled to accept; this action on the part of the local trade immediately brought into the field, especially in the driedfruit branch of the trade, an army of men representing eastern commission houses, who represented to the grower the superior advantages of a commission house located in the center of consumption, and soon great quantities of fruit began to be shipped by growers for sale by persous situated thousands of miles distant from the owners, and of whom the growers had only such knowledge as was afforded by the business card left by the bright solicitor who obtained the consignment. Such a condition of affairs of course opened the door wide to all sorts of fraudulent practices, and as the opportunity to commit frauds attracts those disposed to such practices, the commission business became infested with a great number of utterly unscrupulous persons, whose dealings brought discredit upon the whole business, and drew down upon all who were engaged in the indiscriminate wrath of the producers. Having no means of distinguishing the honest from the dishonest, they condemned them all alike. This was the more natural since annually the increasing pressure to sell wrought constantly increasing tendency to lower prices, so that even the most reliable commission houses were unable to make returns approaching the expectations, and, in fact, the necessities, of the consignors; this again was aggravated from the fact that only the very largest marketing centers were generally recognized among the growers, and these were the dumping-ground for everybody's product; and merchants there, with little need to inyest capital of their own, were enabled to supply their wants from week to week, as one after another of the growers, or of those who had advanced money on the product, directed the goods to be sold for whatever they wonld bring, and with the purchases at such sales were able to successfully compete in the smaller interior wholesale markets with products remaining in growers' hands, or in the hands of such local buyers as still remained in the business. During all this time 
there was a gradually accumulating series of disappointments to those who had so lately, and with such high hopes, embarked in what they expected to find a delightful and exceedingly profitable occupation. First it was discovered that the annual dividends would be less than anticipated; then that for a time they would be very small indeed; then that they must employ cheaper help and less of it; then that they must find the interest on the mortgage from some source other thin the orchard; finally, that the orchard never would pay the interest on the mortgage, and that no sale of the property could be malle except at an enormous sacrifice.

While the orchardist and the vineyardist were discovering these things, the merchant was learning that expenditures were being curtailed, and accounts no longer paid at maturity; and bankers and capitalists were ascertaining that the investments in orchards and vineyards in the state had reached such a figure that the serious loss which was threatened upon them was certain to disturb all values. It was seen that, while the industry in the end would right itself through the merciless process of the survival of the fittest, the operation would involve widespread distress and failure, not only among those actually engaged in the industry, but upon all the business interests of the state, which were inextricably involved with and dependent upon the paying and purchasing power of the orchardists and vineyardists. Under these circumstances, and since it was evident that, with continued competition under the ordinary laws of trade, serious disaster affecting all interests in the state was imminent, the fruit industry of California was ripe for cooperative effort. 


\section{CHAPTER III.}

\section{THE CALIFORNIA FRUIT UNION.}

THE first branch of the fruit business to suffer from bad methods in marketing was the eastern trade in fresh deciduous fruits. This was because the limit of possible customers-that is, those who could pay over eight cents a pound for table fruits-was the easiest to reach, and also on account of the great risk of loss involved in shipping delicate fruits so long a distance. It is essential to this trade that the collection of even car-loads be assured at the varions shipping stations each day, as the fruit can not, without loss, be detained for car-loads to accumulate. At the beginning of the season very few, even of the largest growers, are able to fill a car on any one day, and the great majority of growers are never able to do so. The large shippers, who were the pioneers in this trade, naturally united for this purpose as they had occasion, and as the local buyers grew less disposed to risk their money, local organizations of small growers were gradually formed for this purpose. There was, however, no further concert in shipping, and it frequently occurred that an eastern market which could very well take care of one car-load once or twice a week would receive several car-loads from different shippers, with the necessary result of serious loss to all, while other markets that would gladly have taken part of the surplus were left bare. The plan was, therefore, conceived of uniting all the growers of the state in one organization, which should receive all fresh fruit offered for the eastern trade, distribute the shipments according to the ascertained eapacity of the several markets, arrange for its sale through commission houses of recognized standing, and under heary bonds to the association, and collect and distribute the proceeds, charging therefore the actual cost of the service, and no more.

For the preparation of this plan several large conventions (452) 
were held, which were fully reported by the press; many of the large growers freely gave their time and expenses in visiting various parts of the state. The project was received with enthusiasm and unanimity, and apparently every grower in the state was likely to join in a movement so obviously to their advantage. The California Fruit Union was, therefore, incorporated in November, 1885, with an authorized capital stock of $\$ 250,000, *$ and the basis of stock subseription was made at $\$ 1.00$ per acre of orchard, an amount which it was estimated would yield an ample capital for the purpose, after paying all the expenses of organization. $\Lambda$ certain fixed commission was charged for marketing the fruit, out of which all expenses, including six per cent dividend on the capital stock, were to be paid, and the balance, if any, paid over to the growers according to the amount shipped by each.

But it was soon found that action did not necessarily follow talk; all were anxious to see the union established, but few were willing to risk the dollar per acre. The great majority of the growers remained idly at home waiting for some one no more interested than they to come and talk to them, when they might decide to join the movement, or quite as likely want time to think it over. No one was willing that the plan should be given up, but nearly all were determined that some one else should bear the burden. At no time did the paid-up capital stock exceed $\$ 15,000$, representing about onetenth of the acreage more or less interested in the deciduous fresh-fruit trade. All this was consumed in expenses of organization-that is, in printing, postage and the traveling: expenses of those seeking to induce their fellow-growers to unite with them.

The organization, however, was effected before the results were apparent, the directors being mostly large growers, well informed as to the methods of conducting the fresh-fruit

* The committee recommended that the capital stock should be $\$ 100,000$, but the convention would not listen to such a thing. A quarter of a million it must be, at the very least, which was very comical in view of the actual subscriptions finally made. 
trade. Organized as it was, however, it must do business to live, as certain expenses were necessary in order to do anything; and as there was little or no capital stock with which to meet any deficit, the failure to earn commissions meant bankruptcy. Before incurring these expenses some actual assurance of business seemed necessary, and while the large shippers who were most active in the movement could supply a great deal, they could not guarantee sufficient to insure success; and they could not be assured from other sources, because the majority of the growers were determined that others than themselves should take all the risk, while they would continue to make use of the old shipping firms which they unanimously said they wished to get rid of, until it should be demonstrated hy others that a growers' shipping organization should succeed. The forwarding houses, who of course did not wish to lose their business, made no open opposition to the movement, but quietly, as occasion offered, encouraged distrust and suspicion either of the leaders of the movement or of the particular plans proposed.

But the leaders were determined men, and when they realized that the mass of the growers could not be depended on to sustain them in anything, in the end they did the only thing possible by practically compromising with the then principal forwarding house, making it the principal eastern agent of the Fruit Union, on condition of its refraining from direct seeking for business from growers, at least in the districts where the union was strong. This placed the union in a condition to do business safely, and it at once became the principal agency for the eastern deciduous fresh-fruit shipping business, a position which it retained while it continued in business, its sales exceeding, for some years, an average of a million of dollars, ${ }^{*}$ all conducted without the loss of a cent. Its weak point was that its agency was far stronger than itself, having abundant capital, and the control of the most important eastern outlets for distribution, and also of the special refrig-

* Its gross sales in 1886 were $\$ 345,416.98$; in $1887, \$ 675,864.44$; in 1888 , $\$ 773,117.42$; a year or two later, $\$ 1,501,023.56$. 
erating cars, which were in due time brought into use. In 1894 , after a prosperous year's business in 1893, the union went out of business.

The causes of this failure in cooperative effort were due, first, to dissensions among some of the large shippers, who were the original leaders, involving a lack of unity in pushing the proselyting work, at a time when the influences, if heartily united, were strong enough to unite every grower, and make it impossible for competing agencies to establish themselves. Second, the senseless folly of the majority of the growers, who were ready to suspect the motives, and criticize the acts of those charged with the duty of directing the affairs of the union. As the business increased, new shipping-houses naturally made efforts to get in, with no care whatever for the interests of the growers, which imperatively demanded, in this branch of industry, one directing head controlling the entire volume of the business. These new firms found that their readiest means of obtaining a foothold was to instil into the minds of growers a suspicion of their own agents; the notion was spread widely that the eastern agents controlled the business, and that, as a matter of fact, it was not their own agency which the growers were supporting, but a private forwarding-house, and they were so utterly silly that, with that notion once in their heads, their strong impulse was to at once rush into the arms of some opposition concern. As a matter of fact, it is unlikely that the forwarding-house ever troubled itself in the least about the control of the union. It had no motive to do so. The union collected the fruit for shipment, and the eastern agents received and sold most of it. The more the union could collect, the more the agents would have to sell; and the more prosperous the union, the more profit there was for the agents; and it made no difference to the grower whether the forwarding-house controlled it or not; the important thing was to concentrate the fresh shipping fruit under one management; and it made no difference to the growers what that management was, so that it was competent; and in this case incompetence was never charged. In fact, it was very competent. The main thing with the growers 
seemed to be a determination that no one who served them should make money, especially when they themselves were not prosperous; and in their blind resentment against those who served them well and did make money, they turned against their own business, and gave their shipments to outside parties, in nearly all cases paying more money for no better service, and to no better men, and with no better results to themselves, in fact, with not nearly so good results, for in the general scramble for business many irresponsible concerus got in, and many losses occurred through the spoiling of fruit intrusted to those who had no facilities for promptly moving and selling it, and from the failure in business of others. As a matter of fact, it was impossible for any but the growers themselves to control the Fruit Union, if they would only take the trouble to attend the aunual meetings and vote for directors of their choice, or place their proxies with those who would do so; but they did neither; the annual meetings often had to do business without a quorum, or to go without doing business at all. The owners of the business would not see it done to their satisfaction, or refrain from finding fault with the way it was done.

Another source of difficulty to the union was the gradually-increasing embarrassment of many growers who had engaged in the business with high anticipations but without adequate capital, and who, after a time, began to require large cash advances to cultivate and harvest their crops. These advances could be obtained from the forwarding firms, upon contracts to ship their fruit, and usually from no other source, as a growing fruit crop is worthless for security except to persons in a situation to market the product. Some of the directors of the union came to be chosen from among large shippers who bought fruit. These, of course, were really interested to have no outlet except through themselves, in their own vicinity, but they never hindered their neighbors from organizing, and often encouraged them to do so; and as none gave so much business to the union as they, or were so competent and interested to manage it well, they were proper persons for directors; and yet their neighbors, while complain- 
ing that they had no local organization for loading cars, and perhaps blaming the directors for it, would almost never themselves get together for that purpose, or take any step whatever to do so. In short, the growers made it evident that they could be depended upon for nothing except to find fault with their own agents, and yet make no effort to change them. In the end the directors got tired, and the forwarding-houses, by aid of the growers, having so multiplied that the union was but one agency among many, and no hope remaining of accomplishing the original intent of the union, the directors grew weary of managing a business for which they were not paid, which yielded them no profit, but only abuse, and decided to stop. 


\section{CHAPTER IV.}

THE CALIFORNIA RAISIN ASSOCIATION.

I order to understand fully the methods of organization pursued in the raisin districts, some explanation of the methods of raisin-making is essential. The grapes, when ripe, are cut and placed by the vines on light, shallow trays some thirty or thirty-six inches square; after remaining for some days, they are turned by covering the grapes with an empty tray, and reversing the two, leaving the grapes on the new tray, with what was before the lower side now exposed to the sun; when sufficiently dried, the trays are stacked either in the fields or under sheds; the grapes-now become raisinsare then sorted, bunch by bunch, and placed in boxes about four feet square and a foot deep, holding about one hundred pounds; the very largest bunches, suitable for table use, and later to become the raisins known to commerce as "layers," are placed by themselves, and those with smaller or uneven berries or partly-filled bunches are placed in other boxes. The profit of the vineyard depends largely on the proportion of "layers" it will produce, and this again depends on the quality of the soil, and the care in cultivation. The raisins so packed in these large boxes are more or less uneven in dryness, but in due time will equalize themselves, and all become moist and pliable; and on this account the boxes are called "sweatboxes."

Up to this point raisin-making is pure horticulture, requiring no special or expensive facilities. Beyond this, however, the small grower can not usually go without expenditure for appliances. The layers, before packing, have to be steamed to make them pliable, while the inferior bunches, which are to make "loose goods," must be stemmed by machinery. At this point, therefore, there is a natural division in the business In the beginnings of the raisin industry in California, or at 
least when the pioneers had established the value of the product, a class of packers grew up who purchased and paid for the raisins "in the sweat-box," delivered at their packinghouses, thereafter themselves taking all the risk. 'This was eminently satisfactory to the growers, and under normal conditions would have continued until the Socialists shall be prepared to carry out their program and abolish all profit. Under the actual conditions, as heretofore described, involving continual downward tendency in values, packers found the business too hazardous, and, after numerous failures had oecurred, deeided among themselves that they would take no further risk, but would receive the goods in the "sweat-box," make advances upon them, pack them at a fixed price, sell them upon commission, and account for the proceeds. The firms engaged in this business became known as " commission packers." The result of this was that the commission packers had to bear all the odium of the constant sink in the prices of raisins. The growers did not understand that their investments in the way of adrances were so heary as to guarantee their utmost effort in maintaining values, or realize that constant underselling of one by another was largely a manifestation of the pressure of those from whom they had borrowed for the benefit of the growers; nor would they learn from some serious failures among the commission packers, from overadvances, that the pressure grew out of real danger of loss. All they could see was that their fruit, when sold, sometimes did not bring the sum advanced upon it, and very seldom much more. Especially was this true of weaker growers, who were usually found upon the lightest soil, and whose vineyards were likely to have the poorest tillage, with the consequent lighter erops, and a greater ratio of poorer grapes bringing the lower prices. They found loss and poverty their portion, while, upon the whole, the commission packers prospered, and, with the characteristic common to all unfortunates, blamed everybody but themselves for their trouble. And there is no doubt that, like all embarrassed persons, they paid far more than a due price for service rendered. The packing charges and commission rates generally charged were more than the 
able and solvent growers needed to pay or did pay, and more than were customary in other branches of the dried-fruit business.

In the raisin industry, as in the fresh-fruit trade, serious trouble brought earnest talk of cooperation. The growers were exasperated beyond measure at the commission packers who were serving them, and great conventions met and resolved they must and would assume the marketing of their own fruit. There were, however, practical difficulties. The largest growers, who had naturally had most commercial experience, were not found to work harmoniously together; the small growers had not the commercial experience or much money. With the commercial experience of the large growers faithfully supported by small growers, money could have been had for all legitimate uses; capital was required to erect and equip packing-houses. and the growers had it not, ${ }^{*}$ or at least it could only have been raised by a pretty uniform assessment according to acreage, which was not found practicable. The handling of raisins after they leave the sweat-box involves two distinct operations not necessarily connected with each other: First, the packing, which requires a packing-house with its equipment, which a cooperative society can manage with perfect ease; and, second, the sale of the packel product, which is effected by brokers in eastern markets; and to direct this well requires a certain amount of commercial training, which may or may not be found available in a society.

The result of the agitation was the formation of a number of cooperative packing societies, which, with ordinary management, should have nearly paid for themselves in the saving of packing charges each year. In most cases, however, but a small amount was paid in on stock subscriptions, and the packing-house was left incumbered with all the inclebtedness it could be made to carry. This impaired the credit of the socicties, who were consequently mostly unable to obtain

* It is really absurd, after all, to say that these growers, even indebted as they were, could not have raised the necessary funds to handle their crops, if they had ehosen to do so. 
banking accommodations for advances to their members; these, consequently, were compelled, one by one, to go to the commission packers for financial relief, which, of course, involved taking their business away from their own packinghouse, leaving the burden of supporting it to a smaller number than was anticipated, and making more or less bad feeling between those who "deserted" and those who stood by, and having the further result that, with the diminished pack, the cost of packing was more than was expected, which, with the interest and depreciation, and the more or less bad management incident to new undertakings, made the outcome, in many cases, very unsatisfactory. With freedem from debt, and the improvement in management certain to come with experience, all should have worked through, and thus taken the first step toward the general union of all raisin producers, which was desired; but, weighted down by debt, and the neighborhood quarrels which were its result, nearly all the cooperative packing-houses gradually fell into the hands of the commission packers by sale or lease. During the season of 1894 but two of the concerns were able to run independent of commission packers, as was intended, of which only one sold its own pack through its own agencies. "By 1897 cooperative selling had disappeared, and there was little, if iny, cooperative packing.

The selling of the product, as has been pointed out, is an entirely distinct business from packing it. As the supply year by year more exceeded the demand, the obtaining the orders required more energy and skill, and more expert judgment was required in determining when and at what price to sell, and the management of the sales, in unskilled hands, was not always wise. For the most part, the conduct of the sales was placed in the hands of commission houses, usually in San Francisco, who could obtain the necessary advances, but some societies employed some of their own members, sending them east to solicit orders, which was a good plan, if they were sure to retain the services of those for whose business education they were paying. Upon the whole, however, the mercantile ability available in their own nembership was not usually 
found satisfactory, or at least it was insufficient to make the business profitable in a falling market. As it was a prime article of faith in the raisin district that there was "no overproduction"-any suggestion of that kind meeting with prompt resentment-the blame for the continually decreasing net returns inevitably fell upon the cooperative management, just as it had before fallen on the commission packers. In the meantime, however, one or two well-managed societies, either out of debt, or not involved beyond their means, and with good credit at their banks, for a time proved helpful to their members, but in the end were forced to succumb.

It has been the constant aim of all cooperative effort in the fruit districts of California, to concentrate the sale of the entire crop under one management; in plain English, to form a growers' Trust. Apparently the only way in which such a result could be reached-if it could be reached at all-was by first uniting the growers of the various neighborhoods in cooperative packing associations such as have been described, and then uniting the officers of these societies in one general association. This, however, requires time; it can not be accomplished in one year or in two, and the community, in the face of the general distress, was never willing to settle down to the sure and slow process. For years there was annually a series of mass conventions, wherein were considered plans for uniting all the raisin producers of the state in one organization, to which each should give his written assent, the agreement to be binding on the signers when seventy-five per cent of the growers, or of the acreage, should have signed. After each of those conventions, for some years in succession, a new plan was agreed upon and committees formed to carry it out.

Those who were most active in forming these plans did not usually understand the practical difficulties in the wa: and, not realizing the difficulties, provicled no effective means for overcoming them. In the first place, there are nearly three thousand persons engaged in the industry, but a small fraction of whom ever attend the conventions. All these individuals must be visited and canvassed in order to obtain signatures. Experience shows that, however easy it may seem, there must 
be more than a day's work devoted to canvassing for each five names secured; this means, for canvassing the principal raisin district, at least the equivalent of two full years of work by one very competent person, besides conveyances, railroad fares, hotel bills, postage, printing, etc. This work must be prosecuted in a systematic and orderly way, under the superintendence of some capable person devoting his entire time and thought to the subject. Allowing for much volunteer work, a large amount of paid service is also required, as well as funds for general expenses, and no provision whatever was made to meet these expenses. It would seem that signatures could be obtained very rapidly at the conventions, but American popular conventions are assembled for talk, and talk they will to the last moment, and do nothing else; the prosaic work of signing agreements-which are sometimes present, prepared for signature-at once empties the hall. It is found that nothing but a house-to-house canvass will accomplish any considerable results, and the average time taken with each person will be very nearly two hours. And this was never provided for. Another difficulty to be met is the matter of advances. A well-organized packing association, free from debt, can manage this readily, with the aid of the loeal banks, who can deal with the cases one by one as they arise, among them carrying the load easily, providing funds gradually as needed; but when provision is attempted for all in one organization, it becomes a large financial operation, beyond the means of any local bank, and requiring the aid of large capitalists. This invariably brings in outside people, with or without experience in the raisin business, usually without capital themselves, but professing to be able to "interost" it. All these were listened to, committee ineetings lield to consider the high finance of the movement, while meantime there was not a dollar raised to prosecute the organization. These financial propositions, when sifted, were always found to involve elements of security for the capital proposed to be supplied, which only a strong, thoroughly organized society, witl some capital of its own, could give. While they were discuss. ing these things, the organization did not go on; one after 
another the growers' necessities drove them to the commission packers for advances, and the business went on as before. Sometimes organizations were actually formed, but they were always in the nature of a compact between the commission packers and a portion of the growers, agreeing to sell raisins only at prices fixed by some committee arranged for the purpose. In practice the prices fixed were usually higher than the market would bear, with the result that those outside the organization sold, while those inside did not. This at once resulted in pressure from the real owners of the money invested in advances, applied to the commission packers, through whom the advances had been made. This inevitably led to weakening on the part of some party to the compact, and very soon to a complete breaking up, the remainder of the season being occupied in mutual accusations between the commission packers in regard to who first broke the compact, and in renewed and inultiplied curses of the growers upon all of them; for the growers could not understand that the same financial pressure which compelled them to place their products for sale in the hands of the commission packers, retaining no control of the prices at which the goods should be sold, compelled the commission packers to market them before the falling market should jeopardize the advances. The commission packers standing before the growers in the light of large capitalists, apparently preferred to incur the charge of deliberate bad faith, which was probably seldom deserved, to frankly stating that they were as powerless as the growers to hold the goods.

In this way things kept annually going from bad to worse. A large portion of the growers practically gave up the fight They would have nothing to do with cooperative packing or selling, or with commission packers, if they could help it. The one thought seemed to be to put down the prices of raisins in the sweat-box to a price at which some one would buy them in that condition, stay on their farms as long as they were allowed to and could manage to live there, and when they must, to move off and begin life over again. This was real distress, and it was widespread, for indebtedness was general. There were some foreclosures, but they were com- 
paratively few, for the banks could do nothing with property for which there was no sale, and they did not care to draw public attention to the financial condition of the district. In some cases farmers packed up and abandoned their mortgaged vineyards. In many more, they confessed to the banks that they could not pay either principal or interest, and offered to convey the property if the debt were released. These were all urged to remain and pay what they could, or nothing.

The time was now ripe for real cooperative work. Not only were small raisin-growers in real distress, but the largest financial interests of the raisin districts had become thoroughly alarmed. The banks were all strongly connected, and well managed, and there was apparently no fear of their solvency; but one small San Francisco savings bank, which had placed most of its funds in mortgages in the district, made a disastrous failure. Other banks and capitalists had large landed interests in the valley, which were rapidly depreciating in value. The entire mercantile community was seriously involved, although for a long time credits had been curtailed or refused, and cash payments demanded for merchandise. Real estate in the towns became unsalable, and mortgage foreclosures on improved property were frequent. The most capable and influential men of the community realized that the time had passed when the strong could safely regard only their own interests, but that all must unite in effort for the general prosperity, in which only lay the hope of prosperity for any one.

In the spring of 1898 , according to the annual custom, a mass-meeting of raisin-growers was called to devise a plan of organization. These proposals had always had the support and counsel of the financial men of the valley, who usually agreed very well in their advice, but could never prevail against the contentions and jealousies which divided the mass of the growers, and which had often been fostered by many of the commission packers, who did not desire that their business should be in any way interfered with, and who, by advances, or actual ownership, controlled an acreage sufficient to prevent any effective combination to which they were not a 30 
party. In 1SsS, however, the commission packers themselves, who, of course, were, as a class, just as good citizens as the members of other classes, and of whom some had always favored efforts of the growers to organize themselves, were as strongly convinced as others of the necessity of united action, and were ready to put the acreage which they influenced or controlled into any combination which did not endanger their large investments in buildings and packing machinery, or take from them the mercantile business which they had been years in building up. What they desired was that they should be permitted to continue to do the packing for the growers at the prices which had been usually paid, and to continue to do the selling at the customary commission. With these essentials granted, they were willing that an organization of growers should control pretty much everything else, including the fixing of the prices, and were ready to enter into such contracts with the growers' organization as should assure to the latter complete control of the business. They were also willing to continue to employ their capital and credit in advances to growers, and generally to accept the situation of agents of the growers, employed to pack and sell goods, and subject, in these matters, to the control of their employers, who, in turn, must accept full responsibility for results, and, in the main, for the financing of the enterprise. The packers, of course, could not and did not object to growers packing their own raisins, or to the employment of such cooperative packing plants as were in existence, but did object to systematic and aggressive action on the part of the organization to increase the number of such plants. Upon this point there was no explicit agreement, but it was doubtless tacitly understood. upon both sides.

It is unnecessary to detail the conventions and meetings and consultations, public and private, by which organization was effected substantially upon these lines. The packers formed an organization of their own, and the public movements were, doubtless, largely based upon private understandings, more or less informal and indefinite, between the leaders of the two parties. In several mass-meetings of the growers 
a form of organization was elaborated and agreed upon, and leading growers selected to incorporate the society and serve as directors for the first year. This done, a form of contract was prepared to be signed by individual growers, which gave to the California Raisin Association absolute control of the crop of 1898. The contracts of growers whose crops were mortgaged for advances must be endorsed by the mortgagee, whose claim would be satisfied by the association. A carefully prepared list of raisin-growers and acreage was made, and the contracts were not to be binding until signed by owners of at least seventy-five per cent of the acreage. They were then to become binding upon the growers who had signed, after which the association had a certain time in which to exercise its option whether or not it would accept the contracts and itself sign. This was for the purpose of permitting the association to complete its contract with the packers, which could not be done until the association itself had something to deliver.

The movement, as stated, had the support of all the large growers but one or two, and of the entire mercantile and financial elements. An active canvass was commenced, and in due time, and after the greatest effort on the part not only of the directors but a large number of others, the requisite percentage was secured, and, after further protracted negotiations between the association and the packers, a committee of disinterested bankers being frequently called in to arbitrate upon matters of detail, the contracts on all sides were closed, and the association began business. It is unnecessary to follow the history further. The details of the management would hardly be understood by the general reader, without lengthy explanations, and are not essential. 'Like all new enterprises, the association had its troubles, not the least of which were underselling by the few who did not sign, and who had no confidence in the ability of the association to sustain itself, and who wished to aroid the avalanche which they expected to follow its speedy dissolution. But the affairs of the association were in the hands of men of great ability. They established a thorough system of inspection and branding, 
and the association brand at once commanded a preference, as a guaranty of an honest pack. The directors had the confidence of the banks, and thus could command capital, and when foolish men put their goods on the market at cut prices, the association, through its brokers, secretly bought them in, inspected and branded them, and resold them at a profit, thus making a langhing stock of the outsiders.* The prices fixed were very reasonable, not such as would pay interest on inflated values of property, but such as thrifty men could live by and save a little. Interest was generally paid on mortgages; old store bills were paid off. Some who had exceptionally good crops paid off, or made payments on, mortgages. The sum distributed to growers up to April 1, 1899, was two cents per pound for average raisius in the sweat-box, a rate which no more than pays costs on the poorer lands, with a further dividend to be expected later.

In 1899, the contracts having been for but one year, a new canvass was begun, this time for two-year contracts, which, at the time when these pages are printed, is understood to have been successful. The association itself has reorganized for convenience, under another law. The new contract with the packers involves a reduction of twenty-five per cent in packing charges, and nearly thirty-three and one-third per cent in commissions on sales, witl more stringent regulations for the prevention of irregular practices. These reductions involve very large sums, and show the effectiveness of organized action and financial independence. They appear to have been a compromise on the part of the packers to prevent a proposed increase of cooperative packing.

The history of cooperation among raisin-growers very well illustrates the manner in which all classes whose interests conflict, may, and in the future are generally likely to, compro-

* This was a very dangerous departure from the principles of cooperative marketing, justified, if at all, by the peculiar circumstances of the case, and the exceptional ability of those particular directors. They did not err in judgment of values, but some other board might. It will not do to let outsiders get the idea that they can force the cooperators to buy their products. 
mise upon clear-cut agreements to mutual advantage. The commission packers are doing work which must be done by somebody, and for which they are at present better equipped than the growers. They have, doubtless, been getting higher pay for their services than the business justified, but it required only united action by the growers to secure rates which are entirely reasonable. 


\section{CHAPTER V.}

\section{THE DRIED FRUIT AND NUT ASSOCIATIONS.}

LMOST simultaneously with the beginnings of coopera-
tive effort in the San Joaquin raisin district, producers
of dried fruit in Santa Clara County evolved a class of organizations which have thus far proved very successful, although they have never yet controlled the crop, or approached the effectiveness of a Trust. Although originating in Santa Clara County, the example has been followed in all parts of the state, and there are now a large number in successful operation. These societies do not differ in principle from the cooperative raisin-packing societies already described, but they were, for some years, far more successful than those societies, mainly for the reason that, situated in the midst of an older and richer community, they have had no financial trouble. They also had the advantage of beginning while the fruit business was still remunerative, and, while they have not been able: to arrest the downward morement in prices, inevitably following the enormously rapid increase of production, they have greatly steadied the descent, and assisted to equalize the pressure among all engaged in the business. Their character and methods will be better understood after a brief description of the dried-fruit business.

The Santa Clara Valley lies south of the southern arm of the Bay of San Francisco, San Jose, the commercial center of the valley, being fifty miles distant from the eity of San Francisco. Originally a great wheat field, some of its inhabitants were prompt to see the attractions of the fruit business, and to engage in it. The plums known to commerce as "prumes" were found to sueceed admirably, and large areas were rapidly planted to these trees, as well as to apricots, peaches, pears, and, in fact, nearly all deciduous fruits; but the prune was largely in the lead. The apricot grows and 
bears well, but is longer maturing than elsewhere in the state, thereby obtaining a thicker and firmer flesh, but ripening too late for profitable shipping, as the apricot, fresh, does not sell well in competition with peaches, excellent varieties of which are in the market from the earlier districts before the Santa Clara apricots are ready. The peaches and pears, also, from this district are said not to bear the long overland journey so well as fruit from interior districts. These conditions, with the fact that the prune, which is almost exclusively a drying fruit, was the largest fruit product of the valley, naturally led to the drying or canning of the greater portion of the crop. This business for some years proved very profitable, and the industry increased until large districts in the valley were almost completely covered with orchards ranging in size from five acres to three hundred acres, and San Jose became by far the largest shipping-point in the state for dried fruits; of prunes, especially, it supplied for some years almost the entire output of the state, and while, with the enormous increase of the industry elsewhere, its relative importance in the trade has diminished, as late as 1893 there were shipped from San Jose seventy-five per cent of the prunes and twentyfive per cent of all the other dried fruits exported from California.

The fruit for drying-except prunes-is jitted, under sheds, placed on shallow wooden trays usually three by eight feet, bleached by exposure to sulphur fumes, and then dried in the sun. Prunes, of course, are neither pitted nor bleached. To secure uniformity in drying, prunes are graded by machinery before drying, and other fruits either by machinery or by band. To handle the pitted fruits properly, a good deal of extra labor is required, and a few days of unusually hot weather coming on may require the picking and pitting force to be suddenly doubled in order to save the fruit, and this extra labor is not always available when needed. Considerable vacant space must be left in the orchard for drying ground, and on small farms this space was grudged from the orchard. The investment in trays and machinery was considerable if the fruit was to be properly cared for, and the labor of feeding 
and caring for the extra help bore heavily on the women of the household. There grew up, therefore, very naturally, a class of local dealers located near shipping-points and where labor was available, who bought the fruit, picked and delivered at their grounds, where it was dried and marketed. This had the advantage to the grower of giving him his money, in full, at once, and relieving him of the burden of securing help except for picking, and it was good for the industry in that the average quality of the dried product was better than if dried by a liundred persons, mostly unskilled and imperfectly provided with appliances. The evil of it was that the growers, being at such a distance from the great markets, and usually having to sell before the prices of the season were fully established, and, moreover, being generally not well informed as to the usual shrinkage in drying, were at a great disadvantage with the more astute and better-informed buyers. It was also true that the buyers were accustomed, at the begimning of the season, to scour the district in search of growers whose debts pressed them, and with whom hard bargains could be driven by the temptation of a certain amount of ready cash paid down; and a few sales of this kind having been made, under pressure, the season's prices became pretty firmly established, and it was hard to raise them, the result being that the prices for all the crop were set by that portion of the growers who were the least competent to judge of its value, or insist on receiving it. Undoubtedly there was another side to the question, for it often happened, especially in years of short crops, that competition among buyers rapidly ran prices up, with the result of serious losses to the buyers, and sometimes failure. In some cases the loss from failure of buyers fell upon growers who sold upon short time, intending to give the buyer opportunity to dry and sell before payment. The fruit dried on the farms was also largely purchased by those engaged in drying, as well as by others, who visited the orchards, and bought and paid for the fruit on delivery at the packing-houses, where it was graded and sold in car-load lots to the trade.

As a result of this system, a feeling of animosity grew up 
among the growers toward the wuyer's of their product, not, however, by any means so intense as that among the raisingrowers towards the commission packers. The feeling, however, was less intense only for the reason that the growers were in better circumstances, and at the time were receiving better prices than the raisin men were obtaining, and also, as a rule, were actually selling and getting the money at some price, the increasing production not having then so demoralized markets as to drive local buyers from the field, although it was beginning to make them cautious, and their growing unwillingness to meet the views of growers was leading an increasing number of growers to consign their goods east in the expectation-almost never realized-of obtaining better results.

Under these conditions, during the winter of 1890-1891 a movement originating in one or two local societies of fruitgrowers led to the organization, in a fruit district near Santa Clara, of the West Side Fruit Union, a cooperative society for drying, packing, and marketing the fruit of its stockholders. The plan accepted the principle of bringing the fruit for drying to the drying-grounds of the society, thus concentrating the fruit for shipment in car-load lots, and so performing one of the functions of the local buyer. But it added other features. The buyers, after receiving and paying for the fruit, graded it, and packed it according to grade, and not in lots as purchased, and as they bought as cheaply as they could, and at varying prices, different growers received different prices for fruit which went into the same bin; this grading was necessary, and as the detail of keeping each owner's lot of each grade separate was very great, and as prices would vary more or less during the season, so that if kept separate one person was sure to get more than amother for the same grade, the union determined to make no attempt to keep lots separate, but to grade the fruit as brought, giving receipts for the quantity of each grade, and then selling as if the product of one owner. At the end of the season each owner received in payment for each grade of his fruit the average price received during the season for that grade. As the season went on, and sales were made, growers received 
money on account as was required; final settlement was made when all was sold. The plans of the association were elastic, and any grower who preferred to dry his fruit at home might do so, and bring it dried to the packing-house, where it was graded and then mingled with the fruit dried by the society. The accounts were so kept that the expenses of selling were shown separately from those incurred in drying, and the grower bringing his fruit dried was charged only for the expense of selling.

The society, of course, was incorporated, the par value of the shares being $\$ 25$, all of which was paid in at once or during the season. The idea, being new to most growers, was received as new ideas are generally received by the public, who were quite ready to meet at the schoolhouses and approve them by resolution, but extremely slow to sign their names to subscriptions to stock. The promoters, however, were not easily discouraged, and, being all men of substance and standing in the community, eventually succeeded in selling the required amount of stock, divided among some eighty or more orchardists, some of whom lived too far away to ever expect to make use of the organization, but benevolently gave the $\$ 25$ "to help it along," never expecting to see their money again. It was intended that stock subscriptions should be made upon the basis of acreage in orchard, and to a certain extent this was done, but as success was earnestly desired, the promoters were not very particular, in consequence of which some "benevolent" growers obtained for \$25 the privilege of drying-grounds and plant for large orchards which they could not have provided by themselves for fifty times the money. Ten acres of land were purchased, a building erected, trays and machinery provided, and in the fall of 1891 the association was ready for business.

The stockholders were afraid to trust their own business agency. Of eighty or more who had undertaken to coopcrate, but five or six were found ready to intrust their fruit to the care of the men of their choice, and their servants. What they were afraid of it would be luard to say, but they were afraid. Especially they disliked pooling their fruit with that 
of their neighbors; almost every one was of the opinion that his fruit was better than that of his neighbors, and that he would somelow lose if he allowed it to lose its identity. Fruit prices opened that year at what was considered a moderately fair rate, although lower than the year before, and one by one the stockholders sold out. It began to look serious, for the plan of operation involved the agreement that interest at eight per cent upon all stock issued should be charged as an item of expense, against the fruit handled, and it began to appear as if the fruit of a very few growers would have to bear the entire interest charge upon the cost of a plant large enough to handle ten times the quantity. Fortunately for the society, it was a year of large fruit crops, and the buyers soon began to get enough, and prices began to fall, and when they reached a point lower than fruit had ever before brought in the valley, the few who had not sold out, agreed, with some apparent misgivings, to patronize their own business, instead of competing with it. In all there were seventeen out of the eighty who took the fearsome venture. The fruit was dried and sold, and when settlement was made, it was found that those who had been so reckless as to trust themselves with their own product, had all made a handsome gain as compared with the average of those who refused to stand by, and that in the face of bearing the burden of interest on all the stock. The result was so encouraging that the next year nearly one-half of the stockholders had the full courage of their convictions, and marketed the fruit through the association. It was a short erop, but buyers opened the market with very moderate offers, but prices went up towarls the close of the season to as high a figure as they had ever reached- $\$ 60$ a ton for fresh prunes, which, if it could be had regularly, would soon make millionaires of the growers. At this figure it was almost impossible to hold the stockbolders, and many of them sold; indeed, some had done so long before, at $\$ 40$ to $\$ 48$ per ton. When the settlement was made by the association, however, an average of $\$ 85$ per ton, fresh, was distributerl after paying all expenses. Another similar society which had that year been started near by, had a similar experience, and 
the whole Santa Clara Valley went wild over the profits of the prune business, and the profits of cooperation.

As a matter of fact, the phenomenal results of cooperation in that year could never have been anticipated, and can hardly occur again. The prune crop was very short, and prices very high, but the principal gain to the drying associations arose from the phenomenally small shrinkage in drying which occurred in that year, and which made the returns per ton of fresh fruit exceedingly high, although the crop was so short that the incomes of the growers, while large, were not at all beyond reason. Many of those who dried their own fruit at lome, and sold independently, did nearly or quite as well as those who sold through the two drying associations, for all the information and acts of the unions were public, and imparted as freely to outsiders as to their own members, and all growers who used reasonable diligence could through them be perfectly informed of market conditions, and obtain full prices, as the demand was brisk and there was no difficulty in making sales. There were, of course, many who were not informed and who got less than the associations, but it was their own fault. What the associations did do, however, was to demonstrate the fact that it was unwise to sell the fruit before drying, because in the long run, and one year with another, there was a profit in drying which the grower could not afford to lose, although it was also doubtless true that an experienced grower could often sell his fruit, fresh, to an inexperienced buyer for more than its value; in the long run the odds were against the grower, and he did better to dry his own fruit, either at home or through a cooperative association. It also seemed clear that a grower, with drying-grounds and appliances, who made no account of the wear and tear of these, or of his own time, or that of his family and teams, could show a less net cost of drying than the cooperative associations would show; but if he included in his cost the actual worth of these items, his net cost of drying would be greater; but it became very evident that the average quality of the fruit dried cooperatively was far better than the average of the same fruit home-dried, although no better than, if so good as, 
the product of the most skilful and painstaking growers. It was evident that the gain to the stockholders in the one year 1892 far more than repaid the total cost of the cooperative establishments, so that even if no further use should be made of them there lad still been a profit, but the greatest gain of all was in the diffusion among growers of definite knowledge of their own business, including the normal shrinkage in drying of all fruits, the best methods of manipulation, the necessity and profit of painstaking in every step of growing and preparing, and the beginnings of an intelligent study of marketing. No one has ever questioned the economic value of these drying associations. - In districts where orchards are too much scattered, they are not possible, as the ripe fruit can not be earried over two or three miles in wagons without too much bruising and waste, and the expense of hauling the fruit before drying will average four or five times the cost of hauling the dried product.

In the spring of 1892 the promoters of cooperative organization, encouraged by the success of the first year's work of the drying association, called a mass-meeting of fruit-growers, which was held in April, in San Jose, and was largely attended, the largest hall in the city being crowded to overflowing. The discussions at the meeting developed a wonderful ignorance among the growers as to almost everything connected with their business, beyond the actual growing of the fruit. The wildest statements were made, and the most glowing predictions were ventured, as to the results to be expected from cooperation. The meeting lasted all day, resulting in a resolution to effect an organization which should embrace the entire district tributary to San Jose as a shipping-point, and which should market the product of the drying associations formed and to be formed, together with that of individuals drying their own fruit, and a committee was raised to formulate a plan to be reported to an adjoumed meeting. In due time this committee reported articles of incorporation and by-laws to the adjourned meeting of the convention, which, although not more than half so large as the first, was enthusiastic and united, and, having agreed upon the form of the 
articles, selected nine persons to serve as directors, and pledged subscriptions of stock to the amount of about $\$ 2,000$ of the $\$ 200,000$ which was proposed as the capital to be raised. It was intended to interest the local buyers in the movement, and four of the nine directors were of that class. They were bright men and always served the Exchange faithfully, giving freely of their experience in perfecting the organization, and subsequently in the conduct of the business, which, indeed, without their help, would have been exceedingly awkward at first, but the inveterate hostility of most growers towards all the customers for their goods always made their presence on the board of directors a sort of weakness, by exciting distrust of the management. The organization thus formed is known as the Santa Clara County Fruit Exchange, and is one of the best known and most successful societies in the state.

The directors incorporated, as directed, in May, and immediately, through the press and by circulars, requested the enthusiastic growers who directed the organization, to send in their subscriptions for stock. Not a single dollar, not a single subscription, ever came in as the result of this effort, except one from an enthusiast in a distant county, who sent his subscription for ten shares, and a check for $\$ 100$ to pay for them, although he could never hope to, and never did, receive any advantage from the society except such information about markets as it could give him. The thousand growers who shook the rafters with their cheers at the first meeting remained silent as the grave when the time came to supply the money; and it was not from porerty, as they were mostly prosperous and well-to-do. It very soon became evident that the Exchange could not get realy for business that year, which was the less needful as it was a year of short crops and full prices, with no difficulty in selling at very profitable rates. The directors, however, continued to meet regularly, studying the business and perfecting plans, and endeavoring as they could to obtain stock subscriptions. The press of the county gave its columns freely to the movement, so that the subject was for a time kept before the people, but in the last' of October, at the end of the fruit season, not only had no prog- 
ress been made in getting money, but the very memory of the movement begun so enthusiastically had almost faded from the public mind.

The directors, however, were determined men, and some of them, especially, were so prominently and publicly connected with the movement that they could not, without great mortification, see it fail. It was determined, since volunteer effort produced no results, and there was none of their number who was able to leave his own business, without compensation, to visit the individual growers, to see what could be done by paid service, and one of the directors was chosen manager, at a moderate compensation, and instructed to proceed and complete the organization, which he accordingly did, but instead of accomplishing it in a few weeks, as was expected, fully six months were required, during which the manager received some paid and a great deal of volunteer assistance. It was found that the growers who, when assembled in convention, seemed ready to mortgage their farms for the sake of cooperation, would do absolutely nothing towards establishing the business, except as solicited with the sume tact and vigor that is required in selling patent rights. The exceptions were too few to be taken into account. At the end of six montlis something over $\$ 18,000$ of stock subscriptions had been secured, at the cost of over $\$ 1,400$, including all the preliminary expenses, and the total number of subscribers was less than the number present at the conventions, where they could have subscribed with no expense to anybody. The average cost of a subseription was $\$ 3.00$, exclusive of time spent by volunteer canvassers. Three hours of earnest work was frequently required to obtain one name, and many individuals required visiting several times. Such work must be expected by the promoters of all cooperative societies.

In beginning the canvass some time was lost in seeking to enlist the local buyers. It was the desire of the promoters to unite all interests and make an organization sufficiently powerful to control the dried-fruit business of the valley, and, as already stated, four or five directors were buyers but it was found impossible to enlist the buyers as a class. 
Some were financially dependent on commission houses, and all thought they saw that any organization which should thoroughly educate the growers, and furnish them an independent outlet for their product, would not be to their interest, and but two or three, except those already in the board, would subscribe stock, and of these none ever sold their pack through the Exchange; nor, in fact, did the buyers who were on the board of directors. It became evident that a cooperative society of producers must depend upon producers for membership and support. As the permanent management of the Exchange would be attended with considerable expense, and as its means of living could only come from commissions on sales, it was essential that a large business should be reasonably assured before going on, and when it became evident that the support of the local buyers would be wanting, the management of the Exchange, in self-defense, promoted the organization of three more drying associations, whose fruit was expected to be sold through the Exchange, and thus assist in its support-the Exchange taking the place of the commission houses which had been accustomed to handle the product. The manager of the Exchange spent considerable of his paid time in this work, and the president and some of the directors much volunteer time. The total result of the cooperative movement, up to May, 1893, was the establishment of the Exchange and five cooperative drying associations, with an aggregate paid-up capital at that time of about $\$ 75,000$, since considerably increased. The Exchange purchased five acres of land in the outskirts of San Jose, and erected and equipped a substantial warehouse, and the drying associations supplied themselves with the plant and ground required for their work.

In May, 1893, the Exchange was ready for business, but before starting, an effort was made to secure such pledges of business as would assure an adequate support, from commissions, to the Exchange. It was found, however, that absolutely no pledges, except that of the manager, could be secured. The original society, whose success gave the impetus

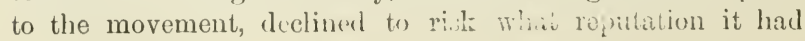


gained, in any new enterprise; one of the newly-formed drying associations also prepared to work alone. The other three associations in the end sold their fruit through the Exchange, although they did not agree to for some time; and, in fact, the effort to secure pledges in advance had to be given up, and the stock was called in, and the buildings erected and equipped without the certainty of a dollar's worth of business to come to them; in the end, however, business did finally come, aggregating sales, for the year, approaching a half a million of dollars, the commission upon which fully paid all expenses of the Exchange, including six per cent interest on paid-up stock, and, except for a loss by a bad debt, would have permitted a small rebate. There were sold by the drying associations outside the Exchange about $\$ 200,000$ additional. The business was conducted to the general satisfaction of the growers, although the net results to growers selling through the Exchange were no better than those obtained through buyers and commission men, the information as to markets obtained by the Exchange being freely given out for the benefit of the public, thus practically controlling the price of dried fruit in the valley. It was, however, universally conceded that the existence of the Exchange and the drying associations was of great value to the fruit-growers of the district.

The experience of 1893 disclosed two points of special importance, the one decidedly favorable to cooperation, the other perhaps debatable. The first related to financial management. The year 1893 was a year of commercial panic. The banks of San Jose, although solvent and prosperous, were in such danger of a "run" that they could not and did not lend a dollar to the Exchange. One stockholder lent the Exchange $\$ 1,000$, which was advanced to those in need of money, and with that exception the entire pack of the season was moved without borrowing a dollar. Of course there was some hardship; some growers desired money who could not get it until their fruit was sold, but they got along somehow. In a short time, as sales were made, money accumulaterl which was not called for by the well-to-do orchardists, and this money was 
advanced to those requiring it, without charge for interest, as none was paid. In other words, the Exchange did a free banking business, to the great advantage of its poorer stockholders, and to the injury of none. The other point had reference to the free information regarding markets, which was made public by weekly bulletins and through the press, and benefited members and non-members alike. The organization of the bulletin system required a good deal of time, which, in connection with the cost of publication and mailing, cost about one-fifth of one per cent of the total output handled. This expense was charged against the fruit handled, so that the owners of that fruit paid for the information given, not only to stockholders who sold outside the Exchange, but to the general public. The owners of the fruit did not like this, but, on the other hand, could not help themselves, since it was believed that, if the information was withleld, ill-informed growers would sell at less than market rates, and thus prevent the sale of Exchange fruit except at similar rates, and all to the advantage of speculators, since the real eastern market price was fixed by law of demand and supply. It was a perplexing question, as the real cooperators disliked intensely to have their money used for the benefit of those who would not cooperate, and there was doubtless a tendency on the part of many to reserve to themselves what they thought the advantageous freedom of an outsider, and let those who would foot this particular bill, since all got the benefit alike.

The business of the Exchange for 1893 was closed with great satisfaction to all concerned, and in 1894 there was a general tendency to sell through the Exchange or the drying associations. On the part of the latter, however, there was increasing disposition to manage their own affairs without reference to the Exchange. None of the associations this year put their fruit unreservedly in the hands of the Exchange, which was therefore left to such income as could be made from commissions on fruit intrusted to it by individual stockholders. These, however, supplied fruit in abundance, far exceeding the storage capacity of the Exchange warehouse. Money was easy, the credit of the Exchange was high, and there was no difficulty 
in obtaining funds for all necessary advances. Unfortunately, the general tendency of the market was downward, the purchasing power of eastern buyers proving very small. This tendency the Exchange and the drying associations undertook to withstand by publicly setting the prices above the market, and refusing to sell for less. The drying associations and the Exchange worked together in this matter, their presidents meeting weekly and agreeing upon uniform prices, usually above the market. Their lead was generally followed by other cooperative societies, organized in other parts of the state, nearly all of whom held their goods mostly on borrowed money, while outsiders sold out; and still the market went down. In the end, while the Santa Clara societies made many sales at better rates than were generally obtained, and while their action, with that of the other cooperative societies, had great effect in steadying the market and preventing utter demoralization, they liad to give in, after paying considerable interest, and sell, in the spring market, for no more and perhaps less than outsiders realized in the fall. This result brought out the great weakness of cooperation; the growers who could not say too much for the Exchange in a year when all went well, and who were perhaps strongest in urging the Exchange to hold firm at the begimning of the season, were prompt to condemn the action of their agents when it appeared that they had been mistaken in judgment; and a general desertion followed. The following year the business of the Exchange and the Unions was sinall, but since that time they have rapidly regained the confidence of the people, and in the season of 1S9S-99 the number of persons selling fruit through the Exchange was reported as slightly greater than the total number of stockholders, which may be an error, as the Exchange will not ordinarily handle fruit not the property of its members. While the object, at the beginning of the movement in the Santa Clara Valley, was to obtain entire control of the product of that section, no serious effort has ever been made to accomplish that end. The Exchange and Unions are the largest and most influential factors in the trade. The Exchange brand is the acknowledged 
standard of excellence in dried fruit. They have a substantial and well-managed business, and make no attempts to increase their own membership, or even to holil the business of their stockholders, much less to promote the formation of additional cooperative societies.

I have stated that the Exchange was organized to be a common selling agent for all the Unions, and that, after its organization, local influences of various kinds prevented the Unions from accepting leadership of any kind. Precisely like individuals, they desired absolute independence, and a spirit of rivalry and distrust began to grow up among them, such as always grows up between competitors everywhere. To put a stop to this feeling and its attendant evils, negotiations, begun in 1894, resulted in the establishment, in 1895, of a common agency, known as the "California Fruit Agency," through which the Exchange and three of the Unions have since that time made their sales. This has obvious advantages in economy and in other ways, but two of the Unions have thus far declined to come in, and these continue to make sale of their products through San Francisco commission houses.

During 1894 and 1895, and later, quite a number of driedfruit associations similar to those of the Santa Clara Valley were organized in other fruit districts of the state, most of which died after a more or less feeble existence. Of those established during that period, three only, I think, survive. No one of these has any such volume of business as would justify it in making any effective canvass of distant markets -an experience which is essential to a mastery of the art of marketing. They have not thought best to unite with the Santa Clara Exchanges, and, while they are useful, and apparently to be permanent local societies, they have as yet none of them approached the limit of success in cooperative marketing.

The principal fruit industry of the seven southern counties of California is the citrus fruits-oranges, lemons, and pomelos. For a long lime it was not thought that that these counties were adapted to the production of deciduous fruits, except apricots, and, at any rate, the citrus industries had greater 
attraction for the people. Gradually, however, the area devoted to deciduous fruits increased, and the product was marketed dried. The growers were new to the business, and knew little about either the cultivation or the curing of the fruit, and the result was a generally inferior product, which did not bring the price of the northern dried fruit, or any satisfactory returns to the producers. The farmers of the southern counties of California, however, are perhaps the most intelligent and enterprising rural population in the world, and were not likely to, and did not long rest contented with such a state of affairs. The deciduous-fruit interests began to draw out from the shadow of the great citrus industry, to meet and organize for mutual advantage, and to talk of cooperation, whose possibilities were well shown by the success of the citrus associations, to be described in a later chapter. At length, after a number of conferences, in October, 1897, the Los Angeles Chamber of Commerce called a mass convention of those interested in the deciduous-fruit industry to consider the subject of cooperative marketing. After a day spent in discussion, a committee was appointed to prepare a plan of organization, which was duly reported to an adjourned meeting of the convention a month later, and vigorously discussed for another full day. At the close of the discussion it was resolved to form the "Southern California Deciduous Fruit Exchanges," which was to consist of an incorporated society with that name, whose members should be local "Exchanges" or "associations" for collecting and curing the fruit, like the "Unions" of the Santa Clara Valley. None of these local societies were in existence, and they, of course, must be created before they could join in the creation of the central society. This involved months of hard canvassing, and traveling by rail and private conveyance over a district comprising many thousand square miles. Evidently this would cost money, and, after unanimously requesting the most earnest of the promoters to undertake the great labor of organization, those present assessed themselves one dollar each to pay the expenses! There were thirty-seven of them who paid, and there were thirty-seven dollars-perhaps enough to pay the postage bills, 
but certainly not sufficient to buy stationery. Another effort was made, which brought the total up to $\$ 139$, an amount perhaps sufficient to pay the postage, printing, and stationery bills, but leaving nothing for traveling expenses, much less compensation for the gentleman whom they had asked to conduct the organization, and who was one of their own number, and, presumably, no better off than the rest. That - sum, however, was perhaps the fair share of the few delegates present, and the convention appointed a "finance committee" to procure the rest of the money, and went home. The finance committee could raise no money, and then the energetic organizer went to work and organized eleven local societies, which, with a few large individual growers, met and organized the Central Exchange, which began business on June 23, 1898, and sold, during the year, for its members, dried fruit to the amount of $\$ 63,721$, the small sale being due to a drought so severe as to practically destroy the crop, some of the local associations not having a pound of fruit to dispose of. I mention the monetary details of these organizations for the reason that they are seldom publicly spoken of, the farmers appearing to think that the funds for such work are supplied as the Israelites were supplied with manna, which is distinctly not the fact. If the Lord provides for such expenses, He does it by inspiring with an altruistic spirit some capable man, who goes down into his pockets and digs up the money. Whether the organizer of these southern deciduous Exchanges was ever reimbursed for his expenses, I do not know. I presume he was. But if he had not succeeded he would not have been, which would have been wrong. Those engaged in an industry have no moral right to ask one of their number to assume such a work without sharing the risk. Altruism is properly displayed in behalf of really suffering humanity, but farmers with homes, and horses, and credit, and enough to eat, ought not to ask charity of this kind. It must not be thought that these furmers of southern California are worse than others. On the contrary, that convention did more towards raising money than any other I ever knew of, except one, for which reason I select it for my principal illustration, 
and also because, while I had no connection with the movement, I happen to be familiar with the facts. Cooperation in marketing implies cooperation of persons of some means, and should be begun and prosecuted on business principles. The work of these southern societies has been satisfactory to the membership, and their number and membership are increasing.

As these pages are being printed, there is in progress a more ambitious cooperative effort than I have known of elsewhere, in connection with marketing. This is nothing less than the organization of a "Pacific Prune-growers' Association," whose object is to combine under one head all the driedfruit societies which I have mentioner, together with all other similar societies and all individuals engaged in the production of prunes in the Pacific Coast states. The organization, as proposed, will be almost precisely on the lines of the reorganized Raisin Association, already described, and including similar agreements with the private packers and commission merchants, who are understood to be generally favorable to it, and without whose cooperation it could not, at present, succeed. Whether it can yet succeed with their aid is quite doubtful, as the prune-growers are widely scattered orer a large area comprising several states, and it will be contrary to all experience if they can be induced to sign the necessary contracts without a long and very expensive canvass, if at all. So far as California alone is concerned, whose people are coming to be fairly well educated in cooperation, this proposal is not visionary, although it may not succed. But the essential feature of the growers' contracts is the sale of an undivided twentieth (five per cent) interest in each man's crop, in consideration of services to be performed, with absolute control, as a partner, of the whole crop as soon as harvested. It will be very strange if the fruit-growers of Oregon, Washington, and Idaho shall be found willing, without previous instruction or experience in cooperation, to at once proceed to the exercise of this highest development of the art.

Among the earliest and most effective of the cooperative marketing societies was that of the walnut growers. This is 
due to the fact that the Persian walnut, while it grows luxuriantly in most parts of California, has thus far been found commercially profitable only in limited areas in a few of the southern coast counties, with the result that the number of growers is small, and the work of organization comparatively easy. Organization, however, did not come at once. In 1887 about twenty walnut-growers of Los Angeles County organized the Los Nietos and Ranchita Walnut-growers' Association. This, for a long time, was the only walnut-growers' society, but with the increase of the product, and increasing competition with each other, other associations were gradually formed, until they now number seven, and include nearly all the growers. They have, as yet, formed no central organization except an informal one of representatives of each society, which meets as occasion requires, to fix the prices of the crops to which each association adheres. The associations control the output of California waluuts, and fix prices, subject to the competition of the French crop. The sales of this society, in 1898 , were over $\$ 400,000$. The original society now numbers two hundred twenty growers, and, in 1898, shipped over two hundred car-loads of walnuts. 


\section{CHAPTER VI.}

\section{THE CALIFORNIA FRUIT EXCIIANGE.}

I $\mathrm{N}$ the autumn of 1893, while the Santa Clara County Fruit Exchange was in the full tide of its activity, the California State Horticultural Society held a special session at San Jose for the purpose of studying its operations. In the enthusiasm of the moment it was voted to establish a state Exchange, whose function should be to unite all branches of the fruit industry throughout the state for common action for common purposes. Just what purposes wonld prove to be common were probably not then well defined in the mind of any one, but that would work itself out. A committee was appointed on the spot, instructed to choose directors from their own number who should proceed to organize the growers of the state into one borly, with the state Exchange at the head. When, however, the directors were chosen, they consented to act only temporarily, until a special state convention of growers should formally determine whether a state Exchange was desirable, and, if so, mark out the general lines upon which it should proceed, and select directors to serve for the first year. In due time the convention was called and met, with a large representative attendance from most fruitgrowing counties of the state. The plans which had been formulated by the temporary organization were, after a full discussion, unanimously approved, permanent directors were selected to incorporate the Exchange and serve for one year, and the Exchange was formally recognized as the "authorized agent of the fruit-growers of California." The plans had a short time before been approved by a regular annual state fruit-growers' convention, which had met in the meantime, and by such local bodies of growers as there had been opportunity to consult. The special convention was unanimous and enthusiastic, voting very heartily to begin subscribing 
for stock then and there, but unon subscriptions being called for the hall was nearly emptied within a few minutes, with only some hundreds of dollars subscribed, by less than a dozen subscribers, but one of whom ever made good his subscription.

In due time the directors met, subscribed to the stock, organized, and incorporated. The manager who had acted during the temporary organization, was the same who had served the Santa Clara Exchange during its period of organization, and was therefore assumed to have had a useful experience. He undertook to serve only until the enterprise was well started, but remained in service for over a year. The character and scope of the work which the Exchange should undertake had, in general terms, been outlined by the convention, from which, of course, directors chosen by that convention would not feel at liberty to materially depart for the first year. The outlined program, however, contained far more than could be undertaken at once, and the obvious first duty was to establish an effective organization, with the necessary capital and income, and to this effort the manager addressed himself.

The press of the state lent itself very cordially to the movement, but was of course unable by its own utterances to treat the subject in any such way as to really contribute to the education of the people, upon which everything depended. The majority of the growers, and at first the majority of the directors, regarded the state Exchange as a proposed selling agent for the fruit of the whole state, somewhat on the plan of the California Fruit Union, then just going out of business; and, in fact, most people considered it as connected exclusively with dried fruits. Those connected with the press, as well as most growers, having little or no idea either of the real bonds of connection between the different branches of the industry, or of the limitations of possible state cooperation imposed by matters of finance and detail, were unable to discuss the subject intelligently, and the manager was compelled to expend a great part of his vital force in combating erroneous impressions, and warning against extravagant anticipations. With so large an undertaking as 
the welding of twenty thousand fruit-growers distributed unevenly over a territory two hundred miles wide, and of a 'length extending from the latitude of Connecticut to the latitude of Georgia, into a compact mass, knowing the same facts, and consequently thinking the same way, the obvious course was to enter upon a year's campaign of education, attempting no positive action until all were prepared to act together. The conditions for this were in many respects favorable; the columns of the entire press of the state were open to the Exchange, the transportation companies were glad to contribute to the movement by the free carriage of those engaged in promoting it, the manager's experience and abilities were well adapted to that work, but the effort failed for the lack of the few thousand dollars necessary to pay the expenses of the first year or two. Its history, however, is of value.

The composition of the board of directors illustrates one of the greatest difficulties of cooperation on a large scale. selected by a convention of members mostly unacquainted with each other, the choice was necessarily somewhat hapliazard, but resulted - as was almost certain to be the case-in the choice of excellent men. Of course, however, they were entirely unacquainted with each other, and for the most part, were without experience in cooperation or positive views in regard to it, and were so widely scattered throughout the state that the cost of each meeting was over $\$ 100$. They were very slow in reaching conclusions or in formulating a definite policy or plans. They were also unacquainted with the manager, and it did not occur to them to instruct him to proceed at his own discretion, on the lines upon which he had been working, and which had been approved by conventions of growers, until the directors should have had time to become familiar with the situation, agree upon an order of proceeding, and select a permanent manager. In consequence, an entire month was lost in inaction, which in a movement of this kind, is quite sufficient to have it pass from the public mind. The impetus thus lost was never recovered, although in due time the directors did meet and 
properly authorize the prosecution of the work. The greatest trouble with cooperative societies operating over large areas is likely to be inefficiency, of which one of the chief causes is the wide scattering of directors, growing out of the insistence upon geographical distribution. Cooperators will not consent to intrust the direction to a few capable men so situated as to be able to meet often with little or no expense, and the cost of frequent meetings of widely-scattered directors is beyond the means of a new organization.

In connection with selling the stock of the state Exchange, the manager devoted his time to the promotion of local organizations of growers, which should be the foundation upon which the Exchange should rest. It was evident, as the experience of the California Fruit Union had shown, that no central organization could deal, with advantage, with the thousands of individual growers, scattered over wide areas: before uniting them in any state organization, it was essential that local societies should be formed. It was also evident that the natural method of growth would be to await the formation of the local societies, which should by natural attraction come together in a state Exchange, supported and eontrolled by them as a common head. But, on the other hand, there were very few local societies in existence, and those were not formed on any common plan; nor had they any acquaintance with each other, or any expressed disposition to unite; and there was no likelihood that, except as the result of an organized campaign of education, their number would very rapidly increase; it was also evident that, after their organization, they must pass through a period of unprofitable competition with each other, before developing any spontaneous disposition to unite. This would put off the period of state organization so far into the future as to promise no relief except at the end of a long and exhausting struggle, involving serious injury to the fruit industries of the state and the many other interests dependent upon it. The example of the raisin industry showed the evil of delaying organization until growers had no money wherewith to organize, and it was determined to make a serious attempt to forestall disaster by 
organizing in time; it was therefore determinerl, as the definite policy of the Exchange, that it should boldly assume, for the first year, the position of leader, and in that capacity promote the formation of local societies everywhere, which, when organized, should, by ownership of stock, control the Exchange, which should then become their mouthpiece and servant, just as it would naturally have been had their organization precerled its own.

In the prosecution of this work the manager was reasonably successful. Interest was everywhere awakened, his presence, and that of the other officers, being earnestly sought from all quarters, to explain the methods of operation, and aid in perfecting the details of organization. There was a great difficulty, however, in the lack of organizing ability in the various districts. One or two individuals would invite the manager to meet their people at a fixed time, and when he arrived, there would be nobody to hear him, because the district had not been properly canvassed. In nearly every case a second and sometimes a third meeting had to be called before getting people out, and the local promoters in no instance ever came to the meetings with definite detailed plans and estimates of expenditure, although earnest efforts were always made to induce them to do so. The mass of the growers were distrustful and suspicious, and would trust nothing to the common sense and honesty of their chosen agents. They insisted on hearing and discussing the minute details of the projected business, which consumed time and tended to lead to nothing. The meetings, however, invariably passed the resolutions requested, and appointed committees to proceed to organization. If left to themselves, however, the committees ordinarily did nothing, it being usually necessary for the manager of the state Exchange to stay and assist, for a time at least, in the house-to-house canvass. This, however, was not always the case, and before the close of the season a large number of societies were organized.

But the principal difficulty was the financial one. The more substantial growers almost universally held themselves aloof from the movement; all these were anxious to have 
"the small growers" unite, for the purpose of steadying the market, but declined to compromise themseives in regard to it in any way, and, as a rule, to contribute to its support. There were, of course, exceptions. The smaller growers very generally sustained the movement with a good deal of enthusiasm until it reached the point of footing the bills; there they drew the line. When local associations were started, the growers at once became absorbed in providing for their own local interests, and would do nothing for the state Exchange.* The manager was necessarily compelled to originate and lay out the work, covering all parts of the state, attend to the correspondence, address meetings, write for the press, prepare a weekly bulletin of information, aid in the formation of local associations, and canvass for stock with which to pay the bills. With his experience in obtaining funds for the Santa Clara Exchange, he was of the opinion, and so advised the directors, that, with the whole state to draw from, he could readily secure the small sum needed for expenses, by the sale of stock upon which twenty-five per cent of the par value was paid in, and on the strength of his statement the directors borrowed a few hundred dollars with which to start work. The manager found himself wholly mistaken. In the Santa Clara case one hundred twenty-nine days of paid service secured four liundred stock subscriptions, averaging about $\$ 45$ each, or a little over three subscribers per day, and $\$ 135$. To produce those four hundred subscriptions, however, in addition to the paid service, there was a very much greater amount of volunteer service, by directors and others; relying upon a similar amount of volunteer assistance, and upon the expresser interest of the members of the special convention which created the Exchange, and of many other prominent growers, the manager said that he could doubtless, in addition to his

\footnotetext{
* In consequence of this failure of local organizations to recognize that they needed leadership, and a bond to unite them with each other, and, in any event their unwillingness to pay for it, or even to return what had been expended for them, nearly all the associations thus formed soon died, and none ever became influential. The growth had been forced, and they could not live without careful cultivation.
} 
other work, sell stock to the amount of, at least, $\$ 1,200$ or $\$ 1,500$ per month, twenty-five per cent paid in, which would pay the current expenses, leaving the balance as a gradually increasing fund to be called in later, if needed as working capital. The manager said that he expected much more, but so much he felt sure of, and the directors relied on his judgment. Never was a man more mistaken. The Santa Clara Valley is a thickly populated and homogeneous community, and while, as stated in describing the Santa Clara Exchange, it was hard to raise money there, torards the close of the canvass, the persistent work of six months in one neighborhood began to tell. All growers came to know about the county Exchange, and to take interest in it, as a thing really likely to materialize in brick and mortar before their eyes, and to talk of it with their neighbors, as something real and not a dream, so that, towards the last, less time was occupied in converting individuals. In securing funds, however, for the state Exchange, but little time could be devoted to any neighborhood; and in spite of the wide publicity supposed to have been given to the plans, it was always a new thing, to be fully explained from the very beginning to each individual, usually requiring interviews of several hours, nearly killing both parties thereto; and when it came to reducing the infinite weariness of so much talk to the concrete financial result of a stock subscription, with an immediate cash payment thereon, it was like drawing a tight cork from a wine bottle. It was usually the case that the strongest talkers for cooperation were the hardest to get money from. Besides, the money in the Santa Clara case was at least to go into tangible property, which the stockholders could use, while that sought for the state Exchange was avowedly to be used in experiment, and might be lost. The manager, in his estimates, had allowed for the different circumstances, and assigned twenty-five per cent of the proposed capital stock for the expenses of organizing, as against seven and one-half per cent actually expended in the Santa Clara organization, but he did not allow enough. There were other disappointments; the "representative growers" of the special convention whose supposed enthusiasm had 
deluded eleven of their number into accepting the responsibilities of directors, were utter humbugs, who cooperated only with their mouths; of the whole hallful, but one, except those chosen as directors, could ever be dragooned into risking one dollar in the enterprise. The directors chosen were many of them very substantial men; they subscribed properly to the support of the movement, but did not feel called upon to pay its entire expense, and none of them developed any faculty of inducing others to come in with money. The president, in the end, did something, but for a long time he contented himself with explaining the plans of the Exchange and receiving the warmest endorsement of their utility, he assuming, of course, that well-to-do growers who so strongly favored cooperation, would of themselves send in their subscriptions and their checks. It took him a year to learn how contemptible well-to-do people could be in money matters, and that the promoters of important cooperative enterprises must either pay the bills themselves or wrest the money almost by force from reluctant victims. The smaller growers were far the easiest to get money from, but of course they subscribed in small amounts, and upon experiment it was found that the expenses of reaching and canvassing them exceeded the cash payment of twenty-five per cent upon their stock, and that no one less fully informed than the manager, or less determined, could get anything. In the formation of local societies the request was constant that they should not, while they were themselves organizing, be asked to aid the state morement, as they needed all their strength at home. If it were called to their attention that they would not liave organized if some one else had not paid the expense of agitating the matter anong them, and showing them how, and that they should assume their share of the general work from which they had specially benefited, they, of course, could not answer, but they would not pay. In short, the entire year's work of the directors and officers of the Exchange was one constant struggle to raise the money to pay the very modest current bills. In no month, for the entire year, did the eash income equal the current expense, although the par value of the stock subscrip- 
tions was, of course, more than the current expenses. The directors and manager agreed, lowever, that unless twentyfive per cent of the stock subscribed would pay for organizing, it would not be best to proceed. They, themselves, paid up their stock in full.

It may occur to some that these details are unnecessary. I am giving them fully as affording the only means of an accurate study of cooperation. I an reasonably familiar with the literature of cooperation, but what lias fallen in my way appears to have been largely the work of enthusiasts, or of mere observers. I have thought it useful to give accurately and in detail the results of personal experience in cooperative work, in order to make clear where the main difficulty lies in the promotion of cooperative work among farmers. They will not pay the expense of organizing, which, when on an important scale, is too large for a few altruistic individuals to assume.

The expectation had been that the manager, in a few months of preliminary work, would secure funds sufficient to employ the staff required to make a beginning of the actual work which the Exchange was created to perform. As already stated, experience showed that he could hardly secure enough to pay current expenses, and, although some pains were taken to let it be known that a permanent manager would soon be wanted, and that a desirable position would soon be open to any one who should develop a combined talent for organization and business, no one appeared, except the temporary manager, who could make any headway. Obviously it was absurd to continue an organization whose entire energy was consumed in providing for its own existence, and it was determined, after a few months, to attempt the fulfilment of at least one of its duties. All growers, from the beginning of the season, had been anxious for correct information in regard to crop prospects, foreign and domestic, existing stocks of fruit, and the huudred items which go to determine the market prices of agricultural products. Tague or incorrect information on these points was worse than useless, and information safe to do business upon costs money. No local newspaper 
could afford the necessary expenditure, and what the trade learned at their own expense they naturally wished to use for their own purposes; all current information was believed by growers to be colored in the trade interests, and they placed little reliance upon it. There was no doubt that there was a really earnest desire on the part of growers for information compiled by their own agents. It was estimated that this could be supplied them, not thoroughly, at first, but reasonably well, and better than had before been available, for about $\$ 5,000$ per year, and it was not doubted that more than five thousand growers would gladly pay $\$ 1.00$ per year for that information. This belief was greatly strengthened by the great demand for a weekly bulletin, published for a portion of the previous year, by the Santa Clara County Exchange, for the benefit of its stockholders, and regularly given to the press. It was therefore determined to begin actual work by the publication of such a bulletin, with the price fixed at $\$ 1.00$. Sample numbers were widely distributed among growers, and every effort was made to obtain subscriptions, short of putting actual canvassers in the field, which the price fixed did not admit, and which, besides, was not in accord with the cooperative principle. The bulletin, as issued, was regularly given to the press. After three months' trial, it was found that just four hundred and eleven persons-about one hundred of whom were tradesmen-were willing to pay $\$ 1.00$ per year for information; the remainder of the growers, although perfectly aware that the existence of the bulletin depended entirely upon the subscriptions received, would pay nothing, since they could get it for nothing in the papers which they received. The bulletin was therefore stopped, with a loss of about $\$ 100$, including the sum necessary to reimburse those who had paid, by supplying another journal.

The policy of the Exchange, as it existed in the minds of its promoters, did not contemplate the actual selling of fruit. Sales were to be made by the local Exchanges, the state Exchange serving as a bond to unite them and transacting for all a large amount of business essential to all alike. The majority of growers, however, having little conception of the 
detail of a large business, and not realizing the impossibility of suddenly effecting so large a concentration, conceived of the Exchange mainly as a common selling agent, which should eventually control the entire fruit product of the state, and some large growers outside the Exchanges expressed strong desires that the Exchange should sell fruit. The creation of an effective system of agencies, however, through which to market a large volume of any commodity, requires time and money, which the Exchange did not possess; in order, however, to comply with an apparent demand, the directors arranged with a very responsible concern, for whose fidelity they were willing to stand responsible, for a more effective selling service than the growers had ever had at their disposal, at a rate so low as to involve a certain loss to the contracting house except as the result of a very large volume of business. The result again showed the unreliability of producers in the matter of supporting their agents, and their tendency to believe evil of them rather than good. Not a single grower of those who had demanded the service, or a single association, except one very small one, voluntarily placed a pound of fruit at the disposal of the Exchange agency in any such way as justified the expenditure of money or effort to find a market for it,* and when the manager of the Exchange visited some of the local societies for the purposes of securing their business, which, by the arrangement, would yield a small percentage to the support of the state Exchange, he was usually regarded with rather more suspicion than if he had appeared as a solicitor for a commercial concern, and the few contracts which he obtained he got by more effort than a competitive concern would have been obliged to expend.

This, of course, put both the Exchange and the manager in a false position, and they ceased to solicit. The suspicious

* What growers would do was to first try every other possible means of selling their fruit, first carefully getting all the free information which the Exchange could give them, and failing to sell, would give the Exchange the chance of selling, if it could, and provided that the owner did not sell otherwise. Evidently it would not pay to spend money to find customers under such conditions. 
disposition of the people was strongly encouraged by the more disreputable members of the trade, who insinuated, and, indeed, openly charged that those officially connected with the Exchange were receiving large private commissions on all business entrusted to it. These charges, perhaps, the directors and the manager were prepared for, but what was unquestionably a surprise to them was the fact that, well-known as they were, not a soul, so far as was ever learned, ever openly expressed his disfaith in the statements, or defended the character of the heretofore reputable men whom they had asked to gratuitously serve them. The result was that the contracting firm speedily became disgusted, withdrawing from the contract after a few weeks, no business ever actually being done under it.

The directors, however, were determined to struggle on under the load which had been put upon them, and spent the remainder of the season in doing all that could be done in serving the common interest. A little money was from time to time raised-largely out of their own pockets-and the work continued till towards the close of their year. As that approached it was determined to make a final and determined effort. As a result of the whole cooperative movement nearly sixty local cooperative societies were in existence, the majority of which had been established as a direct result of the work of the Exchange, and largely by the personal aid of its officers; so much, at least, it had done of the work which it was established to do, and it was ready to take the next step, which was to transfer the responsibility for its continuance and maintenance to the local societies. To this end a convention of local societies was called. Delegates were sent with written credentials from the incorporated societies which sent them, and fully authorized to speak for them, up to the point of pledging money for the work, for which they had no authority. The convention was in session for two days, and thoroughly reviewed the work of the past year, which was fully approved. The course for the future was adopted precisely as outlined by the management of the Exchange, which involved a definite 
pledge on the part of the soeieties represented, of a small, but in the aggregate a suffieient, sum for the support of the state Exchange, to be charged as an item of expense against the fruit handled the next year, by the loeal soeieties, this being the plan as originally marked out, when the societies should be established. The representatives present, upon a eall of the roll, each rose and promised that he would report to his society favoring the endorsement of the action of the convention and advising the pledge of the required financial support.

As the result of the meeting it is not known what reports were made to the loeal societies; in many cases there were none; but, at any rate, very few plenges of the promised support were ever received, and those usually from the smallest societies. When the board of direetors convened, the temporary manager, whose resignation had been before the lirectors for some time, pressed its acceptanee, but continued to perform the duties for some time. This is mentioned in order to add as a further illustration of an unfortunate weakness of cooperation, that delegates from eertain societies deelared that they would not come in if he did not resign. It was a repetition of the experience of the California Fruit Union, when one faction would not stay in if a certain man was manager. The faction in this case was very small, but it was deemed best to yield to it, although the interest of the service required that the manager should complete his work, and turn over the Exchange in working order to his sueeessor, which he was willing to do; although anxious to be relieved, he wished to leave a completed work. The objections to the manager appeared to arise from his continual statements that no effective business organization on a large scale, whether competitive or cooperative, could be run without considerable expenditure, for which an adequate income must be assured; this was considered "visionary" by a few good men, some of whom doubtless felt sure that the manager desired a good income for the Exchange in order that he might become permanent manager, and obtain a "fat salary" 
out of it, ${ }^{*}$ and this they desired to prevent at all hazards; others believed that the ends of the Exchange could be accomplished for far less money than the budget of the manager proposed, and with no ill will to him, or question of his honesty or ability, desired some one of a more economical turn of mind; and feeling as they did, it was wisest to give them an opportunity to show what conld be done with small expenditure. The result was as expected, that they did nothing.

This feeling of some growers toward the manager of the Exchange and his plans very well illustrates the unwillingness of farmers to permit those serving them cooperatively to receive for their services any such compensation as competitive business offers for similar services; it also, possibly, shows the unwistom of making any trained business man a responsible, salarierl officer of a cooperative society at its beginning. An

* It seems impossible for the majority of farmers to believe that any one will actively promote cooperative movements except. with the intent to profit ly. them. As a matter of fact, promotion of such work is always largely altruistic. In California, those engaged in it, if they devote their entire time, expect their expenses and a small salary to compensate them for the neglect of their own business. In this case the temporary manager was a person in fairly comfortable circumstances who neither sought nor desired the employment, and stipulated from the first that he would serve only until the right man appeared to go on with the work. This fact was publicly stated upon all proper occasions, partly in hopes that the announcement would bring out the right man, and partly to allay the suspicions of personal interest which were fully anticipated. It would not do. Members of the trade who were adverse to the movement eirculated lies about the president and manager, which were generally believed, because these officers were necessarily personally unknown to the majority of the fruit-growers. As a matter of fuct the president devoted a large part of his time for a year to the Exehange, paying even his personal expenses, with, as events proved, very severe loss from neglect of his own business. The manager did not lose so much beeause he had not so much to lose, but his neglect of his own affairs resulted quite seriously to him. Neither of these gentlemen have since had anything to do with eooperative work, except merely to cooperate, and probably neither could be induced to again accept responsibility in business cooperation of an important nature. Of course this is not the stuff that grent cooperators are made of, but it is the stuff that most human beings are made of. Suspicion and ingratitude deprive the public of much service which would be ghadly rendered by those who, while altruistic, are not altruistic enough to patiently endure much bad usage. 
experienced man, knowing the detail of business, and its necessary cost, if he is honest, must make an estimate of expense which seems, to farmers, very extravagant; if he needs or desires the position, he will be tempted to make inadequate estimates, in order to encourage his people and retain his place. The most successful cooperative enterprises have grown from small beginnings, conducted by inexperienced men whose ideas expanded with experience. The circumstances of the California fruitgrower seemed to renler it desirable to begin operations on a large scale; selling goods in large quantities, from first hands, requires a rarer ability and costs much more money than buying goods, or than selling at retail, and this is true whether the operations be couducted on a cooperative or competitive basis. For operations on this scale farmers are not well prepared; and when, as in this case, the management pointed out the detail of selling fruit as conducted by those in the trade, and estimated the necessary, but much smaller, expense of the same work done in the same way, but cooperatively, and wholly in the growers' interest, many at once lost confidence, and were inclined to listen to those who proposed to accomplish large results with trifling expenditure. If cooperation can accomplish this, it will be a great boon, but the danger to be apprehended in the attempt is the furnishing of an ineffectjve service, which will not satisfy those who are to support it, or be able to retain their business. The experience of the state Exchange also made it quite evident that it was more difficult to unite a large number of societies under a common head than to bring individuals into the local societies. The moment there is a feeling of strength, there is an unwillingness to conperate. The local socicties seemed to the small farmers who controlled them, perfectly able to stand alone; to this was added a certain amount of sectional jealousy. The Santa Clara societies,' especially, felt that their district was the largest producer of dried fruit, and should be the headquarters of cooperative action. The Santa Clara societies, also, having enjoyed the reputation of lealership in cooperation, were unquestionably, although quietly, averse to the establishment of any state Exchange which should seem to put them in a 
subordinate position. Their officers, generally, knew little o1 the fruit interests of the state outside of their own valley, and were not moved by conceptions including all interests. The result of the whole movement was finally a suspension of active work on the part of the state Exchange, with the intent to let the growers of the state grow up to a comprehension of the proper work of such a body, the necessity of its prosecution, and the wisdom of uniting in the expense of sustaining it. Whether this will ever happen remains to be seen. 


\section{CHAPTER VII.}

THE CITRUS EXCHANGES OF SOUTHERN CALIFORYIA.

I all ages the orange grove has been the emblem of the beauty and the poetry of horticulture, and in truth there is not, in all cultivated nature, any sight more beautiful than it affords. To the stranger, coming with imagination already stimulated with glowing descriptions, the transition from the icy blasts and leaden skies of the eastern winter to the warm sun and the pleasant breezes of a February day in California, is very grateful, and the next day's drive among the laden orange groves completes the fascination, and makes the wayfarer a willing victim to the combined seductions of the climate and the landseller. The rise of southern California began with the completion of direct rail communication between Los Angeles and the East. The circumstances were propitious. The large Spanish grants which covered the most desirable lands had mostly passed into American hands, and were available for subdivision, and capuitalists or strong companies, buying or bonding large tracts at low prices, could afford to spend large sums in attracting immigration. The owners of the new railroad, earnestly desiring traffic therefor, joined hands with the land speculators, and their combined efforts, in the course of two or three years, produced a landbuying and orange-planting craze, which attracted the attention of the world. The attractiveness and productiveness of the country were not overstated; indeed, it would be difficult to do so; the errors of investment which were made grew out of exaggerated impressions of the cheapness of cultivation, the certainty of large crops, and the assurance of the sale, at high prices, of any producible quantity of the fruit. With authentic statements before him, of orchards yielding many hundreds of dollars per acre, the newcomer of a few years since was in no condition to inquire into the drawbacks, if 
any, or dispute the enthusiastic assertions that the world was and always would be clamoring for the product, and that the happy producer had only to name his price. And it seemed reasonable. Before their eyes they saw the great packinghouses thronged with workers, and the orchard owners watching from verandas the harvesting of their crops by those to whom they had sold them on the trees. Allured by these manifestations of success, and by the rapid building of the towns and cities which thrived by it, southern California was rapidly peopled by an exceedingly enterprising community of solid principles and sterling worth.

The fundamental error in the calculation of the citrus enthusiasts was in supposing that the phenomenal incomes of the early orange-growers could long continue in the face of the wide area of the earth adapted to orange culture, with sea transportation to America enough cheaper than any transcontinental movement ever could be, to overcome any duty to which the country would probably submit. The orange, under favorable circumstances, is a great bearer, and it was only a question of time to fill vacant land with orange groves to glut the market. Of the special drawbacks I can not speak so well, as I have not myself raised oranges; I only know that much of what $I$ have said in regard to the cultivation of decidnous fruits applies equally well to orange culture, and in a still greater degree to the cultivation and curing of lemons; there is no more poetry in ploughing orange groves than in ploughing cabbages; the care of a single variety, while simpler than that of a mixed orchard of deciduous fruits, is also more monotonous; the orange, while thriving wonderfully in suitable locations, does not do well everywhere, and there are thousands of acres of orange groves which should never have been planted, and which never can yield a profit; the crop is exhausting to the soil, and an extensive use of fertilizers is required; the annual water tax is a burden never to be avoided, and irrigation provokes the growth of weeds as well as of fruit. For some years it seemed likely that the scale insects would destroy the groves, and when, after many costly experiments, that pest was in a great measure overcome, the owners of many unprofitable orehards had become almost imporerished. 
With improved methods of combating the scale, and the increased output resulting, more and more of the later plantings came into bearing, and gradually the once prosperous orange-growers began to pass through the experience of the fresh deciduous fruit shippers and the raisin men already deseribed. Under a constantly falling market the packers were more and more cautious about buying the crop on the trees, and finally ceased buying at all, and the era of consignment set in, with the same result that occurred in the deciduous fruit industries; the fruit often brought less than the cost of production and delivery east, and sometimes less than the freight and charges alone. In no case would the product do much, if anything, toward meeting the interest charges, or paying off mortgages; more and more the weaker growers who were largely in debt for land and improvements obtained at high prices, began to fall behind, and a disaster seemed imminent, which, involving as it did the main industry of the country, would be appalling in its results.

In this erisis the natural thought of all was toward cooperation. For this form of selling, the citrus industry was far more favorably situated than the deeiduous fresh fruit industry; confined to one product far less perishable, and bearing transportation better than most deciluous fruits, reaching market in the winter, when no refrigeration was required, and the market bare of other fresh fruits, the principal varieties few and well known, and the method of grading by size, very simple, the problem of selling was far easier than that of marketing any other fruit exeept raisins. Instead of being seattered over a whole state, the growers were concentrated in three or four counties, and along irrigation systems, where they could be reckoned up and visited; as citrus fruits are only sold fresh, there was no such complication of interests as existed between the dried and fresh deciduous fruit shippers of the north; in a word, not only was the problem of selling simpler, but the work of organization easier. Adiled to this, the larger eapital required to plant and mature an orange grove, together with the peculiar excitement attending the development of the country, had drawn into 
the business more men of business aptitude and experience than were engaged in any other branch of the fruit industry, so that the problem was not only more simple than that of the north, but the people were better qualified to deal with it; or at least it can be said that from an early date the cooperative movement in southern California commanded the adhesion and energy of many of the large and wealthy orchardists, which the northern movement seldom did. The result was that when the problem was attacked the movement had greater force, stronger support, and better direction than was for a long time attained by the northern movements.

At an early date there were cooperators in the orange business. In 1888 or 1889 there was formed the Pachappa Fruit Association, in a district about two miles from Riverside, which attempted, in a very crude way, to accomplish about the objects of the northern fresh fruit shipping associations already described. As one of the original founders lately expressed himself to me, they knew very little of the orange marketing business, and groped about rather blindly and without much effect. Their original idea seems to have been a simple neighborhood agreement to hold their fruit for the highest price obtainable from the local buyers, and to sell all together. Afterwards they undertook their own shipping, with no flattering results. They were not incorporated, and of course did not hold together very well, but the persistence of some led to a continued study of the subject, and prepared the way and made possible the better achievements of a later lay. In 1892 the Riverside Fruit Exchange was organized, under the auspices of some of the solid men of Riverside, and continued in operation during the year. With the details of this enterprise I am not familiar; it was intended as an organization to market the fruit of its members, but it never had any such general adherenee of growers as to render it master of the situation, and the manager, who was an experienced and able man, seems to have been allowed what he could make it pay him by commissions. It did a good business, in a manner presumably satisfactory to those who sold through it, and was a step along the path it was desired to follow. 
In March, 1593, a mass meeting of orange-growers was called to meet at Colton, during the progress of a citrus fair at that place; the attendance was not large but the interest manifested by those present warranted an adjournment for a week in the expectation of a larger number. At the arljourned meeting a clear-headed gentleman from Riverside, who had been educater for some years in the experience of the Pachappa and Riverside Associations, of the first of which, at least, he was a member, outlined a plan of operations by which, as he believed, the growers could be united, and their crop marketed at less expense than had been usual, and with far better results. Substantially it was to be an orange Trust,* designed to embrace all producers, and to market the fruit of all, sending forwark only what could be sold at rates to give the grower something above marketing expenses, and apportioning the shipments among growers in proportion to their recorded crop, so that if any fruit should be left over unsold, that unsalable surplus would be borne by all alike. It was to become binding among those agreeing to unite, whenever seventy-five per cent of the growers had signed the agreement. This form of organization was made possible by the concentration of the orange industry in a few contiguous counties, so that every producer could be ascertained and visited. The raisin industry affords an opportunity for a similar organization, and the successful attempts of the raisin-growers toward that end have already becn described.

* This paragraph was written in 1894 , and the manuscript of the history to that date was submitted to a prominent officer of the southern Exchanges, for correction. This gentleman reported the facts correctly stated, but vigorously denounced the term "Trust" as applied to an innocent society of hornyhanded farmers. I was obliged to reply to the gentleman that as I could sce no difference between the aims and methods of those societies and those of the other industrial organizations popularly known as "Trusts," or any difference except in effectiveness, it seemed desirable to include all under the name which was commonly in use. Since that time this squeamishness has mostly disappeared. Farmers generally, in California, understand very well that producers' marketing societies which seek to control an entire product do not, in principle or methods, materially differ from organizations of other interests for the accomplishment of the same object. 
The convention was so much pleased with the outline proposed by the liverside grower that he was requested to formulate it in full for general distribution, and a further adjourmment of a week was taken, to meet at Los Angeles. At the Los Angeles meeting, which was the largest yet held, it was resolved to proceed to organization, and a committee, leaded by the author of the plan, was appointed to promote it. At a subsequent meeting, a month later, many local meetings in the citrus-growing centers having been held in the meantime, and growers generally, through the press and otherwise, having been made familiar with the plan, it was finally agreed upon substantially as originally proposed. Proper provision was also made for the expenses of organization.

The plan was simple and business like. It provided for:-

1. Local neighborhood Associations, owning the necessary packing facilities, and for that purpose incorporated. 'To these local packing-liouses the grower delivered his oranges in bulk, just as he had been accustomed to deliver them to the packinghouses of the buyers or commission men, and they were there graded and boxed, with those of others, each grower getting a receipt showing the amount and the grade of fruit delivered. This ended the duty of the grower; from that time on his fruit was mingled with that of other growers, and marketed by his Association.

2. District "Exchanges," composed of representatives from each Association in the district. These Exchanges received the orders and apportioned them among the local Associations in proportion to their total crops, previously ascertained, by each Association, by actual canvass. As orders were received and apportioned, each Association directed its menbers to pick and deliver their fruit. The intent was to ship only such fruit as was actually sold before picking. The district Exchange attended to the shipments, collected the returns, and distributed to the local Associations, which paid them to the owners of the fruit. Thus the local societies attended to the collection and packing, and the district Exchanges to the shipment and collection. The district Exchanges were not incorporated. The districts were made large enough to supply business sufficient 
to justify the employment of a competent secretary for each, devoting his entire time for the year.

3. An Executive Board consisting of a representative from each distriet Exehange, which should have entire charge of the appointment of eastern agencies, and, in general, of fixing prices, making sales, prorating the orders to the Exchanges, and attending to such other duties as pertained to the general policy to be pursued or tended to the welfare of all. The intention was that the Executive Board should make all the sales and prorate the orders, but in practice many sales were made by the district Exchanges, the Executive Board, however, retaining control of prices, so far as it was necessary to do so. The method of business pursued, after the completion of the organization, was for each local association to annually canvass the district allotted to it, contracting with each grower for his crop for the season. As all expenses incurred were a first charge on the proceeds of the fruit handled, no capital was required, except for packing facilities for the local associations.

The above form of organization having been agreed upon, and provision made for the expenses of organization, the entire summer and autumn was deroted to local meetings and a house-to-house canvass of the growers. The same difficulties were met here that lave been described in comnection with the deciduous fruit societies, but the movement having the support of the wealthier men of the community, the strength to overcome the difficulties was far greater. The commission houses which had eontrolled the business did not wish to lose it, and did not intend to if they could help it, no matter what became of the growers, and by means of free advances to those in need of them, they retained control of a good deal of fruit; then, of course, was the contemptible class found in every community, of those who saw plainly the general benefit to be derived, and who had not the excuse of porerty to plead, but who still held aloof from the movement, hoping and expecting to reap some personal advantage at the expense of their neighbors. Many of this class were dragged in by the pressure brought to bear on them, but some stayed out. I do not wish it to be understood as complaining of those who saw no advan- 
tage in the movement for not joining and assisting in it; no one should be forced into a business transaction against his convictions; but there were apparently no such persons among the orange-growers; all knew, and usually acknowledged, that nothing else would prevent a general bankruptcy among the orange-growers who were in debt, and loss and trouble to all others, and I refer to those who believed this and yet would not cooperate.

In the end more than seventy-five per cent of the growers signed contracts for their fruit, and by November the organization was practically complete and the Executive Board selected. Representatives were sent east to lay their plans before the trade, and a competent general eastern agent appointed. With a less amount of friction than was to be expected in a new organization of the kind, the business of the season of 1894 was managed to the general satisfaction of those concerned. The Exchanges did not do all they hoped to do, but they did so manage the business as to bring the growers better returns than they had received for years, and on the whole such as they could live by. One immediate result was the reappearance of the local cash buyer, an unfailing evidence of a stiffening in the market. The unhoped-for opportunity to sell for cash at home proved too much for the good faith of a few, and in defiance of their written contract, they sold their fruit to go into competition with the Exchanges; suits were promptly brought, and the court sustained the contracts. Much was learned as to the best method of conducting the business, but it was with reference to detail, and did not involve the principle of the organization, which remained unchanged. At the close of the season the canvass for contracts for 1895 promptly began, and about ninety per cent of the product secured, and the business of that year was transacted to the general satisfaction of the membership. Some changes of methods and organization were made, as shown by experience to be desirable. The Executive Board found it necessary to incorporate in order to do business legally, and did so, under the name of the "Southern California Fruit Exchanges," with a permanent office in Los Angeles. The stock 
is nominal. It is probable that the district Exchanges have also incorporated.

The Exchanges, however, did not find it all plain sailing. There were dissensions among themselves. The fruit of some localities was better than that of others, or at least better known, or believed to be better, and at any rate was in most demand. It was found that at a uniform price the fruit from these localities would be taken first, leaving that of other localities largely in the orchards, until the better or the better known products had been disposed of. The favored districts thereupon strenuously objected to the prorating of orders, according to the plan, stoutly insisting that they were entitled to the benefit of the better reputation of their fruit. The eastern buyers, also, insisted that when their orders specified the fruit of any locality, they must be supplied with the fruit of that locality, and no other. The less-favored districts, on the other hand, insisted with equal vigor that they conld not be expected to engage in an enterprise for the general good whose result, to them, should be the leaving a large share of their fruit on their hands, at least until the close of the season. The result was a great amount of internal friction, and a probability, in 1896, that the Central Exchange would be discontinued, and that the local Exchanges would compete freely among themselves. This was finally prevented, by a close vote in some of the Exchanges, with the result, however, that a number of independent local Exchanges were organized and are still maintained. These usually sell their fruit loaded on the cars at home. Those in the best-known localities sell mostly upon telegraphic orders from eastern buyers, the others usually selling to local buyers. The main body, known as the "Southern California Fruit Exchanges," maintains a corps of agents in the east who supervise the business there, directing the cars, when on the way, to the points where the best demand exists, and arranging for sale, either by auction or through brokers, upon arrival. The sales of these Exchanges, including the independent societies, for the past year have been $\$ 2,067,962$, after deducting freights paid, and as to some portion at least, all expenses of every kind. 
Encouraged by these dissensions among the growers, the forwarding houses which, during 1594 and 1895, had generally been compelled to close their establishments, returned in full force and recommenced business, and for a year or two there was a very bitter triangular war between the associated and independent Exchanges and the commission merchants. Each year there was an active and expensive canvass on the part of the Exchanges, for contracts, which was more or less openly opposed by the forwarders, the contest being accompanied by a wonderful outpouring of printer's ink and bad language. The associated Exchanges, in the face of such opposition and misrepresentation, were unable to longer secure seventy-five per cent of the crop, and the practical control of the market, nor could they do so with the aid of the independent Exchanges, with whom, had that been done, some common plan of action could have been arranger. In the end these annual contests were abandoned. The Exchanges, as I understand it, have ceased to solicit, and do only the business which the cooperative element voluntarily brings to them. This business, as has been stated, is large, well managed, satisfactory to the membership, and appears to be increasing. They seem to control about one-third of the citrus product.*

* The following letter, received after the text was prepared, from Mr. A. H. Naftzger, president of the Southern California Fruit Exchanges, will be found of interest, as giving some details for which there is hardly space in the text. Mr. Naftzger says:-

"Referring to your favor of late date, I have to say that there is, perhaps, not much that is new to be said on the subject of the eooperative system anong citrus fruit-growers of California. So much has been said and written, that perhaps every phase of the subject has been thoroughly gone into.

"However, as you say that your information brings the matter down to 1894, there may be some facts of later development not unimportant. I shall not attempt to give you anything that would be in form for the printer. I take it, you simply want me to make such suggestions as might be serviceable to you.

"The Exchange system was rather crude in the year 1894, in fact, we did not incorporate until 1895 , since which time we have been in shape to operate in a business-like way. Tou ask if we still canvass for signatures from year to year. I am not entirely familiar with the amount of work that is done in the different communities, but I am under the impression that the loeal Exchanges and Associations are generally organized now, and have either contracts for a term 
of years, or make the growers stockholders of a corporation, and are governed by its by-laws.

"I think it sufficient to say that very little work is done to induce growers to eonnect themselves with the Exchange. Our business is on a sound and legitimate basis, and unless the grower sees it to his advantage to join it, it is quite as well for the movement, perhaps, that he remain out. If he comes in voluntarily, it is because he has confidence in the system, and if he were not convineed that the system was advantageous lo would probably be more or less of a disturbing element if he came in.

"The Southern California Fruit Exchange aets purely and solely as a marketing agent for the various local Exchanges, of which there are twelve. The loeal Exehanges and Associations eonnected with it determine all the questions of grading, packing, ete, and we have to do with the goods when they are put on board the cars ready to go forward.

"We have what we believe to be the most thorough organization and system that has ever been organized for the handling of perishable produets. We have our own salaried agents in the principal cities of the United States whose sole business is to sell our goods.

"In Chicago we have a general agent, into whose office all the agents report regarding the market conditions in their districts every day, and this office in Chicago, acting as a Clearing House, gives back to the different agents the conditions in all other markets. By this system all of our agents are kept thoroughly adrised of the markets in all other portions of the United States, and the agents are therefore afforded the best possible weapons for use, and the best possible argument to enable them to bring their markets up to the average. This system enables us also to gauge the requirements of the different markets and distribute the fruit aceording to the wants of the different places.

"Of course this can not be so thorough and effective as if we controlled eighty or ninety per cent of the crop.

"Perhaps the best proof that we have thoroughly organized and systematized our business is the fact that during the season of 1896-7 we sold one million six hundred thousand dollars worth of citrus fruits, and sustained a total loss of two hundred and twenty dollars from bad accounts. During the season of 1897-8 our sales exceeded three millions of dollars, and our loss from bad accounts amounted to six hundred dollars. So far this season we have sold over two thousand car-loads, the aggregate amount I am not able to state, and thus far this season we have not suffered any loss from bad aceounts.

"This record I believe to be unparalleled. I feel absolutely safe in stating that we get more money for our fruit than is obtained through any other channels for any large amount of like grades and qualities. Our system gives us the advantage of a rise in the market after date of shipment, as we sell delivered instead of free on board ears. This season the markets bave been almost steadily advaneing from the middle of January to the middle of $\Lambda$ pril, and we have had large benefits from selling delivered, as against free on board sales. It is well known, that if the markets decline, the so-called free on board sales are 'rejected' anyway, so that by our system we do not stand to lose, but have always an opportunity to gain on a rising market. 
"I may say that our cost for marketing last year on a more than three millions of dollars gross sales was approximately three and a half per cent, covering all expenses and charges of every kind from the time the fruit was put into our hands until the proceeds were returned to the shippers.

"Our business is not so large this year as last, because the crop is much lighter.

"It is certainly believed by the citrus fruit-growers generally, and I think, that the Exchange is here to stay. Its system is correct, and we can certainly operate more cheaply and with better results than under any other method that has been tried so tar.

"We have repeatedly publicly challenged a comparison of figures either as to net results or operating expenses-the first might apply to all shippers, and the second, of course, could only legitimately and fairly apply to associations that are operating on a cooperative basis-but so far our challenge has not been answered. I am, very truly,

"A. H. Naftzger." 


\section{CHA PTER VIII.}

\section{THE WINE-MAKERS' CORPORATION.}

\section{$\mathrm{T}$}

HE fathers of the old California Missions made a rough wine from a prolific grape which they introduced from some unknown quarter, and which, in time, became generally diffused through the state, and known as the Mission grape. It is a very palatable table grape, but is gradually disappearing from the markets and from cultivation. The similarity of the climate of California to that of some of the great wine-producing countries, the abundant growth of the vine, and its prolific bearing in the virgin soil, led the early horticulturists, and especially those of foreign birth, to a profound belief in the capacity of California to produce good wine, and at an early day cuttings of all desirable grapes from the wine districts of the world were introduced and propagated. Wine and oil have in all ages been symbolical terms, implying a special fertility and charm of climate in the land of their production, and prosperity, and happiness in its inhabitants. The Mission grape had been widely planted and been found unprofitable, no sufficient market for it existing as a table grape, and the wine being of a low grade. Gradually, however, the imported cuttings became propagated, and winemaking began on a large scale by men, usually of European birth, and with adequate capital. There were in addition, however, very large areas of wine grapes planted by those without experience, or much knorrledge of the capital required, or who do not expect to make wine, but to sell the grapes to neighboring wine-makers.

To understand the difficulties in which those in the wine business soon found themselves, some explanation of the processes of wine making is required. The crushed grapes go into large vats for the first fermentation. In that condition the grape juice is known as "Must." For red wine the skins 
and stems are allowed to remam with the juice, which absorbs their tannin and coloring matter. In the process of fermentation the solid matter rises to the top, and when fermentation has sufficiently proceeded, the wine is drawn off from the bottom into casks. White wine is made from the juice as it comes from the press, with all solid matter eliminated. It is of an amber color, varying somewhat according to the variety of grape used and the details of treatment. The wine in the casks must be kept at a substantially uniform temperature, requiring in cold countries deep and expensive cellars; in California substantial brick or stone buildings, partly below ground, are usually found satisfactory, although cellars are built in some places.

It will be seen, therefore, that to make good wine there is required, in addition to the vineyards, considerable capital to be invested in buildings, or cellars, power, and cooperage. When the wine is in the casks it requires constant attention as the fermentation proceeds; it must be "racked off" frequently into clean casks, and the sediment cleaned out; evaporation goes on constantly through the casks, which must be kept filled, as any considerable amount of air in the casks will spoil the wine. The attention must be constant for two or three years, when, if desired, the wine can be bottled. Care and cleanliness are essential in every step.

The celebrated wines of the world are made from old vineyards from which the rank exuberance of the virgin soil has been long since eliminated, and whose owners have learned, by the experience of centuries, the most approred methods of fertilization and treatment, and who are able, by the cheap labor of women and children, to handle the grapes with extreme delicacy, and who treat the wine in the cellars in the light of traditions coming down through many generations.

It is not possible, in a new comntry where labor is dear and unskilled, and whose teeming soil imparts to the grape and through it to the wine, the varying flavors of its rankness, to successfully compete with the great wines of the world. These great wines will be produced in California in future years, but not now. Such wines, however, cut little figure; they repre- 
sent great outlays in preparation, and great profits, and are for the rich. The lighter soils and mountain slopes of California already produce, under the improved treatment of later years, an abundance of sound, wholesome, and palatable light wines, thoroughly fit for any company and any table, but it is evident from what has been said of the care required, and the labor and capital essential to the making of good wine, that in a new country with scant capital, dear labor and abounding inexperience, there would also be great quantities of very poor wine.

In practice, the hest California wines have been largely sold under foreign labels, thus depriving California of the credit of its best wines, while compelling it to bear the stigma of the poor. The notive for this is obvious; a bottle of wine, which as domestic, could be sold at a good profit for fifty cents, with no extra expense except the affixing of a new label, may bring, as imported, a dollar and a half, and the customer be just as well pleased and as well served. Labels of all known brands, with imitations of special corks, bottles, or other peculiarities, are kept constantly in stock in all.cities, at trifling cost, to be used for this purpose.

The result, therefore, of inadequate capital, and insufficient knowledge on the part of the wine-growers, combined with the bad reputation resulting from selling all the poor wines under their true name, and most of the best wines under foreign names, was the gradual impoverishment of the growers, who, unable to treat their wines properly, or carry them to maturity, were compelled to sell as fast as made, to the wine merchants, for any price they could get. For years this went on from bad to worse, until in 1893 and 1894, the bulk of the light wines was purchased at from six to eight cents per gallon, at which rate an anuual deficit could be expected with certainty by all growers. A majority of the wine merchants organized a corporation known as the California Wine Association, thus practically eliminating the competition of buyers, and leaving all but the strongest growers helpless, and these with no hope of profit.

Under these circumstances, the wine-growers, like others 
under similar conditions, turned to cooperation for relief. After a year or two of preliminary discussion, meetings were called and a plan of organization agreed upon, substantially, in principle, like that of the citrus associations, except that no local organizations were provided for. A central corporation was to be formed, which should contract for the output of its members for a term of years, at a gradually increasing scale of prices, the agreement to become binding when contracts for seventy-five per cent of the acreage of vineyards were secured. This plan was a failure. The detail of visiting and laboring with so large a number of vineyardists, many of whom were in no financial condition to make or keep any contract, was exhausting and excessively annoying, but as the movement was led by the large growers, there was no lack of means for expenses, and in the end, as it was claimed, agreements covering the required seventy-five per cent were secured. The proposition that the proposed corporation should contract with its members at certain rates had been based on a verbal understanding with members of the California Wine Association that it should take the wines from the new corporation at the same rates. When, however, the written proposal came to be formally acted upon by the California Wine Association, it failed of adoption, and the project had to be abandoned.

It was evident to those who had conducted the canvass among the growers, that any new proposals which slould involve a pro rata contribution of the capital necessary to enable the growers to be independent of the California Wine Association, and other established wine merchants, could not be carried through. But while there were perhaps thousands of vineyardists, there were at the most but two hundred or three hundred wine-makers equipped with the plant necessary to produce good wine on any commercial scale. These made their own wines, and bought grapes from their neighbors, and so took the place of local associations in other branches of the fruit business. While most of them were seriously involved, and some in distress, they were yet mostly sensible business men, and formed practicable units of organization. If they came in they brought with them the vineyards whose grapes they purchased. 
A canvass was therefore at once instituted among this class, and, within a reasonable time, completed by the signatures of those controlling more than the required seventy-five per cent. of the output of dry wines, and the "Wine-makers" Corporation" was then duly formed.

The essential features of this corporation and its operations are as follows:-

1. Subscriptions to the stock of the corporation according to annual product by all wine-makers.

2. The immediate grading, by experts appointed by the corporation, of all wines in the cellars of its members, and prompt distillation of all unsound and inferior goods into brandy.

3. The purchase, by the corporation, of all merchantable stock, at an agreed price, ninety per cent payable in cash as sold, and five per cent to be applied in payment of stock subscriptions.

4. Necessary advances by the corporation, in advance of sales by it, at usual rates of interest, upon all wines thus turned over to it.

5. A privilege to each wine-maker to withdraw from the wine sold by him to the corporation, all wines needed by him for his private trade, under a guarantee that they shall not be sold at prices less than those fixed by the corporation for wines of the same grade.

6. The lease, by the corporation, of the buildings and plant of each wine-maker, the corporation to re-lease to the owner, under conditions insuring that the business shall be carried on in the manner prescribed by the corporation for the general good.

This plan is evidently effective and business like. It was rendered possible by the fact that wines being, under proper care, non-perishable, are highly available as security, and the officers and directors of the corporation being men of capital and business experience, there was no trouble in conducting its financial operations. It is more substantial than the cooperative societies concerned in other fruit products for the reason that wines are non-perishable and more staple than other fruit 
products. It is an effective Trust so long as it controls the output.

As soon as it became evident that the corporation would from the first have ample credit, and within a few years a large cash capital, its position was assured. The established wine-merchants, with their wide-spread business connections, were an important factor in the trade which there was no disposition to antagonize. The Wine-maker's Corporation, owning the wines, and fully equipped with the means for effective distribution, had yet no desire to engage in that branch of the business, preferring to leave that to others, so long as they as wine-makers were assured living rates for their products. But being known to be strong, the corporation was not called to exert its strength, but was able to promptly dispose of its wines to the California Wine Association and others, at better rates than that corporation refused to give when they were offered practical control. The prices were at once advanced to living rates, and the subscribers to the stock of the Winemaker's Corporation, after paying for one-tenth of their stock the first year, had coming to them in cash far more than they had been accustomed to receive. The wine business of California seemed firmly settled on a sound financial basis, and the Wine-maker's Corporation gave more promise of stability than any other cooperative enterprise of its character. Meantime there was little talk, no friction, and the regular channels of trade were not disturber. The vineyardists who were not wine-makers, it is true, had no protection, and were more or less at the mercy of the wine-makers, to whom they must sell; but they could not help sharing in the increased prosperity of the business, and that they themselves had no actual contributary and controlling part in it, was due simply to the fact that the majority wore out the patience of the organizers by their endless talk, criticism, suspicion, and delay.

No cooperative enterprise of this kind must expect plain sailing. Trouble is sure to come, the outcome of which will depend partly upon the circumstances of the case, and partly upon the mental caliber of the cooperators, which is quite sure to be fairly represented in the board of directors. After one 
or two years of prosperous business, the Wine-makers' Corporation became engaged in a deadly conflict with the Wine Association, which was its principal, if not sole, customer. It is not necessary to go into the occasions of this quarrel, or the details of its progress. One cause, whether openly avowed or not, was the desire, common to all Trusts, whether of farmers or others, to obtain the highest possible prices for their products. The IVine Association had undertaken to purchase the entire output of the Wine-makers' Corporation at prices to be agreed upon each year, after the size of the coming vintage could be estimated. There came a time when the prices demanded by the wine-maker's were higher, in the opinion of the Wine Association, than it could pay without loss. In the opinion of these dealers, if they should take the wines at the price demanded, the increase of importations and of adulteration would be such that the association could not dispose of the product so bought without loss. Apparently this feeling led to a general disposition to quarrels, for which there are always occasions when the disposition exists, and the result was an outbreak resulting in protracted litigation, the engaging by the corporation in marketing upon its own account, and a contest for the control of the crop. While the wine-makers were bound to their own corporation by five-year contracts, they, of course, controlled no grapes except those of their own vineyards. The IVine Association could easily start in business wine-makers in their own interest, of whom there had always been some, and they did so, and the two opposing forces engaged in a contest for the purchase of the grapes of the new wine-making vineyardists. Success in this was vital to the association, as the corporation controlled the majority of the wine then in existence, without which the association in a short time would be unable to supply its trade, which it would therefore lose to the Wine-makers' Corporation. The latter thereupon sought by public meetings to create such a feeling as would prevent grape-growers from selling to the winemakers of the association, which was able, by reason of its larger cash capital, to offer a larger immediate cash payment than the corporation could make. Had the capital of the 
association been large enough, they would have won, if they had chosen to risk it, for in spite of the fact that the press and impartial public sentiment was strongly in favor of the corporation, it is unlikely that the independent growers, who had suffered somewhat at the hands of the wine-makers of the corporation, when they had things their own way, would have refused substantially better offers from the association for the purpose of aiding the corporation. They would have taken their chances for the future. But the capital and credit of the association, though large, had a limit easily reached, and the fierce competition in sales which then existed between the two bodies had so reduced the prices of wine that bankers were very cautious in lending money upon it. The administration of the estate of a member of the association made public the fact that its stock had greatly depreciated, and, upon the whole, it took the wise course of not making extravagant offers. The result was that the corporation retained control of the output, while the litigation went in favor of the association. This afforded the basis for a compromise, which at once restored both to prosperity. The price of wine was raised to a fair but reasonable price, at which it freely went into consumption, and every one was making money again. Just at this time the contracts of the wine-makers with their corporation expired, and as these pages go to press a canvass is in progress for their renewal.

While in the foregoing chapters of this book, I have not always made prominent the advantages to producers, which have immeriately followed cooperation in California, I may say, once for all, that they have been substantial, and this, whether actual control of the product involved was secured or not. I speak of the completed and successful societies. The failures, of which there have been many, have been necessary steps in the progress of education. I know of no one who has successfully cooperated who does not think that it has paid.

As to the future, it scems to me that, in California, the prospect of continued and successful cooperation among farm- 
ers will depend upon the assurance of reasonable reward to those competent to manage cooperative enterprises. Until lately there has been no career open to capable men engaging in cooperation, on any large scale, except one of disappointment and annoyance. Capable men can secure for themselves and their families more comfort and greater respect in competitive than in cooperative work, and consequently seek competitive business. Young enthusiasts may embrace it until their illusions are dispelled, and elder'y men may dabble in it in the hope to round out their lives with some useful work, lut the vigorous men of affairs will, exeept in exceptional cases, let it alone. The feeling is that the farmers are now paying very heavily for the distribution of their products, as shown by the general prosperity of those engaged in that business on a large scale. No such compensation as is now paid is expected, but reasonable compensation and a prospect of a permanent career is expected. It is not considered that the farmers are unable to pay, or that there is occasion to invoke, in their behalf, that higher spirit of altruism which is claimed and inspired by the misfortunes of those who have only their labor to sell. In default of this willingness to pay reasonably, und above all things to sustain heartily, bright young men are more desirous to comnect themselves with the cooperation of capitalists. I presume this will be found to be the case in farming communities elsewhere in America. The great Trusts of the world are administered by the most capable men, and their rewards are magnificent. The popular antagonism to the Trust is almost never directed to the personal management, who, according to their personal qualities, enjoy not only the comforts attainable by a large income, but the respect and the deference of those with whom they come in personal contact. Few who could be responsible servants of a cooperative society of capitalists would be inclined to accept the service of a cooperative society of farmers. But farmers can get service of this grade whenever they are ready to reward it with moderate money payment and a large measure of honor.

This condition can only be bronght about as to cooperative enterprises of producers when large masses of men realize that 
they have need of the man of brains and power, while he has no need of them, and when the machinery has been created whereby the capable man may be surely found, and by proper steps advanced to the conduct of affairs with the same certainty of adequate compensation and security in his position that he finds in competitive business.

One would indeed be foolish to attempt to predict the final resultants of existing social forces, and much more to prophesy as to possible changes in the nature and direction of the forces themselves which may grow out of the evolution of human nature; but from observed fucts we may with confidence infer some things at least as to the immediate future. As frequently intimated in these pages it does not seem to me improbable that the affairs of mankind will ultimately be transacted cooperatively. As has been frequently pointed out. great portions of this business is now so transacted, and the fact that cooperation began among the ablest for their personal enrichment as against the rest of mankind, is good evidence of its wisdom and its possibility. It is only necessary that John Smith and John Jones should become as wise and strong as Jay Gould and Cornelius Vanderbilt to make cooperation as effective among the Smiths and Joneses as it is now among the railroad magnates; and it is only necessary that there should be reasonable wisdom and ability in the masses, to produce reasonably satisfactory results.

At present, possibly, that reasonable ability may not generally exist. It certainly seems to exist in some places, and be absent from others. Mankind, upon the whole, does not seem to be very wise, and yet it is true that the general consensus of opinion in civilized countries agrees very well with the loctrines of philosophy. The humanity which poets exalt, and enthusiasts die for sometimes, seems to exist largely in imagination. Whoever deals in the concrete with the atoms of humanity finds in them much that does not resemble the ideal. Here and there a pure and lofty soul is found buried under the feet of the struggling masses, and is held up by the poet as the exemplar of humanity. He is not. At the same time, when we remember that descendants of the wily savage, 
whose chief virtues were deceit and treachery, have in the course of generations learned to confide in others, and combine in Trusts, against the world, and that some of our ancestors of only three centuries ago doubtless witnessed with approval the burning of martyrs, it is perhaps not too much to expect that a few centuries more may fit the world for cooperation. The changes of social force, in nature and direction necessary to make universal cooperation possible, do not seem to me greater than those that have taken place since the dawn of history.*

* My personal experience in cooperative work among furmers has possessed, for myself, a sort of grim humor, and may be entertaining to others. It has, at any rate, a certain educational value, and as $I$ am in a position to write with entire frankness, I give the substance of it for what it is worth, reminding my readers that this was not a case of cooperation among or for absolutely poor people, but among those quite able to protect their own interests if they cooperated as they said they wished to. For many years I had been in charge, upon.the Pacific Coast, of certain eastern interests which, in due time, developed into a Trust. The owners of the business never struck me as wicked men, but simply as ordinary good eitizens, wishing, like bonest farmers and workmen, to set the highest possible price for their product, and somehow compel people to pay it. They were kindly men, prominent at the missionary box, and elsewise in good words and works, but never, in any conference to which I was admitted, was the publie welfare made the basis on which prices were fixed. I had no instructions to consider the public weal, and never did, but got all I could, reeeiving therein the cordial support of my principals, with complimentary telegrams upon the happening of a lucky stroke of business. In the meantime, in my little personal world, whose attitude towards one does so much towards making life cheerful or otherwise, I had evidence of general good-will, with some special esteem and respect as for one concerned with a IIonopoly of some consequence for those days. I never heard of an unpleasant word said about me by anybody, and I suppose I had not an eneny in the world. Life was very rosy.

When I left that sinful employment, and was soon after born in to the kingdom of cooperation, I cheerfully accepted the tasks which were set me, and discharged them with the same zeal with which, in my unregenerate days, I had served the arch enemy. As unexpected obstacles arose, inbred contrariness impelled me to strive to surmount them, in which endeavor I worked harder than ever before in my life, or than $I$ ever intend to again. The aggregate wealth of the people who had asked me to serve them was far greater than that of my former employers, while I was not rich, and in fact, although $I$ did not know it at the time, was quite poor. There was therefore no reason why they should not pay or I should not receive compensation for what 
I had been asked to do, and I did take what I thought I needed, which was about one quarter of what a self-respecting Monopoly would have expected to pay for similar effort. I never thought myself incompetent for what I had undertaken, and supposed myself to be donating the greater part of the value of what I did. But the humor of the situation appeared in the attitude of $\mathrm{my}$ employers, the People, and of the outside world. Having always been respected as the emissary of a Monopoly, I anticipated greater esteem as the representative of the People. Having been accustomed to hear nice things said when I did good work for an evil cause, I expected still prettier compliments for harder work done in a good cause. I got none of them. The mass of my employers profoundly distrusted me, and the world at large thought me engaged in very trifling business. There was a distinct lowering of social standing, which is never agreeable. When my motives were attacked by those opposed to cooperation, no employer, that I ever heard of, defended me, and many repeated and enlarged upon the evil stories. I had left business because I had become too lazy to work hard, and wild horses could not have dragged me back into the details of affairs, but I became satisfied that the opinion was well-nigh universal that I was exploiting the poor farmers for a permanent job at a "fat salary," not otherwise attainable, and was accompanied by a grim determination that I should never get it. I have sought in a number of cases to be actively helpful to some class, I being one of the class, but never, I think, without having my motives impugned, lies told about me, and raising a crop of enemies within the class which I was seeking to benefit. At first, of course, this was very annoying, but later the humor of the situation prevailed, and I amused myself with trying to understand why people should like a man so long as he was exploiting them, but hate him as soon as he began to try to help them exploit other folks. But I never could.

Of late years I am cooperating with everybody who wishes to cooperate, but extending no invitations of the kind, and otherwise strictly attending to my own business. As a result of this process my own little affairs are prospering fairly, and I seem to myself to be gradually regaining the esteem of mankind; so much so, in fact, that I am not without hope that I shall some time be thought of as kindly as when I was serving a Monopoly. So far as a restless soul impels me to meddle with other people's business, I find most enjoyment, and the prospect of most usefulness, in promoting useful aims by whose accomplishment I can not possibly benefit, and in doing so at my own expense. I don't like the Public as a master and will not work for it any more. I have said elsewhere that I do not think altruism a proper basis for cooperative business, but for myself I am too selfish to engage in it from any other motive. I will not surrender my peace of mind.

While I have made the foregoing statement hoping that it may aid in securing for faithful servants of cooperating farmers more considerate treatment than they sometimes receive, I slould be very ungrateful, and do injustice to many, did I not in the same breath recognize the cordial support and enduring friendships which came to me, and have come to others, as the result of labor in cooperative work among furmers. There was much of this, and yet, upon the whole, the general impression which I received is as above stated. 
It is also proper to say that not all of our cooperators are so weak-minded as myself. Far more evil than was ever said about me has been said for years against better men than $I$, who go steadily on with their work, and in time have a following who stand by them and make them comfortable. This, I suppose, will in time happen to every one who does his duty and is patient. There are many such men in California, without whose aid cooperative work could not be carried on. I simply do not happen to be patient.

After all there is nothing tragic about cooperative work among farmers. It is cooperation among the fairly well to do. It does not particularly appeal to the sympathies, nor eall for much self-denial that one does not feel inclined to. It is cooperation among the really suffering that stirs the blood. It is when one thinks of such men as Mitchell in England, and Raiffiesen in Germany, and men like them, that he raises his hat and is silent a moment. 


\section{APPENDIX.}

THE body of this volume is based mainly upon the experience and observation of the author, with little or no reference to the experiences of others, and no reliance whatever upon "authorities." I wished my own conclusions to go for what they may be worth. The appendix is intended to supplement my own observations with the experience and observation of others upon some of the same subjects, to illustrate more freely some topics which were necessarily treated but briefly in the text, to indicate to general readers not having access to large libraries, the sources from which, at least expense, they may inform themselves further upon any of the subjects here treated in which they may be specially interested, and to serve, in some measure, as a statistical hand-book. As will be noted, however, I have not liesitated to introduce discussion in connection with any subject upon which I thought discussion or explanation would be helpful, in which respect this differs from the usual conception of an "appendix."

All statistical and other matter not original has been credited to original sources, when known, and otherwise to the publications in which it was found. The diagrams illustrating the subject of the Currency have, unless otherwise specified, been prepared for this volume from data familiar to all students of the subject.

E. F. 1 . 


\title{
Appendix A.
}

\author{
ORGANIZATION OF U. S. DEPARTMENT OF AGRICULTURE, \\ AND LEGISLATION IN AID OF AGRICULTURAL, \\ COLLEGES AND EXI'ERIMENT \\ STATIONS.
}

[The descriptive matter in Appendix $\mathrm{A}$ is from a Department publication.]

\section{LAW CREATING THE DEPARTIENT OF AGRICTLTERE.}

The Department of Agrieulture was established by an at of Congress approved by President Lincoln, May 15, 1862. The full text of the aet is as follows:

AN ACT to es:ablish a Department of Agriculture.

Be it enacted by the Senate and House of Representatives of the United States of America in Congress assembled, That there is hereby established at the seat of the Government of the United States a Department of Agrieulture, the general designs and duties of which shall be to acquire and to diffuse among the people of the United States useful information on subjeets connected with agriculture in the most general and comprehensive sense of that word, and to proeure, propagate, and distribute among the people new and valuable seeds and plants.

SEc. 2. And be it further enacted, That there shall be appointed by the President, by and with the advice and consent of the senate, a "Commissioner of Agrieulture," who shall be the chief exeeutive officer of the Department of Agrieulture, who shall hold his office by a tenure similar to that of other civil officers appointed by the President, and who shall reeeive for his compensation a salary of three thousand dollars per anoum.

SEc, 3. And be it further enacted, That it shall be the duty of the Commissioner of Agrieulture to acquire and preserve in his department all information coneerning agriculture which he can obtain by means of books and correspondence and by practical and seientific experiments (aecurate records of which experiments shall be kept in his office), by the collection of statistics, and by any other appropriate means within his power; to colleet, as he may be able, new and valuable seeds and plants; to test by cultivation the value of suel of them as may require such tests; to propagate such as may be worthy of propagation, and to distribute them among aurieulturists He shall annually make a general report in writing of his acts to the President and to Congress, in which he may recommend the publication of papers forming parts of or accompanying his report, which report shall also contain an account of all moneys received and expended by him. He shall also make speeial reports on particular subjeets whenever required to do so by the President or either House of Congress, or when he shall think the subject in his charge requires it. He shall 
receive and have charge of all the property of the agricultural division of the Patent Office in the Department of the Interior, ineluding the fixtures and property of the propagating garden. He shall direct and superintend the expenditure of all money appropriated by Congress to the department and render accounts thereof, and also of all money heretofore appropriated for agriculture and remaining unexpended. And said commissioner may send and receive through the mails, free of charge, all communieations and other matter pertaining to the business of his department, not exceeding in weight 32 ounces.

SEc. 4. And be it further enacted, That the Commissioner of Agriculture shall appoint a chief clerk, with a salary of two thousand dollars, who in all cases during the necessary absence of the Commissioner, or when the said prineipal office shall become vacant, shall perform the duties of Commissioner, and he shall appoint such other employees as Congress may from time to time provide, with salaries corresponding to the salaries of similar officers in other departments of the government; and he shall, as Congress may from time to time provide, employ other persons, for such time as their services may be needed, including ehemists, botanists, entomologists, and other persons skilled in the natural sciences pertaining to agriculture. And the said Commissioner, and every other person to be appointed in the said department, shull, before he enters upon the duties of his office or appointment, make oath or affirmation truly and faithfully to execute the trust committed to him. And the said Commissioner and the chief clerk shall also, before entering upon their duties, severally give bonds with sureties to the Treasurer of the Tnited States, the former in the sum of ten thousand dollars and the latter in the sum of five thousand dollars, conditional to render a true and faithful account to him or his successor in office quarter-yearly accounts of all moneys which shall be by them received by virtue of the said office, with sureties to be approved as sufficient by the Solicitor of the Treasury; which bonds shall be filed in the office of the First Comptroller of the Treasury, to be by him put in suit upon any breach of the conditions thereof.

Approved May 15, 1862.

\section{CHANGE IN RANK OF TIIE DEPARTMENT.}

The department was made an executive office of the first rank under the law approved by President Cleveland February 9, 1889. By that act the title of the head of the department was changed from Commissioner to Secretary, and he became a member of the President's calinet.

AN ACT to enlarge the powers and duties of the Department of Agriculture and to ereate an Exeeutive Department to be known as the Department of Agrieulture.

Be it enacted by the Senate and House of Representatives of the Inited States of America in Coregress assembled, That the Department of Agriculture be an Executive Department under the supervision and control of the secretary of Agriculture, who shall be appointed by the President, by and with the advise and eonsent of the senute; and section one hundred and fifty-eight of the Revised Statutes is hereby amended to inelude such department, and the provis. ions of title four of the lievised Statutes, including all amendments thereto, are hereby made applicable to said department.

SEC. 2. That there shull be in said department an Assistant Secretary of $\Lambda$ griculture, to be appointed by the President, by and with the advise and consent of the Senate, who slatl perform such duties as may be required by liw or preseriled by the Secretary.

Sac. 3. That the Secretary of $\Lambda$ rriculture shall receive the same salary as is paid to the Secretary of each of the Exeeutive l) "partments, and the salary of the Assistant Seeretary of $\Lambda$ rriculture shall be the same as that now paid to the First $\Lambda$ ssistunt Secretary of the Department of the Interior. 
SEc. 4. That all laws and parts of laws relating to the Department of Agriculture now in existence, as far as the same are applicable and not in conflict with this act, and only so far, are continued in full force and effect.

Approved, February 9, 1889.

Several other changes have been made in the law, including an amendment which repeals the requirement that the Commissioner (Secretary) and chief clerk give bond. Neither is now charged with any government property or money.

$$
\text { BUREAUS, DIVISIONS, AYD OFFICES. }
$$

The bureaus, offices, and divisions of the department as now organized are as follows:

\section{THE WEATHER BUREAU.}

The Weather Bureau had its origin in the publication by the department, beginning in 1863, of meteorological data gathered by the Smithsonian Institution, and in the recommendation by Commissioner Newton, the First Com. inissioner of Agriculture, that daily weather reports by telegraph, under the direction of the government, be distributed to the country. This service was authorized by an act of Congress of February 4, 1870, and was conducted by the chief signal officer of the army for twenty years. By the act of October 1,1890 , the Weather Bureau as such was officially recognized, and was transferred to the Department of Agriculture, the general details of its organization being defined in that act. On July 1, 1891, the actual transfer took place.

The duties of the Weather Bureau are the forecasting of the weather, issue of storm warnings, display of weather and flood signals for the benefit of agriculture, commerce, and navigation; the gauging and reporting of rivers, the maintenance and operation of seacoast telegraph lines, and the collection and transmission of marine intelligence for the benefit of commerce and navigation; the reporting of temperature and rainfull conditions for the cotton, sugar, rice, and other interests; the display of frost and cold-wave signals; the distribution of meteorological information in the interests of agriculture and commerce, and the taking of such meteorological observations as may be necessary to establish and record the climatic conditions of the United States, or as are essential to the proper execution of the foregoing duties.

The Bureau now has 150 fully-equipped meteorological stations; 258 stations specially equipped for the display of danger warnings to mariners; 261 stations for the taking of telegraphic reports of temperature and rainfall in the growing fields, and over 3,000 stations where voluntary observers make records of temperature and rainfall with standard instruments.

\section{BUREAU OF ANIMAL INDUSTRY.}

The Bureau of Animal Industry, established in 1884, now comprises subdivisions as follows: Inspection division, miscellaneous division, pathological division, biochemic division, zoological laboratory, dairy division, experiment station. Its duties are to make investigations as to the existence of contagious pleuro-pneumonia, and other dangerous communicable diseases of live stock; to make original investigations as to the nature and prevention of such diseases, and to superintend measures for their extirpation; and to report on the condition and means of improving the animal industries of the country. The Bureau also has charge of the inspection of import and export animals, of the inspection of vessels for the transportation of export animals, and of the quarantine stations for imported neat cattle; supervises the interstate movenent of cattle; and inspects live stock and their products slaughtered for food consumption. 


\section{DIVISION OF GARDENS AND GROUNDS.}

The propagating garden, started in 1858 , was turned over by the Commissioner of Patents to the Department of Agriculture shortly after the ereation of the department, in May, 1862, and the Division of Gardens and Grounds was organized as an experimental garden in September, 1862. The superintendent is charged with the care of keeping the lawns and other ornamentations of the park, and with all duties connected with the introduction and propagation of desirable economic plants, and their dissemination.in suitable climates throughout the States.

\section{DIVISION OF CHEMISTRY.}

The Division of Chemistry, established in 1862 , makes investigations of the methods proposed for the analysis of soils, fertilizers, and agricultural products and such analyses as pertain in general to the interests of agriculture. It also conduets researches on all subjects in which ehemistry and agriculture are conjoined. The study of the eomposition of human foods and their adulterations is one of the ehief functions of this division. It can not undertake the analyses of articles of a miscellaneous nature, but application for such analyses should be made to the directors of agricultural experiment stations of the different states. The division does not make assays of ores nor analyses of minerals, except when related to general agrieultural interests, nor analyses of water.

\section{DIVISION OF ENTOMOLOGY.}

The Division of Entomology, organized in 1863, conducts investigations concerning injurious and beneficial insects; disseminates information regarding the results of these investigations and the best remedies to be used against injurious inseets, by means of correspondence, cireulars, bulletins, and reports; prepares specimens for illustrative and museum purposes; and in general aets as a bureau of information on all matters relating to economic entomology.

\section{DIVISION OF STATISTICS.}

The Division of Statistics, established in 1863 , eollects information as to the eondition, prospects, and harvests of the prineipal crops, and of the numbers and status of farm animuls through a corps of country eorrespondents, and with the aid of a supplementary organization under the direction of State Agents. It obtains similar information from European countries monthly through the deputy consul-general at London, assisted by consular, agricultural, and commercial authorities. It reeords and tabulates and coordinates statisties of agricultural production, distribution, and consumption, the authorized data of governments, institutes, socicties, boards of trade, and individual experts; and writes, edits, and publishes a monthly bulletin for the use of editors and writers, and for the information of producers and consumers, and for their protection against combination and extortion in the handling of the products of agriculture.

\section{DIVISION OF BOTANY.}

The Division of Botany was established in March, 1869. It maintained the United States National Herbarium until July 1, 1896, when that work was transferred to the Smithsonian Institution. The chief of the division, however, continues to have charge and the specimens are used by his assistants. The division now publishes information of the treatment of weeds, experiments with poisonous and medicinal plants, tests seeds with a view to their increased purity and commereial value, and investigates other questions of economie botany. 


\section{DIVISIONS OF ACCOUNT AND DISBTRSEMENTS.}

The Division of Accounts and Disbursements, establisbed July 1, 1880, audits and pays all accounts and adjusts claims against the department; decides questions involving the expenditure of public funds; prepares advertisements, schedules, contracts for annual supplies, leases, and agreements; issues requisitions for the purchase of supplies, requests for passenger and freight transportation; prepares the annual estimates of appropriations, and attends to all other business relating to the financial interests of the department.

\section{DIVISION OF FORESTRI.}

The Division of Forestry, organized by order of the Commissioner in 1881, and reorganized by Congress as a division in 1886, is occupied with experiments, investigations, and reports dealing with the subject of forestry, and with the dissemination of information upon forestry matters.

\section{DIVISION OF BIOLOGICAL SURVEY.}

The Division of Biological Survey (established as the Division of Ornithology and Mamnalogy in 1886) studies the distribution of animals and plants, and maps the natural life zones of the country; it also investigates the economic relations of birds and mammals, and recommends measures for the preservation of beneficial and the destruction of injurious species.

\section{DIVISION OF POHOLOGY.}

The Division of Pomology, established in 1886, collects and distributes information in regard to the fruit interests of the United States, investigates the habits and peculiar qualities of fruits, their adaptability to various soils and climates, and conditions of culture, and introduces new and untried fruits from foreign countries.

\section{DIVISION OF VEGETABLE PHYSIOLOGI AND PATHOLOGI.}

This division was originally established in 1886 as a section of mycology in the Division of Botany under F. Lamson-Scribner; the following year it was changed to a section of vegetable pathology, and in 1891 became a separate division. In 1895 the scope of its work was enlarged and name altered to Division of Vegetable Physiology and Pathology.

The division has for its object a study of normal and abnormal life processes of plants. It seeks by means of both field and laboratory investigations in plant physiology, plant breeding and selection, and the morphology and classification of fungi, to determine the causes and methods of prevention of plant diseases, the amelioration of economic plants, and rational methods of growing commercial erops.

\section{OFFICE OF E.TPERIMENT STATIONS.}

The Office of Experiment Stations, established in 1888, represents the Department in its relation to the experiment stations, which are now in operation in all the States and Territories. It seeks to promote the interests of agricultural education and investigations throughout the United States. It collects and disseminates general information regarding the colleges and stations, and publishes accounts of agricultural investigntions at home and abroad. It also indicates lines of inquiry, aids in the conduct of cooperative experiments, reports upon the expenditures and work of the stations, and in general furnishes them with such advice and assistance as will best promote the purposes for which they were established. It is also charged with the investigation of the nutritive value and economy of human food. 


\section{OFFICE OF FIBER INIESTIGATIONS.}

Fiber investigations were begun in the Division of Statistics in 1889 , and in 1890 the Office of Fiber Investigations was established. It collects and disseminates information regarding the cultivation of textile plants, directs experiments in the culture of new and hitherto unused plants, purchases seed and plants for limited distribution for experimental purposes, and investigates the merit of new machines and processes. for extracting the fiber and preparing it for manufacture.

\section{DIVISION OF PUBLICATIONS.}

The Division of Publications was established in 1889 as a section of the Division of Statisties, which had originally been eharged with the work of editing the department reports. In 1890 it was organized and separately appropriated for as the Division of Records and Editing, becoming the Division of Publications in 1895. This division has entire supervision of the editing, printing, and publishing of the department, and the distribution of all publieations, being especially charged, furthermore, with the preparation, publication, and distribution of Farmers' Bulletins. The division issues advance notices and a monthly list of publications, and prepares for publication any information of special interest to agriculturists.

\section{OFFICE OF ROAD INQUIRY.}

The Offiee of Road Inquiry, established in 1893, collects information concerning the system of road management throughout the United States, conducts investigations into methods of road making, directs the building of sample roads at the agriecltural colleges and experiment stations, and prepares publications on the subject of roads and road laws.

\section{DIITSION OF AGROSTOLOGY.}

The Division of Agrostology, formerly in the Division of Botany, was established as an independent division July 1, 1895, under the present chief, F. Lamson-Seribner. It is charged with the investigations of the natural history, geographical distribution, and uses of grasses and forage plants, their adaptation to speeial soils and climates, the introduction of promising native and foreign kinds into cultivation, and the preparation of publications and correspondence relative to these plants.

\section{DIVISION OF SOILS.}

The Division of Soils (formerly Division of Agricultural Soils in the Weather Bureau) was established as an independent division of the Department in 1894. It has for its object the investigation of the texture and other physical properties of soils and their relation to erop production.

\section{SECTION OF FOREIGN MARTETS.}

The Section of Foreign Markets was instituted Mareb 20, 1894, under a clause in the act of appropriations for the Department of Agriculture setting aside $\$ 10,000$ for the purpose of making "investigations concerning the feasibility of extending the demands of foreign markets for the agricultural products of the United States." The work of the section eonsists chiefly in the prepuration of bulletins and eireulars designed to convey information regarding such opportmuities as exist for the extension of our export trade in American farm products. 


\section{LIRRARY}

The library of the department was first officially recognized by the appointment of J. B. Russell as librarian in 1871. The collection of books had it: origin in the transfer in 1896 of the works on agriculture from the library of the Patent Office. Additions have licen made from time to time by exchange and purchase. The library now contains 58,000 volumes, and is undoubtedly the best separate collection on agriculture and allied subjects in the United States-probably the best in the world. It comprises complete sets of statc agricultural publications and files of many of the agricultural journals from the beginning; a large collection of the official reports on agricultural subjects issued by foreign governments; important collections in botany, horticulture, forestry, zoology, and entomology; numerous sets of scientific serials; a wellselected collection of encyclopedias, atlases, and other general reference works, and a small collection of̂ biography, history, and general literature. A quarterly list of the additions to the library is published, and several lists of books on agricultural subjects have been issued.

\section{THE MUSEUM.}

The museum had its beginning in the old agricultural bureau of the Patent Office, the nucleus of the collection being a large series of fruit models and tuffed birds, the work of Prof. Townsend Glover, of that Bureau. When the Department of Agriculture was organized, in 1862, Mr. Glover became its entomologist, and the museum was established under him in 1864 as a recognized institution. From this time forward its collections were steadily increased by donations and purchases, and when the plans were being drawn for a separate building for the Department of Agriculture, the large hall now used for the library was planned, to be devoted to museum purposes. The building was occupied about the beginning of 1868 , and the museum moved from the Patent Office. About this time the Glover collection of fruit models, birds, and insects was purchased by a spccial appropriation of $\$ 10,000$, the government having had the loan of it for over ten years.

\section{LANDS FOR AGRICLLTLRAL COLLEGES.}

The day following the establishment of the Department the law granting public lands for the establishment of agricultural colleges was approved by President Lincoln. The original bill for this purpose was introduced in the House in 1857 by IIon. Justin S. Morrill. It was passed, but was vetoed by President Buchanan. In December, 1861, Mr. Morrill introduced his bill again, but on May 2, 1862, Senator Wade offered a sinilar bill in the Senate, and in June it passed both houses.

The act passed through the efforts of Hon. William Hatch, the Morrill law of 1890 (p. 50), and this act constitute the largest government aid to education in the history of this country.

[Act of July 2, 1862.]

AN ACT donating public lands to the severnl states and Territories which may provide colleges for the benefit of agriculture and the mechanic arts.

Be. it enacted by the Senate and House of Representatires of the Inited states of America in Congress Assembled, That there be granted to the several states, for the purposes hereinafter mentioned, an amount of public land, to be apportioned to each state a quantity equal to thirty thousand acres for each senator and representative in Congress to which the states are respectively entitled by the apportionment under the census of eighteen hundred and sixty: 
Provided, That no mineral lands shall be selected or purchased under the provisions of this act.

SEc. 2. That the land aforesaid, after being surveyed, shall be apportioned to the several states in sections or subdivisions of sections, not less than onequarter of a section; and whenever there are public lands in a state subject to sale at private entry at one dollar and twenty-five cents per acre, the quantity to which said state shall be entitled shall be selected from such lands within the limits of such state, and the Secretary of the Interior is hereby directed to issue to each of the states in which there is not the quantity of public lands subject to sale at private entry at one dollar and twenty-five cents per acre, to which said state may be entitled under the provisions of this act, land scrip to the amount in acres for the deficiency of its distributive share; said scrip to be sold by said states and the proceeds thereof applied to the uses and purposes prescribed in this act, and for no other use or purpose whatsoever: Provided, That in no case shall any state to which land scrip may thus be issued be allowed to locate the same within the limits of any other state, or of any territory of the United States, but their assignees may thus locate said land scrip upon any of the unappropriated lands of the United States subject to sale at private entry at one dollar and twenty-five cents, or less, per acre: And provided further, That not more than one million acres shull be located by such assignees in any one of the states: And provided further, That no such location shall be made before one year from the passage of this act.

SEc. 3. That all the expenses of management, superintendence, and taxes from date of selection of said lands, previous to their sales, and all expenses incurred in the management and disbursement of the moneys which may be received therefrom, shall be paid by the states to which they may belong, out of the treasury of said states, so that the entire proceeds of the sale of said lands shall be applied without any diminution whatever to the purposes hereinafter mentioned.

SEc. 4. That all moneys derived from the sale of the lands aforesaid by the states to which the lands are apportioned, and from the sales of land scrip hereinbefore provided for, shall be invested in stocks of the United States, or of the states, or some other safe stocks, yielding not less than five per centum upon the par value of said stocks; and that the moneys so invested shall constitute a perpetual fund, the eapital of which shall remain forever undiminished (except so far as may be provided in section fifth of this act), and the interest of which shall be inviolably appropriated, by each state which may take and claim the benefit of this act, to the endownent, support, and maintenance of at least one college where the leading olject shall be, without excluding other scientific and classical studies, and including military tactics, to teach such branches of learning as are related to agriculture and the mechanic arts, in such manner as the legislatures of the states may respectively prescribe, in order to promote the liberal and practical education of the industrial classes in the several pursuits and professions in life.

SEC. 5. That the grant of land and land serip herehy authorized shall be made on the following conditions, to which, as well as to the provisions hereinbefore contained the previous assent of the several states shall be signified by legislative acts:

First. If any portion of the fund invested, as provided by the foregoing section, or any portion of the interest thereon, shall, by any action or contingency, be diminished or lost, it shall be replaced by the state to which it belongs, so that the capitul of the fund shall remain forever undiminished; and the annual interest shall he regularly applied without diminution to the purposes mentioned in the fourth section of this act, except that a sum, not exceeding ten per centum upon the amount received by any state under the provisions of this act, may be expended for the purchase of lands for sites or experimental furms, whenever authorized by the respective legislatures of said states.

Second. No portion of said fund, nor the interest thereon, shall be applied, 
directly or indirectly, under any pretense whatever, to the purchase, erection, preservation, or repair of any building or buildings.

Third. Any state which may take and claim the benefit of the provisions of this act shall provide, within five ycars, at least not less than one college, as described in the fourth section of this aet, or the grant to such state shall cease; and said state shall be bound to pay the I nited States the amount received of any lands previously sold, and that the title to purchasers under the state-shall be valid.

Fourth. An annual report shall be made regarding the progress of each college, recording any improvements and experiments made, with their cost and results, and such other matters, including state industrial and economical statistics, as may be supposed useful; one copy of whieh shall be transmitted by mail free, by each, to all the other eolleges which may be endowed under the provisions of this aet, and also one copy to the Secretary of the Interior.

Fifth. When lands shall be seleeted from those which have been raised to double the minimum price, in consequence of railroud grants, they shall be computed to the states at the maximum price, and the number of acres proportionately diminished.

Sixth. No state while in a condition of rebellion or insurrection against the Government of the United States shall be entitled to the benefit of this act.

Seventh. No state shall be entitled to the benefits of this act unless it shall express its acceptanee thereof by its legislature within two years from the date of its approval l,y the President.

SEc. 6. That land scrip issued under the provisions of this act shall not be subject to location until after the first day of January, one thousand eight hundred and sixty-three.

SEc. 7. That the land officers shall receive the same fees for locating land scrip issued under the provisions of this act as is now allowed for the location of military bounty land warrants under existing laws: Provided, Their maximum compensation shall not be thereby increased.

SEc. 8. That the governors of the several states to which serip shall be issued under this act shall be required to report annually to Congress all sales made of such scrip until the whole shall be disposed of, the amount received for the same, and what appropriation has been made of the proceeds.

A pproved July 2, 1862.

THE SECOND MORRILL ACT. ENDOWMENT OF AGRICULTURAL COLLEGES.

[Morrill law, August 30, 1890.]

AN ACT to apply a portion of the proceeds of the publie lands to the more eomplete endowment and support of the colleges for the benefit of agrieulture and the mechanic arts established under the provisions of an aet of Congress approved July second, eighteen hundred and sixty-two.

Be it enacted by the Senate and Hunse of Representatives of the United States of America in Congress assembled, That there shall be and hereby is, annually appropriated, out of any money in the Treasury not otherwise appropriated, arising from the sales of public lands, to be paid as hereinafter provided, to each state and territory for the more completc endowment and maintenance of colleges for the benefit of agriculture and the mechanic arts now established, or which may be hereafter established, in accordance with an act of Congress approved July second, eighteen hundred and sixty-two, the sum of fifteen thousand dollars for the year ending. June thirtieth, eighteen hundred and ninety, and an annual increase of the amount of such appropriation thereafter for ten years by an additional sum of one thousand dollars over the preceding year, and the annual amount to be paid thereafter to each state and territory shall be twenty-five thousand dollars, to be applied only to instruction in agriculture, the mechanic arts, the English language, and the various branches of 
mathematical, physical, natural, and economic science, with special reference to their applications in the industries of life, and to the facilities for such instruction: Provided, That no money shall be paid out under this act to any state or territory for the support and maintenance of a college where a distinction of race or color is made in the admission of students, but the establishment and maintenance of such colleges separately for white and colored students shall be held to be a compliance with the provisions of this act if the funds received in such state or territory be equitably divided as hereinafter set forth: Provided, That in any state in which there has heen one college establisbed in pursuance of the act of July second, eighteen hundred and sixty-two, and also in which an educational institution of like character has been established, or may be hereafter established, and is now aided by such state from its own revenue, for the education of colored students in agriculture and the mechanic arts, however named or styled, or whether or not it has received money heretofore under the act to which this act is an amendment, the Legislature of such state may propose and report to the Secretary of the Interior a just and equitable division of the fund to be received under the act between one college for white students and one institution for colored students established as aforesaid, which shall be divided into two parts and paid accordingly, and thereupon such institution for colored students shall be entitled to the benefits of this act and subject to its provisions, as much as it would have leen if it had been included under the act of eighteen hundred and sixty-two, and the fulfilment of the foregoing provisions shall be taker as a compliance with the provision in reference to separate colleges for white and colored students.

SEc. 2. That the sums hereby appropriated to the states and territories for the further endowment and support of colleges shall be annually paid on or before the thirty-first day of July of each year, by the Secretary of the Treasury, upon the warrant of the Secretary of the Interior, out of the Treasury of the United States, to the state or territorial treasurer, or to such officer as shall be designated by the laws of such state or territory to receive the same, who shall, upon the order of the trustees of the college, or the institution for colored students, immediately pay over said sums to the treasurers of the respective colleges or other institutions entitled to receive the same, and such treasurers shall be required to report to the Secretary of Agriculture and to the Secretary of the Interior, on or before the first day of September of each year, a detailed statement of the amount so received and of its disbursement. The grants of moneys authorized by this act are made subject to the legislative assent of the several states and territories to the purpose of said grants: Provided, That payments of such instalments of the appropriation herein made as shall become due to any state before the adjournment of the regular session of Legislature meeting next after the passage of this act shall be made upon the assent of the governor thereof, duly certified to the Secretary of the Treasury.

SEC. 3 . That if any portion of the moneys received by the designated officer of the state or territory for the further and more complete endowment, support, and maintenance of colleges, or of institutions for colored students, as provided in this act, shall, by any action or contingency, be diminished or lost, or be misapplied, it shall be replaced by the state or territory to which it belongs, and until so replaced no subsequent appropriation sliall be apportioned or paid to such state or territory; and no portion of said moneys shall be applicd, dircetly or indirectly, under any pretense whatever, to the purchase, erection, preservation, or repair of any building or buildings. An annual report by the president of each of said colleges shall be made to the Secretary of Agriculture, as well as to the Secretary of the Interior, regarding the condition and progress of each college, including statistical information in relation to its receipts and expenditures, its library, the number of its students and professors, and also as to any improvements and experiments made under the direction of any experiment stations attached to said colleges, with their costs and results, and such other industrial and economical statistics as may be regarded as useful, one copy of which shall be transmitted by mail free to all other colleges further endowed under this act. 
SEC. 4. That on or before the first day of July in each year, after the passage of this act, the Secretary of the Interior shall aseertain and eertify to the Secretary of the Treasury as to each state and territory whether it is entitled to receive its share of the annual appropriation for colleges, or of institutions for colored students, under this act, and the amount which thercupon each is entitled, respectively, to receive. If the Seeretary of the Interior shall withhold a certificate from any state or territory of its appropriation, the facts and reasons therefor shall be rcported to the president, and the amount involved shall be kept separate in the treasury until the close of the next Congress, in order that the state or territory may, if it should so desire, appeal to Congress from the determination of the Secretary of the Interior. If the next Congress shall not direct such sum to be paid it shall be covered into the Treasury. And the Seeretary of the Interior is hereby charged with the proper administration of this law.

SEc. 5. That the Secretary of the Interior shall annually report to Congress the disbursements which have been made in all the states and territories, and also whether the appropriation of any state or territory has been withbeld, and if so, the reasons therefor.

SEC. 6. Congress may at any time amend, suspend, or repeal any or all of the provisions of this act.

Approved, August 30, 1890.

\section{LAW ESTABLISHING AGRICULTURAL EXPERIIENT STATIONS.}

\section{[Hatch Act, March 2, 1887.]}

AN ACT to establish agricultural experiment stations in connection with the colleges established in the several states under the provisions of an act approved July second, eighteen hundred and sixty-two, and of the acts supplementary thereto.

Be it enacted by the Senate and House of Representatives of the United States of Ameriea in Congress assembled, That, in order to aid in acquiring and diffusing among the people of the United States useful and practical information on subjects connected with agriculture, and to promote scientific investigation and experiment respecting the principles and applications of agricultural seience, there shall be established, under direction of the college or colleges or agricultural department of colleges in each state or territory established, or which may hereafter be established, in accordance with the provisions of an act approved July second, eighteen hundred and sixty-two, entitled "An act donating public lands to the several states and territories which may provide colleges for the benefit of agriculture and the mechanic arts," or any of the supplements to said act, a department to be known and designater as an " agricultural experiment station:" Provided, that in any state or territory in which two such colleges have been or may be so established, the appropriation hereinafter made to such state or territory shall be equally divided between such colleges, unless the Legislature of such state or territory shall otherwise direct.

SEc. 2. That it sliall be the object and duty of said experiment stations to conduct original researches or verify experiments on the physiology of plants and animuls; the diseases to which they are severally subject, with the remedies for the same; the chemical composition of useful plants at their different stages of growth; the comparative advantages of rotative clopping as pursued under a varying series of crops; the eapacity of new plants or trees for acelimation; the analysis of soils and water; the ehemical composition of manures, natural or artificial, with experiments designed to test their comparative effects on crops of different kinds; the adaptation and value of grasses and forage plants; the composition and digestibility of the different kinds of food for domestic animals; the scientific and economic questions involved in the production of butter and cheese; and such other researches or experiments bearing directly on the agricultural industry of the United States as may in each case be deemed advisable, 
having due regard to the varying conditions and needs of the respective states or territories.

SEc. 3. That in order to secure, as far as practicable, uniformity of methods and results in the work of said stations, it shall be the duty of the United States Commissioner of Agriculture to furnish forms, as far as practicable, for the tabulation of results of investigation or experiments; to indicate from time to time such lines of inquiry as to him shall seem most important; and, in general, to furnish such advice and assistance as will best promote the purpose of this act. It shall be the duty of each of suid stations annually, on or before the first day of February, to make to the governor of the state or territory in which it is located a full and detailed report of its operations, including a statement of receipts and expenditures, a coly of which report shall be sent to each of said stations, to the said Commissioner of $\Lambda$ griculture, and to the Secretary of the Treasury of the United States.

SEc. 4. That bulletins or reports of progress shall be published at said stations at least once in three months, one eopy of which shall be sent to each newspaper in the states or territories in which they are respectively located, and to such individuals actually enguged in farming as may request the same, and as far as the means of the station will permit. Such bulletins or reports and the annual reports of said stations shall be transmitted in the mails of the United States free of charge for postage, under such regulations as the Postmaster-General may from time to time prescribe.

SEC. 5. That for the purpose of paying the necessary expenses of conducting investigations and experiments and printing and distributing the results as hereinbefore preseribed, the sum of fifteen thousand dollars per annum is hereby appropriated to each state, to be especially provided for by Congress in the appropriations from year to year, and to each territory entitled under the provisions of section cight of this act, out of any money in the Treasury proceeding from the sales of public lands, to be paid in equal quarterly payments on the first day of January, A pril, July, and October in each year, to the Treasurer or other officer duly appointed by the governing boards of said colleges to receive the same, the first payment to be made on the first day of October, eighteen hundred and eighty-seven: Provided, however, That out of the first annual appropriation so received by any station an amount not exceeding one-tifth may be expended in the erection, enlargement or repair of a building or buildings necessary for carrying on the work of such station; and thereafter an amount not exceeding five per centum of such annual appropriation may be so expended.

SEC. 6. That whenever it shall appear to the Secretary of the Treasury, from the annual statement of receipts and expenditures of any of said stations, that a portion of the preceding annual appropriation remains unexpended, such amount shall be deducted from the next succeding annul appropriation to such station, in order that the amount of money appropriated to any station shall not exceed the amount actually and necessarily required for its maintenance and support.

SEC. 7. That nothing in this act shall be construed to impair or modify the legal relation existing between any of the said colleges and the government of the states or territories in which they are respectively loented.

SEC. 8. That in states having colleges entitled under this section to the benefits of this act, and having also agricultural experiment stations established by law separate from said colleges, such states shall be authorized to apply such benefits to experiments at stations so established by such states; and in ease any state shall have estahlished under the provisions of said act of July second, aforesaid, an agricultural department or experimental station, in connection with any university, college, or institution not distinctively an agricultural college or scbool, and such state shall have established or shall hereafter establish a separate agricultural college or school which shall have connected therewith an experimental farm or station, the Legislature of such state may apply in whole or in part the appropriation by this act made to such separate agricultural college or school, and no Legislature shall by contract, express or implied, disable itself from so doing. 
SEc. 9. That the grants of moneys authorized by this act are made subject to the legislative assent of the several states and territories to the purposes of said grants: Provided, That payment of such instalments of the appropriation herein made as shall become due to any state before the adjournment of the regular session of its Legislature meeting next after the passage of this act shall be made upon the assent of the governor thereof, duly certified to the Secretary of the Treasury.

SEc. 10. Nothing in this act shall be held or construed as binding the United States to continue any payments from the Treasury to any or all the states or institutions mentioned in this act, but Congress may at any time amend, suspend, or repeal any or all the provisions of this act.

Approved, March 2, 1887. 


\title{
Appendix B.
}

\author{
THE WORK OF A FIRST-CLASS DAIRY SCHOOL.
}

[This description of Dairy School work is from a bulletin of the University of Wisconsin. Other Dairy Schools endeavor to do similar work, and do so so far as means are provided. Several other Agricultural Colleges have Dairy Schools of the first class, but the Wisconsin course will indicate the nature of the work in all.]

\section{COURSE OF STUDY IN THE WISCONSIN DAIRY SCHOOL.}

1. Twenty-four lectures by Dr. S. M. Babeock on the constitution of milk, the various methods of milk testing, the conditions which affect creaming and churning, the principles involved in the manufacture of cheese, the relation between composition of milk and yield of cheese, and allied subjects.

2. Sixteen lectures in dairy bacteriology, by Dr. H. L. Russell, on the relation of bacteria to dairy problems, including the care and treatment of milk in its natural state, normal and abnormal fermentations in milk, butter, and cheese, and the preservation of milk for economic purposes.

This course will be based upon text-book work, supplemented by lectures and demonstrations. Quizzes, involving the practical relation of above subjects to modern dairy principles, will be held from time to time.

3. Creamery management and dairy book-keeping, by Prof, E. H. Farrington, including instruction in recording milk at the intake, calculating patrons' dividends, shipping accounts, and other matters relating to the business of the creamery and cheese factory.

4. Ten lectures on the theory and art of cheese-making, by Mr. J. W. Decker.

5. Ten lectures and demonstrations, by Prof. A. W. Richter, Instructor in Engineering, on the care and management of the boiler and engine.

6. Eight lectures, by Prof. F. H. King, on heating, ventilation, and other physical problems connected with dairy practice.

7. Eight lectures by Prof. W. L. Carlyle, on the breeding and selection of dairy cows.

8. Eight lectures, by Prof. W. A. Henry, on the feeding and general management of dairy cows.

9. Eight lectures, by Dr. Simon Beattec, on the common diseases of the dairy cow.

\section{FACILITIES FOR INSTRUCTION.}

In Hiram Smith Inall the University of Wisconsin has a dairy building which, for size, appearance, and equipment, is in some fair degree commensurate with the great dairy interests of our commonwoalth. It is constructed of Dunville white sandstone and white brick, the exterior of the upper stories 
being finished in pebble and beam work. With equipment it represents an outlay of about $\$ 40,000$. The main structure is seventy-five feet front by fifty-four feet in depth, and three full stories in height. The boiler room and refrigerator form an addition twenty feet by forty-eight feet, one story in height. In the boiler room are a sixty horse-power steel boiler and a twentyfive horse-power Allis-Corliss engine.

The university operates the ereamery, also the milk and cream pasteurizing departments in the Dairy school building throughout the yeur, receiving milk from about sixty farms in the vieinity of Madison. The milk supply varies from tive thousand to ten thousand pounds per day, according to the season of the year. The products of the I airy School are fancy print and larger packages of butter, full cream cheddar cheese, and pasteurized cream. These are delivered daily to families in Madison and other cities. Daily shipments are also made to Chicago and Milwaukee. Pasteurized milk is supplied to invalids and ailing infants upon doctors' preseriptions, the results proving highly satisfactory. Six persons are employed regularly in manufacturing and delivering the products. By handling milk in such quantities, and catering to a select trade, those in charge of the school are compelled, by the very nature of the work, to keep well to the front in dairy knowledge and practice.

The purpose of the present plan of operating the factory is not money-making, but that there may be the largest opportunity for investigation and that the instructors may be practical and up to date in their knowledge of dairy matters.

\section{THE CREAMERY.}

The c-eamery room, thirty-six by forty-eight feet in size, is on the first floor. Milk is delivered at a covered driveway in the rear, and, from the weigh can, flows by gravity into a large receiving vat on a platform in the creamery. All of the latest forms of the leading power separators will be in use for instruction.

Near the front of the room are two three hundred gullon cream ripening vats, beside which are two box churns of different patterns and a four hundred and fifty-gallon combined churn and butter-worker. In front of these is the IIason power butter-worker and other apparatus incident to the creamery. A Wicks refrigerator opens off the creamery for the storage of butter.

Two instructors direct the work of the students running the separators, which will include the leading kinds and latest forms of centrifugal-power cream separators, while one instructor supervises the students in charge of the cream and the churning and working of the butter. Professor Farrington gives general supervision and receives the blanks filled out daily by the students, each one of whom is marked upon his work.

From time to time samples of butter secured from different sources will be scored by the class, for the purpose of increasing their knowledge of the wants of the market.

Butter made by the students is also inspected and its defects as well as the points of excellence are explained and traced to their causes.

The process of butter-making will be conducted daily on the creamery plan, from analyzing the milk at the intake to marking packages for shipping from the refrigerator.

\section{IIILK INSPECTION.}

A detail of students, in charge of an instructor, receives the milk daily as it is delivered by the sixty patrons at the creamery intake. The students are taught to inspect the different lots of milk as they arrive, using the Wisconsin curd test, which aids in detecting those lots of milk that are particularly injurious in cheese making, also to test the acidity of each lot of milk and how to take the composite sumples for the weekly fat tests. 
The automatic skim milk weigher is also used for apportioning to each patron his share of the skim milk. A test of the speed, capacity and skimming effieiency of the separators is made by the students each day. After they have become sufficiently familiar with the different machines, they are given an opportunity to note the effect which a change of speed of the separator bowl, variation in temperature of milk, and an increase or decrease in the amount of milk separated per hour, has on the cream and skim milk obtained from the different separators. The effect of various changes in the cream ripening, churning and butter-working processes is also studied, as well as the packing and shipping of butter in different styles of packages.

Printed blanks are used in the instruction to help the students understand the work expected of them each day. Various observations and records of weights and tests are reported on these twenty different blanks, and the students are marked on the neatness and appearance of their daily blanks, as well as on the accuracy and faithfulness with which their work has been done.

\section{THE CHEESE ROOM.}

The cheese room adjoining the creamery is twenty-seven by thirty-three feet in area. In this there are eight steam-heated cheese vats of three hundred pounds capacity, each equipped with a complete set of cheese-making apparatus. An elevator carries the chees other materials from this room to the upper floors. Adjoining the cheese room is a testing room, a store-room and a pressroom, with gang cheese presses.

In the cheese room the students will be drilled in the use of the rennet test, which has done so much to advance cheese-making, the use of curd mills, lactometers, and acid tests as applied to cheese-making, and are given a thorough drill in judging cheese. Milk from the different patrons will be examined by the Wisconsin curd test, which has proved so valuable in detecting those lots that are of doubtful quality in cheese-making. The hot-iron test, both for indicating the time for drawing the whey and when to put the curd to press, will be used. The milk and whey will be tested, so that the losses in the process of manufacturing may be located. Instruction will be given in the proper bandaging, pressing, and dressing of cheese, as well as the proper temperature of the curing room and care of cheese on the shelves. Samples of cheese from different sources will be secured, and the students given practice in scoring them, estimating their worth, and recognizing the demands of the market.

Some one of the students at each vat is given a foreman's blank each day, while others give special attention to the rennet test, temperatures, salting, bandaging, and pressing the cheese. The work is systematically arranged so that every student gets a thorough drill in the various manipulations of cheesemaking. Experiments are also made to show the effect which changes in the temperature of cooking the curd, as well as different amounts of rennet or salt, have upon the quality of the cheese.

Three instructors are required to direct the work of the students in the cheese room. The head instructor gives general directions and receives the blanks filled out daily by each student, and marks all students under his charge. Each of the remaining instructors has charge of the students on duty at four cheese vats.

\section{PASTEURIZATION.}

The pasteurization of inilk and eream has grown to such importance that this work has been given a room under charge of a special instruetor in this braneh.

Here is found a power pasteurizer, a power bottle-washer, and other pieces of apparatus and devices requisite to handling pasteurized eream and milk in a commercial way. 
A special course in the preservation of milk and cream for direct consumption will be given during the latter part of the Dairy School. Several lectures on this subject will be given by Dr. Russell, who will have general supervision of the work. The course will include an exposition of the bacteriological prineiples underlying the methods of pasteurizing and sterilizing of milk and cream. The student will be taught the conditions essential in apparatus for this purpose, the methods of manipulating the same, methods of restoring the viscosity of pasteurized cream, and the way that milk and cream should be handled so as to be guaranteed free from all disease germs.

Owing to the present restricted space at our disposal, only a limited number of students can be accepted. Those students whose average standing in the mid-term examination is eighty-five or above, and who show special proficiency in bacteriology and the practical creamery work will be eligible to this course. A special fee of $\$ 1.00$ will be charged for this course.

An opportunity will be offered those students who desire to remain after the close of the school to do further practical work in the pasteurizing room.

\section{THE OFFICE, LABORATORI, ETC.}

In the second story is the office, with fire-proof vault, lockers tor workclothes of one hundred students, toilet and bath rooms; also a cheese-curing room and a large room for instruction in farm dairying and advanced cheese-making. In the third stnry is a reading room, lecture room, and a large laboratory for milk analysis, also a private laboratory for advanced work.

All of the rooms are heated directly by steam radiators and indirectly by hot air forced to the several rooms by a Sturtevant fan, run by its own two horsepower engine. The building is designed wholly with reference to practical instruction in dairying, and is arranged for the accommodation of one hundred students.

\section{MILK TESTING.}

To be abreast of the times, the creamery operator and the cheese-maker must be thoroughly skilled in the use of the Babcock test, an apparatus invented by Dr. Babcock, one of the instructors in the Dairy School. Students will be given thorough instruction in the use of the Babcock and other simple milk tests, and will be taught to determine accurately the amount of fat in samples of full milk, skim milk, buttermilk, and whey. Steam turbine, belt, and hand-power Babcock test machines will be provided. By the use of the test in connection with the Quevenne lactometer students are taught to detect watering and skimming; with this test and a balance he will determine closely the amount of fat in a given sample of cheese $\mathrm{He}$ will also be taught to determine approximately the amount of fat in a given sample of butter. Lastly, he will be shown how to measure the necks of the test bottles in such a way as to know if they are correctly graduated.

This course will be under the direction of Professor Farrington,

\section{DIVISION OF DITIES.}

Dairy instruction will be divided into five courses-lectures on dairying, milk-testing, butter-making, cheese-making, and pasteurization. The class will be divided into three sections, one of which will be assigned to the laboratory, a second to the creamery, and the third to the cheese room. All dairy students will meet in the lecture room on week days daily from eight to nine o'clock, for the lecture on dairying. At the close of the lecture each section will pass to its assigned duties in the laboratory, creamery, or cheeseroom. By changing from day to day, each student will spend two days each week in each of the three departments. 


\section{FARY DAIRY INSTRECTION.}

This circular will fall into the hands of some who do not intend to become factory operators, but rather dairy farmers. Such students should take the Short Course in Agriculture, which opens and closes at the same time as the Dairy Course.

In the Short Course every line of instruction is arranged to give the largest amount of help possible to young farmers who have but a limited time for study. Not only are the leading lines of agriculture considered, but farm bookkeeping and business accounts, farm blacksmithing, farm carpentry, etc., are taught. There are thirteen instruetors in this course.

There will be lectures on dairying by Dr. Babcock and practical instruction in butter-making by an assistant.

Thorough instruction will be given in the use of the Babcock milk test and the separation of cream by all the leading hand separators. The churning of cream and working and packing of butter will constitute a portion of this instruetion.

An Illustrated Circular describing the Short Course studies will be sent on application to R. A. Moor E, Madison, Wis.

\section{EXAMINATIONS.}

At intervals during the term, and at its close, the students in each of the sub-courses will be subjected to examination, written and practical. During the term students are given fifteen written examinations, and they are also marked by five instructors in the different lines of piactical work. This includes the running of the separators, cream ripening, butter-making, cheesemaking, and milk testing. The students are marked on the seale of one hundred as perfect and sixty as failing to pass. At the close of the term a written stateinent, signed by the dean, will be furnished, giving the work performed and his standing, as shown by the examinations. No statement of standing will be given except to students who have attended the full term and who have taken all the examinations.

\section{FACTORY AND ADIANCED DAIRY INSTRLCTION.}

Opportunity is offered for dairy instruction along theoretical and practical lines at other seasons of the year than during the session of the Dairy School.

This instruction will embrace the two following lines of work :-

1. Practical creamery work.

2. Advanced dairying.

\section{PRACTICAL INSTRUCTION.}

During that part of the year in which the Dairy School is not in session a limited number of young men without previous fuctory training will be accepted as "fuctory pupils" in our creamery, coming for the purpose of preparing themselves thoroughly for the Dairy School instruction given in the winter.

A circular deseribing this work will be sent to any one applying for it.

Opportunity will also be given for students who have taken the Dairy Course or its equivalent to continue practical work in special lines. The University makes no charge for this instruction, nor will it pay anything to the pupil for the work he may do. 


\section{ADIANCEI) DAIRY INSTRECTION.}

Work in the following lines is offered to students whose previous training, as determined by exuminations, enables them to carry on advanced work advantageously.

The aim of the advanced course is to prepare the student for the duties of instructor in dairying or to assume responsible positions in advanced practical dairy lines.

Dairy Bacteriology, by Dr. H. L. Russell. This course begins at the opening of the university year, Sept. 29, 1898, and continues until IIarch, 1899. It will consist largely of laboratory work supplemented with lectures and collateral reading. Only students thoroughly familiar with the compound microscope will be admitted.

The fee for this course is $\$ 8.00$, which covers use of microscope and cost of materials.

DAIRY Chemistry, by Dr. S. M. Babeock. Laboratory instruction in chemical analysis of dairy products. Previous training in chemical manipulation will be required of students admitted to this course. This instruction is given from the close of the Dairy School term until July. The fee for this course is $\$ 5.00$.

Experimental Dairying, by Prof. E. H. Farrington. Experiments of various kinds are in progress at all times. Students who have had sufficient training will be allowed to take part in this work, which includes tests of various machines, apparatus, and methods.

\section{DAIRY CERTIFICATES.}

To secure a dairy certificate the candidate must have spent a full term with us and passed a satisfactory examination in all the sub-courses. A standing below sixty in any one examination makes the student ineligible to a dairy certificate. Further, he must have worked in a creamery or cheese factory for two seasons of not less than seven months each. One of these seasons must follow the period spent with us, and during this time the candidate must have practical charge of the factory in which he is working. He will report the operations of his factory monthly, or as often as directed, on proper blanks furnished by the university. The university holds the right to send an authorized person to inspect the factory of the candidate, and no certificate will be issued if an unfavorable report is made by the inspector. If all of the conditions are satisfactorily complied with, the candidate will receive a dairy certificate. Owing to the expense of inspection, the university does not agree to grant certificates to students operating factories in other states.

\section{SHORT COLRSES IN AGRICULTURE.}

Many, and perhaps most of the Agricultural Colleges have what are termed "Short Courses in Agriculture." These short courses are intended for the benefit of ambitious young (and old) men and women who feel the need of more knowledge than they possess, and yet do not expect to take a full college course. They are usually planned either for one or two terms of three or four months. The terms usually begin in November and end in March. "Twoyear courses" usually mean two terms attended in successive years. There are no entrance examinations and no educational requirements for admission except a common-school education and sufficient maturity to enable the student to deal with the subject presented. In some states they are largely attended, and students with gray hair and spectacles are not at all uncommon.

The courses vary greatly, according to the requirements of the agricultural industries of the state and the equipment of the college. In a great dairy state 
that industry would be made most prominent, and in a stock-raising state the kindred industry of cattle breeding and management, while in grain-growing and herticultural states those interests would appear most prominently. It is therefore not desirable to give any actual course, lest it should be misunderstood by the casual reader to be the usual course, when, as a matter of fact, there may be no two colleges in the country which give the same course. The proper thing is for any one desiring to take a short course in the university to address the director of the Experiment Station of his state, who is always connected with the Agricultural College, and usually the head of it, and ascertain what course is offered. Instruction is usually free to residents of the state. In California, and perhaps other states, no regular "short course" is announced, but any student is welcome to come at any time, take whatever studies be desires and is prepared for, and leave when he chooses, or when he must.

The subjects most suitable for a general short course are AGRICULTURAI PHYsics, including not only the physies of the soil, but the principles affecting the draft of wagons and machinery, the building of country roads, wells, pumps, and windmills, construction of silos, and the like.

PLANT LIFE is a fundamental topic, including seed and its germination and all the process of growth.

Plant Pathology logically follows the study of plant life, dealing, as it does, with diseases of plants, and, usually, their remedies. with

BreEding AND JUDGING LIVE STock of all kinds is a usual topic, together

Feeds AND Feeding, in which the student learns the principles of animal nutrition, and the science of feeding in such a manner as to derive most profit from the outlay.

VETERINARY SCIENCE is naturally included in a study of the care of live stock, and usually forms part of a short course. A two-year (two-term) course would usually include lectures in

Agricultural. Chemistry, of which, in any ease, the student would absorb a good deal.

The Economics of Agriculture is included in the short course of one university, and is likely to appear in more. It deals with such topics as are discussed in this volume.

In different colleges, as already stated, different topics are included. Among them are such subjects as Farm Mechanics, Dairying, Bacteriology, Farm Bookkeeping, Organization of Farms, Entomology, and the like.

No one should imagine that in a course of two terms it is possible to obtain any great mastery of any of these subjects. But the student's eyes will be opened. He will breathe the university air. He will be inspired by contact with earnest and wise men. He will begin to learn how to think, and how to investigate, and if there is anything in him of value, he will be made a student for the rest of his life. 


\section{Appendix C.}

\section{AGRICULTURAL EDUCATION IN THE COMMON SCHOOLS OF NEW YORK.}

The beginnings of systematic instruction in agriculture in the common schools of New York is unique in that it resulted from a popular movement originated and earried through by the farmers themselves. Such movements seldom, if ever, crystallize into law, unless actively promoted by those interested. This involves not merely the adoption of "resolutions," which cost nothing, but the sending of some qualified person to the capital of the state during the session of the Legislature, to press it upon the attention of members of that body until the necessary votes are secured. This costs money, unless some public-spirited person is found able and willing to serve at his own expense, and it is greatly to the credit of western New York that they originated the plan and sent their agent to Albany to attend to the passage of the law. As first enacted the law was local, appropriating a comparatively small sum to be expended, at the discretion of Cornell University. The language of the first act was substantially the same, in this respect, as that of the law of 1899 , which is given below. This general language left the university free to use its judgment as to methods, and the first work was avowedly experimental. The success, however, was so immediate and marked that after the first year or two the appropriation was largely increased, and was directed to be expended "throughout the state," as expressed in the act of 1899 , which is here printed as a model for farmers in other states to work for. Its great value is that it leaves the university authorities untrammeled. Conditions in different states will seldom be the same, and it is wisest to leave the university authorities free to deal with whatever conditions may exist, they being held responsible that interest among farmers shall be actually awakened, and agricultural instruction actually brought to the homes of the people. As the result of the New York law, the director of the Cornell Station lately wrote me that the station was directly influencing more than 200,000 persons.

\section{THE NEW YORK LAW.}

The people of the state of New York, represented in Senate and Assembly, do enact as follows:-

Sectiox 1. For the promotion of agricultural knowledge throughout the state, the sum of $\$ 35,000$, or so much thereof as may be necessary, is hereby 
appropriated out of any money in the treasury not otherwise appropriated to be paid to the College of Agriculture at Cornell University, to be expended in giving instruction throughout the state by means of schools, lectures, and other university extension methods, or otherwise, and in conducting investigations and experiments; in discovering the diseases of plants and remedies; in ascertaining the best method of fertilization of fields, gardens, and plantations; and best modes of tillage and farm management and improvenent of live stock ; and in printing and disseminating agricultural knowledge by means of lectures or otherwise; and in preparing and printing for free distribution the results of such investigations and experiments; and for republishing such bulletins as may be useful in the furtherance of the work; and such other information as may be deemed desirable and profitable in promoting the agricultural interests of the state. Such College of Agriculture may, with the consent and approval of the commissioner of agriculture, employ teachers and experts and necessary clerical help to assist in carrying out the purposes of this bill. Such teachers, experts, and clerical help may be removed by the College of Agriculture in its discretion; and may be paid for their services such sum or sums as maty be deemed reasonable and proper and as shall be approved by the commissioner of agriculture. All of such work by such teachers and experts who shall be employed under this bill shall be under the general supervision and direction of the commissioner of agriculture. The sum appropriated by this act shall be paid by the treasurer of the state upon the warrant of the comptroller to the treasurer of Cornell University, upon such treasurer filing with the comptroller a bond in such sum and with such sureties as the comptroller my approve, conditioned for the faithful application of such sum to the purposes for which the same is herely appropriated. Such sum shall be payable by the treasurer of Cornell University upon vouchers approved by the officers or agents of such university having charge of such College of Agriculture, and such vouchers shall be filed by the treasurer of Cornell University in the office of the comptroller of the state.

SEC. 2. This act shall take effect immediately.

[This act is renewed every year.]

\section{HELPS FOR TEACHERS.}

Under this law actual university work is being carried directly to the homes of the farmers of New York. This is done partly by means of "itinerant schools," conducted for a day or two at a time in rural sehool-houses or elsewhere, by competent persons sent out by the university. The necessity of this work will tend to disappear as rural teachers become better qualified for the work. As an aid to teachers in qualifying themselves the university from time to time issues "leaflets," some of which describe the nature of the work to be done, while others give sample lessons in full. I give examples of both classes of the leaflets, which are, of course, intended for teachers, although they will do the pupils no harm.

\section{A DESCRIPTIVE LEAFLET.}

[This leaflet is entitled “Teacher's Leaflet, No. 6," and was issued by the College of Agriculture, Cornell University, May 10, 1898.]

\section{WHAT IS NATURE STUDY?}

BY L. II, BAILEY.

It is seeing the things which one looks at, and the drawing of proper conclusions from what one sees. Nature study is not the study of a science, as of 
botany, entomology, geology, and the like. That is, it takes the things at hand and endeavors to understand them, without reference to the systematic order or relationships of the objects. It is wholly informal and unsystematic, the same as the objeets are which one sees. It is entirely divorced from definitions, or from explanations in books. It is, therefore, supremely natural. It simply trains the eye and the mind to see and to comprehencl the common things of life; and the result is not directly the acquirement of science but the establishing of a living sympathy with everything that is.

The proper objects of nature study are the things which one oftenest meets. To-day it is a stone; to-morrow it is a twig, a bird, an insect, a leaf, a flower. The ehild, or even the high-sehool pupil, is first interested in things which do not need to be analyzed or changed into unusual forms or problems. Therefore, problems of ehemistry and of physies are for the most part unsuited to early lessons in nature study. Moving things, as birds, insects and mammals, interest children most and therefore seem to be the proper subjects for naturestudy; but it is often difficult to seeure speeimens when wanted especially in liberal quantity, and still more diffieult to see the objeets in perfectly natural conditions. Plants are more easily had, and are, therefore, more practicable for the purpose, although animals and minerals should by no means be excluded.

If the objects to be studied are informal, the methods of teaching should be the same. If nature study were made a stated part of a eurriculum, its purpose would be defeated. The ehiefest diffieulty with our present school methods is the necessary formality of the eourses and the hours. Tasks are set, and tasks are always hard. The only way to teach nature study is, with no eourse laid out, to bring in whatever objeet may be handy and to set the pupils to looking at it. The pupils do the work, - they see the thing and explain its strueture and its meaning. The exercise should not be long, not to exceed fifteen minutes at any time, and, above all things, the pupil should never look upon it as a recitation, and there should never be an examination. It should come as a rest exercise, whenever the pupils become listless. Ten minutes a day, for one term, of a short, sharp, and spicy observation upon plants, for example, is worth more than a whole text-book of botany.

The teacher should studiously avoid definitions, and the setting of patterns. The old idea of the model flower is a pernicious one, simply because it does not exist in nature. The model flower, the complete leaf, and the like, are inferences, and pupils should always begin with things and not with ideas. In other words, the ideas should be suggested by the things, and not the things by the ideas. "Here is a drawing of a model flower," the old method says ; "go and find the nearest approach to it." "Go and find me a flower," is the true method, "and let us see what it is."

Every child, and every grown person too, for that matter, is interested in nature study, for it is the natural method of aequiring knowledge. The only difficulty lies in the teaching, for very few teachers have had any drill or experienee in this informal method of drawing out the observing and reasoning powers of the pupil wholly without the use of text-books. The teacher must first of all feel the living interest in natural objects which it is desired the pupils shall acquire. If the enthusiasm is not catching, better let such teaching alone.

All this means that the teacher will need helps. He will need to inform himself before he attempts to inform the pupil. It is not necessary that he become a seientist in order to do this. He simply goes as far as be knows, and then says to the pupils that he can not answer the questions which be can not. This at once raises his estimation in the mind of the pupil, for the pupil is convinced of his trutbfulness, and is made to feel-but how seldom is the sensation!-that knowledge is not the peculiar property of the teacher but is the right of any one who seeks it. It sets the pupil investigating for himself. The teacher never needs to apologize for nature. He is teaching simply 
because he is an older and more experienced pupil than his pupil is. This is just the spirit of the teacher in the universities to-day. The best teacher is the one whose pupils farthest outrun him.

In order to help the teacher in the rural schools of New York, we have conceived of a series of leaflets explaining how the common objects ean be made interesting to ehildren. Whilst these are intended for the teacher, there is no harm in giving them to the pupil; but the leaflets should never be used as texts to make reeitations from. Now and then, take the children for a ramble in the woods or fields, or go to the brook or lake. Call their attention to the interesting things which you meet-whether you yourself understand them or not-in order to teach them to see and to find some print of sympathy ; fior every one of them will some day need the solace and the rest which this nature love can give them. It is not the mere information which is valuable; that may be had by asking some one wiser than they, but the inquiring and sympathetic spirit is one's own.

The pupils will find their lessons easier to aequire for this respite of ten minutes with a leaf or an insect, and the school-going will come to be less perfunctory. If you must teach drawing, set the pieture in a leaflet before the pupils for study, and then substitute the object. If you must teach composition, let the pupils write upon what they have seen. After a time, give ten minutes now and then to asking the children what they saw on their way to school.

Now, why is the College of Agriculture of Cornell University interesting itself in this work? It is trying to help the farmer, and it begins with the most teachable point, - the child. The distriet school can not teach agriculture any more than it can teach law or engineering or any other profession or trade, but it can interest the ehild in nature and in rural problems and thereby fasten its sympathies to the country. The child will teach the parent. The coming generation will see the result. In the interest of humanity and country, we ask for help.

\section{A SAMPLE LESSON.}

[This is entitled "Teacher's Leaflet No. 1," and was issued by the College of Agriculture, Cornell University, May 10, 1898.]

NotE.-These leaflets are intended for the teacher, not for the scholars. It is their purpose to suggest the method which a teacher may pursue in instructing ehildren at odd times in nature stualy. The teacher should show the children the objects themselves, - should plant the seeds, raise the plants, colleet the insects, etc, ; or, better, he should interest the children to collect the objects. Advanced pupils, however, may be given the leaflets and asked to perform the experiments or make the observations which are suggested. The scholars themselves should be taught to do the work and to arrive at independent conclusions. Teachers who desire to inform themselves more fully upon the motives of this nature-study teaching, should write for a copy of Bulletin 122 of the Cornell Experiment Station, Ithaca, N. Y.

\section{HOW A SQUASH GETS OIT OF THE SEED.}

BY L. H. BAILEY.

If one were to plant seeds of a Hubbard or Boston Marrow squash in loose warm earth in a pan or box, and were then to leave the pareel for a week or ten days, he would find, upon his return, a colony of plants like that shown in Fig. 1. It he had not planted the seeds himself or had not seen such plants before, he would not believe that these curious plants would ever grow into squash vines, so different are they from the vines which we know in the garden. This, itself, is a most

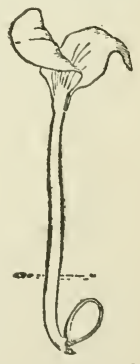

1. $S q u a s h$ plant a week old. 
curious fact, - this wonderful difference between the first and the later stage of all plants, and it is only beeause we know it so well that we do not wonder at it.

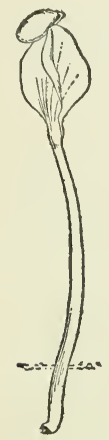

2. Squash plant which has brought the seed-coats out of the ground.

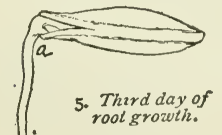

It may happen, however-as it did in a pan of seed which I sowed a few days ago-that one or two of the plants may look like that shown in Fig. 2. Here the seed seems to have come up on the top of the plant, and one is reminded of the curious way in which beans come up on the stalk of the young plant. If we were to study the matter, however-as we may do at a future time-we should find a great difference in the ways in which the squashes and the beans raise their seeds out of the ground. It is not our purpose to compare the squash and the bean at this time, but we are curious to know why one of these squash plants brings its seed up out of the ground whilst all the others do not. In order to find out why it is, we must ask the plant, and this asking is what we eall an experiment.

We may first pull up the two plants. The first one (Fig. 1) will be seen to have the seed coats still attached to the very lowest part of the stalk below the soil, but the other plant has no seed at that point. We will now plant more seeds, a dozen or more of them, so that we shall have enough to examine two or

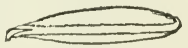

\section{Germination just} beginning.

or two after the seeds are planted, we shall find a little point or root-like portion breaking out of the sharp end of the seed, as shown in Fig. 3. A day later this root portion has grown to be as long as the seed itself (Fig. 4), and it has turned directly downwards into the soil. But there is another most eurious thing about this germinating seed. Just where the root is breaking out of the seed (shown at $a$ in Fig. 4), there is a little peg or projection. In Fig. 5, about a day later, the root has grown still longer, and this peg seems to be forcing the seed apart. In Fig. 6, however, it will be seen that the seed is really being forced apart by the stem or stalk above the peg, for this stem is now growing longer. The lower lobe of the seed has attached to the peg (seen at $a$, Fig. 6), and the seed leaves are trying
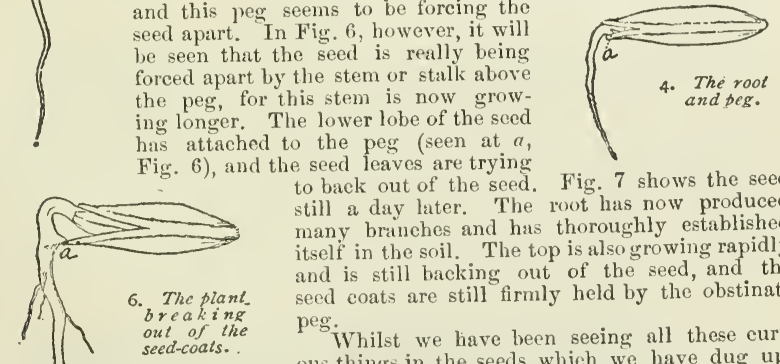
to back out of the seed. Fig. 7 shows the seed still a day later. The root has now produced many branches and has thoroughly established itself in the soil. The top is also growing rapidly and is still backing out of the seed, and the seed coats are still firmly held by the obstinate peg.

iWhilst we have been seeing all these curious things in the seeds which we have dug up, the plantlets which we have not listurbed have been coming through the soil. If we were to see the plunt in Fig. 7, as it was "coming up," it would look like Fig. 8. It is tugging away trying to get its head out of the bonnet which is pegged down underneath the soil, and it has "got its back up" in the operation. In Fig. 9 it has escaped from its trap and it is laughing and growing in delight. It must now 


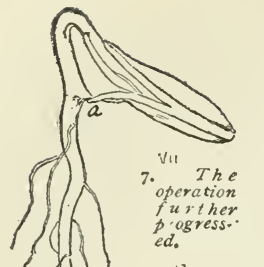

strengthen itself up, as it is doing in Fig. 10, and it is soon standing proud and straight, as in Fig. 1. Te now see that the reason why the seed came up on the plant in Fig. 2 is because in some way the peg did not hold the seed coats down (see Fig. 13), and the

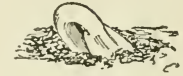

8. The plant just. coming $u p$. expanding leaves are pinched together, and

they must get themselves loose as best they can.

There is another thing about this curious squash plant which we must not fail to notice, and this is the fact that these first two leaves of the plantlet came out of the seed and did not grow out of the plant itself. We must notice, too, that these leaves are much smaller when they are first drawn out of the seed than they are when the plantlet has straight. ened itself up. That is, these leaves increase very much in size after they reach the light and air. The roots of the plantlet are now

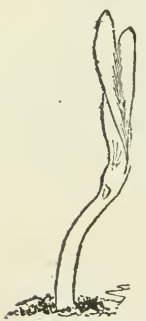

10. The plant straightening $u p$. established in the soil and are taking in food which enables the plant to grow. The next leaves which appear will be very different from

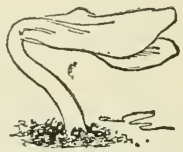

9. The plant liber. ated from the seedcoats. these first or seed leaves.

These later ones are called the true leaves. They grow right out of the little plant itself. Fig. 11 shows these true leaves as they appear on a young crookneck squash plant, and the plant now begins to look much like a squash vine.

We are now curious to know how the stem grows when it backs out of the seeds and pulls
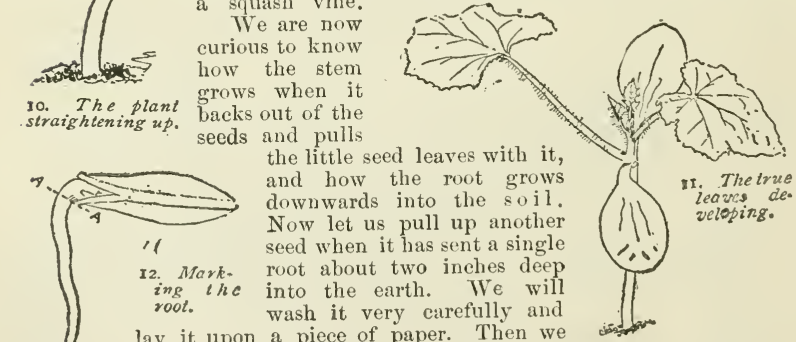

the little seed leaves with it, and how the root grows downwards into the soil. Now let us pull up another seed when it has sent a single root about two inches deep into the earth. IVe will wash it very carefully and lay it upon a piece of paper. Then we
will lay a ruler alongside of it, and make
an ink mark one-quarter of an inch from the tip, and two or
three other marks at equal distances above (Fig. 12). * We will
now carefully replant the seed. Two days later we will dig it

"NOTE.-Common ink will not answer for this purpose because it "rums" when the root is wet, but indelible ink, used for marking linen or for drawing, should be used. It should is wet, but indelit the root of the common pumpkin, and of the summer bush squasnes, is also be said that the root of the common should be stated, also, that the root does not grow too fibrous and branchy for this test. It should be stated, also, that the root does not gut the determination of at its very tip, but ehiefly in a narrow zone just back of the tip; but the determination of of this tract. 
up, when we shall most likely find a eondition something like that in Fig. 13. It will be seen that the marks $\mathrm{E}, \mathrm{C}, \mathrm{B}$, are practically the same distance apart as before, and they are also the same distance from the peg $\mathrm{A} A$. The point of the root is no longer at DD, however, but has grown on to F. The root, therefore, has grown almost wholly in the end portion.

Now let us make a similar experiment with the stem or stalk. We will

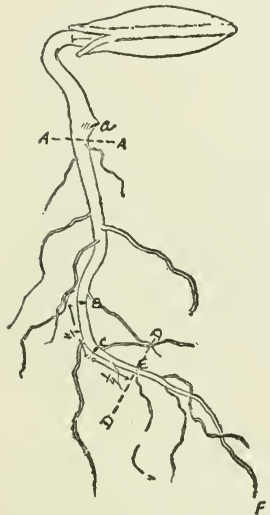

13. The root grows in the end portions.

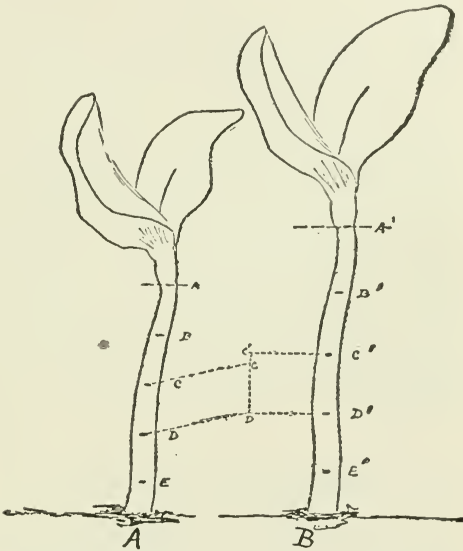

14. The marking of the stem, and the spreading apart of the marks.

mark a young stem, as at $\mathrm{A}$ in Fig. 14; but the next day we shall find that these marks are farther apart than when we made them (B, Fig. 14). The marks have all raised themselves above the ground as the plant has grown. The stem, therefore, has grown between the joints rather than from the tip. The stem usually grows most rapidly, at any given time, at the upper or younger portion of the joint (or internode); and the joint soon reaches the limit of its growth and becomes stationary, and a new one grows out above it.

Natural science consists in two things, - seeing what you look at, and drawing proper conclusions from what you see.

Of course it will be understood that the idea of "nature study" did not originate at Cornell University. Nature study has been the dream of the best teachers for a century, and perhaps always, and of late years is made prominent in all the best schools. Its value as a preparation for life on the farm is also sufficientiy obvious, and was pointed out long before Cornell University took up the work. The credit due to Cornell University is that of being the first to actually carry out the work on a great scale, and of putting it in forms so 
attractive and clear as to at once excite interest and carry conviction. I do not know, in history, of any other such success in popularizing the best form of educational work.

In addition to this work carried on directly with the common schools, a farmers' reading course wus established, on the "Chautauqua plan," which, in 1898 , had a membership of four thousand eight hundred, and was rapidly increasing. This course occupies four winters, and leads to a certificate to all who complete the course and pass the examinations. In this way real university education is brought to the very doors of the farmers. $A n$ interesting feature of the Cornell work is the organization of children of rural districts into "Cornell Junior Nationalists' Clubs," for the purpose of promoting systematic study of natural objects.

While Cornell University, as the leader in this work, is entitled to the recognition here given, it must not be supposed that it is any longer alone in it. Its great success has stirred the whole country, and universities and normal schools everywhere are every day putting more stress not only upon nature study, but upon its importance as a foundation for successful work on the farm. The facts here given are intended as a stimulus to such farmers as may see them, to lead them to appreciate the economic value of the work, and aid the authorities of their own states in establishing it among themselves, or to demand it, as the farmers of Western New York did, if the authorities are not acting.

\section{AGRICULTURAL EDUCATION IN FOREIGN COUNTRIES.}

Space permits only such reference to agriculture in foreign countries as may serve to disabuse any minds of the impression that systematic instruction in agriculture is a new thing, or peculiar to the United States. Although we are now doing more in this direction than any other country, we were by no means the earliest in the field. Agricultural instruction in schools of all grades dates back, in several countries of Europe, to the early part of the nineteenth century, and perhaps longer. On the continent of Europe there is perhaps no country in which provision is not made for agricultural instruction wholly, or more usually partly, at public expense, and in many it begins in the public schools. Information on this point may be had by those interested in the later reports of the United States Commission of Education, nearly all of which have more or less reference to the subject. These reports can be found in any considerable public library. In this, as in other respects, each country develops according to its necessities and the character of its people. The principles involved must be the same everywhere, but the methods both of procedure and administration will difler. For Americans, up to the present time. the best example is unquestionably that of the state of New York, and naturally so since it is our richest state, and can spend most money in this direction. Not all our states can yet do what New York is doing, but a somewhat careful study of whatever $\mathrm{I}$ have been able to find as to agricultural instruction abroad suggests nothing of value for imitation which will not be found in the work of Now York and all other states which are following her lead. 


\section{Appendix D.}

\section{HOW TO OBTAIN PUBLIC DOCUMENTS.}

Agricultural literature is of three kinds:-

1. Elaborate reports, or similar doeuments, usually eontaining exhaustive statements of facts, with statistical tables, diagrams, maps, and more or less discussion. The preparation of such papers is very expensive, owing to the great amount of valuable time employed, and the cost of the experiments or surveys of which they give the results. Such papers are properly ealled "authorities," beeause they contain the results of original research, properly authenticated. They supply the faets upon which discussion proceeds. The facts contained in these documents would never be collected at private expense, nor would any publishing house undertake to print them. They are almost exclusively government publieations. Tery valuable statisties are gathered by leading trade organizations in regard to prices and crops.

This most expensive of all literature can usually be had, postage free, for the asking, provided the proper authorities are satisfied that good use will be made of what is asked for. The editions, however, are usually limited. Such books can usually be found in all large libraries.

2. Brief monographs, usually ealled "bulletins" or "circulars," giving the gist of existing information on a single topic, and usually intended for popular reading. The most notable of these are the "Farmers' Bulletins," published by the United States Government and the Bulletins of the Experiment Stations. Nearly all such publications ean be obtained free, although some of those published by the United States are sold at cost.

State publications are usually, and perhaps always, sent free, upon applieation, to residents of the state. Where possible state officials will usually send them to applieants residing in other states. To obtain state documents it is only necessary to address the state " hureau," "eommission," "board," or "department," which issues them, stating what is desired. It is not necessary to know the name of any official, although, when known, it may be used. The address of these bodies is nearly always at the eapital of the state. It is the business of a good farmer to know, as to his own state, the proper titles of the officers issuing publications, and to address them for any publication desired.

Experiment Stations, although mainly supported by the United States, are considered, in respect to publications, as state institutions. They are under no legal obligation to send their publications outside the states in which they are located, and a few of them are rather illiberal in that respect. For the most part, however, the Experiment Stations send their publications to all applicants, wherever located. All Experiment Stations, probably, keep lists of 
addresses of farmers within the state, to whom the station publications are mailed, regularly, as they appear, and without application. Any one may have his name placed on that list, by sending it, with his address, to the station. Many state boards, and perhaps all, pursue a similar course. All farmers should get their names onto all such lists.

In writing to Experiment Stations for publications, or for information, it is always as well, and frequently best, to use no name of any official. He may be absent, or have left the institution, and the letter remain a long time unanswered. The better form of address is, "Director U. S. Agricultural Exp. Station."

The location of the stations does not change, and there is always a director. $\mathrm{He}$ will receive the letter, and send the publication asked for, or, if it is a request for information, refer it to the proper member of the staff for reply.

The following is a list of the United States Agricultural Experiment Stations, with the name of the college or university with which each is connected.

LOCATION OF EXPERIMENT STATIONS AND AGRICULTURAL

COLLEGES.

State.

Alabama

CaNEBRAKE STATION

Arizona Sub-station

ARKANSAS

CALIFORNIA

SUB-STATIONS

Forestry Stations

Colorado

Connecticut

DELAWARE

Florida

Georgia

IDAIIO

ILLINOIS

INDIANA

IowA

KANSAS

KENTUCKY
Post-office.

Auburn

Uniontown

Tucson, Phønix

Fayetteville

Berkeley

Paso Robles

Tulare

Jackson

Chino

S Chico

Santa Monica

Fort Collins

New Haven

Storrs
Name of college with which station is connected.

Agricultural and Mechanical College of Alabama.

University of Arizona.

Arkansas Industrial University. University of California.

Agricultural College of Colorado

Storrs Agricultural College.

(These stations are independent of each other.)

Newark

Lake City

Experiment

Moscow

Urbana

Lafayette

- Ames

Manhattan

Lexington
Delaware College.

Florida Agricultural College.

Georgia State College of Agriculture and Mechanic Arts.

University of Idaho.

University of Illinois.

Purdue UUniversity.

Iowa State College of Agriculture and Mechanic Arts.

Kansas State $\Lambda$ gricultural College.

Agricultural and Mechanical College of Kentucky. 
State.

Post-office.

Name of college with which station is connected.

LOUISIANA

No. 1, Sugar Exp. Audubon Park, Station

No. 2, State Exp.

No. 3, North Louisiana

Exp. Station

MAINE

MARYLAND

MASSACHUSETTS-

(State Station)

Hateh Station

MICHIGAN

MiNNemota

MIRSISSIPPI

MINROURI

Montaxa

Nebraska

NeVADA

New HaMpshire

NEW JERsEY-

(State Station)

(Ag. College Station)

NEW Mexico

New York-

(State Station)

(Cornell Station)

North Carolina

North Dakota

OHIO

OKLAHOMA

OREGON

Pennsyltania

Rilode IsLaNd

South Carolixa

South Dakota

TEXNESSEE

Texas

UTA H

Vermont

VIrginia

WASHINGTON

W EST VIRGINIA

Wisconsin

W YOMING

New Orleans

Baton Rouge

Calhoun

(Orono

College Park

Amherst

Amherst.

Columbia

Bozeman

Lincoln

Reno

Durham

New Brunswiek

New Brunswick

Mesilla Park

Geneva

Itbaca

Raleigh

Fargo

Wooster

Stillwater

Corvallis

State College

Kingston

Brockings

Knoxville

College Station

Logan

Burlington

Blacksburg

Pullnan

Morgantown

Madison

Laramie

$$
\text { College. }
$$

Agrieultural College Michigan Agricultural College. St. Anthony Park University of Minnesota.

Agricultural College Mississippi Agricultural and Mechanical College.

University of Missouri.

Montana Agricultural College. University of Nebraska.

Nevada State University.

New Hampshire College of Agriculture and the Mechanic Arts.

Clemson College
At Rutgers College.

Rutgers College.

New Mexico College of Agriculture and the Mechanic Arts.

Cornell University.

North Dakota Agricultural Col.

Oklaboma Agricultural and Mechanical College

Oregon State Agricultural Col. Pennsylvania State College.

Rhode Island College of Agriculture and Mechanic Arts.

Clemson Agricultural College.

South Dakota Agricultural Col.

University of Tennessee.

Agricultural and Mechanical College of Texas.

Agricultural College of Utah.

University of Vermont.

Virginia Agricultural and Mechanical College.

Washington Agricultural Col.

IVest Tirginia University.

[ niversity of $\mathrm{W}$ isconsin.

University of $\mathrm{W}$ yoming.

The process of obtaining United States publications is somewhat less simple, as there are several avenues through which they may be obtained. 
Publications of speeial value to farmers are published mainly by the Departments of State, the Interior, and Agriculture.

The Department of State issues a monthly publication called "Consular Reports." It is regularly sent, free, to all who apply for it. The majority of the monthly numbers contain matter of great importance to farmers in the way of information as to what their competitors in foreign lands are doing. To obtain the "Consular Reports," address Secretary of State, Washington, D. C., and ask to have it sent. Be sure to specify "monthly edition," as there is a daily edition of the same matter. The daily edition is intended for editors and is not in form for preservation.

The Department of the Interior (Geological Survey) issues reports and papers in regard to water supply and irrigation, which are distributed free. These documents must be applied for, by title, as they appear. Address Secretary for the Interior, Washington.

The Department of Agriculture publishes a great number of documents for farmers, of which most may be obtained, free, from the Secretary of Agriculture or Senators and Representatives in Congress. Some, however, can not be obtained free, but must be purchased of the Superintendent of Publie Documents. The Department of Agriculture issues a monthly list of its publications. Any person can have this document mailed to him, regularly, upon application to the Secretary. This is the only document of the Department of Agriculture regularly mailed free to anybody. All other publications must be applied for by title. But one copy of any document will be mailed to a single address.

The following suggestions will be found useful to those desiring to obtain the publications of this department:-

(a) Send on your name to receive the "Monthly List of Publications."

(b) Apply for such as you desire as soon as you reeeive the list. Editions are often small, and become exhausted.

(c) If ordering of the Superintendent of Public Documents, do not send stamps in payment. The government sells stamps but does not buy them back. They will not be reeeived under any circumstances.

(d) The "Year Book" of the Department of Agriculture can never be obtained of the department by individuals. Apply to a Senator or the Representative from your congressional district. During sessions of Congress, they should be addressed at Washington. Address Hon._—_ Senate Chamber (or House of Representatives), Washington, D. C. When Congress is not in session they should be addressed at their homes. The "Farmers' Bulletins," also, are mainly distributed * by Senators and Representatives, although these may sometimes be obtained from the department.

* This distribution of documents (and seeds) is a fine example of the manner in which "humbug" is employed to influence farmers. The farmer receives a bulky package, nuder the "frunk" of his representative, and is pleased to know that the distinguislied gentleman has him in mind. He easually mentions the fact to his friends, and is inelined to the belief that they have a good man in Washington. He may or may not read the books or plant the seeds. As a matter of fuct, the Congressman has probably purchased a list of names from those who compile them for sale to other advertisers, and which his elerk sends to the docnment or sued room, where the clerks send out what he orders under his frank. It is very wasteful. 
(e) The monthly list of publieations always tells how to get the books published in the month of its issue. There is no way to find out how to get older publications, or whether any have been issued upon any subjeet, or whether or where they ean be had, if at all, exeept to write to the Seerctary of Agriculture and ask.

( $f$ ) Postage must be paid on all communications addressed to government officials.

The following is the official statement of the department in regard to its publications :-

\section{NOTES REGARDING DEPARTMENT PUBLICATIONS.}

The publications of the United States Department of Agriculture are of three classes: (1) Serial publications; (2) scientific and technical reports; and, (3) popular bulletins.

The first two classes are issued in limited editions and are not intended for general distribution, being particularly designed for scientific students and for libraries and institutions of learning. They are distributed free to persons cooperating with or rendering the department some service. Sample copies will be sent if requested, but miscellaneous applicants should apply to the Superintendent of Documents, Union Building, Washington, D. C., to whom all publications not needed for official use, except circulars and bulletins printed by law for free distribution, are turned over in aecordance with the following provision of the act providing for the publie printing and binding and the distribution of public documents, viz.:

SEction 67. All documents at present remaining in charge of the several Executive Departments, bureaus, and offices of the government not required for official use, shall be delivered to the Superintendent of Documents, and hereafter all public documents be delivered to the Superintendent of Documents, and hereafter all public documents accumulating in said departments, bureaus, and offices not needed for official use shatl
be annually turned over to the superintendent of Doeuments for distribution or sale.

The Farmers' Bulletins treat in a practical manner of subjects of particular interest to farmers, and are issued with a view to the widest possible circulation. These bulletins and cireulars of information are free, two-thirds of them being set aside under the law for distribution through senators, representatives, and delegates in Congress. Applications may be addressed to the Secretary of Agriculture, stating both the number and title of the publieation desired.

The department has no list to whom all publications are sent; the variety of the subjects treated naturally restricts the distribution of most of them to the sections of eountry to which they are especially suitable and to specialists. The Ionthly List of Publications, issued the first of each month, will be mailed to all who apply for it. In it the titles of the publications are given, with a note explanatory of the ebaracter of each, thus enabling the reader to make intelligent application for sueh bulletins and reports as are certain to be of interest to him.

The department ean not undertake to furnish complete sets of either Farmers' Bulletins or other publications.

For the pablieations of the Weather Bureau, requests and remittances should be directed to the Chief of that bureau.

For publications mentioned in the Monthly List preceding, to which a price is attached (with the exeeption of those issued by the Weather Bureau), application must be made to the Superintendent of Documents, Union Building, Washington, D. C., accompanied by the price thereof as fixed by him in accorddance with the provisions of sections 61 and 67 of the net providing for the public printing and binding, and the distribution of public documents, approved January 12,1895 , and all remittances should be made to him and not to the Department of Agriculture; such remittances should be made by postal money order and not by private eheck or stamps. 
The Superintendent of Documents is not permitted to sell more than one copy of any public document to the same person.

The Superintendent of Documents is not an official of the Department of Agriculture.

A pplications for all other publications of this department should be addressed to the Secretary of Agriculture, Washington, D. C.

Do not inclose stamps when writing to the department about publications; it is not necessary in order to secure a reply.

Please advise the department of any change of address.

In all cities where there are free or other large public libraries, they can, upon establishing their standing and capacity for storage, be made "depositories" of public doctuments, to which copies of all publications are sent. Farmers living near any such library, or in most cases any college or university, will find sets of publie documents.

Granges, or other organizations of farmers whose secretary will take the trouble to keep watch of what the government or state publishes, and apply for them promptly, may very soon collect an exceedingly valuable library; that is, it will be valuable if kept strictly for reference, properly arranged and accessible. If loaned out to members, who can each get the books for themselves by applying, they will be scattered and lost. If piled up in heaps under benches, and covered with dust, they are of no value. It will not pay any Grange to start a reference library unless it is certain that members will use it. A reference library involves a great deal of work, and in two or three years, may come to occupy a great deal of space. Some one must be in charge of it, know what is in it, and where to look for what is wanted.

The state and United States publications are of the utmost value to farmers, and should be made use or.

3. The third class of books for farmers includes formal treatises on sueh subjects as soils, irrigation, fertilizers, fruit-growing, dairying, and the like, and special treatises on the cultivation of different crops, as tobacco, cotton, the sugar beet, etc. This class of subjects is fairly well covered by government bulletins on these subjects, but to the real student no brief bulletin can take the place of a thorough treatise. The bulletins are printed and distributed at public expense because it is in the public interest that farmers should learn how to reduce costs of production, and they can seldom be induced to expend money for that purpose. The more these brief bulletins are circulated, however, the greater will be the demand for the more extensive information which is supplied by the many excellent books upon the various branches of husbandry which are now rapidly issuing from the press. All books of this lass are issued by private publishers, and must be purchased.

\section{A FEW BOOKS OF INTEREST TO FARMERS}

The following list of books on various brunches of husbandry and its related sciences, will be found convenient. There are grent numbers of such looks, and I have simply chosen from those with which 1 happen to be familiar. The selection, under each head, will be found to cover the subject fairly well for the general reader. The absence of auy good book published in this coun. try from the list, merely shows that I am not personally familiar with it, or 
that it is too extensive or abstruse for popular reading, or too expensive, or, possibly, that it has been published many years, and may be out of print, or likely to be soon superseded. The books named here are standard works, easy to read and understand.

All these books can be obtained at the prices named, either by ordering from the nearest book store or by remitting the amount direct to the publisher, who will send them postage paid.

I have roughly classified the publications under some of the headings of the Books of this volume. Subjects run into each other so much that no exact classification can easily be made.

\section{THE LARGER ASPECTS OF FARM LIFE.}

This Book consists of a brief exposition of accepted opinion as to the social tendencies of our race. Literature upon this subject is abundant, if not excessive, but I know of no publication, other than the brief statement of the text, which singles out the farmer and his interests for special discussion. The reader, however, who desires to look into the subject more deeply may be aided by the following suggestions:-

The doctrine which we call Evolution is a growth which blossomed and fructified in the writings of Charles Darwin, ${ }^{*}$ whose patient investigations, extended over many years, supplied the first data which were generally accepted as an adequate physical basis of the doctrine. His conclusions, advanced tentatively, and with a modesty unusual even in a great scholar, have been abundantly justified by the results of the labors of two generations of investigators, but his great book-" The Origin of species "- has never been superseded, and is not likely to be. The student who desires to acquire any adequate conception of the doctrine of evolution as applied to the moral, social, and spiritual world, will do best to begin with the "Origin of Species." There must be some basis of fact upon which to reason intelligently. This is best supplied by a study of the physical history of the development of the existing forms of vegetable and animal life; and the original study, when confirmed, as in this case, by the observations of all later observers, is always the best. It has a certain life which is necessarily wanting in all subsequent discussion.

"The Origin of Species" may be obtained in the United States in editions as stated below.

The collection and digestion of the facts which form the physical basis of evolution possibly mark the limit of the powers of the human intellect in that direction. The phenomena of social evolution are so vast and varied that it seems impossible to collect, classify, and comprehend them in any such manner as to make of them a sound basis of inductive reasoning. Mr. Herbert Spencer ("Principles of Sociology ") has done, perhaps, all that can be done in this direction, but it does not satisfy the mind as do the physical facts collected by Darwin and his successors. To me, and probably to most men, the doctrine

* Mr. Darwin was by no means the first to advocate the doctrine of evolution of species. 
of social evolution is not an induction from observed facts, but is, rather, inferred, deductively, from the general course of history, and from the conviction that one plan runs through all the operations of the universe.

And yet there is no doctrine more firmly implanted in human conviction than that which teaches that all human progress is the result of irresistible natural forces, operating by immutable natural laws, to produce inevitable results. While perhaps incapable of demonstration in any scientific sense, this seems to accord with all human experience. The doctrine has passed into the current thought of the people.

There is great danger in that doctrine. However true it may be, it is still dangerous. It tends to fatalism, and to the belief that man is controlled by his environment and is irresponsible. The social force is the result of the social will. The social will is the aggregate of the individual wills. The individual will is what the individual makes it. Each individual is therefore responsible for a fixable quantity of the social will and social force, and to the extent that his will is good or evil he changes the course of human progress. If he is a mighty man his infuence is mighty. Cresar, Napoleon, Wilberforce, Lincoln, Moody were tremendous influences of social force. If the man is trifling his influence is trifling. But whether weak or mighty the responsibility of the man is the same. Man is influenced by his environment, but not controlled by it. And he largely creates his environment. It is unhealthy for men to come to think otherwise than this, and I an unwilling to advise general readers to study social evolution without warning them against inferenees not justified by facts, and which educated evolutionists do not make.

As I write this upon a railroad train I overhear two brutes, sitting in front of me, talking disgustingly. They are in human form, well dressed, with delicate hands, evidently with money to spend. Hardly a word that they say could be printed. When they turn their faces to me I see that they are degenerates. I recognize that the extinction to which they are hastening is desirable for mankind, and merciful to thenselves. They are corrupting each other as they talk, and doubtless eorrupt many whom they meet. Their own bad wills have made them what they are, and they change the aggregate of existing social force in ways for which they are responsible. Evolution does not teach fatalism.

If the general reader who has become familiar with Darwin's great work will then obtain a copy of Dr. Jordan's "Foot-notes on Evolution," he will be as well equipped as is necessary for appreciating current forms of reasoning upon social topies. If he wishes to go further, and is prepared to do some rather hard thinking, he ean perhaps do no better than to get two books which have had a wide cirenlation in Ameriea, namely, "Kidd's Social Evolution," with which he may or may not fully agree, and "Drummond's Ascent of Man." Those who have well read all the foregoing books, will find themselves thereby introduced into a great sea of literattre upon social topics, over which they need no further guidanee from me.

The titles, publishers, and prices of these books are as follows:-

Tire Oriarn of Species,-By Charles Darwin. D. Appleton \& Co., New York. Price, $\$ 2.00$. 
The same, a cheaper edition, published by A. L. Burt \& Co., 97 Reade Street, New York. Price, 75 cents.

Foot-notes on Evolution.-By David Start Jordan, president of Leland Stanford Jr. University. D. Appleton \& Co., New York. Price, \$1.75.

Social Evolition.-By Benjamin Kidd. The IIremillan Company, New York. Price, \$1.50. Paper cover, 25 cents.

The Ascent of Man,-By Henry Drummond. James Pott \& Co., 119 West Twenty-third Street, New York. Price, $\$ 1.00$.

\section{THE FARUERS' EDUCATION.}

A eareful reading of the books named in the following list will go far to make one an edueated farmer. It is a good selection of late books on many farm topics. Upon some practical subjects I know of no books which I am willing to recommend.

\section{Nature Study.}

Lessons with Plants.-By Prof. L. H. Bailey. The Maemillan Company, New York. Price, $\$ 1.10$ (postage in addition).

Tine Great World's Fakm. - By Selina Gage. The Macmillan Company, New York. Price, \$1.50.

\section{Theory and Practice of Husbandry.}

THE RURAL SCIENCE SERIES.

All the books of this series are published by Macmillan \& Co., New York, under the editorial supervision of L. H. Bailey, Professor of Horticulture in Cornell University. Each book is written by a specialist in the subject treated. New volumes are constantly added to the series, and readers will be entirely safe in ordering them as they appear. The numbers issued or announcol at the time this book is published are as follows:-

Tнк Sorl.-By Prof, F. H. King. Price, 75 cents.

Tie Fertility of the Laxd.—By Prof. I. P. Roberts. Price, \$1.25.

Tile Principles of Agriculture.-By Prof. L. H. Bailey and others. Price, $\$ 1.25$.

Fertilizers.-By Prof. E. B. Voorhees, Priee, $\$ 1.00$.

Principles of Fruit-growing.-By Prof. L. H. Bailey. Price, \$1.25. The Sprayixa of Plants.-By Prof. E. (千. Lodeman. Price, $\$ 1.00$.

The Horticulturalists' Rule Book,-By Prof, L. II. Bailey. Price, 75 cents.

The Erolution of Our Native Fruits.-By Prof. L. H. Bailey. Price, $\$ 2.00$.

The Prunixg Book.-By Prof. L. H. Bailey. Price, $\$ 1.50$.

The Foreing Book.-By Prof, L. H. Bailey. Price, $\$ 1.00$.

Garden Making._By Prof. L. H. Bailey and others. Price, $\$ 1.00$.

Busir Fruits,-By Prof. F. W. Card. Price, $\$ 1.50$.

The Nursery Book.-By Prof. L. H. Bailey. Price, $\$ 1.00$.

The Survival of the Unlike (Philosophy of Plant Development). - By Prof. L. H. Bailey. Price, $\$ 2.00$. 
Plaxt Breeding.-By Prof. L. H. Bailey. Price, $\$ 1.00$.

Milk and Its Products, - By Prof. H. H. Wing. Price $\$ 1.00$.

Principles of tile Breeding of Animals.-By Prof. W. H. Brewer.* Tile Physiology of Plants.-By Prof. J. C. Aerthen.*

There are announced for this series the following, all by specialists in their subjects :-

Plaxt Pathology.

Seeds and Seed Growing.

Leguminous Plants and Nitrogen Gathering.

Irrigatron and Drainage.

Rural Wealth and Welfare.

Farm Poultry.

The Rural Science Series, so far as issued, is the most valuable collection of books on rural topics in the English language. There is no reason to doubt that the volumes to follow will be of equally high character.

Other Books on Farm Topics.

How Crops Feed.-By Prof, S. W. Johnson, Orange Judd Co., New York, 1890. Price, $\$ 2.00$.

How Crops Grow.-By Prof. S. W. Johnson. Orange Judd Co., New York, 1868. Price, $\$ 2.00$.

These two books by Professor Johnson, of Yale University, are standard books on their subjects, but, like nearly all books of their class, published more than ten years since, devote more space to pure science than is now thought desirable.

Agriculture in Some of Its Relations with Chemistry.-By Prof. F. H. Storer. Charles Scribner's Sons, New York. In two volumes. Price, $\$ 5.00$. This, like the two volumes immediately preceding, is a standard work, requiring careful thought. There are many excellent books of the same class, but upon the whole it seems to me that the more modern books of general agriculture are likely to be more helpful to the modern farmer. They usually go right to the pith of farm practice, introducing only so much of science as is necessary to illustrate the subject in land.

\section{Horticulture.}

Califoria Vegetables,-By Prof. E. J. Wickson. Pacific Rural Press, San Franciseo, 1897. Price, $\$ 2.00$.

Califorvil Frults.-By Prof. E. J. Wickson. Pacific Rural Press, San Francisco, revised edition, 1899. Price,

These are the standard books for Pacific Coast practice, which, in many respects, differs from eastern practice. A new edition of California Fruits is in preparation, to be issued during the season of 1899 .

Tre Raisix Ixpustro.-By Gustave Eisen. H. S. Croeker \& Co., San Francisco, 1890. Price, $\$ 2.00$.

* Not yet published. May, 1s99. 
Grape Culture and Wine Making.-By Prof, Geo. Husman. Payot, Upham \& Co., San Francisco, 1887. Price, $\$ 2.00$.

(This should be supplemented by later publications of the University of California, on varieties and resistant vines.)

The Amerifin Fruits,-By John J. Thomas. Wm. Wood \& Co., New York, Revised 1897. Price, \$2.50.

The Nut Culturist.-By Andrew S. Fuller. Orange Judd Co., New York, 1896. Price $\$ 1.00$.

\section{Dairying.}

The Darryan's Mavual.-By Henry Stewart. Orange Judd Co., New York, 1888. Price, $\$ 2.00$.

American Dairying.-By H. B. Gurler. The J. H. Sander's Publishing Co., Chicago, 1894. Price, $\$ 1.00$.

Testing Milk and Its Pronucts.-By Prof, E. H. Farrington and Prof. F. W. Woll. Price, $\$ 1.00$.

A B C in Cheese-making,-By J. H. Monrad. Orange Judd Co., New York, 1894. Price, 50 cents.

Outlines of Dairy Bacteriology.-By Prof. H. L. Russell. Orange Juçd Co., New York, 1898. Price, $\$ 1.00$.

\section{Livestock.}

Feeds and Feeding. By Prof. W. A. Henry. Published by the author, Madison, Wis. Price, $\$ 2.00$.

Stock Breeding.-By Prof. Manley Miles, D. Appleton \& Co., New York, 1883. Price, $\$ 1.50$.

The Domestic Sheep.-By Henry Stewart. American Sheep Breeder, Chicago, 1898. Price, $\$ 1.00$.

American Horses and Horse Breeding.-By John Dimon. Olange Judd Co., New York, 1895. Price, \$3.50.

American Cattle. By Lewis F. Allen. Orange Judd Co., New York. Price, $\$ 2.50$.

Swine Husbandry.-By F. D. Coburn. Orange Iudd Co., New York, Price, $\$ 1.75$.

\section{Poultry.}

The American Standard of Perfection in Poultry,-Price, \$1.00. (This book is published and revised from time to time, by the American Poultry Association. It describes the "points" of all recognized breeds. It may be obtained from the Orange .Judd Co., New York.)

\section{Bees and Bee-keeping.}

A Practical Treatise on tile live and Honey Bee.-By L. L. Langstroth, 1859, revised. Price, \$1.00. May be obtained of Orange Judd Co., New York.

The A B C of Bee Culture,-By A. L. Root. Orange Judd Co., New York, 1895. Price, $\$ 1.25$.

\section{Miscellaneous.}

Irrigation Faruing.-By Lute Wilcox. Orange Judd Co., New York, 1895. Price, $\$ 2.00$. 
The American Sugar Ixdustry.-By Herbert Myrick, and Prof. W. C. Stubbs. Orange Judd Co., New York, 1898. Price, 50 cents. (Sugar beets.)

The Toвacco Leaf.-By J. B. Killegrew and Herbert Myrick. Orange Judd Co., New York, 1897. Price, $\$ 2.00$

Economic Entonology.-By John B. Smith. J. B. Lippincott Company, Philadelphia, 1896. Price, $\$ 2.50$.

Plant Life on the Fara.,-By Maxwell T. Masters. Orange Judd Co,, 1885. Price, $\$ 1.00$.

Drainage for Profit and Drainage for Health.-By Geo. E. Waring, Jr. Orange Judd Co., New York, Price, \$1.50.

Government Forestry Abroad.-By Gustave Pinchot. The Macmillan Co., New York. Paper, 75 cents, with postage added.

Practicability of the American Forest Adimistration.-By B. E. Fernow. The Maemillan Co., New York. Paper. Price, 75 cents, plus 10 cents for postage.

Forest Planting.-By H. Nicholas Jarchow. Orange Judd Co., New York, 1897. Price, $\$ 1.50$.

In addition to the foregoing and many more books of a general nature, there are excellent special publications giving the experience of practical men in the production of all crops and the conduct of all farm operations. Their names ean be learned from the publishers' catalogues and the advertising columus of the agricultural press.

The Orange Judd Co., New York, publishes more strictly agricultural books than any other American house, and, in addition, it includes in its catalogue the more important publications of other publishers. The Macmillan Company perhaps comes next. The catalogues of these two houses will almost certainly indicate to any farmer just how to get any special information which he needs. The wonderful intellectual awakening of the farmers which is now going on is stimulating the preparation of books on rural topics, and within a short time it is probable that the lists of most publishers will contain many books of importance on rural topies.

Upon the topics treated in Book Fourth I know of little literature of a popular nature. The best means of information in regard to banking and railroads are official reports, state and national, and articles in such periodieals as the Forum, North American Reviero, Popular Science Monthly, American Journal of Economics, and similar periodicals more or less familiar to all. Perhaps the best sources of information on these and kindred topies, including finance in all its aspeets, and eivic and social movements, are the publientions which are appearing every year, of the American Economic Associntion, Columbia University (both these obtainable from the Macmillan Co.), the University of Pennsylvania (Philadelphia), and the Johns IIopkins University (Baltimore). All these ean be found in any large library, or catalogues containing titles and authors can be obtained at the addresses given. These papers are all monographs by some of the ablest men of $\Lambda$ merica, and are written from all sides of most important questions. They are somewhat expensive lut a good popular demand would soon result in reduced prices. Conant's IIIsToRY of Monfry Banks of Isiste is interesting to the general reader. Published by G. P. Putnam's Sons, New York, 1896. Price, $\$ 3.00$. 
COOPERATION.

The literature of cooperation is abundant, but I have found few books published in America which deal specially with the details of cooperation among furmers. There are books published in Great Britain treating of productive cooperation in farming, which has been found sucessful there when the produce was assured of a preferential home market. This occurs only when the land is owned by a "cooperative store" which retails the produce. For the most part the authors of books upon mereantile cooperation have in mind a saving by buying ehenply, while the object of farmers' marketing assoeiations is to gain by obtaining high prices. Both seek to eliminate unnecessary middlemen, and to themselves, so far as possible, do the work of those which are neeessary. The eooperation of labor does not usually consist in forming societies to sell the labor, but for regulating its price, and preventing those not members of the societies from getting work. These are called trade unjons, and the literature concerning them is voluminous. The books on cooperation are sometimes written by enthusiasts who have not had practical experience with its difficulties. The English Cooperative Wholesale Society issues a great number of valuable tracts, apparently mailed free to any applicant. Address the Central Cooperative Buard, City Buildings, Corporation Street, Manchester, England. The Cooperative News is a weekly paper, the official organ of English cooperative sucieties. Address, Cooperative News, Long Millgate, Manchester, England. It is published at one penny a week. Something is doubtless added for foreign postage. The same society publishes the Reports of the annual meetings of the British Cooperative Congress, which are wonderful documents. I do not know the price.

The following books on some of the forms of cooperation have been selected from a large number of titles, and together will give a very fair idea of what different people understand by cooperation and the progress which it is making in this and other countries.

A Treatise on Cooperative Savings axd Loan Baxks, By Seymur Dexter. D. Appleton \& Co., New York, 1894. Price, \$1.25.

How to Cooperate.-By Herbert Myrick. Orange Judd Co., New York. Cloth, $\$ 1.00$; paper, 25 cents.

Labor Copartinerint.-By Henry D. Lloyd, Ilarper \& Brothers, New York, 1898. Price, $\$ 1.75$.

Profit Sharivg betweex Employer axd Employek-By N. P. Gilmore. Houghton, Miftlin \& Co., Boston, 1889. Price, $\$ 1.75$.

History of Cooperation in America.-By Prof. E. W. Bemis, Prof. Amos G. Warner, Dr. Albert Shaw, Mr. Charles H. Shinn, and Mr. David R. Randall. Johns Hopkins University Press, Baltimore, 1888. Price, \$3.50. (This book gives an excellent summary of cooperative work in America up to the date of its publication, but it has, I believe, no mention of any cooperative marketing society.)

People's Baxks.-By Henry W. Wolf. Longmans, Green \& Co., London, 1893. (This is an English book, and I am not able to give the price. It is a book of only 261 pages, and will not be found expensive. It may be ordered 
of any bookseller or of Charles Scribner's Sons, New York, who are large importers of English books. It describes cooperative banking as it exists in various countries of Europe.)

\section{The Tariff Question.}

It is a little curious, but it seems to be the fact that there is no strictly modern, non-political, American book, of moderate price, by an able man, which takes the side of "Protection" in the tariff" controversy. As stated elsewhere, the non-political writers all secm to be free traders. A few such books which have been written seem mostly out of print. The best I can find is the following, written by an Englishman:-

Sophisms of Free Trade.-By Sir John Bernard Byles. Henry Carey Baird \& Co., Philadelphia, 1884. Price, $\$ 1.25$.

A good book on the free trade side is-

Protection, or Free Trade.-By Henry George. Doubleday \& MeClure Co., New York. Price, $\$ 1.00$; in paper, 25 cents.

\section{The Single Tax.}

The leading book favoring the single tax is, of course-

Progkess and Poverty.-By Henry George. Doubleday \& McClure Co., New York. Price, $\$ 1.00$; paper, 25 cents.

Another good book on the same side is-

Natural Taxation.-By Thomas G. Shearman, Doubleday \& MeClure Co., New York. Price, $\$ 1.00$; paper, 25 cents.

On the opposite side there is a great dearth of good books, although in this ease the great majority of the social and financial lights oppose the single tax. Their utterances, however, must be mostly looked for in the periodical literature of a few years back, which is hardly accessible, except in public libraries. "Property and Progress," by H. W. Mallock, is a reply to Mr. George, and may be found in many libraries, but now seems to be out of print. Perhaps the best "reply" in book form is that of the Duke of Argyle, which first appeared in the nineteenth century for April, 1884, and is republished in this country, by Mr. George's publishers, with Mr. George's rejoinder. The title of this book is-

The Land Question.-Doubleday \& McClure Co., New York. Price, $\$ 1.00$; paper, 25 cents.

Excellent books to read on the general subject of taxation are:-

Essays in Taxation,-By Prof. E. R. A. Seligman. The Macmillan Co., New York. Price, $\$ 3.00$.

Also a smaller work-

Equitable Taxation,-By Walter E. Weyl and others. T. Y, Crowell \& Co., New York, 1892. Price, 75 cents.

\section{Currency}

The best book for popular reading, on the gold side of the money question, is Sone Facts about Moner. By. Prof. J. Laurence Laughlin. The publishers of this book, however, are not now in business, and I ean not find that the book is in print. The following, however, will be found satisfactory :- 
The Case aganst Bimetalism,-By Robert Giffen. The Macmillan Co., New York, 1892. Priee, $\$ 2.00$.

A good book for those who wish to see an impartial discussion of the subject is-

International Binetalism.-By Prof. Francis A. Walker. Henry Holt \& Co., New York, 1896. Price, $\$ 1.25$.

Those who wish to see the silver side presented by a strong man who will not stoop to misrepresentation should read-

An Honest Dollar.-By President E. Benjamin Andrews. The Macmillan Co., New York. Paper, 75 cents, plus 10 per cent for postage.

It is claimed by some that, conceding the appreciation of gold, it is more than offset by the depreciation of interest. Those who would like to look into this are referred to-

Appreciation and Interest.-By Prof. Irving Fisher. The Macmillan Co., New York. Price, 75 cents, plus 10 per cent for postage.

Trusts. .

A good book about "Trusts" is-

Trusts or Industrial Combinations in tile United States, - By Erust Von Halle. The Macmillan Co, New York, 1895. Price, \$1.25.

\section{The Referendum.}

The Swiss Coxfederatiox.-By Sir Francis Ottiwell Adams. The Macmillan Co., New York, 1894. Price, \$2.50.

The Referendum in America.-By E. P. Oberholtzer. The University of Pennsylvania, Philadelphia, 1893. Price, $\$ 1.50$.

\section{Socialism.}

Out of a great mass of literature it seems to me that the following is as good a selection as ean be made for the general reader:-

The Cooperative Commonwealtit.-By Laurence Gronlund. Lee $\mathbb{E}$ Shepberd, Boston. Price, $\$ 1.00$. (Socialistic.)

The Quintessence of Socinlism.-By. Dr. A. Schaflle. Charles Seribner's Sons, New York. Price, \$1,00. (Socialistic.)

Socralism.-By Prof. Richard T. Ely. T. Y. Crowell \& Co., New York, 1894. Price, \$1.50. (Impartial.)

The Trranny of Socialism.-By I'ves ('xuyot. Charles Seribner's Sons, New York, 1894. Price, \$1.00. (Anti-socialistic.)

Anarcinsm. By E. V. Zenker. G. P. Putnam's Sons, 1897. Price, \$1.50. (Anti-anarehistic, and showing the opposition of Anarchism to Socialism.)

The "labor question" will be found quite sufficiently covered in the foregoing works on Socialism.

The foregoing list has been prepared for the benefit of those who wish in inform themselves upon the topies considered, but do not lave access to large libraries, or any convenient means of finding out what books to buy. It is hoped that it will be found helpful. 


\section{Appendix E.}

I. SOME STATISTICS RELATIN(: TO BANKS, FROM THE REPORT OF THE COMPTIOLLR OF THE CURRENCY FOR 1897.

\section{NATIONAL BANKS}

Number of national banks organized since 1863 . . . . . 5,095

Number voluntarily ceasing business since beginning of the system ....................... 1,125

Became insolvent . . . . . . . . . . 353

Total passed out of the system . . . . . . . 1,478

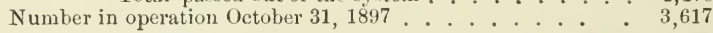

Capital stock paid up . . . . . . . . . . \$637,615,445

Surplus and undivided profits . . . . . . . . . 334,752,000

Total capital ........... $\$ 972,367,445$

Decrease in No. banks since 1892 . . . . . . . . . . 192

Decrease in capital . . . . . . . . . . . $\$ 35,533,620$

No, shareholders, July, $1897 \ldots$

No. sharebolders holding $\$ 1,000$ or less . . . . . . 169,948

No. holding $\$ 1,000$ to $\$ 5,000$.............. 79,756

No. holding $\$ 5,000$ to $\$ 30,000$. . . . . . . . . . $\quad 29,541$

No. holding over $\$ 30,000$. . . . . . . . . . . . $\quad 1,980$

Average holding, per stockholder . . . . . . . $\$ 2,250$

No. women shareholders . . . . . . . . . . . 101,944

Value of shares held by women . . . . . $\$ 141,854,200$

National bank-notes extant November, $1897 \ldots 230,131,005$

" " "

Profit on national bank circulation, based on deposit of United States four-percent bonds, as compiled by the government actuary:-

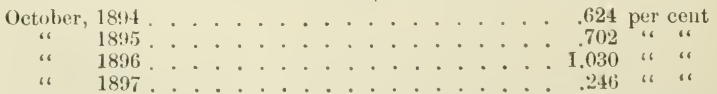

The above is based upon the estimate of six per cent interest received by the banks for currency loaned.

The account for 1897 is made up as follows:- 
Bonds deposited ............... $\$ 1,000,000$

Currency received . . . . . . . . . . 9090

Received by bank:-

Interest on $\$ 90,000$, six per cent . . . . . $\$ 5,400$

Interest on bonds, fuur per cent ...... 4, . 4000

Reductions:-

Tax............. $\$ 90000$

Cost of redemption......... . . 4500

Express charges . . . . . 300

Plates . . . . . 750

Agents' feet ............ 700

Sinking fund . . . . . . . . 41856

Net receipts ................... $\frac{\$ 1,38106}{\$ 8,01894}$

Interest at six per cent on market value of bonds . . . 7,702 50

Profit by circulation, above what eould have been made by loaning the cost of the bonds at six per cent . . . . \$31644 Or .246 per cent per annum.

(Compare the rough statement figured out in the text, page 144.)

Deposits in national banks, October 5, 1897 . . . . $\$ 1,869,000,000$

It should be evident that the profits of national banks are mainly derived from loaning this vast amount of money deposited, rather than from the trivial profit on circulation.

Net earnings of national banks for a series of twenty-eight years, computed on capital and surplus:-

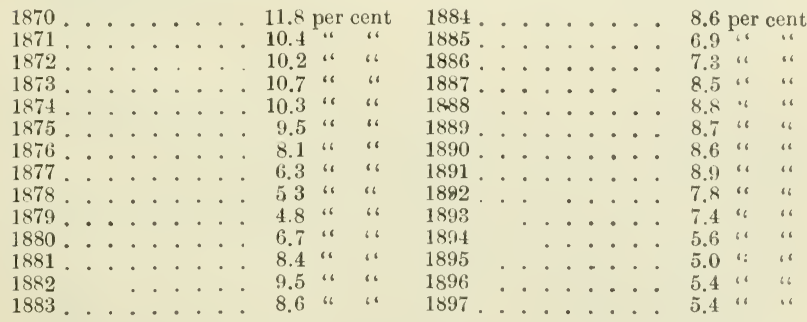

From the above it will be noted that as the country grows richer and money more abundant, the profits of banking decrease. With all the risk of loss, it evidently pays best to lend money to poor people. Note the reduction in banking profits immediately following the panic years of 1873 and 1893. This was partly due to losses from bad debts in those years, and partly because people were restricting their business operations, and not borrowing money.

It is also important to note the very large number of shareholders in national 
banks, and especially the number of women. This shows that the owners of national banks are not all rich men, but largely comparatively poor people, depending upon the earnings of their money for a livelihood.

\section{ST.ATE (COMHERCIAL) BANKS.}

Number of state banks, 1896-7. . . . . . . . . . 3,857

Total eapital stock . . . . . . . $\$ 228,677,088$

Surplus and undivided profits . . . . . . . . . 102,359,024

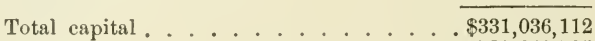

Deposits . . . . . . . . . . . . 723,640,795

The comptroller of the currency is unable to obtain from the state banks and trust companies such detailed reports of profits as the law compels national banks to furnish, but of five hundred fifty-seven banks and one hundred sixtyseven trust companies reporting, the banks averaged seven per cent on their capital, and the trust companies seven and eight-tenths per cent. Had all reported, the average rate of dividends would doubtless be less, as it would usually be the least successful coneerns that would dislike to report. Their average earnings are doubtless about the same as the national banks.

\section{STATE LOAN AND TRUST COMPANIES.}

Loan and trust companies are usually banks receiving deposits, but not transacting the collection and other minor functions of a bank, and in most cases confining their business to large operations.

Number of loan and trust companies reporting to comptroller $1896-7$. . . . . . . . . . . 251

Capital stock . . . . . . . . . $\$ 106,963,253$

Surplus and undivided profits . . . . . . . . . $89,025,267$

Total capital . . . . . . . . $\$ 195,993,520$

Deposits . . . . . . . . . . . . . . $566,922,205$

The ownership of the capital of the state banks and trust companies is doubtless distributed among small and large stockholders, like that of the national banks. There are no general statistics upon this point.

The above is not a complete statement of the business of the loan and trust companies, as many, not being so required, failed to report to the comptroller. Returns gathered earlier in the year by the New York Financier and quotcd by the comptroller, are as follows:-

Number of companies. . . . . . . . . . . . . . 458

Capital tock. . . . . . $\$ 141,278,000$

Surplus and undivided profits. . . . . . . . . 97,853,000

Total capital ........... $\$ 239,131,000$

Deposits . . . . . . . . . . . . 675, . . . . . . . . . . . . . .

In this ease, also, complete returns of earnings were not mude, but the dividends paid by the companies of New York City averaged, for the previous year, fifteen and one-third per cent, which shows the enormous profit attending 
the great operations which these companies conduct. Their great profits come largely from percentages on placing great loans for corporations and governments. A considerable part of these great dividends in the year in question were doubtless profits upon the United States three per eent bonds sold to maintain the gold reserve of the United States in the face of a large deficit in the revenue. When a government gets into a pinch it has to pay for it, just as a poor man does.

\section{PRIVATE BANKS:}

Of these concerns seven hundred fifty-nine only reported to the comptroller, which he states to be about twenty per cent of the whole number.

Number of private banks reporting. . . . . . . . . . . . . 759

Capital. . . . . . . \$ \$ $\$ 18,246,007$

Surplus and undivided profits . . . . . . . . $7,113,121$

Total eapital . . . . . . . . . $\$ 25,359,128$

Deposits . . . . . . . . . . . . 50,278,243

\section{SAVINGS BANKS.}

Number of mutual savings banks. . . . . . . . 666

(These bave no capital stock.)

Number of stock savings banks . . . . . . . . . . 312

Total savings banks. . . . . . . . . . 980

Capital stock (stock banks only). . . . . . \$26,199,430

Surplus (all savings banks) . . . . . . 159,954,756

Total capital. . . . . . . . . $\$ 186,154,186$

Deposits subject to check . . . . . . . \$ $44,037,529$

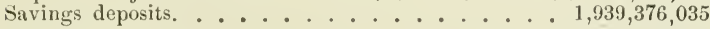

Total deposits............ . $\$ 1,983,413,564$

Number of depositors . . . . . . . . . . . . . . 5,201,132

Average deposit. . . . . . . . . . . . . $\$ 372.88$

In a sarings bank, it is the depositors who receive the profits, less the expenses of the bank, and such payment to the capital stock, if any, as the by-laws of the bank preseribe.

The rate of interest earned for depositors in savings banks varied in different groups of states, ranging from three to five per cent.

The cost of management of savings banks, was, in Maine, one-fifth of one per cent of the deposits; and in Massachusetts one-fourth of one per cent. Statisties are lacking as to other states.

\section{SUMMARY.}

The banking capital available for loaning consists of the capital stock, surplus and undivided profits, and deposits, less sums invested in premises and furniture, and the necessary reserves. Without making these deductions, the amounts are as follows:- 
National Banks.

Capital and surplus. . . . . \$972,367,445

Deposits. . . . . . . $1,869,000,000$

Total resources. . . . . . . . . . $\$ 2,841,367,445$

State Banks:

Capital and surplus. . . . . . . \$331,036,112

Deposits . . . . . . . . $723,640,795$

Total resources. . . . . . . . . . $\$ 1,054,676,907$

Loan and Trust Companies.

Capital and surplus ..... . . . \$239,131,000

Deposits . . . . . . 675,100,000

Total resources. . .............. $\$ 914,231,000$

Private Banks:*

Capital and surplus . . . . . . $\$ 25,359,128$

Deposits. . . . . . . . . . $50,278,243$

Total resources.............. $\$ 75,637,471$

Savings Banks.

Capital and surplus . . . . . \$ $\$ 186,154,186$

Deposits . . . . . . . . 1,983,413,564

Total resourees .............. $\$ 2,069,567,750$

Total capital for loaning (less reserves as above) . . $\$ 6,955,480,573$

And this is the money power.

\section{THE RAILROAD QUESTION.}

\section{DECISIONS OF THE INTERSTATE COMMERCE COMIISSION.}

The proeeedings of the Interstate Commerce Commission are, in many respects, like those of a eourt. Complaints are filed, answers made, evidenee taken if neeessary, argument heard, and a decision rendered. If, however, the parties do not comply with the decision, the Commission has no power to enforee them. For that purpose recourse must be had to at court, where the entire question may be tried over again, as if it had never been heard by the Commission. Under our constitution there is no way to avoid this, but it is possible to make evidenee taken before the Cormmission available before the court, in support of the decision of the Commission, which the law has made mima facie evidence of what is true. Those who have oceasion to complain of railroads are not usually able to bear the expense of litigation, and when they have once proved a thing some means should be found of making that evidence available once for all for what it is worth. The Commission can also be clothed with greater power of compelling witnesses to testify. The tedinus processes of the American courts are the strongest refuge of evil-doers. In dealing with

* About one-fifth of the private banks only. 
the powerful corporations the people need a strong tribunal, not bound by technicalities, with power to go at once to the pith of any matter presented, do equity at once and have its decisions enforced, until set aside by due course of law. The Interstate Commerce Commission was designed as such a tribunal. Its authority is insufficient for its duties. The people en power if they have a mind to. If they will not do this, it is childish to eomplain of oppression in Interstate Commerce.

The following decisions of the Commission, while not necessarily having the force of law, have been nearly always complied with. The Commission, up to the close of 1898, had made nine hundred eighty-five decisions, eovering most of the points that are likely to arise between the people and the rail. roads in Interstate Commerce. The following selections from those decisions will be found of interest. The selection has neeessarily been confined to deeisions establishing general principles. It will be noted that in nearly all cases the contest was between localities, rather than between individuals. Duubtless this has been because the discriminations against individuals have been better concealed. Discriminations between localities are olvious, and are usually taken up by boards of trade or other influential commercial bodies. The numbers prefixed to the decisions indicate the number of the decision on the docket of the Commission.

5. The Interstate Commerce Commission has not been given the authority to authorize the grant, by railroad companies, of special privileges to individuals or corporations, or to sanction such as are not in harmony with the act to regulate commerce, or to suspend that act for the benefit of particular industries.

7. A petition was presented by a manufacturing corporation, which recited in substanee that railroad conmanies had been accustomed to permit it to procure its raw material at a distance, manufacture its goods therefrom, and then ship the goods to a market at the same aggregrate rate for transportation of both raw material and manufactured goods as would be eharged had there been no stoppage in transit and no manufacture; that this privilege of manufacturing in transit was valuable to the corporation and to the community in which its business was located, and wronged no one; and petitioner prayed that it might be sanctioned by the Commission. But no authority to that effect having been conferred upon the Commission, the petition was dismi-sed.

12. It seems not to be illegal for railroad companies conneeting Boston witl eastern points to make the rates from such points to Boston upon grain and provisions for export as low as the rates to New York, although the rates upon like property for local consumption are higher to Boston than to New York, the distance being somewhat greater.

15. So far as a railrond company, whose line is entirely within one state, issues through bills of lading over its connecting lines to points in other states, and makes through rates, it falls under the provision of the Interstate Commerce Act.

19. That the phrase "under substantially similar circumstances and conditions " in the fourth section, is used in the same sense as in the second section; and under the qualified form of the prohibition in the fourth section carriers are required to judge in the first instance with regard to the similarity or dissimilarity of the eircumstances and conditions that forbid or permit a greater charge for a shorter distance.

20. That the judgment of earriers in respect to the circumstanees and conditions is not final, but is subject to the authority of the Commission and of the courts, to decide whether error has been committed, or whether the statute has 
been violated. And in ease of complaint for violating the fourth section of the act the burden of proof is on the carrier to justify any departure from the general rule preseribed by the statute by showing that the circumstances and conditions are substantially dissimilar.

22. That the existence of actual competition, which is of controlling force, in respect to traffic important in amount, may make out the dissimilar circumstances and conditions entitling the carrier to charge less for the longer than for the shorter haul over the same line in the same direction, the shorter being included in the longer in the following cases:

I. When the competition is with carriers by water, which are not subject to provisions of the statute.

II. When the competition is with foreign or other railroads which are not subject to the provisions of the statute.

III. In rare and peculiar cases of competition between railroads which are subject to the statute, when a strict application of the general rule of the statute would be destructive of legitimate competition.

23. The Commission further decides that when a greater charge in the aggregate is made for the transportation of passengers or the like kind of property for a shorter than for a longer distance over the same line in the same direction, the shorter being included in the longer distance, it is not sufficient justification, therefor, that the traffic which is subjected to such greater charge is way or local traffic, and that which is given the more favorable rates is not.

24 . Nor is it sufficient justification for such greater charge that the shorthaul traffic is more expensive to the carrier, unless when the circumstances are such as to make it exceptionally expensive, or the long-haul traffic exceptionally inexpensive, the difference being extraordinary and susceptible of definite proof.

Nor that the lesser charge on the longer haul has for its motive the encouragement of manufactures or some other branch of industry.

Nor that it is designed to build up business or trade centers.

Nor that the lesser charge on the longer haul is merely a continuation of the favorable rates under which trade centers or industrial establishments have been built up.

The fact that long-haul traffic will only bear certain rates is no reason for earrying it for less than cost at the expense of other traffic.

28. The practice of paying commissions to the agents of other roads on tickets sold over the road of the company paying the same, condemned as demoralizing, and as an improper drain on corporate resources.

32. Where complaint is made of rates as excessive, the burden is upon complainant to make proof of the fact alleged, and if no proofs are put in by either party the complaint will be dismissed. This held in a case in which the rates were much higher than they had at one time been on the same line.

33. An offer by a railroad company to give a discount to any consignee who, within a year, shall receive at any one station a specified amount of freight, which offer purports to be made to secure speedy despatch, but it is not conditioned on speedy despatch being made, is void, and if a discount is made to one dealer in pursuance of it, all others will be entitled to a like discount.

34. If the real consideration of the offer were to secure speedy despatch, it should have been open to all who could accept it, regardless of quantity.

53. Mileage tickets when issued must be sold impartially to all who apply for them, and on the same terms.

63. A common carrier of live stock is subject to the legal duty to provide reasonable and proper facilities for receiving and discharging from its cars such live stock as is oflered for transportation, free of all except the customary transportation charges. It does not fully discharge this duty by receiving on and discharging from its ears live stock at a depot, access to which must be purchased.

64. A railroad company as earricr of live stock had undertaken to give to a 
stock-yards company an exclusive right at one of its stations, and to require all stock at thatstation to be received and delivered on the platform of the chutes of that company, the company being authorized to charge lottage therefor. Complainants established by the track of the railroad company ehutes of their own, through which they demanded the right of receiving and delivering the stock of themselves and their customers. The conveniences furnished by them being suitable, it was held that their demand must be complied with.

69. The sale of "land explorers' tickets" and "settlers' tickets" at less than the regular rates charged to passengers at the usual ticket offices, as practiced by the Northern Pacific Railroad Company, is unjust discrimination.

71. The rule under which passenger transportation should be conducted requires absolute equality of payment from all persons enjoying the same accommodations.

74. When the same carrier operates parallel lines, and for any cause accepts low rates on one of them, it should provide sufficient corresponding advantage to the patrons of the other line to preserve the substantial equality contemplated by the statute.

75. Low charges upon one of two routes operated by the same carrier should not be made up by relatively high charges upon the other, when the result disastrously affects the business of communities situated upon the latter line.

82. If a railway company in establishing charges on different divisions and branches of its road so adjusts them as to divert trade and business to one locality which naturally, under an equitable adjustment of charges, would go to another, such preference is not excused by the fact that some of such charges are not entirely voluntary, but result from competition between carriers.

83. If determining what is a just and reasonable rate for a particular commodity (for example, wheat) the Commission will take into consideration the earnings and expenses of operating, rates charged upon the same commodity upon other roads as nearly similarly situated as may be, the diversities between the railroad in question and such other roads, the relative amount of through and local business, the proportion borne by the commodity in question to the remainder of the local traffic, the market value of the commodity and its gradual reduction, the reduction made by the carrier upon the articles which are consumed and necessarily required by the producers of the article in question, and all other circumstances affecting the traffic of itself and as related to other considerations entering into the charges of the carrier.

94. Colored people who buy first-class tickets must be furnished with accommodations equally safe and comfortable with other first-class passengers. The Commission finds that the car furnished complainant was only second-class in comforts for travel, and that he was thereby subjected to undue prejudice and unreasonable disadvantage in violation of the act to regulate commerce.

100. Express business, conducted by an independent organization, acquiring transportution rights by contract, held not to be described in the act with sufficient precision to warrant the Commission in taking jurisdiction thereof.

105. By reason of extraordinary circumstances a railroad company cannot promptly meet all calls for cars; it should furnish them ratably and fairly to ali shippers, in proportion to the freights offered by them respectively, until the emergency has passed, and it is again enabled to move promptly all the freights tendered.

108. Rates established by a common carrier in order to keep upon its line material for which the road has use, or to keep the price low for its own adrautage, cannot be justified.

109. Producer of railroad material is entitled to sell it when $\mathrm{h}=$ wishes, in the best available market. Common carriers are forbidden wo attempt to prevent this by applying disproportionate or unreasonable rate:

111. It is not a ground of complaint against a railros. company that it equalizes its rates as between small and large towns, er n though the effect 
may be prejudicial to the large towns, which before had been speeially favored.

115. A carrier is not compellable by law to give to the merchants of a town on its line the privilege of shipping their goods from the point of purchase to their own locality, and again from thence to the place at which the goods may be sold by them, at the same rate which would have been charged had there been but one shipment from the point of purchase to the point of ultimate delivery.

116. The fact that a refusal to give the through rate as for one shipment operates prejudicially to the town desiring the privilege and favorably to another, does not make the refusal operate as unjust discrimination when the carrier applies the same rule to all towns and aceords the privilege to none.

129. As a rule, in the transportation of freights by railroads, while the aggregate charge is continually increasing the further the freight is carried, the rate perton per mile is constantly growing less all the time, making the aggregate charge less in proportion every hundred miles after the first, arising out of the character and nature of the service performed, and the cost of the charges of this mode of transportation from and to the most distant portions of the country.

130. The act to regulate commerce, so far from throwing hampering restrictions or obstacles in the way of the operation of this salutary rule, gives it all the benefit and aid of its sanction and safeguards by providing that the carrier shall be entitled to receive a reasonable compensation for the service performed upon open published rates, against which no competitor can take advantage by allowing shippers secret rebates and drawbacks in order to get the business.

137. A railroad company, chartered by the state of Tennessee, owns a short road wholly in that state, but has never owned any rolling stock nor operated its road. The road was used and operated as a means of conducting interstate traffic in coal by companies owning connecting interstate roads. Held, that the short road thus used is one of the facilities and instrumentalities of interstate commerce, and the carriers using it are subject to the provisions of the act to regulate commerce.

143. When two methods for the transportation of an article of merchandise are nominally offered by the carrier, for only one of which it offers rolling stock, and for the other of which the shipper must supply his own rolling stock at considerable expense, it ean not be said that the resort to the latter by the shipper is so far a matter of choice that he has no concern with the charges for transportation in the other mode. The man of small means compelled to make this choice by reason of the carrier's failure to supply rolling stoek for the other mode, has a right to insist that the eharges by transportation in the two modes shall be relatively just and equal.

144. When oil is transported in tanks permanently affixed to car bodies, the tank is to be considered as part of the car; and for oil transported therein the charge for transportation should be the same for the hundred pounds that the carrier charges for transportation between the same points of barrels filled with like oil and taken in car-load lots. The carrier is guilty of unjust diserimination if the shipper in barrels is charged a higher rate.

145. Neither the fact that the shipper in the one case supplies the rolling stock, nor the alleged fact, which is not found sustained, that for the tanks there is a greater probubility of return loads, nor the further alleged fact that with harrel shipments there are greater risks to the earrier's property and that which it carries, ean justify imposing upon the barrel shipments the greater burden.

149. Regular patrons are not entitled to preference in the use of equipment of common carriers; the public must be justly and equally served.

151. Selection of either goods or customers is forbidden to common carriers; less desirable traflic which is ordinarily the subject of transportation and not dangerous to handle, must be accepted upon reasonable terms as well as that which is more desirable. 
152. It is not a ralid excuse for refusal to furnish a fair allotment of a certain class of cars that they can be more profitably employed, and can supply the wants of a larger number of shippers upon another portion of the line.

162. Underbilling, a device by which a shipper pays for the transportation of a less quantity of freight than is actually carried, and thereby obtains a reduced rate upon the gross shipment, is forbidden by the act to regulate commerce.

172. Classification of dried fruits and raisins, both California products, in different classes, taking diflerent rates of freight, works an injustice to shippers. In all matters of classification, clearness and simplicity should be aimed at, and irregularities and inconsistencies should be eliminated.

180. Trade centers of large commercial towns are not, as a matter of right, entitled to have more favorable rates than the smaller towns for which they form distributing centers; and if carriers will give to such smaller towns rates as farorable as to the larger, the Commission will not interfere.

181. The fut that, under rates which are impartially arranged as between large and small towns, one large distributing center may have an advantage over another in competition for the business of the small towns, does not make out a case of undue preference in favor of the one distributing center as against the other. Impartial rates are not rendered illegal by their effect upon the business of lucalities.

182. A distributing center, however great or important, can not demand, as a matter of right, that the rates from a common suurce of supply to more distant and smaller towns shall be made up of the sum of the rate to itself and the rate thence to such smaller towns; but the carriers may make rates from the common source of supply to the smaller towns directly, as single rates; and if the single rate is less than the sum of the two which are made to and from the distributing center it is not, for that reason, necessarily objectionable.

186. The method of testing the freight rates of a railroad by the rate per ton per mile is one by which these rates may be brought down to the narrowest point of scrutiny, and in this sense is valuable, but it is like looking at them with a microscope, for it ignores all other tests except that which it alone furnishes, and doe's not take into consideration any of the surrounding circumstances and conditions that enter into the making of the rate, no matter how compulsory or imperious these may be, and for this reason it can not be considered a controlling rule in determining the reasonableness of rates.

187. To determine the rensonableness and justness of any freight rate made by a railroad company, all the surrounding circumstances and conditions must be considered, as well as the rights of the shipper, and if these circumstances and conditions are so compulsory or imperious that they fairly and justly exercise any controlling influence in the making of a rate, they can not be disregarded in a proceeding in which the reasonableness and justness of the rate is presented for determination.

188. The words "substantially similar circumstances and conditions," as found in the second and fourth sections of the act to regulate commerce, in certain important particulars define the rights and duties of carriers and the rights of shippers as well. For example: If the carrier claims to act under the compulsion of circumstances and conditions of his own creation or convenience in the making of an exceptional rate, then these will not avail him. Or if the carrier claims to act under a compulsion of circumstances and conditions in the making of an exceptional rate which he could obviate by reasonably fair and just exertion on his part, then they will not avail him. But if the carrier is in good faith acting under a compulsion of circumstances and conditions beyond his control, not of his own connivance, and which he could not obriate by any reasonably fair and just effort on his part, and to avoid large loss adopts exceptional rates on a portion of his line, not unreasonable in themselves, and forced upon him by the action of an independent state railroad, which is not subject to the act to regulate commerce, and which is operating a slightly 
shorter and competing line with his own, these are eircumstances and conditions under the operation of the statute which justify him in adopting such exceptional rates thus foreed upon him on this portion of his line.

196. The difference between the cost of service by which the local business of this railroad and its through business is done relatively, examined and considered by the commissioner so far as they are involved in this proceeding.

197. Comparison of rates charged by railroad companies under circumstances and conditions substantially dissimilar, really prove nothing, and can not be adopted as standards in arriving at the reasonableness and justness of rate.

198. Exceptional cases of rates made lower than other rates by a carrier on one portion of its live, by the action of a competitor, and in which it is without fault itself, under the operation of the act to regulate commerce, can not be adopted as the standard as to other rates upon a far-distant portion of its line, where no such exceptional conditions exist, and the reasonableness of its rate must be determined by altogether different considerations.

209. Assurances made by a carrier that if one will locate in business on the line of its road his property shall be taken for transportation as belonging to a specified class, can not bind the carrier so as to compel a classification accordingly. A right to special rates can not be made out in that way; the classification must have the same construction in favor of all persons; the law requires uniformity and impartiality in the dealings of a carrier with all persons.

245. A leading purpose of the act to regulate commerce is to prevent the giving of unjust preferences and advantages as between localities, in railroad transportation. This purpose would be defeated if any one carrier, by making unreasonably low rates to any locality, would thereby entitle all other carriers competing with it to make on their lines greater charges upon the shorter hauls to other stations than were made over the same line in the same direction to the locality thus favored.

253. The existing arrangements by which the same rate is charged for the transportation of milk from all points reached ly the regular daily milk trains of the defendant roads found to be not illegal, and, on the whole, to be the best system that can be devised for the general good of all interested parties.

257 . Where, on a question of rates, it appears that bigher rates are made upon the shorter hauls on the same line and in the same direction, the carrier making them must take the burden of proof to show their reasonableness.

259 . The offense, under section 2 of the act to regulate commerce, of giving free transportation to an individual, consists in the charging, demanding, collecting, or receiving by the carrier from some other person or persons a compensation for a like service, when none is contemporaneously charged or received from the persons thus transported free.

261. When freight-for example, grain-is hauled to the seaboard for export, or to New England points, from the northwestern states and teritories of the American Union; or when freight is hauled from the seabourd or New England points to the uorthwestern states or territories through the eities of Detroit and Chicago, the rule invoked by the petitioners in this case us a basis of relief, namely, that an estimate portion of this through rate as between the points of origin of the freight and Detroit must not be lower in proportion to distance than the rate upon the freight from such points of origin destined to Detroit, is one that can not be sustained.

262. Rates must be relatively fair and reasonable as between localities in essential respects similarly situated, not according to any rule of mathematical precision, but, in substance and in fact, having regard to the geographical and relative positions of the localities, so that one will not be favored to the unjust prejudice of the other.

265. $A$ tariff naming a rate from one loeality lower than that enjoyed by its neighbor, when the circumstances are the sume, tenders a preference or advantage to the first; and when any shipper is damaged by the exuction of an addi- 
tional burden, the preference becomes undue and unreasonable, unless it can be justified upon some sound and substantial ground.

266. Common carriers are under obligations to take all descriptions of ordinary traftic from all points, and it is right that the rates should be known and announced publicly in advance of the offering of traffic.

267. Under the act to regulate commerce, slippers are not to be put in a position of subserviency to common carriers, nor required to ask for rates, but are entitled to equal and open rates at all times.

268. Discriminations are made and undue advantages are given by the special tariffs in question, in giving different rutes to places named and those not named; to manufactured articles named and those not named; to jobbers at places named and those not named; to manufacturers and to jobbers and other dealers.

271. There is nothing illegal or wrongful in a railroad company making a rate for immigrants as a class, and declining to give the same rate to others for whom different accommodations are furnished.

276. Free transportation issued in the form of an annual pass to a person not in the regular and stated service of the carrier, nor receiving any wages or salary under a contract of employment, lut requested by him as compensation for throwing in its way what business he conveniently could, held to be illegal.

277. In deciding a cuse against one or more carriers who are charged with making rates which are unjustly discriminating in a certain line of traftic, the decision made upon the facts of the particular case does not necessarily govern rates in other sections of the country where the facts bearing upon them may be altogether different.

292. A passenger-rate war, in which rates were repeatedly reduced by several competing lines to an exceedingly low basis on a particular class of traffic, without any filing of tariffs, was contrary to the requirements of law, as well as against the true interest of each party thereto.

293. Reductions in competitive passenger rates can not legally be made without at the same time reducing intermediate rates, as required by the fourth section of the act.

294. No necessity or compulsion is created by a war of rates which justified disobedience of the statute.

295. The employment of ticket brokers and scalpers for the sale of railroad tickets placed in their hands to be disposed of at reduced rates under the pretense of paying commissions thereon, held illegal.

296. Rates lower than the established tariff are prohibited by law.

297. Rates obtained from ticket brokers lower than those offered at the regular offices of the company effect unjust discrimination.

307. The rate of thirty and one-half cents per one hundred pounds on wheat, flour, and mill stuffs from Minneapolis via IIilwaukee to New York and consmon billing points, established by the defendants and their connecting lines, February 1, 1888, was a through rate.

308. The percentage amounting to twenty-five cents per one hundred pounds, received by the defendants and their connecting lines east of MIilwaukee as their proportion of this through rate on shipments from Minneapolis and points west of Milwaukee, and between Milwaukee and Minneapolis while the defendants charge twenty-five and one-half cents per one hundred pounds on the same class of freight originating at Milwaukee and transported over their lines and connecting lines to eastern points, was not an unjust discrimination against Milwaukee, nor did it injure the business of Milwaukee, nor was it a violation of the act to regulate commerce approved February 4, 1887.

312. Through rates, like any other agreements that parties competent to contract may make, admit of very great variety in the forms they assume; and such rates, when reasonable and fairly adjusted, in their relations to local business, are greatly farored in the law because they furnish cheapened rates and greater facilities to the public, while at the same time they give increased employment and earnings to a larger number of carriers. 
323. A railroad company is under special obligation to give reasonable rates for its local business, but there are many influences which may affect through rates while not bearing upon local rates at all, or, if at all, in less degree.

324. Through rates are not necessarily illegal which when divided between carriers give them less than their local rates, provided that the through rate itself is not less thin some one of the loculs, or unjustly discriminating against individuals or localities, or so low as to burden other business with part of the cost of the business upon which it is imposed.

333. A departure from the rule of equal mileage rates as applied to the several branches of the road is not conclusive that such rates are unlawful, but the burden is on the company making such departure to show its rates to be reasonable when disputed.

338. A group rate for a particular district upon a commodity for which a large demand exists, and intended to place producers in the district upon an equality among themselves and with producers of the same commodity from other districts, all competing in a common market, is not unlawful merely on account of differences in the geographical location of different producers and their respective distances from the market.

339. Actual undue prejudice or damage of which the rate is the cause must result to the more favorably-situated producers to render a group rate unlawful.

340 . In determining the question of undue prejudice from a rate, distance is only one of the factors, and other material facts, such as character and quality of the commodity, cost of production, extent and nature of the competition in the business itself by other transportation lines, and the interests of the public in the use of the commodity and its market cost are to be considered.

348. Mileage, excursion, or commutation passenger tickets must be offered impartially to all who accept the conditions on which they are issued, and the rates at which they are sold must be published. The general requirements of the act to regulate commeree as amended are as applicable to these classes of tickets as to any others.

349. Party rates and passengers' car-load rates lower than contemporaneous rates for single passengers constitute discrimination between persons entitled to transportation at equal rates, and are therefore illegal.

359 . The provisions of the act to regulate commerce apply to foreign as well as domestic common carriers engaged in the transportation of passengers or property, for a continuous carriage or shipment, from a place in the United States to a place in an adjacent foreign country.

360. The common carriers engaged in such transportation are subject to the provisions of the act in respect to the printing of schedules of rates, fures, and charges for the traffic they carry, the posting and filing with the Interstate Commerce Commission of copies of such schedules, the notice of adrances and reductions, and the maintenance of the rates, fares, and charges established and published and in force at the time.

362. The carriage of freights can not be prevented from being treated as one continuous carrage from the place of shipment to the place of destination by any means or devices intended to evade any of the provisions of the act.

367 . It is a lawful duty that a carrier, like the defendant, owes to the traveling public, in carrying out its rule of furnishing separate cars to white and colored passengers on its line engaged in interstate travel, to make them equal in comforts, accommodution, and equipment, without any discrimination.

368 . It is a lawful duty which a carrier, like the defendent, owes to the traveling public, engaged in interstate travel over its line, to afford the equal protection of the law alike to all such passengers, without regard to race, color, or sex, against undue prejudice and disadvantage from disorderly conduct on the part of other pasengers or persons.

370 . When, pending $n$ proceeding begun to test the reasonableness of rates, the rates are reduced and made sutisfactory to the complainunts, the Commission will not consider the question whether the rates before reduction were or were not excessive; that question having by reduction made become purely abstract and speculative. 
392. When rates on the line of a carrier are on their face disproportionate or relutively unequal, the burden is on the earrier to justify them when ehallenged.

393. Grain, and grain products, elassified alike, are presumptively entitled to equal rates, and if a lifference is made by a carrier it assumes the burden of sustaining it by satisfactory evidenee.

395. A practice has existed on the part of eertain carriers of live cattle to make a car-load rate irrespective of weight, leaving the shipper to load into the car as many eattle as he pleased and was able to put into it. The carriers substituted for this practice the rule that while naming a ear-lot rate they preseribed a minimum weight for a ear-load, and then charged by the hundred pounds in proportion to the car-lot rate for any excess over the minimum. Held that this rule was not unlawful.

414. A discrimination between the rate on corn and its direct products from a given locality resulting from a reduction of the rate on corn below the rate on its direct products, which subjected persons in that loeality engaged in the business of manufacturing corn into its direet products, and of selling the same, to unreasonable prejudice or disadvantage, and was without necessity or advantage to the earrier, or any reason founded on the character or condition of the traflic. Held to be in violation of section three of the act to regulate commeree, notwithstanding the new rate on corn was open to all persons equally and with equal service.

420. Classification of freight for transportation purposes is in terms recognized by the act to regulate commerce, and is therefore lawful. It is also a valuable convenient e both to shippers and earriers.

421. A classification of freight designating different classes for car-load quantities for transportation at a lower rate in ear-loads than in less than earloads is not in contravention of the act to regulate commerce. The circumstances and conditions of the transportation in respect to the work done by the earrier and the revenue earned are dissimilar, and may justify a reasonable difference in rate. The public interests are subserved by car-load classifications of property that, on account of the volume transported to reach markets or supply the demands of trade throughout the country, legitimately or usually moves in such quantities.

422. Carriers are not at liberty to classify property as a basis of transportation rates and impose eharges for its carriage with exclusive regard to their own interests, but they must respect the interests of those who nay have occasion to employ their serviees and conform their charges to the rules of relative equality and justice which the act prescribes.

423. Cost of service is an important element in fixing transportation eharges and entitled to fair consideration, but is not alone controlling nor so upplied in practice by carriers, and the value of the service to the property carried is an essential factor to be recognizud in connection with other considerations. The public interests are not to be subordinated to those of carriers, and require proper regard for the value of the service in the apportionment of all eharges upon traffic.

424. A difference in rates upon car-loads and less than car-loads of the same merchandise between the same points of carriage so wide as to be destructive to competition between large and small dealers, especially upon articles of general and necessary use, and which, under existing conditions of trade, furnish a large volume of business to carriers, is unjust and violates the provisions and principles of the act.

425. A difference in rute from a solid car-load of one kind of freight from one consignor to one consignee, and a car-load quantity from the same point of shipment to the same destination consisting of like freight or freight of like character from more than one consignor to one consiguee, or from one consignor to more than one consignee, is not justified by the difference in cost of handling.

428. It was a regulation of the respondent company, published on its public tariff schedules filed and posted as required by the act to regulate commerce, 
that the conductor should collect fare on trains from passengers without tickets by adding twenty-five cents to single-trip rates, held that it was not unjust discrimination against the complainant to exact this addition from hin.

433. When questions involve the reasonableness of rates upon the transportation of cotton from the southern states by all rail lines to northern and eastern mills and Atlantic ports upon through rates and a long haul, on the one hand, and, on the other, the local rates of rail carriers to a near port upon a short haul at which their service terminates, they having no associated line of steamships for a continuous carriage to ultimate destination, but the cotton so carried by them to such near port being chiefly for export, and all such rail lines penetrating the same territory and competing for the same business, running north, south, and east in opposite directions, such questions can only be disposed of on broad lines and not from narrow considerations.

434. In considering such questions thus presented, the circumstances and conditions surro'snding the traffic in the respective services performed in its carriage by the rail carriers may be, and in these proceedings are found to be, substantially dissimilar and wholly unlike.

438. In solving questions of this character the Commission will look at and consider every fact, circumstance, and condition surrounding the traffic and of the service performed in its transportation, and if the competition of water carriers at any point is such as to be large, active, and of controlling force, the all-rail lines competing for the traffic at the same point may make rates that are reasonable and just in view of such competition, and which will enable them to participate in the carriage of the traffic, and are not obliged to go out of the business and leave it as a monopoly to water carriers.

452. Where a common carrjer subject to the act to regulate commerce has established and published its schedule of rates and charges for a station on its line, free curtage furnished by the carrier for the collection and delivery of freight carried on its road to or from such stations operates as a reduction or rebate from the schedule charge and is unlawful. If free cartage at a station has the effect to reduce a rate below the charge at another station nearer the point of shipment it is unlawful as a less charge for a longer distance over the same line and in the same direction, the less being included within the greater.

458. Where a carrier by its published general traffic charges the general public from and to all points upon a large portion of its lines certain rates upon a class of freight, and at the same time publishes and puts into force a special tariff by which it charges a class of persons named, from and to the same points on jts lines less than one-half in amount of the rates on the same clnss of freight that it charges the general public in its general tariffs, such a discrimination is unjust and is violative of the act to regulate commerce.

459. Such a discrimination can not be sustained upon the ground that the special tariff is made to aid "emigrants" in moving from one state to another where land is cheap, and to develop a sparsely settled country, and to build up business along the carrier's lines, and upon the supposition that this constitutes substantially dissinilar circumstances and conditions to what exists when similar services are rendered by the carrier for the general public.

465. In arranging the elassification of articles of commerce their market value and the shipper's representations to the public as to their character may properly be taken into account in ascertaining the analogy they bear to other articles, and deternining the class to which they justly belong. This is especially applicable to articles in wh:ch there is no free competition anong producers and shippers. And carriers are not required to estimate the intrinsic value of freight as distinguished from its commercial value for purposes of elassification and rates.

166. The volume of traffic supplied by an article for transportation is also an element that may be considered in its classification, as a basis for rates that are reasonable both for earriers and shippers.

468. A lower charge for a longer distance for transportation of like traffic important in amount; and among the circumstances and conditions that may 
be considered in estimating the dissimilurity created by water competition are the charaeter of the roads, the character of the traffic, the preponderance of empty cars moving in a direction in which the traflic must be taken, and the legitimacy of the eompetition by the rail carrler.

569. The transportation of traffic under circumstances and conditions that force a low rate for its carriage, or an abandonment of the business, but which affords some revenue above the osst of its movement, and works no material injustice to other patrons of a carrier, is to be deemed legitimate competition. When, however, its carriage is at a loss, and imposes a burden on like traffic at other points, and on other traffic, it is to be deemed destructive and illegitimate competition.

470. Rates can not be arbitrarily charged in the mere discretion of a earrier. They are to be equitubly adjusted with regard to the public interests as well as the carriers. Reduced rates at points where competitive influences are controlling must not fall below some revenue from the traffic in excess of cost, and higher rates at other points, required for the necessary revenue of a carrier, must be reasonable in themselves, and also relatively reasonable in comparison with the competitive rate.

472. Where a reduced rate is made at the terninus of a through route, under the compulsion of competition, a town not located on the line of the through route, but reached over a lateral connecting road, has a disadvantage of situation entailing some additional expense, and a reasonably higher rate to such town than the forced competitive rate to the more distant terminus of the through route is not unjust discrimination.

474. A manufacturer's deseription of an article to induce its purchase by the public also describes it for transportation, and carriers may aecept his description for purposes of classification and rates. Carriers are not required to analyze freight to ascertain whether it is in fact inferior to the description or public representations under which it is sold, in order to give it a lower rate corresponding to its actual value.

476. The rate of compensation which railroad companies may lawfully receive for transportation services can not be so limited that the shipper may in all cases realize actual cost of production.

477. Charges for transportation service should have reasonable relation to cost of production and to the value of the service to the producer and shipper, but should not be so low on any as to impose a burden on other traftic.

478. In the carriage of great staples, which supply an enormous business and which in market value and actual cost of transportation are among the cheapest articles of commerce, rates yielding only moderate profit to the carrier are both necessary and justifiable, and where the carriers frequently put in force and continue for considerable periods of time tariffs of rates and charges, it is a fair inference that such rates and charges are profitable.

484. In fixing reasonable rates, the requirements of operating expenses, bonded debt, fixed charges, and dividend on capital stock from the total traflic are all to be considered, but the claim that any particular rate is to be measured by these as a fixed standard, below which the rate may not lawfully be reduced, is one rightly subject to some qualifications, one of which is the obligations must be actual and in good faith.

514. The mere fact that one article is of more general use and therefore shipped in greater quantities than another, when each as a rule is shipped in less than car-load quantities, and of no considerable difference in bulk, weight, and value, and of no appreciable difference in expense of handling and of haul, constitutes in itself no reason why the first should receive a lower rate than the last. In such a case mere quantity, not measured by any recognized unit of quantity adapted to carriage, and lessening the expense of handling and carriage, cannot be allowed to affect rates in the transportation of property.

522. A line of steamships plying between New York and Boston every other day makes the distance in twenty-four hours, does the largest part of the carrying trade of the grocers of Boston on shipments from New York, carries 
flour from New York to Boston for eight and one-half cents per one hundred pounds; other lines, part water and part rail, known as the "Sound Lines," make daily trips between New York and Boston, and carry flour from New York to Boston at nine cents per hundred pounds; an all-rail line composed of the lines of the defendants upon through billing and through rates to Boston alone on shipments from New York, makes daily runs between these points and carries flour from New York to Boston at nine cents per hundred pounds. Each and all of these carriers are in actual competition for this business, and it involves the carriage of traffic important in amount. Held, upon the facts, that this is a case in which the circumstances and conditions in the carriage of this commodity are substantially dissimilar at Boston to what they are at Readville, an interior town about eight miles from Boston, on the line of the all-rail carriers, where no competition exists between the all-rail carriers and the waterlines, and justifies the all-rail carriers in meeting the rate by the water-line at Boston, by charging nine cents per hundred pounds on flour, while the combined local rates of the two rail carriers are higher upon shipments of this kind of freight from New York to Readville than they are upon the joint through rate from New York to Boston.

561. Classification of freight. Freight classification is deemed by the railroads convenient and essential to any practical system of rate-making, and is so recognized, though not enjoined by the act to regulate commerce.

562. Same. When classification is used as a device to effect unjust discrimination or as a means of violating other provisions of the statute, the act requires the Commission to so revise and correct such classification and arrangement as to correct the abuse.

581. For a special serviee by a carrier, such as the transportation of perishable freight requiring quick movement, prompt delivery at destination, special fitting up of cars, their withdrawal from other service, and their return empty on fast time, all involving greater expense to the carrier, a higher rate than for the carriage of ordinary freight is warranted by the conditions of the service, and is reasonable and just.

582. But the higher rate for a special service should bear a just relation to the value of the service to the traffic, and is not wholly in the discretion of the carrier. While a carrier should be fully compensated, the public interests require that the traffic should not be rendered valneless to the producer if the charges of the carrier have such an effect and can be reusnnably reduced.

583. The requirement of the statute that all rates shall be reasonable and just involves a consideration of the commercial value of the traffic, and implies that rates should be so adjusted that producers of traffic, as well as carriers, may carry on their pursuits sucessfully, if practicable for both, and without injustice to the earrier. The public good requires what is plainly the spirit of the law, that the transportation interests are not alone to be considered, but that in the just exercise of regulation care should be taken that the lawful and necessary occupations of citizens are not unjustly burdened.

586. The relation of rates ought to rest upon fixed and stable conditions, The fluctuations of markets are so frequent, especially as to competitive artieles, and oftentimes unexpected, that commercial considerations alone would not furnish a sufficiently stable and fixed rule for guidance in making a rate that should remain substantially permanent through all fluctuations. The Commission does not, by a fixing of rates, attempt to overcome advantages which one producer or dealer may have in his geographical location, and to produce equality between competitors in all markets. It would be a useles task, even if it had the power, to attempt to accomplish such a result. The proper relation of rates for transportation of strictly competitive articles over the same line should be determined by reference to respective costs of service ascertained with reasonable accuracy.

587. Violation by one carrier of principles laid down in this case as governing relative rates on competitive articles clues not justify similar violations by its competitors. 
589. A firm of cattle dealers in the city of New York, who procured their cattle on a large scale from Chicago and other western points for domestic consumption as well as for export, make an arrangement with two interstate rail carriers, constituting a through line from Chicago to New York, that the said firm will, under a name of an express company of their own creation, furnish not less than two liundred or more than four hundred improved livestock cars for the transportation of these cattle. For the rental of these improved stock cars the carriers pay this express company three-fourths of a cent jer mile whether loaded or empty. Extraordinary facilities and rights of way are given these cars to enable them to make a large mileage, and they make more than twice the mileage of ordinary stock cars. Besides this, the carriers pay fifty cents for the loading of each of said cars with cattle at the Union Stock Yards in Chicago, for which no charge is made against the express company or the firm represented by it. In addition to this the carriers pay this firm yardage at the rate of three and one-half cents per hundred pounds on all their cattle, and upon all other cattle handled for other firms in the care of this firm owning the express company, to its yards at pier forty-five, East River. This yardage charge is thus paid to the said firm by the said carriers for keeping their cattle in the firm's own yards after delivery of them to the firm, and then this yardage charge is deducted from the tariff rate charged by the carrier. The amount of these rebates to this firm in rates on these cattle by these carriers more than pays the entire cost of the improved stock cars within two years after operations are commenced with them, including the expenses of operation, leaving said firm owning the cars and still operating them with all these advantages, and rates, and facilities. Held:(1) This is an unlawful preference to the firm owning these improved stock cars and a violation of the act to regulate commerce. (2) It is an unlawful and unjust prejudice to other cattle firms and dealers in New York who are competitors in the business of said firm owning said improved stock cars.

595. Same rate for longer and shorter distances. Ordinarily longer distances warrant higher charges, but carriers may lawfully accept the same aggregate, though less profitable, rates for longer distances, provided such carriers do not "subject any particular person, company, firm, corporation, or locality, or any particular description of traffic, to any undue or unreasonable prejudice or disadvantage."

609 . For the carrier to pay the larger expense of the transportation of a remote shipper's merchandise to the station, and not to pay the less expense of such transportation of the nearer shipper's merchandise, would be the equivalent of a rebate to the former, the railroad service proper being the same to each and at the same rate; nor would it be treating all patrons with statutable equality to bear a part of the cartage expenses for one shipper and not bear a part of $i t$ for : inother.

620 . The possible influence of water competition upon rates for the transportation of oranges and the nonexistence of such competition in the carriage of berries, because the latter can not be carried by water in any considerable quantities, does not authorize defendants to take advantage of the situation and charge unreasonable rates on berries.

632. Comparison with rates in other localities where dissimilar conditions and modifying circumstances are found is not sufficient to establish the unreasonableness of the charges complained of. When no discrimination is alleged as between points of production tributary to the same market, or on account of disproportionate rates on different kinds of traffic similar in character and volume, it must affirmatively appear that the charges assailed are unreasonable and ought to be reduced.

637. The Commission possesses no authority to compel carriers subject to its jurisdiction to provide any particular kind of cars or other special equipment, but, in the absence of adequate equipment freely afforded to all patrons alike, carriers should so adjust rates between those who can not furnish their own conveyance that in the relative charges to each there shall be no discrimination against the dependent shipper. 
657. The continued reduction of relative rates when brought about by the removal of artificial and unnatural differences is not undesirable, but where the difference results from dissimilar circumstances and conditions and the true difficulty appears to be a real and natural advantage which the one region has and enjoys over the other, such continuing disturbances of rates ought not to be inaugurated, especially when the charges are commodity rates not shown to be unreasonable in themselves.

652 . Salt requires and gets a commodity rate lower than class rates, and the roads should only be limited as to such lower rating by the rule that a commodity shall not be carried at such unremunerative rates as will impose burdens upon other articles transported to recoup loss incurred in carrying that commodity.

655. That rates should be fixed in inverse proportion to the natural advantages of competing towns with the view of equalizing "commercial conditions," as they are sometimes described, is a proposition unsupported by law, and quite at variance with every consideration of justice. Each community is entitled to the benefits arising from its location and natural conditions, and the exaction of charges unreasonable in themselves or relatively unjust, by which those benefits are neutralized or impaired, contravenes alike the provisions and the policy of the statute.

663. The competition of carriers subject to the act to regulate commerce does not create circumstances and conditions which the carriers can take into account in determining for themselves in the first instance whether they are justified under the fourth section in charging more for shorter than for longer distances over their lines.

664. The competition of markets on different lines for the sale of commodities at a given point served by both lines does not create circumstances and conditions which the carriers can take into account in determining for themselves in the first instance whether they are justified under the fourth section in charging more for shorter than for longer distances over their lines. To determine the force and effect of such competition involves consideration of commercial questions peculiar to the business of shippers, such as advantage of business location, comparative economy of production, comparative quality and market value of commodities, all of which are entirely disconnected from circumstances and conditions under which transportation is conducted. Carriers can not create abnormal situations by making rates which equalize advantages and disadvantages of localities and thereupon claim justification for greater charges on shorter hauls on the ground that the lesser long-haul charges which accomplish such equalization are necessary to secure increase in traffic over their lines.

665. The carrier has the right to judge in the first instance whether it is justified in making the greater charge for the shorter distance under the fourth section in all cases where the circumstances and conditions arise wholly upon its own line or through competition for the same traffic with carriers not subject to regulations under the act to regulate commerce. In other cases under the fourth section the circumstances and conditions are not presumptively dissimilar and carriers must not charge less for the longer distance except upon the order of this Commission.

669. Ownership of a car rented to a carrier and for the use of which the carrier pays a full consideration does not of itself entitle the owner to the exclusive use of such car, and, if the owner may in the contract of hire to the carrier stipulate for the exclusive use of the car, it must be upon such terms as shall not constitute an unjust discrinination against shippers of like traffic in cars owned by the carrier and who are excluded from the use of the car so hired.

676. Transportation by rail from eastern points to the "Pacific Coast terminals," Portland, Tacoma, and Seattle, is affected by the competition of controlling forco and in respect to traffic important in amount, of water carriers reaching the same terminals, but such competition does not affect like trans- 
portation from said points to the eity of Spokane, Wash. Held, therefore, that defendants are justified, by reason of sueh dissimilarity in eircumstanees and conditions, in mantaining higher rates on shipments of like property from said points for the slorter distance to spokane than for the longer distance to said Pacilie terminals.

The competitive position and attitude of the Canadian Pacific Railway, a foreign carrier, considered in connection with existing water competition, but the separate eflect of competition by the Canadian route not found or determined.

681. Continuance of a system of unjust rates ean not be required or exeused on the ground that parties have made investments, and entered into the business affeeted thereby on the faith of assuranees from carriers of their maintenance, although a change might work injury to the parties whom such rates had unduly favored.

682. An advantage resulting from just rates, coupled with the enterprise and outlay necessary to utilize them, is legitimate, and carriers should not undertake to deprive a shipper of this advantage by a change of such rates.

688. In passing upon the reasonableness of rates, the question whether they afford the carrier a proper return for the service rendered is to be considered as well as the result of the business to the shipper or producer of the traffic.

694. When great disparity exists between charges which are lower to competitive than to intermediate points much less remote, the inference is irresistible that the lower rate must be unremunerative upon any theory, or else the larger rate gives unwarranted return for the service rendered.

696. A town favorably situated with respect to one through route, but competing in a common market with another town more favorably located on another through route, should not have a reduction of the local rate over roads connecting the two through routes for the purpose of overcoming the natural advantage which the latter competing town enjoys.

704. Manufacturing industries should not be deprived, through a carrier's adjustment of relative rates, of advantages resulting from their favorable location in respect of cost of raw material supplied from a common source, or of distance to the common market for the finished product.

709. Unreasonable or unjust classification of a commodity is not shown by evidence of lower classification for articles widely dissimilar in the elements of risk, weight, bulk, value, or general character. The proper method of comparison is the classification aeeorded by the carriers to analogous articles.

722. The facts that one city is much larger and has nore important and extensive business interests than another, and has been treated by the carricrs in making rates to surrounding points as a "trade center," is no justification for a continuation of discriminatory rates in filvor of such eity. The object of the act to regulate commerce was to eradicate the existing system of rebates and unjust discriminations in favor of particulatr localities, special enterprises, and favored individuals.

732. When an article of traffic does not move on account of burdensone rates and the carrier is hauling a considerable number of empty cars in the direction such article would naturally move if accorded a lower rate, the carrier may be justified in earrying at a rate sufficient to induce the movement of such traffic, provided no extra or additional charge is in consequence put upon other articles carried; but the fact that freight will furnish return loads for empty cars is not a reason for the reduction of rates on such freight when it does not appear that the rates are unreasonable.

741. While the circumstances and conditions in respeet to the work done ly the carrier and the revenue earned are dissimilar in the transportation of freights in car-loads and less than car-loads, and a lower rate on car-loads than on less than car-loads is, therefore, not in contravention of the statute, yet the difference between the two rates must be reasonable.

744. Rates maintained and which may be reasonable under the conditions existing in one section or part of the country afford no safe criterion by which 
to measure reasonable charges in other localities where the expense of operating a road and other conditions affecting transportation are widely ditierent.

750. The practice of making one rate on the same product over a large district is only justifiable under special and exceptional circumstances, and is not to be encouraged when the difference in the transportation expense from the various parts of such district is considerable and substantial.

751. That railroad investments may be as secure as other property, the reasonable rates should be liberal until carnings are sufficiently large for a fair return on actual expenditure.

752. Where the market price yields but a scant return for the labor and expense of production, the cost of transportation needs to be as moderate as may be consistent with justice to the carrier.

758. A rate which may be reasonable when applied to the transportation of egg cases as a disconnected service may be unreasuliable if the carriage of returned cases at favorable rates is in fact a special service, the discontinuance of which would unduly burden the business of shipping eggs to points of sale.

764. Each locality competing with others in a common market is entitled to reasonable and just rates at the hands of the carriers serving it, and to the benefit of all its natural advantages, and no departure from the rule requiring rates in all cases to be reasonable in themselves can be justified on the ground that it is necessary in order to maintain existing trade relations, or to "protect competing markets," or to "equalize commercial conditions," or to secure to carriers traffic from certain territory assumed to be exclusively theirs.

773. Under the proviso to the fourth section of the act to regulate commerce it is left to the Commission, in the exercise of a reasonable and lawful discretion, to determine the description or exceptional character of the "special cases" in which the Commission may, after investigation, authorize common carriers to charge less for longer than for shorter distances, and to the extent to which such carrier may be relieved from the operation of this section of the act.

782. Where a carrier pays mileage for a car which it employs in the service of shippers it is the carrier and not the party or company from whom the car is rented who furnishes the car to the shipper, and in such cases there is no privity of eontract between the car owner and the shipper.

783. It is the duty of the carrier to furnish an adequate and suitable car equipment for all the business it undertakes and also whatever is essential to the safety and preservation of the traftic in transit.

784. When carriers undertake the transportation of perishable traffic requiring refrigeration in transit, ice and the facilities for its transportation in connection with that traffic, are incidental to the service of transportation, and the charge therefore is a charge "in connection with" such service within the meaning of section 1 of the act to regulate commerce, in respect to the reasonableness of which the carrier is subject to that provision of the statute.

795. While carriers operating shorter lines have the advantage, both in making rates and in carrying under them, they ean not dictate a system of charges which the operators of longer lines may not charge as to their own roads, though it may be true as a rule, and as claimed by defendants, that, to get business, longer lines must take it as low as rates at the time in force over more direct routes.

821. Excess of manufacturing cost to a complainant at one point over that of its competitors in other localitics, by reason of inferior raw material and fuel, condition of its plant, cost of labor or other like causes, is not to be considered in ascertaining the rightful relative adjustment of rates from such places, nor does the magnitude of a complainant's enterprise, the number of persons for whom it provides employment and support, the developing results of its business upon the natural resonrces of a state, the impracticability of moving its plant to other localities, or the fact that it produces matcrial largely used on railroads for construction or repair, entitle such complainant to different consideration in respect of just rates than individuals and small concerns should reccive; but such facts demonstrate the far-reaching extent to which scrious 
injury may be effected directly and indirectly, by methods and practices which the statute was designed to prohibit.

825. The action of a carrier in diverting through traffic from a shorter route over which it participates in carriage, so as to require for itself greater aggregate revenue through a long haul by a different poute over which it is also engaged in transportation, sometimes results in diseriminations and prejudices, both as to rates and facilities; and inequality in treatment of shippers and localities, having no other justification than this end, is indefensible.

852. When rates are relatively unjust, so that undue preference is afforded to one locality or undue prejudice results to another, the law is violated and its penalties incurred, although the higher rate is not in itself excessive, and such rule is especially applicable where a given relation in rates, long continued and concededly equitable, is suddenly and almost completely reversed, merely because other carriers to the longer distance point have disregarded their legal duty.

860. A railway company owning the entire stock of a development company, which had been organized for the purpose of holding the title to certain lands of the railway company, caused grain to be purchased in Kansas City in the name of the development company, transported over the lines of the railway company to Chicago, and there sold upon the market. The development company had no bona fide interest in the transaction. Neither the railway company nor the development company purchased the grain for the purposes of ownership, the whole transaction being simply a device to secure its transportation at other than the published rate; and the only rate paid was the profit upon the transaction, which varied with each shipment. Held, that this constituted a violation of the second, third, and sixth sections of the act to regulate commerce.

867. Complainant offered the defendant a car-load of potatoes at Verona, Miss., and asked that the shipment be forwarded to Cleveland, Ohio, via a connecting line, with which defendant had at the time through billing arrangements and through rates, but defendant's agent refused to receive and route the shipment in accordance with such direction, and complainant was thereby damaged to the extent of $\$ 100$. Held, that complainant was entitled to have his merchandise carried over the route which he directed, and that the failure of defendant to receive and forward the shipment accordingly was a discrimination against complainant in violation of the act to regulate commerce. Reparation ordered.

878. Charging the same aggregate rates on like traffic for longer and shorter distances over the same line in the same direction does not contravene the provisions of section 4 of the act to regulate commerce.

882. A uniform or blanket rate on milk, and also on cream, from all stations on the defendant lines to Weehowken, Hoboken and Jersey City, N. J., or through Jersey City to New York, N. Y., namely, thirty-two cents on milk and fifty cents on cream per can of forty quarts, regardless of distance or difference in amount of service rendered. Held, to be unreasonable, unjust and unduly prejudicial and in violation of sections 1 and 3 of the act to regulate commerce.

902. Water competition, to justify higher shorter-distance charges under the fourth section, must be actual competition for the transportation involred, and such as to dictate the rate by rail. $\Lambda$ railroad rate so low as to drive water transportation ont of existence cannot be justified by showing the possibility of water competition; the law permits railroads to meet, not to extinguish, such competition.

903. Competition between markets, or between carriers subject to the regulating statute, does not create such dissimilarity of circumstances and conditions as will justify carriers in charging more for the short than for the long haul, under the fourth section, without an order of the Commission.

905 . Railroad companies have the right to earn a proper return upon some investment, just what has not been very definitely determined; but in earning 
such return they must operate their properties in accordance with the provisions of the statute forbidding discrimination between localities and charging more $\mathrm{fcr}$ the short than for the long haul.

928. The public right to a just relation of rates between rival communities arises from the statute which forbids discriminating charges, and that right cannot be abridged or enlarged by agreements of carriers with each other, nor by promises made to shippers.

935. Although the act to regulate commerce requires that transportation charges shall be reasonable and just, and complainant prayed in his petition that defendants be ordered to establish and maintain such rate on coal in carloads from Cumberland, Md., to North Garden, Va., as should be deemed just, reasonable, and lawful, the act as recently interpreted by the courts, makes no provision under which carriers can be required or ordered to maintain any rate other than such rate of charges as any such carrier may fix and establish for itself.

941. Wrongs caused by improperly adjusted rates over independent lines from competing cities to a common destination cannot be corrected without authority to prescribe both a maximum and minimum rate, and the Commission is not empowered to do either.

960. Any person or association is entitled to eomplain before the Commission of any failure on the part of carriers to publish and enforce transportation or terminal charges, rules, and regulations, and that such failure results from special privileges allowed to shippers on many important lines.

967. Railroad companies are not prohibited by section 3 of the act from preferring one locality over another, unless the preference is undue or unreasonable, but a preference which is without legitimate excuse, is, in and of itself, unreasonable.

969. Carriers frequently disregard distance in making their rates, and they may lawfully do so under some circumstances; but distance should be regarded wherever possible, and no previous decision is authority for a ruling that a carrier may be compelled to disregard it for the purpose of placing two communities upon a commereial equality.

980. The exaction of as high rates for a shorter haul as for a longer haul over the same line in the same direction, the shorter haul being included within the longer, is itself a diserimination, and, if not justified by a substantial dissimilarity of circumstances and conditions, is an unjust discrimination.

981. In respect to competition as justifying discrimination, the Supreme Court of the United States has only gone to the extent of holding that it " may in some cases" be such as "having due regard to the interests of the public and of the carrier, ought, justly, to have effect upon rates," and that the mere fact of competition, no matter what its character or extent," does not necessarily relieve carriers from the restraints of the third and fourth sections of the act to regulate commerce.

982. The Supreme Court of the United States, while denying power in the Interstate Commerce Commission to enforce the provision of section 1 of the act to regulate commeree, namely, that all charges shall be reasonable and just-by orders prescribing reasonahle maximum rates, expressly recognizes the authority and duty of the Commission to enforce sections 2, 3, and 4 of the act.

\section{EXTRACTS FROM THE REPORT OF THE INTERSTATE COM}

\section{MERCE COMLIISSION FOR 1898.}

After stating that the Commission, in former reports, has called the attention of Congress to the vital defects of the act to regulate commerce, and has thereby performed its full duty, the report goes on to say :-

"Meanwhile the situation has beeme intolerable, both from the standpoint of the public and the carriers. Tarif's are disregarded, discriminations con- 
stantly occur, the price at which transportation can be had is fluctuating and uncertain. Railroad managers are distrustful of each other and shippers all the while in doubt as to the rates secured by their competitors. Enormous sums are spent in purchasing business, and secret rates accorded far below the standard of published charges. The general public gets little benefit from these reductions, for concessions are mainly confined to the heavier shippers. All this augments the advantages of large capital and tends to the injury and often to the ruin of smaller dealers."

In discussing attempts of the Commission to extort the truth as to these practices from railroad officials, the following expressions are used by the Commission:-

"The inquiry was greatly hampered by the disappearance of material witnesses;" and the "inability of several who did testify to recall transactions of then recent date." "All of the railway witnesses denied knowledge of any violation of the statute," but "it was nevertheless established that secret rate concessions had been generally granted on this traffic, and that the carriers had allowed larger rebates to some of the flour shippers than to others."

Several pages of the Report of 1898 are devoted to matter of this kind affecting many railroads, and some of the methods adopted to violate the act without detection are exposed. It is evident that the Commission believes that the entire railroad system of the country is permeated by frauds, by means of which the rich oppress the poor, but which the Commission is without power to remedy.

The farmers will do well to see that the Commission is clothed with the power, or that their congressmen tell them the reason why not.

\section{STATISTICS OF RAILWAYS IN THE UNITED STATES.}

FROM THE REPORT OF THE U. S. INTERSTATE COMMERCE COMMISSION FOR 1898.

Total railway mileage, June $30,1897 \ldots \ldots$

Increase over previous year. . . . . . . . .

Total mileage, including side tracks and double tracks

Increase over previous year. .........

No. railway corporations. . . . . . . .

No, actually operating roads . . . . .

No, roads in hands of recievers . . . . . . . .

Mileage operated by same. . . . . . . . .

Decrease from previous year . . . . . . . .

Total No. of locomotives in service . . . . . . .

Total No. of cars.............

Total number of men employed. . . . . . .

No. of men to each 100 miles of line. . . . . . . .

The employees were distributed as follows:-

Administration (doubtless including solicitors). . . .

Maintenance of way and structure. . . . . . .

Maintenance of equipment. . . . . . . .

Conducting transportation . . . . . . . . . . 378,361

Unclassified. . . . . 7,704

Amount paid in wages and salaries . . . . . \$4 465,601,681

Decrease from previous year . . . . . . . . $3,222,950$

Total nominal capital . . . . . . . 10,635,008,074

Nominal eapital per mile. . . . . . . . . . 59,620 
The capital was divided as follows:-

Bonds . . . . . . . . . .

$85,364,642,255$

Stock paying no dividends . . . . . . . . . .

Bonds paying no interest. . . . . . . . . . . .

Total dividends paid on stock. . . . . . . .

Average dividend paid by dividend paying stocks . .

Current (unfunded) liabilities. . . . . . . .

Interest paid on funded debt . . . . . . . .

No. passengers carried . . . . . . . . .

No. passengers carried one mile. $\ldots$

Tons freight carried . . . . . . . . . .

Tons freight carried one mile. . . . . . . .

Gross earnings. . . . . . . . . . .

Earnings from passenger service. ......

Earnings from freight service. ........ \{

Earnings from express. ...........

Earnings from mail $\ldots$

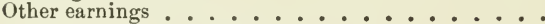

Total operating expenses. . . . . . . . . .

$3,761,092,277$

$867,950,840$

$87,110,599$

5.43 per cent

\$ $578,501,635$ $247,880,230$

$489,445,198$

$12,256,939,647$

$741,705,946$

$95,139,022,225$

$\$ 1,122,089,773$

$251,135,927$

$6,629,980$

$772,849,314$

4209,657

$24,901,066$

$33,754,466$

$28,609,363$

$752,524,764$

Divided as follows:-

Maintenance of way and structures . . . . . .

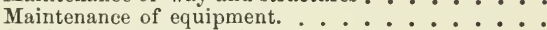

$\$ 159,434,403$

$122,762,358$

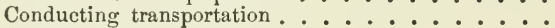

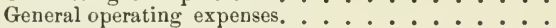

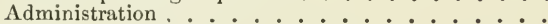

Interest on funded debt.

Taxes. . . . . . . . . .

Permanent improvements. . . . . .

$432,525,862$

$36,481,269$

508,598

$247,880,230$

$43,137,844$

$4,544,813$

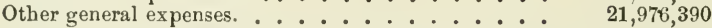

The sums disbursed for interest on funded debt and for dividends represent the net income of the roads. These were:-

Dividends on stock. .......... . $\$ 87,110,599$

Interest on bonds. . . . . . . 247,880,230

Total income divided. . . . . . . . . $\$ \$ \$ 334,990,829$

This sum paid in dividends or interest represents:-

At $6 \%$ a capital of. . . . . . . . . . $\$ 5,575,160,482$

At $5 \%$ " . . . . . . . . . . $6,699,816,580$

At $4 \%$ " " . . . . . . . . . $8,374,770,725$

These sums may therefore be taken as the actual current value of the railroads of the United States, regardless of their prospects for the future, the larger or the smaller sum being taken, according as one may believe, four, five, or six per cent to be the proper rate of interest. In this case, also, the net income is spread over the whole mileage, although some roads were operated at a loss. If we deduct from the total capitalization of the roads (stock and bonds) the amount of stock which paid no dividends, and is, to a great extent, doubtless, mostly "water," there remains the sum of $\$ 6,873,915,797$, which is 
very nearly the sum upon which five per cent interest was paid in 1897. Upon the average, therefore, railroad investments in America pay very wुell indeed, all this being free of taxes, or, at least, mostly free, and very much better than investments in farms. The wish of the railroad owners is to make the roads pay as good interest as possible upon their entire paper capitalization. It is the wish of the farmers and others that this should not happen, but that increasing business should be accompanicd by such diminution of rates as will keep down revenue so that it no more than pays fair interest on actual and honest investment, reserving the "unearned increment" to the people. The railroad owners claim that they are entitled to the unearned increment because they took the risk of construction, and in many cases have lost money. That is one phase of the "railroad question." 


\section{Appendix F.}

COOPERATION.

\section{COOPERATION AMONG FARMERS.}

There are few statistics of cooperation among farmers in the United States for business purposes. There is probably mueh more of it than we know anything about. As is inevitable in the beginning of the practice, large numbers of societies are started without adequate foundation and amount to nothing. Still others start off well, but develop no staying qualities, and soon pass away. In many cases societies-especially cooperative creameries-are started by those who do not develop the business capacity to make them profitable, and so pass into the hands of better business men, as private concerns, while still retaining the cooperative title.

The purposes for which cooperative societies of farmers have been formed in this country, are, in the probable order of their relative importance, ereameries, irrigating ditch companies, fire insurance companies, marketing societies, general stores, and flouring mills. Our decennial eensus reports ought to show the facts as to the progress of cooperative work, but thus far have not done so. I understand that there is a probability that some inquiry will be made as to these facts in the census of 1900 . I am not able to find data from which to form any estimate of the present status of cooperation in the United States, and therefore do not attempt it.

I gathered, in 1898, for the United States Department of Agriculture, as good a list as was possible by correspondence, of the farmers' cooperative societies of California. It included seventy-three irrigating diteh companies (certainly incomplete), three flouring mills, and two fire insurance companies. It was impossible to obtain by correspondence a list of the cooperative creameries. Some of the granges and farmers' clubs do more or less purehasing for their members. There were once a good many cooperutive stores, but none were ever managed on the Rochclale plan, and while some are still in existence and retain the cooperative title, if any remain really cooperative I do not know it.

The following is a list, very nearly correct, of the cooperative fruit marketing societies of California which actually did business in 1898 , or are so organized as to give reasonalle assurance of permanenee. Quite a number of new ones are in process of organization; the sules of these societies, in 18,98- 
1899 aggregated over $\$ 5,000,000$, with a membership of something less than seven thousand. An estimate of the average capital of the members at $\$ 3,000$ each would give a total product capital of $\$ 21,000,000$.

Citrus Fruit Societies, Selling through the Southern Californin Frnit Wxchanges, 122 West Third Street, Los Angeles.

Duarte-Nonrovia Fruit Exchange, Duarte.

San Antonio Fruit Exchange, Pomona.

Semi-Tropic Fruit Exchange, Los Angeles.

Azusa-Covina-Glendora Fruit Exchange, Azusa.

Riverside Fruit Exchange, Piverside.

San Bernardino Fruit Exchange, Colton.

Orange County Fruit Exchange, Orange.

Queen Colony Fruit Exchange, Corona.

Ontario-Cucamonga Fruit Exchange, North Ontario.

Santa Barbara Lemon-Growers' Exchange, Santa Barbara.

San Diego County Fruit Exchange, Chula Vista.

Chula Vista Fruit Exchange, Chula Vista.

Fallbrook Fruit Association, Fallbrook.

Fillmore Citrus Association, Fillmore.

El Cajon Fruit Exchange El Cajon.

\section{Independent Citrus Exchanges.}

Redlands Orange-Growers' Association, Redlands.

Redlands Fruit Association.

Highland Orange-Growers' Association, Messina.

East Highland Orange-Growers' Association, East Highland.

Golden Belt Fruit Company, Fullerton.

Placentia Fruit Exchange (?), Fullerton.

\section{Dried Fruit Marketing Societies.}

Santa Clara County Fruit Exchange, San Jose.

West Side Fruit-Growers' Union, Santa Clara.

East Side Fruit-Growers' Union, San Jose.

Berryessa Fruit-Growers' Union, Berryessa.

Campbell Fruit Union, Campbell.

Willow Glen Fruit Union, Willow Glen.

Woodland Fruit Exchange, Woodland.

Niles Cooperative Fruit Association, Niles.

Pajaro Valley Fruit Exchange, Watsonville. (Handles fresh fruit also.)

Napa Fruit Company, Napa.

Visalia Fruit-Grower' Union, Visalia.

The Following Dried Fruit Associations are affliated with, and Sell through, the Southern California Deciduous Fruit Erchanges, 123 West Third Street, Los Angeles.

Pasadena Fruit Exchange (three associations), Pasadena. 
Burbank Fruit Association, Burbank.

Manzana Fruit Association.

San Gabriel Fruit Association, San Gabriel.

Duarte Fruit Association, Duarte.

North Pomona Fruit Association, North Pomona.

San Jacinto Fruit Association, San Jacinto.

Perris Fruit Association, Perris.

Anaheim Fruit Association, Anaheim.

Fillmore Fruit Association, Fillmore.

Cucamonga Fruit Association, Cucamonga.

Fallbrook Fruit Association, Fallbrook.

(The societies selling through the Southern California Deciduous Fruit Exchanges were all organized in 1898. Owing to the drought of that year some of them had no fruit to sell, and have, therefore, never yet actually transacted business. At the present time other organizations are forming, and the central organization also handles the fruit of some individual growers.)

\section{Walnut Marketing Associations.}

Los Nietos and Ranchita Walnut-Growers' Association, Rivera.

Mountain View Walnut-Growers' Association, El Monte.

Santa Ana Valley Walnut-Growers' Association, Santa Ana.

Saticoy Walnut-Growers' Association, Santa Paula.

Santa Barbara Walnut-Growers' Association, Santa Barbara.

Fullerton Walnut-Growers' Association, Fullerton.

Golden Belt Fruit Company, Fullerton.

(The Golden Belt Company, and possibly others, also handle citrus fruits. The walnut-growers' associations annually meet and agree upon a common seale of prices, to which all adhere. The associations control the walnut market, subject to the competition of imported walnuts.)

$$
\text { Raisins. }
$$

California Raisin-Growers' Association, Fresno.

Wine.

California Wine-Makers' Corporation, Crocker Building, San Francisco.

$$
\text { Fresh Fruits. }
$$

Contra Costa Fruit-Growers' Union, Martinez.

Florin Fruit-Growers' Association, Florin.

\section{Honey.}

California Beekeepers' Exchange, Lang.

The most important cooperative societies of farmers outside the United States are the "Agricultural Syndicates" of France. These, in the main, are societies for the purchase of supplies, especially fertilizers, and of farm machinery for rental to the members. Some of them also do more or less marketing. The aggregate membership of these societies is very large, but I 
have not been able to find late statistical information in regard to them or in regard to the "peoples' banks," which are established in many countries of Continental Europe, and in many cases almost exclusively for the benefit of farmers. Cooperative creameries seem to succeed better in Denmark than anywhere else, and there are some in Ireland. In England there is little or no cooperation among furmers, as we usually think of them in the United States, but there is more or less systematic effort to promote organization of small societies of farm laborers for the rental or purchase of land to be farmed cooperatively. This is favored by some of the cooperative stores as a means of employment of their surplus capital, to be used in this manner in aid of the farm laborers. Quite a number of such societies have been formed, but thus far have usually been unsuccessful, except when the cooperative store supplying the capital afforded a home market for the product of the farm. The British cooperators, however, expect to solve the problem of cooperation among farmers for productive purposes.

\section{COOPERATION AMONG OTHERS THAN FARMERS,}

Whatever the form which the struggle for existence may take with individuals, they invariably turn, whenever it becomes severe, to the idea of cooperation. It is an instinct pervading all nature, whose exercise is recognized by social philosophers as the panacea for all curable ills of society. We are not all philosophers, however, and sometimes our views of cooperation, being confined to the bounds of our immediate necessities, are very narrow. The ant's conception of cooperation may be simply of help enough to carry off a dead beetle. The Californian farmer thinks of cooperation as a device to enable him to get higher prices for his wheat at Liverpool. The British farmer thinks of it as a means for preventing his Californian competitor from selling in Liverpool at all, while the British artisan thinks of it as a means of getting cheap bread. I am unable to see any difference between the principle which leads Tim and Mike to join, under the persuasion of a benevolent society, in a cooperative dairy in Ireland, and that which moves Smith and Jones, under the persuasion of a shrewd promoter, to join in buying Mr. Carnegie's steel plants for six hundred millions of dollars. Of course there is a great difference between the motives which inspire the society in the one cuse, and the pro. moters in the other, but as for Tim and Mike and Smith and Jones they all alike wish to increase their incomes. Of course, also, my own feelings towards the two enterprises are very diflerent. I earnestly desire that Tim and Mike may succed, because they are not now receiving proper reward for their own hard labor, while I shull be quite content to see Smith and Jones lose their money because they are seeking, by cooperation, to obtain what other people must work to pay for. And I wish Tim and Mike well none the less because I know that if ever they find themselves strong enough they will ruthlessly make me pay $\$ 10$ a pound for my butter or go without it. As I think, so thinks society, which almost unanimously favors the association of the weak. while opposing that of those who are already strong. The one it calls "cooperation," while the other is termed a "combine." It seems to me that this instinctive feeling in all of us is an expression of sound, logical common sense, 
We must encourage the cooperation of those whose sacrifices do not procure for them just satisfactions, while vigorously restraining that of those who are getting what they do not earn. I recognize that the object of the farmers Raisin Trust of California is to compel me to pay the highest possible prices for my raisins, just as that of the Sugar Trust is to compel me to pay the highest possible prices for my sugar, and yet I would support the one and subdue the other, because the one, at present, seeks justice, and the other injustice. Whenever the Farmers' Trust attempts to do injustice, as it will if it ever has the power, I would subdue that also. I think it very desirable that farmers come to take this broad view of cooperation, and hence include in this appendix a few facts regarding cooperation by others than farmers.

In regard to the general statistics of cooperation in the United States, it must be said that there is the same lack of information that exists in regard to cooperation among farmers. One cause of this is the lack of proper legislation. One of the first things to be done in this country in the cause of cooperation is the drafting of a proper law for the regulation of cooperative societies and their registration under it. Such a law would provide for complianee with certain conditions essential to security and stability, define the rights and obligations of membership, and provide for registration and regular annual reports. This is done in older countries, and is necessary here. Such a law, when drafted, could be passed without difficulty, by a little organized effort in all the states. In California, and probably in some other states, no proper law could be passed, except after a constitutional amendment. In Appendix D will be found references to a few books giving such information as there seems to be about cooperation in this country. I sought to obtain later information, but could get little or none. The following letter from Mr. N. O. Nelson, of St. Louis, which is all of value which I have been able to get, is given in full because of its general interest, although not intended for publication, and referring to various matters not closely connected :-

St, Louis, Mo., March 22, 1899.

Dear Mr. Adaus :-Cohn \& Co., musical instrument makers, Elkhart, Ind.; Proetor \& Gamble, soap makers, Cincinnati, Ohio; Spencer, Trask \& Co.. bankers, New York, are the only profit-sharing concerns of consequence that now oceur to me in this country. [Mr. Nelson should have included his ownThe N. O. Nelson Mfg. Co., Leclaire, Ill., E. F. A.] The system keeps growing in France, and still more so in England, where an active propaganda is carried on by an association. The plan was adopted by a considerable number of concerns in this country in the later eighties, but was abandoned by most of them in the course of a year or two. There are, no doubt, a great many scattered over the country, which have been given no publicity. There was an association formed in 1892 under the leadership of N. P. Gilman, author of "Profit-Sharing between Employer and Employees," but it was abandoned for" lack of sufficient support. Fifteen hundred dollar's is the largest salary paid to English cooperative managers. Mr. Fawcett, who has long been the head of the great Leeds Society, with its 33,000 members and annual business of about five million dollars, gets this amount. He is of a ealiber to easily command ten thousand in private employment. J. T. W. Mitchell was chairman of the English Wholesale for twenty-one years, building it up from one nillion to fifty millions a year. He never took beyond one thousand a year, and out of this he bore some incidentals connected with lecturing trips and attendance on meetings, where his expense account was overlooked. He was a man of so 
much all-around ability that just before his death he was elected a trustee of the great Manchester Ship Canal, which, however, he declined. Salaries in large concerns are quite as liberal in England as in this country. He could, no doubt, have obtained twenty-five thousand a year, had he been willing to resign his more attractive work and dutiful life at the head of the eopperative business.

In this country, the ehief cooperative stores are the Arlington, at Lawrence, Mass., with thirty-five hundred members, three hundred thousand dollars sales, seven and one-half per cent regular dividends on purchuses, besides the interest on capital, and liberal additions to the surplus fund; the Johnson County Cooperative Association at Olathe, Kansas, which is eonfined to Patrons of Husbandry, but sells to the general public. It is twenty-two years old, has a business of two hundred and fifty thousand dollars a year, has two branehes, and from it have sprung the leading bank of the town and a good insuranee company. I have been at both of these plaees and found them unusually vigorous and progressive. There are well-established and important stores at Lyons, Iowa, Trenton, N. J., and Galveston, Texas. There are a great many smaller and younger ones in the East and in the Mississippi Valler. The West is full of cooperative ereameries, small flour mills and canneries. Of cooperative colonies, the ones at Ruskin, Tenn., Commonwealth, Ga., and Belfast, Wash., are the more important. They are doing tolerably well. I have visited the former two at different times. I have coneluded that there is not much outcome to the colonies when not inspired by anything but economic motives. I exceedingly regret that I can give you so very little information, but, as you say, it is harder to get at in this country than in foreign lands. Yours very truly,

N. O. Nelsox.

In Great Britain cooperation has developed mainly on the lines of merchandising and production. It has had a normal, although surprising development. Beginning with a eapital of a few pounds, contributed by workmen, in sums of a few shillings each, for the establishment of a retail store, the movement has grown to the proportions about to be described. The faithfulness of the Rochdale pioneers assured suecess for their enterprise, and their success led to the establishment of similar stores elsewhere. The opposition of private traders in some cases prevented the cooperative stores from obtaining supplies from wholesale merehants, and this led to the establislument of the great English and Scottish wholesale stores. The eapital of these great societies is mainly contributed by the retail stores, to which, only, the wholesale societies sell. As trade has increased, the wholesale societies have engraged in the manufacture of some of the merchandise most in demand. They hare branch establishments for buying in all countries in whose produce they deal, and own a fleet of several steamers. Being constantly eharged with the eustody of the surplus funds of the soeieties, they were led to open banking departments. They bid fair to, in the end, cover the entire field of manufacturing articles most in demand by the retail trade.

The greater part of the eapital of the cooperative societies of Great Britain has been derived from the profits of the business. Goods ure invariably sold at the retail prices charged by private firms. The profits go, first, to the payment of a small dividend on the share capital, next to the creation of a surplus fund. as security against losses, and the remainder as rebates to purchasers. In some cases the salesmen and other employees, as such, receive a portion of the profits, and in other cases they do not. In most cases regular provision is made from the profits for carrying on educational work, and many of the more prosperous 
societies own halls, which are used for such purposes. Purchases and sales are made for cash only, thus inculcating a spirit of thrift. The educational work is yearly becoming more prominent, and cooperation among all classes is promoted in the true missionary spirit. The cooperative movement in Great Britain has developed a body of wonderful men, practically all of whom are individually poor, and yet carrying on with great ability, and constantly extending business enterprises involving the wise employment of great sums of money, and the organization and direction of a great force of employees. The English Wholesale Society is the largest strictly mercantile business in the world. There is only space here for a very brief statistical summary, condensed from the report of the Thirtieth Annual Cooperative Congress of Great Britain (1898), which is a volume of 286 large quarto pages. The pounds sterling may be roughly turned into United States money by multiplying by five.

\section{DISTRIBUTIVE (RETAIL) SOCIETIES.}

THE POSITION OF COOPERATION IN GREAT BRITAIN, 1898.

\section{General Statistics.}

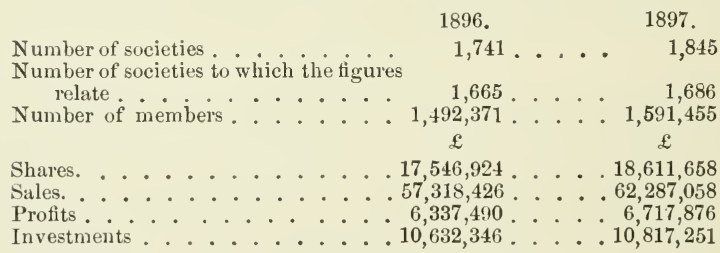

These figures are made up in the following manner:-

\begin{tabular}{|c|c|c|c|c|c|c|}
\hline & \multicolumn{2}{|c|}{ Societies. } & Members. & $\begin{array}{c}\text { Shares. } \\
£\end{array}$ & $\begin{array}{l}\text { Sales. } \\
£\end{array}$ & $\begin{array}{l}\text { Profits. } \\
£\end{array}$ \\
\hline ele & 1896 & 2 & 1,327 & 870,524 & $14,937,638$ & 383,264 \\
\hline & 1897 & 2 & 1 , & 940,237 & 5,464 & 346,040 \\
\hline ies & .1896 & 1,453 & $1,378,036 \quad 15$ & $5,367,319$ & $36,942,030$ & $5,724,535$ \\
\hline “ & 1897 & 1,469 & 3416 & $3,318,760$ & 40 & 6,14 \\
\hline soci & 1896 & 259 & 38 & 771,806 & 947 & 156,59 \\
\hline & 1897 & 339 & & 808 & 87 & 166,329 \\
\hline$i i$ & 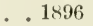 & 17 & & 53 & & 73,06 \\
\hline " & 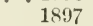 & 19 & 81,2 & 541,673 & 2,72 & 64,46 \\
\hline cieti & 1 & 10 & 332 & 1,115 & 02 & \\
\hline & 1897 & 16 & 1,255 & 2,523 & 113,398 & 2 \\
\hline
\end{tabular}

The following table will show the advance made by distributive cooperation in recent years:-

\begin{tabular}{|c|c|c|c|c|c|}
\hline & Societies. & Members. & Shares. & Sales. & Profits. \\
\hline $\begin{array}{l}1887 \\
1897\end{array}$ & $\begin{array}{l}1,348 \\
1,469\end{array}$ & $\begin{array}{r}858,237 \\
1,465,564\end{array}$ & $\begin{array}{c}f \\
8,461,888 \\
16,318,760\end{array}$ & $\begin{array}{c}\mathbf{f} \\
22,343,651 \\
40,125,359\end{array}$ & $\begin{array}{c}\underset{f}{f} \\
2,940,337 \\
6,140,821\end{array}$ \\
\hline
\end{tabular}

* Under this head are included the numerous Irish Agrieultural and Dairy Societies, 


\section{Productive Societies.}

\begin{tabular}{|c|c|c|c|c|c|c|}
\hline & $\begin{array}{c}\text { Number } \\
\text { of } \\
\text { Societies. }\end{array}$ & $\begin{array}{l}\text { Number } \\
\text { of Em- } \\
\text { ployés. }\end{array}$ & $\begin{array}{c}\text { Capital } \\
\text { Em- } \\
\text { ployed. }\end{array}$ & $\begin{array}{c}\text { Trade } \\
\text { during } \\
\text { Year. }\end{array}$ & Profit. & Loss. \\
\hline & 12 & 5,9 & $\stackrel{£}{£}$ & $\stackrel{£}{ \pm}$ & $\stackrel{f}{f}$ & $\stackrel{f}{f}$ \\
\hline " " $1897 \ldots \ldots \ldots$ & $1:$ & 6 , & 946,238 & $2,211,904$ & 106,036 & $\begin{array}{l}1,042 \\
4,255\end{array}$ \\
\hline Seotland, ${ }_{1896} 189 \ldots \ldots \ldots \ldots$ & 24 & 1,37 & 268 & 411,125 & 48,272 & - \\
\hline Ireland, 189 & 23 & 1,52 & 275 & 475 & $\begin{array}{r}55,362 \\
4,602\end{array}$ & \\
\hline " & 118 & 1 & $\begin{array}{l}33, \\
39,\end{array}$ & $\begin{array}{l}252 \\
276\end{array}$ & $\begin{array}{l}4,602 \\
4,540\end{array}$ & 9 \\
\hline *English Wholesale, 1896 . & 1 & 5,634 & 639 & $1,149,390$ & 35,666 & 3,7 \\
\hline * " " 1897. & 1 & 6,809 & 695, & 1,385 & 34,421 & 5,19 \\
\hline †Seottish Wholesale, ${ }_{*}{ }^{1896}$. & 1 & & & 720,713 & 35,938 & \\
\hline . & & & & 1.10 & & \\
\hline $\begin{array}{c}\text { Total, } \\
\text { “ } \\
18967 .\end{array}$ & $\begin{array}{l}261 \\
274\end{array}$ & $\begin{array}{l}16,512 \\
18,458\end{array}$ & $\begin{array}{l}2,181,944 \\
2,324,445\end{array}$ & $\begin{array}{l}4,496,081 \\
5,458,406\end{array}$ & $\begin{array}{l}228,193 \\
256,044\end{array}$ & 1,0 \\
\hline
\end{tabular}

*Twelve productive departments.

†Eleven productive departments.

In Continental Europe the greatest development of cooperation has been in the dirtection of credit and loan associations_- "People's Banks." These had their origin in Germany, but have spread all over continential Europe. There are two forms of these banks, known from the names of their originators, as the Schulze-Delitzsch and the Raiffeisen banks. The latter are the more altrustic in spirit and the most widely extended. The main principle of nearly all these banks is the unlimited liability of every member of an association for all debts of the association. With this security the banks are enabled to borrow money very cheaply, to be loaned to their members, with only sufficient profit to pay expenses upon the most economical scale. There are also, of course, the proceeds of the stock taken up by the members, and the deposits. I do not find, where I write, any late statistics of the business done by these banks, but in the aggregate they amount to hundreds of millions of dollars annually, and form altogether the most imposing display of the power of cooperation in business affairs.

Other forms of cooperation are the trade unions and other friendly societies in the matter of life and health insurance, fire insurance societies, building and loan societies, and profit sharing. Taken together, the amount of cooperative business done in the world is astounding to those who first come to the study of it. It has been demonstrated many times over that the aggregate savings of the poor are far in excess of the aggregate capital of the rich, and that there is quite as much capacity for the wise employment of capital, and its profitable direction, among the poor as among the rich. The poor, therefore, having in the aggregate more capital and more business ability than the rich, as well as enormously greater physical strength, have no need to fear the encroachments of concentrated capital. They need only to cooperate to fully protect themselves. 


\section{Appendix G.}

\section{STATISTICS RELATING TO CURRENCY QUESTIONS.}

1. OBJECt AND Method of Study.-A popular study of the "Currency Question" is generally understood to have for its object the formation of a judgment in regard to the effect of changes in the character and volume of the currency upon the standard of life. From the standpoint of the farmers who, in the aggregate, always carry an enormous permanent indebtedness, secured by mortgage, nothing more directly affects the standard of living than the ease or difficulty with which they are able to meet the interest and principal of this long-time indebtedness; nor is there any better index of the farmer's material prosperity or want of it, than the extent of his ability to meet these engagements promptly. The farmer whose debts do not trouble him can, and usually does, enjoy the comforts of life, and many of its luxuries. For the farmer, therefore, nothing is more important, in connection with the currency, than its justice as a standard of deferred payments. But it is not the only important thing for the farmer to consider, for like the day laborer, who may own no property, the farmer is also a large buyer of commodities, and profits by the cheapness of such as he has to buy.

A very common method of conducting such a "study" is to first form the "judgment," and then diligently hunt for the "stutisties" to sustain it. Sometimes people do not even "form" their judgments, but accept them ready made at the hands of some political or social orator or publication. It need not be said that this is a very bad way indeed to "study" a question. No good can come from such a method. A much better way, and indeed the only good way, is to obtain, so far as possible, all the statistical facts bearing on the problem, arrange them in an orderly and logical way and then sit down and try to see what, when they are all taken together, they prove. Such a brief paper as this appendix must be, can contain only a few summaries from the vast quantity of the statistics which have been gathered upon the eurrency question, nor will it be possible to include as much of explanation as would be desirable for those not familiar with these studies; but an attempt has been made to include what is most important, including all that are commonly used in popular discussion in this country, with such explanatory matter as will cuable a person of ordinury education to reach an independent judgment, and feel that he is able to defend it. A wrong judgment which is the result of 
independent study is of far more value to a man than a correct judgment accepted from somebody else; for one man's error cun do no great harm to suciety, while the acquirement of the art of study will be of infinite value to the man, and probably enable him, in due time, to correct early erroneous judgments, perhaps founded on insufficient, or inaccurate data. The proper order of topics for the study of eurrency questions seems to me to be, first, the statistics bearing on the volume of eurrency; secondly, those relating to the ratio, past and present, between gold und silver, and finally, those relating to prices,

2. Some Cautioxs about the Use of Statistics.-It is, perhaps, desirable to say something about the use of statistics. In the first place they are not always entirely accurate, because in the nature of things they can not be made so. The receipts and expenditures of governments can be stated to the smallest fraction, but valuations of exports and imports, for example, are not nearly so accurate. Valuations made for the purpose of assessment of ad valorem duties are substantially correct, but those assigned to importations to be sold upon commission, and upon which the duty to be collected is "specific," are sometimes hardly rough approximations. A cargo of lemons, for example, may be certified by a consul in Sicily at $\$ 1.50$ per box, and yet not actually sell for much more than freight money. We know exactly the amount of gold and silver coined in all countries, for a long period back, and the amont of governmènt, and, usually, of bank paper money in circulation, but we do not exactly know the movement of the precious metals, coined or uncoined, from one country to another, the amount used in the arts, or the stocks of them in the world at different periods, or at present. For everything not the subject of actual bookkeeping and balance sheets we are dependent upon estimates. These estimates, however, are not made at random. They are the work of capable men whose profession is the compilation and arrangement of statistics, who are fully aware of, and carefully consider the danger of, error, and give, after careful consideration, their judgment of the fuets. In such matters as the amounts of the precious metals in the world, four hundred years since, when the study of statistics was hardly thought of, we can place little reliance upon the tables, and we do not know very well, even to-day, the quantity of gold and silver annually used in the arts. The production of these metals, however, has for many centuries been a matter of government reeord in all civilized countries, in most of which a royalty upon the product of mines is exacted by the government, and a rigid accounting required. In our own country no such accounting is kept, but the authorities of the mint, with the aid of the express companies and banks, make a very close approximation to our production. From such semi-civilized countries as China statisticians get the best information possible and make up their judgments upon it. Gold and silver passing from one country to another by sea, as freight or express, must be entered upon the manifests of the vessels, and is recorded in custom houses. That which passes to and fro upon the persons of travelers must be estin.ated or disregarded. In the main the monetary statisties of the past fifty years, so far as they are those of civilized countries, may be regarded as reliable, for what they purport to be. 
It is not, however, always as easy as it might seem to know what statistics really teach when we have them. For example, statistical tables and diagrams which follow show that the purchasing power of gold has enormously increased during the past thirty years, and that the farmer who for that period has kept alive an old mortgage, by renewals, must now dispose of far more produce to pay the debt, than would have paid it when originally contracted. On the other hand, tables of current rates of interest, for the same period, equally authentic, and indeed with less liability to error, show that in 1896 it required twice as much money invested in gilt-edged bonds, to produce an income of $\$ 1,000$, as would have produced that income in 1870 . To arrive at a correct conclusion these two tables, possibly, upon analysis, not so contradictory as they seem, must somehow be reconeiled. A skilful controversialist, by using only one set of these tables, can make an argument, unansweral,le by a popular audience, which will show that debtors are suffering very severely by the appreciation of money, and immediately thereafter take the other table before another audience, and with equal conclusiveness, prove that the poor creditors have practically lost half their debts. One can prove almost anything by statistics, so long as he is permitted to select his tables. Imperfect as many of them are, statisties are invaluable for the study of economic problems, as long as they are intelligently and honestly employed, and all the facts, insteud of only part of them, are considered. This is sometimes very difficult. Not only is our information limited, but our mental powers, which largely accounts for the zeal with which good men differ on economic problems. It is not everyone who has the intellectual grasp to compass great subjects.

Statistical tables make a very dreary looking page for the ordinary reader, and are, of course, not intended to be read by any one, but to be referred to when it is desired to make use of the facts which they show. For the purpose of quickly conveying the facts of statistical tables to the reader, it is a common practice to employ diagrams, drawn to a scale, upon which the fluctuations of the tables are shown by lines. This is a very useful practice, as it enables the eye to take in at a glance the lesson of a long column of figures. Like many other good things, however, the method may be easily abused, and, in the hands of designing persons, be made to convey impressions not at all warranted by the facts. The trick is very simple, and consists merely in making the vertical spaces of the scale large or small, in relation to the horizontal spaces, according as the draughtsmen desire to convey the impression of great or small fluctuations. For example, the ratio of silver to gold previous to 1873 was constantly fluctuating, and yet the variations were so small, that popular discussions of the relations of silver and gold usually take no account of them, and silver and gold are often, and properly enough, represented on diagrams by an identical line, for some years previous to 1873 . It would be very easy, however, for a series of those years, by constructing a diagram in which vertical spaces of one inch should represent one per cent of variation, and horizontal spaces of one-half inch represent yeurs, to convey the impression that the ratios of the two metals were fluctuating within very wide limits. The increasing use of these diagrams in popular discussion, sometimes very disingenuously, makes it proper to give this caution. Economists and students, and political 
writers in their private studies, pay very little attention to diagrams illustrating controverted topics, because they must constantly guard against false impressions. They study the tables, and if they desire diagrams they construct them, which any one can do who will take the trouble to draw the spaces evenly.

I can best illustrate this by an example, and for this purpose will take a subject which is illustrated in this way perhaps more frequently than any other -the variations in the ratio between gold and silver since 1873. Diagrams I., II., and III. represent precisely the same thing, as a careful inspection will show, and yet, when drawn separately, upon a blackboard, they would produce a very different effect upon an audience. Diagram I. differs from II. merely in having its vertical spaces twice as large, while diagram III. differs from II. only in having the horizontal spaces doubled. They all represent the appreciation of gold, as compared with commodities, according to the tables of the London Economist, for the period covered. (See pages 614 and 615.)

3. Statistical Authorities. - The original authorities relating to the production and stocks of the precious metals, and emissions of paper money, are mainly the records of the governments of the world. The principal nations now publish this information annually, compiled from official sources. The earlier estimates were compiled by eminent statisticians from researches in governmental archires, and such other sources as in their judgment are entitled to respect. The basis of confidence is in the competence of the compiler. None are included here which have not received the endorsement of the Director of the United States Mint, or the Finance Committee of the United States Senate by being included in official publications. The same may be said as to the table of ratios. In regard to prices, the most exhaustive study ever made in any country is that made under the direction of a sub-committee of the Finance Committee of the United States Senate, and found in Senate Report No. 1,394, Fifty-second Congress, second session (1893). The period covered begins with 1840 , and ends with 1891. These tables include the course of wholesale prices of from two to three hundred articles in the United States. These tables have never been continued. There are many similar tables compiled by statisticians, of which those most commonly referred to are those of Dr. Augustus Sauerbeck, of London, of forty-five articles in England, and the London Economist, of twenty-two commodities. These are regularly continued each year. Another very valuable set of tables is that of Dr. Adolf Soetbeer, of Germany, and continued, after his death, by others. These tables give the wholesale prices of one hundred commodities in Germany, and fourteen English articles. Other recognized statistical authorities are the Journal of the Royal Statistical Society, London, which is made up of original contributions, and Mulhall's Dictionary of Statistics, which is a compilation. For convenient reference Waldron's Handbook of Currency and Wealth (Funk \& Wagnalls, New York, 1896. Price fifty cents) is an excellent compendium, containing most of the tables to which it is usual to refer in discussing currency topics. For careful study all these tables require the aid of explanatory matter which always accompanies their original publication, but for which there is no space in a compact summary. 
APPRECIATION OF GOLD, MEASURED BY ITS PURCHASING POWER. From 1873 to 1892. From Coinage Laws of the U. S.

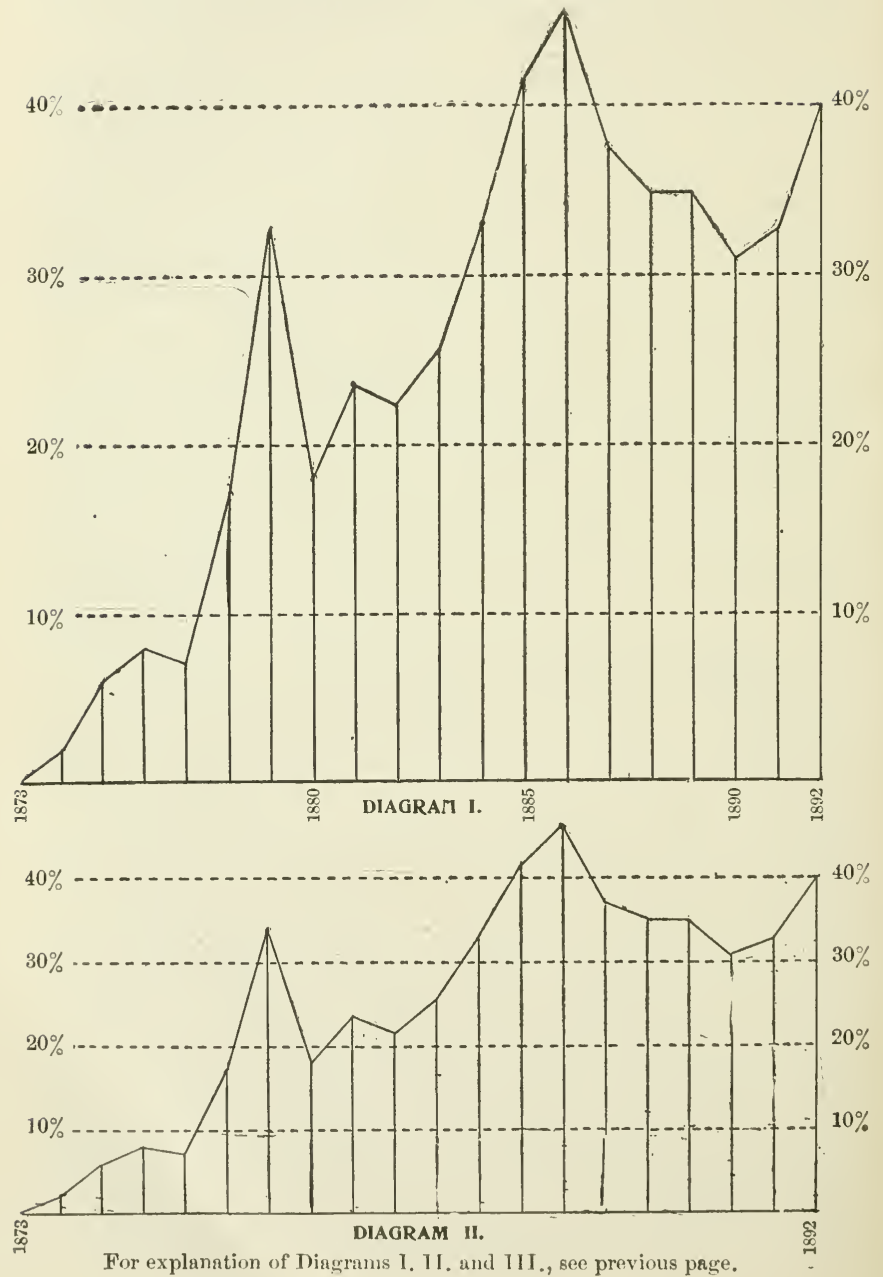


APPENIIX.

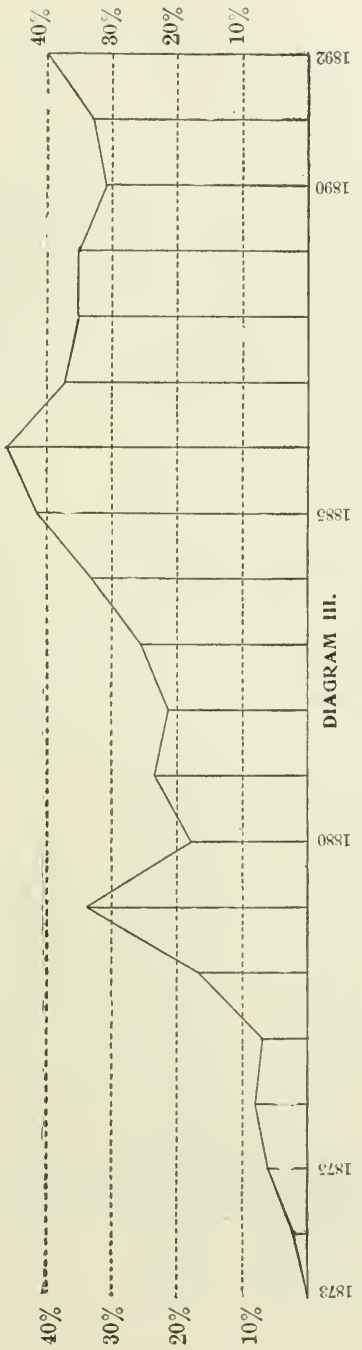

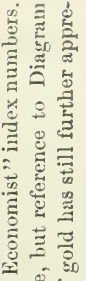

도

$\stackrel{2}{\leftrightarrows}$

㟧

क

๘

$\cong$

สํㅠㄹ

उั

4.5

के क्षै

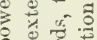

․․ㄹ

结

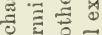

苋.

运它

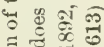

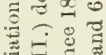

चี जै

호 를

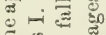

$\stackrel{n}{\Xi} \stackrel{\Xi}{\Xi}$

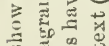

क

$\Xi \mathcal{3}$

$\Xi \underbrace{0}_{0}$

․ㅡㄹ

こ芯苛

$\therefore \geqslant$

है के क्षे

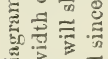

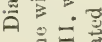

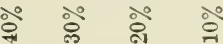

हैं 
4. THE WORLD'S STOCK OF GOLD AND SILVER.

WORLD'S STOCK OF GOLD.

\begin{tabular}{|c|c|c|c|c|c|c|}
\hline YEAR. & Coined. & Uncoined. & Total. & Coined. & Uneoined. & Total. \\
\hline 1600 & $\begin{array}{r}\text { Tons. } \\
208\end{array}$ & $\begin{array}{l}\text { Tons. } \\
622\end{array}$ & $\begin{array}{r}\text { Tons. } \\
830\end{array}$ & $\begin{array}{r}\text { Fine ounces. } \\
6,795,000\end{array}$ & $\begin{array}{l}\text { Fine ounces. } \\
20,318,000\end{array}$ & $\begin{array}{l}\text { Fine ounces. } \\
27,113,000\end{array}$ \\
\hline $1700 .$. & 537 & 773 & 1,310 & $17,542,000$ & $25,251,000$ & $42,793,000$ \\
\hline $1800 \ldots$ & 908 & 1,822 & 2,730 & $29,661,000$ & $59,519,000$ & $89,180,000$ \\
\hline 1848. & 1,125 & 2,450 & 3,575 & $36,750,000$ & $80,033,000$ & $116,783,000$ \\
\hline $1873 *$ & 4,650 & 2,550 & 7,200 & $151,900,000$ & $83,300,000$ & $235,200,000$ \\
\hline $1880 \ldots$. & 5,250 & 2,550 & 7,800 & $171,500,000$ & $83,300,000$ & $254,800,000$ \\
\hline $1890 \ldots$ & 5,640 & 3,180 & 8,820 & $184,240,000$ & $103,880,000$ & $288,120,000$ \\
\hline $1894^{*} \ldots \ldots$ & 6,300 & 3,300 & 9,600 & $205,800,000$ & $107,800,000$ & $313,600,000 \mathrm{v}$ \\
\hline
\end{tabular}

WORLD'S STOCK OF SILVER.

\begin{tabular}{|c|c|c|c|c|c|c|}
\hline YEAR. & Coined. & Uncoined. & Total. & Coined. & Uncoined. & Total. \\
\hline 600 & $\begin{array}{l}\text { Tons. } \\
8,500\end{array}$ & $\begin{array}{c}\text { Tons. } \\
14,500\end{array}$ & $\begin{array}{l}\text { Tons. } \\
23,000\end{array}$ & $\begin{array}{l}\text { Fine } \\
277,6\end{array}$ & $\begin{array}{r}\text { Fine ounces. } \\
473,666,010\end{array}$ & $\begin{array}{r}\text { Fine ounces. } \\
751,333,000\end{array}$ \\
\hline & 22,500 & 22,500 & 45,000 & 00,000 & 000 & 1,47 \\
\hline & & 46,000 & 880 & 1,37 & 1,5 & 00 \\
\hline & & 6 & 11 & 1,4 & 2,2 & 3,691 \\
\hline 1873 & 64 & 00 & 135 & 2,10 & 2,30 & $, 000,000$ \\
\hline & 73 & & 145 & & 2,3 & 67,000 \\
\hline & & & & & 2,5 & $5,390,000,000$ \\
\hline 1894 * & 99,900 & 80,100 & 180,000 & $3,263,400,000$ & $2,616,600,000$ & $5,880,000,000$ \\
\hline
\end{tabular}

COMPARISONS OF THE TWO METALS.

\begin{tabular}{|c|c|c|c|c|c|c|c|}
\hline \multirow{2}{*}{ YeAR. } & \multicolumn{2}{|c|}{ Per cent coined. } & \multicolumn{3}{|c|}{ Ounces of silver to one of gold. } & \multicolumn{2}{|c|}{$\begin{array}{l}\text { Per ct. annu'y } \\
\text { added to stock. }\end{array}$} \\
\hline & Gold. & Silver. & Coined. & Uneoined. & Total. & Gold. & Silver. \\
\hline 600 & 25 . & 37. & 40.9 & 23.3 & 27.7 & 0.94 & 1.80 \\
\hline 1700 . & 41 & 50 & 4 & 29 & 3 & 0.88 & 0.76 \\
\hline 1800 . & 33. & 47 & 46 & 25 & 32.2 & 0.64 & 0.99 \\
\hline & 31 . & 40 & 40.2 & 27.7 & 31.6 & 1.53 & 0.82 \\
\hline $1873 \%$. & 64.6 & 47.8 & 13.9 & 27.6 & 18.7 & 1.98 & 1.66 \\
\hline $1880 \ldots$ & 67.3 & 50.8 & 14.0 & 28.0 & 18.6 & 2.02 & 1.56 \\
\hline 18 & 63.9 & 53 & 15. & 24.2 & 18.7 & 2.00 & 2.34 \\
\hline $1894 *$ & 65.6 & 55.6 & 15.9 & 24.3 & 18.7 & 2.77 & 2.82 \\
\hline
\end{tabular}

* Estimates for the years 1873 and 1894 are made by Mr. G. B. Waldron, based on the world's production and coinage. Estimates for other years in tons on the authority of Mulhall. Converted into fine ounces at the rate of $32 \% 3$ thousand ounces to the ton of 2240 pounds. 
APPENDIX.

5. WORLD'S PRODUCTION OF GOLD AND SILVER FROM 1492. 1

From 1493 to 1840 the estimates are those of Dr. Adolph Soetbeer; after 1840 of the U.S. Mint.

\begin{tabular}{|c|c|c|c|c|}
\hline \multirow{2}{*}{ CALENDAR Years. } & \multicolumn{2}{|c|}{ World's produetion of gold. } & \multicolumn{2}{|c|}{ World's production of silver. } \\
\hline & Fine ounces. & Value. & Fine ounces. & Coining value. \\
\hline $1493-$ & $5,221,160$ & $\$ 107,931,000$ & $42,309,400$ & $\$ 54,703,000$ \\
\hline $1521-1540$. & $5,524,656$ & $114,205,000$ & $69,598,320$ & $89,986,000$ \\
\hline $1541-1560$. & $4,377,544$ & $90,492,000$ & $160,287,040$ & $207,240,000$ \\
\hline $1561-1580$ & $4,398,120$ & $90,917,000$ & $192,578,500$ & $248,990,000$ \\
\hline $1581-1600$ & $4,745,340$ & $98,095,000$ & $269,352,700$ & $348,254,000$ \\
\hline $1601-$ & $5,478,360$ & $113,248,000$ & $271,924,700$ & $351,579,000$ \\
\hline $1621-$ & $5,336,900$ & $110,324,000$ & $253,084,800$ & $327,221,000$ \\
\hline $1641-$ & $5,639,110$ & $116,571,000$ & $235,530,900$ & $304,525,000$ \\
\hline $1661-1680 \ldots \ldots \ldots$ & $5,954,180$ & $123,084,000$ & $216,691,000$ & $280,166,000$ \\
\hline $1681-1700 \ldots \ldots \ldots$ & $6,921,895$ & $143,088,000$ & $219,841,700$ & $284,240,000$ \\
\hline $1701-$ & 3,260 & 03,000 & $228,650,800$ & $295,629,000$ \\
\hline $1721-$ & $12,268,440$ & $253,611,000$ & $277,261,600$ & $358,480,000$ \\
\hline $1741-$ & $15,824,230$ & $327,116,000$ & $342,812,235$ & $443,232,000$ \\
\hline $80 \ldots \ldots \ldots$ & $13,313,315$ & $275,211,000$ & $419,711,820$ & $542,658,000$ \\
\hline $00 \ldots \ldots \ldots$ & $11,438,970$ & $236,464,000$ & $565,235,580$ & $730,810,000$ \\
\hline $1801-$ & 627 & $118,152,000$ & $287,469,225$ & $371,677,000$ \\
\hline $1811-$ & $3,679,568$ & $76,063,000$ & $173,857,555$ & $224,786,000$ \\
\hline $18: 1-$ & $4,570,444$ & $94,479,000$ & $148,070,040$ & $191,444,000$ \\
\hline $1831-1$ & $6,522,913$ & $134,841,000$. & $191,758,675$ & $247,930,000$ \\
\hline $1841-1848 \ldots . . . .$. & $14,084,090$ & $291,144,000$ & $200,732,500$ & $259,520,000$ \\
\hline 1849. & 39,875 & $37,000,000$ & $30,164,000$ & 0,000 \\
\hline $1850 \ldots$ & $2,150,269$ & $44,450,000$ & 4,000 & 0,000 \\
\hline $1851 .$. & $3,270,150$ & $67,600,000$ & $30,937,500$ & $40,000,000$ \\
\hline 1852. & $6,421,781$ & $132,750,000$ & $31,402,000$ & $40,600,000$ \\
\hline ............ & $7,519,894$ & $155,450,000$ & $31,402,000$ & $40,600,000$ \\
\hline $1854 \ldots$ & $6,165,378$ & $127,450,000$ & $31,402,000$ & $40,600,000$ \\
\hline $1855 .$. & $6,534,253$ & $135,075,000$ & $31,402,000$ & $40,600,000$ \\
\hline $1856 \ldots$ & $7,140,150$ & $147,600,000$ & $31,440,800$ & $40,650,000$ \\
\hline $1857 \ldots$ & $6,447,177$ & $133,275,000$ & $31,440,800$ & $40,650,000$ \\
\hline $1858 \ldots$ & $6,029,944$ & $124,650,000$ & $31,440,800$ & $40,650,000$ \\
\hline $1859 \ldots$ & $6,039,619$ & $124,850,000$ & $31,517,600$ & $40,750,000$ \\
\hline 1860. & $5,758,719$ & $119,250,000$ & $31,556,250$ & $40,800,000$ \\
\hline 1861 .. & $5,505,075$ & $113,800,000$ & $34,572,700$ & $44,700,000$ \\
\hline $1862 .$. & $5,212,406$ & $107,750,000$ & $34,959,400$ & $45,200,000$ \\
\hline $1863 \ldots$ & $5,173,706$ & $106,950,000$ & $38,053,000$ & $49,200,000$ \\
\hline $1864 \ldots$ & $5,466,375$ & $113,000,000$ & $39,986,700$ & $51,700,000$ \\
\hline $1865 .$. & $5,814,675$ & $120,200,000$ & $40,180,000$ & $51,950,000$ \\
\hline $1866 \ldots \ldots \ldots \ldots \ldots \ldots$ & $5,858,213$ & $121,100,000$ & $39,252,000$ & $50,750,000$ \\
\hline $1867 \ldots$ & $5,043,094$ & 104,025000 & $41,939,600$ & $54,225,000$ \\
\hline $1868 \ldots \ldots \ldots \ldots$ & $5,307,947$ & $109,725,000$ & $38,845,900$ & $50,225,000$ \\
\hline $1869 . \ldots \ldots \ldots \ldots . . . .$. & $5,138,634$ & $106,225.000$ & $36,738,200$ & $47,500,000$ \\
\hline $1870 \ldots \ldots \ldots \ldots$ & $5,168,869$ & $106,850,000$ & $39,890,000$ & $51,575,000$ \\
\hline $1871 \ldots$ & $5,176,125$ & $107,000,000$ & $47,183,600$ & $61,050,000$ \\
\hline 1872. & $4,818,150$ & $99,600,000$ & $50,466,800$ & $65,250,000$ \\
\hline $1873 \ldots$ & $4,653,675$ & $96.200,000$ & $63,267,000$ & $81,800,000$ \\
\hline $1874 \ldots \ldots \ldots \ldots$ & $4,390,031$ & $90,750,000$ & $55,300.000$ & $71,500,000$ \\
\hline $1875 \ldots \ldots \ldots \ldots$ & $4,726,563$ & $97,500,000$ & $62,262,000$ & $80,500,000$ \\
\hline & $5,016,488$ & $103,700,000$ & $67,753,000$ & $87,600,000$ \\
\hline $1877 \ldots \ldots \ldots \ldots \ldots$ & $5,514,750$ & $114,000,000$ & $62,648,000$ & $81,000,000$ \\
\hline
\end{tabular}


WORLD'S PRODUCTION OF GOLD AND SILVER. (Continued.)

\begin{tabular}{|c|c|c|c|c|}
\hline \multirow{2}{*}{ CALENDAR YEARS. } & \multicolumn{2}{|c|}{ World's production of gold. } & \multicolumn{2}{|c|}{ World's production of silver. } \\
\hline & Fine ounces. & Value. & Fine ounces. & Coining value. \\
\hline & 5 & $119,000,000$ & $73,476,000$ & $95,000,000$ \\
\hline & & & & \\
\hline & 5 & 106,500 & & \\
\hline & 4 & 103, & 78 & 10 \\
\hline & & 102 & & \\
\hline & & & & 11 \\
\hline & & 101 & 8 & 10 \\
\hline & & & & \\
\hline & & & & 20 \\
\hline & & 105 & 96 , & 12 \\
\hline & & 110 & 108 & \\
\hline & & & & 00 \\
\hline & & 11 & 12 & 16 \\
\hline 1 & 39 , & 814 & & \\
\hline & & $202,682,300$ & 50 & 900 \\
\hline & 11,4 & $237,504,800$ & $183,096,0$ & 236,7 \\
\hline & & $\$ 501$, & & $\$ 9$ \\
\hline & & & & \\
\hline & & 12 & & 2,3 \\
\hline 18 & & $\$ 7$ & & 00 \\
\hline & & & & \\
\hline & & & & \\
\hline 1801 & $285,730,153$ & $\$ 5,906,565,500$ & $3,983,963,106$ & $\$ 5,150,968,900$ \\
\hline $1493-1897 \ldots \ldots \ldots$ & $446,017,990$ & $\$ 9,220,012,1$ & 167 & $* \$ 10,977,685,20$ \\
\hline
\end{tabular}

* It will be noted that the total here given is the "coining" value, presumably at the ratio of 15.98 to 1 , as the footing is that of the U. S. Mint. (Report for 1898, page 273.) The commercial value would of course be less than half as much.

\section{RATIO OF SILVER TO GOLD FOR 400 IEARS.}

It would be quite natural to suppose that the commercial ratio of silver to gold would bear a somewhat close relation to the ratio of production. The following table was arranged and apparently, in part, computed by Mr. Geo. B. Waldron, and is from his Handbook of Currency. It shows that the commercial ratio has no apparent connection with the ratio of production. Concerning this table Mr. Waldron says: "We have prepared the table below showing the amount of silver produeed to one unit of gold in dollars and in ounces for each of the periods of the table of production. For purposes of comparison we have added Dr. Soetbeer's estimates of the commercial ratio of gold to silver down to 1832, the estimates of Pixley and Abell from 1833 to 1878, and those of the Director of the Mint from 1879 to 1894." 
RATIO OF SILVER TO GOLD.

\begin{tabular}{|c|c|c|c|c|c|c|c|c|c|}
\hline \multirow{2}{*}{$\begin{array}{c}\begin{array}{c}\text { CALENDAR } \\
\text { YEARS. }\end{array} \\
1493-1520 .\end{array}$} & \multicolumn{2}{|c|}{$\begin{array}{l}\text { Silver } \\
\text { produced to } \\
\text { one of gold. }\end{array}$} & \multicolumn{2}{|c|}{$\begin{array}{l}\text { Commercial } \\
\text { ratio. }\end{array}$} & \multirow{2}{*}{$\begin{array}{c}\begin{array}{c}\text { CalENDAR } \\
\text { YEARS. }\end{array} \\
-1868 \ldots . . . . .\end{array}$} & \multicolumn{2}{|c|}{$\begin{array}{l}\text { Silver } \\
\text { produced to } \\
\text { one of gold. }\end{array}$} & \multicolumn{2}{|c|}{$\begin{array}{c}\text { Commercial } \\
\text { ratio. }\end{array}$} \\
\hline & $\begin{array}{l}\text { Ounce } \\
8.10\end{array}$ & $\begin{array}{ll}\text { es. } & \\
\text { to } & 1\end{array}$ & $11.30 \mathrm{t}$ & to 1 & & $\begin{array}{l}\text { Oune } \\
7.32\end{array}$ & $\begin{array}{l}\text { es. } \\
\text { to } 1\end{array}$ & 15.59 & to 1 \\
\hline $1521-1540$ & 12.60 & "6 & 11.20 & 6 & 1869 & 7.15 & 6 & 15.60 & "6 \\
\hline $1541-1560$. & 36.62 & “ & 11.50 & 6 & 1870. & 7.72 & 66 & 15.57 & “ \\
\hline $1561-1580$. & 43.79 & " & 11.50 & “ & $1871 .$. & 9.12 & 16 & 15.59 & " \\
\hline $1581-1600$. & 56.76 & "“ & 11.90 & "6 & 1872. & 10.47 & 16 & 15.63 & “ \\
\hline $1601-1620$. & 49.64 & “ & 13.00 & “ & $\begin{array}{l}1873 . \\
1874 .\end{array}$ & $\begin{array}{l}13.59 \\
12.60\end{array}$ & 66 & $\begin{array}{l}15.92 \\
16.17\end{array}$ & " \\
\hline $1621-1640$. & 47.44 & “ & 13.40 & $" 6$ & 1074. & & & & \\
\hline $1641-1660$. & 41.77 & 66 & 13.80 & 16 & 1875. & 13.17 & 66 & 16.59 & 6 \\
\hline $1661-1680$. & 36.39 & " & 14.70 & $" 6$ & $1876 .$. & 13.51 & 66 & 17.88 & " \\
\hline $1681-1700$. & 31.76 & 6 & 14.97 & " & 1877. & 11.36 & 6 & 17.22 & "6 \\
\hline $1701-1720$. & 27.74 & "6 & 15.21 & " & $\begin{array}{l}1878 . . \\
1879 .\end{array}$ & $\begin{array}{l}12.76 \\
14.08\end{array}$ & 66 & $\begin{array}{l}17.94 \\
18.40\end{array}$ & “" \\
\hline $1721-1740$. & 22.60 & “ & 15.09 & " & 1880 ... & 14.55 & 66 & 18.05 & “ \\
\hline $1741-1760$. & 21.66 & 64 & 14.75 & " & $1881 \ldots \ldots$ & 15.83 & 16 & 18.16 & " \\
\hline $1761-1780$. & 31.53 & " & 14.73 & "6 & $1882 \ldots \ldots \ldots$ & 17.53 & 66 & 18.20 & "6 \\
\hline $1781-1$ & 49.41 & "6 & 15.09 & 6 & 1883. & 19.32 & 66 & 18.64 & "6 \\
\hline 1801-1810.. & 50.30 & $"$ " & 15.61 & 66 & $1884 .$. & 16.59 & 66 & 18.57 & 6 \\
\hline $1811-1820$. & 47.25 & “ & 15.49 & " & 1885. & 17.48 & “ & 19.41 & 66 \\
\hline $1821-1830$. & 32.40 & 66 & 15.80 & “ & $1886 .$. & 18.19 & “6 & 20.78 & " \\
\hline $1831-1840$. & 29.40 & "6 & 15.76 & $" 6$ & $1887 .$. & 18.79 & 66 & 21.13 & ؛: \\
\hline $1841-1848$. & 14.25 & 16 & 15.85 & "6 & $1888 \ldots \ldots \ldots$ & 20.41 & 66 & 21.99 & “ \\
\hline & & & & & $1889 \ldots \ldots \ldots$ & 20.12 & 6 & 22.10 & "6 \\
\hline $\begin{array}{l}1849 . . \\
1850 .\end{array}$ & $\begin{array}{l}16.85 \\
14.03\end{array}$ & "6 & $\begin{array}{l}15.78 \\
15.70\end{array}$ & "6 & $1890 \ldots \ldots \ldots$ & 21.93 & 66 & 19.76 & $"$ \\
\hline $1851 \ldots$ & $\begin{array}{r}14.03 \\
9.46\end{array}$ & "6 & $\begin{array}{l}15.70 \\
15.46\end{array}$ & "6 & $1891 \ldots . . . \ldots$ & 21.70 & & 20.92 & 4 \\
\hline $1852 .$. & $\begin{array}{l}9.40 \\
4.89\end{array}$ & $" 6$ & $\begin{array}{l}15.46 \\
15.59\end{array}$ & " & $1892 \ldots \ldots \ldots$ & 21.63 & 66 & 23.72 & 4 \\
\hline $1853 \ldots$ & 4.18 & "6 & $\begin{array}{l}15.59 \\
15.33\end{array}$ & " " & $1893 \ldots \ldots \ldots$ & $\begin{array}{l}21.27 \\
18.89\end{array}$ & 16 & 26.49 & " \\
\hline $1854 \ldots$ & 5.09 & 66 & $\begin{array}{l}15.33 \\
15.33\end{array}$ & 6 & $1894 \ldots \ldots \ldots$ & $\begin{array}{l}18.89 \\
17.15\end{array}$ & “6 & 32.59 & $"$ \\
\hline $1855 \ldots$ & 4.81 & "6 & $\begin{array}{l}15.33 \\
15.38\end{array}$ & 6 & $1896 \ldots \ldots \ldots$ & $\begin{array}{l}17.15 \\
15.93\end{array}$ & 66 & 30.66 & "6 \\
\hline $1856 \ldots$ & 4.40 & " " & $\begin{array}{l}15.38 \\
15.38\end{array}$ & " & $1897 \ldots \ldots \ldots$ & 15.93 & & 34.28 & " \\
\hline $1857 \ldots$ & 4.88 & " " & $\begin{array}{l}15.38 \\
15.27\end{array}$ & 6 & 1493-1600.. & 30.25 & 66 & 11.48 & 6 \\
\hline $1858 \ldots$ & 5.21 & “ & 15.38 & "6 & 1601-1700.. & 40.81 & $" 6$ & 13.97 & "6 \\
\hline $1859 \ldots$ & 5.22 & $" 6$ & 15.19 & " & $1701-1800$. & 30.02 & 16 & 14.97 & 66 \\
\hline $1860 \ldots$ & 5.48 & 6 & 15.29 & $"$ " & & & & & \\
\hline $1861 \ldots$ & 6.28 & $"$ & 15.50 & " & 1801-1848.. & 28.98 & 66 & 15.69 & " \\
\hline $1862 \ldots$ & 6.71 & 6 & 15.35 & $"$ & 1849-1872.. & 6.64 & 66 & 15.48 & " \\
\hline $1863 \ldots$ & 7.36 & 66 & 15.37 & $" 6$ & $1873-1894$. & 17.39 & 66 & 20.22 & \\
\hline $1864 \ldots$ & 7.31 & " & 15.37 & $"$ " & & 1 & 6 & 1 & \\
\hline $1865 \ldots$ & 6.91 & 6 & 15.44 & 6 & 1801-1894.. & 13.94 & & 5 & \\
\hline $\begin{array}{l}1866 \ldots \\
1867 \ldots\end{array}$ & $\begin{array}{l}6.70 \\
8.32\end{array}$ & "6 & $\begin{array}{l}15.43 \\
15.57\end{array}$ & "6 & 1493 & 193 & 66 & 13. & " \\
\hline $1867 \ldots$. & 8.32 & 66 & 15.57 & & 1493 & 19.34 & 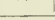 & 10.90 & \\
\hline
\end{tabular}

It will be interesting to note whether there is any closer connection between the commercial ratio of gold and silver, and the ratio of existing stocks. I have therefore computed this ratio from the table of world's stocks on page 616 . 
COMMERCIAL RATIO AND RATIO OF STOCKS.

\begin{tabular}{|c|c|c|c|c|}
\hline YEAR. & $\begin{array}{l}\text { Total Gold } \\
\text { Coined and } \\
\text { Uncoined. }\end{array}$ & $\begin{array}{l}\text { Total Silver } \\
\text { Coined and } \\
\text { Uncoined. }\end{array}$ & Ratios of Stocks. & $\begin{array}{l}\text { Commercial } \\
\text { Ratio. }\end{array}$ \\
\hline $\begin{array}{l}1600 \\
1700 \\
1800 \\
1848 \\
1873 \\
1880 \\
1890 \\
1894\end{array}$ & $\begin{array}{r}\text { Tons. } \\
830 \\
1,310 \\
2,730 \\
3,575 \\
7,200 \\
7,800 \\
8,820 \\
9,600\end{array}$ & $\begin{array}{r}\text { Tons. } \\
23,000 \\
45,000 \\
88,000 \\
113,000 \\
135,000 \\
145,000 \\
165,000 \\
180,000\end{array}$ & $\begin{array}{l}27.71 \text { to } 1 \\
34.35 \text { “ } \\
32.23 \text { “ } \\
31.61 \\
18.33 \text { “ } \\
18.72 \\
18.71 \\
18.75 \text { " “ }\end{array}$ & $\begin{array}{l}12.10 \text { to } 1 \\
14.81 \text { " " } \\
15.68 \text { " " } \\
15.85 \\
15.92 \text { " " } \\
18.05 \\
19.76 \text { " " } \\
32.56 \text { " }\end{array}$ \\
\hline
\end{tabular}

The form in which tables are given in the report of the Director of the Mint for 1898 does not permit me to conveniently continue the calculation of Mr. Waldron, but the totals of production as estimated by the mint from 1493 to July 1,1898 , make the total stock at that time 18.72 fine ounees of silver to one of gold. The commercial ratio for 1897, as given in the report (average for the year), was 34.28 to 1 , and for nine months of $1898,35.40$ to 1 .

\section{COMMERCIAL RATIO.}

EARLY Ratios.-The commercial ratio of gold to silver, from the time of Herodotus (born 484 в. с.) down to the year 1717, is shown in the following from the letter of Lord Liverpool to the king of England (see "Coinage Laws of the United States, 1894," page 435):-

In Persia, according to Herodotus ........ 1 to $11 \frac{2}{3}$

In Greece at same period . . . . . . . . . 1 to 13

In Greece in the time of Plato........ 1 to 12

In Greece it is stated by Xenophon at....... 1 to 10

After the plunder of gold from the Temple of Apollo, according to Menander, it was. ........ 1 to 10

In the reign of Alexander the Great it was . . . . 1 to 10

In Rome, according to Pliny the Elder it was. . . . . 1 to $10 \frac{13}{2}$

In Rome, after the tribute from the Etolians . . . 1 to 10

The plunder of gold from the Gauls by

Julius Cras reduced the proportions to .... 1 to $7 \frac{1}{2}$

In the reign of Claudius, Tacitus states it at . . . . 1 to $12 \frac{1}{2}$

Until the reign of Alexander Servius it contained. . . . 1 to $12 \frac{1}{2}$

In the reign of Constantine the Great. ...... 1 to $1 \frac{1}{2}$

The disorders in the Roman Empire under Arcadus and

Honorius raised it to .......... 1 to $14 \frac{2}{5}$

From which it appears that gold, unless when depressed by sudden and unusual oecurrenees, or enhaneed by a dread of public insecurity, may be stated to have been for upward of 900 years in the proportion of. . . . 1 to 10 or 12 
In England, in the reign of Henry III., 1216 to $1272 \ldots 1$ to $9 \frac{1}{2}$ In England, in the reign of Edward III., 1330 to 1377. . 1 to $12 \frac{1}{2}$ In England, in the reign of Henry IV., 1400 to 1412 . . 1 to 10 ? In England, in the reign of Edward IV., 1461 to 1477. . 1 to 11? In England, in the reign of Ilenry VIII., 1510 to 1547.1 to 11.10 In England, in the reign of Queen Elizabeth, 1560 . . 1 to 11 In England, in the reign of King James I., 1604 . . . . 1 to 12 ! In England, in the reign of King James I., 1611. . . 1 to 13 ? In England, in the reign of Charles II., 1665. . . . . 1 to $14 \frac{1}{2}$ In England, in the reign of George I., 1717. . . . . . 1 to 151 Relative proportions in China, according to Humboldt. . 1 to $12 \frac{1}{2}$ Relative proportions in Japan, according to Humboldt . 1 to $8 \frac{1}{2}$ Relative proportions in Bengal, according to bullion report1 to 14.86 Relative proportions in Madras, according to bullion report1 to $13 \frac{7}{8}$ Relative proportions in Bombay, according to bullion report1 to 15 In the China diaries it is stated at $\mathbf{1 6}$ taels of silver to $\mathbf{1}$ tael of gold of 100 touch of pure gold. If it is meant to be of pure silver also, the proportion would be 1 to 16 ; but it is believed to be the average fineness of silver in dollars, which would be........ 1 to 14.296

LEGAL RATIOS IN THE UNITED STATES.

Act of 1792 . : . . 15 to 1 . . Silver standard.

Act of $1834 . .16 .002$ to 1 . Silver standard (apparently).

Act of $1837 . \ldots 15.98+$ to 1 . . Bimetallie standard.

Act of 1873. . . . 15.98+to 1 . . Gold standard.

There has been no change in the legal ratio since.

COMMERCIAL RATIO OF SILVER TO GOLD EACH YEAR-1867 TO 1898.

[NotE.-From 1687 to 1832 the ratios are taken from Dr. A. Soetbeer; from 1833 to 1878 , from Pixley and Abell's tables; and from 1879 to 1898 from daily eablegrams from London to the Bureau of the Mint. Report of the Director to the Mint, 1898.

\begin{tabular}{c|c|c|c|c|c||c|c||c|c} 
Year. & Ratio. & Year. & Ratio. & Year. & Ratio. & YEar. & Ratio. & YEar. & Ratio. \\
\hline 1687 & 14.94 & 1700 & 14.81 & 1713 & 15.24 & 1726 & 15.15 & 1739 & 14.91 \\
1688 & 14.94 & 1701 & 15.07 & 1714 & 15.13 & 1727 & 15.24 & & \\
1689 & 15.02 & 1702 & 15.52 & 1715 & 15.11 & 1728 & 15.11 & 1740 & 14.94 \\
1690 & 15.02 & 1704 & 15.17 & 1716 & 15.09 & 1729 & 14.92 & 1741 & 14.92 \\
1691 & 14.98 & 1705 & 15.11 & 1717 & 15.13 & & & 1742 & 14.85 \\
1692 & 14.92 & 1706 & 15.27 & 1719 & 15.11 & 1730 & 14.81 & 1743 & 14.85 \\
1693 & 14.83 & 1707 & 15.44 & & & 1731 & 14.94 & 1744 & 14.87 \\
1694 & 14.87 & 1708 & 15.41 & 1720 & 15.04 & 1732 & 15.09 & 1745 & 14.48 \\
1695 & 15.02 & 1709 & 15.31 & 1721 & 15.05 & 1734 & 15.39 & 1746 & 15.13 \\
1696 & 15.00 & & & 1722 & 15.17 & 1735 & 15.41 & 1748 & 15.26 \\
1697 & 15.20 & 1710 & 15.22 & 1723 & 15.20 & 1736 & 15.18 & 1749 & 14.80 \\
1698 & 15.07 & 1711 & 15.29 & 1724 & 15.11 & 1737 & 15.02 & & \\
1699 & 14.94 & 1712 & 15.31 & 1725 & 15.11 & 1738 & 14.91 & 1750 & 14.55 \\
\hline
\end{tabular}


COMMERCIAL RATIO OF SILVER TO GOLD. (Continued.)

\begin{tabular}{l|l||c|c||c|c||c|c||c|c} 
YEAR & RATIO. & YEAR. & RATIO. & YEAR. & RATIO. & YEAR. & RATIO. & YEAR. & RATIO. \\
\hline 1751 & 14.39 & 1781 & 14.78 & 1811 & 15.53 & 1841 & 15.70 & 1871 & 15.57 \\
1752 & 14.54 & 1782 & 14.42 & 1812 & 16.11 & 1842 & 15.87 & 1872 & 15.63 \\
1753 & 14.54 & 1783 & 14.48 & 1813 & 16.25 & 1843 & 15.93 & 1873 & 15.92 \\
1754 & 14.48 & 1784 & 14.70 & 1814 & 15.04 & 1844 & 15.85 & 1874 & 16.17 \\
1755 & 14.68 & 1785 & 14.92 & 1815 & 15.26 & 1845 & 15.92 & 1875 & 16.59 \\
1756 & 14.94 & 1786 & 14.96 & 1816 & 15.28 & 1846 & 15.90 & 1876 & 17.88 \\
1757 & 14.87 & 1787 & 14.92 & 1817 & 15.11 & 1847 & 15.80 & 1877 & 17.22 \\
1758 & 14.85 & 1788 & 14.65 & 1818 & 15.35 & 1848 & 15.85 & 1878 & 17.94 \\
1759 & 14.15 & 1789 & 14.75 & 1819 & 15.33 & 1849 & 15.78 & 1879 & 18.40 \\
& & & & & & & & & \\
1760 & 14.14 & 1790 & 15.04 & 1820 & 15.62 & 1850 & 15.70 & 1880 & 18.05 \\
1761 & 14.54 & 1791 & 15.05 & 1821 & 15.95 & 1851 & 15.46 & 1881 & 18.16 \\
1762 & 15.27 & 1792 & 15.17 & 1822 & 15.80 & 1852 & 15.59 & 1882 & 18.19 \\
1763 & 14.99 & 1793 & 15.00 & 1823 & 15.84 & 1753 & 15.33 & 1883 & 18.64 \\
1764 & 14.70 & 1794 & 15.37 & 1824 & 15.82 & 1854 & 15.33 & 1884 & 18.57 \\
1765 & 14.83 & 1795 & 15.55 & 1825 & 15.70 & 1855 & 15.38 & 1885 & 19.41 \\
1766 & 14.80 & 1796 & 15.65 & 1626 & 15.76 & 1856 & 15.38 & 1886 & 20.78 \\
1767 & 14.85 & 1797 & 15.41 & 1827 & 15.74 & 1857 & 15.27 & 1887 & 21.13 \\
1768 & 14.80 & 1798 & 15.59 & 1828 & 15.78 & 1858 & 15.38 & 1888 & 21.99 \\
1769 & 14.72 & 1799 & 15.74 & 1829 & 15.78 & 1859 & 15.19 & 1889 & 22.10 \\
1770 & 14.62 & 1800 & 15.68 & 1830 & 15.82 & 1860 & 15.29 & 1890 & 19.76 \\
1771 & 14.66 & 1801 & 15.46 & 1831 & 15.72 & 1861 & 15.50 & 1891 & 20.92 \\
1772 & 14.52 & 1802 & 15.26 & 1832 & 15.73 & 1862 & 15.35 & 1892 & 23.72 \\
1773 & 14.62 & 1803 & 15.41 & 1833 & 15.93 & 1863 & 1537 & 1893 & 26.49 \\
1774 & 14.62 & 1804 & 15.41 & 1834 & 15.73 & 1864 & 15.37 & 1894 & 32.56 \\
1775 & 14.72 & 1805 & 15.79 & 1835 & 15.80 & 1865 & 15.44 & 1895 & 31.60 \\
1776 & 14.55 & 1806 & 15.52 & 1836 & 15.72 & 1866 & 15.43 & 1896 & 30.66 \\
1777 & 14.54 & 1807 & 15.43 & 1837 & 15.83 & 1867 & 15.57 & 1897 & 34.28 \\
1778 & 14.68 & 1808 & 16.08 & 1838 & 15.85 & 1868 & 15.59 & $* 1898$ & 35.40 \\
1779 & 14.80 & 1809 & 15.96 & 1839 & 15.62 & 1869 & 15.60 & & \\
1780 & 14.72 & 1810 & 15.77 & 1840 & 15.62 & 1870 & 15.57 & & \\
\hline & & & & & & & & &
\end{tabular}

* Nine months.

\section{DEMONETIZATION OF SILVER.}

Up to the year 1816 , both silver and gold were recognized and coined as full legal tender in all civilized countries; and for many years after the two metals circulated freely together at a ratio between fifteen and sixteen to one. At present the only countries nominally upon a bimetallic basis are the United States and Latin Union and certain countries in which neither metal circulates by reason of an inflated paper currency. All other countries are upon either a gold or silver basis. The ITnited States, although nominally on a bimetallic basis, is really upon a gold basis, by reason of the pledge of the United States to maintain its silver coinage on a par with gold, at the ratio of fifteen and ninety-eight one-hundredths to one. "Demonetization" of a metal consists in depriving it of its character as legal tender, except for small sums. Partial demonetization occurs when a metal is refused coinage at the mints for private 
account, even though, as in India, United States, the Latin Union and else where, it continues to circulate as full legal tender money. The principal dates in connection with the demonetization of silver are as follows:-

1816. England adopted gold standard.

1849. Brazil adopted gold standard.

1854. Portugal adopted gold standard.

1867. First International Monetary Conference in Paris.

1871. Germany adopted gold standard. In effect 1873.

1872. Netherlands suspended coinage of silver per private account.

1873. United States adopted gold standard.

Suspension of silver coinage for private aecount in France, Belgium, and Holland.

Denmark, Sweden, and Norway (Scandinavian Union) adopted gold standard.

1875. Suspension of coinage of silver for privatc account in Italy and the Dutch colonies.

1877. Finland adopted gold standard.

1878. Remonetization of silver by the United States and provision for the purchase and coinage into silver dollars of silver to the value, at market price, of not less than $\$ 2,000,000$ and not more than $\$ 4,000,000$ per month. Coinage of silver for private account prohibited. (Bland-Allison Act.)

Second International Monetary Conference at Paris.

1881. Third International Monetary Conference at Paris.

1885. Russia suspended coinage of silver for private account.

1890. United States Congress repeals act of 1878 , and directs the purchase of $4,500,000$ fine ounces of silver per month to be coined at the rate of $2,000,000$ ounces per month until July 1, 1891, and thereafter as might be required.

1892. Austro-Hungary adopted gold standard.

1893. India suspends coinage of silver for private account, and the United States repeals purchasing clause of the act of 1890 .

1895. Chili adopted gold standard.

1896. Costa Rica adopted gold standard.

1897. Japan and Russia adopted gold standard.

Peru suspended coinage of silver for private account.

PURCHASES OF SILVER INDER THE ACT OF JULY 14, 1890.

\begin{tabular}{|c|c|c|c|c|c|}
\hline $\begin{array}{c}\text { YEAR. } \\
\text { ENDING } \\
\text { JUNE } 30 .\end{array}$ & Fine ounces. & Cost. & $\begin{array}{c}\text { Coinage } \\
\text { value. }\end{array}$ & $\begin{array}{l}\text { Seignor- } \\
\text { age. } b\end{array}$ & $\begin{array}{c}\text { Average } \\
\text { cost per } \\
\text { ounce. }\end{array}$ \\
\hline $891 a$ & 48 & $\$ 50,577,4$ & $\$ 62,568,873$ & $\overline{\$ 11,991,375}$ & $\$ 1.0451$ \\
\hline 1892. & $54,355,7$ & $51,106,607.96$ & $70,278,139$ & $19,171,531$ & .9402 \\
\hline $1893 \ldots$ & $54,008,162.60$ & $45,531,374.53$ & $69,828,736$ & $24,297,361$ & .8430 \\
\hline "Nov. 1 & $7,658.78$ & $8,715,521.32$ & $15,408,690$ & $6,693,169$ & .7313 \\
\hline Total... & $168,674,682.53$ & $\$ 155,931,002.25$ & $218,084.438$ & $\mid 362,153,436$ & 8.9244 \\
\hline
\end{tabular}

$a$ Beginning Aug. 13, 1890. $b$ Coinage value less cost. 
COINAGE OF SILVER DOLLARS, ACT OF JULY 14, 1890.

\begin{tabular}{|c|c|c|c|c|c|}
\hline $\begin{array}{c}\text { YEAR } \\
\text { ENDING } \\
\text { JUNE } 30 .\end{array}$ & $\begin{array}{l}\text { Dollars } \\
\text { Coined. }\end{array}$ & $\begin{array}{l}\text { Fine } \\
\text { ounces } \\
\text { used. }\end{array}$ & $\begin{array}{l}\text { Cost of } \\
\text { bullion. }\end{array}$ & $\begin{array}{l}\text { A ver'ge } \\
\text { cost of } \\
\text { a dollar }\end{array}$ & $\begin{array}{l}\text { Purchased but } \\
\text { not } \\
\text { coined. }\end{array}$ \\
\hline & $\$ 27,292,475$ & 23.63 & $\$ 22,747.860 .42$ & $\$ 0.8335$ & $\$ 39,79$ \\
\hline & $3,450,995$ & $2,669,128.95$ & $2,577,838.19$ & .7470 & 67.682 \\
\hline & $5,343,715$ & $4,133,029.56$ & $3,784,417.64$ & .7082 & $66,027,008.11$ \\
\hline $1893, I$ & 100 & 77.35 & 70.36 & .7036 & $15,406,933.92$ \\
\hline & $\$ 36,087,285$ & $\overline{27,911,259.49}$ & $\$ 29,110,186.61$ & $\$ 0.8067$ & $\$ 188,911,715.75$ \\
\hline 169 & 658 & & 460.63 & .7000 & 18 \\
\hline & $3,956,011$ & $3,059,727.26$ & $2,680,825.10$ & .8762 & $185,851,479.47$ \\
\hline Total. & $\$ 40,043,954$ & $30,971,495.67$ & $\$ 31,791,472.34$ & & $\$ 185,851,479.47$ \\
\hline
\end{tabular}

* Beginning Aug. 13, 1890. + Beginning Nov. 1, 1893.

LONDON GOLD, PRICE OF SILVER, PER OUNCE STERLING FROM 1870.

\begin{tabular}{|l|l|l|l|l|l|l|l|}
\hline $1870 \ldots \$ 1.328$ & $1875 \ldots \$ 1.246$ & $1880 \ldots \$ 1.145$ & $1885 \ldots \$ 1.065$ & $1890 \ldots \$ 1.046$ & $1895 . . \$ .654$
\end{tabular}

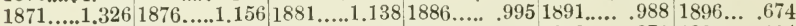

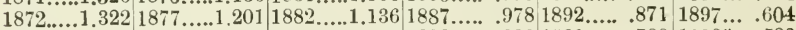
$1873 \ldots \ldots 1.2981878 \ldots \ldots 1.152 \quad 1883 \ldots \ldots 1.110 \quad 1888 \ldots \ldots .9391893 \ldots \ldots . .780 \quad 1898^{*} . . .583$

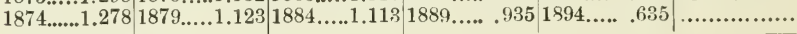

* Nine months.

\section{MONETARY SISTEMS OF THE WORLD.}

The present monetary systems of the eountries of the world are as follows:

(FROM REPORT OF DIRECTOR OF THE MINT 1898.)

Austro-Hungary-Gold. Aetual eurreney government paper.

BELGIUM-See Latin Union.

Bolivia-Silver.

Braz1L-Gold. Aetual curreney inconvertible paper.

British Indi - Silver. Silver eoined only on government account.

BULGARIA-Gold and silver. Has no mint.

CANADA-Gold.

Costa Rica-Gold.

CHILI-Gold. Actual curreney paper.

China-Silver.

Cura-Same as Spain. See Latin Union.

Columbia-Silver. Aetual eurreney paper.

DENMARK-See Seandinavian Union.

ECUADOR-Silver. Actual eurreney depreciated paper.

EGYPT-Gold.

Finland-Gold.

Germany-Gold.

Great Britain and Colonies-Gold.

GreECE.-See Latin Union.

HAITI-Gold. Aetual curreney depreciated paper.

JAP A N-Grold.

LATiN Union (France, Belgium, Italy, Switzcrland and Greece)-Gold and silver. Silver not coined for private account.

Mexico-Silver.

NETHERLANDS-Gold, with silver coined previous to 1875 .

Norw AY - See Seandinavian Union.

Paraguay-Silver. Aetual currency depreciated paper.

Persia-Silver. 
PenU-Silver. Actual currency depreciated paper.

Portugal-Gold.

RouMANIA-Gold.

Russia-Gold. Actual currency depreciated paper.

Scandinavian Union (Sweden, Norway, and Denmark)-Gold.

Servia-Assimilated to Latin Union-Gold and silver.

SiAM-Silver.

Spain-Same as Latin Union. Actual currency depreciated paper.

SwITzERLAND-See Latin Union.

TURKEY-Gold and silver. Silver not coined.

United States-Gold and silver. Silver not coined.

VenEzUELA-Silver.

APPROXIMATE STOCKS OF MONEY IN THE WORLD.

From the Report of the Director of the Mint for 1898.

\begin{tabular}{|c|c|c|c|c|c|c|c|c|}
\hline \multirow{2}{*}{ Countries. } & \multirow{2}{*}{ Population } & \multirow{2}{*}{ Gold. } & \multirow{2}{*}{ Silver. } & \multirow{2}{*}{$\begin{array}{l}\text { Uncovered } \\
\text { paper. }\end{array}$} & \multicolumn{4}{|c|}{ Per capita. } \\
\hline & & & & & Gold & Silver & Paper & Total \\
\hline United & $74,500,000$ & $\$ 925,100,000$ & $\$ 638,200,000$ & $\$ 326,100,000$ & $\$ 12.42$ & $\$ 8.56$ & $\$ 4.38$ & $\$ 25.26$ \\
\hline United Kingdom & $39,800,000$ & $438,000,000$ & $121,700,000$ & $112,000,000$ & 11.01 & 3.06 & 2.81 & 16.88 \\
\hline Framce.................. & $38,500,000$ & $810,600,000$ & $419,800,000$ & $124,600,000$ & 21.06 & 10.90 & 3.23 & 35.19 \\
\hline Germany & $52,300,000$ & $668,500,000$ & $212,800,000$ & $13: 2,200,000$ & 12.78 & 4.07 & 2.53 & 19.38 \\
\hline Belgium & $6,500,000$ & $30,000,000$ & $45,000,000$ & $79,100,000$ & 4.62 & 6.92 & 12.17 & 23.71 \\
\hline Italy...... & $31,300,000$ & $96,500,000$ & $42,500,000$ & $169,500,000$ & 3.08 & 1.36 & 5.41 & 9.85 \\
\hline Switzerland.. & $3,000,000$ & $24,000,000$ & $10,700,000$ & $14,300,000$ & 8.00 & 3.56 & 4.77 & 16.33 \\
\hline Greece.. & $2,400,000$ & 500,000 & $1,500,000$ & $30,600,000$ & .21 & .62 & 12.75 & 13.58 \\
\hline Spain .. & $18,000,000$ & $45,500,000$ & $49,800,000$ & $137,500,000$ & 2.53 & 2.76 & 7.64 & $12.9: 3$ \\
\hline Portugal. & $5,100,000$ & $5,200,000$ & $6,100,000$ & $39,000,000$ & 1.02 & 1.20 & 7.64 & 9.86 \\
\hline Roumania............ & $5,400,000$ & $14,500,000$ & $10,609,000$ & $33,700,000$ & 2.69 & 1.96 & 6.24 & 10.89 \\
\hline Servia .................. & $2,300,000$ & $1,200,000$ & $2,700,000$ & $2,700,000$ & .52 & 1.17 & 1.17 & 2.86 \\
\hline Austria-Hungary & $4 \overline{5}, 400,000$ & $227,700,000$ & $145,500,006$ & $86,200,000$ & 5.02 & 3.20 & 1.90 & 10.12 \\
\hline Netherlands......... & $4,900,000$ & $21,900,000$ & $56,100,000$ & $45,500,000$ & 4.47 & 11.45 & 9.28 & 25.22 \\
\hline Norway.. & $2,000,000$ & $7,800,000$ & $2,300,009$ & $3,800,000$ & 3.90 & 1.15 & 1.90 & 6.95 \\
\hline Sweden..... & $5,000,000$ & $8,600,000$ & $5,700,000$ & $27,700,000$ & 1.72 & 1.14 & 5.54 & 8.49 \\
\hline Denmark... & $2,300,000$ & $15,300,000$ & $5,400,000$ & $7,000,000$ & 6.95 & 2.35 & 3.04 & 12.09 \\
\hline Russia ................ & $129,200,000$ & $756,600,000$ & $128,400,000$ & (n.............. & 5.86 & .99 & & 6.81 \\
\hline Turkey. & $24,100,000$ & $50,000,000$ & $40,000,000$ & & 2.07 & 1.66 & & 3.71 \\
\hline Australasia......... & $5,000,000$ & $132,100,000$ & $7,000,000$ & $22,500,000$ & 26.42 & 1.40 & 4.50 & 32.39 \\
\hline Egypt..... & $9,700,000$ & $30,000,000$ & $6,400,000$ & & 3.09 & .66 & & 3.76 \\
\hline Mexico. & $13,000,000$ & $8,600,000$ & $106,000.000$ & $* 4,000,000$ & .67 & 8.15 & 3.07 & 11.85 \\
\hline Central America & $3,300,000$ & $1,300,000$ & $19,000,000$ & $8,400,000$ & .39 & 5.76 & 2.54 & 8.66 \\
\hline South America.. & $37,500,000$ & $7 \overline{7}, 500,000$ & $35,000,000$ & $750,600,000$ & 2.07 & .93 & 20.01 & 23.00 \\
\hline Japan.................. & $45,000,000$ & $79,900,000$ & $60,400,000$ & ..................... & 1.77 & 1.34 & $\cdots$ & 3.15 \\
\hline India .... & $296,900,000$ & ......................... & $592,100,000$ & $117,300,000$ & $\ldots \ldots \ldots$ & 1.99 & .40 & 2.30 \\
\hline ('hina................... & $383,300,000$ & ...... & $\mathbf{7 5 0 , 0 0 0 , 0 0 0}$ & *.* & ............ & 1.96 & & 1.94 \\
\hline Straits Settlem'ts & $3,900,000$ & & $242,000,000$ & & & 62.05 & & 62.05 \\
\hline Canada............... & $5,300,000$ & $16,000,000$ & $5,000,000$ & $35,000,000$ & 3.01 & .95 & 6.60 & 10.53 \\
\hline Cuba.... & $\mathbf{1}, 800,000$ & $2,000,000$ & $1,500,000$ & . & 1.11 & .83 & & 1.94 \\
\hline Haiti ........ & $1,000,000$ & $4,000,000$ & $4,500,000$ & $4,100,000$ & 4.00 & 4.50 & 4.10 & 12.60 \\
\hline Bulgaria .... ........ & $3,800,000$ & $1,000,000$ & $6,800,000$ & ...................... & 30 & 2.06 & $\ldots$ & 2.36 \\
\hline Siam. & $5,000,000$ & $20,000,000$ & $193,400,000$ & ......... & 4.00 & 38.68 & & 42.68 \\
\hline Haw & 100,000 & $4,000,000$ & $1,000,000$ & & 40.00 & 10.00 & & 50.00 \\
\hline Cape Colony........ & $1,800,000$ & $37,500,000$ & $1,000,000$ & & 20.83 & .55 & & 21.38 \\
\hline South Africa....... & 900,000 & $29,200,000$ & $1,200.000$ & & 32.44 & 1.33 & & 33.77 \\
\hline Finland ... & $2,600,000$ & $4,300,000$ & 400,000 & $9,400,000$ & 1.65 & .15 & 3.62 & 5.42 \\
\hline
\end{tabular}

* Evidently an error here or in per capita column.

\section{THE COURSE OF PRICES AND WAGES.}

The table below shows the comparison for 53 years between wages and prices in the United States. The figures are compiled from the results of the special Senate committee investigation, transmitted to the Senate March 3, 1893. The 40 
investigation was made by a sub-committee on tariff, with Nelson W. Aldrich as chairman.

The comparative percentages on prices are based on quotations of wholesale prices of 223 articles, covering the period from 1860 to 1892 , and of 85 articles covering the whole period from 1840. In most cases these were actual prices paid during the month of January, and not average prices for the year. In a few instances, when the January price is not the typical price for the year, the quotations for another month are taken; potatoes, for example, being quoted for October. All these quotations of the 223 articles were reduced to relative percentages with 1860 as 100 .

It would be manifestly unfair to give equal weight to all the quotations and strike a general average for each year, so the attempt was made to give each quotation the weight it would have in the expenditures of the average family. The hasis taken was the investigations of the Commissioner of Labor as reported in the seventh annual report (1891), in which the average expenditures of 2,561 normal families are found to be as follows:

Rent, 15.06 per cent; food, 41.03; fuel, 5.00; clothing, 15.31; light, 0.90; all other purposes, 22.70; total, 100.00 per cent. The articles included in table of prices constitute 68.60 per cent of the expenditures of an average family.

RELATIVE PRICES AND WAGES IN CURRENCY, GOLD AND SILVER.-1840 TO 1892.

[All figures are in percentages, with the year 1860 as 100.]

\begin{tabular}{|c|c|c|c|c|c|}
\hline \multirow{2}{*}{$\begin{array}{l}\text { YEAR. } \\
\text { JANUARY. }\end{array}$} & \multicolumn{2}{|c|}{ Relative Prices in- } & \multicolumn{2}{|c|}{ Relative Wages in- } & \multirow{2}{*}{$\begin{array}{l}\text { Combined } \\
\text { Prices and } \\
\text { Wages. } \\
\text { Gold. }\end{array}$} \\
\hline & \begin{tabular}{c|c} 
Cur- & Gold. \\
reney. &
\end{tabular} & Silver. & \begin{tabular}{c|c} 
Cur- & Gold. \\
rency. &
\end{tabular} & Silver. & \\
\hline$\overline{1840 \ldots \ldots . . . . . . .}$ & 97.7 & 95.4 & 82.5 & 80.6 & 90.1 \\
\hline $1841 \ldots \ldots \ldots \ldots$ & 98.1 & 95.8 & 79.9 & 78.6 & 89. \\
\hline $1842 \ldots \ldots \ldots$ & 90.1 & 89.1 & 84.1 & 83.2 & 86.6 \\
\hline $1843 . . . \ldots \ldots . .$. & 84.3 & 83.7 & 83.0 & 82.5 & 83.6 \\
\hline $1844 \ldots \ldots \ldots \ldots$ & 85.0 & 84.5 & 83.2 & 82.7 & 84.1 \\
\hline $1845 \ldots$ & 88.2 & 87.8 & 85.7 & -85.3 & 86.9 \\
\hline $1846 \ldots . . . \ldots \ldots$ & 95.2 & 94.8 & 89.1 & 88.7 & 92.1 \\
\hline $1847 \ldots \ldots \ldots \ldots$ & 95.2 & 93.2 & 91.3 & 89.4 & 93.2 \\
\hline $1848 . . . . . . . . .$. & 88.3 & 88.0 & 91.6 & 91.3 & 89.9 \\
\hline $1849 \ldots \ldots \ldots$ & 83.5 & 82.5 & 90.5 & 89.4 & 87.0 \\
\hline $1850 \ldots$ & 89.2 & 88.1 & 90.9 & 89.8 & 90.1 \\
\hline $1851 \ldots \ldots \ldots . .$. & 98.6 & 94.4 & 91.1 & 87.2 & 94.8 \\
\hline $1852 \ldots . . . \ldots . .$. & 97.9 & 93.7 & 91.8 & 87.9 & 94.8 \\
\hline $1853 \ldots \ldots \ldots \ldots$ & 105.0 & 100.9 & 93.2 & 89.6 & 99.1 \\
\hline $1854 \ldots . . . . . .$. & 105.0 & 100.5 & 95.8 & 91.7 & 100.4 \\
\hline $1855 \ldots \ldots \ldots \ldots$ & 109.2 & 104.6 & 97.5 & 93.4 & 103.3 \\
\hline $1856 \ldots . . . . . .$. & 112.3 & 108.5 & 98.0 & 94.7 & 105.1 \\
\hline $1857 \ldots . . . . .$. & 114.0 & 108.0 & 99.2 & 94.0 & 106.6 \\
\hline $1858 \ldots . . . \ldots . .$. & 113.2 & 108.6 & 97.9 & 93.9 & 105.5 \\
\hline $1859 . \ldots \ldots \ldots . .$. & 102.9 & 98.4 & 99.7 & 95.0 & 101.3 \\
\hline $1860 \ldots \ldots \ldots$ & 100.0 & 94.9 & 100.0 & 94.9 & 100. \\
\hline $1861 \ldots \ldots$ & 94.1 & 90.5 & 100.7 & 96.9 & 97.4 \\
\hline
\end{tabular}


APPENDIX.

RELATIVE PRICES AND WAGES IN CURRENCY. (Continued.)

\begin{tabular}{|c|c|c|c|c|c|c|c|}
\hline \multirow{2}{*}{$\begin{array}{l}\text { YEAR. } \\
\text { JANUARY. }\end{array}$} & \multicolumn{3}{|c|}{ Relative Prices in- } & \multicolumn{3}{|c|}{ Relative Wages in- } & \multirow{2}{*}{$\begin{array}{l}\text { Combined } \\
\text { Prices and } \\
\text { Wages. } \\
\text { Gold. }\end{array}$} \\
\hline & \begin{tabular}{|} 
Cur- \\
rency.
\end{tabular} & Gold. & Silver. & $\begin{array}{c}\text { Cur- } \\
\text { reney. }\end{array}$ & Gold. & Silver. & \\
\hline $1862 \ldots$ & $10+.1$ & 101.6 & 90.8 & 103.7 & 101.2 & 97.4 & 101.4 \\
\hline $1863 \ldots \ldots \ldots . . .$. & 132.2 & 91.1 & 87.1 & 118.8 & 81.9 & 78.3 & 86.5 \\
\hline $1864 \ldots \ldots \ldots \ldots$ & 172.1 & 110.7 & 105.0 & 134.0 & 86.2 & 81.8 & 98.4 \\
\hline 1865. & 232.2 & 107.4 & 102.9 & 148.6 & 68.7 & 65.8 & 88.0 \\
\hline $1866 \ldots$ & 187.7 & 134.0 & 128.4 & 155.6 & 111.1 & 106.4 & 122.5 \\
\hline $1867 \ldots \ldots \ldots \ldots$ & 165.8 & 123.2 & 119.4 & 164.0 & 121.8 & 118.0 & 122.5 \\
\hline $1868 . . . \ldots \ldots . .$. & 173.9 & 125.6 & 122.2 & 164.9 & 119.1 & 115.9 & 122.3 \\
\hline $1869 \ldots . . . \ldots \ldots$ & 152.3 & 112.3 & 109.0 & 167.4 & 123.5 & 119.9 & 117.9 \\
\hline 1870. & 144.4 & 119.0 & 115.8 & 167.1 & 136.9 & 133.2 & 127.9 \\
\hline $1871 \ldots$ & 136.1 & 122.9 & 119.7 & 166.4 & 150.3 & 146.4 & 136.6 \\
\hline $1872 \ldots \ldots \ldots$ & 132.4 & 121.4 & 117.6 & 167.1 & 153.2 & 148.4 & 137.3 \\
\hline $1873 . . . \ldots \ldots . .$. & 129.0 & 114.5 & 111.0 & 166.1 & 147.4 & 142.9 & 130.9 \\
\hline $1874 \ldots . . . . . .$. & 129.9 & 116.6 & 117.1 & 162.5 & 145.9 & 146.5 & 131.2 \\
\hline 1875. & 128.9 & 114.6 & 117.4 & 158.0 & 140.4 & 143.9 & 127.5 \\
\hline $1876 .$. & 122.6 & 108.7 & 115.5 & 151.4 & 134.2 & 142.6 & 121.4 \\
\hline $1877 \ldots$ & 113.6 & 107.0 & 109.6 & 143.8 & 135.4 & 138.7 & 122.2 \\
\hline $1878 \ldots . . . . . . .$. & 104.6 & 103.2 & 113.4 & 140.9 & 139.0 & 155.2 & 121.1 \\
\hline $1879 \ldots \ldots \ldots \ldots$ & 95 & & 111.4 & 139. & & 163.4 & 117.2 \\
\hline $1880 \ldots$ & 104 & & 117.9 & 143. & & 160.7 & 123.9 \\
\hline $1881 \ldots \ldots . . . . .$. & 108 & & 124.7 & 150.7 & & 173.3 & 129.5 \\
\hline $1882 . . \ldots \ldots \ldots$ & 109 & & 123.8 & 152. & & 1735 & 131.0 \\
\hline $1883 . . . . . . . . . .$. & 106 & & 125.0 & 159. & & 186.8 & 132.9 \\
\hline $1884 \ldots . . \ldots \ldots$ & 102 & & 119.0 & 155. & & 179.8 & 128.8 \\
\hline $1885 .$. & 93 & & 110.8 & 155. & & 185.0 & 129.6 \\
\hline $1886 \ldots$ & 93 & & 117.9 & 155.8 & & 196.6 & 124.6 \\
\hline $1887 \ldots \ldots \ldots . . .$. & 94 & & 119.0 & 156.6 & & 197.2 & 125.5 \\
\hline 1888........... & 96 & & 1279 & 157.8 & & 209.9 & 127.0 \\
\hline $1889 . . . \ldots . . . .$. & 98 & & 136.6 & 162.5 & & 225.8 & 130.7 \\
\hline 1890. & 93 & & 124.2 & 168 & & 222.9 & 130.9 \\
\hline $1891 \ldots$ & 94 & & 116.1 & 168. & & 207.4 & 131.5 \\
\hline 1891 , Oct.... & 92 & & 122.8 & 168. & & 215.9 & 130.6 \\
\hline 1892 , Oct.... & & & 138.9 & 166. & & 251.4 & 128.8 \\
\hline $1840-49 \ldots \ldots$ & 90 & & 89.5 & 86. & & 85.2 & 88.3 \\
\hline $1850-59 \ldots \ldots$ & 104 & & 100.6 & 95. & & 91.7 & 100.1 \\
\hline $1860-69 \ldots$ & 151.4 & 110.0 & 105.0 & 135.8 & 101.4 & 97.5 & 105.7 \\
\hline $1879-79 \ldots$ & 123.7 & 112.3 & 114.9 & 156.3 & 142.2 & 145.9 & 127.2 \\
\hline $1880-89 \ldots \ldots$ & 100 & & 122.3 & 155. & & 188.9 & 127.9 \\
\hline
\end{tabular}

In the foregoing table the effect of an inflated paper currency is shown by the currency prices from 1862 to 1878 .

The course of prices and wages will be more readily seen by constructing diagrams from the figures of the foregoing table, omitting the currency column, as of no pressing interest at the present time. Diagram IV. (page 629), shows the gold prices; diagram V. (page 629), the silver prices; diagram VI. 
(page 630), gold wages; * and diagram VII. (page 631), gold wages and gold prices combined. Diagram VIII. (page 632), shows the course of the price of silver as a commodity, as compared with English gold prices of commodities by Sauerbeck's tables.

In considering the question of wages, the important thing is not what money is received, but what comforts the day's labor will procure. I find the following table in Waldron's Handbook, evidently computed from the Aldrich Report. Diagram IX (page 633), which follows, is prepared from the column showing the relative purchasing power of ten hours' labor.

PURCHASING POWER OF A DAY'S LABOR.

[AIl figures are in percentages, with the year 1860 as 100.]

\begin{tabular}{|c|c|c|c|c|c|c|c|}
\hline $\begin{array}{c}\text { YEAR. } \\
\text { JANUARY. }\end{array}$ & 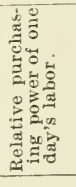 & 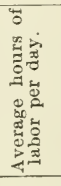 & 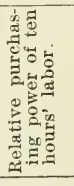 & $\begin{array}{c}\text { YEAR. } \\
\text { JANUARY. }\end{array}$ & 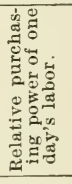 & 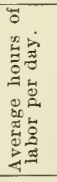 & 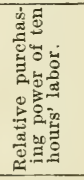 \\
\hline $\begin{array}{l}1840 \ldots \ldots \ldots \\
1841 \ldots \ldots . . \\
1842 \ldots \ldots \ldots \\
1843 \ldots \ldots \ldots \\
1844 \ldots \ldots . .\end{array}$ & $\begin{array}{l}84.4 \\
81.4 \\
93.3 \\
98.5 \\
97.9\end{array}$ & $\begin{array}{l}11.4 \\
11.5 \\
11.4 \\
11.5 \\
11.6\end{array}$ & $\begin{array}{l}74.0 \\
70.8 \\
81.8 \\
85.7 \\
84.7\end{array}$ & $\begin{array}{l}1870 \ldots \ldots . . \\
1871 . . . \ldots . \\
1872 \ldots \ldots . \\
1873 \ldots \ldots . \\
1874 \ldots \ldots\end{array}$ & $\begin{array}{l}115.7 \\
122.3 \\
126.2 \\
128.8 \\
125.1\end{array}$ & $\begin{array}{l}10.5 \\
10.5 \\
10.5 \\
10.5 \\
10.5\end{array}$ & $\begin{array}{l}110.2 \\
116.5 \\
120.2 \\
122.7 \\
119.1\end{array}$ \\
\hline $\begin{array}{l}1845 \ldots \ldots \ldots \\
1846 \ldots \ldots \ldots \\
1847 \ldots \ldots . . \\
1848 \ldots \ldots \\
1849 \ldots \ldots\end{array}$ & $\begin{array}{r}97.2 \\
93.6 \\
85.9 \\
103.8 \\
108.4\end{array}$ & $\begin{array}{l}11.5 \\
11.4 \\
11.5 \\
11.3 \\
11.2\end{array}$ & $\begin{array}{l}84.5 \\
82.1 \\
83.4 \\
91.9 \\
92.7\end{array}$ & $\begin{array}{l}1875 \ldots \ldots \\
1876 \ldots \ldots \\
1877 \ldots \ldots \\
1878 \ldots \ldots \\
1879 \ldots \ldots \\
\end{array}$ & $\begin{array}{l}122.6 \\
123.5 \\
126.6 \\
134.7 \\
146.7\end{array}$ & $\begin{array}{l}10.3 \\
10.3 \\
10.3 \\
10.3 \\
10.3\end{array}$ & $\begin{array}{l}119.0 \\
119.9 \\
122.9 \\
130.8 \\
142.4\end{array}$ \\
\hline $\begin{array}{l}1850 \ldots \ldots . . \\
1851 \ldots \ldots . . \\
1852 \ldots \ldots . \\
1853 \ldots \ldots . \\
1854 \ldots \ldots\end{array}$ & $\begin{array}{r}101.6 \\
92.4 \\
93.8 \\
88.8 \\
91.2\end{array}$ & $\begin{array}{l}11.5 \\
11.4 \\
11.2 \\
11.3 \\
11.1\end{array}$ & $\begin{array}{l}88.6 \\
81.1 \\
83.8 \\
78.6 \\
82.2\end{array}$ & $\begin{array}{l}1880 \ldots \ldots \\
1881 \ldots \ldots . \\
1882 \ldots \ldots \\
1883 \ldots \ldots \\
1884 \ldots \ldots\end{array}$ & $\begin{array}{l}136.3 \\
139.0 \\
140.2 \\
149.3 \\
151.2\end{array}$ & $\begin{array}{l}10.3 \\
10.3 \\
10.3 \\
10.3 \\
10.3\end{array}$ & $\begin{array}{l}132.3 \\
135.0 \\
136.1 \\
145.0 \\
146.2\end{array}$ \\
\hline 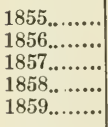 & $\begin{array}{l}89.3 \\
87.3 \\
87.0 \\
86.5 \\
96.9\end{array}$ & $\begin{array}{l}11.1 \\
11.0 \\
10.9 \\
11.0 \\
11.1\end{array}$ & $\begin{array}{l}80.5 \\
79.8 \\
79.8 \\
78.6 \\
87.3\end{array}$ & $\begin{array}{l}1885 \ldots \ldots \ldots \\
1886 \ldots \ldots \ldots \\
1887 \ldots \ldots . . \\
1888 \ldots \ldots \ldots \\
1889 \ldots \ldots \ldots\end{array}$ & $\begin{array}{l}167.1 \\
166.8 \\
165.7 \\
164.1 \\
165.3\end{array}$ & $\begin{array}{l}10.3 \\
10.2 \\
10.0 \\
10.0 \\
10.0\end{array}$ & $\begin{array}{l}162.2 \\
163.5 \\
165.7 \\
164.1 \\
165.3\end{array}$ \\
\hline $\begin{array}{l}1860 \ldots \ldots \\
1861 \ldots \ldots \\
1862 \ldots \ldots \\
1863 \ldots \ldots \\
\end{array}$ & $\begin{array}{r}100.0 \\
107.0 \\
96.6 \\
89.9\end{array}$ & $\begin{array}{l}11.0 \\
10.9 \\
10.8 \\
10.8\end{array}$ & $\begin{array}{l}90.9 \\
98.2 \\
92.2 \\
83.2\end{array}$ & $\begin{array}{l}1890 \ldots . . . . \\
1891 \ldots \ldots \\
1891 \text {, Oct. } \\
1892 \text {, Oct. }\end{array}$ & $\begin{array}{l}179.5 \\
178.6 \\
181.5 \\
181.0\end{array}$ & $\begin{array}{l}10.0 \\
10.0 \\
10.0 \\
10.0\end{array}$ & $\begin{array}{l}179.5 \\
178.6 \\
181.5 \\
181.0\end{array}$ \\
\hline $1864 \ldots \ldots \ldots$ & 77.9 & 10.8 & 72.1 & $\overline{1840-49 \ldots}$ & $\begin{array}{l}95.4 \\
91.5\end{array}$ & $\begin{array}{l}11.4 \\
113\end{array}$ & $\begin{array}{l}83.2 \\
82.0\end{array}$ \\
\hline $\begin{array}{l}1865 \ldots \ldots \ldots \\
1866 \ldots \ldots \\
1867 \ldots \ldots \\
1868 . . \ldots \\
1869 . \ldots \\
. \ldots .\end{array}$ & $\begin{array}{r}64.0 \\
82.9 \\
98.6 \\
94.8 \\
109.9\end{array}$ & $\begin{array}{l}10.7 \\
10.8 \\
10.8 \\
10.6 \\
10.6\end{array}$ & $\begin{array}{r}59.8 \\
76.8 \\
91.3 \\
89.4 \\
103.7\end{array}$ & $\begin{array}{l}1850-59 \ldots \\
1860-69 \ldots \\
1870-79 \ldots \\
1880-89 \ldots \\
1890-92 \ldots\end{array}$ & $\begin{array}{r}91.5 \\
92.5 \\
127.2 \\
154.5 \\
180.2\end{array}$ & $\begin{array}{l}11.3 \\
10.8 \\
10.4 \\
10.2 \\
10.0\end{array}$ & $\begin{array}{r}82.0 \\
85.8 \\
122.4 \\
151.5 \\
180.2 \\
\end{array}$ \\
\hline
\end{tabular}

* Diagrams VI. and VII. are prepared from tables in Fisher's Appreciation and Interest eredited to the Aldrich Report, but Professor Fisher seems to have computed the change from the currency prices given in the Report, and I follow his figures. I the change from the currency tarles the diagram for combined wages and prices, by adding priees and wages and dividing by two. 
A PPENDIX.

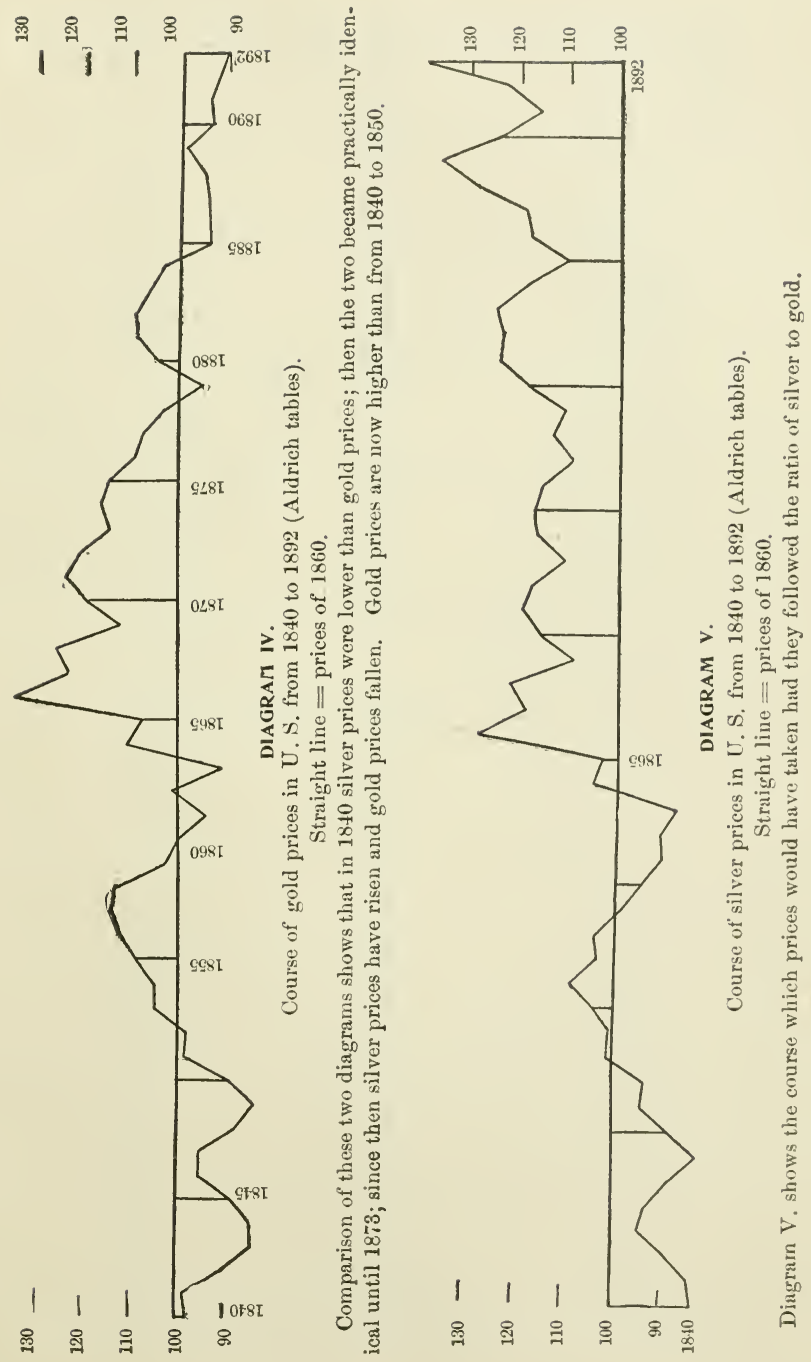




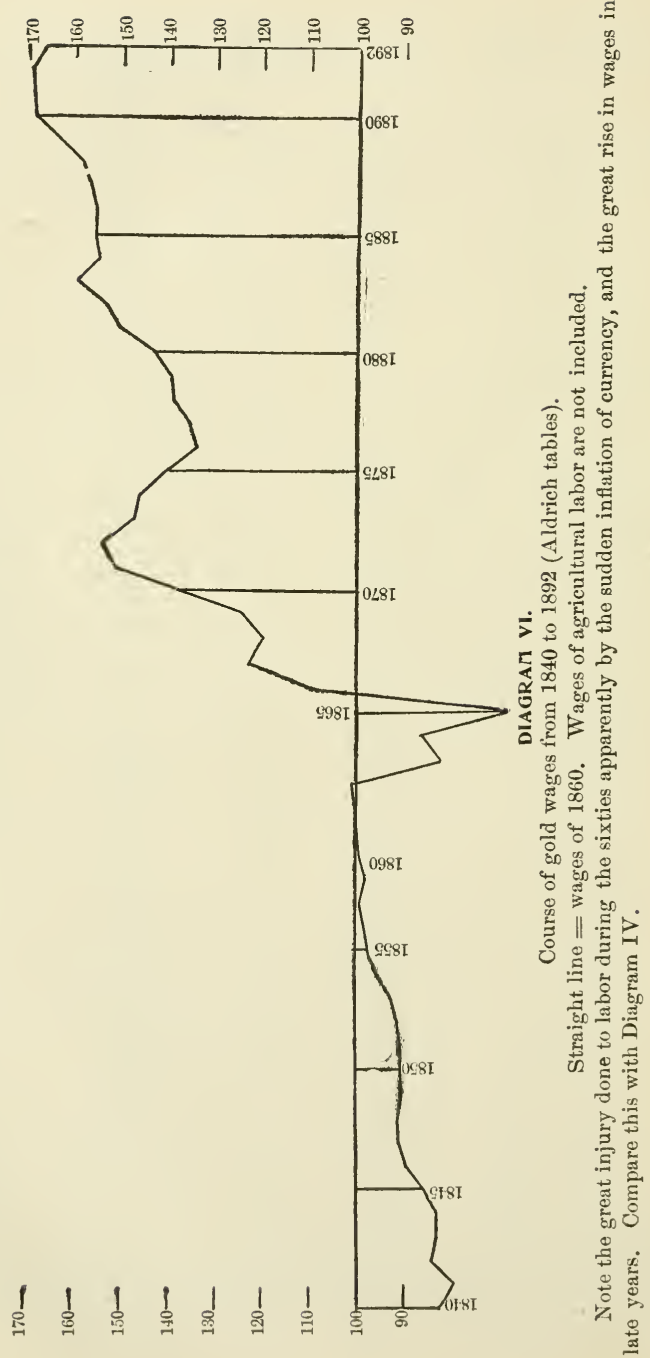


APPENDIX.

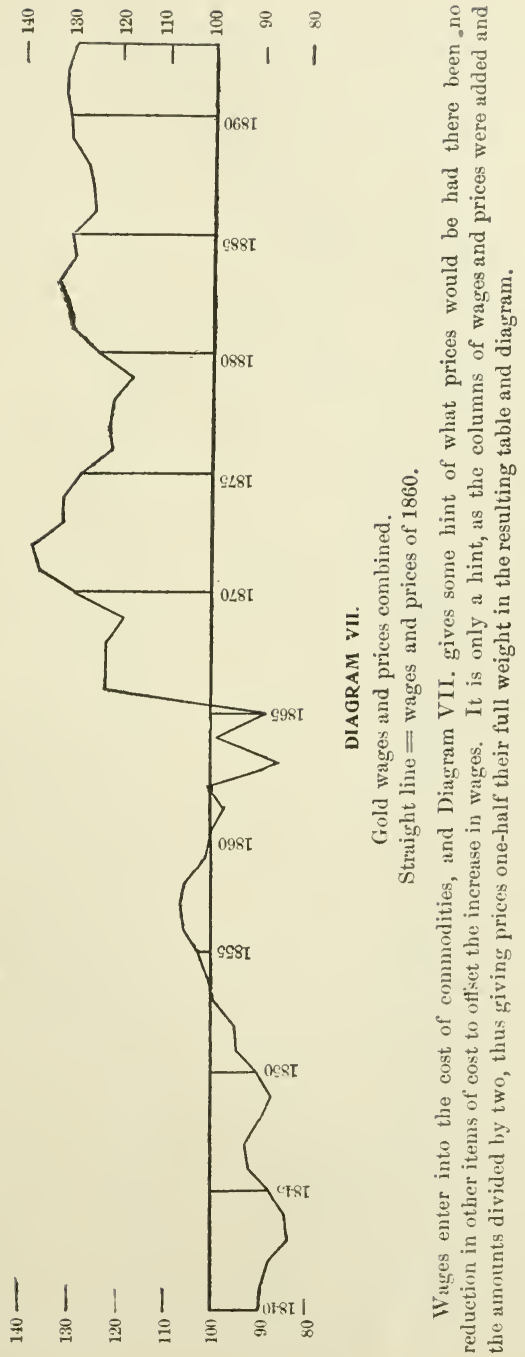




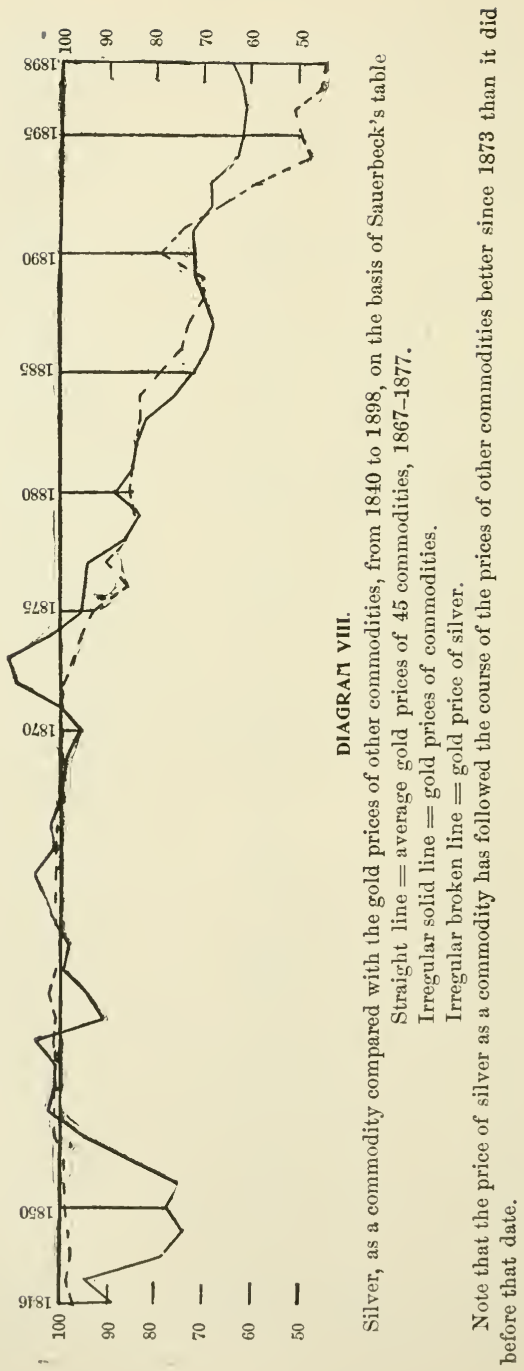


APPEXIIX.

(ii.)

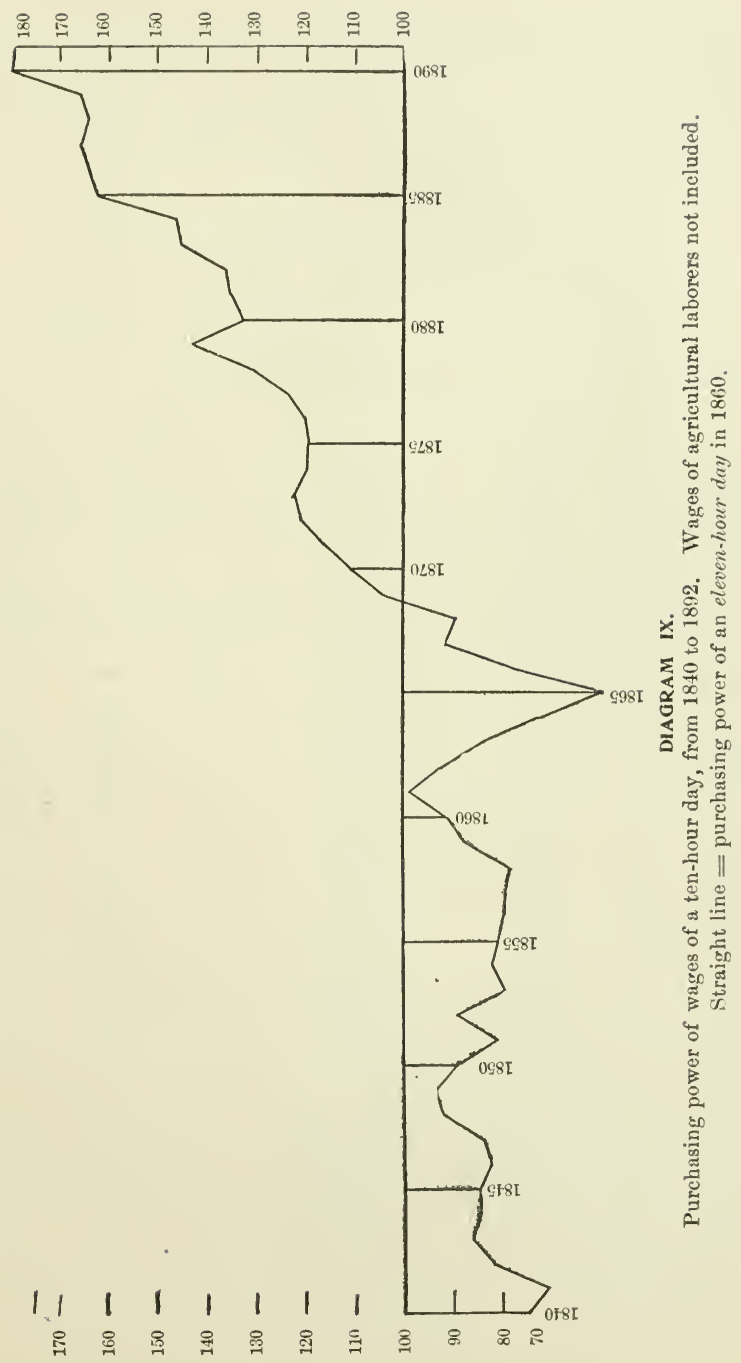


It is interesting to compare the course of prices of farm products with that of wages. The Aldrich Report segregates the prices of farm products, but computes the index numbers only from 1860. Waldron's Handbook contains a table, credited to the Voice, computed in a manner similar to that of the Aldrich Report, but which gives index numbers from 1840. It is based on the wholesale prices in New York City and is given below. Diagram X. (page 635 ), is prepared from the column of gold prices.

\section{RELATIVE COMBINED AVERAGE OF NINE FARM PRODUCTS.*}

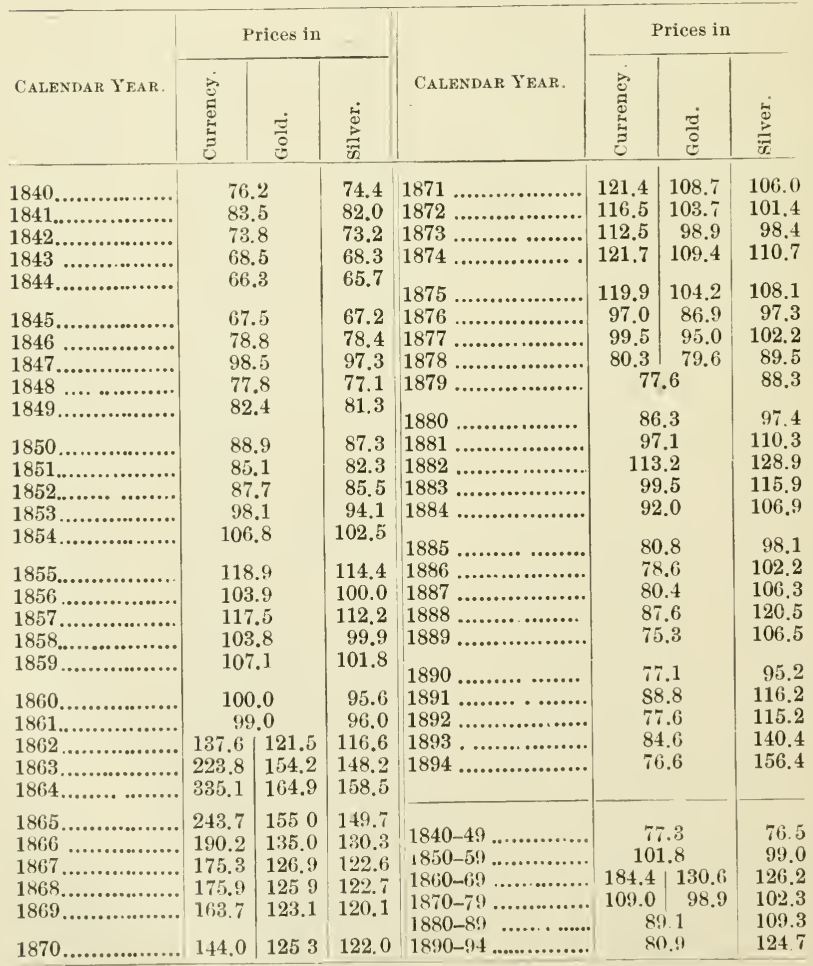

* Wheat, rye, oats, corn, upland cotton, refining sugar, Kentucky leaf tobaceo, fresh beef and iresh pork. 


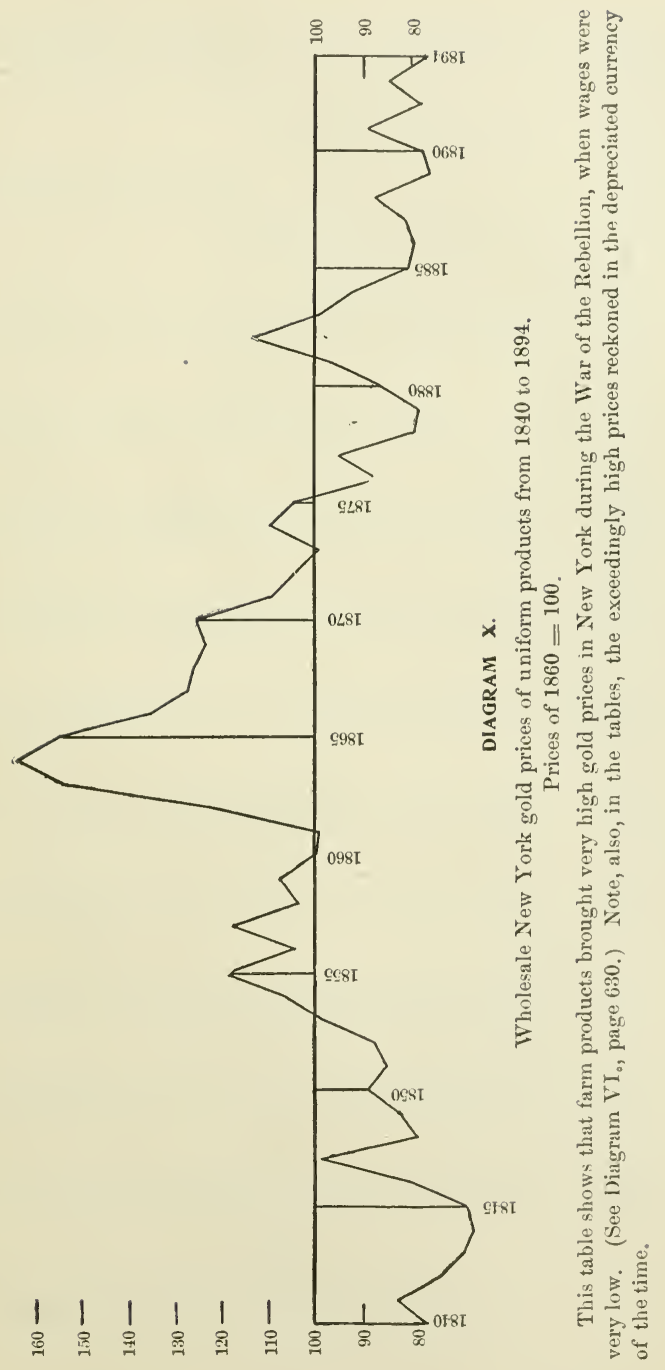


A PI'ENIST.

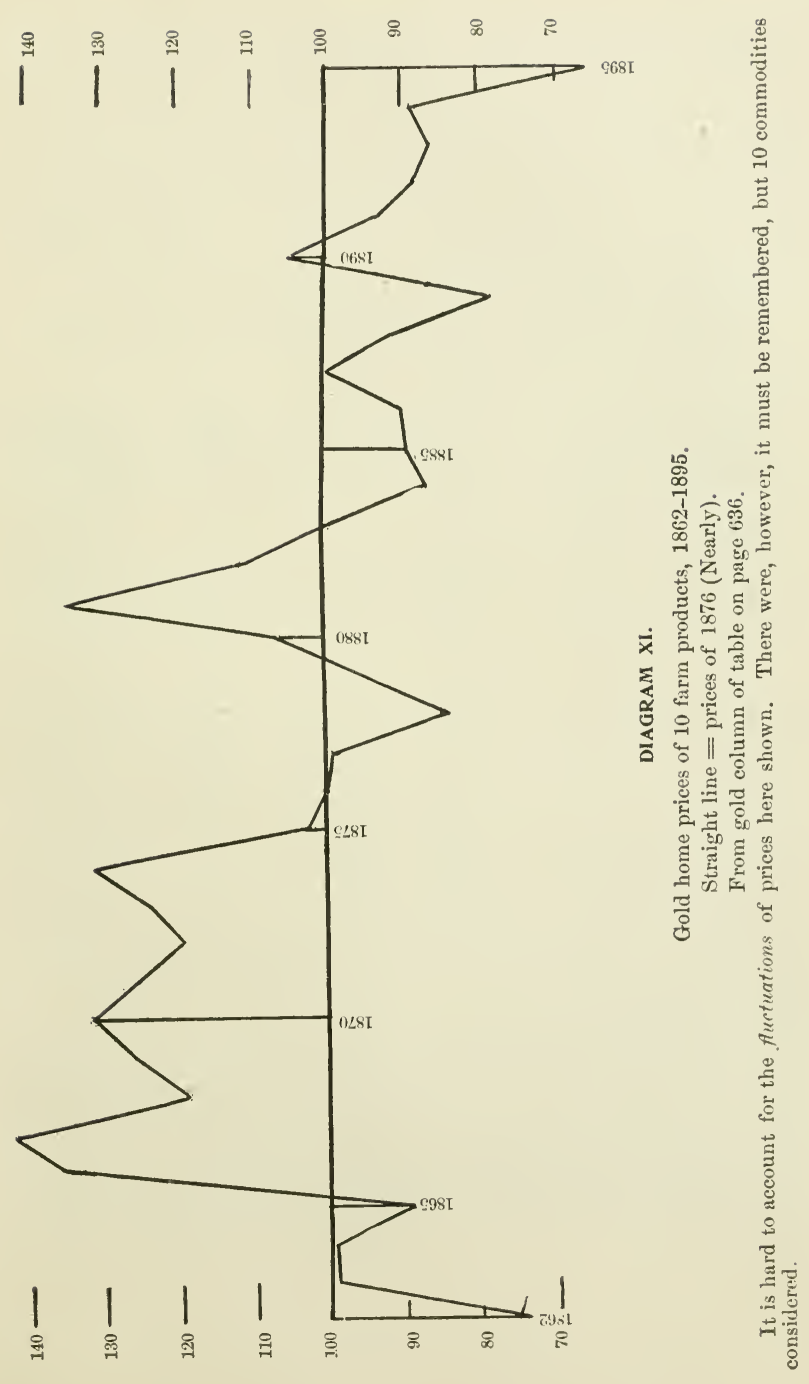


The United States Department of Agriculture has computed, since 1862, the home prices of a number of farm products, which it is interesting to compare with the course of New York prices of farm products, although the products are not identical. The table on page 636 gives the home value per bushel, ton, or pound of ten of these leading erops. The three right hand columns of the table show the ratio of the prices of the combined products in currency, gold, and silver. The currency ratio is obtained by dividing the total value of these products by the total quantity in a certain fixed proportion for each of the ten products. From this the gold and silver prices are computed. Diagram XI (page 637) is prepared from the column of gold prices. This proportion, in the form of "quantity units" in the table, is as follows:-

Corn, 250 bushels; wheat, 125 bushels; oats $333 \frac{1}{3}$ bushels; barley, rye, buckwheat, each $166 \frac{2}{3}$ bushels; potatoes, 200 bushels; hay, 10 tons; cotton, 1,000 pounds ; tobacco, 1,250 pounds.

These quantities were chosen because, at the average values of these products for the past thirty years, the same amount of money would purchase each of the products in the proportion given. For example, two bushels of corn are found to be equivalent to one bushel of wheat, and two bushels of barley, rye, or buckwheat to one of oats, ete.

The ratio of prices is computed by dividing, in each year the total value of the products by the number of quantity units computed as above, and the numbers are not, therefore, percentages of the prices in a selected year. They show the course of prices, but are not otherwise comparable with the preceding tables.

All the above tables and diagrams except Diagram VIII. refer to the United States. It would be interesting to make an exact comparison with prices of the same commodities during the same period, in Europe. There are, however, no data for this. The commodities in the Sauerbeck, Economist and Soetbeer tables do not coincide with those in the Aldrich tables, the periods covered are not altogether the same, and the years taken as the base lines for comparison differ. This last difficulty was met by the statisticiun of the Aldrich Committee, by transposing the figures of the foreign tables so as to make the year 1860 the basis of comparison, as in the United States. In constructing the diagrams the figures of the transposed tables have been used, but for convenience of reference the tables themselves give both the original and the transposed figures. The original figures of all these tables are of course those usually quoted. In all these European tables the index numbers are obtained by dividing the table of prices by the number of articles, thus giving to ench article the same weight, whether of every day use in great quantity, like wheat, or of comparatively small importance like indigo. In this, also, as already explained, they differ from the Aldrich tables which are prepared in such a form as to give to each article its relative importnnee in fanily purchuses. The Aldrich tables of wages are also "weighted" by giving the wages paid in each industry a relative importance in accordance with the number of persons employed in it. 

gives the figures as transposed to make the year 1860 the basis of comparison.

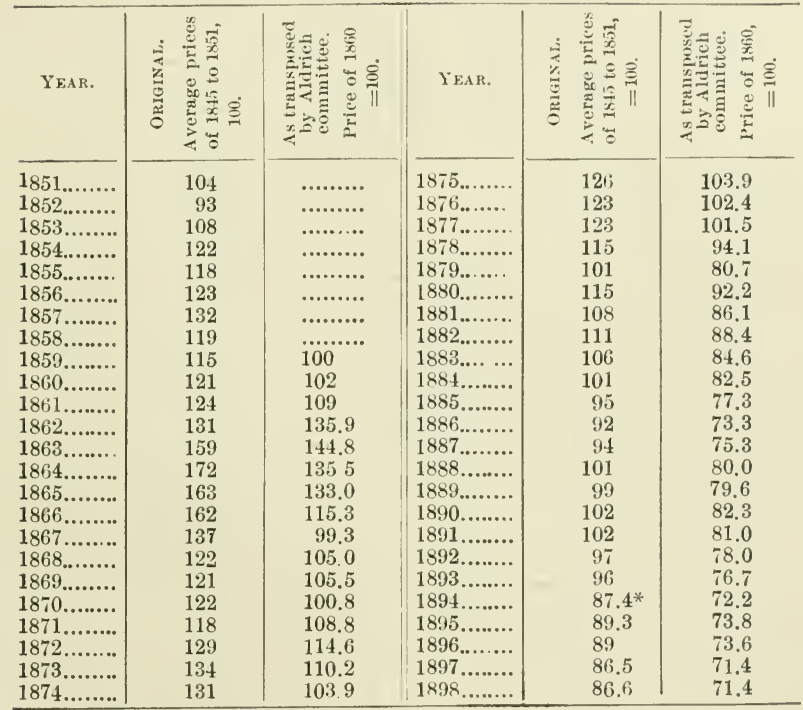

See Diagram XII. (page 610.)

* For Deeember, 1894. The Aldrieh Report contrins the Economist Index numbers to 1893 . In seeking to continue them to date, I have been unable to find a set of the Economist in San Franciseo. A student in Stanford University has been able to supply me with the totals of Eeonomist prices for the end of each quarter of $1895,1896,1897$, and 1898 , of which I have taken the average from which to compute the annual index number, although $I$ infer from an expression in the Aldrich Report that the number usually quoted as the Economist number is that of Janury in each year. For $1894 \mathrm{my}$ data includes only the quotation for December, which I have, therefore, taken. I have transposed the index numbers of these years to the basis of 1860 , by dividiug eaeh by the index numbers for 1860 . The result is in any ease sufficiently aceurate for the purposes of this book, but this explanation is given for the benefit of students who may have occasion to refer to these tables. 


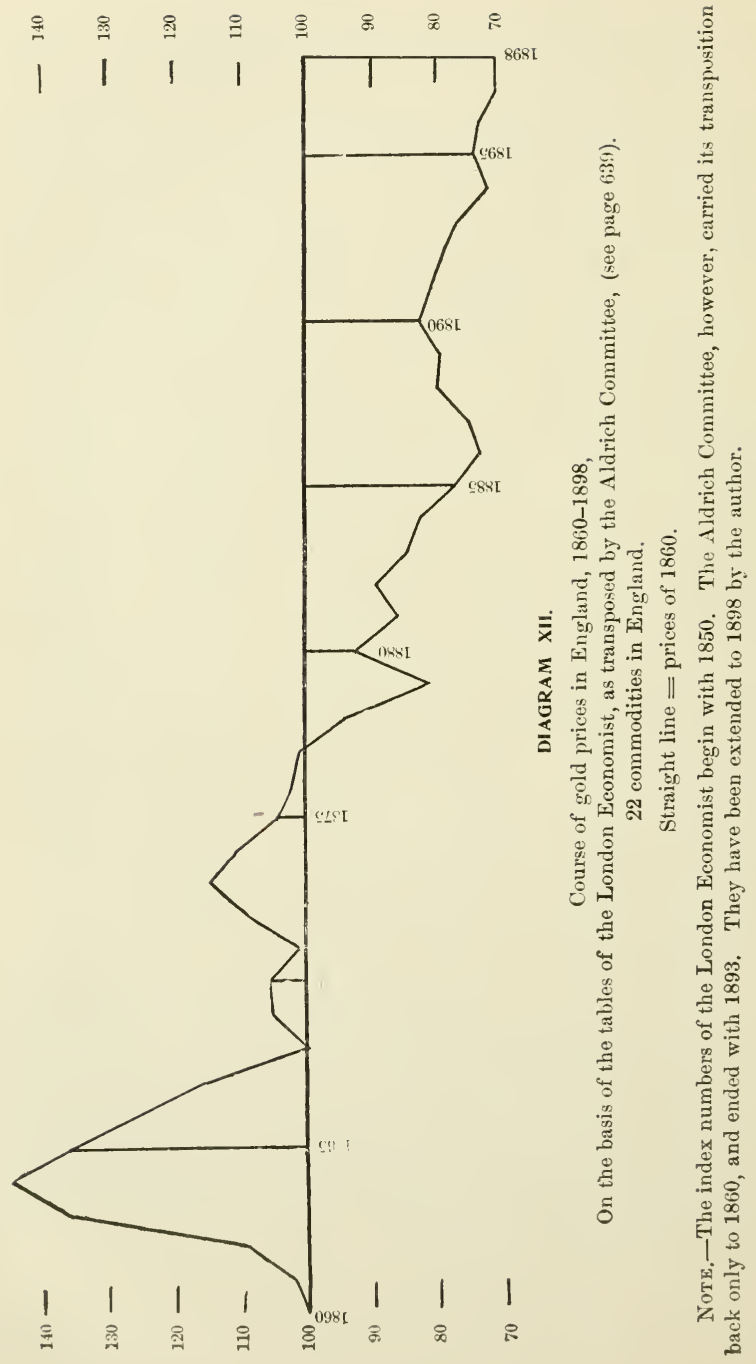


TABLES OF DR. A. SAUERBECK.

Relative Prices of 45 Commodities in England, 1846 to 1S98. Original and as transposed by Aldrich Committee to correspond with the American tables.

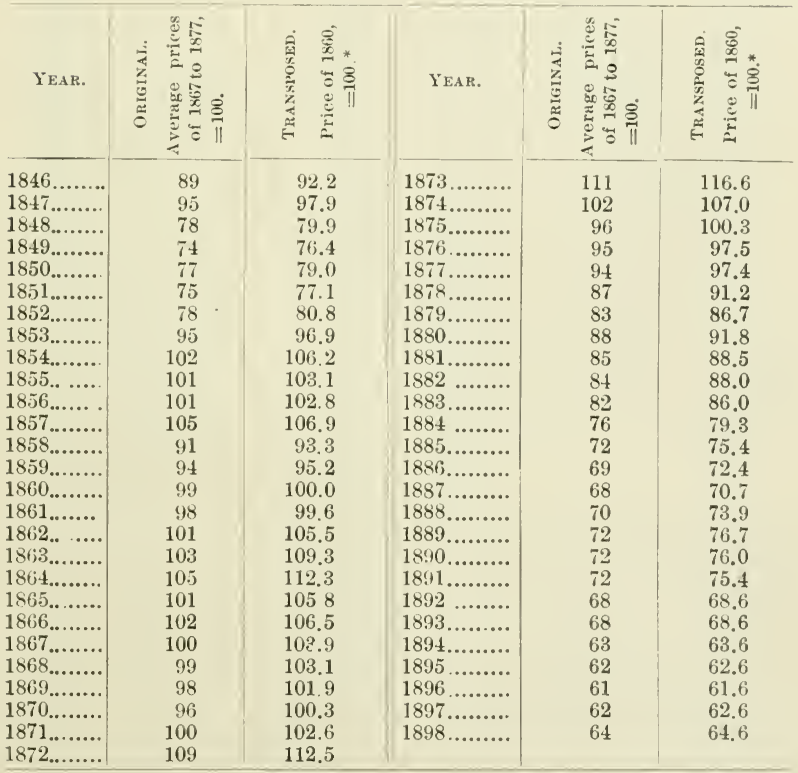

See Diagram XIII. (page 642).

* The transposition of Senate Committee ends with 1891. From that year it is continued by the author by dividing the price of each year by the price of 1860 . 


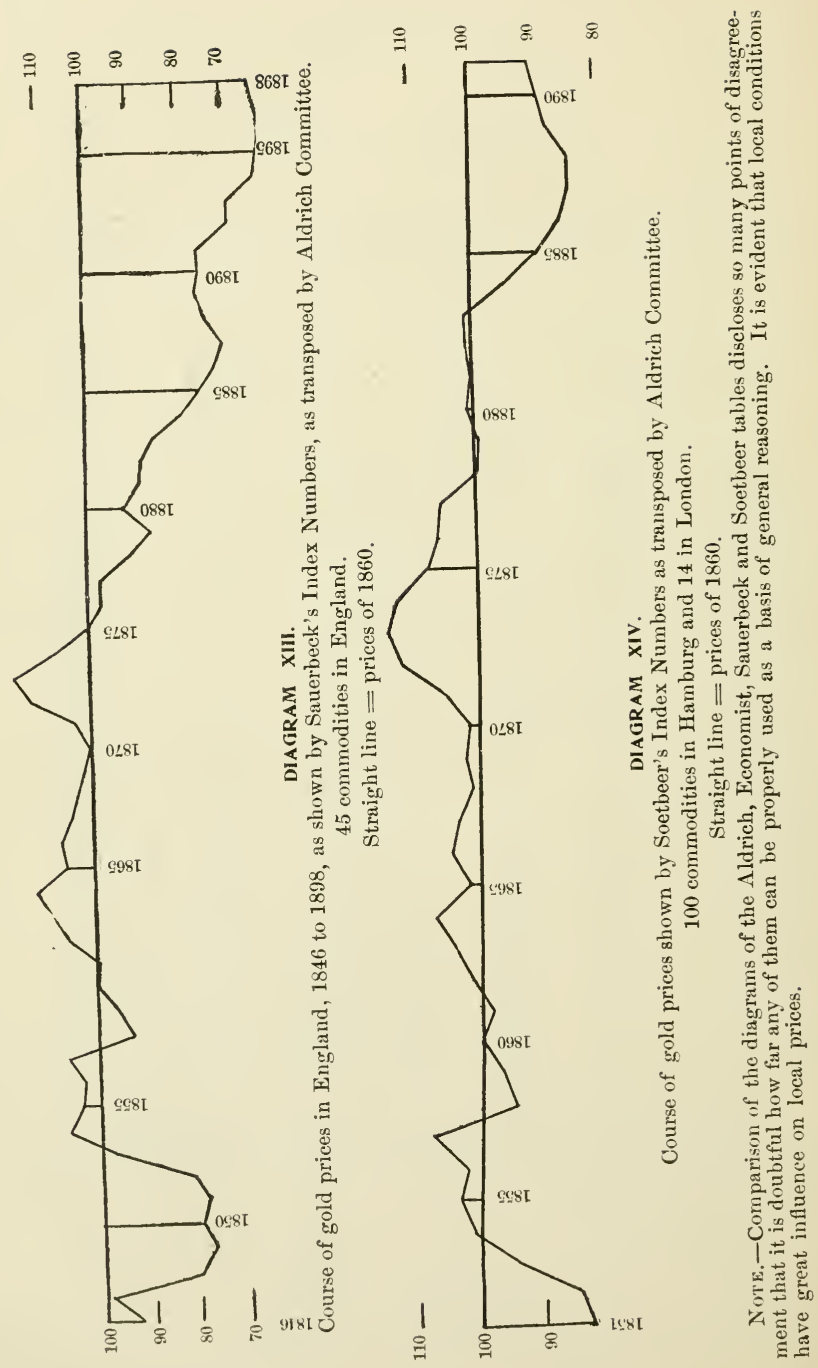


TABLES OF DR. A. SOETBEER.

Relative Prices of 100 Lealing Articles in Hamburg, and 14 articles of Britush export, original, and as transposed by Aldrich Committee to correspond with American tables.

\begin{tabular}{|c|c|c|c|c|c|}
\hline YEAR. & 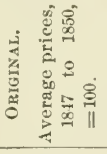 & 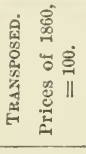 & YEAR. & 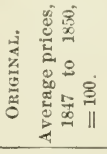 & 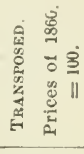 \\
\hline $1851 \ldots \ldots \ldots$ & 100.21 & 82.8 & $1872 .$. & 135.62 & 112.1 \\
\hline $1852 \ldots \ldots .$. & 101.69 & 84.1 & $1873 \ldots$ & 138.28 & 114.3 \\
\hline $1853 . . . . .$. & 113.69 & 94.0 & $1874 \ldots$ & 136.20 & 112.6 \\
\hline $1854 . \ldots . .$. & 121.25 & 100.2 & $1875 \ldots$ & 129.85 & 107.3 \\
\hline $1855 \ldots \ldots$. & 124.23 & 102.7 & $1876 \ldots \ldots \ldots$ & 128.33 & 106.1 \\
\hline $1856 \ldots \ldots \ldots$ & 123.27 & 101.9 & $1877 \ldots$ & 127.70 & 105.6 \\
\hline $1857 \ldots \ldots \ldots$ & 130.11 & 107.5 & $1878 \ldots \ldots \ldots$ & 120.00 & 99.7 \\
\hline $1858 . . . . .$. & 113.52 & 93.8 & $1879 \ldots$ & 117.10 & 96.8 \\
\hline $1859 \ldots \ldots \ldots$ & 116.34 & 96.2 & $1880 \ldots$ & 121.89 & 100.8 \\
\hline $1860 \ldots \ldots .$. & 120.98 & 100.0 & $1881 \ldots \ldots \ldots$ & 121.07 & 100.1 \\
\hline $1861 \ldots \ldots \ldots$ & 118.10 & 97.6 & $1882 \ldots$ & 122.14 & 101.0 \\
\hline $1862 \ldots \ldots \ldots$ & 122.65 & 101.4 & $1883 \ldots$ & 122.24 & 101.0 \\
\hline $1863 . . . \ldots .$. & 125.49 & 103.7 & $1884 \ldots$ & 114.25 & 94.4 \\
\hline $1864 \ldots \ldots .$. & 129.28 & 106.9 & $1885 \ldots$ & 108.72 & 89.9 \\
\hline $1865 . . . . .$. & 122.63 & 101.4 & $1886 \ldots$ & 103.99 & 86.0 \\
\hline $1866 \ldots \ldots$ & 125.85 & 104.0 & $1887 \ldots \ldots$ & 102.02 & 84.3 \\
\hline $1867 \ldots \ldots \ldots$ & 124.44 & 102.9 & $1888 \ldots$ & 102.04 & 84.3 \\
\hline $1868 \ldots \ldots$. & 121.99 & 100.8 & $1889 \ldots$ & 106.13 & 87.7 \\
\hline $1869 . . \ldots \ldots$ & 123.38 & 102.0 & $1890 \ldots$ & 108.13 & 89.4 \\
\hline $1870 \ldots \ldots$ & 122.87 & 101.6 & $1891 \ldots \ldots \ldots$ & 109.19 & 90.0 \\
\hline $1871 \ldots \ldots \ldots$ & 127.03 & 105.0 & & & \\
\hline
\end{tabular}

The course of silver as compared with commodities has been shown in diagram $V$. in which it is seen that according to the computations of Dr. Sauerbeck it follows commodity prices quite closely. In that diagram silver is simply considered as one commodity compared as to price, with the average of forty-five other commodities in England, a country of gold standard. It would be interesting to compare with the gold prices, heretofore given, the course of silver prices in countries with the silver standard. Unfortunately the dita for this are very meager. Mr. F. J. Atkinson has made a laborious calculation of the course of silver prices in India, which is to be found in the Journal of the Royal Statistical Society for 1897, and extends from 1861 to 1895 . I also find upon page 463 of a U. S. Senate Document entitled "Coinage Laws of the United States" (Government Printing Ottice, 1894) a table of index numbers of prices of twenty Chinese stiple commodities from 1873 to 1892 , and printed without comment. So far as I know there are no other data covering this branch of the inquiry. As will be scen below they hardly agree at any point. The calculations of $\mathrm{Mr}$. Atkinson, given in full in the place of original publication, give evidence of a great amount of labor intelligently applied, but for reasons fully set forth by Mr. Atkinson, do not throw much light upon the 
problem of the probable result of the use of a silver standard, as conditions in India are abnormal. An index table constructed upon silver prices in China would have much greater promise of value, but I have no knowledge of the methods employed by Mr. Wetmore. I assume his competence from the fact that his table is included in a public document whose compilers must have been fumiliar with the facts.

The two tables with the diagrams prepared from them are as follows and are given for what they are worth:-

RELATIVE SILVER PRICES IN INDI.A.

Table of Index Numbers, prepared from his own calculations, by F.J. Athinson, Juurnal Royal Statistical Society, $189 \%$.

Prices of $1871=100$.

\begin{tabular}{|c|c|c|c|c|}
\hline 1861 & 99 & 1870 & 1879 & 1888 . \\
\hline 1862 & .......... 99 & $1871 \quad \ldots \ldots . .100$ & $\begin{array}{llll}1880 & \ldots \ldots . . & 117\end{array}$ & $1889 \quad \ldots \ldots . .125$ \\
\hline 1863 & .......... 104 & $1872 \quad \ldots \ldots . .105$ & $1881 \ldots \ldots .106$ & $1890 \ldots \ldots .125$ \\
\hline 1864 & ......... 112 & $1873 \div \ldots . . .107$ & $1882 \ldots \ldots .105$ & ... 128 \\
\hline 1865 & ......... 117 & $1874 \ldots . . .116$ & $1883 \ldots \ldots . .106$ & $1892 \ldots \ldots .141$ \\
\hline 1866 & .......... 133 & $1875 \ldots \ldots . .103$ & 1884 & 1893. \\
\hline 1867 & ......... 126 & $1876 \ldots \ldots . .107$ & $1885 \ldots \ldots .113$ & $1894 \ldots \ldots .131$ \\
\hline 1868 & .......... 114 & $1877 \quad \ldots \ldots .138$ & $1886 \ldots \ldots, 110$ & $1895 \ldots \ldots .128$ \\
\hline 1869 & .......... 126 & $1878 \ldots \ldots 148$ & $1887 \ldots \ldots .111$ & \\
\hline
\end{tabular}

See Diagram XV. (page 645).

According to the foregoing table, silver prices of commodities in India fluctuated violently and were 28 per cent higher in 1895 than in 1871 .

RELATIVE SILVER PRICES IN CHINA.

Table of Index Numbers compiled by W.S. Wetwore from calculations based on the records of the Impcrial Customs of China.

Prices of $1873=100$.

\begin{tabular}{|c|c|c|c|c|}
\hline $1873 .$. & $1877 \ldots \ldots 101.5$ & $1881 \ldots \ldots 97.0$ & $18 \times 5 \ldots \ldots .92 .7$ & 1889 \\
\hline 907 & $1878 \ldots$ & 99.3 & 92.9 & 1890 \\
\hline .. 89 & 1879 & 18 & 88.7 & 18 \\
\hline 96.5 & 1880 . & 1884 & 1888 & $1892 \ldots . .8$ \\
\hline
\end{tabular}

See Diagram XVI. (page 645).

According to $\mathrm{Mr}$. Wetnore's table, silver prices in China were quite stable, and were twelve per cent lower in 1892 than in 1873.

I am not able to throw much light upon the question as to which of these two tables, if either, indicates the normal course of silver with respect to commodities, but taking into consideration the fact that local conditions affecting prices were more nearly normal in China than in India, and the general coineidence of Mr. Wetmore's table with the eourse of silver and commodities in England, as shown in Diagran V., I am compelled to believe that Mr. Wetmore's table comes nearer to showing the probable result of the general use of the silver standard thun Mr. Atkinson's. But one swallow does not make a summer, and it must not be so imagined in either ease. 

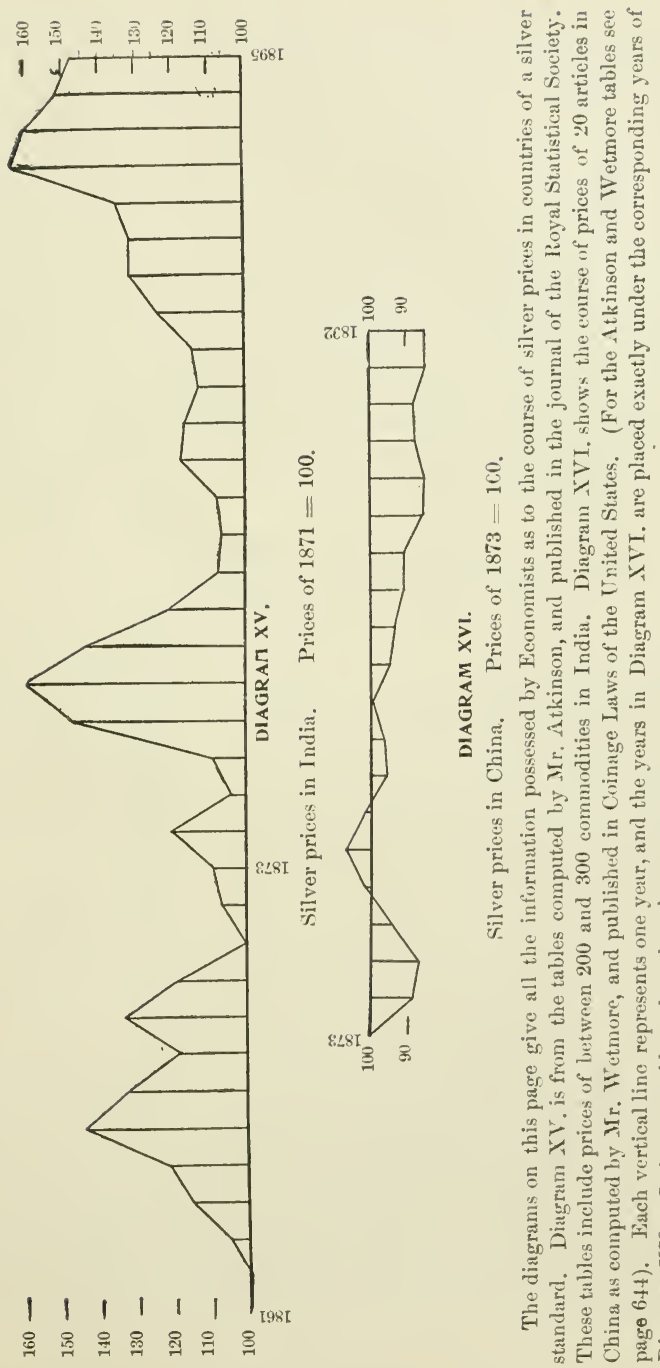

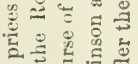
के के

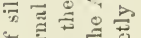

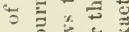
. ซี $\dot{\Xi} \cong 5 \dot{\Xi}$

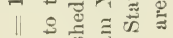

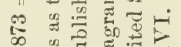

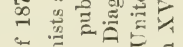

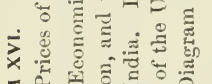

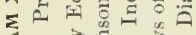

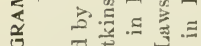

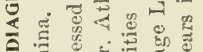
ฮี

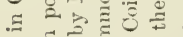
कू

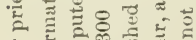

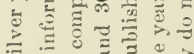
$\overline{\mathrm{i}}$ $\cong \frac{0}{5} 8$ ह इ

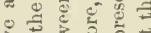
เ o ह 0 है। E.

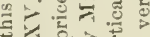
ㄴ.

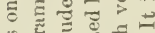
है 额

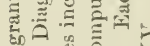

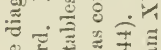

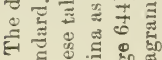

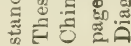


The item of transportation enters so largely into the cost of products delivered at the great wholesale centers that no treatment of the subject of prices-especially from the farmer's standpoint-is complete without a consideration of the relative prices of transportation. Unfortunately the data upon this subject, for the earlier part of the period covered by the foregoing tables, are very meagre, as to railroad transportation, and I have found no statistics, whatever, covering transportation by sea or inland waters. The statistician of the Interstate Commerce Commission supplied to the Aldrich Committee all the data relating to early freight tariffs which could be gathered by that office. Since the creation of the Interstate Commerce Commission the data are ample, but no one, that I am aware of, has summarized the facts and constructed an index table or other device to show the course of cost of transportation. The most convenient method of showing relative freight rates is by a comparison of the average rates per ton per mile. The information on this point which was available in 1893 will be found on page 615 of the Aldrich Report. From the facts there given'I select the following. While they apply in each case, only to the railroads named; they will give an idea of the decrease in the cost of transportation during the last quarter of a century.

\section{AIERAGE FREIGHT RATES PER TON PER MILE.}

SOME TYPICAL CANES SELECTED FROM DATA ON PAGE 615 OF THE REPORT OF THE ALDRICH COMMITTEE.

\begin{tabular}{|c|c|c|c|c|}
\hline & & & rate per $t$ & nI \\
\hline burg 1 & & . 1852 & $\begin{array}{ll}\text { Cts. } \\
3.12,1892\end{array}$ & .925 \\
\hline ilroad & & 1866 & $2.85 \quad 1890$ & .777 \\
\hline York \& New England Railroad & & .1886 & 6.40 .1892 & 1.155 \\
\hline York, New Haven \& Hartford Railroad & & .1857 & 3.80 .1892 & 1.756 \\
\hline I Railroad & & .1855 & $3.02 \cdot 1892$ & .700 \\
\hline S. Railroad & & .1854 & 3.51 .1892 & .687 \\
\hline incinnati \& St. Louis & . & .1853 & 3.03 .1892 & .710 \\
\hline a & & 1852 & 5.42 .1892 & .647 \\
\hline \& Miss. Railroad & & .1858 & 3.25 .1892 & .911 \\
\hline Northw & & . . 1868 & $3.13 \cdot 1892$ & 1.013 \\
\hline acific Railroad & & . .1872 & 2.34 .1892 & 1.081 \\
\hline ison, T. \& S. ] & & .1873 & 3.10 .1892 & 1.130 \\
\hline
\end{tabular}

The foregoing will give an idea of the reduction in cost of transportation, and may be as valuable as an average for the United States were it known.

\section{APPRECIATION AND INTEREST.}

It is claimed by some that while gold has very likely appreciated, with respect to commodities, interest upon invested capital has fallen so rapidly that the possession of $\$ 10,000$ of loanable capital will now bring to its owner no more annual income than $\$ 5,000$ would have procured in 1870 . The table below is from Professor Fisher's "Appreciation and Interest," in which, substantially, that view is taken. The figures are doubtless authentic but require some explanation for the reader untrained in finance. The rates of interest quoted are all upon securities upon which principal and interest can ordinarily be counted on to be paid upon the day they become due. The element of risk 
is eliminated, so far as is possible in human affisirs. The column showing rates (per annum) upon sixty-day paper represents money louned by commercial banks to merchants, the money being mainly the balances of depositors, and so subject to check at sight. When business is lively, interest upon sueh loans tends to rise by reason of increased demand, and in times of panic, it tends to rise still more, by reason of distrust of security offered, and the unwillingness of banks to lend money whose owners are likely to call for it at any moment. This accounts for the raise of interest rates in the panic years of 18571873 , and 1893.

On the other hand, the columns showing eurrent rates of interest upon giltedged bonds represents money intended to be permanently invested, and, as will be noted, the interest rate is not aflected by business conditions.

While these figures are doubtless reliable as to interest rates received by capitalists for large sums, when security is believed to be perfect, every farmer knows that they bear no relation to the rates which he has to pay upon mortgage loans. I can find no evidenee of any reduction in the rate of interest upon small loans upon such security as the farmer ean offer. The "retail" price of money has not fallen according to my observation, but I know of no data establishing the fact.

INTEREST RATES REALIZED.

(From Fisher's "Appreciation and Interest.")

\begin{tabular}{|c|c|c|c|c|c|c|c|}
\hline \multirow{2}{*}{ Year. } & \multicolumn{2}{|c|}{ Bonds. } & \multirow{2}{*}{$\left|\begin{array}{c}\text { Money. } \\
60 \text {-day } \\
\text { paper } \\
\text { (New } \\
\text { York). }\end{array}\right|$} & \multirow{2}{*}{ Year. } & \multicolumn{2}{|c|}{ Bonds. } & \multirow{2}{*}{\begin{tabular}{|c} 
Money. \\
60-day \\
paper \\
(New \\
York).
\end{tabular}} \\
\hline & Coin. & $\begin{array}{l}\text { Cur- } \\
\text { rency. }\end{array}$ & & & Coin. & $\begin{array}{l}\text { Cur- } \\
\text { rency. }\end{array}$ & \\
\hline - & & & $\begin{array}{c}\text { Yearly } \\
\text { Average. }\end{array}$ & & & & $\begin{array}{l}\text { Yearly } \\
\text { Average. }\end{array}$ \\
\hline $\begin{array}{l}1849 . . \\
1850 \ldots\end{array}$ & $\cdots \cdots$ & n............ & 7.8 & $1874 \ldots \ldots$ & 5.0 & 5.0 & 6.0 \\
\hline $\begin{array}{l}1850 \ldots \\
1851 \ldots\end{array}$ & ............. & .............. & 7.2 & $1875 \ldots \ldots \ldots$ & 5.1 & 4.7 & 5.5 \\
\hline $\begin{array}{l}1851 \ldots \\
1852 \ldots\end{array}$ & n.......... & ............. & 8.3 & $1876 \ldots \ldots \ldots$ & 4.7 & 4.4 & 5.2 \\
\hline $\begin{array}{l}1852 \ldots \\
1853 \ldots\end{array}$ & …......... & ............. & 7.3 & $1877 \ldots \ldots \ldots$ & 4.5 & 4.4 & 5.2 \\
\hline $\begin{array}{l}1853 \ldots \ldots \\
1854 \ldots \ldots\end{array}$ & ............ & n........... & 10.1 & $1878 \ldots \ldots \ldots$ & 5.0 & 4.6 & 4.8 \\
\hline $1854 \ldots$ & .............. & .. .......... & 12.5 & $1879 \ldots \ldots \ldots$ & 3.7 & 4.5 & 5.0 \\
\hline $1855 \ldots \ldots \ldots$ & & .............. & 9.3 & $1880 \ldots$ & 3.8 & +.0 & 5.2 \\
\hline $1856 \ldots \ldots \ldots$ & ............. & .............. & 9.9 & $1881 \ldots \ldots \ldots$ & 3.3 & 3.4 & 5.2 \\
\hline $1857 \ldots \ldots \ldots$ & ............. & $\ldots$ & 10.4 & $1882 \ldots \ldots$ & 3.0 & 3.5 & 5.7 \\
\hline $\begin{array}{l}1858 \ldots \\
1859 \ldots\end{array}$ & ............ & ............... & 6.7 & $1883 \ldots$ & 2.9 & 3.3 & 5.5 \\
\hline $\begin{array}{l}1859 \ldots \\
1860 \ldots\end{array}$ & ............. & ............. & 7.2 & $1884 \ldots \ldots$ & 2.6 & 2.9 & 5.2 \\
\hline $1860 \ldots \ldots \ldots$ & ........ & ............. & 7.7 & $1885 \ldots \ldots \ldots$ & $2.7 a$ & $2.7 a$ & 4.1 \\
\hline 1861. & & & 6.6 & $1886 \ldots \ldots \ldots$ & 2.6 & 2.6 & 4.7 \\
\hline 1862. & ........... & $\cdots \cdots$ & 5.4 & $1887 \ldots$ & 2.3 & 2.6 & 5.7 \\
\hline $\begin{array}{l}1863 . . \\
1864\end{array}$ & ............. & .............. & 5.8 & $1888 \ldots \ldots$ & $23 b$ & $2.9 b$ & 4.9 \\
\hline $1864 .$. & n............ & $\ldots$. & 8.0 & $1889 \ldots \ldots \ldots$ & 2.2 & 2.6 & 4.8 \\
\hline $1865 .$. & .............. & .............. & 8.2 & $1890 \ldots \ldots$ & $2.1 a$ & $2.6 a$ & 6.0 \\
\hline $1866 \ldots \ldots \ldots$ & .............. & ................ & 6.3 & $1891 \ldots \ldots \ldots$ & $2.4 c$ & $3.0 \mathrm{c}$ & 5.7 \\
\hline $1867 .$. & …......... & .......... & 7.2 & $1892 \ldots \ldots \ldots$ & 2.6 & 3.1 & 4.3 \\
\hline 1868. & n.......... & ............ & 7.3 & $1893 \ldots \ldots \ldots$ & $2.8 b$ & $3.1 b$ & 7.1 \\
\hline $1869 \ldots$ & ......... & ........... & 9.1 & $1894 \ldots \ldots \ldots$ & $2.7 g$ & $3.5 g$ & 3.4 \\
\hline $1870 \ldots$ & 6.4 & 5.4 & 7.2 & $1895 \ldots \ldots$ & $2.8 h$ & $3.6 h$ & 3.8 \\
\hline $1871 \ldots . . .$. & 6.0 & 5.3 & 6.1 & $1896 \ldots \ldots \ldots$ & $3.2 h$ & $4.3 h$ & 5.8 \\
\hline $1872 \ldots . . . .$. & 5.3 & 4.9 & 8.0 & $1897 \ldots \ldots$ & .......... & .............. & 3.7 \\
\hline $1873 \ldots \ldots \ldots$ & 5.7 & 5.1 & 10.3 & $1898 \ldots \ldots$ & .......... & ............. & 3.8 \\
\hline
\end{tabular}




\section{AMERICAN TRUSTS.}

It is said that one day when the Emperor Nero was out of sorts, he expressed the wish that all the Roman people had but one neck, so that he could the more easily cut it off. Capital seems to be trying to put itself in a position where it can be similarly dealt with. When one army is greatly inferior to another, its best course is ordinarily to take to the bush and carry on a guerrilla warfare. The power of capital is vastly inferior to that of the people, and if it deliberately proposed to make war upon the public, its most prudent course would be to conceal itself, and fight under cover. There is no such intention. Capital is not organized as a whole, and competes with itself as vigorously as farmers or commission merchants compete with each other. Each capitalist, however, is striving to make the most possible for himself, and at the present time there appears to be a craze among owners of industrial plants to unload their possessions, at high prices, upon the investing public. They are, therefore, rapidly organizing Trusts by the methods described on page 411, and endeavoring to sell out. Investors are allured by the promise that as the result of the consolidations for which they are asked to supply the capital, prices can be raised to a point which will enable the concerns to pay dividends upon the enormously inflated stock. In this they will usually fail, and the investors will lose their money. In its present shape, therefore, the campaign for the formation of Trusts is a campaign against investors. The people can rest perfectly easy. No harm can come to them, for the consolidation of interests will render them vastly easier to deal with. The logical outcome of a Trust formed in the normal manner, as the result of unbearable competition, and with plants put in at bedrock prices, and in the absence of excitement, is profit to those concerned in it, and a raise in prices to just below the point at which new competition will be invited. This will do no harm. It is desirable that all business be done at a reasonable profit. On the contrary, it may do good, as tending to counter organization among farmers, working men, and other classes. The logical result of such a campaign as is now going on is a financial panic when investors shall have discovered the true value of the properties which they have purchased. It is to be hoped that it will not advance to that point. The most of the Trusts now torming will probably not succeed. They are competing with each other for the money of investors, and the crop of fools, although large, is after all, limited. Some of the proposed combinations appear to be really consolidations of enormous capital, with the intent, and possibly, for the present, the power to oppress. These may have to be dealt with, possibly by constitutional amendment. It is easy enough to tax out of existence combinations of capital which are dangerous to society. The wild laws which some legislatures are now passing can do no good, and are most of them not only unconstitutional, but more injurious to business than the evils at which they are aimed. What the public, and especially the farmers, most need, in order to deal successfully with combinations of capital, is perfectly clear minds and perfectly cool heads.

The following list of Trusts is compiled from the San Francisco Chronicle Almanac for 1899, and a late number of the San Francisco Argonaut. It 
appears to have been largely made up of items from press despatches, and is as good as any other list. There is no authentic list of Trusts, and if there were, it would not be correct for a week. I might have added largely to the list, in the way that I presume this was made up, but it is not worth while. The best way is for all to assume that every thing which they buy is sought to be controlled by a Trust, and that in some cases the attempt has been successful, but in many other cases not.

PARTIAL LIST OF TRUSTS.

Acid trust (forming)

Aleohol trust.

American corn harvester trust Anglo-American thread trust Anthracite coal combine, Pennsylvania .............. Asphalt trust................... Ax trust..................... Baking powder trust............. Barbed wire trust, Chicago... Biscuit and eracker trust..... Bituminous coal trust........ Bleachery combine............ Bolt and uut trust................ Boiler trust, Pittsburg......... Borax trust, Pennsylvauia.... Brass trust.

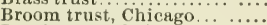
Brush trust, Ohjo..............

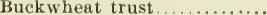

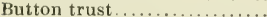
Cars trust.

Carbon candle trust, cleveland.

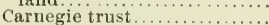
Cartridge trust.

Cash register trust

Casket and burial goods trust Castor oil trust, St. Louis. Celluloid trust.

Cigarette trust, New York.... Clothes wringer trust.

Colorado conl combine trust Coudensed milk trust, Illinois Confectioners' trust........... Copper ingot trust............ Cordage trust.

Corn harvesters trust ......... Cornstalk trust

Cotton duck trust

n.....

Crockery trust.....

('ubin tobaceo trust.

Cutlery trust (forming).......

Distilleries trust.

Dressed beef and provision trusts (two)

Dye and chemical combine

Electrical combine No. 2

Electrie light trust............

Electrie supply trust............

Enameling trust.................

Envelope trust .................

Fish trust......

Flint glass trust, Pennsylvania........................ Flour trust (forming)........... Fruit canners' trust ............

Fruit jar trust.................. Fur combine. . ..................... Furniture trust ....................
Capital.

$\$ 50,000,000$

$5,000,000$

$50,000,000$

$18,000,000$

$85,000,000$

$3,140,000$

$15,000,000$

$20,000,000$

$10,000,000$

$12,000,000$

$15,000,000$

$10,000,000$

$10,000,000$

$15,000,000$

$2,000,000$

$10,000,000$

$2,500,000$

$2,000,000$

5, 000,000

$3,000,000$

$60,000,000$

$3,000,000$

$25,000,0400$

$10,000,000$

$10,000,000$

$1,000,000$

500,000

$8,000,000$

$25,000,000$

$2,000,000$

$20,000,000$

$15,000,000$

$2,000,000$

$20,000,000$

$35,000,000$

$50,000,000$

$50,000,000$

$10,000,000$

$6,000,000$

$20,000,000$

$15,000,000$

$20,000,000$

$2,000,000$

$24,000,000$

$100,000,000$

$2,000,000$

$1,800,000$

$25,000,000$

$10,000,000$

$30,000,000$

$7,000,000$

$5,000,000$

$8,000,000$

$150,000,000$

500,000

$1,000,000$

$10,000,000$

$12,000,000$
Galvanized iron and steel trust, Pennsylvania steel Glove trust, New York......... Gossamer rubber trust ....... Glucose trust

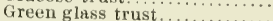

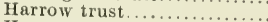

Harvester trust....

Heating apparatus trust.....

Hinge trust

Hop combine.

Indurated fiber trust..........

International Silverware Company trust (forming)........

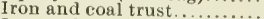

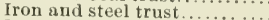

Iron ore trust.

Iron pipe trust..................

Iron tube trust. . . . . . . . . . .

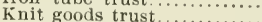

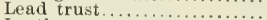

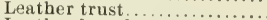

Leather board trust..............

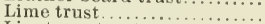

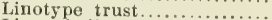

Linseed oil trust.

Lithograph trust, New Jersey

Locomotive tire trust........

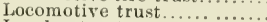

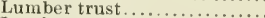

Lumber trust. . . . . . . . . . . . .

Matting trust.

Manila tissue trust ...........

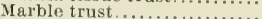

Mateh trust ................

Match trust, Chicago.............

Menhaden trust. .

Merchants' steel trust..........

Norocco leather trust.......

Naval stores combine trust...

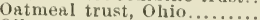

Oil trust.

Oileloth trust $\ldots \ldots \ldots \ldots \ldots$

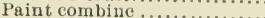

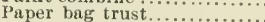

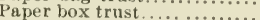

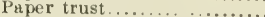

Patent leather trust.............

Pitch trust.

Plate glass trust, Pittsburg...

Plug tobaceo trust...........

Pocket eutlery trust................

Pork combine.

Powder trust.

Preserves trust, West V.

Pulp trust

Refrigerator trust (forming).

Ribbon trust.

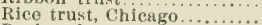

Rock salt combine.............

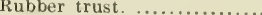

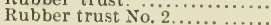

Capital.

$2,000,000$

$2,000,000$

$12,000,000$

$40,000,000$

$4,000,000$

$2,000,000$

$1,500,000$

$10,000,000$

$1,000,000$

500,000

500,000

$30,000,000$

$10,000,000$

$75,000,000$

$30,000,000$

$30,000,000$

$60,000,000$

$30,000,000$

$30,000,000$

$124,483,000$

500,000

$3,000,000$

$5,000,000$

$18,000,000$

$11,500,000$

$2,000,000$

$5,000,000$

$40,000,000$

$2,000,000$

$30,000,000$

\& $2,000,000$

$20,000,000$

$30,000,000$

$8,000,(100)$

$10,000,000$

$25,000,000$

$2,000,000$

$1,000,000$

$3,500,000$

$12,000,000$

$2,500,000$

$2,000,000$

$2,000,000$

$5,000,000$

$55,000,000$

$5,000,000$

$10,000,000$

$8,000,000$

$60,000,000$

$2,000,000$

$20,000,000$

1,50r1,000

$8,000,000$

$5,000,000$

$8,000,000$

$18,000,000$

$2,500,000$

$5,000,000$

$50,000,000$

$7,000,000$ 
Safe trust

Sandstone trust, New York.

Sandpaper trust

Sash and toor combine........

Sash, door and blind trust...

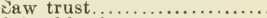

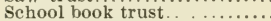

School furniture trust.......

Sewer pipe trust.............

Sheet copper trust...........

Sheet steel trust.............

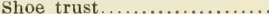

Skewer trust..............

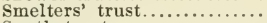

Snath trust

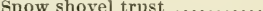

Soap trust.

Soda water apparatus trust..

Spirits trust.

Spool bobbin and shuttle trust

Sponge trust

Standard Oil Company trust.

Standard Distilling Company

(new whisky trust)........

Starch trust

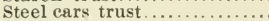

Steel rail trust..............

Steel wire trust.

Steel manufacturers trust....

Stove trust

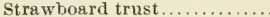

Structural steel trust..........
Capital.

$2,500,000$

$1,000,000$

$1,000,000$

250,000

$20,000,000$

$1,500,000$

$5,000,000$

$2,000,000$

$15,000,000$

$2,000,000$

$40,000,000$

$2,000,000$

$20,000,000$

60,000

$25,000,000$

500,000

200,000

500,000

$3,750,000$

$7,350,000$

2,000,000

500,000

$100,000,000$

$24,000,000$

$10,000,000$

$25,000,000$

$60,000,000$

$90,000,000$

$200,000,000$ 200,000

$8,000,000$

$5,000,000$
Sugar trust................

Tack trust.

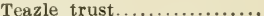

The Iron League trust.......

Telephone trust.............

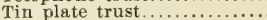

Tissue paper trust............

Thread trust...............

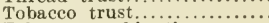

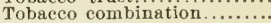

Tombstone trust.............

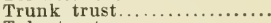

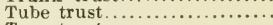

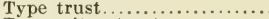

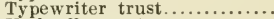

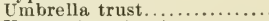

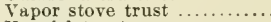

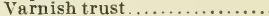

Wallpaper trust.............

Western flour trust.........

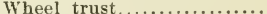

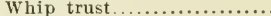

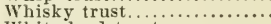

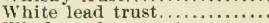

Window glass trust...........

Wire trust. ................

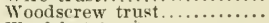

Wool hat trust .............

Wrapping paper trust.......

Yellow pine trust...........

Total,

$3,284,548,000$

Capital.

$75.000,000$

$3,000,000$

200,000

$60,000,000$

$26,000,000$

$50,000,000$

$10,000,000$

$12,000,000$

$24,000,000$

$2,500,000$

100,000

$2,500,000$

$11,500,000$

$6,000,000$

$18,015,000$

$8,000,000$

$1,000,000$

$36,000,000$

$20,000,000$

$10,000,000$

$1,000,000$

500,000

$35,000,000$

$30,000,000$

$20,000,000$

$10,000,000$

$10,000,000$

$1,500,000$

$1,000,0) 1$

$2,000,000$

Total,

To the foregoing should be added the California Raisin Association-the pioneer farmer's Trust of America. Its " capital stock" is small, but it is practically, so long as it lasts, a consolidation of the product of the capital of its members. In 1898 these numbered 2,064. The average capital of those engaged in the production of raisins was certainly not less than $\$ 3,000$, which would make the capital of the farmers' raisin Trust $\$ 6,192,000$.

The Wine-makers' Corporation of California is a Trust whose members are, for the most part, both producers and buyers, but as their interests as producers are probably in nearly every case greater than their interests as buyers, it should perhaps be called a farmers' Trust. 


\section{INIEX.}

ABILITY, Business, what it consists of, 248 . Agric-lture, Department of; law-changing, rank of, 534 .

- Law-creating, 533.

- Organization of, 535 .

Agriculture in Common Schools, 60, 553.

- Beginnings of in the United States, 60 .

- Cornell University, helps for teachers of, 554 .

- Demand for it in rural districts, 64 .

- Demand for good teachers will finally get them, 65 .

- Desirability of special teachers, 65 .

- Development of the child's mind, 62 .

- Difficulty of getting good teachers, 65 .

- Does not include farm operations, 62.

- Evidence of ability to be required of teachers, 65.

- How to secure its immediate int roduction in any district, 65 .

- Introduction likely to be resisted by advocates of other studies which must give way, 67 .

- Instruction must be suited to age of pupils, 62 .

- Must be confined to study of nature, 62 .

- No text-book needed, 61 .

- Not wise to push it in advance of public sentiment, 66.

- Progress of the work in the country, 61

- Proper compensation for special teachers, 66.

- Some educational questions involved, 64 .

- Some experience in California, 66.

- Special teachers employed in Europe, 66.

- Study delightful to children, 63 .

- Suitable teachers the first requisite, 63

- Tends to keep the boys on the farm, 6 .

- The best foundation on which to build a good farmer, 63 .

- Vagueness of the term, 6r.

- What is learned is never forgotten, 63 .

- What is meant by it, 60 .

- Will be had when the farmers demand it, 65 .

- Work in New York, 60, 553.

Agriculture; not in danger, 26.

- Short college courses in, 551 .

- Whether to be exploited or not, 26.

Agricultural Chemistry; not yet fully understood, 70 .

Agricultural Colleges, 39.

-Advantages of their connection with great universities, 39 .

- Also Colleges of Mechanics, 39.

- Syndicates, 604 .

- Cost of maintaining, 40 .

- Course in as a preparation for farm work, 41.

- Educating boys away from the farm, 40.

- Effect of political influences, 47 .

- Erroneous opinions in regard to, 40 .

- Few students take full courses, 44.
Agricultural Colleges, good instructors not always good farm managers, 46.

- Graduates of, 41 .

- Graduates not necessarily working farm ers, 43.

- Graduates professional men, 43.

- Fncreasing demand for graduates, 44.

- List of in U.S., 562.

- Morrill Act donating land for, 539.

- Morrill Act for endowment of, $54 \mathrm{I}$.

- Office of, 40 .

- Nature of the course in, 42 .

- Result of insufficient revenue, 40.

- Some graduates return to the farm, 44.

- Students generally poor, 44 .

- The orignal idea, 46 .

- Time required for graduation, 43.

- IVill do special work for farmers, 4I.

Agricultural Documents; state and uational, $72,56 \mathrm{I}$.

Agricultural Education; commercial view of it, 44 .

- Higher; demands the full strength of the student, 46 .

- In foreign countries, 560.

- The broader view of it, 44 .

Agricultural Experiment Stations; list of in U. S., 562 .

Agricultural Journals, 72.

- Intricacy of questions with which they must deal, 73 .

- Limitations of usefulness, 72

- Must cater to those who supply their revenue, 72 .

- Not properly sustained by farmers, 73 .

- Sources of their information, 74 .

- Value of correspondence from practical farmers, 74 .

- What they do for the farmer, 74.

Agricultural Papers and Books, 69.

- Schools, special, 5I.

- Synidcates, 604.

Aldrich Commitlee, 625 .

- Index tables of, 626 .

Alliance, Farmers', 290.

Altruism, definition of, тог, 279.

- Economic science does not deal with it, ror.

- In cooperation, 279.

- No man without it, 280 .

Amusements; those in rural districts not alway's decorous, 96 .

Analysis of soils; its use and value in agriculture, 69 .

Antagonism, economic ; should not produce enmity, 384 .

Appreciation of gold, and interest, 646 .

Arbitration in labor contests, 390.

Atkinson, F. J., index table of silver prices in India, 644 .

Audiences, popular; susceptible to emotional oratory, 115 . 
BANK ACT, National, I4o.

Bank Deposits; mostly money of poor people, 134.

Banker; Hecessary qualities of, I32.

- The farmers' best counselor in financial matters, I33.

Bank Failures, causes of, 132.

Banking, methods of, 13 I.

- Sound; how farmers can promote it, 132.

- Sound; farmers' interests in it. 132.

- Source of profits of, 13I.

Bank Loans; necessity of prompt collection, I34.

Banks, causes of farmers' dislike for, 133 .

- Cooperative, 605, 609.

- Different classes of, 135 .

- Do not desire to foreclose mortgages, III.

- Large; functions of, 134.

- Large; not themselves monopolists, but essential to monopolists, I 34 .

- Late proposal for security of circulation, 146.

- Managers of, not usually rich men, I3I.

- National; canses and results of their establishment, I42.

- National; great profits of the earlier ones, 143.

- National; notes of, 140.

- National; not now making undue profit on circulation, 143 .

- National ; present actual profit on circulation, 144,576 .

- National, statistics of, 576 .

- National; their notes the first good paper currency we ever had, 142.

- Not the enemies of farmers, 133.

- Notes of; condition under the state bank system, I 4 I.

- Notes of; history of their use in the United States, $138-143$.

- Notes of; resilits when inadequately secured, I39.

- Notes of, vs. government issues, 146-149.

- Private, statistics of, 579 .

- Question of allowing them to issue circulating notes, 143,145 .

- Results of "runs" upon, 136.

- Savings, 135.

- Savings, statistics of, 579 .

- State commercial; statistics of, 578 .

- State; notes of counterfeited, i4r.

- State; supervision of, I5I.

- Summary of statistics of, 579 .

- Their function of issuing paper money, 137 .

- Their dislike of foreclosures, 136.

- Will get highest interest rates possible, 134.

Bimetalism, international not probable, 366.

Bonds, United States; reason for not paying in silver, 364

Book Farming; faults of early farm books, 69 .

- Modern farm books contain the experience of practical men, 71 .

- Most of the old books really valuable, 70.

- Nearly all books on farming lately published are valuable, $7 \mathrm{r}$.

- Prejudice against, 60.

- Prejudice arising from exaggerated expectations, 69 .

- Prejudice partly due to the fact that farmers do not read the books which they condemn, 70 .

Books, list of for farmers, $566-575$.

- The farmer's family should have them, 94 .

Borrower, controlled by his creditor, $2 \times 3$.

Boys, Farmers'; drift to cities for easier life rather than for more money, 97.

- Have duties to parents, 92.

- Inclined to drift off among strangers, 94.
Boys, Farmers'; shiftless; probably defect ives, 92 .

- Will be happier in the country than in the city, 93 .

- Will devclop according to ability, 94

Bounties on production, experience of in U. S., 319.

Bounty, export, see export bounty.

Brokers, definition and methods of business of, 275 .

Bulletins of Experiment Stations; how to get them, $49,56 \mathrm{I}$.

- Of U.S. Department of Agriculture; how to get them, 50, 564 .

Business, a science, 205.

- Certain to flow in easiest channels, 212 .

- Cooperative, laws of identical with those of private business, 206, 207, 216.

- Elements of success in, 202.

- In farming differs from trade, 205.

- Liabilities of, 210.

- Principles of apply to farming, 205.

CALIFORNIA, Conditions of fresh fruit trade in, $45^{2}$.

- development of, 442.

- Errors of orchardists of, $444-447$.

California Fruit Exchange, causes of failure of, 503 .

- Cost of organization of, 496 .

- Experience of, 490-502.

- Final effort of, 500 .

- Objects of, 498 .

- Organization of, $48 \mathrm{~g}$.

- Origin of, 480 .

- Relations of to local exchanges, 492.

- Work of, 497.

California, fruit industries of, 442 .

California Fruit Union, $45^{2}$.

- Annual sales of, 454 .

- Capital of, 453 .

- Not sustained by growers, 454 .

- Organization of, 453.

- Reasons for going out of business, 455-457.

- Weak points of, 454 .

California Raisin Association; beginnings of, 465 .

- Benefits of to growers and others, 468 .

- Experience of, 467.

- Nature of, $467,65^{\circ}$

California Wine-makers Corporation, 517 .

- Condition of in 1899.524.

- Conditions leading to organization of, 519

- Difficulties of, 522 .

- Difficulty of organization of, 520 .

- Early success of, 522

- Nature of, 521, 650 .

- Relations of vineyardists, 522 .

Cases, Granger the, 287 .

Capital, certain to protect itself, 2I2.

- Control of in hands of borrowers more necessary than in hands of owners, 150.

- Growth of in cooperative stores, 215.

- Tendency of to concentration, 149.

Capitalists, farmers are, 19.

- Large, do not receive high interest, 135.

Changes, greater in the last fifty years than in the previous five hundred, I9.

Checks, bank, perform the functions of money, 137.

Circulation, per capita, 349 .

Civil Service, 192-194.

Clubs, farmers', 291.

Coinage, Free, of Silver, 363 .

- Argument against, 371-376.

- Argument for, 376-384.

- As law stands U. S. would have to maintain raticrat 16 to 1,365 . 
Coinage, By U. S. involves change from gold to silver standard, 366 .

- Demands of advocates of, 363 .

- Difficulties cf question of, 381 .

- Expediency of, 380 .

- International not probable, 360 .

- Justice of, 376 .

- Position of European nations in regard to, 366.

- Proper method of studying the question, 382.

- Resuits of uncertain, $365-382$.

- The monetary "question of the day," 363-366.

Coinage, law of 1834,357 .

- Law of 1873,358 .

- Law of 1878,361 .

- Silver, in U. S., 362

- Silver, discontinued by Latin Union, 362

Colleges, Agricultural (see Agricultural Colleges), 39

Commerce, one law of, 127

Commission Business, a trust business requiring state regufation, 155

- Fraudulent practices in, 154 .

- Fundamental wrong in, 154

- Laws regulat ig, 152 .

- Proper methirels of regulation, 155.

- Unsatisfactory condition of, 152 .

Commission Merchants, 152.

- Attacks on by faimers, 154 .

- Competition amons, 155

- Conflict in duties of, 153

-Duty of, 152.

- Folly of accepting advances from, 157.

- How to get a good one, 156.

- Impropriety of dealing for his own account, 153.

- Profits of, 156

- Sales of to themselves, 154.

- Should be confidential agent and friend of the farmer, 156 .

- Their old methods, 153 .

Commodities, relation of to silver and gold, $369,625,645$.

Common Schools, Agriculture in (see Agri(culture in Common Schools).

ompetition, all inen compete with all others for the possession of money, $10 \mathrm{r}$.

Always results in combination, 127.

An element in all exchanges, ror.

is conducted by merchants, 102.

1) ifferent $k$ inds of, 104.

Economic science assumes it, ror.

- How it operates, soo.

The public press will not properly inform iarniers, 103.

- I'niversal in its effects, 100.

ompetitors, cost of learning about them must he borne cooperatively, 104

- How the jarmer can inform himself about them, I04.

- Knowledge regarding them the most important for the larmer, 36.

(i) the farmers, who thes are. 103

Consumers, importance of stimulating demand, 37 .

imperation, altruism in, 279.

. Itruism in Great Britain, 281.

Altruism not a sale foundation for cooperative enterprise, 280.

operation, among farmers, 602 .

Imong farmers in U.S., $44 \mathrm{I}$.

Imong farmers in Europe, 604.

Imong others than farmers, 605, 609 .

Among farmers, result of same forces that produce cooperation among business Imen, 282.

lrguments for identic a I for all forms, 439.
Cooperation, a sign of excessive competition, 208.

- Benefits of in California, 524

- Californian, effort of to form Trusts, 462.

- Definition of as used in this volume, 204

- Desirable only as it increases comforts of membership, 210.

- Development of in different countries, 435 .

- Distributive, 205.

- Economic gain illustrated by an example. 259-267.

- Economic gain sufficient to justify, 258 .

- Essential to a successful fight with nature 128.

- How induced among the California fruitgrowers, $443,447-451$.

- How regarded by Socialists, 203, 261.

- In California, 434, 435 .

- In California ; degree of altruism in, 440.

- In California; relations of wealthy pro ducers to, 440 .

- In California; some experiences of, 440.

- In California, special interest of. 438.

- In Great Britain, statistics of, 607, 608 .

- In marketing; conditions oi success in, 525-526.

- In marketing dried fruits, beginnings of in California, 473.

- In marketing dried fruits; conditions leading to, 470,473 .

- ln marketing dried fruits, methods of in California, 473.

- Leaders of in California, 435-438.

- Likely to begin among least prosperous of the class involved, 210.

- Most common forms of, 204.

- Motives of identical with those of trusts, 440.

- Natural resuit of excessive competition 207.

- Nature of, 202, 203

- Of classes, 438 .

- Of farmers, difficulties of identical with those of cooperation of capitalists, 439 .

- Popular ideas of possible gain by often exaggerated, 257.

- Proper field for alt ruism in, 280.

- Relation of to Socialism, 428 .

- Salaries paid by, 438 .

- Should not be based on sentiment, $210,2 \mathrm{rr}$.

- Ultimate success of not improbable, 527.

Cooperative Banks, 605, 609.

Cooperative Business, compensation of salaried service in, $250-255$

- Fair compensation with honor, the best assurance of fidelity in management, 256.

- How at a disadvantage compared with competitive business, 249 .

- Impossible without some risk, 218 .

- Influences to be guarded against in, 255.

- Managers of may be largely compensated in honor, 254.

- Managers of not generally respected, 255

- Must assure itself of support belore start ing, 211 .

- Must be transacted by a corporation, 207.

- Personal expense of managers of, if in cities, 253.

- Requires adequatc capital, 209, 229.

- Results when capital is inadequate, 209.

- Some kinds not safe for farmers, 214.

- Successful only when intelligently managed, 213 .

- Success of depends on personal equation of membership, 206.

- Will not he sustained if inconvenient to members, 212 .

Cooperative Corporations, effect of good management on credit of, 225-227. 
Cooperative Marketiug Societies, attention to detail the key to success, 275 .

- Caution in making advances essential, 230. - Control of retailers by, 260 .

- Cost of organization of, 486,494 .

- Difficulty of organizing, 493 .

- Difficulty of raising funds for, 493, 495

- Economic gain by associated credit, 269.

- Economic gain by assurance against losses, 268.

- Economic gain by assurance of honest pack, 268.

- Economic gain by diffusion of business knowledge, 269 .

- Economic gain by elimination- of local buyers and commission men, 267 .

- Economic gain by extending period of sale, 267 .

- Economic gain confined to initial stages of the progress of the product to market,

- Economic gain in advertising, 261.

- Economic gain possible only with an assured volume of business proportioned to outlay for plant and expenses, 273

- Employment of brokers vs. traveling salesmen, 275-277.

- Local; difficulty of uniting them under one head, 492,503

- Methods necessary to the sale of products, 275

- No economic gain in elimination of wholesaler or retailer, 264

- Not yet usually competent to maintain branch selling agencies, 274 .

- Objects of in California, 232.

- Opposed to law of natural selection, 271.

- Relations of with wholesale merchants, 260.

- Should not borrow from commission men. 213.

- Substantially Trusts, 509, 52\%

- Summary of economic gains by, 270

- Vs. cooperative purchasing societies, 260 , 278

Cooperative Societies, British, 211.

- Business capacity of indicated by directors, 213.

- Can not safely incur debt, 229

- Caution in beginning business essential,

- Danger from ignorance of stockholders, 234.

- Danger from infirm will of stockholders, 236.

- Danger from neglect of stockholders, 234

- Danger from incompetent management, 238.

- Danger from suspicion of stockholders, 235 .

- Directors should not pledge their persona credit for, 228 .

- Ecouromic gain by raising the standard of business morals, 271-273

- Encouraged by those who will not join,

- How to determine qualifications of possible managers, 246-260.

- Illustrative instance of failure of, 223, 237.

- Importance of good secretary and presi dent, 227.

- List of in Califorma, 603

- Nanagement quite sure to be honest, 227.

- Managers must be honest, 240 .

- Managers must be vigorous, 243.

- Managers must have ability, 243

- Managers must have experience, or societies must pay for their mistakes, 2.44

- Managers must have tact, 2.44.
Cooperative Societies, managers must not be pecuniarily distressed, 247.

- Managers not necessarily accumulating men, 239 .

- Managers require all the cardinal and minor virtues, 245 .

- Managers sure to be suspected, 242.

- Managers sure to be tempted, 241 .

- Management of, 240 .

- Members not entitled to half-paid service, 256.

- Membership always responsible for failure of, 221 .

- Must do business only for cash, 214 .

- Objects of among larmers, must be simple, 233, 602 .

- Perfect managers probably not attainable, 240.

- Suspicion of managers of, 502.

- Waste of energy in holding membership together, 245 .

- When may be expected to succeed, 214.

Cooperative Stores, 94, 210, 602.

- How made successiul, 214.

Cornell University; work of in common schools of New Ýork, $60,553,560$.

Corporations; advantages oi, 219

- Assessments on paid-up stock evidence of mismanagement, 221.

- Assessments on stock of, 220, 22 r.

- By-laws of, 224.

- Can do only such business as charter specifies, 223.

-Caution in drawing up the charter essential, 224.

- Definition of, 219

- For cooperative purposes, 218 .

- Legal advice in forming desirable, 225.

- Popular prejudice against, 2 r8

- Safer than partnerships, 220.

Corners, speculative; how settled, 178 .

- Speculative, meaning of, 177 .

- Results oi, 177 .

Corruption in Legislatures; how it affects railroads, 159

- Opportunities for in legislative positions, 117.

Costs, decrease in manufactured goods, 33.

- Farmers must learn to reduce, 33

- Of produce not generally known by farmers, 35 .

- Reduced by studies of scientific men, 33 .

- Reduction possible only by study of details, 35 .

- IVork of chemists and engineers in reducing, 33 .

Country Life easier than city life, 92 .

Courses, short : in agriculture, 51, 551.

Cover crops; plants suitable for, 86 .

Credit; business transactions depend upon it, 355 .

- Results of failure of, 355 .

Creditors; will respect manliness and courage in debtors, iII.

Crime, of 1873 a myth, 359 .

Crop; necessity of adaptation to soil, 88 .

Currency, bad; the poorest people suffer most by it, 139 .

- Bank: elasticity of, 148

- Goverument; danger of overissues, 148

- Goverument; loans to the people of 148 .

- Government vs. bank notes, 146, 149

- Inflated; not good money, 344, 347

- Ouestion, object of study of, 610 .

- Statistical authorities for, 613

- Statistics of, 610-645. 
DAIRY SCHOOLS ; compensation of graduates, 53 .

- Course of study in, 53, 546 .

- Methods of, 52,546 .

Death; what evolutionists mean by it, 23 .

Deht; the cause of most deviations from honesty, 247 .

- Linless to run a long time not relieved by free coinage, 375 .

Dehtors ; formerly sold as slaves, I10.

- Must frankly look their condition in the face, 109.

Deferred payments; standard of, 367.

Demonetization, of sifver, 622 .

Department of Agriculture; Bulletıns, and how to get them, 50, 561- 566 .

Depreciation of silver, 360 .

Diagrams, statistical, caution in regard to use of, $612,614,615$.

Dirert Legislation; arguments for, 413.

- Common in U. S. in locaf affairs, 413.

-Educational value of, 419 .

- If wise would require all the time of the people, 417 .

- Initiative and reierendum, 415.

- In Switzeriand, 420.

- In municipal affairs, 416, 420.

- Likely to be conservative, 420

- Necessary limitations of, 418, 419.

- Not desirable that it advance too rapidiy, 415 .

- Not yet a real question of the day, 418 .

- Obstacles to its progress, 414.

- Rapidly gaining support, 415.

- Some proper subjects of, 418 .

- Very expensive, 418

Discontent; causes of, do not operate uniformly, 122 .

- Of the weaker and indebted, 121 .

- Part of man's nature, 124.

Discontent of the Farmer, 120.

- Causes of, I2I, 122.

- remedies for, 126.

- Result of proposed remedies, 128 .

Discriminations; railroad, 167 .

Distress : resuit of changes occurring more rapidly than man can adjust himseli to them, 19 .

Documents; state and national agricuitural ; how to obtain them, 72, 561-566.

Drainage; importance of, $b 7$.

Dried Fruits; early methods of handfing and marketing in California, $47 \mathrm{I}$.

ECONOMIC ANTAGONISM should not produce enmity, 384

Economics, problems of; rest upon ethica problems, 124

Economic Science; assumes competition, 100.

- Does not deal with altruism, ror.

Economics; some knowledge of is essential to successful farming, 38 .

- What it is, 37 .

Econemist, index tables of, 639 .

Economists; high character of, 303.

- Modern, mostly free traders, 303.

- Reasoning of in regard to tariff, 303.

Education, Agricultural; commercial view of it, 44 .

- The broader view of it, 44 .

Education of the iarmers' children, 93.

Education, the farmers; what is and what is not meant by it, 32 .

- The higher agricultural; demands the full strength of the student, 46 .

Elections; use of money in, i1 7 .
Elections, who supply money for, 118 .

Employees, the Farmers', 94.

- socially the larmers' equals, 95.

Environment, infuence of, 18 .

Exchanges, modern; inextricably interwoven, 101 .

- Speculative; how conducted, 178 .

- What they actually are, roz.

- What they would be with an ideal race, 102.

Existence, struggle for, Ior.

- How modified, 1or

Expenditures, Public; in U. S., 298.

- Possible economies in, i8g.

Experimental farms can never yield a net income, 47.

Experimenting an art, 48 .

Experiment Stations, Agricultural; Hatch Act for establishment of, 543 .

- Extremely valuabie work of, 48,49 .

- Means limited, 49 .

- National appropriation for, 48 .

- Necessity arose from impossibility of good farming by students, 47 .

- The, 46 .

- Value not fully recognized, 48 .

- Work seldom appreciated by neighboring farmers, 47 .

Experiments in digestion; value of, 48 .

Export Bounty, as a question of the day, 313

- Certain results of, 317 .

- Cost of to U. S. if given as proposed, 318.

- Definition of, 313 .

- European experience in, 315, 316, 319, 320.

- Justice of, as claimed by its advocates, 313 .

- No part of policy of protection, 315 .

- Not endorsed by any economist, 315 .

- Not endorsed by any national organization, 313.

- Reiation of, to question of protection and free 1 rade, $3 I_{4}$.

- Results of, as claimed by its advocates, 314.

- Sufficient objection to, 316

Evolutionists; not understood by farmers, 20.

Evolution, of the farmer, 18.

- Of species, 18, 567.

- Possible result of, 127 .

- IVhat it means, 127.

FAMILIES, Shiftless; in process of extinction, 32.

Farm, adaptability for home, 82 .

- As a source of income, 8.4 .

- Considerations determining value of, 82 .

- Fertile; means one which wilf produce crops at profit, 84

- Is a factory, 87 .

Farm Life; lacks social intercourse, 96 .

Farm, most common abuses of, 84

- Practice, local; usuafly welf understood by farniers, 32.

- Practice; to be learned only on the farm, 32.

- Products, danger of accepting large advances on, 231.

- The products of; largely determined hy focation with reference to markets, 88 .

-Products, profits of: most profit in the crops requiring most brain work, 8 .

- Products, value of as security, 230, 231.

- Robbing the soif of, 85 .

- Sources of fertility atuindant, 85 .

- The storehouse of vigor, 25.

- Value affected by character of community, 83. 
Farm, value affected by roads of vicinity, 83 . - Value affected by character of surrounding land, 83 .

- What is included in, 84 .

- What the study of consists in, 88 .

Farmer, American; ambitions of, 124.

- His condition as compared with others of his race, 24 .

- Seldom fails in efforts for his children's weliare, 93 .

- And his competitors, 100.

- And his creditors, 106

- And the eight-hour day, 124 .

- And his iamily, 89 .

- And his fellows, 96 .

- And the laborer, 384 .

- And the politician, i13.

- At a disadvantage in business transactions, 7 .

- At a disadvantage with other classs, 19.

- Attitude of towards Socialism, 432.

- Being distanced by wiser classes, 27 .

- Can inform himself only by cooperation, I7.

- Can not succeed if constantly changing his products, 88 .

- Competes in distant markets which he can not visit, 16 .

- Competes with all other farmers, 15.

- Could not now live without the aid of what science has done, 34 .

- Danger of debt, 16 .

- Decadence of prosperity unnecessary, 25.

Farmer; difficulty of informing himself as to competition, 103.

Farmer, Discontent of, 120.

- Causes lie deep, 128.

- Remedies for, 126

- Result of proposed remedies, 128.

Farmer; duty to family measured by his ability, 93 .

- Evolution of, 18.

- Fails to understand woman's nature, go.

- His boys must have some trade or protession, 92 .

- His children subject to illusions, 91.

- His lot easier than that of other classes, 104.

- His wife urovides half the income, 91 .

- Hope of, 22.

- How affccted by monopolies, 126.

- Life of, 124, 430.

- Life of incompatible with Socialism, 431.

- Mental competence ol, 120 .

- Modern; conditions under which be lives, 32.

- Modern; nothing new in this book, 7 .

- Modern; useful to others than farmers, 8.

- How to make political influence felt, $x 17$.

- Interested in a stable currency, 16.

- Interests intertwined with others, 8.

- In the end must cooperate, 128.

- In what offices most interestrd, 115

- Isolate life tends to discontent, 120 .

- Must study in order to vote intelligently,

- Must study the forces which control him, 8.

- Must watch his competitors, 102

- Must be a hroadly educated man, 17.

- Must be considered in connection with others, 128 .

- Must cooperate or fail of success, 19.

- Must know something of economics, 16.

- Must not expect politicians to present subjects fairly, 114

- Must olten borrow money, i6.

- Necessity of accurate knowledge of competition, 103.
Farmer, New; must be first of all a business man, 15 .

- New; must protect himself by his vote, I6.

- New; uses far more money than the old farmer, 15.

- None but the strong can realize their reasonable ambition, 125 .

- Not always the best judge of his own ailments, 126.

- Objections of, to Socialism, 420

- Obligations to his children, 91 .

- Obligations to his wife, 89 .

- Often misled by demagogues, 17.

- Old life of the farmer not now possible or desirable, 15 .

- Old; his life in the middle of the ninetenth century, II-I4

- Old; saw very little money, 14 .

- Old; social and intellectual condition, 13.

- Old; well nourished and happy, 14.

- Only essential class, 8.

- Pecuniarily affected by politics, 115 .

- Points of difference and agreement with laborers, 385

- Position of in reference to demands of labor, 388.

- Should produce what most interests him, 87.

- Small; conditions upon which his continued existence depends, 15.

- Small; danger to his existence as a class, 17.

- Real causes of his discontent, I23.

- Relations as a business man, 7 .

- Relations to other classes, 123, I26.

- Result of voting after studying only one side of a question, 115 .

- Standard of life, 123,125 .

- Successlul; need not be a scientific man, 31.

- The Scientific, 28

- Thrifty; must devote some time to study,

- Training does not prepare for public speech, 20.

- Unscientific in competition with the student of farming, 30 .

- What should he get from his farm, 122

- Who can produce cheapest will survive at the expense of others, 16.

Farmer's Alliance, 290,

- Radicalism of, 291 .

- Relations of, to Graı ge, 290, 291.

- Relations to political action, 290.

Farmers; belong to the capitalist class, I9.

- Business education essential for, rg.

- Can stop waste of money on country roads 200.

- City, 7 I.

- Clubs, 291.

- Clubs, weakness of as compared with ritualistic societies, 292.

- Causes of lack of prosperity. 33 .

- Condition early in nineteenth century, 106.

- Cooperation among, 602.

- Desire of, for cheaper money, 150.

- Errors of, in dealing with commission merchants, 154 .

- Evidence of increasing power, 27.

- Fail in knowledge of what their competitors are doing, 102 .

- Feeling of many in regard to science applied to agriculture, 28 .

- Financial strength ol, when combined, 212.

- Great sums of public money spent for their benefit, 50 .

- Habit of reasoning on false premises, 27. 
Farmers, have not usually understood railroad questions, 159 .

- Have the basis of success in physical strength, 26

- How they should deal with trades men, 184.

- Indebted; benefits arising from compromise of indebtedness, 112 .

- Indebted; consider their creditors his enemies, r ro.

- Indebted; not required to remain slaves, IIo.

-Indebted; should be perfectly frank with their creditors, III.

-Indebted; steps to be taken for payment or compromise, III.

- Indebted; they are hurt by worry more than by work, 112 .

- Indebtedness of; largely incurred for land at too high prices, 108 .

- Insist on payment of debts due to themselves, 110.

Farmers lnstitute; the, 55 .

- Aims and methods, 59 .

- Difficulty of obtaining good non-professional instructors, 57 .

- Farmers who say they can learn nothing from them, 59 .

- Gets farmers to thinking and talking, 55.

- How controlled in different states, 56 .

- Importance of enlisting local talent, 56.

- Management of, 56,58 .

- On Pacific Coast, 57 .

- Nature of topics discussed, 56.

- Professional vs., non-prolessional instructors, 57 .

- Requirements for non-professional instructors, 58 .

- Supported by state iunds, 56 .

- What it is, 55

Farmers; largely mortgaged, 100

- likely to engage in cooperation without adequate capital, 209.

- List of books for, $566-575$.

- Must adapt themselves to their changing environment, 21 .

- Must learn to reduce costs, 33.

- Organizations of, 284 .

- Proper course of with regard to banks, I.jo-I5I.

- Should vote to strengthen the Interstate Commerce Commission, 175.

- Scurces of the most valuable information for, 72 .

- Unrest of American, 33.

- Value, to farmers, of the habit of writing to farm papers, 74 .

Farm Products, home prices of, 636-638.

- Relative New York price of, 634 .

Farms; unprofitable unless actually worked by owners, 7I.

Farming; books (see Book Farming), 69.

- Scientific, prejudice against the term, 28.

Fertilizers, commercial; uses of, 86.

Fertility, causes of loss of, 85 .

Fit, the survival of, 21 .

Flattery; empioyed to influence farmers, 114

Foods; compete with all other foods, soo.

Fortunes, great, result of exceptional ability with accumulating instinct, 258 .

Freights (see Railiroads).

- Rates per ton per mile, 646 .

Fruit Fxchange, California (see California Fruit Exchange).

- Santa Clara County (see Santa Clara County Fruit Exchange).

- Fruit Exchange, Southern California (see Southern Caliornia Fruit Exchanges)

Funds, party; names of contributors should be public, $\mathbf{1 1} 8$.

- Public; result of wasteful expenditure, 187.
GEOGRAPHY, PHYSICAL ; importance not yet recognized in universities, 37.

- The first thing for the farmer to study, 36 .

- Well understood by commercial men, 37 .

C. I, a commodity, 368 .

- Appreciation of, 378,6 r4 .

- Ratio of to silver, 618-622.

- Relation of, to commodities, $369,625,645$.

Gold Standard, argument for, $371-376$.

- Expediency of, 373

- Justice of, 371 .

Gold, value as compared with silver, 356 .

- World's production of, 617 .

- World's stock of, 616 .

Governments, credit of; as compared with banks, 147.

Graduates of Agricultural Colleges, 4I.

- Professional men, 43.

- Some return to farm, 44 .

Grange, the; influence of woman in, 289.

- Influence of, in contest with railroads, 287 .

- National and state, 288.

- Objects of, 285.

- The: position in regard to speculation in farm products, 180 .

- Rise and progress of, 286.

- Ritual of, 289.

- "Secresy" of, 280.

- Subordinate, work of, 288.

Granger cases the, 287 .

Grange's dealings, with tradesmen, 184

HATCH, WM., Introduces bili for establishment U. S. Agricultural Experiment Stations, 543

Hope of the larmer, 22.

- in what it consists, 27

Humbug; farmers considered susceptible to, 113.

- The most effective weapon of politicians, II 3 .

Humus, chemical action of, 86 .

- How to replenish, 85 .

- Importance of in soil, 85 .

- Result of exhaustion of, 85 .

IMMIGRATION, European; its effect on American farmers, 106.

Income, larmers', affected by causes beyond his control, 37.

- Vary in ratio of definite facts known, 22.

Indebtedness, farmers'; as the result of speculative development of industries, 109 .

Index Tables, 370. (See, also, Aldrich, Atkinson, Economist, Sauerbeck, Soetbeer, and Wetmore.)

- Best available standards for estimating value of precious metals, $37 \mathrm{I}$.

Industries, household, itt old times, I2.

Infertility, most common causes of, 84 .

Information, necessary; cost of too great for single farmers to acquire, 19.

Initiative, 415.

Institute, Farmers' (see Farmers' Institute) 55.

Interest, rates of; have not fallen on farm loans, 377 .

Interest, rates in U.S., 647 .

Interstate Coinmerce Commission, 168

- Necisions of, 580-598.

( $\tilde{N}$ OTE.-The decisions of the Interstate Commerce Commission are not indexed in detail, in $t+$ volume.)

Interstate Commerce Commission, Extracts from Report of, 598 .

Issues National ; less important to farmers than local, ri6. 
JOURNALS, Agricultural (see Agricultural Journals), 72 .

Judgments; do not differ when men agree upon facts, 9 .

KNOWLEDGE, If real influences action, 22. - Money value of, 22.

- More required for production for the world's markets than for a home market, 36 .

- Not scught except as it affects income, 22.

- The most important for the farmer, 36 .

- Unprofitable to acquire what will not be used, 42.

- not vague speculation but mastery of facts, 27.

LABOR, claim of that the judiciary unduly favors capital unfounded, 392.

Labor contests, arbitration in, 390.

Labor, demands of as to hours of work, $3^{86 .}$

- Demand of that military shall not be employed in strikes, 391 .

- Farmers' relation to, 384

- Organized, 385.

- Organized, at variance with unorganized labor, 385 .

- Organized demands of, 385.

Labor, physical; how it clashes with demands of the class-room 13.

- Physical, not possible while acquiring higher education, 46 .

- Purchasing power of 628 .

Labor Question, definition of, 385 .

- Relations of farmers to, 385.

- Short hours of not desirable, 430.

- Socialistic, demands of, 394

Land, agricultural; now as dear as it is likely to be, 107 .

- Not economically cultivable by capitalistic methods, 431 .

- Sanction of society for ownership of, 430.

- Speculation in, 107 .

- Unearned increment of, 429.

- Value of ownership of, 429 .

- Values, taxation of, $34^{\circ}$.

- Worth less than improvements on, 429.

Law, judge made; ignorant legislators responsible for most of it, 393 .

Learning, great, no assurance of happiness, 430.

Legal tender, 348,351 .

Legislation, direct. (See Direct Legislation and Referendum.)

Legislators, dishonest, influence of, 418 .

Legislatures ; corporations prefer them to be honest, 158.

Life Insurance, as affected by change to silver standard, 375 .

Life, Law of, 21.

- Law of; operation on man, 21 .

Loan and Trust Companies, statistics of, 578 .

MAN; conditions of survival, 21 .

- Subject to the universal law of life, 2 I.

- The accumulating; characteristics of, 130 .

- The unjust; not usually a banker, 130 .

Marketing ; art of, not usually understood by farmers, 35.

- Cooperative, highest exercise of the art of cooperation, 434 .

Men; classed as owners and non-owners of property, 24 .

- Those who know most have most, 22.

Merchandise, cost of selling from first hands, $263,277$.
Merchants, retail, relations with wholesalers, 262.

- Commission, 152.

Money, actual, ratio of used in transacting modern business, 349 .

- Actual ; uses of, 349 .

- Actual value imparted to it by making it legal tender, 351 .

- As a measure ot value, 350 .

- As a méasure of value; essential qualities of, $35 \mathrm{I}$.

- As a medium of exchange not a question of the day, 342 .

- Bad; can not be forced to circulate with good, 352.

- Bad, may do the work of good, 343.

- Coined gold and silver the best, 353 .

- Depreciated; poor suffer most by it, 348 .

- Fiat, results of use of, 346 .

- Fiat, use of not desirable, 348 .

- Gold and silver always used for, 356

- Good, one essential quality of, 342 .

- Government paper, objects of issue of, 347.

- Gresham's law of, 354 .

- Ideal, 347 .

- Increase of raises prices, 352.

- International, 343.

- Irredeemable; theoretically may be made satisfactory, but practically never has been, 353 .

- Loans of by government to the people, I48.

- Made scarce and dear by overtaxation, 150.

- Necessity of, I37, 345.

- Non-exportable, 348, 353

- Of the world must be considered as one stock, 353.

- Per capita, 349.

- Power, control of our gravest problem, 149.

- Relations of supply of to prices, 354 .

- Representative, 343.

- Representative not international, 343.

- Standard of deferred payments, 367 .

- Stocks of in world, 625 .

- Substitutes for, 345 .

- Supply of, as affecting prices, 367 .

- Use of in elections, 118 .

- Usual definition of, 350 .

- Will always be found where desired products are for sale, 344 .

Monetary Systems of the world, 624 .

Monopolies; how they affect the farmer, I 26.

Morrill, J. S., introduces Agricultural College Bill, 539 .

- Introduces second act for endowment of Agricultural Colleges, 541 .

Mortgages; banks dislike to foreclose them, III.

NAFTZGER, A. H., Letter from, 514.

Nature; does not consider abuses but conditions, 20.

- Law of, 127.

- Man can conquer only by cooperation, 128.

- Phenonena of, 42 .

- Relentless and remorseless, 20.

- Study (see agriculture in comnion schools), $60,553,560$.

- What she requires of man, 23.

Nelson, N. O., letter from, 606.

Nominatious, improper; how best prevented, 116.

OFFICIALS, Public; can not practice private economy, 190.

- Usually personally honest, $1 \mathbf{r} 3$

Offices, appointive, 118 .

- The most important to a farmer, Ir5. 
Offices, which should seek the man, 117 .

- Which the man may properly seek, 117

Orange-growing in southern California, 505.

Orange-growers: miscalculations of, in southern Califormia, $5 r 6$.

Orange-marketing: early cooperation in, 508 .

Orators, political; what they aim to accomplish, 114.

PAPERS; The daily paper a nulsance on the farm, 70 .

Parties, political; usefulness of, 116.

Party, politiral; poverty the most honorable eondition of, 118.

Patrons of husbandry (see Grange).

Personal equation, $2 \mathrm{c} 6$.

Plat forms, political : how usually coust ructed, 114,115 .

Politician, and the farmer, 113 .

- Honesty of, 113 .

- May become a statesman, 113.

- Meaning of the term, I13.

Politicians; opposed to reform in eivil service, 194 .

Political speakers; do not present questions fairly, 114 .

Precious metals, stability of value of, 368 .

Prices, as affected by money supply, 367 .

- Course of, 625 .

- Fixed by credit more than by money supplv, 355 .

Produce; cost of, not generally known by farmers, 35 .

Production, art of ; generally well understood by tarmers, 35 .

- For the home market different from production for the world's market, 36.

Products, agricultural; farm costs but little reduced, 377 .

Protection (see Tariff).

Prune-growers' Association, Pacific, 487.

Public questions; alway's involve economic problems, 115 .

RAILROADS, Abuses by, I 68.

- Best controlled through Interstate Commerce Commission, 175 .

- Can be controlled by the people, 173.

- Capitalization of, in United States, 161, 599.

- Capital honestly invested in entitled to protection, 165.

- Circumstances making discrimination proper, 169

- Competition among, 169 .

- Different kinds of competition among, 170 .

- Difficulties which they meet, 158 .

- Discriminations by, 167 .

- Dividends of; problems concerning, 163165

- Early administration of, 163 .

- Entitled to no secrets from the public, 173.

- Farmers' true policy regarding, 175 .

- Folly of indiscriminate attacks upon, 159.

- Freights ; cost of 165,646 .

- Freight tariffs of; how constructed, 166.

- Fundamental principle underlying effectual control, i73.

- Government ownership of, 172

- Interests usually identical with communities served by them, 159 .

- Interstate Commerce Commission, 168

- Interstate Commerce Commission reports best source of information concerning, I74.

- Largely built on horrowed money, ro8.

- Not always wisely managed, 159.

- Officers of: some honorable anó some otherwise, 171 .
Railroads, officers of, will seek to get a revellue somehow, r7 $\mathrm{I}$.

- Perjury by officials of, 168

- Problens concerning, very complicated, 160.

- Problems of control of, 173 .

- Questions concerning; sliould be studied without passion, 158

Railroad questions; usually contests between localities, $16 \mathrm{n}$.

Railroads, receipts of, in $18,6,162$.

- Regulation of, 160

- Statistics of, in Li. S., 599

- Tariffs of; must be reasonable, 163

- Tariffs of, really a tax, 162.

- True functions of state commissions of,

- "Watered " stocks of, 161.

- Will carry all freight which yields any profit, 170.

Raisin Association, of California (see California Raisin Association).

Raisins, early methods of sale, 459, 46r.

Raisin-growers, condition of, in 1897,46 .

- Difficulties of effecting cooperation among, 462.

- Difficulties of, in marketing, 459 .

- Early cooperation among, 460 .

Raisins, methods of production, 458 .

Ratio, changes in legal, in U. S.. 357 .

Ratios of gold and silver, $356,360,618-622$

Ratios of gold and silver, greater than 16 to 1 , 367 .

Ratio of silver to gold never has been permanent, 357 .

Rational enioyment; a proper end of life, 98.

Recall, power of not desirable, 416 .

Recreation, does not consist in hoeing potatoes, 46.

Referendum, 415, 417

Reform, social (see Social Reform).

Reforms, always first advocated by extremist $\mathrm{S}, 414$.

Rent, economic, in Great Britain, 328.

- Economic, meaning of, 324 .

- Economic, tends to be absorbed by labor. 431.

Roads, country; cost of moving freight on, I06.

- Country, effect of good, in European countries, 197.

- Country, large expenditure on, Ig6.

- Country, method of computing what can profitably be expended on them, 198, 199.

- Country, question of state aid to, 200.'

- Country; wisdom of incurring public debt for depends on circumstances, 200.

- Farmers can stop waste of money on, 200.

- Good country ; common sense must be used in expenditure for, I97.

- Good country; effect on value of land, I99.

Rural effort, essential to existence of the race, 422 .

SAl.ARIES, Large, the price paid for great knowledge, 23 .

- Of cooperative managers, 606 .

- Public, often not high enough, I92.

- Public, wastefulness in, 189

Satisfactions; economic definition of, I01.

Santa Clara County Fruit Exchange, beginnings of, 477.

- Begins business, 480 .

- Benefits of, to growers, $48 \mathrm{r}$.

- Cost of organization of, 479 .

- Difficulties in organization, 478 .

- Experience of, $482-484$.

- Relations of, to local trade, 479. 
Santa Clara County Fruit Exchange, Success of, $48 \mathrm{r}$.

Santa Clara Valley, fruit marketing societies of, 476,480 .

Sauerbeck, A., index table of, 641 .

Science, rests upon verified facts, 20.

- What it has done for the farmer, 34 .

Science in Agriculture ; incident showing feeling of some farmers in regard to it, 29.

- Incident showing its progress, 34 .

- Until lately neglected in America, 30.

- What it is and is not, 30 .

- What it has effected, 31 .

- Work of the different professions, 33, 34

Scientific knowledge expensive, 3 I.

Scientific Men; the only really practical men, 20.

- Their patience in the study of detail, 20.

Senators, United States; effects of contest for that office, 156 .

Service, civil, 192-194.

- Civil; not an aristocracy, 194

- Public; abuses in connection with, 190, 191

- Pubilc; how to reform it, 192-194.

- Public; responsibility for abuses in, 192.

Settlers, early; entitled to advance in land created by their enterprise, 107.

Shiftless boys; probabiy defectives, 92.

Short Courses in Agriculture, 51 .

- Individual guidance given, 51 .

- Lead to no degree, 51 .

- No special preparation required, $5 \mathrm{r}$.

- Students at least learn how much they do not know, 52.

- Students must be mature, $5 \mathrm{I}$.

Silver, a commodity, 368,632 .

Silver, coinage of, 624

- Changes of legal ratio in U. S., 357, 621.

- Demonetization of, 622 .

- Free coinage of, 363 .

- Free coinage of ; argument for, 376-382.

- Free coinage of; as law stands U.S. would have to maintain ratio of 16 to 1,365

- Free coinage of; proper method of studying the question. 382 .

- Justice of free coinage of, 376

- Legai tender for U.S. bonds and private debts, 364 .

- London price of, 624,633 .

- Purchases of, 623 .

- Questions concerning not fairly discussed by political writers or speakers, 382 .

- Ratio of to gold, 618-622.

- Relation of to commodities, 369 .

- Results of free coinage of uncertain, 382.

- See ratio and coinage.

- Standard, effect on Life Insurance, 375.

- U. S. unable to sustain price of, 362 .

- Value as compared with gold, 356.

- Value of ; must be restored by inspiring confidence in it, 380 .

- Worid's production of, $6 \mathrm{r} 7$.

- World's stock of, 616 .

Single Tax, as a means of social reform, 329.

- As advocated by Henry George, 340 .

- As a fiscal measure, 335

- As it would work on the basis of California assessments, 336-340.

- Claims of its advocates, 324-326.

- Definition of, 324 .

- If just should be adopted, 329 .

- Lack of data for estimating result of, 327.

- Not a new doctrine, 340 .

- Reply to arguments for, 325 .

- Result of, to farmers, 327.

- Similar to one of the doctrines of Socialism, 325 .

Socialism, attitude of the farmer towards, 432.
Socialism; cooperation differs from, 203.

- Demands of, 424 .

- Fallacy of, 429 .

- Good it has accomplished, 425 .

- Grandeur of conception of, 425 .

- If established must be based on rural and not urban life, 427 .

- Not reconcilable with rurai life, 433.

- Not to be lightiy reckoned with, 424

- Propositions on which it rests, 423.

- Ranks of inciude good men, 424.

- Relations of to organized labor, 427.

- Reiation of to cooperation, 428 .

- Reply to claims of, 426-427.

- Some of its aims favored by non-Sociafists, 425.

- Uitimate aims of, 423 .

-- What it necessarily implies, 424 .

Socialistic Labor Party, demands of not Socialism, 394-395.

Social Reform, discussion has centered about urban interests, 42 .

- Discussion of not unprofitabie, 422.

- Farmers ignored in plans for, 423.

- Must begin with rurallife, 423.

- Probability of, 432 .

Social Reforms, many proposed overlook infirmities of human nature, 258 .

Social Intercourse, an important economic factor, 99 .

- Difficulties attending it in rural districts, 96.

- Essential to a happy life, 96 .

- How best promoted in rural districts, 98.

- If left unregulated tends to deterioration,

- Lacking in farm life, 96.

- Should be enjoyed by young and oid together, 97 .

- The labor fails mostly on women, 98 .

- The lack of it one cause of the farmer's discontent, 97 .

- The young must and will have it, 97.

Society, an uncompleted evolution, 37 .

Soetbeer, A., index tables of, 643 .

Southern California, orange industry of, 505 .

Southern California Deciduous Fruit Ex changes, expenses of organization of, 486 .

- Organization of, 485 .

Southern California Fruit Exchanges (Citrus), 505 .

-Beginning of business of, 512 .

- Character of, 500

- Conditions leading to organization of, 566-508.

- Difficuities of, 513-514

- Methods of, 513

-Organization of, 510 .

- Success of, 514

Soil, analysis of; its use and value in agriculture, 69 .

- Drainage of, 87 .

- Importance of physical condition of, 87 .

- Result of leaving it naked, 86.

- Should be kept constantly covered with growing plants, 86 .

Special Agricultural Schools, 5I.

Speculators, conflict of bulls and hears, 177

Speculation, effects of reaction from on land values, 108 .

- How conducted on Exchanges, 178.

- In farm products; results to farmers I79-180.

- Its effects on American farmers, 107.

- Meaning of, $1-6$

- Most effective method of suppressing, 18I.

Speculators, different classes of, 176 .

Standard of Life, the farm the farmer's standpoint, I24. 
Standard of Life; the farmers', 123. - Essential nature of, 368 .

Standard of Value, best available, 370.

Statistics, caution in regard to use of, 611 .

- Of currency, authorities for, 613 .

Stores, Cooperative, 210.

- How made successful, 214.

Strikes, causes and results of, 386 .

- Duty of society with regard to, 387 .

- Great seldom peacelul, $5^{87}$.

- Peaceful, a legitimate proceeding when necessary, 386.

- Responsibility for riots in, $3^{87}$.

Struggle, absence of is death, 127 .

- For existence, tor.

Study of the Farm, 76 .

- A study as the author would conduct it, 78 .

- A study as Mr. Clinton would make it, 82 .

- Advantage of crops fargely produced in the vicinity, 80 .

- Consists in finding out the essential things that are not already known, 77 .

- It involves a study of costs, 78 .

- It is the waste of efiort that kills, 81.

- If a good farm does not pay, the fault is with the farmer, 78 .

- No two men would proceed in the same way, 76 .

- The tarm the only place to learn farming, 76.

- The farmer must be honest with himself, 77.

- The greatest of all means of seli-improvement, 76.

- The many things which all farmers know about their farms, 77 .

- The need of the capacity to see things, 77 .

Subsistence, sufficient produced for all, 22 .

Success, farmer who constantly changes his products cannot achieve it, 88 .

- Probable, best evidence unusual effectiveness, 92.

Survival of the $\mathrm{Fit}, 2 \mathrm{r}$.

- Evidence of power of, 24.

- Power of in American farmer, 24.

Syndicates, agricultural, 604 .

TABLES, Index (see Index Tables).

Tax, single (see Single Tax).

Taxation, ad valorem, can not be made just, 329.

- Affected by political action, 115 .

- A very difficult subject, 334 .

- Difficulty of levying justly, 296 .

- Double, 333.

- Extravagance in, 188.

- Evaded by rich men, 329-331.

- In America, 295.

- In Cafifornia, 336 .

- Incidence of, 300 .

- Inequalities of, 188 .

- Injustice of in U. S., 297.

- In U.S. in 1890,335

- Limit of, 187 .

- Men will lie to evade it, 188 .

- Methods of in highly taxed countries, 2,6 .

- Not adequately studied in U. S., 296.

- Of Chicago banks, 330.

- Of Chicago land, 334 .

- Of money, 331 .

- Of mort gages, 333 .

- Of personal property opposed by many who are not single taxers, 331 .

- Of stocks, 332.

- Perjury to escape, 330.

- Present system very unjust to farmers, 329.
Taxation, pressure of in U. S., 187 .

- Ratio of assessed on land and personal property, 335 .

Taxes, export prohibited in U. S., 297.

- Indirect, 298-301.

Tender, legal (see Legal Tender).

Theorists, common errors in regard to them. 29.

- Real meaning of the term, 20.

- What some larmers suppose them to be, 29.

Tillage, thorough, results of, se.

Tarifi, as affected by conflicts of sectional interest, 302 .

- As a part of a revenne system, 295.

- As a ifuestion of the day, 294, 301.

- Details are matters of expert knowledge, 303.

- For protection, 301

- I.egislation in U.S. hefore and after Civif War, 297.

- Party platíorms on, 295

- Problenis of, how complicated in U. S., 302.

- Objects of the chapter on, 295.

- Opinions on, how formed and changed, 302.

- Position ol extremists on both sides, 294.

- Protective, nature of popular discussion ol1, 306.

- Protective, summary of arguments against, 309, 310.

- Protective, summary of arguments for, $307,308$.

- Protective, usual argument for, 304.

- Reasoning of most economists on, 303.

- Relation of balance of trade theories to, 310,312 .

- Reply to the reasoning of free trade economists, 304 .

- The kind we all really desire, 302.

Trade, balance of, 310-312.

- Retail: everywhere infected with fraud, 185 .

Tradesman, country, must charge high prices if he sells on credit, $18_{3}$.

Tradesmen; danger of debt to them, 185

- Dealings of Granges with, 184 .

- How farmers should deal with them, 183 .

- Retail, economic value of to farmers, 183.

- Retail, profits of, 182 .

Trade Unionism, aims of, 385,428 .

Transportation, cost of, 646 .

- Study of problems in, 158 .

Transportation Srstem; affect of its development on land prices and speculation, 108.

Trusts, American, 648 .

- A permanent feature of civilization, 397.

- As originally conceived not now existing, 396.

- Can not he prevented without paralyzing business, 411 .

- Causes leading to their formation, 390.

- Danger of inflammatory methods of treating them, sir.

- Debauching politics, their most serious abuse, 406

- Desirable, if controlled, otherwise not, 408 .

- Doing nothing that farmers would not like to do, 399 .

- Entitled to have 110 business secrets, 408 .

- Farmers should lead the campaign for their control, 412 .

- Fear the people more than the people fear them, 412 .

- First step towards their control, 406 .

- How formed at present, 397.

- Improper use of money to control political action, 405.

- Industrial, how enabled to thrive, 406 .

- Legislation for control of, 408 . 
Trusts, methods of accomplishing their ends,

- Must be considered without prejudice, 368 .

- Not harmed by wild denunciation, 41 I

- Of farmers and others alike, 399.

- Of farmers need encouragerhent, 399.

- Origin of common use of the term, 396 .

- Popular meaning of, 396.

- Present conditions ridiculous and should be changed, 408 .

- Present generation not likely to deal with them wisely, 4 og.

- Present rapid formatio't of largely speculative, 4 Io.

- Problems in connection with. 397.

- Protected by patents and tariff, $403,404$.

- Relations to political partie; and politicians, 405, 406

- Should be formed by farmuss, 398 .

- Special methods of control of, 412 .

- Speculative, how formed, 410.

- Speculative, will fleece investors rather than the public, $4 \mathrm{Ir}$.

- Sugar, 399.

- Those first formed ineffective, 399 .

- The ideal result of cooperative marketing, 203.

- To be defied-not feared, 412

- We all desire to be in them, $4 \mathrm{II}$.
Trusts, will control most articles purchased by farmers, 404 .

UNEARNED INCREMENT, program for reserving it to society, 432 .

- Tends to be reahsorbed by society, 431 .

United States; credit of during the Rebellion, 142.

- Nominally bi-metallic, really on a gold basis, 363 .

Union, Latin, 360.

University, cost of maintaining, 40 .

Unthifty, the; end of, I 39.

VALUES, Of land speculative in U.S., 328.

Vigor; the source of all prosperity, 25 .

WAGES, Course of, 625 .

Walnut Marketing Associations, of California, 487 .

West Side Fruit Union, 473.

- Success of, 474 .

Wetmore, W. S., index table of silver prices in Cinina, 644.

Wine, in California, 518

- Method of making, 517

Work, public; should be let by contract, 195 





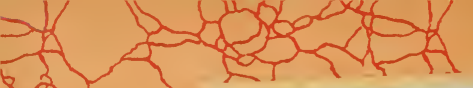

THIS BOOK IS DUE ON THE LAST DATE STAMPED BELOW

AN INITIAL FINE OF 25 CENTS WILL BE ASSESSED FOR FAILURE TO RETURN THIS BOOK ON THE DATE DUE. TH THE FOURTH WILL INCREASE TO 50 CENTS ON TEVENTH DAY DAY AND
OVERDUE.

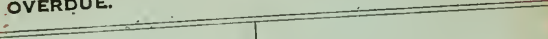




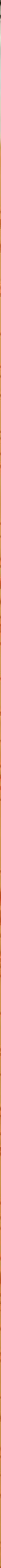


